UNIVERSIDADE DE SÃO PAULO

FACULDADE DE ECONOMIA, ADMINISTRAÇÃO E CONTABILIDADE DEPARTAMENTO DE ADMINISTRAÇÃO PROGRAMA DE PÓS-GRADUAÇÃO EM ADMINISTRAÇÃO

CRIANDO SENTIDO PARA AS INCERTEZAS IMPREVISÍVEIS EM PROJETOS INOVADORES

Rosária de Fátima Segger Macri Russo

Orientador: Prof. Dr. Roberto Sbragia

SÃO PAULO 
Prof. Dr. João Grandino Rodas

Reitor da Universidade de São Paulo

Prof. Dr. Reinaldo Guerreiro

Diretor da Faculdade de Economia, Administração e Contabilidade

Prof. Dr. Adalberto Américo Fischmann

Chefe do Departamento de Administração

Prof. Dr. Lindolfo Galvão de Albuquerque

Coordenador do Programa de Pós-Graduação em Administração 


\section{CRIANDO SENTIDO PARA AS INCERTEZAS IMPREVISÍVEIS EM PROJETOS INOVADORES}

Tese apresentada ao Departamento de Administração da Faculdade de Economia, Administração e Contabilidade da Universidade de São Paulo, para a obtenção do título de Doutor em Ciências.

Orientador: Prof. Dr. Roberto Sbragia

Versão corrigida

(versão original disponível na Faculdade de Economia, Administração e Contabilidade)

\section{SÃO PAULO}


Tese defendida e aprovada no Departamento de Administração da Faculdade de Economia, Administração e Contabilidade da Universidade da Universidade de São Paulo - Programa de Pós-Graduação em Administração, pela seguinte banca examinadora:

\section{FICHA CATALOGRÁFICA}

\section{Elaborada pela Seção de Processamento Técnico do SBD/FEA/USP}

Russo, Rosária de Fátima Segger Macri

Criando sentido para as incertezas imprevisíveis em projetos inovadores / Rosária de Fátima Segger Macri Russo. - São Paulo, 2012.

$284 \mathrm{p}$.

Tese (Doutorado) - Universidade de São Paulo, 2012.

Orientador: Roberto Sbragia.

1. Administração de projetos 2. Administração de risco 3. Administração de inovações tecnológicas 4. Psicologia organizacional I. Universidade de São Paulo. Faculdade de Economia, Administração e Contabilidade. II. Título. 
Aos meus três grandes amores: Renato, Daniela e Marco. 
O período de desenvolvimento de uma tese de doutorado requer muito esforço e concentração do doutorando, o que exige compreensão de todos que estão ao seu redor, pelo tempo que ele não pode dedicar às atividades normais de uma vida social e familiar. Assim, agradeço imensamente todos.

Agradeço prioritariamente ao meu orientador, Dr. Roberto Sbragia, que, com toda a sua sabedoria e amizade, soube dosar flexibilidade e direcionamento, auxiliando-me a enfrentar os enormes desafios a que me propus, ao mesmo tempo me proporcionando oportunidades de crescimento pessoal e profissional. Agradeço também todos os que participaram da pesquisa, o compartilhamento de suas experiências, sua abertura a situações nem sempre confortáveis de serem mencionadas, suas críticas construtivas e a disponibilidade de seu precioso tempo.

Felizmente tenho muitos amigos, que, de alguma forma, sempre me incentivaram e me deram apoio. Seria difícil nomear todos, mas, mesmo sabendo que serei injusta com alguns, gostaria de mencionar uns poucos. O Marcos Píscopo por ser uma fonte de inspiração, tanto por sua belíssima tese de doutorado, quanto por sua luta pela plenitude do saber e pela vida. O Bjorn Werner Biben Frederick e a Ivete Rodrigues, doutores que, com suas teses, inspiraram-me e auxiliaram a perceber formas de desenvolver um bom trabalho. A minha amiga Franciane Silveira que, com sua energia e determinação, foi uma companheira para todas as horas e situações.

Agradeço aos professores da FEA, FFLCH/USP e FGV, aos estudantes de pósgraduação, ao pessoal da secretaria e às assistentes do Departamento de Administração. O grupo DECIDE foi relevante neste percurso pela oportunidade de me aprofundar em alguns aspectos da tomada de decisão, inclusive muito utilizados nesta tese.

Finalmente, o meu núcleo familiar que permitiu que eu chegasse até este momento com muita serenidade. Meus pais, minhas tias e meus sogros que, com seus valores, princípios e demonstrações de carinho e de orgulho, fortaleceram-me de forma que eu pudesse enfrentar os desafios. Meus filhos, Daniela e Marco, representantes da geração Y, que não me deixaram estacionar no conhecimento já alcançado, ao mesmo tempo em que me fazem feliz por suas demonstrações de carinho e por saber que gerei frutos tão inteligentes, criativos e determinados. Meu amado marido, Renato, que esteve ao meu lado todo o tempo, torcendo, respeitando minha ausência e colaborando com o que pôde para que eu chegasse até aqui. Meu amor e admiração por vocês só cresce... 


\section{RESUMO}

As inovações, motores do desenvolvimento global, viabilizam-se nas organizações por meio dos projetos. Quanto maior for o nível de inovação nesses projetos, maior é a probabilidade de existirem incertezas imprevisíveis. A identificação dos sinais precoces de uma mudança permitiria perceber essas incertezas, porém, para o reconhecimento antecipado desses sinais, é preciso também dar sentido ao que está ocorrendo, pela criação de sentido (sensemaking). Assim, este estudo tem como objetivo principal entender qual é o fator gerador da incerteza imprevisível, quais são os fatores motivadores de sua identificação e quais práticas contribuem para a criação de sentido dessas incertezas em projetos inovadores. Para tal, foi feito um levantamento de campo, de maio a dezembro de 2011, no qual foram utilizados: um questionário para se obterem informações iniciais sobre os projetos que poderiam ser considerados inovadores e, posteriormente, uma entrevista aprofundada, direcionada por um roteiro com perguntas abertas, com um dos participantes do projeto. Foram enviados 152 convites para gestores de projetos, dos quais apenas 16 projetos atenderam aos requisitos exigidos, transformando-se em unidade de análise. A cada uma dessas unidades foram solicitados, também, pelo menos dois eventos imprevistos, materialização da incerteza imprevisível, obtendo-se a quantidade de 35. Esses eventos imprevistos foram considerados unidade de análise incorporada. A análise dos dados foi inicialmente qualitativa, com a geração de variáveis e categorias avaliadas estatisticamente; posteriormente, por meio de provas não paramétricas. Com base nas análises efetuadas, foi possível observar que o nível mais alto de eficiência na identificação da incerteza imprevisível - perceber a incerteza imprevisível previamente e ter menos impacto - ocorre preferencialmente em eventos com a percepção do sinal precoce feita pelo gerente do projeto ou pelo sponsor, no início do projeto; com a existência de um fator facilitador organizacional; com a utilização de um processo de criação coletiva de sentido. O nível mais baixo de eficiência - percepção tardia do evento imprevisto e existência de mais impacto - associa-se, porém, à causa externa da incerteza imprevisível, à ausência da percepção de um sinal precoce, à presença de um fator bloqueador à identificação com origem nas características pessoais, baixo número de atividades coletivas, entre outras. Recomenda-se incorporar o diagnóstico da incerteza na gestão de riscos dos projetos, buscar informações sobre as áreas incertas do projeto e interagir para socializar o conhecimento. Futuros estudos ampliados, para se obter um número maior de eventos e projetos, poderão permitir novas associações, assim como gerar um modelo multivariado. $\mathrm{O}$ uso de métodos alternativos de gestão de projetos inovadores também se mostra como um relevante tema de pesquisa. 


\begin{abstract}
The organizations enable innovations, engines of global development, through the projects. The more innovative a project, the greater is the probability of occurrence of unforeseeable uncertainties. The identification of early signs of a change would realize this kind of uncertainty, but for the early recognition of these early signs is necessary to give sense to them, sensemaking. Thus, this study aims to understand what the main factor that generates the unforeseeable uncertainty is, what the motivating factors for their identification are and what the practices that contribute to the creation of meaning of these uncertainties are on innovative projects. To this end, a field survey has been done, from May to December 2011, with: a questionnaire to obtain initial information about the projects that could be considered innovative, and subsequently an in-depth interview, guided by a script with open questions, with one of the project participants. 152 invitations were sent to project managers, of which only 16 projects met the requirements, becoming a unit of analysis. Each of these units was also requested at least two unforeseen events, materialization of unforeseeable uncertainty, thus obtaining 35 unanticipated events, which are considered the unit of analysis embedded. Data analysis was qualitative, the generation of categories and variables were evaluated statistically through non-parametric tests. Based on the analysis performed it was observed that the highest level of efficiency in identifying unforeseeable uncertainty - it was notice in advance and it had less impact - occurred preferentially when events have had the perception of early sign made by the project manager or the sponsor at the beginning of the project, with the existence of an organizational facilitator factor, and using a collective sensemaking process. Moreover, the lowest level of efficiency - late perception of the unforeseeable event and existence of more impact - were associated with the external cause of unforeseeable uncertainty, the lack of perception of an early signal, the presence of a blocking factor identification originated from the personal characteristics, low number of collective activities, among others. It is recommended to incorporate the diagnosis of unforseeable in risk management of projects, seeking information about the uncertain areas of the project and interacting to share the knowledge. Further studies extended to obtain a larger number of events and projects may allow new associations as well as generate a multivariate statistical model. The use of alternative methods of management of innovative projects to identify unforeseeable uncertainty also appears as a relevant research topic.
\end{abstract}




\section{SUMÁRIO}

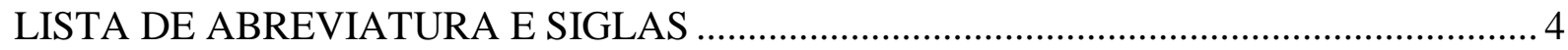

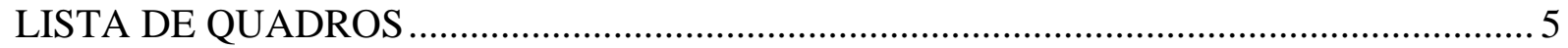

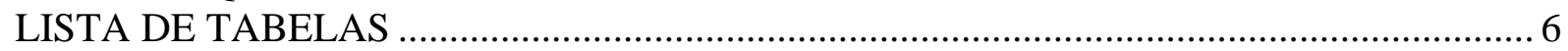

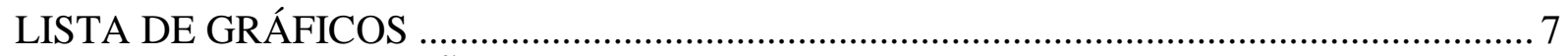

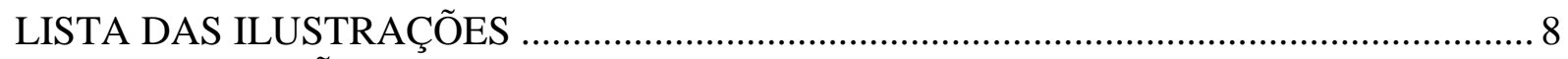

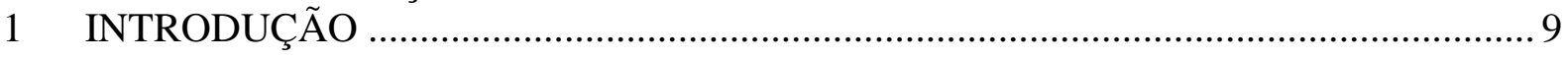

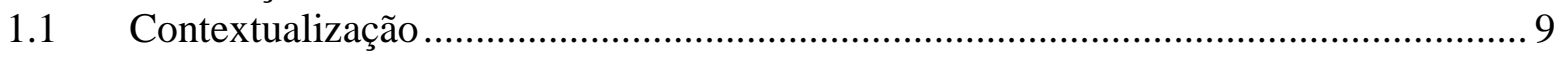

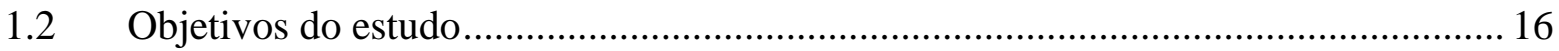

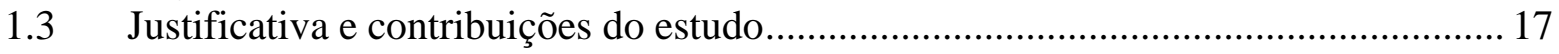

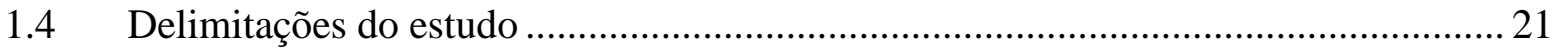

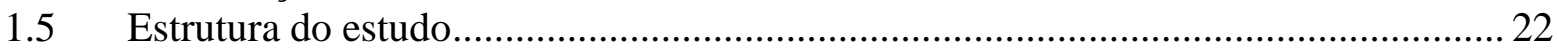

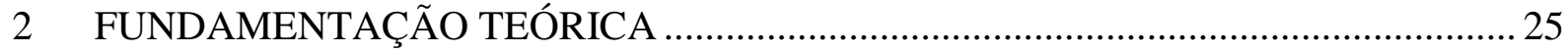

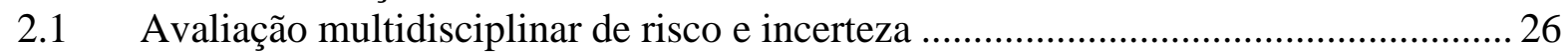

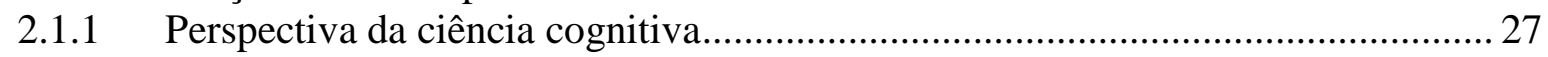

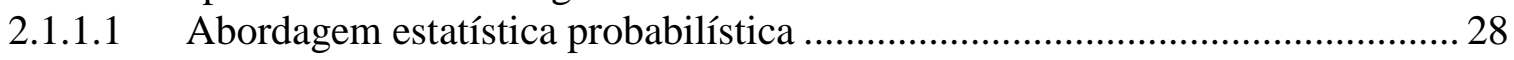

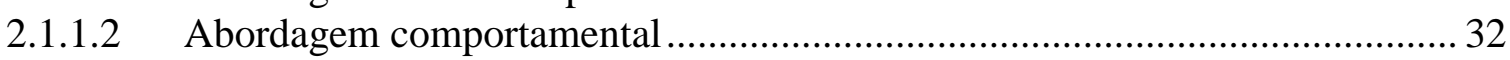

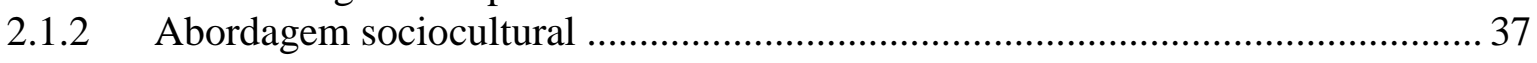

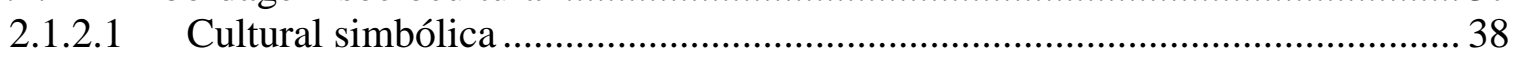

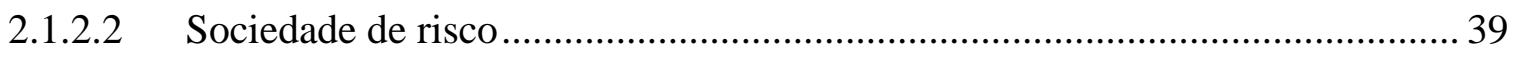

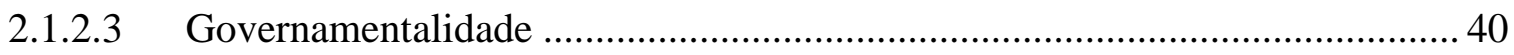

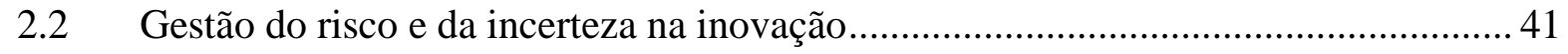

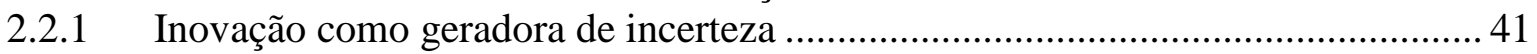

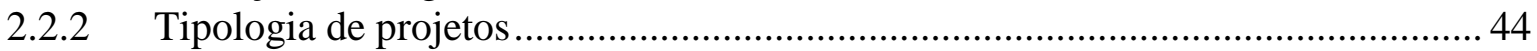

2.2.3 Abordagens diferenciadas para a GP inovadores ............................................ 52

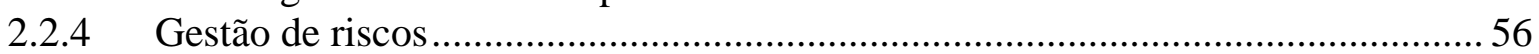

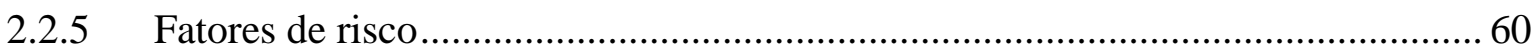

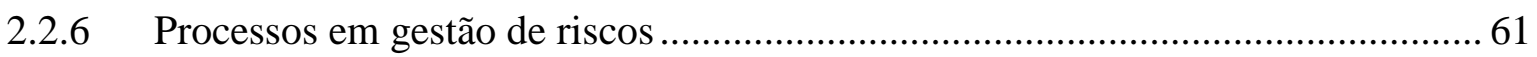

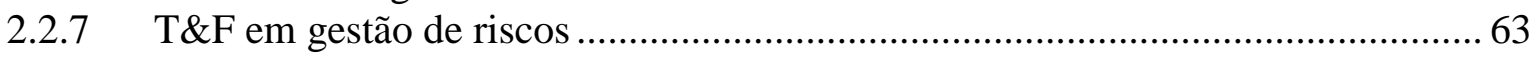

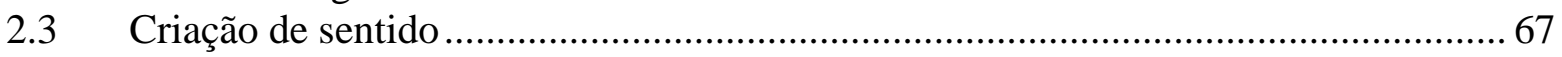

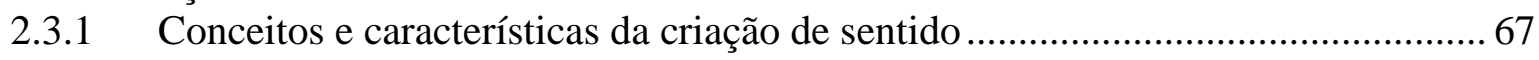

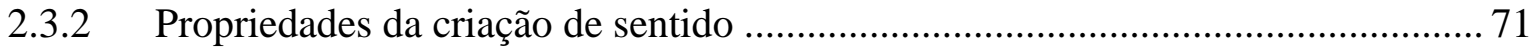

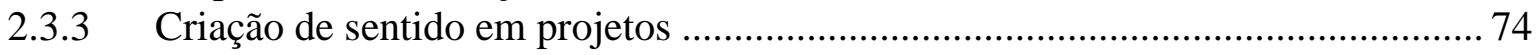

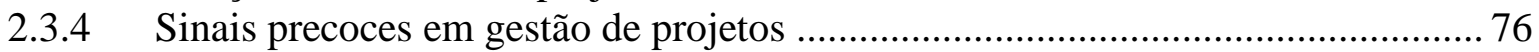

2.3.5 Práticas para a criação de sentido ..................................................................... 80

2.3.6 Fatores facilitadores à criação de sentido de incerteza imprevisível..................... 84

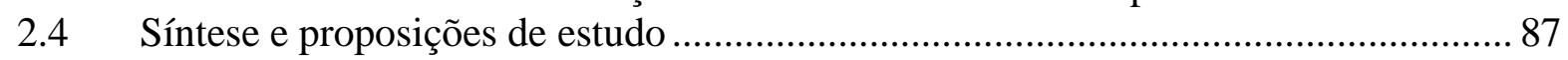

2.4.1 Avaliação multidisciplinar de risco e incerteza................................................... 87

2.4.2 Gestão do risco e da incerteza na inovação .................................................... 90

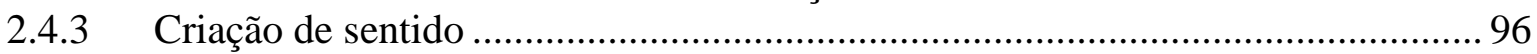

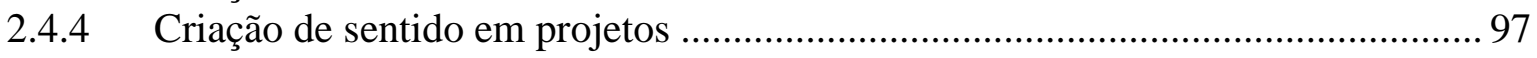

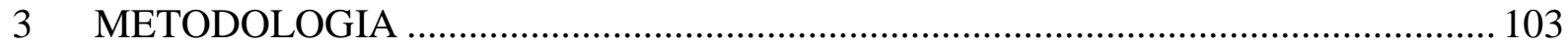

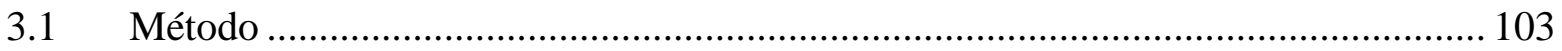

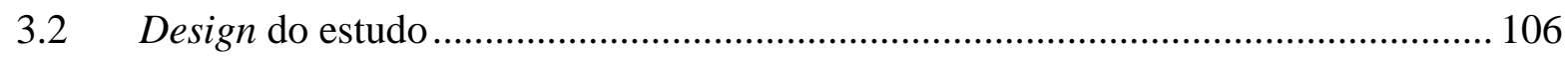

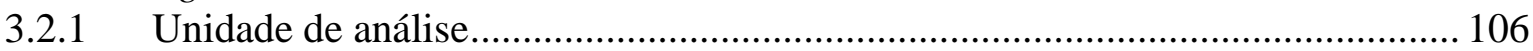

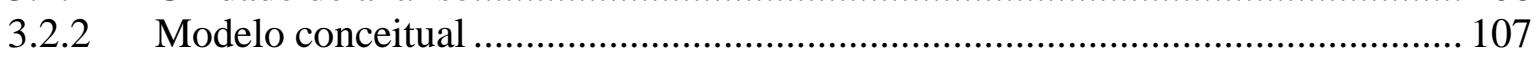




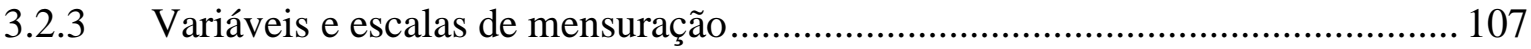

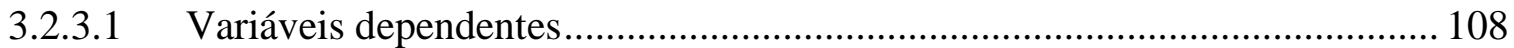

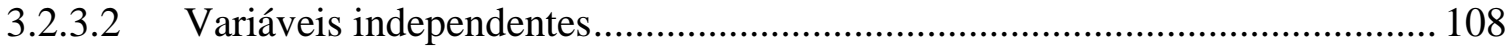

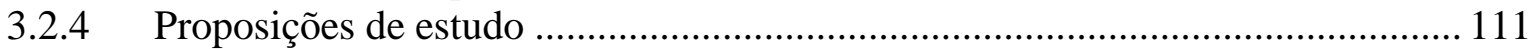

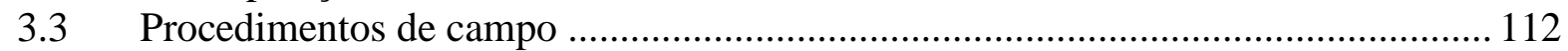

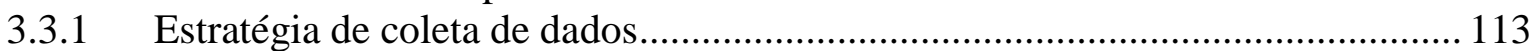

3.3.2 Perfil dos entrevistados, organizações, projetos e eventos imprevistos .............. 114

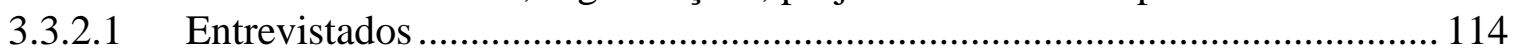

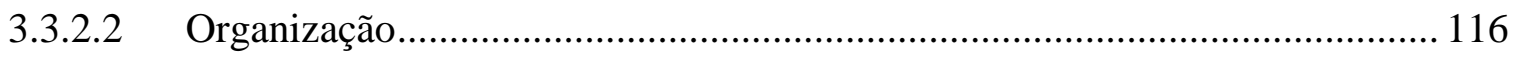

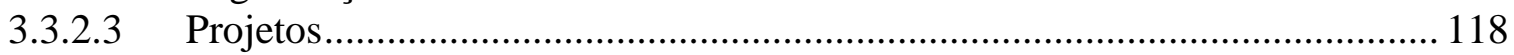

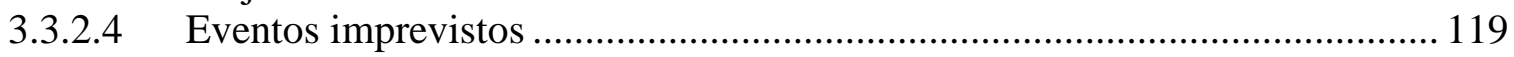

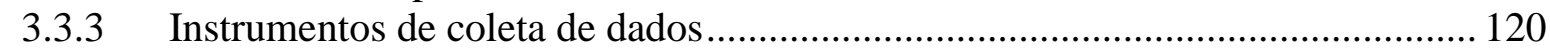

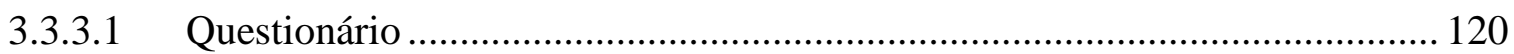

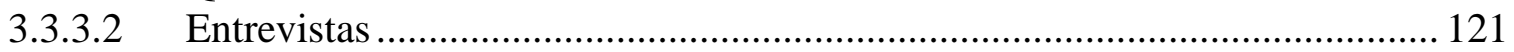

3.3.4 Estratégia e técnicas de análise dos dados qualitativos ..................................... 122

3.3.5 Técnicas de tratamento estatístico dos dados ...................................................... 126

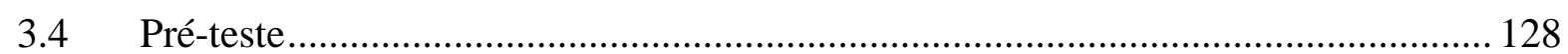

3.4.1 Pré-teste executado antes do processo de qualificação ....................................... 128

3.4.2 Pré-teste executado após o processo de qualificação .......................................... 129

3.5 Confiabilidade, validade e limitações metodológicas ........................................... 130

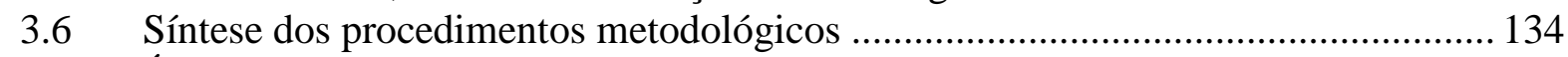

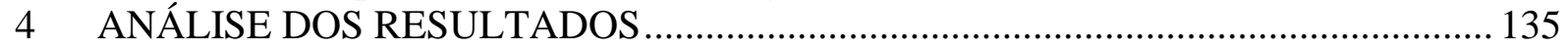

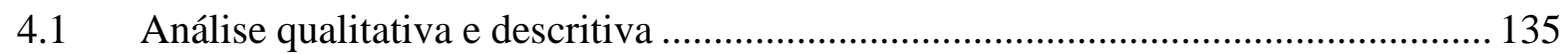

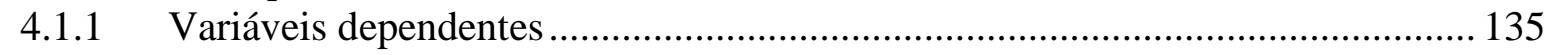

4.1.1.1 Nível de antecipação da identificação da incerteza imprevisível - NAI ....... 135

4.1.1.2 Nível de impacto do evento imprevisto - NIE.............................................. 136

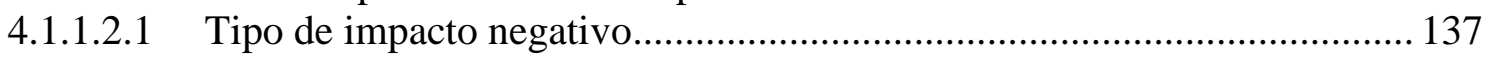

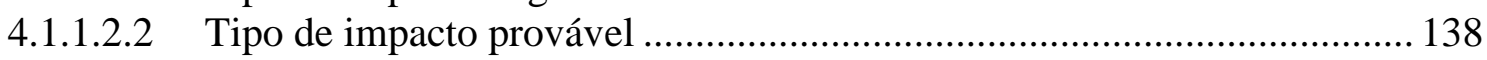

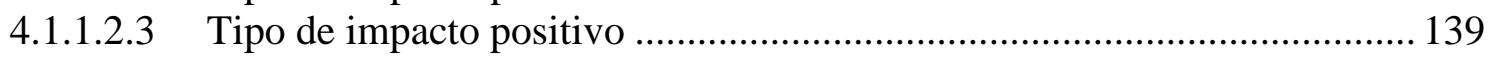

4.1.1.2.4 Relação entre o NIE e os tipos de impacto .............................................. 141

4.1.1.3 Nível de satisfação com o resultado do evento imprevisto (NSR)................. 141

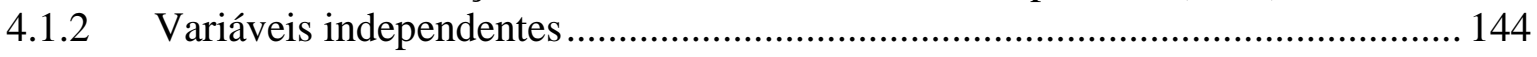

4.1.2.1 Fator gerador da incerteza imprevisível: causas ......................................... 144

4.1.2.2 Fatores motivadores da identificação da incerteza imprevisível..................... 147

4.1.2.2.1 Tipo de gestão prévia da incerteza imprevisível ...................................... 147

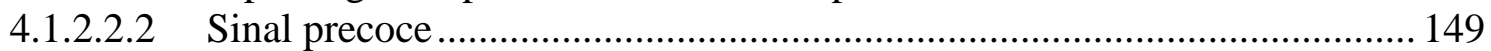

4.1.2.2.3 Relação entre as características do sinal precoce...................................... 155

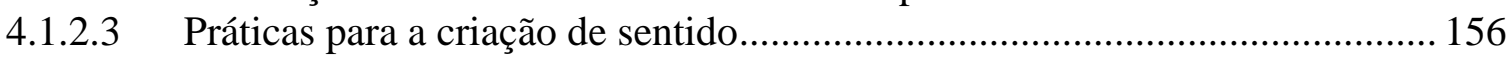

4.1.2.3.1 Atividades para a criação de sentido....................................................... 156

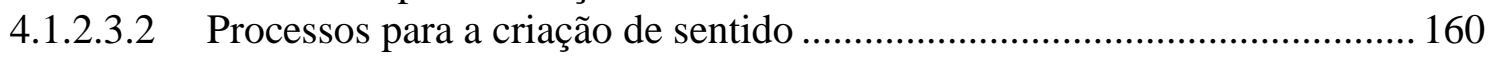

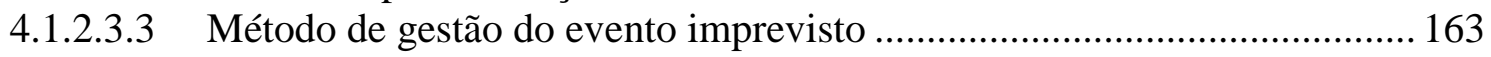

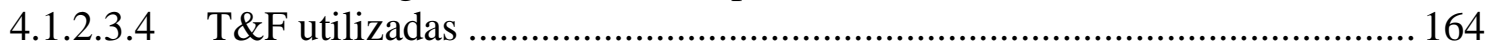

4.1.2.4 Fatores bloqueadores e facilitadores da gestão da incerteza .......................... 165

4.1.2.4.1 Fatores bloqueadores da gestão da incerteza ............................................ 165

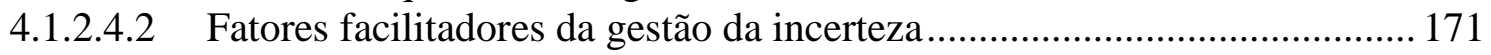

4.1.2.4.3 Fatores facilitadores idealizados da gestão da incerteza............................. 175

4.1.2.5 Características da organização: nível de cultura de atenção ........................... 179

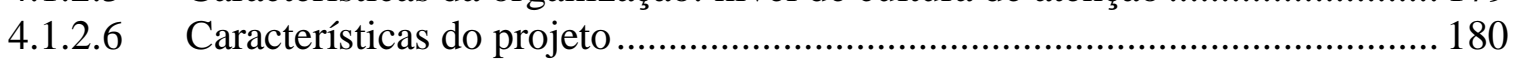

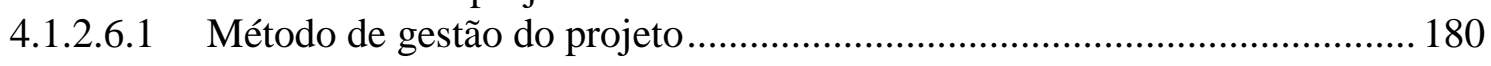

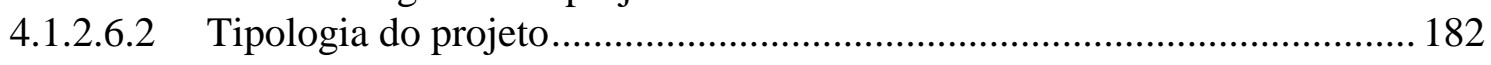


4.1.2.7 Características do gestor do projeto: tempo de experiência ............................ 186

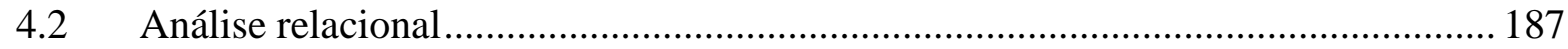

4.2.1 Relação entre as variáveis dependentes............................................................. 188

4.2.2 Relação entre as variáveis independentes e as dependentes................................ 189

4.2.2.1 Relação entre o fator gerador da incerteza imprevisível e o NAI e o NIE..... 191

4.2.2.2 Relação entre os fatores motivadores da identificação da incerteza imprevisível e as variáveis dependentes ........................................................................ 193

4.2.2.3 Relação entre as práticas para a criação de sentido e as variáveis dependentes

4.2.2.4 Relação entre os fatores bloqueadores e facilitadores e as variáveis

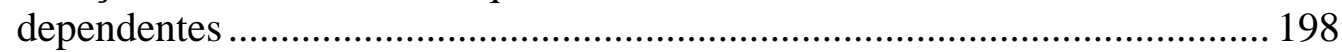

4.2.2.5 Síntese das análises entre variáveis independentes e dependentes ................. 200

4.2.3 Relação entre as variáveis independentes ............................................................ 203

4.2.3.1 Relação do tempo de experiência do gestor do projeto com o tipo de gestão prévia da incerteza imprevisível..................................................................... 203

4.2.3.2 Relação das variáveis independentes com o tipo de inovação do projeto...... 204

4.2.3.3 Relação das variáveis independentes com o NIS ....................................... 207

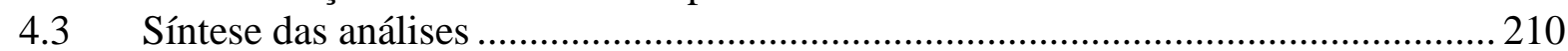

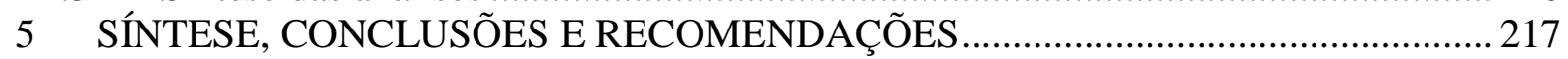

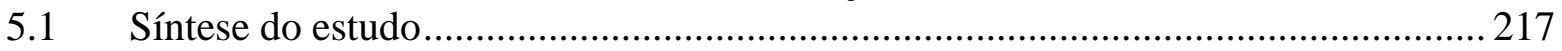

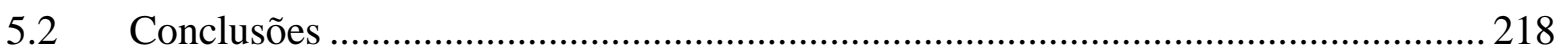

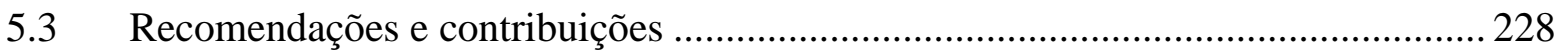

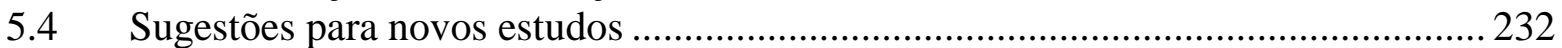

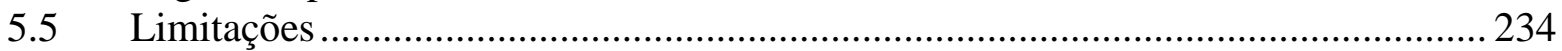

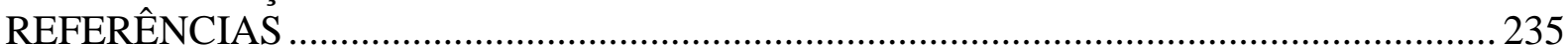

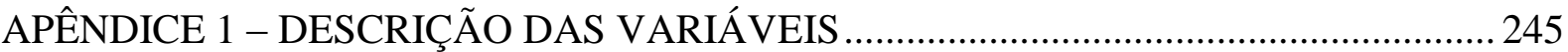

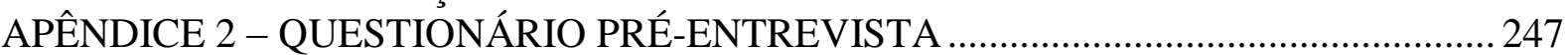

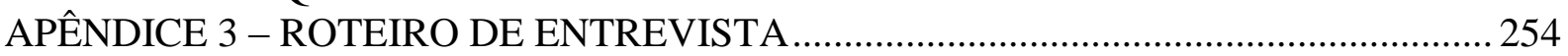

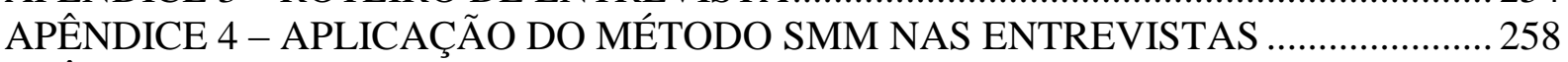

APÊNDICE 5 - ATIVIDADES E PROCESSOS OBTIDOS NAS ENTREVISTAS ............ 264

APÊNDICE 6 - DESCRIÇÃO DOS PROJETOS E DOS EVENTOS IMPREVISTOS ....... 268 


\section{LISTA DE ABREVIATURA E SIGLAS}

AHP: Analytic Hierarchy Process

BPEST: Business, Political, Economic, Social, Technological

COSO: Committee of Sponsoring Organizations of the Treadway Commission

FMEA: Failure Mode \& Effect Analysis

GP: Gestão de projetos

GR: Gestão de Riscos

Guia PMBOK: Project Management Body of Knowledge Guide

HAZOP: Hazard \& Operability Studies

IC: Inteligência Competitiva

ISO: International Organization for Standardization

LCOF: Life Cycle Objective Functions

NAI: Nível de antecipação da identificação da incerteza imprevisível

NIE: Nível de impacto do evento imprevisto

NIS: Nível de inovação em serviços

NSR: Nível de satisfação com o resultado do evento imprevisto

NTCP: N, inovação; T, tecnologia; $\mathrm{C}$, complexidade; $\mathrm{P}$, ritmo

OECD: Organization for Economic Co-Operation and Development

OGC: Office of Government Commerce

ONG: Organização Não Governamental

PESTLE: Political Economic Social Technical Legal Environmental

PMI: Project Management Institute

RBS: Risk Breakdown Structure

RH: Recursos Humanos

SEI: Software Engineering Institute

SMM: Sensemaking Methodology

SRM: Software Risk Management

T\&F: Técnicas e ferramentas

TI: Tecnologia da Informação

Unk unks: Unknown unknowns 


\section{LISTA DE QUADROS}

Quadro 1 - Perspectiva da ciência cognitiva em relação ao risco ........................................ 28

Quadro 2 - Perspectiva da abordagem sociocultural em relação ao risco .............................. 38

Quadro 3 - Cálculo do nível de incerteza do projeto e seus impactos ......................................48

Quadro 4 - Definição de risco e incerteza nos padrões de gestão de riscos ............................57

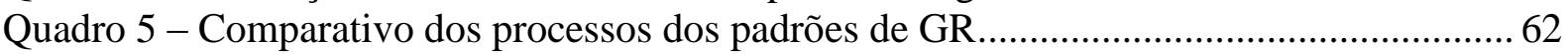

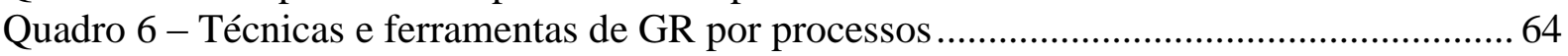

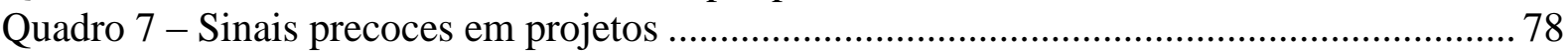

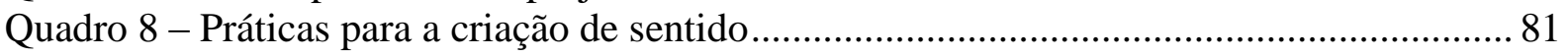

Quadro 9 - Fatores facilitadores na gestão de incertezas e riscos ........................................ 85

Quadro 10 - Ligação entre as proposições de estudo e as variáveis ...................................... 111

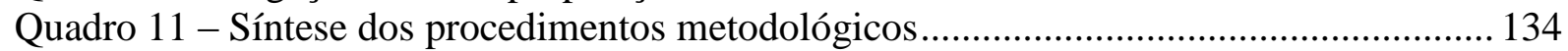

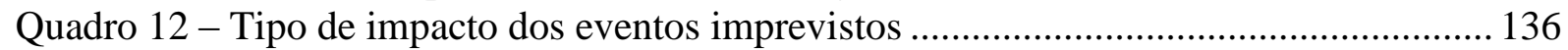

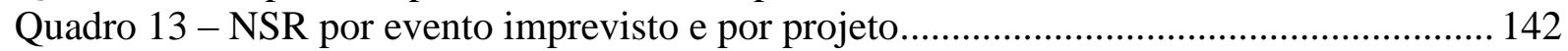

Quadro 14 - Tipos de causa da incerteza imprevisível por evento imprevisto....................... 144

Quadro 15 - Percepção do sinal precoce, quando ocorreu e quem percebeu ........................ 149

Quadro 16 - Atividades para a criação de sentido por tipo de participação e por evento

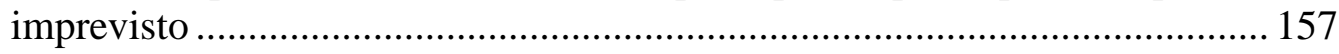

Quadro 17 - Cronologia das atividades e dos processos por evento imprevisto ................... 161

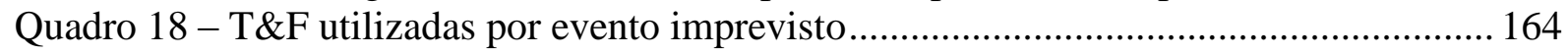

Quadro 19 - Fatores bloqueadores da gestão da incerteza por evento imprevisto ................. 166

Quadro 20 - Fatores facilitadores da gestão da incerteza por evento imprevisto ................... 172

Quadro 21 - Fatores facilitadores idealizados da gestão da incerteza por projeto ................. 176

Quadro 22 - Características dos projetos pesquisados........................................................ 182

Quadro 23 - Indicação da utilização das questões SMM no roteiro de entrevista................. 262 


\section{LISTA DE TABELAS}

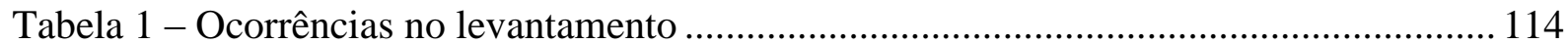

Tabela 2 - Quantidade de eventos imprevistos por NIE e os tipos de impacto ..................... 141

Tabela 3 - Quantidade de eventos imprevistos por tipo de sinal precoce e momento de sua percepção

Tabela 4 - Quantidade de eventos imprevistos por tipo de sinal precoce e quem o percebeu 156

Tabela 5 - Quantidade de eventos imprevistos por momento da percepção e quem o percebeu

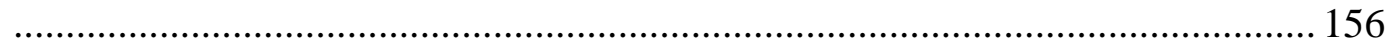

Tabela 6 - Estatísticas do nível de cultura de atenção da organização ................................. 180

Tabela 7 - Estatísticas da quantidade de envolvidos por projeto ........................................... 186

Tabela 8 - Estatísticas do tempo de experiência profissional do gestor do projeto ................ 187

Tabela 9 - Estatísticas do tempo de experiência em GP do gestor do projeto........................ 187

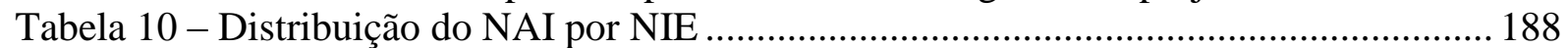

Tabela 11 - Resultado estatístico da relação entre as variáveis independentes nominais / ordinais e as dependentes ................................................................................ 190

Tabela 12 - Resultado estatístico da relação entre as variáveis independentes intervalares e

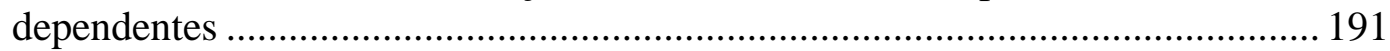

Tabela 13 - Distribuição da ocorrência de causa externa por NAI....................................... 192

Tabela 14 - Distribuição da ocorrência de causa organizacional por NAI e NIE .................. 192

Tabela 15 - Distribuição do tipo de sinal precoce por NAI e NIE ....................................... 193

Tabela 16 - Distribuição de quem percebeu o sinal precoce por NIE ................................... 194

Tabela 17 - Distribuição do momento da percepção do sinal precoce por NAI e NIE ......... 195

Tabela 18 - Distribuição do processo de coleta de informações por NIE ............................. 196

Tabela 19 - Distribuição do processo de criação coletiva de sentido por NAI e NIE ........... 196

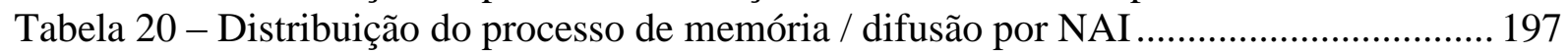

Tabela 21 - Distribuição da atividade de compartilhar por NAI .......................................... 197

Tabela 22 - Quantidade de atividades coletivas do evento imprevisto por NAI e NIE........ 198

Tabela 23 - Distribuição do bloqueador pessoal por NAI e NIE.......................................... 198

Tabela 24 - Distribuição do facilitador organizacional por NAI ............................................ 199

Tabela 25 - Distribuição do facilitador oriundo da GP por NAI e NIE............................... 199

Tabela 26 - Taxa de inércia por dimensão do mapa perceptual ............................................ 201

Tabela 27 - Resultado estatístico da relação do tipo de gestão prévia por tempo de experiência

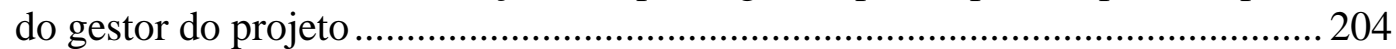

Tabela 28 - Média do tempo de experiência do gestor do projeto por tipo de gestão prévia da

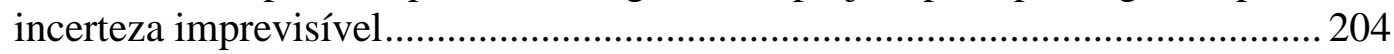

Tabela 29 - Resultado estatístico da relação entre as variáveis independentes e tipo de inovação do projeto ....................................................................................... 205

Tabela 30 - Distribuição da atividade de buscar informação externamente por tipo de

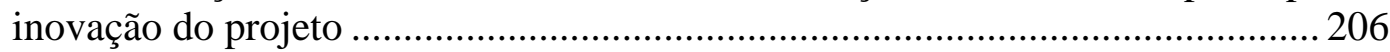

Tabela 31 - Distribuição da atividade de identificar alternativas por tipo de inovação do

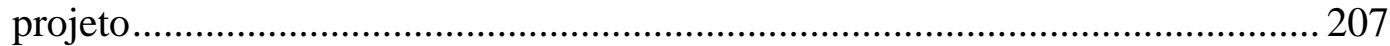

Tabela 32 - Distribuição da atividade de solucionar por tipo de inovação do projeto ........... 207

Tabela 33 - Resultado estatístico da relação entre as variáveis independentes e NIS ........... 208

Tabela 34 - Distribuição de quem percebeu o sinal precoce por NIS ................................... 209

Tabela 35 - Distribuição do momento de percepção do sinal precoce por NIS .................... 210

Tabela 36 - Distribuição de ocorrência de T\&F de avaliação do presente por NIS .............. 210 


\section{LISTA DE GRÁFICOS}

Gráfico 1- Resultados e problemas em projetos conforme tipo de abordagem à GR ............. 18

Gráfico 2 - Perfil dos entrevistados conforme o papel desempenhado no projeto ................. 115

Gráfico 3 - Tempo de experiência profissional e em GP dos entrevistados ........................... 116

Gráfico 4 - Frequência do nível de inovação tecnológica do segmento das organizações .... 117

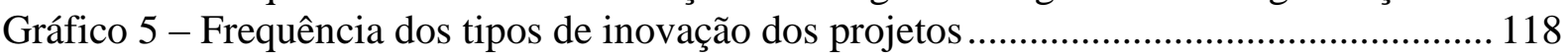

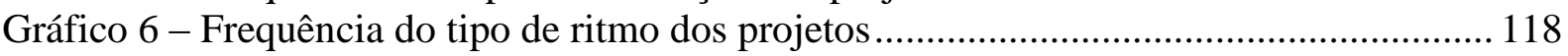

Gráfico 7 - Frequência do nível de impacto provável ou real dos eventos imprevistos ........ 119

Gráfico 8 - Frequência da duração da gestão da incerteza nos eventos imprevistos.............. 120

Gráfico 9 - Frequência dos impactos negativos e positivos nos eventos imprevistos ........... 137

Gráfico 10 - Distribuição do tipo de causa da incerteza imprevisível por tipo de gestão prévia da incerteza imprevisível .............................................................................. 148

Gráfico 11 - Frequência de ocorrência dos tipos de atividade nos eventos imprevistos ....... 158

Gráfico 12 - Frequência de ocorrência da quantidade de atividades por tipo de participação no

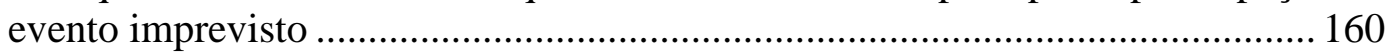

Gráfico 13 - Frequência de ocorrência dos processos para a criação de sentido nos eventos

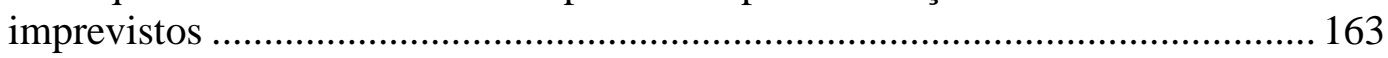

Gráfico 14 - Frequência do método de gestão dos eventos imprevistos .............................. 163

Gráfico 15 - Frequência de ocorrência de utilização de T\&F nos eventos imprevistos ......... 165

Gráfico 16 - Frequência de ocorrência dos fatores bloqueadores nos eventos imprevistos .. 171

Gráfico 17 - Frequência de ocorrência dos fatores facilitadores nos eventos imprevistos.... 175

Gráfico 18 - Frequência do método de gestão do projeto..................................................... 181

Gráfico 19 - Frequência do tipo de inovação em serviços dos projetos ................................ 183

Gráfico 20 - Medidas de discriminação das variáveis nas dimensões do mapa perceptual .. 201

Gráfico 21 - Mapa perceptual da associação entre variáveis dependentes e independentes . 203 


\section{LISTA DAS ILUSTRAÇÕES}

Ilustração 1 - Espectro da incerteza e gestão de riscos em projetos ....................................... 12

Ilustração 2 - Métodos de GP conforme incerteza e complexidade ....................................... 14

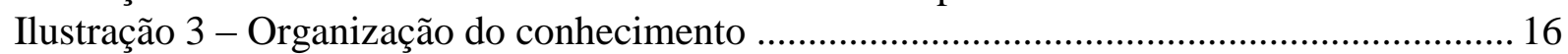

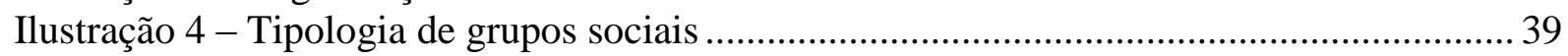

Ilustração 5 - Correntes explicativas da vantagem competitiva ........................................... 43

Ilustração 6 - Tipos de projetos de desenvolvimento ........................................................ 46

Ilustração 7 - Representação de um produto de serviço ........................................................ 50

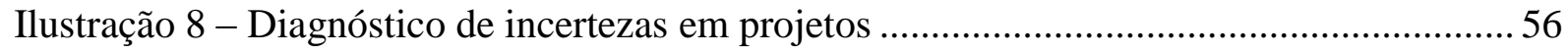

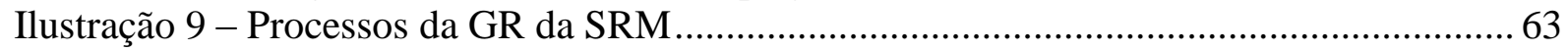

Ilustração 10 - Espectro dos estudos acadêmicos em Sensemaking ........................................ 67

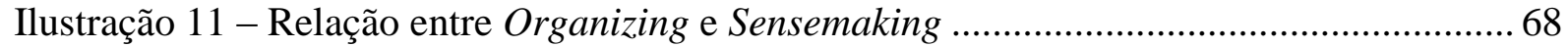

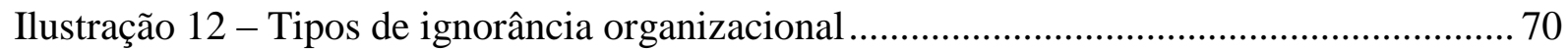

Ilustração 13 - Modelo conceitual de inteligência estratégica antecipada.............................. 81

Ilustração 14 - Processos para criação de sentido da incerteza imprevisível ..........................99

Ilustração 15 - Processo de construção de teoria ................................................................. 104

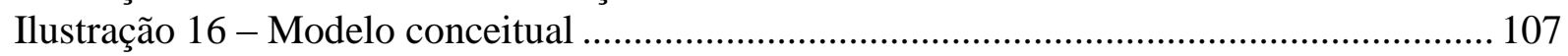

Ilustração 17 - Interação das organizações envolvidas nos projetos .................................. 117

Ilustração 18 - Modelo de processos da gestão da incerteza ............................................... 160

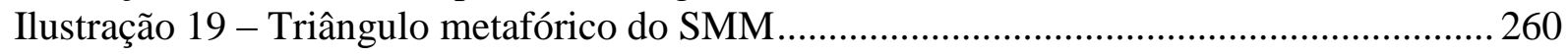




\section{INTRODUÇÃO}

\subsection{Contextualização}

O mundo está vivendo profundas mudanças na esfera política, na organização social, na forma de atuação das empresas, nos mecanismos de funcionamento das redes de confiança vigentes entre estado, empresas e pessoas. Com essa afirmação, Tilly (2001) sugere que no século XXI estamos voltando aos modelos de relações do século XVII. Ele demonstra essas mudanças pela perda da capacidade de atuação abrangente e de controle centralizado do estado, tornando-o incapaz de sustentar o bem-estar das pessoas, o walfare state, e sua condição de estado previdenciário. Ao mesmo tempo, reduz-se o alcance do seu poder para atuar na proteção às empresas num mundo em que os riscos sistêmicos ganham uma proporção superior às fronteiras nacionais. Outra demonstração dessa mudança é a crescente globalização dos mercados financeiros que rompe as fronteiras tradicionais de controle do estado, outrora soberano e, agora, passa a subordinar suas decisões a instituições supraestatais, como o Banco Central Europeu, o Banco Mundial, o FMI - Fundo Monetário Internacional).

Por sua vez, a sociedade reage à incapacidade de resposta do estado, criando novas formas de organização para além das clássicas parcerias entre governo e empresas, dando vida a inúmeras ONGs - Organizações Não Governamentais (TILLY, 2001). Essas atuam, em muitos casos, num espaço antes exclusivo do estado. Simultaneamente, novos mecanismos de interação social nascem da crescente adesão das pessoas às redes sociais virtuais que, em dimensão planetária, estabelecem um mundo sem controle ideológico nem político. Essa questão impõe a governos e às empresas a necessidade de repensar as relações políticas, sociais e econômicas, quebrando muitos dos paradigmas que serviram de referência até este momento.

Esse ambiente socioeconômico de constante mudança impõe enormes desafios às organizações. A busca pela vantagem competitiva torna o ambiente corporativo cada vez mais complexo (DIMAGGIO, 2001): centralização das atividades das empresas nas principais competências, criando novos vínculos empregatícios, como trabalhadores terceirizados; 
arriscados investimentos para aproveitar nichos de mercado; crescimento da colaboração entre as empresas, inclusive concorrentes, por meio de alianças; entre outros fatores.

Nessa linha de pensamento, Hamel (2009) afirma que o modelo de gestão das empresas deverá mudar radicalmente nos próximos anos por três motivos. O primeiro está em que, para atender as demandas do mercado, as organizações precisam mudar profunda, contínua e rapidamente, entretanto o modelo de gestão da época industrial não é capaz de prover ferramentas e técnicas para lidar com essa necessidade. Essa atuação da organização exige comprometimento integral do capital humano, pois não basta que isso ocorra apenas num projeto ou numa determinada área, mas deve-se refletir na maioria das ações organizacionais.

O segundo motivo são as ferramentas que a internet proporciona, permitindo novas formas de trabalho (Ibid.), como: a colaboração gratuita, tendo-se na criação do Linux um exemplo; a possibilidade de os funcionários trabalharem em suas próprias casas, modificando o ambiente de trabalho e a integração entre as pessoas; ou a utilização de equipes virtuais, embora dispersas geograficamente, trabalham de forma conectada e integrada. A internet também cria novos mercados e novas necessidades, por exemplo as mídias sociais, facebook e twitter, e o processamento em nuvem.

Porém, segundo Hamel (2009), o terceiro e mais relevante motivo são os diferentes valores e atitudes da força de trabalho entrante, acostumada a colaborar, criar e aprender na internet. Essa diferença está relacionada com as crenças de que "[...] todas as ideias devem concorrer em igualdade de condições." ; eles não consideram que a posição na hierarquia deva agregar pontos à credibilidade; que "[...] toda informação deve ser acessível.",2 e não apenas quando se precisa dela para atender as funções do cargo e que "[...] as pessoas devem ser medidas com base em suas contribuições e não em suas credenciais." ${ }^{33} \mathrm{Na}$ internet, as opiniões dadas não são questionadas com base na profissão e na escolaridade, mas conforme a experiência e a qualidade da informação compartilhada.

\footnotetext{
1 “[...] all ideas should compete on a level playing field."

2 "[...] all information should be accessible."

3 "[...] people should be measured on the basis of their contributions, not their credentials."
} 
Paradoxalmente, o ambiente de acelerada mudança impõe que as organizações adotem princípios de sustentabilidade como elemento essencial de vantagem competitiva. À luz de uma perspectiva sociológica, pode-se considerar que se vive na sociedade de risco (BECK, 1992), por causa da percepção dos riscos produzidos pela sociedade e, principalmente, pelas organizações de maneira secundária - riscos, neste caso, não previstos e não intencionais. Para Nidumolu et al. (2009), no futuro, apenas as organizações que possuírem a sustentabilidade como objetivo estratégico terão vantagem competitiva, desempenho econômico acima da média de mercado. Portanto, não se requer das organizações apenas a capacidade de inovação, mas também o desenvolvimento da sua capacidade de gestão dos riscos decorrentes da imprevisibilidade imposta pelo ambiente em contínua mudança.

A busca pela inovação, todavia, não se restringe apenas aos projetos estratégicos para o atendimento do mercado com novos produtos, novos negócios ou novos serviços, mas também aparece internamente, em projetos táticos e operacionais no esforço de obter incremento em sua produtividade e minimização de recursos utilizados. Uma inovação só será reconhecida, se contiver algum grau de novidade, ou seja, ela deve ser nova para a organização, para o mercado ou para o mundo (OECD, 2005). O grau de novidade da inovação está relacionado com o nível de incerteza em seu resultado (OECD, 2005) e pode residir no desconhecimento sobre a tecnologia a ser empregada, o mercado a ser atendido, o processo de produção e de distribuição etc. Quanto maior for o grau de novidade, maior será o nível de incerteza sobre o sucesso da inovação.

Logo, para essas inovações se viabilizarem, devem-se transformar em projetos que exigem investimentos, tanto para implementar a própria inovação, quanto para obter o conhecimento necessário para isso. Sobre os projetos, o nível de incerteza pode ser correlacionado com a quantidade de informação existente sobre o tema (WIDEMAN, 1992), conforme Ilustração 1:

a) knowns - quando há informação suficiente e completa sobre o que pode acontecer e sobre o seu impacto nos objetivos do projeto, a certeza é total;

b) known unknowns - se a informação for parcial, sabe-se que há alguma probabilidade de o evento correr e pode-se avaliar o provável impacto sobre os objetivos do projeto; então, a incerteza é específica ou geral;

c) unk unks - unknown unknowns - quando há completo desconhecimento do que pode ocorrer no futuro, a incerteza é total. 


\begin{tabular}{|c|c|c|c|}
\hline $\begin{array}{l}\text { Sem informação } \\
\text { (Unknown } \\
\text { Unknowns) }\end{array}$ & & & $\begin{array}{r}\text { Informação } \\
\text { Completa } \\
(\text { Knowns })\end{array}$ \\
\hline Total & Incerteza & Incerteza & Certeza \\
\hline Incerteza & Geral & Específica & Total \\
\hline
\end{tabular}

Ilustração 1 - Espectro da incerteza e gestão de riscos em projetos

Fonte: Adaptado de Wideman, 1992.

A área de conhecimento dentro da gestão de projetos que trata a incerteza é a GR - Gestão de Riscos. Wideman (1992) indicava que o escopo da GR estava entre a total incerteza e certeza total, desde que a informação a ser tratada fosse conhecida. As metodologias para GP Gestão de Projetos, como o PRINCE2 (OGC, 2005), e melhores práticas, como o Guia PMBOK - Project Management Body of Knowledge Guide (PMI, 2008), sugerem processos, $\mathrm{T} \& \mathrm{~F}$ - técnicas e ferramentas a serem seguidos e utilizados para se atingirem com sucesso os objetivos do projeto, gerindo os eventos que podem impactá-los negativa ou positivamente. Assim, os dois primeiros níveis de incerteza (knowns e known unknowns) estão englobados nessas metodologias e práticas.

O PMI - Project Management Institute (2008, p. 275) indica que "determinados riscos desconhecidos não podem ser gerenciados proativamente, para os quais se sugere que os projetos tenham um plano de contingência." ${ }^{4}$ Porém, para se gerar um plano de contingência, é necessário conhecimento sobre o risco, portanto as melhores práticas do PMI não endereçam as incertezas do tipo unk unks.

A incerteza unk unks também pode ser chamada de:

- $\quad$ risco emergente - “[...] um risco que surge mais tarde em um projeto e que não poderia ter sido identificado previamente." ${ }^{\circ}$ (PMI, 2009). Essa denominação pode incluir também os

\footnotetext{
4 "Specific unknown risks cannot be managed proactively, which suggests that project team should create a contingency plan." Na tradução do PMBOK, em português, o termo unknown foi desconsiderado, o que pode gerar erros de interpretação.

5 “A risk which arises later in a project and which could not have been identified earlier on."
} 
riscos para os quais havia informação anterior, mas por alguma razão não foram identificados nem tratados inicialmente ou

- $\quad$ incerteza imprevisível (LOCH et al., 2006, LOCH et al., 2008) - categorizada pela alta complexidade e alto nível de incerteza do projeto, por causa da lacuna do conhecimento sobre as inovações introduzidas.

Neste estudo será adotada a expressão incerteza imprevisível, pois traduz a incerteza unk unks e esclarece que o objetivo é tornar conhecido o desconhecido e não apenas tratar os eventos imprevistos e inesperados.

Para tratar as incertezas, Loch et al. $(2006 ; 2008)$ criticam as práticas atuais em GP, baseadas em planejamento prévio. Eles indicam o uso de abordagens diferenciadas conforme a combinação de incerteza e complexidade. Para isso, sugerem diagnosticar, previamente, o nível de incerteza do projeto em quatro fases. Na primeira, entende-se a estrutura do problema do projeto, para identificar os objetivos e os fatores de desempenho que devem ser alcançados, assim como as ações que devem ser executadas para alcançá-los. Na segunda fase, divide-se o problema em partes ou subproblemas, com base em forças do mercado ou módulos do projeto, por exemplo. Na terceira fase, avalia-se o nível de conhecimento de cada parte do problema, definindo o perfil de incerteza, como: variação, quando um processo de monitoramento e controle é suficiente para gerir os desvios de um planejamento padrão; incerteza prevista, quando uma GR é apropriada para gerir o nível de desconhecimento aliada à geração de planos de contingência, se necessário e incerteza imprevisível, que exige um planejamento mais flexível, realizado quando há informação suficiente. Na quarta fase, a gestão de cada subproblema é feita paralelamente.

Para a gestão desses subproblemas, os autores sugerem identificar o melhor método, pela combinação de incerteza e complexidade, considerando incerteza como a lacuna no conhecimento, conforme pode ser observado na Ilustração 2:

- baixa complexidade e baixa incerteza - práticas-padrão, por exemplo, o Guia PMBOK (PMI, 2008) e o PRINCE2 (OGC, 2005) são suficientes e eficazes para se obter sucesso nesse tipo de problema;

- baixa complexidade e alta incerteza - para superar a lacuna de conhecimento deve-se ter um aprendizado no processo. Esse aprendizado pode ser feito pelo método de 
improvisação, quando as experiências vivenciadas dirigem as ações a serem tomadas, com o planejamento e a execução ocorrendo simultaneamente; ou pela experimentação, como na tentativa e erro, que, com base num planejamento para um período curto, engloba uma avaliação da periódica da situação, prevendo a possibilidade de se modificar o planejado ou mesmo de se refazer uma parte do já feito;

- $\quad$ alta complexidade e baixa incerteza - os autores sugerem o método de selecionismo, que gera sequencial ou concomitantemente várias soluções para o mesmo subproblema, selecionando a mais adequada num determinado momento;

- $\quad$ alta complexidade e alta incerteza - os autores sugerem obter mais informações, antes de aplicar o selecionismo.

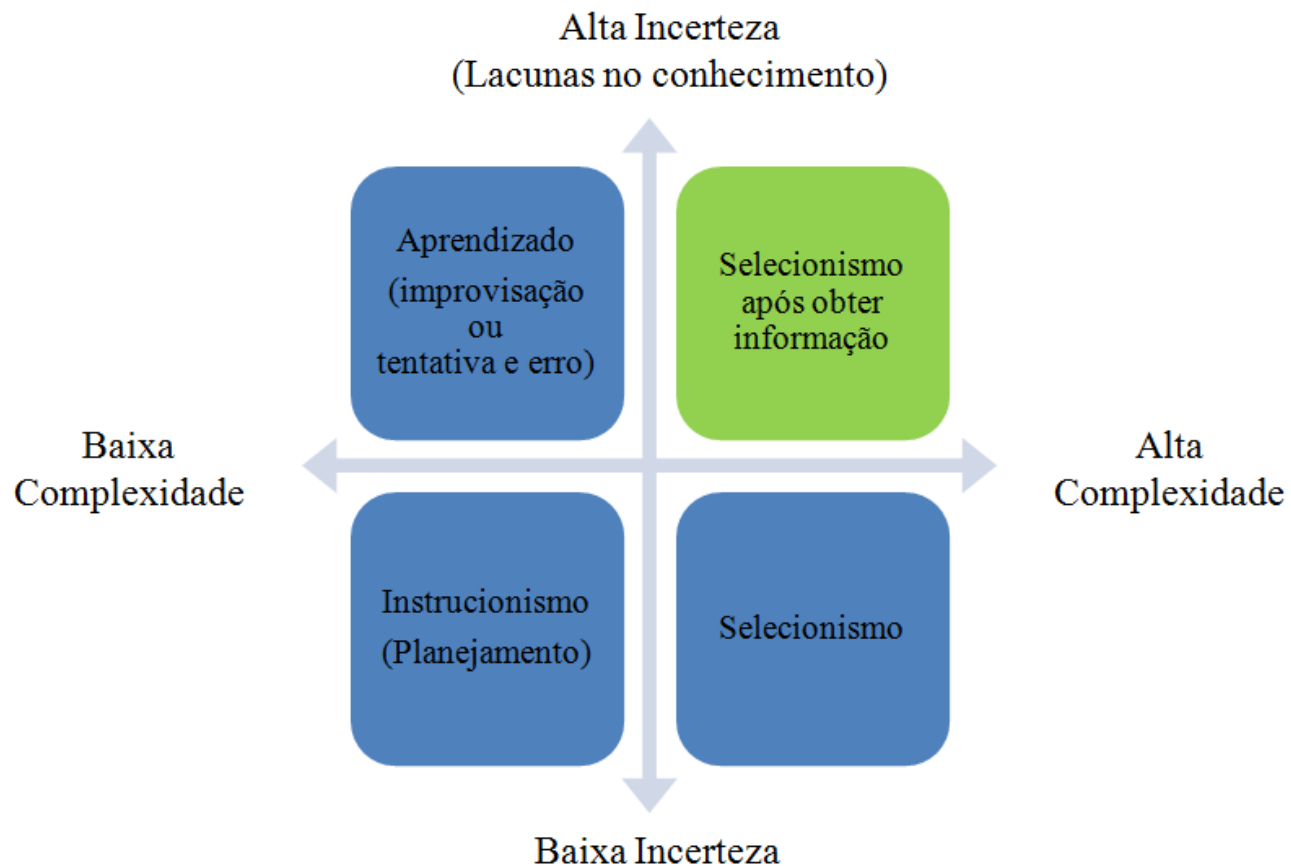

Ilustração 2 - Métodos de GP conforme incerteza e complexidade

Fonte: Adaptado de Loch et al., 2008.

Pode-se deduzir, assim, que a GR em projetos não é suficiente para que as incertezas imprevisíveis sejam identificadas e tratadas adequadamente. De fato, apesar de a GR ser um processo contínuo, Nikander e Eloranta (2001) afirmam que ela ocorre, praticamente, no início do projeto, ressaltando a importância da identificação antecipada dos sinais precoces de mudança no decorrer do projeto. 
A identificação antecipada dos sinais de uma mudança pode-se transformar numa vantagem competitiva significativa, pois pode mostrar uma interrupção no ciclo vigente, uma ruptura, benéfica ou maléfica, para os negócios (ANSOFF, 1975). Nikander e Eloranta (1997) identificaram vários grupos desses sinais: situações conflituosas e informações com conteúdo contraditório; baixa qualidade dos relatórios e respectivo atraso; atmosfera ruim na equipe; demora em decidir; atraso no cronograma e qualidade das entregas abaixo do esperado, entre outros. Apesar da relevância da identificação antecipada dos sinais, Schoemaker e Day (2009) afirmam que os problemas de excesso de informação, filtros das organizações, por exemplo a percepção seletiva e os vieses cognitivos das pessoas, fazem com que os gerentes não percebam esses sinais. Mesmo quando percebem os sinais, podem não interpretá-los corretamente.

Porém, para o reconhecimento antecipado desses sinais, é preciso também a compreensão do seu significado, pela criação de sentido. Esse é o processo pelo qual as organizações e os indivíduos trabalham as incertezas, as ambiguidades, as mudanças, as situações problemáticas, gerando invenções e novas situações, que resultam em ações que levam à solução dos problemas e à estabilidade do ambiente. O principal é que haja sentido no sinal identificado, isto é, que ele seja plausível para os envolvidos, compreensível para eles. Weick (1995) denominou esse fenômeno de sensemaking, traduzido neste estudo por 'criação de sentido'.

Para Choo (1996; 2001), a criação de sentido (sensemaking) é o primeiro de quatro processos complementares, segundo Ilustração 3, pelos quais uma organização do conhecimento usa as informações de forma estratégica. No primeiro processo, as pessoas criam o sentido para as mudanças, eventos e ações no ambiente organizacional, que podem tornar-se conhecimento tácito, difícil de formalizar e comunicar, e / ou explícito, que é o conhecimento formal. O segundo processo é a criação de sentido, a transformação do conhecimento tácito em explícito e do individual em organizacional por meio da qual são gerados novos conhecimentos. Para uma organização orientada para a inovação, essa criação de conhecimento é primordial, pois é fonte das ideias, oportunidades e soluções alternativas, inclusive para a consolidação do aprendizado organizacional. Além disso, as organizações buscam esses conhecimentos e essas informações para sustentarem as decisões a serem tomadas, que é o terceiro processo, principalmente baseadas em escolhas racionais, que requerem informações confiáveis sobre as 
alternativas, suas consequências e preferências para avaliar os resultados. Finalizando, o quarto processo é a ação organizacional que transforma o abstrato em concreto, as ideias em projetos e em realizações.

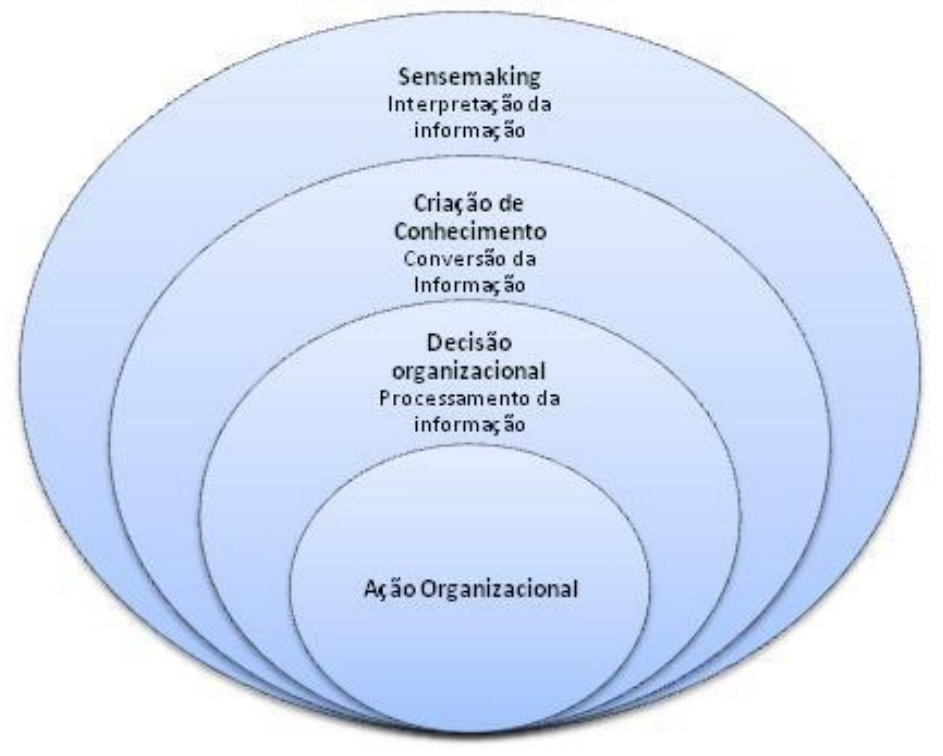

Ilustração 3 - Organização do conhecimento

Fonte: Adaptado de Choo, 2001.

Portanto, nesse mundo de mudanças contínuas, profundas e rápidas, entender a criação de sentido da incerteza imprevisível é importante para compreender como as pessoas agem para interpretar o desconhecido em seus projetos. A criação de sentido é a "realização contínua por meio da qual as pessoas criam suas situações e ações, tentando torná-los racionalmente responsáveis perante si e os outros."6 (ALLARD-POESI, 2005, p. 171). É a própria invenção do significado baseado nas interações diárias, em improvisação, em intuição, em refazer, rotular, descartar velhas e firmes concepções, articular, legalizar, acreditar e principalmente substanciar o sujeito de sua invenção.

\section{Objetivos do estudo}

\footnotetext{
6 “'...] ongoing accomplishment through which people create their situations and actions and attempt to make them rationally accountable to themselves and others."
} 
Os projetos inovadores são caracterizados por apresentarem mais riscos, mais incertezas imprevisíveis. Essas incertezas, lacunas no conhecimento, precisam ser identificadas de forma eficiente e preventiva, para que o projeto possa ser bem-sucedido. Quando a incerteza imprevisível se concretiza, torna-se um evento imprevisto no projeto. Portanto surge a necessidade de se identificarem as práticas - métodos, processos, atividades, técnicas, ferramentas - que levem os gestores e a própria equipe do projeto a criarem o significado e identificarem essas incertezas a partir dos sinais precoces emitidos pelo ambiente ou pela gestão prévia da incerteza.

Assim, o principal objetivo deste estudo é descrever e entender os fatores e práticas que contribuem para a criação de sentido das incertezas imprevisíveis em projetos inovadores. Para tal finalidade, o objetivo principal foi desmembrado nos seguintes objetivos secundários:

a) descrever o fator gerador da incerteza imprevisível - causas - e os fatores motivadores de sua identificação - tipo de gestão prévia da incerteza imprevisível e sinal precoce;

b) levantar as práticas de criação de sentido para a identificação e a gestão da incerteza imprevisível - métodos de gestão do evento imprevisto, processos, atividades, técnicas e ferramentas;

c) entender os fatores que bloqueiam e facilitam a gestão da incerteza imprevisível;

d) avaliar a eficiência da identificação da incerteza imprevisível;

e) analisar as relações da eficiência da identificação da incerteza imprevisível com o fator gerador, os fatores motivadores, as práticas para a criação de sentido, os fatores bloqueadores, os facilitadores e as características organizacionais, do projeto e dos gestores.

\subsection{Justificativa e contribuições do estudo}

A partir das informações de 460 organizações, disponíveis pela pesquisa de Benchmarking no Brasil (PMI BRASIL, 2010), foi gerado o Gráfico 1. Os grupos de colunas estão divididos pelo uso da GR em projeto. Conforme pode ser observado nesse gráfico, a maioria das organizações, $53 \%$, trata a GR de forma informal e uma pequena minoria,11\%, sequer a considera em sua metodologia. Essa evidência corrobora a afirmação de Raz et al. (2002), com base nos projetos avaliados por seu estudo, que a GR não é amplamente usada. Porém 
eles destacam que o nível de utilização é maior nos projetos com mais incerteza tecnológica e nos mais arriscados.

Pode-se perceber que o uso da GR gera uma tendência positiva no sucesso dos projetos, conforme a linha destacada no Gráfico 1, diminuindo os problemas com prazo e qualidade, mas não afetando consideravelmente os problemas com custo. Na pesquisa, cada respondente informou os benefícios obtidos com a metodologia de GP implantada em sua organização. O reconhecimento da minimização dos riscos segue a tendência positiva do sucesso de projetos, pois, quanto mais se usa a GR, mais reconhecimento existe dos respondentes. É interessante observar que, apesar de usarem a GR formalmente, apenas 54\% consideram esse benefício relevante. Logo, pode-se afirmar que ainda há espaço para melhoria da GR dos projetos no Brasil.

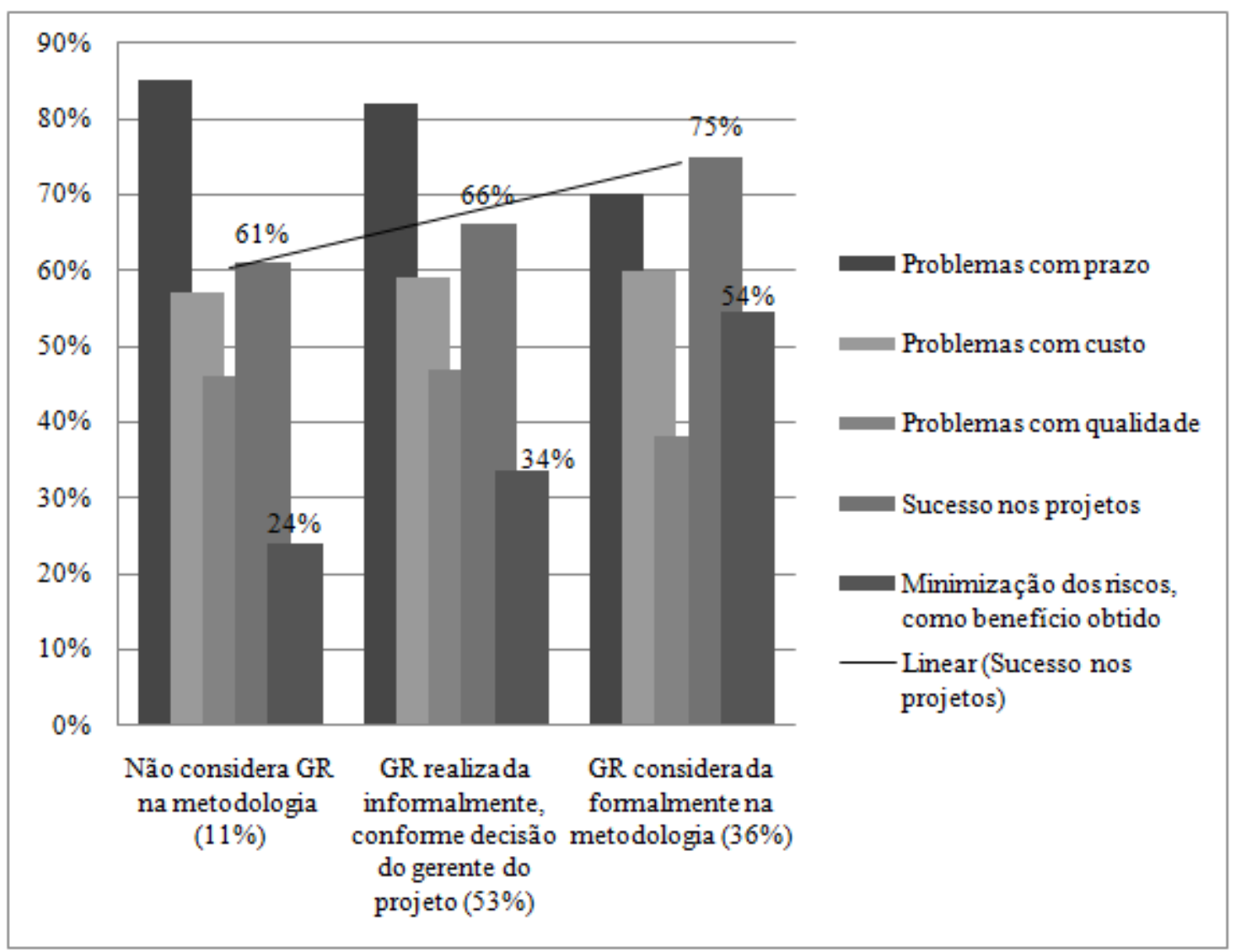

Gráfico 1- Resultados e problemas em projetos conforme tipo de abordagem à GR Fonte: Adaptado de PMI - CHAPTERS BRASILEIROS.

Vários autores (LOCH et al., 2006; MURRAY-WEBSTER, PELLEGRINELLI, 2010; PENDER, 2001; PERMINOVA et al., 2008) afirmam que a GR baseada no planejamento não 
é suficiente para gerir as incertezas geradas pelas restrições e pelas áreas do projeto não definidas claramente. Para solucionar os problemas advindos do nível de incerteza e da ignorância sobre as informações, Pender (2001) recomenda as seguintes soluções para a GP: as reservas de tempo e custo, a abordagem por ondas e a importância da comunicação, principalmente por causa imprecisão ${ }^{7}$ na definição de parâmetros e resultados. Esse autor critica o Guia PMBOK (PMI, 2008) ${ }^{8}$ por não esclarecer detalhadamente como usar essas soluções. Ele sugere, ainda, a abordagem de opções ao planejamento do projeto, de forma que as alternativas sejam avaliadas também pela flexibilidade, permitindo a incorporação de ganhos de oportunidade futuros.

Concluindo a discussão sobre a GP, se a gestão da incerteza imprevisível for tão relevante que justifique uma abordagem diferenciada à GP, como propõe Loch et al. (2008), deveriam existir processos e práticas definidos para isso. Além disso, conforme a Ilustração 2, o método sugerido pelos autores para esse caso é o selecionismo, após se obter mais informação. Porém, no artigo, eles exemplificaram e categorizaram o método usado como aprendizado, logo há espaço para uma avaliação dessa proposição mais aprofundada.

Outro tópico importante para a identificação da incerteza imprevisível são os sinais precoces de mudança. Há vários estudos que avaliaram a gestão dos sinais precoces em projetos, mas alguns os relacionavam com o sucesso dos projetos (KAPPELMAN et al., 2006; SANCHEZ, PEREZ, 2004), com problemas (NIKANDER, ELORANTA, 1997) e ainda com riscos (NIKANDER, ELORANTA, 2001). Porém em nenhum deles as práticas para a criação de sentido dos sinais precoces são avaliadas. A tese de doutorado do finlandês Nikander (2002) é o trabalho que mais se aproxima dos objetivos propostos neste estudo. Sua abordagem, apesar de detalhar o processo de gestão dos sinais precoces nos projetos, foca a relação desses com os problemas e suas respectivas causas. Ele também não explora por qual processo os sinais precoces são entendidos, discutidos, tratados, ou seja, qual é o processo de criação de sentido utilizado.

\footnotetext{
${ }^{7} \mathrm{O}$ autor chama de fuzziness.

${ }^{8}$ No livro de padrão de riscos (PMI, 2009), as reservas continuam a ser sugeridas, mas não há uma fórmula ou técnica mais precisa. É apontado como uma das saídas da simulação de Monte Carlo.
} 
Perminova et al. (2008) sugerem, entre outras coisas, o uso da criação de sentido, que permite flexibilidade e rapidez na decisão sobre as alternativas de ações para responder às situações. No estudo de Winch e Maytorena (2009), foi usada a criação de sentido na avaliação do desempenho na identificação de riscos pelos gerentes de projetos por meio de um experimento. Entretanto os riscos estavam previamente identificados pelo grupo de pesquisadores, não permitindo, consequentemente, avaliar a identificação de incertezas imprevisíveis e emergentes.

Este estudo justifica-se pela pretensão de contribuir e, se possível, estender teorias existentes (LOCH et al., 2006; LOCH et al., 2008), preenchendo lacunas. Como base para a interpretação da realidade dos projetos foi usada a teoria da criação de sentido (WEICK, 1995), muito utilizada na IC - Inteligência Competitiva para entender as incertezas do ambiente externo e interno das organizações. Este estudo também se justifica pela necessidade de as organizações melhorarem seus indicadores de sucesso em projetos, pois o foco é agir de maneira proativa para tornar o desconhecido e incerto em conhecido.

A gestão dos riscos não é uma prática só da área de projetos, nem mesmo é um conceito restrito à Administração. Ele permeia hoje, mais do que em tempos passados, a sociedade, a política e a cultura. Várias áreas estão aprofundando o seu entendimento, que não pode ser compreendido apenas por uma visão racionalista e realista, mas também por uma abordagem construtivista. Por conseguinte, além de estudos baseados em análises quantitativas, devem ser empregados outros métodos, para se conhecer com mais profundidade a prática das organizações. Essa é uma contribuição deste estudo, dado que a abordagem metodológica, como se verá em mais detalhes no Capítulo 3, será a abordagem qualitativa.

A fundamentação teórica baseia-se nas teorias de Loch et al. $(2006 ; 2008)$ as quais se propõe neste estudo aprofundar ou mesmo estender, para identificar métodos mais efetivos para gerir a incerteza e a complexidade dos projetos. Além disso, a incorporação de questões e de teorias de outras áreas nos estudos de GR em projetos enriquece o estudo, na medida em que se amplia o escopo de constructos a serem observados. Kwak e Anbari (2009) mostram que essa é uma tendência na área de projetos e incentivam a ampliação do entendimento dessa gestão pelo domínio de outras áreas. Este estudo coloca-se nessa tendência, pois incorpora conceitos 
amplamente utilizados na área de IC, como o sinal precoce (ANSOFF, 1975) e a criação de sentido (WEICK, 1995), esta última, da área de Psicologia Organizacional.

As recomendações a serem feitas poderão contribuir, na prática, para as organizações identificarem suas incertezas, ou a própria ignorância (WYNNE, 1992) gerada pela inovação e pela complexidade dos inúmeros fatores envolvidos no projeto. Espera-se que as contribuições alcancem também projetos com menos incerteza e menos complexidade, pois incertezas imprevisíveis (unk unks) podem existir em qualquer tipo de projeto.

Com isso pode-se obter maior aprofundamento do fenômeno da incerteza imprevisível, com soluções mais plausíveis e efetivas do que as melhores práticas atualmente estabelecidas para a GR em projetos, de forma que a própria sociedade possa prosperar de maneira mais rápida, eficaz e sustentável.

\subsection{Delimitações do estudo}

Em termos teóricos, o foco deste estudo está na teoria organizacional, na psicologia da organização, na gestão e na estratégia corporativa, que pode ser avaliado tanto na esfera da equipe quanto da organização, especificamente ao tema de GP inovadores. A incerteza normalmente é estudada dentro da subárea da gestão chamada gestão de riscos Essa área foi ampliada, estudando-se como as incertezas imprevisíveis são identificadas e gerenciadas num projeto, sob a interpretação da criação de sentido dessas incertezas.

Estabeleceu-se que o projeto inovador será reconhecido pelo nível de inovação para a organização, o que exige obtenção de novas competências, mesmo o produto do projeto não representando uma inovação para o mercado. A nova competência já embute um alto nível de desconhecimento, que pode gerar as incertezas imprevisíveis.

Entretanto, só é possível avaliar a incerteza imprevisível, após ela deixar esse estado, pois antes não se tem conhecimento dela. Por isso, para este estudo, o foco está na ocorrência do evento imprevisto, portanto materialização da incerteza imprevisível. 
Para estabelecer o limite temporal de observação da identificação e gestão da incerteza imprevisível, assumiu-se a premissa de que as incertezas imprevisíveis emitem sinais que podem ser percebidos antes de sua ocorrência. As pessoas podem ou não perceber esses sinais e, percebendo, podem ou não criar o sentido (sensemaking ou sense-unmaking). Logo, a delimitação do estudo está entre o momento da percepção do sinal precoce ou ações sobre a incerteza imprevisível (unk unks), como a busca de informação, até o momento em que ela se torna conhecida (know unknowns ou know knowns).

\subsection{Estrutura do estudo}

Este estudo consiste em cinco capítulos: introdução, fundamentação teórica, metodologia, análise dos resultados e conclusões. Este capítulo contextualiza o leitor, introduzindo o tema estudado. Expõe-se a necessidade de lidar com as incertezas advindas das inúmeras inovações que a empresa enfrenta ao gerar produtos e serviços inovadores, ao introduzir modificações em sua maneira de trabalhar ou mesmo para se adequar às exigências do mundo atual. A viabilização da inovação na organização ocorre por meio dos projetos, que enfrentam os vários tipos de incertezas. As mais problemáticas são as incertezas imprevisíveis, dado que há completo desconhecimento do que pode ocorrer. A identificação antecipada dos sinais de uma mudança imprevista pode, portanto, transformar-se numa vantagem competitiva significativa. Porém, para o reconhecimento antecipado desses sinais, é preciso também a compreensão do seu significado, pela criação de sentido. Os objetivos deste estudo para descrever e entender os fatores e práticas que contribuem para a criação de sentido das incertezas imprevisíveis em projetos inovadores são formalmente apresentados, assim como a justificativa e suas delimitações.

O segundo capítulo traz a teoria necessária para fundamentar o estudo, abordando os temas de risco e incerteza e criação de sentido. Com relação ao risco e à incerteza, aborda-se a teoria de duas formas: uma visão sociológica - perspectiva da ciência cognitiva e abordagem sociocultural - e uma visão administrativa - gestão do risco empresarial e de projetos explorando os vários tipos de métodos e padrões utilizados. O último item apresenta a criação de sentido e sinais precoces, por meio de seus conceitos e propriedades, além de se apresentarem os estudos ligados à GP. Finaliza-se, com uma síntese e as proposições de estudo. 
No terceiro capítulo, apresentam-se as estratégias e os procedimentos metodológicos adotados neste estudo, demonstrando-os e justificando-os. O modelo conceitual é apresentado, assim como as variáveis e proposições de estudo. Os procedimentos de campo são expostos informando as ocorrências, o perfil dos entrevistados e os instrumentos de coleta de dados. As técnicas utilizadas tanto na análise qualitativa, quanto na quantitativa são explicadas e exploram-se as limitações do estudo, no item seguinte. Finaliza-se com uma síntese dos procedimentos metodológicos.

O quarto capítulo apresenta as análises e resultados obtidos, primeiramente com a análise qualitativa e descritiva das variáveis estabelecidas no modelo conceitual. No segundo item desse capítulo, apresenta-se a análise relacional entre as variáveis independentes e dependentes. Demonstram-se também algumas análises especiais aplicadas para atender proposições de estudo específicas. Finaliza-se com uma síntese da análise efetuada.

No quinto e último capítulo, conclui-se o estudo, apresentando-se uma síntese e relatando os resultados de cada proposição de estudo definida nos capítulos anteriores. Fazem-se recomendações de cunho teórico e prático, a partir dos resultados alcançados, e sugestões de estudos que podem ampliar e expandir as considerações aqui apresentadas, assim como são ressaltadas as limitações deste. 


\section{FUNDAMENTAÇÃO TEÓRICA}

O objetivo deste capítulo é descrever os constructos utilizados neste estudo: incerteza imprevisível, projetos inovadores e criação de sentido (sensemaking). O primeiro item descreve o risco e a incerteza, por intermédio de uma avaliação multidisciplinar, interpretada à luz de várias abordagens, importantes para uma visão global e contextual do problema deste estudo.

O segundo item trata da GR - Gestão de Riscos, e da incerteza, no âmbito administrativo e organizacional, ligando o construto incerteza imprevisível com o construto projeto inovador. Em primeiro lugar, a conceituação de inovação foi necessária para entender o seu significado e a sua influência nas organizações e nos projetos. Na sequência, a tipologia de projetos é descrita para se identificarem as características dos projetos nos quais a incerteza imprevisível é mais provável de ocorrer, os projetos inovadores. Dependendo do tipo de projeto, não basta aplicar uma metodologia-padrão, por isso é importante destacar as atuais abordagens diferenciadas para a GP com alto nível de incerteza. Prosseguindo o aprofundamento dos construtos, a definição de risco e incerteza nos padrões da GR é analisada, por meio de uma avaliação crítica com o foco do tratamento das incertezas imprevisíveis. Os fatores de risco foram descritos, classificados e exemplificados. Em seguida, os processos das melhores práticas são comparados, detalhando-se as $\mathrm{T} \& \mathrm{~F}$ - técnicas e ferramentas indicadas para cada um desses processos.

No terceiro item conceitua-se o construto criação de sentido (sensemaking), com sua origem, características e propriedades, ligando-o com o construto projeto inovador. Neste item também são destacados os sinais precoces em projetos, que permitem identificar antecipadamente a mudança do contexto e, com isso, obter um entendimento ou mesmo a identificação antecipada da incerteza imprevisível. Em seguida, foram identificadas as práticas para a criação de sentido, tanto em projetos quanto em organizações, para avaliar a sua utilização e aplicabilidade nos projetos com incerteza imprevisível. Finalizando o item, os fatores facilitadores da criação de sentido da incerteza imprevisível são descritos. 
Concluindo o capítulo, é apresentada uma síntese dos conceitos destacados acima, para justificar e explicar as proposições de estudo que aqui são declaradas.

\subsection{Avaliação multidisciplinar de risco e incerteza}

Percebe-se uma rápida expansão do interesse e da consciência do risco pela sociedade (TAYLOR-GOOBY; ZINN, 2008). Esse interesse tem origem nas mudanças na sociedade, no alto nível de inovação tecnológica dos produtos e serviços disponíveis, pelo surgimento de novos estilos de vida e de novas profissões, pela diminuição da garantia de emprego com os novos formatos de contrato de trabalho, entre outros.

O vocábulo 'risco' tem origem controversa. Dentre tantas supostas origens, é importante ressaltar a palavra árabe Risq, "algo do qual se pode extrair lucro", e a palavra em latim, Risicum, "o desafio colocado a um navegador por uma barreira de recifes" (TAYLORGOOBY; ZINN, 2008). Esses significados podem ser ligados, respectivamente, aos conceitos atualmente vigentes de oportunidade e risco.

Com o desenvolvimento da matemática e da probabilidade, no século XVIII surgiu o seguro mercantil, primeira utilização do conceito de risco na área de negócios. Os impactos tornaram-se previsíveis, pela possibilidade de se calcular o valor da carga e da ocorrência de um sinistro, de acordo com as leis da chance, obtidas pela experiência dos eventos anteriores (TAYLOR-GOOBY; ZINN, 2008). O conceito foi sendo utilizado cada vez mais em outras áreas devido à: forte evolução tecnológica; mudança da situação da mulher na sociedade; diferentes modos de vida; globalização e flexibilização do emprego; riscos nos negócios, seguros pessoais, saúde, ambiente, crime. Nesses casos, o foco é o perigo, o dano, a ameaça.

Até meados do século $\mathrm{XX}$, os grandes riscos eram bancados pelos governos. Com a incapacidade de eles acompanharem financeira e tecnologicamente as exigências da sociedade, surgiu a necessidade de que os indivíduos também assumissem riscos, gerando novos negócios e novas empresas, criando-se o conceito e o estímulo ao empreendedorismo. Assim, a visão de risco como oportunidade surge novamente no cenário. 
Wynne (1992) considera que, por mais que o conhecimento científico tenha evoluído nos últimos tempos, não se pode assegurar que todas as dimensões de perigo possam ser avaliadas de maneira completa. Ele divide o risco em quatro categorias:

- $\quad$ risco - quando se conhece a probabilidade tanto da ocorrência do evento, quanto de seus prováveis resultados, o que permite o uso de técnicas estruturadas de análise;

- $\quad$ incerteza - as variáveis envolvidas são conhecidas, mas não se conhece a extensão do grau da disponibilidade de sua ocorrência ou de seus resultados; mesmo assim ainda há técnicas sofisticadas que podem ser usadas;

- ignorância - “[...] o qual por definição escapa do reconhecimento.” 9 (Ibid., p. 114). É o mais problemático, pois é preciso reconhecer que o conhecimento é incompleto, desconhecendo-se as várias alternativas de solução;

- $\quad$ indeterminação - é o impacto das redes abertas, pois, apesar do conhecimento sobre as alternativas, ele é limitado a determinados contextos; esses podem ser afetados pelos participantes do processo.

Atualmente, o risco é estudado de maneira multidisciplinar. Esses estudos podem ser divididos epistemologicamente em dois grupos de teorias (LUPTON, 1999): perspectiva da ciência cognitiva, uma abordagem centrada no indivíduo, e abordagem sociocultural, que parte da visão da sociedade e da cultura para o indivíduo. Essas abordagens serão detalhadas nos próximos itens.

\subsubsection{Perspectiva da ciência cognitiva}

No Quadro 1 tem-se o detalhamento de cada teoria da perspectiva da ciência cognitiva, cuja origem vem primeiramente da matemática e da estatística, seguindo pela engenharia, atuária, psicologia, epidemiologia e economia (LUPTON, 1999; TAYLOR-GOOBY, ZINN, 2008).

\footnotetext{
9 “[...] which by definition escapes recognition."
} 
Quadro 1 - Perspectiva da ciência cognitiva em relação ao risco

\begin{tabular}{|c|c|c|c|}
\hline Teoria & Conceito & $\operatorname{Pr}$ & \\
\hline $\begin{array}{l}\text { Abordagem } \\
\text { estatística } \\
\text { probabilística } \\
\text { risco }\end{array}$ & $\begin{array}{l}\text { Risco é a probabilidade da } \\
\text { ocorrência de um evento } \\
\text { multiplicada pela extensão do } \\
\text { respectivo dano devido a sua } \\
\text { ocorrência. }\end{array}$ & $\begin{array}{l}\text { Matemática: cálculos } \\
\text { estatísticos } \\
\text { probabilísticos } \\
\text { Economia }\end{array}$ & $\begin{array}{l}\text { incerteza } \\
\text { idade impossível de } \\
\text { ada } \\
\text { da empresa afeta a } \\
\text { isco }\end{array}$ \\
\hline $\begin{array}{l}\text { Abordagem } \\
\text { comportamental da } \\
\text { tomada de decisão }\end{array}$ & $\begin{array}{l}\text { As pessoas utilizam heurísticas, } \\
\text { modelos mentais (cognitivos), } \\
\text { que reduzem a complexidade do } \\
\text { problema, em geral úteis, mas } \\
\text { às vezes levam a grandes e } \\
\text { sistemáticos erros. }\end{array}$ & $\begin{array}{l}\text { Simon }(1957, \\
\text { racionalidade } \\
\text { limitada) } \\
\text { Tversky e Kahneman } \\
(1974)\end{array}$ & $\begin{array}{l}\text { Testes foram feitos em } \\
\text { laboratórios em condições } \\
\text { artificiais; no ambiente real, } \\
\text { as pessoas têm experiências } \\
\text { relevantes sobre o assunto e } \\
\text { podem pedir auxílio a outras. }\end{array}$ \\
\hline
\end{tabular}

Fonte: Adaptado de Lupton, 1999; Taylor-Gooby, Zinn, 2008.

\subsubsection{Abordagem estatística probabilística}

Essa abordagem é mais usada na economia, na administração e nos negócios, com a tendência de tratar os riscos usando rigorosos conceitos de racionalidade. Segundo Luptom (1999) e Taylor-Gooby e Zinn (2008), ela é representada pelo lado normativo e prescritivo da teoria da decisão, que visa identificar modelos, processos estruturados e práticas para se obter uma decisão ótima para um problema.

Segundo Clemen e Reilly(1996), o objetivo dessa teoria é ajudar o decisor a pensar de forma sistemática sobre problemas complexos, para melhorar a qualidade da decisão. Segundo esse autor, a análise de decisão consiste num arcabouço para lidar com decisões difíceis e a incorporação do julgamento subjetivo é muito importante. Nesse tipo de abordagem existe a decomposição do problema em partes menores e menos complicadas, pois o entendimento de cada parte e o posterior reagrupamento pode melhor representar a situação da decisão.

Essa teoria é composta por oito elementos (HAMMOND et al., 2004):

a) problema - para o qual se exige uma decisão, devendo ser conhecido com uma avaliação de sua complexidade;

b) objetivos - são os resultados a serem alcançados com a decisão, assim como o que está envolvido com aquela decisão; por exemplo, interesses, valores, preocupações, temores e aspirações;

c) alternativas - são os vários cursos de ação que podem ser escolhidos para se alcançarem os objetivos; 
d) consequência - cada uma das alternativas pode gerar consequências distintas no alcance dos objetivos;

e) trocas ou negociação - os múltiplos objetivos podem ser conflitantes entre si, gerando a necessidade de uma priorização e análise para se alcançar a melhor solução;

f) incerteza - está ligada à probabilidade de cada alternativa de solução do problema, assim como aos possíveis impactos de cada uma dessas alternativas;

g) tolerância a riscos - está relacionada ao impacto do não alcance do objetivo e à atitude do decisor frente a isso. Cada nível de um resultado é associado com um nível esperado de prazer ou benefício chamado utilidade (YU, 2011). Por isso escolhe-se a alternativa cuja utilidade esperada é mais alta e não simplesmente pelo valor esperado. A valorização da utilidade não é monetária, é pessoal e mutável. Essa diferença da escolha dentre as opções possíveis é que avalia o nível de aversão ao risco, pela disposição do decisor em ter certeza do resultado. Há três tipos de perfis:

a. averso ao risco - caracteriza-se por selecionar a opção que proporciona menos riscos para se obter o objetivo. Na contratação de um seguro, por exemplo, a pessoa avessa ao risco pagará o seguro para ter mais certeza dos gastos envolvidos, mesmo que o custo exceda o valor da utilidade;

b. tomador de risco - os empreendedores são considerados tomadores de risco ou propensos ao risco, pois consideram viáveis alternativas muito arriscadas, para as pessoas que precisam ou gostam de maior segurança. No caso do seguro de um carro, pode-se não fazer o seguro, por se considerar a probabilidade de acidentes muito baixa e, consequentemente, a alternativa de perda também tem uma utilidade baixa;

c. neutro ao risco - são aqueles que pagarão o valor equivalente e esperado para ter certeza do retorno; por exemplo, a contratação de um seguro, caso ele tenha um valor dentro da expectativa da utilidade esperada;

h) decisões interligadas - a decisão de hoje tanto pode ser a base de uma decisão no futuro, quanto pode ser consequência de uma decisão tomada no passado.

A estruturação da tomada de decisão tem quatro aspectos que a torna difícil (CLEMEN, REILLY, 1996): complexidade, pela quantidade de informações e possibilidades envolvidas e a teoria da decisão responde a isso por métodos para estruturar um problema complexo, por exemplo árvores de decisão e diagrama de influência; incerteza, que é a falta de 
conhecimento de alguma ou de várias variáveis, ou mesmo sobre o resultado da interação entre elas; essa abordagem tenta identificar as fontes e representá-las, tratando-as com ferramentas, como a simulação de Monte Carlo; múltiplos objetivos, que podem ser contraditórios e conflitantes, tratados por ferramentas, como análise multicritérios; diferentes perspectivas levam a diferentes conclusões, tratados por modelos e ferramentas para ajudar a classificar as ideias e discuti-las com outras pessoas.

Há diferentes prescrições sobre como tomar decisões na literatura, como:

- Russo e Schoemaker (2002, p. 29) separam em:

- enquadramento - que representa a avaliação do contexto, com a definição da questão e dos parâmetros que deverão ser considerados e os que são menos importantes;

- reunião de inteligências - a busca de informação para reconhecimento de fatos e de alternativas, para gerar uma avaliação razoável em face à incerteza, evitando os problemas advindos dos vieses e heurísticas;

- conclusão - a escolha é feita a partir de um quadro fundamentado e inteligências, com base em dados obtidos e não apenas na experiência;

- aprendizado pela experiência - o aprimoramento contínuo só é alcançado com o entendimento sobre a decisão e seus resultados, sejam eles de sucesso ou de fracasso;

- Clemen e Reilly (1996, p. 6) consideram:

- identificar a situação e entender os objetivos;

- identificar as alternativas;

- decompor e modelar a estrutura do problema, a incerteza e as preferências;

- escolher a melhor alternativa;

- executar uma análise de sensibilidade;

- avaliar se é necessário mais análise e a que ponto da análise se deve retornar;

- implementar a alternativa escolhida;

- Bazerman e Moore (2009, p. 2):

- definir o problema - entendendo o cerne da questão, para identificar o que pode ser resolvido com a decisão;

- identificar os critérios - como pode haver vários objetivos, é necessário identificar critérios que os atenderão;

- pesar os critérios - dado que cada um dos critérios pode ter um nível de importância diferente, pode-se usar um sistema de pontuação para avaliá-los; 
- gerar alternativas - para um problema poderá haver vários cursos de ação que gerarão resultados distintos;

- avaliar cada alternativa - com cada critério, prevendo a probabilidade de cada resultado;

- calcular a decisão ótima - baseando-se nos critérios e pesos, calcular o valor de cada alternativa para se estabelecer a que fornecerá a melhor solução para aquele problema, com as informações existentes naquele instante.

No entanto, em geral, os processos de decisão não são programados. Os decisores reduzem a decisão total em subdecisões para as quais encontram "formas de cortar caminho", usam processos desestruturados que satisfazem, mas não maximizam os resultados da decisão (MINTZBERG et al., 1976). Com base em vários autores, Choo (2001) afirma que as decisões são limitadas por características individuais, pela extensão do conhecimento, pelas informações possuídas e por valores e propostas que podem, inclusive, divergir dos objetivos organizacionais. Esse autor cita que, apesar de as pessoas pedirem informações e relatórios, muitas vezes a tomada de decisão é feita em reuniões e conversas, sendo formalizada posteriormente, dentro de rotinas e rituais organizacionais.

Assim, há muitas críticas a essa abordagem. Uma das principais refere-se à racionalidade limitada que captura a limitação das capacidades cognitivas das pessoas. Há também críticas da psicologia, pois há ilusões cognitivas e a influência da distorção na percepção dos riscos, além da influência de o risco ser apresentado. Ela também vem sendo criticada pela incapacidade de atender as crescentes incertezas que surgem na vida moderna, que impedem o cálculo da probabilidade de o evento ocorrer (LUPTON, 1999; TAYLOR-GOOBY, ZINN, 2008).

Dentro da teoria da decisão, a abordagem desse problema é um pouco diferente da visão sociológica. A base da abordagem prescritiva é a abordagem normativa, que são as teorias que definem as regras para se encontrarem soluções ótimas para os problemas. Dentro dessa teoria, Savage (1972) já criticava a visão objetivista ${ }^{10}$, pois a "[...] probabilidade só poderia ser aplicada frutiferamente apenas para eventos repetitivos, ou seja, para certos processos"11, portanto era insuficiente para explicar toda a gama de aplicações da probabilidade,

\footnotetext{
10 "Objectivistic"

11 “[...] probabilities can apply fruitfully only to repetitive events that is, to certain processes."
} 
principalmente os enfrentados dentro de ambientes incertos e inovadores. Hoje em dia, YU (2011) considera que a teoria prescritiva, com base na teoria normativa, cada vez mais inclui conhecimentos da abordagem comportamental, gerando novas teorias e ferramentas para melhorar as decisões nas organizações. Por exemplo, a questão da subjetividade da probabilidade pode ser tratada por dois métodos (CLEMEN, REILLY, 1996, p. 299). Um deles é a tradução das expressões subjetivas, por exemplo "pequena", "pouca", "rara", "muita", pelo decisor por meio de uma questão especifica, que representa o quanto ele acredita que isso possa ocorrer. Normalmente esse método pode trazer pouca confiança na previsão realizada. $\mathrm{O}$ outro método questiona quanto o decisor apostaria no resultado, podendo ser complementado por uma estratégia de avaliação de apostas com pequenas diferenças até ser possível gerar uma curva de avaliação.

\subsubsection{Abordagem comportamental}

A abordagem comportamental é o lado descritivo da tomada de decisão. Os pesquisadores descrevem como as decisões realmente são tomadas e avaliam como os julgamentos pessoais são afetados por heurísticas e vieses cognitivos e emocionais.

De fato, as pessoas guiam-se por regras práticas ou modelos mentais ao tomarem suas decisões. São os atalhos para avaliar, calcular e pensar sobre um assunto. Essas estratégias, que buscam simplificar o processo de tomada de decisões, são chamadas de heurísticas. Esse vocábulo também significa "arte de inventar, de fazer descobertas" (HOUAISS, 2001). Se as heurísticas, por um lado, agilizam a decisão, por outro, podem gerar erros sistemáticos por causa dos vieses cognitivos, derivados desse modelo simplificador. $\mathrm{O}$ viés cognitivo é a visão parcial do problema, uma avaliação tendenciosa, que gera discrepância entre o julgamento que está sendo feito e a realidade julgada. Ele tem origem no modo como se processam as informações mentalmente, como se percebe o mundo, como se aprende.

Um viés emocional pode ocorrer de várias maneiras; uma delas, quando se deve fazer uma coisa, mas se quer fazer outra. Ariely (2008) intitula as pessoas de irracionais previsíveis, uma vez que, pelo seu estudo da economia comportamental, verificou que sistematicamente as pessoas decidem irracionalmente, por não quererem perder, por quererem ganhar, por não quererem pagar. 
A seguir são apresentadas algumas heurísticas e vieses (BAZERMAN, MOORE, 2009):

- representatividade - é a heurística acionada quando se tem de identificar a probabilidade de algo - evento ou pessoa ou objeto - pertencer a uma classe ou grupo. Tentase avaliar o nível de similaridade das características principais de um evento que se enquadre numa situação-padrão anteriormente vivida. No entanto pode-se não avaliar adequadamente a quantidade de vezes que o mesmo problema pode ocorrer, pela interpretação errônea das suas chances de repetição. Os vieses decorrentes são:

- insensibilidade ao tamanho da amostra - na determinação da possibilidade de se obter um resultado específico, as pessoas avaliam a média de uma determinada situação, sem considerar o tamanho da amostra que estão analisando. Estatisticamente é muito mais provável que ocorram eventos aleatórios em amostras pequenas do que em amostras grandes, mas, intuitivamente, as pessoas não consideram esse fato; acreditam que um padrão ocorre sempre;

- interpretação errada da chance - as pessoas esperam que uma sequência de eventos gerados num processo randômico representará as características essenciais, mesmo quando uma sequência é curta, ou seja, em milhares de jogadas, a estatística demonstra que 50\% são cara e 50\% são coroa, mas em seis jogadas essa ocorrência é improvável;

- insensibilidade aos índices básicos - há uma tendência de as pessoas ignorarem os índices básicos quando estão avaliando as probabilidades, muitas vezes impactados por eventos recentes;

- regressão à média - há uma tendência de as pessoas pensarem que os eventos extremos sejam seguidos por eventos similares, para permanecerem no mesmo patamar. Porém a probabilidade é de que o próximo evento siga a média anterior desse tipo de evento ou até numa situação oposta;

- associação pressuposta - os indivíduos julgam a frequência com que dois eventos podem ocorrer concomitantemente para realçar a probabilidade de ocorrência. Se for levantada a questão: "O desenvolvimento de produtos inovadores está relacionado com o aumento do faturamento das organizações?" Caso se conheçam empresas que invistam nesse tipo de produto e estejam bem em seus ramos, a resposta será afirmativa. Entretanto poderá ser uma avaliação enviesada, visto que há mais três grupos que não foram avaliados: o das empresas que desenvolvem produtos inovadores, mas o faturamento ficou 
estagnado ou baixou; o grupo das que não desenvolvem produtos inovadores e tiveram aumento e o último, o das que desenvolvem, mas não tiveram aumento de faturamento;

- disponibilidade - julga-se o caso, que pode ser um evento, objeto ou pessoa, com a associação e estruturas mentais que vêm mais rápido à memória, à lembrança, recordando-se mais de eventos frequentes, próximos ou que emocionaram fortemente. Os vieses vinculados a essa heurística são:

- facilidade de lembrança - um indivíduo julga a frequência com que um evento ocorre pela disponibilidade de seus exemplos. Portanto um evento cujos exemplos são mais fáceis de recordar parece ser mais frequente do que aquele cujos exemplos são mais difíceis de recordar. Qual a opção mais provável para a seguinte formulação: "Carlos mora no Rio perto de uma favela. Ele morreu (a) de doença no coração (b) homicídio ou acidente de trânsito?" No Brasil, a maioria das pessoas indicaria a opção b, dado que se veem diariamente na televisão muitas reportagens sobre os perigos das grandes metrópoles, que são a violência no trânsito e a criminalidade. Porém, estatisticamente, há 32,2\% de chance de se morrer por uma doença do aparelho circulatório contra 14,5\% por causa da outra opção $^{12}$;

- recuperação - os indivíduos guardam informações na sua memória de uma forma tal que seja mais fácil de recuperar; assim, podem-se formar estereótipos, para tentar identificar grupos em meio a muitas informações e características sobre os indivíduos;

- $\quad$ ancoragem - ocorre quando se toma uma decisão baseada num valor, em critérios ou requisito inicial, chamados âncora, que poderão afetar de maneira positiva ou negativa a decisão. Se há necessidade de se adquirir um serviço para o qual não se sabe o preço, provavelmente o primeiro orçamento que for recebido será a âncora para avaliar as demais ofertas. Há âncoras numéricas e qualitativas que vão sendo assimilados ao longo do tempo, com o decorrer das experiências pessoais e profissionais;

- excesso de confiança - é um viés cognitivo geral que tem relação direta com o otimismo acerca das probabilidades de sucesso. Moore e Healy (2007) classificaram esse viés em três tipos: overprecision, excessiva confiança na precisão de estimativas subjetivas, quando se tem informação imperfeita sobre seu desempenho; quanto maior a dificuldade ou desconhecimento do problema, maior a probabilidade de o indivíduo superestimar a

\footnotetext{
${ }^{12}$ Esses dados são baseados em 1.006.827 óbitos de 2005, obtidos no Sistema de Informação sobre Mortalidade (SIM), que pertence ao Ministério da Saúde, gerenciado pela Secretaria de Vigilância em Saúde. Obtido em: http://tabnet.datasus.gov.br/cgi/deftohtm.exe?idb2007/c04.def. Acesso em: 20.01. 2009
} 
possibilidade de resolver o problema, podendo gerar alternativas mais simples, ou mesmo não avaliar adequadamente o risco que se está correndo com aquela alternativa; overestimation, que consiste em superestimar o desempenho, as chances de sucesso e o controle da situação, principalmente em atividades que considera difícil, e subestimar suas chances em atividades fáceis; overplacement, que consiste em se posicionar melhor do que os outros, cuja tendência ocorre principalmente em atividades fáceis;

- framing - segundo a Teoria da Perspectiva (KAHNEMAN, TVERSKY, 1979), o decisor tende a evitar o risco em relação a opções de ganho e tende assumir risco quando poderá perder. Por conseguinte, a própria formulação do problema poderá levar a uma decisão que não necessariamente seja a melhor, conforme o decisor interpretar a possibilidade de ganho ou perda na situação em juízo. Por exemplo, se for informado que um projeto tem $60 \%$ de chances de aumentar a produtividade de uma determinada área da empresa, o decisor pode considerar pouco e aguardar novas soluções. Porém, se esse mesmo decisor estiver enfrentando dificuldades com a produtividade, poderá considerar a alternativa viável.

Chugh e Bazerman (2005) criaram o conceito de consciência limitada ${ }^{13}$ que representa a limitação das pessoas em notar, procurar, usar e compartilhar informações que seriam relevantes, úteis, facilmente disponíveis. Eles apontam alguns domínios, como cegueira por desatenção para informações óbvias, quando não ouvimos informações que, depois nos dizem que haviam dito; cegueira para mudanças, principalmente quando elas ocorrem vagarosamente; ilusão por foco, definida por Schkade e Kahneman (1998), baseando-se no conceito psicológico de ilusão, dificuldade ou impossibilidade de avaliar simultaneamente as considerações em foco com as que estão em segundo plano. Assim, surge a tendência de dar mais peso a causas explícitas do que a implícitas. Eles também afirmam que essa limitação ocorre nos grupos, pois, apesar de as pessoas, individualmente, poderem ter informações diferentes sobre o mesmo assunto, elas discutirão mais as informações compartilhadas entre os elementos, do que as que não são.

Dentro da teoria descritiva da tomada de decisão, a expressão decisão naturalista ${ }^{14}$ foi desenvolvida em 1989, durante um congresso organizado por pesquisadores. Zsambok (1997,

\footnotetext{
${ }^{13}$ Bounded awareness

${ }^{14}$ Naturalistic Decision Making - NDM
} 
p. 4) define que "[...] é a forma que as pessoas usam sua experiência para tomar decisões no seu campo de atuação." O foco de pesquisa, naquela época, eram os bombeiros, pilotos de aviões de caça, executivos corporativos e outros. No congresso, os pesquisadores perceberam que os processos e as estratégias dessas pessoas focavam mais em examinar a situação cuidadosamente e usavam o feedback para atualizar e tomar consciência da situação.

As pesquisas sobre as decisões naturalistas são feitas no seguinte contexto:

- $\quad$ problema mal estruturado - problemas reais sem uma definição completa; por exemplo, um bombeiro enfrentando o fogo dentro de um ambiente fechado;

- $\quad$ ambiente incerto e dinâmico - o foco são situações do mundo real, sem a simplificação das avaliações em laboratório;

- $\quad$ objetivos e normas organizacionais - mal definidos ou em mudança;

- $\quad$ ação / reação em cadeia, em contraste com decisões únicas;

- $\quad$ restrição de tempo - não há tempo para a geração de múltiplas alternativas e para compará-las;

- alto impacto - situações nas quais a decisão tem um grande impacto para os participantes do processo;

- $\quad$ múltiplos participantes - a decisão não é individual.

Além disso, há outros três diferenciadores nesse tipo de pesquisa: os participantes, a proposta da pesquisa e o foco de interesse no episódio de decisão. Os participantes são pessoas especialistas na área de aplicação na qual está sendo tomada a decisão, sabem o que precisa ser feito e quais objetivos precisam ser alcançados (DREYFUS, 1997, p.22).

Dreyfus (ibid.) afirma que as pessoas passam por cinco fases: principiante, quando conhecem as atividades, mas não dominam o contexto; iniciante avançado, quando dominam algumas situações reais, no âmbito de suas atividades; competente, quando, dominando as técnicas e processos, procuram novas regras e procedimentos adequados para um planejamento ou perspectiva futura; proficiente, quando a experiência adquirida se torna intuitiva, com a discriminação de situações ou variáveis, ininteligível para os principiantes e, finalmente, o especialista, quando não apenas sabem o que deve ser feito, mas também como fazê-lo, podendo-se chamar esse saber de intuição, percepção e discernimento, independente 
de raciocínio ou análise. Klein (2003) define intuição como “[...] a maneira pela qual traduzimos nossa experiência em ação."15

O outro diferenciador, a proposta de pesquisa, tenta descobrir como essas pessoas realmente decidem num ambiente rico e o mais próximo possível da realidade. Isso requer uma mudança dos métodos tradicionais de desenho experimental e análise estatística para métodos de observação em campo, por exemplo, o etnográfico, e métodos de análise observacional, que requerem muito tempo (ROTH, 1997, p.122). O foco de interesse não está apenas no processo de opção entre as várias escolhas, mas também na consciência da situação ${ }^{16}$. Se o decisor não identificar a situação corretamente, poderá tomar uma decisão acertada, mas não para aquela situação.

A abordagem comportamental é criticada pelo uso de experimentos em laboratórios, pois na vida real as pessoas podem-se comportar de forma diferente, o que não se aplica à decisão naturalista. Além da existência de outros fatores que podem influenciar a decisão, por exemplo, a decisão tomada em grupo, quando as várias abordagens dos decisores podem evitar as heurísticas e vieses individuais.

\subsubsection{Abordagem sociocultural}

O Quadro 2 mostra a abordagem sociocultural que tem como origem a antropologia cultural, a filosofia, a sociologia, a história social, a geografia cultural e os estudos da ciência e tecnologia (LUPTON, 1999).

\footnotetext{
15 "[...] the way we translate our experience into action."

${ }^{16}$ situation awareness
} 
Quadro 2 - Perspectiva da abordagem sociocultural em relação ao risco

\begin{tabular}{|c|c|c|c|}
\hline Teoria & Conceito & Principais autores & Críticas \\
\hline $\begin{array}{l}\text { Cultural } \\
\text { Simbólica }\end{array}$ & $\begin{array}{l}\text { A percepção do indivíduo e suas } \\
\text { respostas ao risco só pode ser } \\
\text { entendida por meio de sua inserção } \\
\text { no contexto sociocultural, assim } \\
\text { como sua identidade como } \\
\text { membro do grupo. Risco é um } \\
\text { fenômeno construído socialmente. }\end{array}$ & Douglas $(1963 ; 1966)$ & $\begin{array}{l}\text { A influência do social é } \\
\text { controversa. A sensibilidade } \\
\text { ao risco pode ser maior do } \\
\text { que a cultura. Interpretação } \\
\text { da cultura como fator } \\
\text { independente e não como } \\
\text { fator geral subjacente. }\end{array}$ \\
\hline $\begin{array}{l}\text { Sociedade } \\
\text { risco }\end{array}$ & $\begin{array}{l}\text { A consciência do risco e as } \\
\text { respostas são interpretadas por } \\
\text { meio da perspectiva de um modelo } \\
\text { geral (macrossocial) da mudança } \\
\text { social pela modernidade. }\end{array}$ & $\begin{array}{l}\text { Beck }(1986 ; 1995) \\
\text { Giddens }(1991)\end{array}$ & $\begin{array}{l}\text { A predominante visão de } \\
\text { identidade e agência } \\
\text { individual também é } \\
\text { criticada, por não avaliar as } \\
\text { diferenças entre os grupos. }\end{array}$ \\
\hline $\begin{array}{l}\text { Governamen- } \\
\text { talidade }\end{array}$ & $\begin{array}{l}\text { Nada é um risco em si mesmo, ele } \\
\text { é um produto histórico, social e } \\
\text { politicamente contingenciado à } \\
\text { maneira de se ver. }\end{array}$ & $\begin{array}{l}\text { Autores baseados em } \\
\text { Foucault (1991) }\end{array}$ & $\begin{array}{l}\text { Funcionalismo top-down, } \\
\text { com visão das pessoas abertas } \\
\text { a serem manipuladas, sem } \\
\text { contar as agendas pessoais. }\end{array}$ \\
\hline
\end{tabular}

Fonte: Adaptado de Lupton, 1999; Taylor-Gooby, Zinn, 2008.

\subsubsection{Cultural simbólica}

A antropóloga Mary Douglas é um dos expoentes nessa perspectiva (TAYLOR-GOOBY, ZINN, 2008) devido a sua concepção de como os riscos são usados para estabelecer e manter limites entre a pessoa e os outros (LUPTON, 1999, p. 25). Ela e Wildavsky (1982 como citado em LUPTON, 1999) criaram um modelo, representado na Ilustração 4, baseado em dois fatores: na identificação do indivíduo com o grupo [GRUPO] e no nível que a vida do indivíduo é regulada ou prescrita por seu papel social no grupo [GRID]. Dependendo do enquadramento do indivíduo no GRID e no GRUPO, sua percepção de risco é influenciada de forma diferente, assim como sua atitude em relação a ele. Portanto, se o seu nível for baixo em ambos, ele tenderá a ser mais empreendedor, por exemplo. Opostamente, se o nível for alto em ambos, o indivíduo tenderá a seguir os procedimentos e regras do grupo para gerenciar os riscos e as incertezas. 


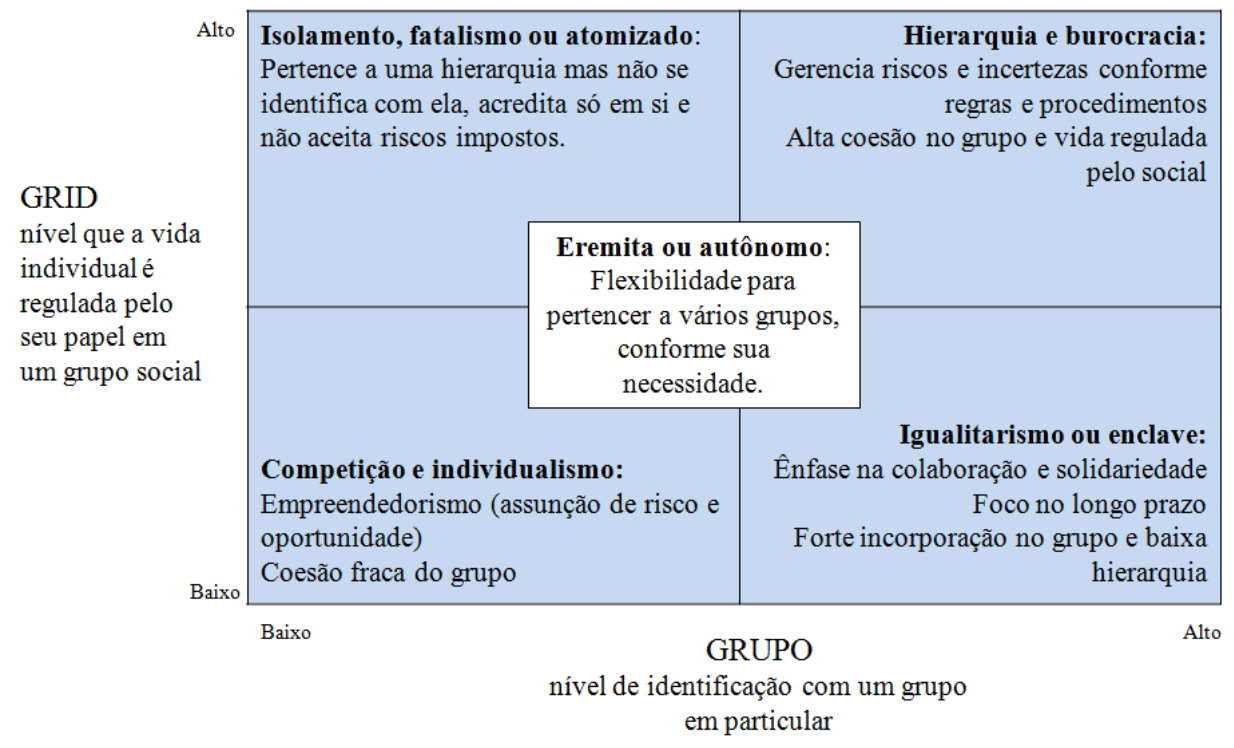

Ilustração 4 - Tipologia de grupos sociais

Fonte: Adaptado de Lupton, 1999.

\subsubsection{Sociedade de risco}

A teoria da sociedade de risco (BECK, 1992) baseia-se na mudança da sociedade moderna, enfatizando dois fatores centrais: novos riscos qualitativos produzidos pela sociedade moderna industrial de maneira não prevista e não intencional (efeitos secundários) e a mudança das desigualdades da esfera das classes sociais para a do indivíduo, pois os riscos são globais e não afeta apenas a uma classe social, um país, uma região.

As pessoas cada vez mais estão sendo responsabilizadas, principalmente no nível psicológico, pelas consequências dos riscos. Isso como consequência de um processo social, pois cada um deve construir a sua biografia. Assim, surge o conceito de individualização, que é a condenação do individuo a se identificar, definindo o que ele quer fazer e ser na vida e na sociedade, de se planejar, agir e se culpar caso não obtenha sucesso. Esse conceito é distinto do individualismo, atitude egoísta das pessoas perante a sociedade, e da individuação, percepção da pessoa como um ser único, sem a discrepância entre o que se é e o que se poderia ser, na construção da identidade, não doente, não patológica, sem distúrbios.

Outro autor importante para essa abordagem foi Giddens (TAYLOR-GOOBY, ZINN, 2008) que focou no fator cultural e na conscientização dos riscos da modernidade tardia pelos cidadãos, o que os leva a criarem sua própria biografia ou estilo de vida. O estilo de vida está 
muito ligado ao conceito de individualização, no sentido de que as escolhas racionais ou não são de responsabilidade do individuo. Porém, o estilo de vida não é definido por uma pessoa, mas por um grupo e dentro de regras explícitas ou não. Castiel (1996) alega que ele “[...] proporciona elementos para um senso de unidade e segurança existencial num mundo incerto e ameaçador." Esse autor sugere que há um "estilo de risco", uma vez que as pessoas também escolhem os riscos a que querem se expor pela forma de viver, com seus comportamentos e escolhas, principalmente no âmbito da saúde.

Nesse sentido, o edgework ${ }^{17}$ (atividade de risco), adotando o conceito de positividade no risco e até como uma virtude (LYNG, 2008), emerge como uma escolha espontânea e voluntária das pessoas por atividades de risco, que envolvem situações limítrofes entre a vida e a morte, a ordem e a desordem, a sanidade e a insanidade. Isso pode ocorrer no trabalho. Por exemplo: no trabalho de alpinistas que instalam a iluminação de Natal na Ponte Estaiada, na cidade de São Paulo a 100 metros de altura; em atividades nas horas de lazer, como o paraquedismo, as corridas no deserto, o balonismo etc.

Featherstone, citado em Castiel (1996), considera que estilo de vida é um modismo manipulado pela cultura de massa, considerando que a definição de habitus seria mais apropriada, visto que cada grupo ou classe possui um. Por mais que o indivíduo queira rebelar-se com um grupo, sempre poderá ser classificado em outro grupo. Outra crítica a essa linha de pesquisa dá-se em relação à não consideração do grupo como um fator relevante na avaliação do risco (TAYLOR-GOOBY, ZINN, 2008).

\subsubsection{Governamentalidade}

A última linha de pesquisa é a Governamentalidade ${ }^{18}$, na qual o risco e a segurança, caracterizados como doença, desemprego e pobreza, são entendidos como elementos centrais de poder e dominação, estratégicos para se governarem as sociedades. O crescimento da comunicação do risco é entendido como uma estratégia dos governos neoliberais, que os

\footnotetext{
${ }^{17}$ Edgework é o trabalho ou atividade dentro dos limites máximos das capacidades pessoais.

${ }^{18}$ Esse termo é a tradução de 'governmentality' (TAYLOR-GOOBY, ZINN, 2008), que foi cunhada para conectar os termos 'governo' e 'mentalidade'.
} 
ajuda a determinar o comportamento individual, sem controle direto das pessoas, dando a impressão de que elas têm liberdade. Os indivíduos são empowered (encorajados) para gerenciarem seus corpos, almas e seu modo de vida para atingirem seus objetivos, conforme a construção da sua realidade.

Concluindo, neste item foi feita uma avaliação multidisciplinar dos conceitos de risco e incerteza. No próximo, a visão da avaliação desses conceitos será focada na administração de projetos e de organizações.

\subsection{Gestão do risco e da incerteza na inovação}

Neste item propõe-se não apenas a discutir a incerteza e os riscos advindos da inovação, a sua ligação com projetos como também a distinguir os projetos mais inovadores. Os vários padrões em GR, tanto de projetos quanto de organizações, são comparados, assim como seus processos, técnicas e ferramentas.

\subsubsection{Inovação como geradora de incerteza}

Uma das definições de inovação mais utilizadas pelas organizações é a feita pela OECD Organization for Economic Co-Operation and Development (2005, p. 46):

[...] é a implementação de um produto (bem ou serviço) novo ou significativamente melhorado, ou um processo, ou um novo método de marketing, ou um novo método organizacional nas práticas de negócios, na organização do local de trabalho ou nas relações externas. ${ }^{19}$

Essa definição compreende quatro tipos de inovação (Ibid.):

- $\quad$ de produto - pode ser um bem ou serviço;

- $\quad$ de processo - refere-se aos de produção ou distribuição;

- $\quad$ de marketing - refere-se às "[...] mudanças significativas na concepção do produto ou em sua embalagem, no posicionamento do produto, em sua promoção ou na fixação de preços"20 (Ibid., p. 49);

19 “An innovation is the implementation of a new or significantly improved product (good or service), or process, a new marketing method, or a new organizational method in business practices, workplace organization or external relations." 
- $\quad$ organizacional - refere-se às novas práticas nos negócios, na organização do local de trabalho ou nas relações externas.

Numa inovação, deve existir algum grau de novidade, ou seja, deve ser no mínimo nova para a organização, ou nova para o mercado, ou nova para o mundo. Portanto tudo o que for alterado na organização que implique falta de conhecimento ou uso novo de um conhecimento existente é uma inovação. No Brasil, das 106.800 empresas pesquisadas pelo PINTEC 2008 (IBGE, 2010), uma minoria (38,6\%) inovou em algum produto ou processo. Porém, dessas, a maioria $(69,0 \%)$ realizou ao menos uma inovação organizacional e 59,5\%, alguma inovação de marketing.

Quanto maior o grau de novidade, maior a incerteza sobre os resultados da inovação e, consequentemente, dos investimentos necessários para se obter a inovação. A decisão de inovar pode ser, portanto, influenciada por fatores exógenos, como: o ambiente, aspectos econômicos do mercado e da indústria de atuação da organização; por fatores endógenos, como: defasagem tecnológica da organização e o valor da qualidade, assim como a vontade pessoal dos decisores, correspondendo à tolerância ao risco e à percepção dele (DACORSO, 2000).

Nesse momento torna-se relevante entender o que faz com que as empresas busquem a inovação, como uma vantagem competitiva, que é o desempenho acima da média no seu mercado de atuação. Essa análise deve ser vinculada à vasta teoria de estratégia empresarial, mas será apresentada dentro de um recorte em sua evolução nos últimos anos.

Vasconcelos e Cyrino (2000) enquadraram as várias e diferentes abordagens sobre vantagem competitiva, que surgiram a partir dos anos de 1970, conforme Ilustração 5. Seu modelo possui dois eixos, que dividem as teorias de estratégia empresarial:

a) origem da vantagem competitiva. Por sua vez, esta pode ser: externa, pelo posicionamento de mercado e tipo da estrutura da indústria, ou interna, pelos atributos específicos da indústria que geram desempenho superior e

\footnotetext{
20 " [...] involving significant changes in product design or packaging, product placement, product promotion or pricing."
} 
b) concorrência, com uma visão estática, estrutural e com equilíbrio econômico, ou com uma visão dinâmica, por causa da inovação, descontinuidade e desequilíbrio.

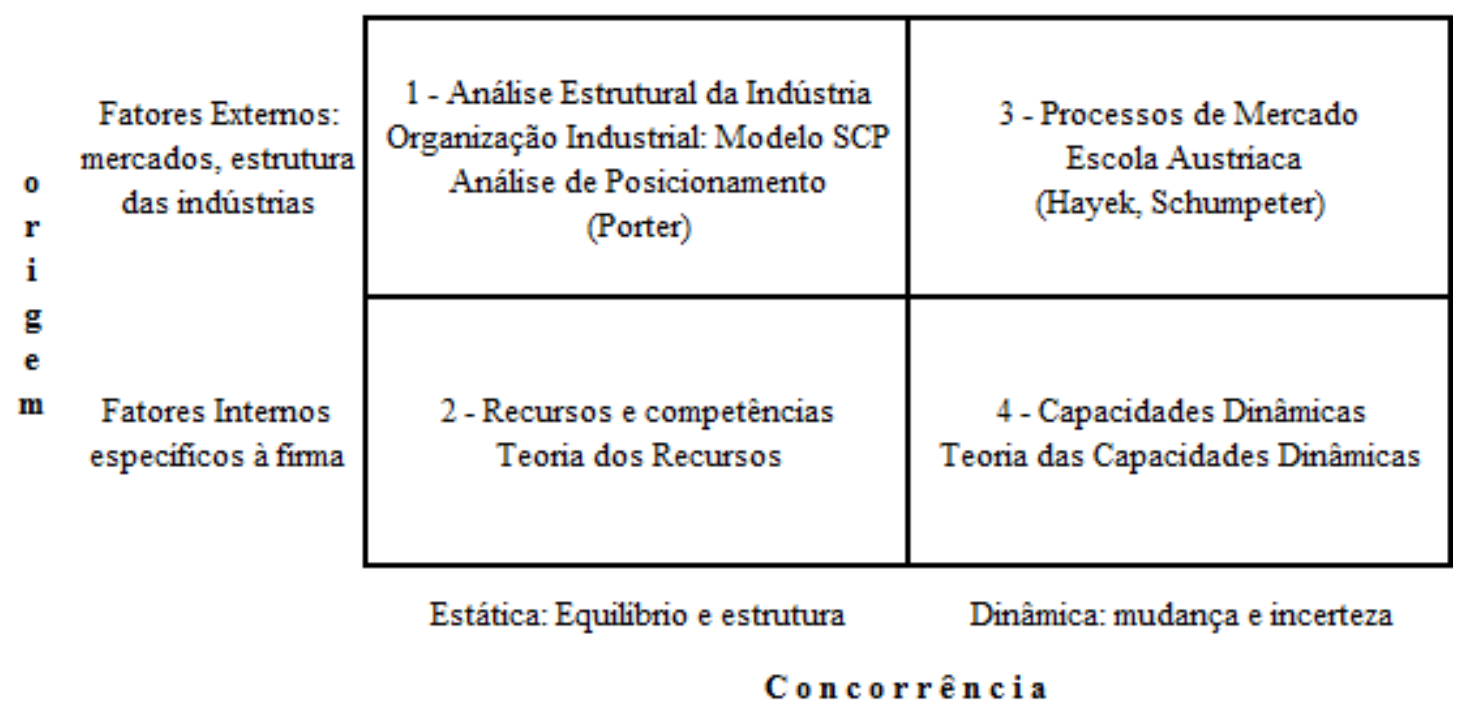

Ilustração 5 - Correntes explicativas da vantagem competitiva

Fonte: Vasconcelos, Cyrino, 2000.

Os autores citam que na abordagem 1 - Análise estrutural da indústria, a maneira de se manter a vantagem competitiva é a geração de investimentos irreversíveis, para fechar oportunidades de mercado ou bloquear o acesso a recursos, o que inibiria a entrada de concorrentes. $\mathrm{Na}$ abordagem 2 - Recursos e competências, o foco está no crescimento pela otimização do uso dos recursos internos, o que pode gerar uma situação natural de desequilíbrio dos mercados, mesmo em condições de concorrência e indústria estáveis. A otimização bem-sucedida constitui a vantagem competitiva. Na abordagem 3 - Processos de mercado, o foco esta na mudança, na inovação, na heterogeneidade das firmas, no papel do empreendedor como agente de mudança e em fatores inobserváveis que constituem a vantagem competitiva. $\mathrm{Na}$ abordagem 4 - Capacidade Dinâmica, a vantagem pode vir de várias fontes, como: acesso a recursos raros ou valiosos, por exemplo, concessões, patentes ou localizações geográficas; capacidade de transformação dos fatores de produção vendáveis, processos distintivos acumulados ao longo do tempo, gerando eficiência; alavancagem de recursos e capacidades, ação deliberada para renovação de seu estoque de recursos e competências; regeneração de recursos e capacidades, com o fluxo contínuo de inovações pelo desenvolvimento de capacidade de geração de novas competências e recursos. 
Avaliando as abordagens citadas, pode-se afirmar que a inovação, praticamente, permeia todas elas, pois quaisquer que sejam os investimentos feitos para manter ou gerar a vantagem competitiva, provavelmente se enquadrarão na definição de inovação vista.

Ligando os conceitos de vantagem competitiva, inovação e nível de incerteza, Courtney et al. (1999) definem quatro níveis de incerteza estratégica: futuro suficientemente claro, quando os gerentes conseguem gerar uma previsão para determinar uma estratégia confiável, dado que há informação ou ela é possível de se obter, por exemplo avaliar uma mudança de estratégia num mercado conhecido; futuro com algumas alternativas, previsivelmente possíveis, visto que algumas variáveis podem mudar, mas não há como saber antecipadamente, como as mudanças nas regulamentações; futuro com um número razoável de alternativas possíveis, com base num número limitado de variáveis, mas não num cenário comum, como no caso de entrar num novo mercado, similar, porém geograficamente distante da matriz e ambiguidade verdadeira, quando várias dimensões de incerteza interagem impossibilitando qualquer previsão, por exemplo no caso do lançamento do i-pod da Apple, que tinha uma nova tecnologia para atender um novo mercado.

Antes de entender como a GP pode tratar os projetos inovadores, é preciso entender como tipificar esses projetos, o que será feito a seguir. Posteriormente serão identificadas estruturas e modelos que permitem essa gestão de forma mais específica.

\subsubsection{Tipologia de projetos}

Há inúmeras maneiras de se categorizar um projeto. Com base numa extensa pesquisa, na literatura e em várias organizações, Crawford et al. (2005) identificaram 37 atributos que as empresas usavam para categorizar os projetos: cada organização usa, em média, oito desses atributos. Os autores agruparam esses atributos em 14 categorias; o detalhamento de cada uma delas depende muito da área de atuação da organização e do produto. São elas:

- $\quad$ área de aplicação ou produto do projeto - como o tipo de indústria ou de mercado a ser atendido;

- $\quad$ estágio do ciclo de vida - fases do projeto que dependem fortemente do produto do projeto, por exemplo conceito, desenvolvimento, realização e término;

- $\quad$ autônomo ou agrupado - como projeto, programa ou portfólio; 
- importância estratégica - como reposicionamento, renovação ou sobrevivência;

- direcionamento estratégico - pelo tempo, custo, qualidade, relacionamento, processo ou contingência;

- $\quad$ geografia da distribuição da equipe;

- $\quad$ escopo do projeto - pelo valor dos recursos alocados ou pelo número de organizações envolvidas;

- $\quad$ tempo - pela duração do projeto;

- $\quad$ incerteza, ambiguidade, familiaridade - pelo nível de conhecimento da tecnologia, pela familiaridade com os elementos do projeto, pela clareza dos objetivos, métodos e processos a serem usados para gerar o produto;

- $\quad$ risco - pela fonte ou nível do risco;

- $\quad$ complexidade - pelo nível de funções e processos requeridos pelo projeto;

- $\quad$ relações com cliente ou fornecedor - se internas ou externas;

- $\quad$ propriedade / financiamento - pela origem do capital investido no projeto que pode ser interno (uma ou várias áreas) ou externo;

- $\quad$ questões contratuais - como o tipo de contrato e aliança.

Contemplando produtos e processos, Wheelwright e Clark (1992) identificaram cinco tipos de projetos, diferenciados pelo nível de mudança no produto e no processo, conforme Ilustração 6. A tipificação permite não só disponibilizar recursos específicos, como também gerir de forma diferenciada. Os tipos de projeto são: pesquisa e desenvolvimento - o precursor de outros projetos, com a criação de novos conhecimentos, desenvolvimento de novos materiais ou tecnologias, podendo ser aproveitado em projetos comerciais ou não; ruptura - projeto de um novo produto ou um novo processo; plataforma - gera mudanças nos produtos / processos, mas não introduz novas tecnologias, novos materiais ou novos processos, como faz o tipo ruptura, porém inclui melhorias em várias dimensões, como agilidade, funcionalidade, tamanho, peso; derivado - introduz melhorias para reduzir o custo, incluir acessórios ou facilitar o uso do produto ou processo existente; alianças e parcerias - que requer uma categoria específica, por exigir recursos diferenciados para que possa atingir os objetivos, e que se subdivide nos quatro tipos anteriores. 


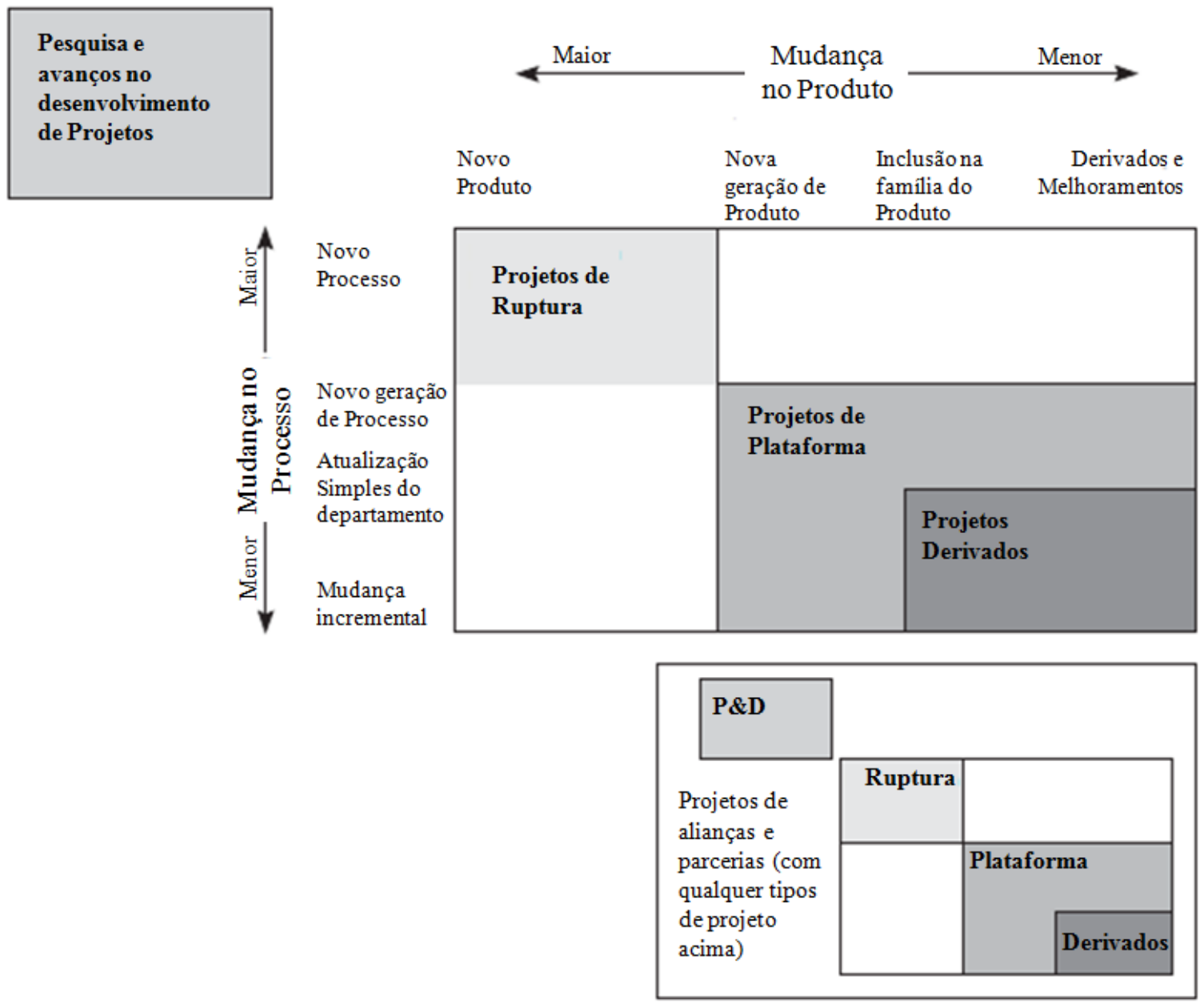

Ilustração 6 - Tipos de projetos de desenvolvimento

Fonte: Wheelwright, Clark, 1992.

Ampliando a combinação de características vistas na tipologia anterior, Shenhar e Dvir (2007) criaram o modelo NTCP, cuja sigla representa quatro dimensões: N - inovação, T tecnologia, $\mathrm{C}$ - complexidade e $\mathrm{P}$ - ritmo. Os autores criaram essa tipologia com o objetivo de permitir uma gestão flexível e específica para cada tipo de projeto.

A inovação representa o nível de incerteza externo, devido ao nível de novidade do produto do projeto para o mercado e para os usuários. Isso determina o nível de confiabilidade requerido da pesquisa de mercado, a ser desenvolvida pela área de marketing; as estratégias de marketing e o tempo para definir e congelar os requerimentos do produto. Essa dimensão possui três níveis:

- derivado - uma modificação, melhoria ou extensão de um produto existente no mercado, gerando pouca incerteza, pois conhece-se o produto e o que deve ser feito; 
- plataforma - uma nova geração de uma linha de produtos, mas há um nível de incerteza maior pela dúvida da aprovação dos usuários, que pode ser avaliado por uma pesquisa de marketing, por exemplo;

- $\quad$ ruptura - a criação de um produto novo com uma inovação radical para o mercado, impedindo que se antecipe a viabilidade de sua aprovação no lançamento, o que insere um alto nível de incerteza no projeto.

A dimensão tecnologia ${ }^{21}$ depende do nível de conhecimento sobre a tecnologia a ser empregada no projeto, que a equipe do projeto possui ou é acessível na organização. É um parâmetro subjetivo. Ela impacta diretamente o nível de competência técnica necessária para a equipe e o gerente de projetos, além do tempo requerido para congelar os requerimentos do escopo. Os exemplos utilizados por Shenhar e Dvir (2007) baseiam-se em produtos tangíveis ou da tecnologia da informação. Para serviços, pode-se subentender que tecnologia representa o método, os processos e as técnicas empregadas, por exemplo para fazer o diagnóstico estratégico de uma organização. Essa dimensão possui quatro níveis:

- baixa, quando a organização domina o conhecimento sobre a tecnologia;

- $\quad$ média, quando a tecnologia é conhecida, mas serão incorporadas novas funções;

- $\quad$ alta, quando a tecnologia está disponível no início do projeto, porém é totalmente nova para a organização;

- $\quad$ muito alta, quando a tecnologia não existe no início do projeto.

Shenhar e Dvir (Ibid.) usam a combinação de inovação e tecnologia para identificar o nível de incerteza do projeto, assim como o número de iterações e de protótipos necessários e o nível de reserva para os recursos de tempo e financeiro para o projeto, conforme descrito no Quadro 3.

\footnotetext{
${ }^{21}$ Tecnologia é a teoria geral e/ou estudo sistemático sobre técnicas, processos, métodos, meios e instrumentos de um ou mais ofícios ou domínios da atividade humana (p.ex., indústria, ciência etc.) (HOUAISS, 2001).
} 
Quadro 3 - Cálculo do nível de incerteza do projeto e seus impactos

\begin{tabular}{|c|c|c|c|c|c|}
\hline $\begin{array}{l}\text { Nível de } \\
\text { incerteza }\end{array}$ & Inovação & Tecnologia & $\begin{array}{l}\text { Número de } \\
\text { iterações }\end{array}$ & $\begin{array}{l}\text { Número de } \\
\text { protótipos }\end{array}$ & $\begin{array}{c}\text { Nível de } \\
\text { reserva em } \\
\text { tempo e custo }\end{array}$ \\
\hline Baixa & Derivativo & Baixa & Poucas (1-2) & Nenhum & $5 \%$ \\
\hline Média & Plataforma & Média & Algumas (2-3) & Poucas (1-2) & $5 \%$ a $10 \%$ \\
\hline Alta & Ruptura & Alta & Várias (3-4) & Várias (3-4) & $10 \%$ a $25 \%$ \\
\hline Muito alta & & Muito alta & Múltiplas $(\mathrm{n}+3)$ & Múltiplas $(n+3)$ & $25 \%$ a $50 \%$ \\
\hline
\end{tabular}

Não há uma definição única para a complexidade em projetos. Muitas vezes confunde-se complexo $^{22}$ com complicado ${ }^{23}$. A diferença entre esses vocábulos está em que, no primeiro, há uma dinâmica nas relações de interdependência que dificultam o seu entendimento e compreensão. Baccarini (1996) definiu a complexidade de um projeto como a interrelação das várias partes do projeto, operacionalizando-a em termos de diferenciação, número dos vários elementos que compõem o projeto, e da interdependência, nível de conectividade entre esses vários elementos. Na visão desse autor, é preciso ficar claro o tipo de complexidade a que está sujeito o projeto, pois ela pode vir de várias fontes: da organização, da tecnologia, dos sistemas, das informações, do ambiente. Revendo essas definições, Willians (1999) identificou duas dimensões para avaliar a complexidade: a incerteza estrutural, que possui os elementos definidos por Baccarini (1996), e a incerteza. Essa dimensão é composta pela incerteza nos objetivos e pela incerteza nos métodos a serem adotados no projeto, que na perspectiva de Shenhar e Dvir (2007) são a inovação e a tecnologia, respectivamente, como visto.

A complexidade de um projeto é categorizada, por Shenhar e Dvir (2007), pela hierarquia de sistema e subsistemas, numa tentativa de gerar uma estrutura livre do contexto:

- baixa complexidade - um projeto de montagem, que pode ser o projeto de um simples componente ou uma função específica, como um subsistema dentro de um sistema maior, por exemplo o desenvolvimento de um teclado para um novo computador;

\footnotetext{
${ }^{22}$ Complexo diz-se de ou conjunto, tomado como um todo mais ou menos coerente, cujos componentes funcionam entre si em numerosas relações de interdependência ou de subordinação, de apreensão muitas vezes difícil pelo intelecto e que geralmente apresentam diversos aspectos (HOUAISS, 2001).

${ }^{23}$ Complicado é composto de elementos que entretêm relações numerosas, diversificadas e difíceis de apreender pelo espírito (HOUAISS, 2001).
} 
- média complexidade - um projeto de um sistema, que lida com várias funções ou mesmo grupo de funções, por exemplo a reestruturação de uma organização em suas várias áreas de negócios, quando normalmente há uma coordenação desses vários departamentos para gerenciar o projeto;

- alta complexidade - o projeto do tipo matriz, centralizador de vários sistemas que funcionam integrados para o atendimento de um objetivo, por exemplo a construção de um metrô, que envolve desde a desapropriação de prédios e compra de terrenos; ao projeto e construção de estações de metrô, túneis, pontes; compra de trens; modificação do entorno das estações para o fluxo de passageiros esperado; integração com outras linhas de metrô, de ônibus e de trem e o próprio metrô em si.

Demonstrando que não há ainda um consenso para identificar a complexidade em projetos, Crawford et al. (2005) incluem a categorização acima de montagem, sistema ou matriz, como exemplo da categoria autônomo / agrupado. Esses autores também incluem a complexidade na categoria de riscos, pois, segundo eles, a complexidade é considerada a maior fonte de riscos. Um dos exemplos dado por esses autores, para categorizar o nível de complexidade, é: - baixa complexidade - projeto com funções ou processos simples, requisitos de tecnologia simples e interfaces simples com outros serviços, produtos ou sistemas;

- média complexidade - projeto com funções ou processos habituais, requisitos de tecnologia habituais e interfaces habituais com outros serviços, produtos ou sistemas;

- alta complexidade - projeto com elevado número de funções ou processos, de requisitos de tecnologia e de interfaces com outros serviços, produtos ou sistemas.

Outra dimensão importante é a dimensão do ritmo, que representa a urgência do projeto para a organização e, consequentemente, quanto tempo disponível existe para o desenvolvimento do projeto. Shenhar e Dvir (Ibid.) sugerem que as maiores consequências do ritmo na organização do projeto são: no tipo de estrutura organizacional, principalmente na autonomia da equipe, nos participantes, nos processos, além do suporte da alta gerência. Foram estabelecidos quatro níveis:

- $\quad$ regular - quando o tempo não é um fator crítico para o sucesso do projeto;

- rápido / competitivo - o tipo mais comum de projeto, pois é aquele que deve atender uma janela de oportunidade do mercado; 
- $\quad$ tempo crítico - quando a data é uma restrição forte e específica, por exemplo o projeto do bug do milênio;

- $\quad$ blitz - para solucionar uma crise ou um evento inesperado, tendo a rapidez como um fator crítico, por exemplo o atendimento a uma população afetada por uma enchente.

Além desses critérios, Shenhar e Dvir (Ibid.) também sugerem avaliar para a categorização de projetos: a ligação com o objetivo do negócio, se operacional ou estratégico; o tipo de cliente, interno ou externo; a ligação com os objetivos estratégicos que podem ser melhoria, estratégico, solução de problemas, manutenção, utilitário, pesquisa e desenvolvimento.

Há uma dificuldade maior em se caracterizar o tipo de inovação na geração de serviços, dado que as tipificações citadas se baseiam na geração de produtos. Os serviços possuem especificidades, como a intangibilidade, que não se ajustam facilmente aos critérios estabelecidos. Gallouj e Weinstein (1997) desenvolveram uma classificação que avalia a inovação não apenas pelo tipo de produto e tecnologia empregada, mas também pela competência gerada e exigida no processo, representada na Ilustração 7. Esta é uma forma geral, que pode ser aplicada tanto a serviços quanto a produtos.

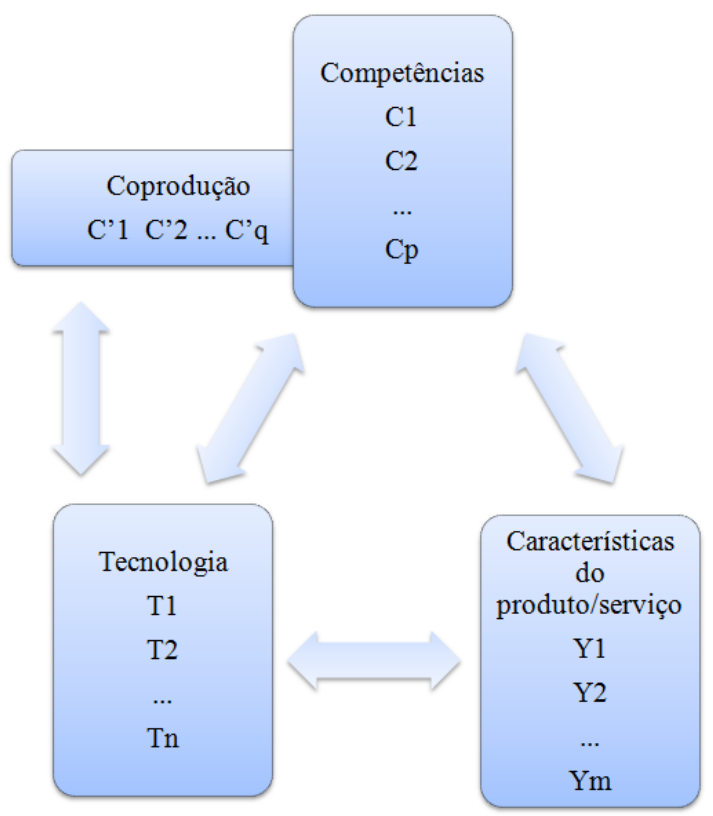

Ilustração 7 - Representação de um produto de serviço Fonte: Adaptado de Gallouj, Weinstein, 1997. 
A competência (C) é o conhecimento individual e habilidades, obtidos pela educação formal, treinamento, experiência e interação (GALLOUJ, WEINSTEIN, 1997, p. 546). Essas competências também podem ser do grupo, mas devem ser claramente delimitadas. Além disso, não se restringem às existentes na equipe do projeto, pois também podem ser obtidas dos clientes e fornecedores que participam do projeto, por exemplo. Na Ilustração 7 elas aparecem como coprodução. As características técnicas ou tecnologia $(\mathrm{T})$ são as ferramentas, modelos e rotinas organizacionais, que podem ser aplicadas pelas habilidades individuais dos empregados ou mesmo da equipe do projeto, repetidamente. O serviço possui determinadas características finais do produto / serviço (Y), obtidas pela combinação das competências e das tecnologias empregadas.

O constructo de vetores - competências (C), tecnologia (T) e características do produto / serviço (Y), proposto por Gallouj e Weinstein (1997), considera que cada novo serviço é uma combinação única de modificações ou adições de elementos aos vetores competências e tecnologias. As diferentes combinações possíveis entre os vetores permitiram a proposição de seis modos de inovação em serviços:

- $\quad$ inovação radical - os vetores $\mathrm{C}, \mathrm{T}$ e Y são totalmente novos, ou seja, não se baseiam na modificação do sistema de vetores de um produto anterior. Mesmo o vetor de competências $\mathrm{C}$ possui novos componentes não presentes em produtos anteriores. Também pode ser aplicada a inovações em $\mathrm{C}$ e $\mathrm{T}$ que não modifiquem as características do serviço prestado, como o caso da troca das carruagens para o carro, pois o serviço de locomoção não foi afetado;

- $\quad$ inovação de aprimoramento - o sistema de vetores não é alterado em sua estrutura, mas em sua qualidade ou nível de desempenho. Um ou mais componentes (já existentes) nos vetores $\mathrm{C}$ ou $\mathrm{T}$ alcançam um nível de desempenho melhor que o anterior, e essa diferença é sensível a uma demanda de mercado (Y) existente;

- $\quad$ inovação incremental - o sistema de vetores é marginalmente modificado, pela adição ou substituição de componentes dos vetores $\mathrm{C}$ e / ou $\mathrm{T}$;

- $\quad$ inovação ad hoc - construída essencialmente por uma interação social com o cliente. Ao enfrentar uma necessidade "particular e específica", a empresa dedica-se a modificar os componentes dos vetores $\mathrm{C}$ e $\mathrm{T}$, não apenas com o objetivo de atender aquele cliente específico, mas também com o de modificar permanentemente a estrutura de vetores que define o serviço. Esse tipo de inovação está intimamente ligado a um processo de aprendizagem e acúmulo de conhecimento, como os da consultoria; é construída 
essencialmente por uma interação social com o cliente, para atender uma necessidade particular e específica, para isso a empresa modifica os componentes dos vetores de competência e tecnologia;

- $\quad$ inovação recombinante - novos serviços são desenvolvidos com base num estoque de conhecimento e tecnologia construídos pela trajetória de produtos anteriores. A estrutura de vetores de uma inovação recombinante é composta por componentes dos vetores $\mathrm{C}$ e $\mathrm{T}$ existentes em outros produtos. Um novo produto pode ser formado com a soma dos componentes de dois outros serviços, ou um serviço existente pode, até mesmo, ter seus componentes dos vetores $\mathrm{C}$ e $\mathrm{T}$ "divididos" para gerar dois ou mais novos produtos. Uma analogia útil para entender essa inovação é o conceito de plataformas de produto, amplamente utilizado na indústria de bens manufaturados;

- inovação pela formalização - ao contrário dos modos de inovação anteriores, este não adiciona nem modifica os componentes da estrutura de vetores que definem o serviço. A inovação ocorre pela delimitação clara do que é o serviço, estabelecendo uma "ordem" e um formato definido que serão compreendidos pelas equipes internas e pelo cliente. Essa formalização é um passo anterior que habilita a empresa a praticar a inovação recombinante descrita.

\subsubsection{Abordagens diferenciadas para a GP inovadores}

Pich et al. (2002) afirmam que, sem informações adequadas, não é possível fazer o planejamento, a execução e o monitoramento apropriado dos projetos. A inadequação das informações precisa ser tratada por outras abordagens metodológicas, tanto pelo desconhecimento de eventos e causas, que os autores chamam de ambiguidade e posteriormente de incerteza imprevisível (LOCH et al., 2006), quanto pela dificuldade de avaliar as consequências da interação das múltiplas variáveis, que chamam de complexidade.

Nessa linha de avaliação, Willians (1999) também afirma que, para gerenciar um alto nível de incerteza estrutural, com muitos elementos interrelacionados dinamicamente, são necessários novos métodos de GP. Isso porque os atuais métodos não tratam os efeitos acumulados das perturbações individuais dos elementos do projeto, não tratam loops de feedback, não convertem incerteza em objetivos e métodos. Shenhar e Dvir (2007) sugerem que a abordagem seja flexível e adaptativa para gerar resultados para o negócio com base em 
multicritérios e não apenas em escopo, orçamento e prazo. O planejamento deve ser feito no início do projeto e replanejado quando as mudanças no contexto assim o exigirem. O tipo de gestão é adaptativo à tipologia do projeto, conforme detalhado no item anterior.

A metodologia de planejamento dirigido à descoberta ${ }^{24}$ (McGRATH, MacMILLAN, 1995) é sugerida para a geração de novos empreendimentos, que compreende principalmente o desconhecido. Uma das principais características é o tratamento das premissas como fatos explícitos no plano. Elas se modificam e se transformam em conhecimento, ao longo do desenvolvimento do empreendimento. Essas premissas são identificadas por meio de quatro documentos: declaração reversa de resultado, documento relativo a fatores econômicos; especificação pró-forma das operações, que desenha as operações necessárias ao negócio; lista de premissas chaves, que garantem a validação e a transformação em conhecimento e um quadro de planejamento de marcos, que inclui o planejamento dos testes de cada uma das premissas. Para realizar um empreendimento de sucesso, os autores citam as seguintes disciplinas (processos): framing - define os parâmetros de sucesso para o empreendimento, incluindo a declaração reversa de resultado; benchmarking - identificar a realidade do mercado e dos competidores, para minimizar o viés otimista; definição de entregas transforma um empreendimento em atividades diárias para se obterem os resultados; teste de premissas - feito ao mesmo tempo em que o empreendimento é desenvolvido, com o menor custo possível; gestão dos marcos - contém o desafio de incluir os testes das premissas; o último passo é a parcimônia, na medida em que os investimentos são mínimos até que as principais premissas sejam testadas e se verifique a viabilidade do negócio.

Uma metodologia bastante conhecida e aplicada nas organizações para o desenvolvimento de novos produtos é o stage-gate (COOPER, EDGETT, 2012) composto por cinco estágios de desenvolvimento de novos produtos - definição de escopo, construção do caso de negócio, desenvolvimento, teste e validação e lançamento do produto. Há uma avaliação ao final de cada estágio, o gate, para se verificar a continuidade ou o cancelamento do projeto. Esse processo também evoluiu com a inclusão de uma fase inicial de descoberta (COOPER et al., 2002a, COOPER et al., 2002b). Essa fase incorpora a obtenção de ideias, com a centralização em uma pessoa que passará as informações para um pequeno grupo que avaliará a ideia, finalizando com o feedback do gerador da ideia, o armazenamento das ideias e sua situação.

\footnotetext{
${ }^{24}$ Discovery-driven planning
} 
Outra maneira dá-se obtendo ideias do cliente, principalmente aqueles inovadores e líderes. As ferramentas mais indicadas são o uso de cenários alternativos de futuro, a identificação do gerador de maior receita ${ }^{25}$ e mapas de oportunidade. Para o desenvolvimento de novas tecnologias, há outros estágios que substituem o estágio de descoberta: avaliação técnica e investigação detalhada.

O Design Thinking (BROWN, 2010) é uma nova metodologia que vem se destacando na área de inovação. Não há um continuum como nas outras metodologias, mas uma alta iteratividade com equipes multidisciplinares e competentes em espaços que se sobrepõem. Esses espaços são: a inspiração - quando o problema ou a oportunidade são inicialmente conhecidos e questionados, com o estabelecimento de metas claras; a idealização - com a geração, o desenvolvimento e os testes das ideias, principalmente por meio de protótipos, para que se passe pelas falhas o mais cedo possível, e a implementação - com o lançamento do produto ou serviço ao mercado. O caráter exploratório do método faz com os insights obtidos em qualquer um dos espaços altere o produto ou mesmo revejam-se premissas básicas. Um primeiro estágio visa identificar as restrições mais importantes, assim como os critérios para sua avaliação. Há três critérios, com ênfase nas necessidades humanas fundamentais: a praticabilidade - com funcionalidades possíveis num futuro próximo; viabilidade - com possibilidade de ser incorporado por um negócio e desejabilidade - o que faz sentido para as pessoas.

Outros trabalhos (PICH et al., 2002; LOCH et al., 2006; LOCH et al., 2008) sugerem uma abordagem diferenciada na gestão dos projetos conforme seu nível de incerteza e sua complexidade, conforme Ilustração 2, página 14:

- $\quad$ instrucionismo - para essa abordagem, a definição de um projeto é “[...] uma coleção de atividades simultâneas e sequenciais que juntas produzem um resultado identificável de valor." ${ }^{26}$ (PICH et al., 2002, p. 1011). Assim, essa abordagem pode ser representada pelas práticas sugeridas pelo Guia PMBOK (PMI, 2008) e PRINCE2 (OGC, 2005). Elas são adequadas a projetos com baixo nível de incerteza e baixa complexidade, pois são baseadas num planejamento de utilização de recursos, sobre os quais se tem informação conhecida.

\footnotetext{
${ }^{25}$ Major revenue generator

26 "[...] a colletion of simultaneous and sequential activities which together produce na identifiable outcome of value."
} 
Para se atingirem os objetivos do plano do projeto, sugere-se a GR com o monitoramento e controle da variação do planejado;

- $\quad$ aprendizado - se o projeto tiver maior incerteza, os autores sugerem o uso de métodos de aprendizado. Há dois modelos - aprendizado na improvisação, quando o planejamento e a execução ocorrem simultaneamente, e aprendizado pela experimentação, cujo tipo mais comum é o método da tentativa e erro. Esse método possui a capacidade de mudar ou gerar novos planejamentos, por causa de mudanças e descobertas, permitindo maior flexibilidade e rapidez à gestão;

- $\quad$ selecionismo - caso o projeto tenha baixo nível de incerteza e alta complexidade, eles sugerem que se gerem múltiplas alternativas ao problema, concorrente ou sequencialmente, com a seleção da melhor solução ex post;

- no caso de alta incerteza e alta complexidade, Loch et al. (2008) sugerem que se busquem mais informações para tornar a incerteza imprevisível conhecida, antes de iniciar a abordagem de selecionismo.

Mas, para se identificar o nível de incerteza e complexidade e decidir pela gestão mais adequada, é preciso um diagnóstico prévio de incertezas do projeto (LOCH et al., 2008), conforme demonstrado na Ilustração 8:

a) entende-se a estrutura do problema para se identificarem os objetivos e os fatores de desempenho que devem ser alcançados, assim como as respectivas ações para alcançá-los;

b) divide-se o problema em subproblemas para entender a situação de cada um deles;

c) avaliam-se os subproblemas, identificando-se para cada um as ações a serem executadas, os riscos e as lacunas de conhecimento, definindo um perfil de incerteza. Esse perfil pode ser: variação, que na linha de incerteza se refere ao nível knowns e no qual o processo de monitoramento e controle deve ser feito pela observância dos possíveis desvios do cronograma e / ou orçamento planejado; incerteza prevista, que pode ser entendido como o nível known unknowns e para o qual a GR e os planos de contingência são os mais indicados e a incerteza imprevisível (nível unk unks) podem ser tratados pelo aprendizado ou pelo selecionismo, após a obtenção de informações que suportarão a escolha do melhor tipo de gestão;

d) a gestão dos subproblemas é paralela e diferenciada, conforme o perfil de incerteza. 


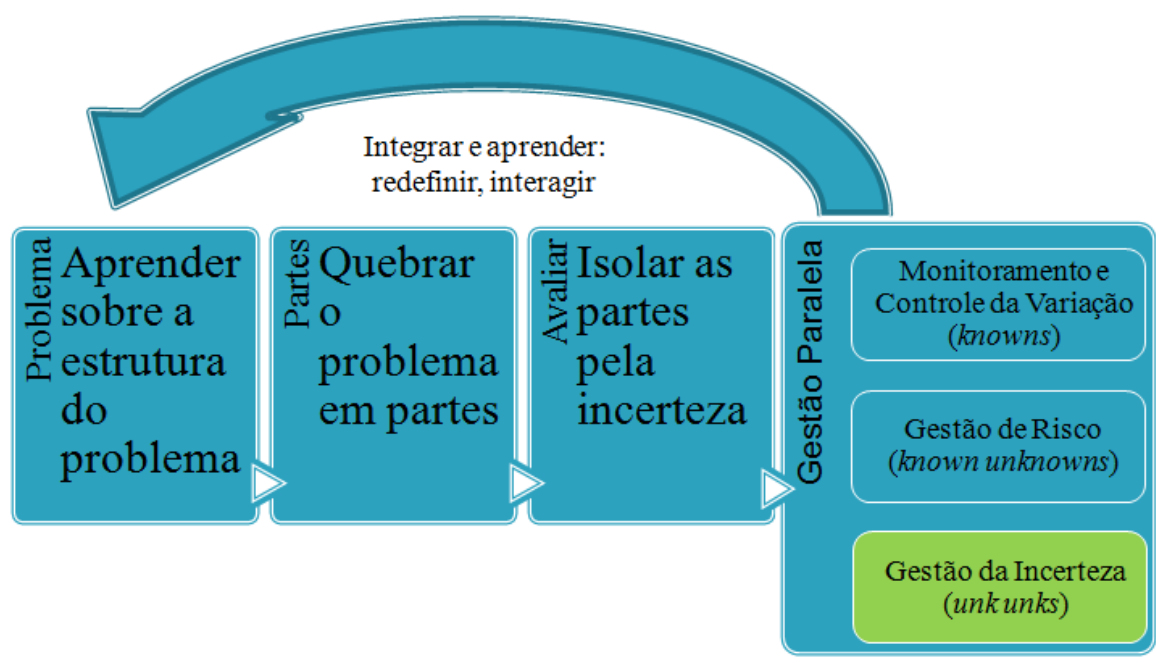

Ilustração 8 - Diagnóstico de incertezas em projetos

Fonte: Adaptado de Loch et al., 2006; 2008.

Esse processo é iterativo e gradual, pois, com o progresso do projeto, o desconhecido torna-se mais conhecido. A gestão também deve evoluir, para que cada vez mais contemple um planejamento, no qual apenas uma pequena variação é esperada. Dentro das práticas atuais de GP, a GR é a responsável por tratar as questões referentes à incerteza, por isso no item seguinte serão identificadas como essas práticas lidam com essas questões.

\subsubsection{Gestão de riscos}

Bernstein (1997) afirma que a essência da gestão de riscos está em maximizar as áreas nas quais temos controle sobre o resultado, baixa incerteza, enquanto minimizamos as áreas sobre as quais não temos controle. Ao se tomar uma decisão sempre há uma consequência. Bernstein (ibid.) indica que sempre que há um risco, ao se tomar uma decisão, aposta-se num resultado, sem ter certeza disso.

No Quadro 4 destacam-se as definições de risco e como a incerteza é tratada em padrões para GR. Os padrões de gestão de risco para organizações avaliados foram: ISO 31000 - um padrão internacional, o sucessor do padrão AS / NZS 4360:2004, cuja primeira edição data de 1995; Gerenciamento de risco corporativo - estrutura integrada, desenvolvido pelo COSO Committee of Sponsoring Organizations of the Treadway Commission (2007) com uma empresa de auditoria, PricewaterhouseCoopers, que visa ser um padrão adotado por organizações privadas, para atender os objetivos estratégicos, operacionais, de comunicação e 
de conformidade; Orange Book (HM TREASURY, 2004) - lista os princípios e conceitos adotados na GR governamental para o departamento do Tesouro da Inglaterra, apesar de ele não se considerar um padrão; o padrão de Risk Management Standard (AIRMIC, ALARM, IRM, 2002) - gerado por três grandes organizações que gerenciam riscos na Inglaterra, tendo como base a terminologia ISO - International Organization for Standardization.

Quadro 4 - Definição de risco e incerteza nos padrões de gestão de riscos

\begin{tabular}{|c|c|c|}
\hline Padrão & Definição de Risco & Gestão da incerteza \\
\hline ISO 31000 & $\begin{array}{l}\text { O efeito das incertezas nos objetivos; efeito é um } \\
\text { desvio no esperado, positivo ou negativo. }\end{array}$ & $\begin{array}{l}\text { A GR explicitamente endereça a incerteza. } \\
\text { Ele é dinâmico, iterativo e responde às } \\
\text { mudanças, pois continuamente as percebe. }\end{array}$ \\
\hline $\begin{array}{l}\text { COSO } \\
(2007)\end{array}$ & $\begin{array}{l}\text { O risco é representado pela possibilidade de que } \\
\text { um evento ocorrerá e afetará negativamente a } \\
\text { realização dos objetivos. }\end{array}$ & $\begin{array}{l}\text { A gestão do risco permite lidar com a } \\
\text { incerteza e associada ao risco e } \\
\text { oportunidade, alavancar a capacidade de } \\
\text { gerar valor da organização. }\end{array}$ \\
\hline $\begin{array}{l}\text { HM } \\
\text { Treasury } \\
(2004)\end{array}$ & $\begin{array}{l}\text { Incerteza do resultado de ações e eventos: é uma } \\
\text { oportunidade, se positivo, ou uma ameaça, se } \\
\text { negativo. É a combinação de probabilidade e } \\
\text { impacto, incluindo a importância percebida. }\end{array}$ & $\begin{array}{l}\text { A gestão do risco trata a incerteza da } \\
\text { organização em obter os benefícios } \\
\text { esperados }\end{array}$ \\
\hline $\begin{array}{l}\text { Risk } \\
\text { Management } \\
\text { Standard } \\
\text { (AIRMIC, } \\
\text { ALARM, } \\
\text { IRM, 2002) } \\
\end{array}$ & $\begin{array}{l}\text { Combinação da probabilidade de um evento e suas } \\
\text { consequências que podem constituir-se em } \\
\text { oportunidades de benefícios ou ameaças ao } \\
\text { sucesso. }\end{array}$ & $\begin{array}{l}\text { A gestão do risco deve diminuir a incerteza } \\
\text { da organização para atingir os objetivos. }\end{array}$ \\
\hline $\begin{array}{l}\text { PMI }(2008, \\
2009)\end{array}$ & $\begin{array}{l}\text { Evento ou condição incerta que, se ocorrer, gerará } \\
\text { um impacto positivo ou negativo aos objetivos do } \\
\text { projeto. }\end{array}$ & $\begin{array}{l}\text { A incerteza é tratada como a probabilidade } \\
\text { do risco ocorrer. Não trata os riscos } \\
\text { desconhecidos. }\end{array}$ \\
\hline $\begin{array}{l}\text { PRINCE2 } \\
(\text { OGC, 2005) }\end{array}$ & $\begin{array}{l}\text { Incerteza do resultado (se oportunidade positiva ou } \\
\text { ameaça negativa). }\end{array}$ & $\begin{array}{l}\text { O processo de monitoramento e controle } \\
\text { avalia os sinais de alerta, assim como as } \\
\text { tendências futuras. }\end{array}$ \\
\hline $\begin{array}{l}\text { SRM } \\
\text { (HIGUERA, } \\
\text { HAIMES, } \\
\text { 1996) }\end{array}$ & $\begin{array}{l}\text { Um evento incerto que, se ocorrer, pode ter um } \\
\text { impacto positivo ou negativo aos objetivos do } \\
\text { projeto. }\end{array}$ & $\begin{array}{l}\text { Visão prospectiva para antecipar resultados } \\
\text { e consequências das decisões tomadas. }\end{array}$ \\
\hline
\end{tabular}

Os padrões de gestão de risco em projetos avaliados foram: PMI $(2008,2009)$ - descreve as melhores práticas em GR em projetos, devendo ser adaptado a cada organização, amplamente adotado pelos Estados Unidos e em vários outros países no mundo; PRINCE2 - metodologia desenvolvida pelo OGC - Office of Government Commerce (2005) para ser utilizada por todas as organizações que desenvolvem projetos para esse departamento do estado, bastante utilizada na Europa, tanto no setor público quanto no privado; Software Risk Management, SRM - desenvolvido para a SEI - Software Engineering Institute (HIGUERA, HAIMES, 1996), associação ligada à Carnegie Mellow University, para endereçar os riscos de todo o ciclo de vida do projeto de um software, focando riscos técnicos. 
Perminova et al. (2008, p. 76) definem incerteza como "[...] um contexto para os riscos, eventos que têm um impacto negativo sobre os resultados do projeto, ou para as oportunidades, eventos que têm impacto benéfico sobre o desempenho do projeto." ${ }^{27}$ Assim, o plano de respostas ao risco deve assegurar que não haverá impactos negativos aos objetivos do projeto, o que depende da habilidade dos envolvidos em usarem os conhecimentos e experiências, em lidarem com situações incertas. A ISO (2008) considera o risco "O efeito das incertezas nos objetivos." ${ }^{28}$ Todos os padrões, detalhados no Quadro 4, relacionam os lados positivo e negativo do impacto do risco, mas centram o detalhamento nos aspectos negativos dos riscos. Pode-se perceber que a ligação do risco aos objetivos do projeto é, praticamente, um padrão, pois apenas o PRINCE2 (OGC, 2005) liga o risco ao resultado do projeto todo.

Baseado numa visão estratégica, Jaafari (2001) propõe um modelo para gerar objetivos funcionais por ciclo de vida do projeto, nomeado LCOF - Life Cycle Objective Functions. Esses objetivos são classificados como financeiros; satisfação do cliente, nos aspectos de utilidade, operabilidade, qualidade e segurança, e due diligence quanto a questões ecológicas. Assim, a GR é base para o planejamento, detalhado por ciclo de vida, o que diminui a falta de conhecimento sobre as variáveis envolvidas. Ele também propõe que a GR seja base para a tomada de decisão, por meio de um planejamento proativo e aberto, permitindo reavaliar as opções de desenvolvimento do projeto. Em outra perspectiva, Murray-Webster e Pellegrinelli (2010) sugerem que se foque numa visão econômica na avaliação dos riscos, selecionando aqueles em que se percebe uma diferença tangível, pelo uso do valor presente líquido.

Para o PMI (2009), a GR endereça a incerteza em estimativas e premissas dos projetos, pois vários de seus processos assumem que todas as informações são conhecidas, por exemplo custos, durações e disponibilidade de recursos. Assim, destacam-se duas dimensões do risco (ibid.): a incerteza, ligada à probabilidade de um evento ocorrer, e o seu efeito nos objetivos do projeto, que é o impacto ou consequência da ocorrência do evento. Outra característica importante é a causa do risco, o que gera a corrente causa-risco-efeito. As ameaças cessam quando se tornam problemas, assim como as oportunidades, quando se tornam benefícios.

\footnotetext{
27 “[...] a context for risks as events having a negative impact on the project's outcomes, or opportunities, as events that have beneficial impact on project performance."

28 "The effect of uncertainty on objectives."
} 
Essa organização faz, ainda, uma distinção entre riscos individuais e riscos globais. Os primeiros são objeto da gestão diária dos riscos e podem afetar um ou mais objetivos do projeto, enquanto os globais afetam o projeto todo. Estes devem fazer parte das decisões estratégicas, da gestão de programas e de portfólio para o estabelecimento de prioridades, sansões ou cancelamentos.

A GR em projetos, porém, é criticada (MURRAY-WEBSTER, PELLEGRINELLI, 2010, PENDER, 2001, PERMINOVA et al., 2008) por não esclarecer e endereçar devidamente as incertezas inerentes aos planos. As estimativas apresentam variabilidade normal, como pelo desconhecimento sobre determinados detalhes de disponibilidade de recursos ou mesmo de sua produtividade, podendo esconder avaliações enviesadas com possibilidades de melhorias. Murray-Webster e Pellegrinelli (2010) ressaltam a falta de geração de valor com a GR, pois, além de não diminuir os vieses das estatísticas, foca a redução do risco, tendendo a negligenciar as ações contingenciais e o uso das opções reais.

É preciso esclarecer que pode haver um problema de agenda. Há um nível de risco implícito no negócio, para que o retorno seja compensador, que pode ser reduzido pelo nível de ações mitigadoras acionadas pelo gerente de projetos para diminuir o risco (ibid.). A gestão deverá agir de maneira que a exposição aos riscos esteja dentro de um nível tolerável, assim como sejam factíveis os custos versus benefícios das ações para gerenciá-los e agir sobre eles (OGC, 2005). Porém a incerteza é uma característica da evolução da organização, da qual o projeto faz parte, portanto não é possível nem é economicamente viável eliminar todas as incertezas.

Murray-Webster e Pellegrinelli (2010) citam que a visão da GR atual não contempla os riscos desconhecidos. Porém, com relação ao tratamento desse tipo de incerteza, apenas o PRINCE2 (OGC, 2005) cita o monitoramento dos sinais precoces, chamando de sinais e avisos antecipados e a ISO 31000 (PURDY, 2009) ressalta a percepção e resposta às mudanças, que podem ocorrer de maneira lenta ou súbita.

Complementando a análise conceitual de riscos e incertezas nos padrões para projetos e para organizações, no próximo item serão destacados os fatores de riscos mais citadas. 


\subsubsection{Fatores de risco}

Os padrões possuem sugestões de listas iniciais de fatores de riscos, para que sejam desenvolvidas e adequadas para a área de atuação e o tipo de organização, tanto na implantação da GR, quanto em sua evolução. A seguir será apresentada uma síntese sobre esses fatores (COSO, 2004; HM TREASURY, 2004), que também podem ser chamados de categorias de risco (HIGUERA, HAIMES, 1996; OGC, 2005; PMI, 2008).

Os riscos podem ser externos, por surgirem externamente à organização podendo apenas ser mitigados, ou internos, relativos às operações internas da organização, para prover capacidade de produção e competência (HM TREASURY, 2004; COSO, 2004). Os fatores de risco externo podem ser:

- políticos - ocorrência de mudanças de governo, política pública, guerra e desordem, por exemplo eleição de agentes do governo com novas agendas, mudança na máquina pública, abertura ou na restrição ao acesso a mercados estrangeiros;

- regulatórios - como mudanças em leis que podem trazer exigência de novos atributos, aumentar o nível de qualidade ou elevar ou reduzir a carga tributária;

- $\quad$ econômicos - as oscilações de preços, nível de emprego, disponibilidade de capital, novos concorrentes podem afetar tanto a organização quanto os projetos;

- $\quad$ sociais - alterações nas condições demográficas e costumes sociais que podem provocar mudanças na demanda de produtos e serviços, expectativa dos clientes e dos usuários;

- tecnológicos - a obsolescência ou surgimento de novas tecnologias podem provocar tanto a oportunidade de encontrar uma tecnologia mais adequada quanto aumento do custo para encontrar a melhor opção no momento;

- meio ambiente - pode-se referir tanto aos eventos da natureza quanto às exigências ou restrições, cada vez mais relevantes, não apenas para se produzirem novos produtos ou serviços como também para continuar a se produzir;

- $\quad$ fornecedores - para projetos este fator também é considerado externo (PMI, 2008).

Os fatores de risco interno podem variar muito conforme o produto, o projeto e a organização. Em termos gerais podem ser classificados em:

- $\quad$ infraestrutura - refere-se à capacidade e habilidade de entregar a produção no tempo devido; 
- $\quad$ pessoal - tudo o que se refere à disponibilidade das pessoas, como doenças e acordos sindicais, que podem causar impacto na reputação ou produtividade;

- $\quad$ processo - a administração e adequação dos processos para evitar ineficiência, erros, retrabalhos, insatisfação do cliente. Classificado em:

- Capacidade, design, execução, dependências / fornecedores;

- Mudança de estratégia organizacional (HM TREASURY, 2004) - prioridades, novas políticas com geração de expectativas;

- Processos específicos de GR (HM TREASURY, 2004) - compliance, ética, procura de falhas, recuperação de desastre e contingências;

- Processos específicos de GP (PMI, 2008) - estimativa, planejamento, controle, comunicação;

- tecnologia - recursos para manter e alavancar a produtividade, com segurança, principalmente os referentes à tecnologia da informação.

Além desses fatores, o Guia PMBOK (PMI, 2008) inclui fornecedores como fator externo e os técnicos em termos de requerimentos, tecnologia, complexidade e interfaces, desempenho e confiança, qualidade, em fatores internos. Essas fontes podem auxiliar a identificação de riscos, mas, como as incertezas imprevisíveis se localizam justamente na falta de conhecimento, a simples listagem de inúmeros fatores não assegura a identificação desse tipo de incerteza.

\subsubsection{Processos em gestão de riscos}

O Quadro 5 compara os processos dos padrões mais usados em GR tanto para projetos (PMI, 2008; OGC, 2005; HIGUERA, HAIMES, 1996) quanto para organizações (HM TREASURY, 2004; COSO, 2004; AIRMIC, ALARM, IRM, 2002; ISO 31000, 2009), detalhados no item anterior. Pode-se notar que todos os padrões têm, praticamente, a mesma estrutura processual.

Enquanto nos padrões para projetos, o planejamento refere-se à tolerância ao risco e ao planejamento para as próximas fases, os padrões organizacionais realçam a definição dos objetivos e do contexto. De forma mais contundente, a ISO 31000 (2009) define que os critérios serão estabelecidos nessa fase, base para as decisões futuras na avaliação dos riscos. 
De maneira geral, no processo de identificação deve-se reconhecer os riscos, identificar a causa e a fonte, os prováveis impactos e registrá-los. O PMI (2009) indica a existência de riscos desconhecidos dizendo que é necessário "Identificar tantos riscos conhecidos quanto possível." ${ }^{29}$ A solução sugerida pelo PMI (2009), para que os riscos se tornem conhecidos, ao longo do ciclo de vida do projeto, é a iteratividade desse processo.

Quadro 5 - Comparativo dos processos dos padrões de GR

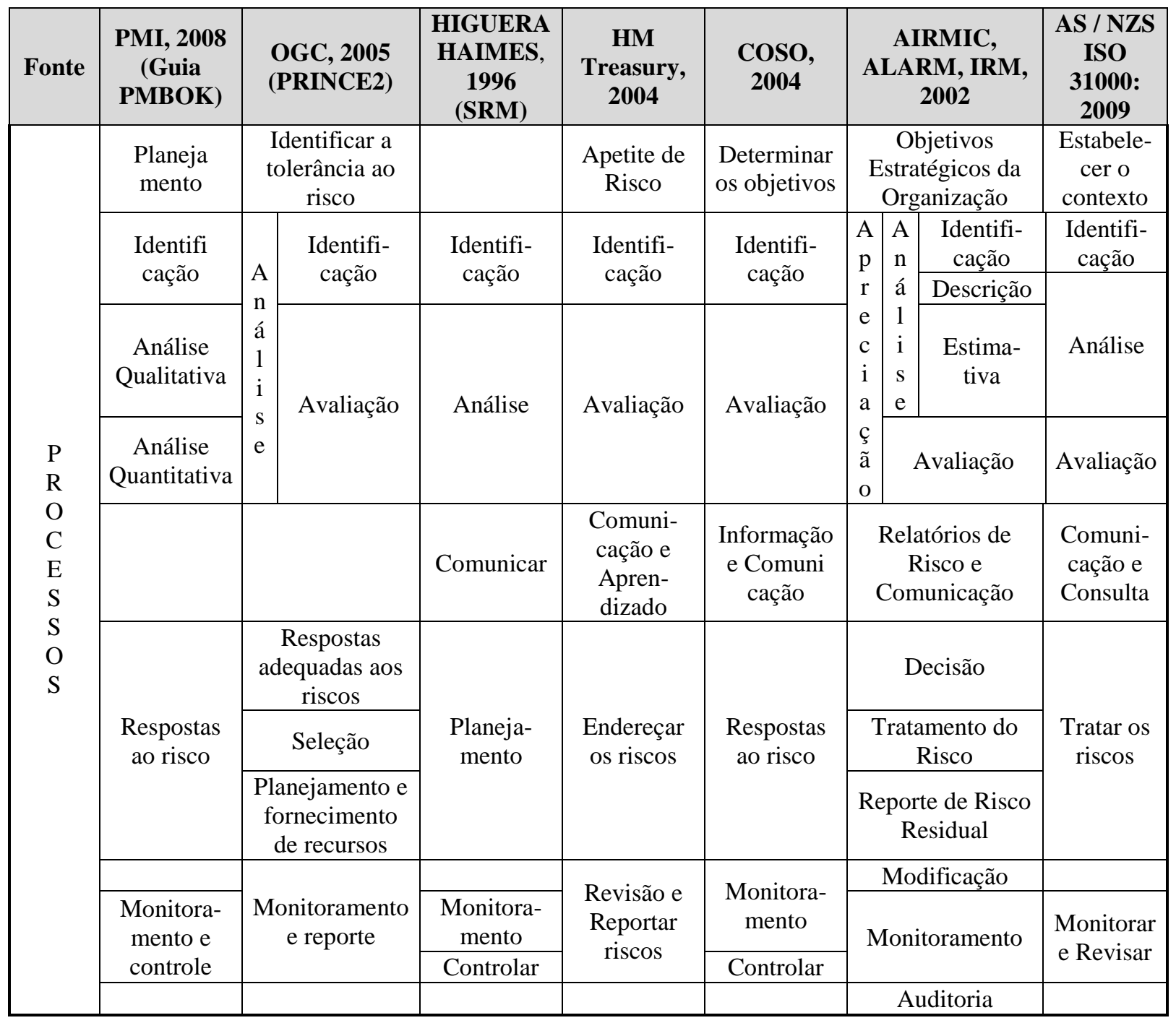

Para a ISO 31000 (2009) e para a AIRMIC, ALARM e IRM (2002), análise e avaliação dos riscos são processos distintos. $\mathrm{Na}$ análise, há o entendimento do risco pela identificação das consequências e probabilidades, na qual são usadas técnicas: qualitativas, na qual se classifica a probabilidade e consequência com termos como alto, médio e baixo; semiquantitativas, na

\footnotetext{
29 "Identifies as many knowable risks as practicable."
} 
qual se usa escalas numéricas de forma a ser possível calcular o nível de risco por meio de uma fórmula, e quantitativas, com uso de técnicas mais sofisticadas e testes estatísticos. No processo de avaliação, os níveis de riscos estimados na análise são comparados com os critérios definidos no processo de estabelecimento do contexto, decidindo-se pelas ações futuras. No PMI (2009), a distinção da análise qualitativa com a quantitativa existe em relação ao uso de técnicas qualitativas no primeiro e, se necessário, a quantitativa com técnicas mais sofisticadas que envolvem teoria da decisão e testes estatísticos.

Conforme Ilustração 9, a comunicação é central no padrão SRM (HIGUERA, HAIMES, 1996) para todos os paradigmas, como são chamados os processos. Entretanto, como pode ser observado no Quadro 5, esse processo não existe no Guia PMBOK (PMI, 2008) e no PRINCE2 (OGC, 2005). Essa ausência é criticada por Pender (2001). Apesar de que o PMI (2009) identifica a comunicação aberta e honesta como fator crítico de sucesso para a GR, assim como o comprometimento organizacional e individual, o reconhecimento do valor da GR, o nível de esforço de gestão compatível com o projeto e a sua integração com a GP.

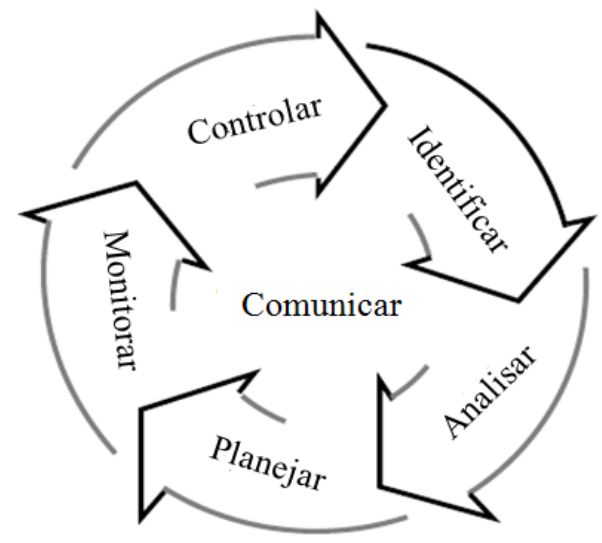

Ilustração 9 - Processos da GR da SRM

Fonte: Adaptado de HIGUERA, HAIMES, 1996.

Outra maneira pela qual as incertezas imprevisíveis podem ser detectadas é pela GR contínua (PMI, 2009) feita durante o processo de monitoramento e controle, incorporando o aumento do nível de conhecimento da equipe. Todavia, se a equipe focar apenas os riscos identificados inicialmente, não perceberá o surgimento de novos riscos.

\subsubsection{T\&F em gestão de riscos}

No Quadro 6 estão listadas 67 técnicas e ferramentas sugeridas para serem usadas na GR (AIRMIC, ALARM, IRM, 2002; COSO, 2004; ISO 31010:2009; PMI, 2009). Com base na estrutura do PMI (2008, 2009), foram identificados os processos nas quais elas são usadas. No 
quadro também está contabilizada a quantidade de padrões que usam cada técnica. $\mathrm{O}$ PRINCE2 (OGC, 2005) prefere não indicar técnicas e ferramentas, afirmando que cada organização deve identificar as que melhor se ajustem a ela. Outra restrição é a do padrão ISO 31010 (2009) que cita ferramentas apenas para os processos de identificação e análise. Portanto a falta de informações não permite avaliar sugestões para todos os processos no mesmo nível de profundidade, principalmente para o plano de respostas e o monitoramento e controle.

Quadro 6 - Técnicas e ferramentas de GR por processos

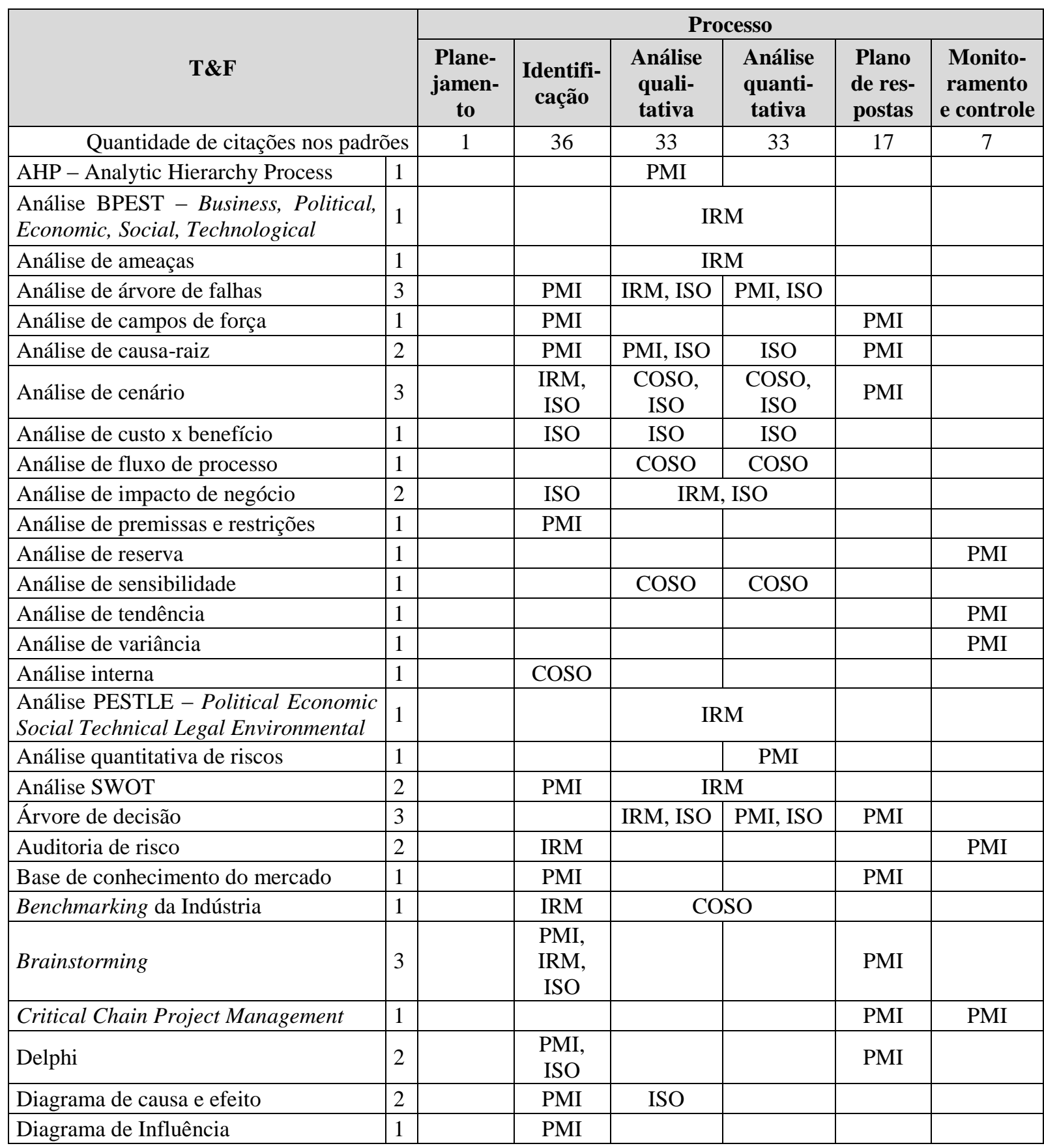




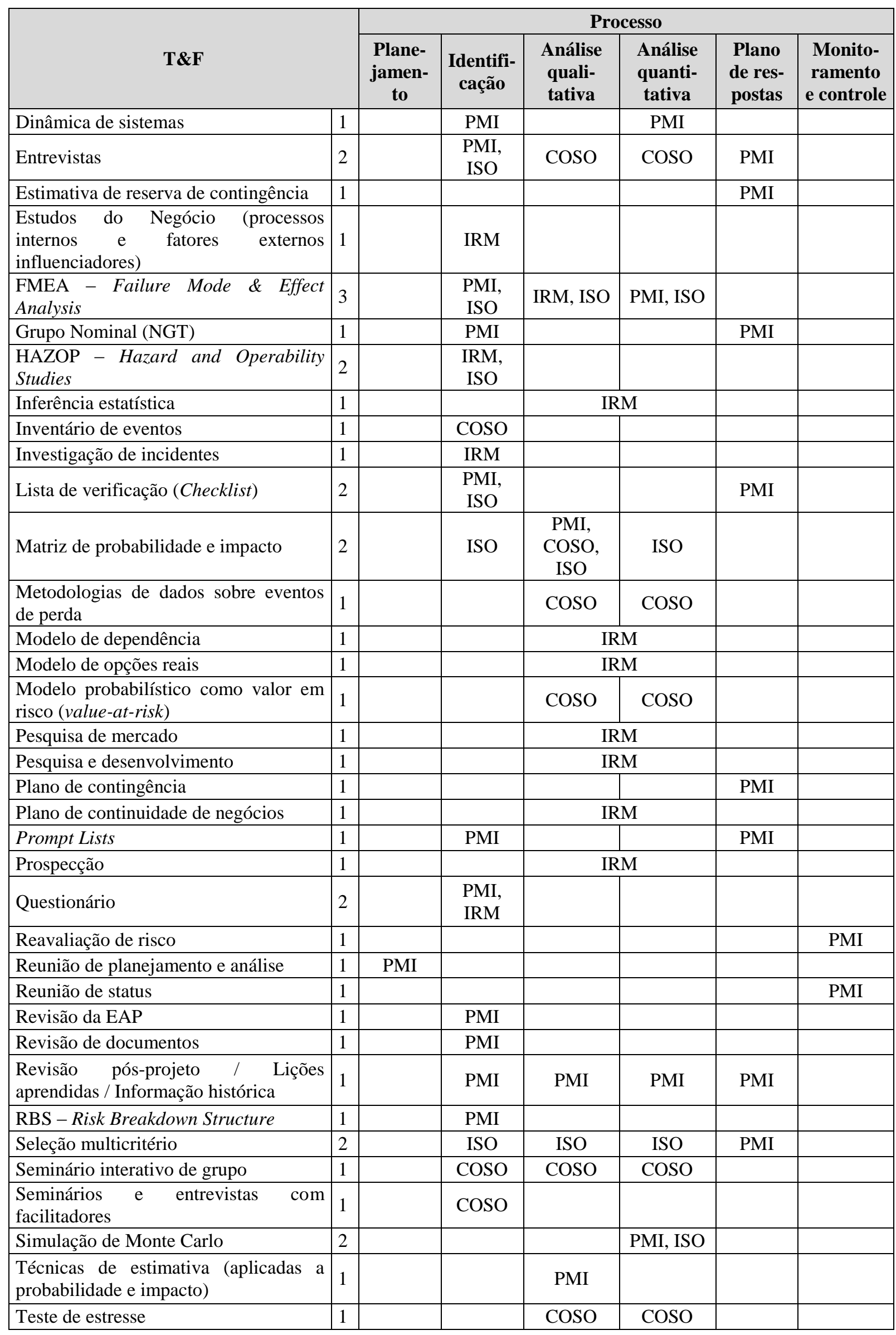




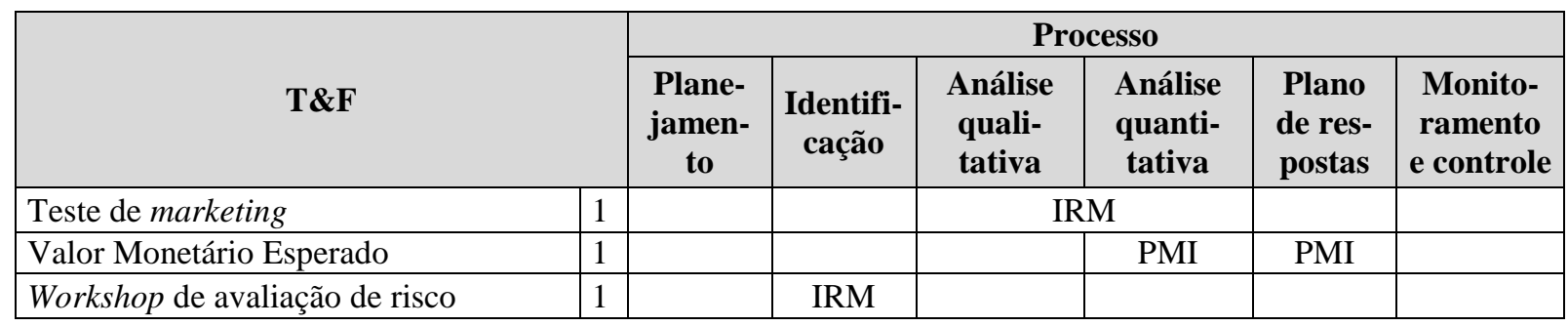

Fonte: COSO, 2007; AIRMIC, ALARM, IRM, 2002; PMI, 2009; ISO 31010:2009.

Algumas práticas são usadas na GR no início do projeto, quando as incertezas são maiores e, quando for necessária uma grande rapidez para participar de processos de licitação, por exemplo (CHAPMAN, WARD, 2000).

Pode-se perceber que as T\&F sugeridas pelo Risk Management Standard (AIRMIC, ALARM, IRM, 2002) têm uma visão mais abrangente e externa, por ser um padrão organizacional, do que as do PMI $(2008$; 2009) que se referem a projetos. Apenas 19 ferramentas são citadas por mais de um padrão e, quando isso ocorre, elas podem ser usadas em processos distintos. Por exemplo, o PMI $(2008 ; 2009)$ recomenda que se use na identificação a técnica de análise de causa-raiz, enquanto na ISO 31010 (2009) não há essa recomendação. Outro destaque é a análise de cenários citada pelos quatro padrões, mas em processos distintos.

O processo de identificação é um dos processos com mais ferramentas, conforme Quadro 6, apesar de que grande parte das técnicas pode ser usada em mais de um processo. Há três tipos de ferramentas (PMI, 2009): as que se baseiam na revisão de informações passadas, por exemplo lista de verificação; as que avaliam o presente, comparando as características do projeto com modelos e estruturas-padrão, por exemplo a avaliação de premissas e restrições e as que usam a criatividade individual ou de um grupo, para identificar possíveis eventos que ocorrerão no futuro, por exemplo brainstorming.

As ferramentas do processo de controle foram percebidas como as que menos contribuíram para o sucesso dos projetos, conforme Raz e Michael (2001). Eles sugerem duas explicações: que realmente as ferramentas existentes não são efetivas, ou por uma questão cultural, os gerentes não as estão aplicando por causa da pressão de tempo e de recursos disponíveis.

Este item finaliza a fundamentação sobre risco e incerteza e no próximo será detalhada a conceituação de criação de sentido e a sua ligação com projetos. 


\subsection{Criação de sentido}

Em 2001, dentro do programa de pesquisa da Secretaria da Defesa dos EUA, foi gerado um seminário sobre a criação de sentido (sensemaking) que concentrou pesquisadores e atuantes de diversas áreas - indústria, academia e governo, para incrementar e compartilhar o conhecimento sobre o tema. Um produto desse seminário foi o espectro, demonstrado na Ilustração 10, das pesquisas acadêmicas nas várias disciplinas e áreas de conhecimento para o entendimento de criação de sentido desde o nível individual até o da sociedade (LEEDOM, 2001).

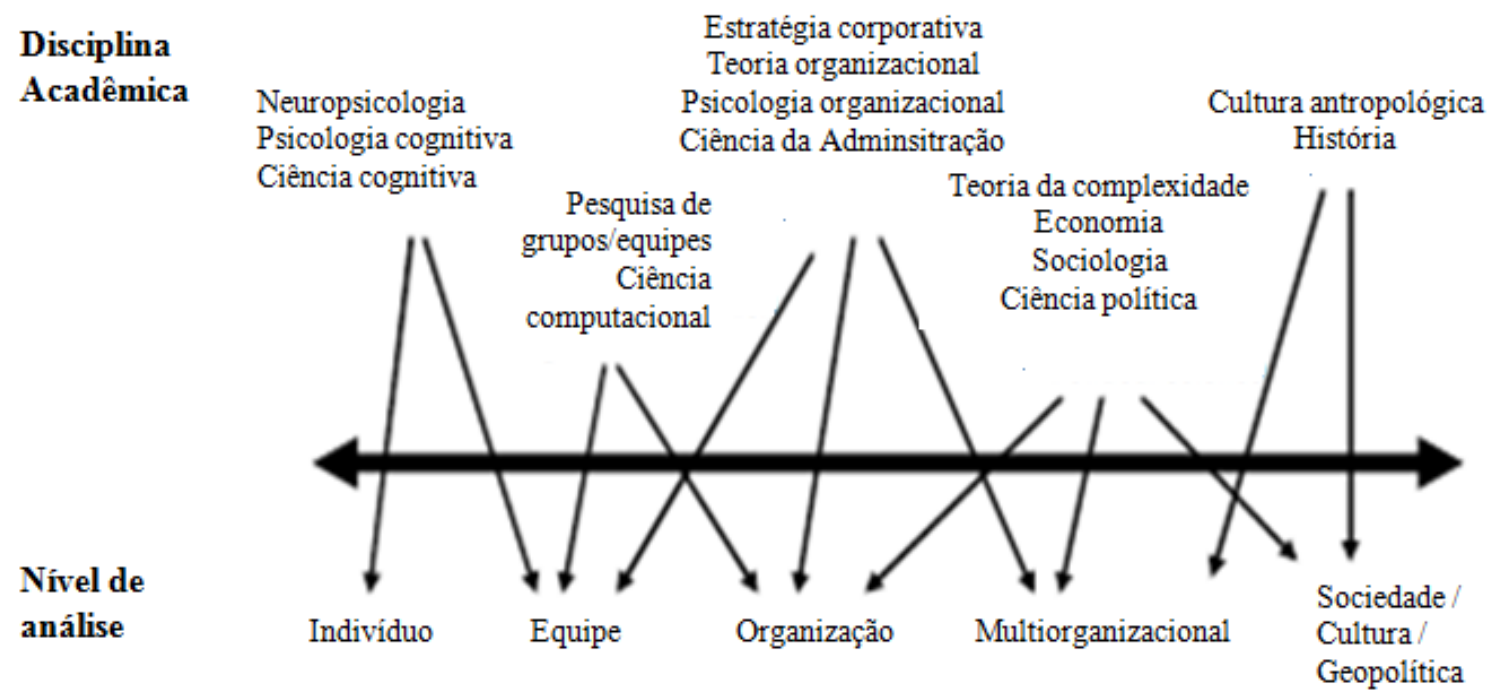

Ilustração 10 - Espectro dos estudos acadêmicos em Sensemaking

Fonte: Adaptado de Leedom, 2001.

\subsubsection{Conceitos e características da criação de sentido}

Para se entender o conceito de criação de sentido (sensemaking) é preciso entender o conceito de organizing, também de Karl E. Weick baseado em seu livro "A psicologia social da organização" 30 , com versões em 1969 e 1979. Esse é um dos livros mais citados na literatura de gestão, segundo Anderson (2006). Esse autor avaliou que os conceitos mais mencionados referentes a essa publicação são: enactment ${ }^{31}$, processo pelo qual os indivíduos ao agir criam as condições de restrição e oportunidade que eles enfrentam; equivocidade, ambiguidade por

\footnotetext{
30 "The Social Psychology of Organizing"

${ }^{31} \mathrm{O}$ verbo enact pode ser entendido como fazer leis, decretar, legalizar, ordenar, articular e também como executar.
} 
ter várias opções de entendimento, muitas vezes conflituosas; ações que precedem os objetivos; organizing, organizando, no formato verbal, versus organização, como um substantivo, assumindo que o processo de organização é contínuo; balanceamento entre geral, simples e acurado na geração de teoria, considerando que é possível desenvolver uma teoria com essas três características simultaneamente; metáforas, que encorajam maneiras diferentes de se ver uma coisa; sensemaking, que é parte natural do processo da ação organizacional, pois os gerentes interpretam os eventos e suas crenças intuitivas que influenciam suas decisões.

O processo de organizing pode ser representado pela sequência, demonstrada na Ilustração 11: mudança ecológica, enactment, seleção e retenção. Quando o processo se torna iterativo, as atividades de criação de sentido ficam muito próximas desse processo, pois as pessoas organizam as informações, as ideias para dar sentido a elas (WEICK et al., 2005).

A criação de sentido começa quando algum sinal ou mudança no ambiente organizacional é percebido, reconhecendo a mudança ecológica, vide Ilustração 11. Esta pode ser identificada de várias formas, por exemplo pela percepção de uma anomalia, num processo de busca, coleta e agrupamento ou recebimento de informação, pela comunicação oral, de uma fonte confiável. Segundo Weick (2006), uma característica da criação de sentido é a impermanência. Ela impõe estranhas restrições à verdade, pois o que é verdadeiro hoje pode não ser mais amanhã.

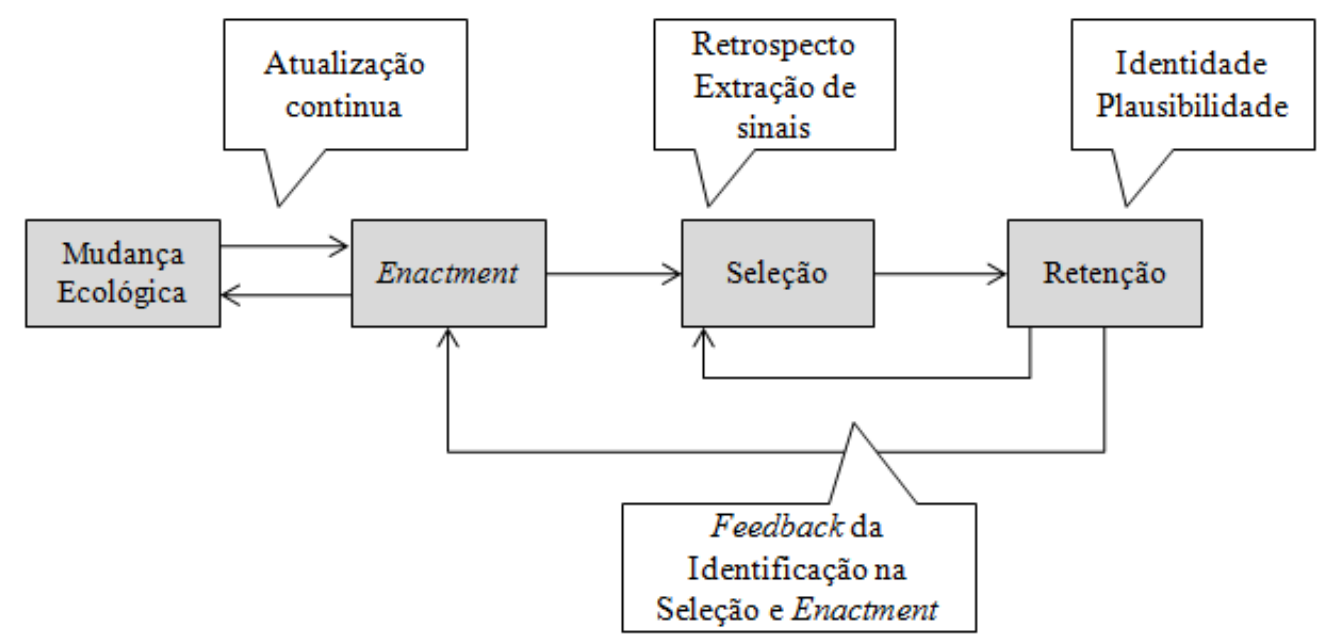

Ilustração 11 - Relação entre Organizing e Sensemaking

Fonte: Adaptado de Weick et al., 2005. 
Na perspectiva de Zack (1999), buscar informações não significa que a organização terá acesso a todas elas, porque pode causar o excesso de informações, que também pode levar à ignorância. Conforme esse autor, no processo de conhecimento, há vários tipos de ignorâncias organizacionais, para as quais devem ser aplicadas estratégias distintas de solução. Uma delas é adquirir mais informações ou mais conhecimento para identificar o significado e a outra é restringir, quando se tem muitas informações. Como demonstrado na Ilustração 12, ele categoriza a ignorância em:

- $\quad$ incerteza - quando não há informações suficientes para descrever ou predizer o futuro. Essa incerteza pode variar conforme o conhecimento da sua probabilidade: certo, que não cabe nesse caso; conhecida, que é o risco, estimada com algum grau de confiança, por meio da probabilidade subjetiva; desconhecida e indefinida, que é completamente incerto. Há duas maneiras de lidar com essa situação, buscar mais informações ou buscar mais conhecimento para tratá-las;

- ambiguidade - quando falta um modelo conceitual para interpretar a informação, gerando inabilidade para interpretar ou dar sentido para a situação, impedindo a identificação do problema ou de sua causa. Nesse caso, a estratégia é obter mais conhecimentos para resolver a situação, o que pode ser feito por ciclos coletivos de interpretação, explanação e consenso;

- complexidade - quando existem muitos elementos interligados - variáveis, soluções, métodos - que devem ser entendidos. Enquanto novatos avaliarão item a item, pessoas mais experientes - os especialistas - ou um grupo de pessoas podem ter uma visão mais completa, podendo ser um diferencial competitivo;

- equivocidade - quando há vários modelos conceituais, inclusive contraditórios, nos quais a informação pode-se enquadrar. Normalmente, isso é gerado por causa da múltipla interpretação da situação, por se adequarem a vários critérios. Da mesma maneira que a ambiguidade, a estratégia pode ter ciclos coletivos de entendimento até se alcançar a melhor alternativa, dirimindo os conflitos. 


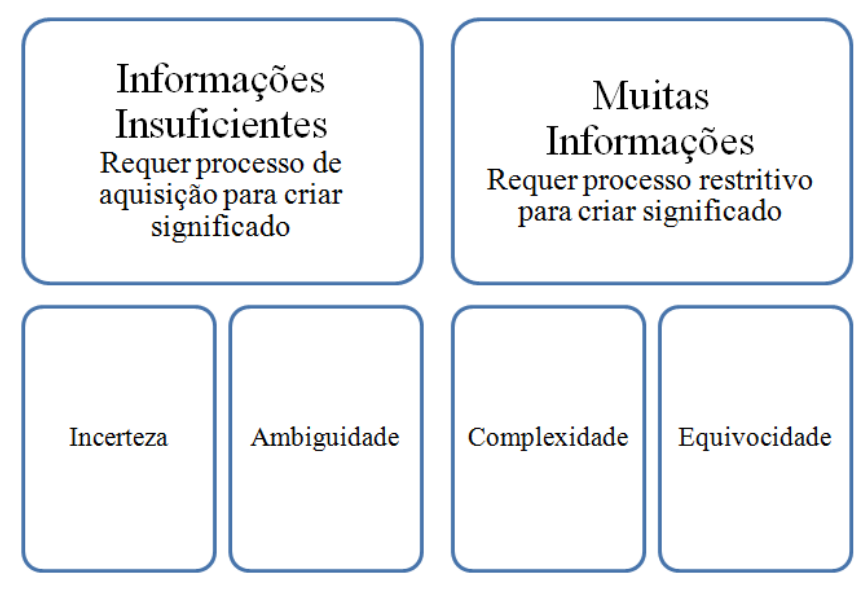

Ilustração 12 - Tipos de ignorância organizacional

Fonte: Adaptado de ZACK, 1999.

Na Ilustração 11, no relacionamento entre a mudança ecológica e o processo de enactment, está a função de entender e determinar o significado das mudanças ecológicas, na tentativa de enquadrá-las num fluxo conhecido ou de criar um novo. A função está no relacionamento, pois as pessoas agem e depois avaliam o resultado de suas ações, de uma forma contínua (WEICK, 1995). Nesse momento, as pessoas envolvidas tentam agrupar ou isolar as informações e identificar as relações existentes entre elas, o que pode gerar uma série de alternativas possíveis. A improvisação é fundamental para o enactment (WEICK, 2006). Como um substantivo, a improvisação é a transformação de um modelo original e, como verbo, é composição em tempo real, que começa com adereços de um modelo simples, mas cada vez incorpora mais adereços para se distanciar da estrutura original e se aproximar da flexibilidade.

O processo seguinte é o de seleção, como se mostra na Ilustração 11, que reduz os possíveis significados identificados naquele ou naqueles mais plausíveis (WEICK et al., 2005), tentando diminuir a ambiguidade e os equívocos. Essas alternativas tentam explicar o que está acontecendo e o significado das mudanças para a organização, usando o conhecimento das pessoas e as experiências individuais e organizacionais, de forma retrospectiva. $\mathrm{O}$ resultado esperado é uma estória plausível. As pessoas ampliam o seu repertório descartando algumas de suas ferramentas, de suas crenças (WEICK, 2006). Um fator que dificulta o descarte das crenças é a "falácia da importância" 32 : os especialistas superestimam o seu conhecimento; não consideram um evento passível de estar ocorrendo, se o desconhecem.

\footnotetext{
32 "fallacy of centrality"
} 
Quando essa plausibilidade se efetiva, a organização entra no processo de retenção, que armazena o conhecimento gerado (CHOO, 1996) para uso futuro, tanto para tomada de decisão quanto para novos ciclos de criação de sentido. Assim, nesse ciclo contínuo, a estória plausível tende a se tornar cada vez mais substancial, transformando-se em experiência.

Assim, criação de sentido é o processo pelo qual as organizações e os indivíduos tratam as incertezas, as ambiguidades, as mudanças, as situações problemáticas, gerando invenções e novas situações, resultando em ações direcionadas à solução dos problemas e à estabilidade do ambiente. O principal é que haja sentido no resultado, que ele seja plausível para os envolvidos.

\subsubsection{Propriedades da criação de sentido}

Weick (2001) aponta a frase, a seguir, como fórmula e base conceitual para a criação de sentido: "Como podemos saber o que pensamos (ou desejamos ou sentimos) até que vejamos o que dissemos (ou não) ${ }^{\prime 3}$. Ele afirma que primeiramente as pessoas agem e depois avaliam e refletem sobre suas ações para interpretar e entender o seu significado.

As várias propriedades da criação de sentido podem ser observadas o item anterior, mas elas serão destacadas aqui. Weick (1995, p. 18) sentencia que um fluxo provável para a criação de sentido seria:

[...] as pessoas preocupadas com a identidade no contexto social com outros atores se empenham nos eventos em curso a partir dos quais elas extraem sinais criando um sentido plausível retrospectivamente, articulando certa ordem, o tempo todo, para os eventos em curso. ${ }^{34}$ (grifo nosso).

$\mathrm{O}$ autor indica que não consta nessa frase o feedback, a continuidade, os processamentos simultâneos, mas também que alguns passos podem não ocorrer. Desse modo, a criação de sentido possui sete propriedades (WEICK, 1995; WEICK, 2001):

\footnotetext{
33 "how can we know what we think (or want or feel) until we see what we say (or do)"

34 “' [...] people concerned with identity in the social context of other actors engage ongoing events from which they extract cues and make plausible sense retrospectively while enacting more or less order into those ongoing events. "
} 
a) construção da identidade - "A receita é uma questão sobre quem eu sou, como sugerido pela descoberta de como e o que eu penso."35 (WEICK, 1995, p.61). A criação de sentido inicia-se no nível individual (sensemaker) com a manutenção ou o estabelecimento de uma identidade pessoal. Na interação com o ambiente, é observado o resultado, sendo o entendimento afetado por várias necessidades dos indivíduos nas organizações (WEICK, 1995, p. 23), como pertencer, evoluir, ser eficaz, destacar-se, confirmar, integrar-se, representar a instituição etc.;

b) retrospecção - "Para saber o que eu penso, eu revejo o que eu disse antes." 36 (WEICK, 1995, p.61). O presente é sempre reconhecido e baseado nas experiências passadas, no conhecimento tácito, inclusive nas decisões passadas sobre a adaptação de planos e objetivos. Para tornar o abstrato em concreto, muitas vezes, as pessoas agem e depois tentam identificar a razão para a sua ação. Weick (1995) reforça a ideia que as ações são reconhecidas apenas após a sua completa execução;

c) enactment - "Eu crio o objeto a ser visto e examinado quando eu disser ou fizer algo."37 (WEICK, 1995, p.61). A criação de sentido é baseada na construção de uma realidade, do mesmo modo que o legislador faz com as leis, pela designação de autoridade a eventos ou sinais dentro de um contexto específico. Nesse sentido, de maneira ativa, as pessoas criam o ambiente, sempre dinâmico, com suas ações ou reações da mesma maneira que o próprio ambiente as cria. A princípio, se procura agrupar e pontuar podendo existir, concomitantemente, a invenção ou construção de algo novo. A geração de sentido também pode existir por outras formas como postergar, parar, passar para o planejamento, redirecionar. Weick (2006) também menciona rotulagem, criticando a maneira atual de as organizações trabalharem por meio de esquemas, estereótipos, categorias e tipos. Esses conceitos sem a percepção das pessoas é vazio, assim como a percepção das pessoas sem os conceitos é cega. Ele sugere ver, entender sem necessariamente nomear o fato, para não restringir o seu significado, distinguindo as diferenças;

d) social - "O que eu digo, destaco e concluo são determinados por quem se socializou comigo e como eu estava socializado, bem como pelo público que vai avaliar as

\footnotetext{
35 "The recipe is a question about who I AM as indicated by discovery of how and what I think."

36 "To learn what I think, I look back over what I said earlier."

37 "I create the object to be seen and inspected when I say or do something."
} 
conclusões a que eu chego." ${ }^{38}$ (WEICK, 1995, p.62). Como o sentido é criado e não descoberto, o compartilhamento do significado e do conhecimento envolve a interação entre as pessoas, seja ela presencial ou não. O significado criado tende a ser aquele que tem suporte social, validação e relevância compartilhada. Mesmo na criação de sentido individual, há uma interação com o que a pessoa imagina que as outras entendem sobre o assunto. Portanto, mesmo sem haver comunicação, as pessoas influenciam umas às outras (WEICK, 1995, p. 40);

e) contínuo - "Minha fala é transmitida através do tempo, disputa a atenção com outros projetos em andamento, e é representada depois de conclusa, o que significa que os meus interesses já podem ter mudado.”39 (WEICK, 1995, p.62). O processo tem como premissa o refinamento do entendimento, pelas ações tomadas e a restauração do equilíbrio, de forma contínua e dinâmica, dentro de um contexto. Pode-se dizer que as ações e decisões são tratadas como um ciclo mais do que de forma linear (WEICK et al., 2005). Elas se tornam um evento apenas quando são definidos os limites dentro desse fluxo ou quando alguma interrupção ocorre (WEICK, 2001). Nas organizações, as pessoas estão sempre dentro de projetos; sua visão é dirigida para as situações, informações, emoções e interrupções que neles ocorrem (WEICK, 1995);

f) extração de sinais - "O 'quê' eu destaquei e concluí como conteúdo do pensamento é apenas uma pequena parte do enunciado que se torna saliente por causa do contexto e disposições pessoais." ${ }^{40}$ (WEICK, 1995, p.62). Os sinais são vistos e extraídos do ambiente para uma contextualização, dentro de modelos mentais, crenças pessoais, regras, procedimentos e outros fatores. Além do social, o contexto também influencia a extração do sinal. Weick (1995) rejeita a palavra interpretação, pois para ele isso significaria a tradução e enquadramento do sinal, mas o caso é de invenção do significado. Weick (2001) conecta os sinais à profecia autorrealizada, porque as ações tomadas anteriormente, na fé de um significado, fazem com que o ambiente mude na direção do esperado. Sendo a criação de sentido um processo contínuo, novos sinais serão observados;

\footnotetext{
38 "What I say and single out and conclude are determined by Who socialized me and how I was socialized, as well as by the audience I anticipate Will audit the conclusions I reach."

39 "My talking is spread across time, competes for attention with other ongoing projects, and is reflected on after it is finished, which means my interests may already have changed."

40 "The 'what' that I single out and embellish as the content of the thought is only a small portion of the utterance that becomes salient because of context and personal dispositions."
} 
g) plausível - "Eu preciso saber o suficiente sobre o que penso, para continuar com meus projetos, mas não mais, o que significa que a suficiência e a plausibilidade prevalecem sobre a exatidão." ${ }^{41}$ (WEICK, 1995, p.62). O resultado esperado é um significado aceitável, plausível, e não a verdade absoluta, acurácia. Assim, pode-se avaliar melhor, continuar a observar o ambiente e os sinais até que se tenha uma situação consistente para agir. A plausibilidade é restringida pelas outras características, como a obtenção do acordo de outros, com o passado recente, os sinais visíveis etc.

No próximo item será descrita a relação entre o construto criação de sentido e o construto gestão de projetos, e consequentemente, com o construto projeto inovador.

\subsubsection{Criação de sentido em projetos}

Christiansen e Varnes (2009) avaliaram, num estudo de caso múltiplo na Escandinávia, como os gerentes e empregados realmente entendem e dão sentido aos métodos estruturados de desenvolvimento de produto. Eles identificaram que a criação de sentido das regras para a prática é implementada por inúmeras traduções baseadas no contexto, na história, nos padrões autorizados e nos processos de feedback. Mesmo as empresas com padrões de regras extensivos e elaborados aplicam-nas de maneira flexível, conforme o entendimento do gerente de projetos e do gerente funcional. Essa aplicação também é influenciada pela interpretação, uso e feedback dos gerentes seniores.

Numa avaliação específica com gerentes de projeto criativos, Simon (2006) identificou que a criação de sentido é uma das quatro características do gestor para tratar a criatividade individual e coletiva. As quatro características são: web-weaver, game-master, flow-balancer e sensemaker. Como web-weaver, ele age como um integrador de pessoas, de dentro ou de fora do projeto. Como game-master, ele mantém o ambiente animado, com uma atmosfera e recursos propícios para incentivar a criatividade e, como flow-balancer, a ênfase está na motivação individual.

\footnotetext{
41 "I need know enough about what I think to get on with my projects, but no more, which means sufficiency and plausibility take precedence over accuracy."
} 
Como sensemaker, ele cria sentido ao esforço da equipe, traduzindo a representação coletiva do projeto num significado compartilhado, por meio de comunicações informais e reuniões formais com todos os envolvidos, sejam eles internos, sejam externos ao projeto, inclusive externos à organização. As atividades são analíticas, cognitivas, psicológicas, simbólicas e discursivas dirigidas pelas questões: "O que nós estamos fazendo juntos?" e "Como nós traduzimos isso em ações concretas?” As atividades relativas a essa característica são:

- $\quad$ aprender fazendo - ele usa um processo de descoberta indutivo, para entender o projeto e para situar os outros envolvidos nas atividades do projeto;

- $\quad$ interpretar a situação - ele não impõe o seu entendimento, mas tenta inserir a questão na perspectiva do projeto, resultando numa co-construção do significado para o membro do time;

- $\quad$ traduzir o projeto para uma visão, objetivos, atividades e tarefas - não é só dividir as tarefas, mas também fazer com que a pessoa perceba o significado da sua atuação no projeto, o que ele faz distribuindo desafios tanto por seu entendimento das capacidades individuais quanto pelo entendimento micro / macro do projeto;

- revelar premissas e crenças - quando há divergência, ele deve esclarecer o seu real significado, identificando as crenças em uso e as premissas assumidas pelas partes;

- construir um significado compartilhado - o significado do projeto é sempre lembrado, não só em reuniões formais, mas também nas tarefas diárias.

Loch et al. (2006) ligam a criação de sentido ao uso da intuição, nos ambientes ambíguos e complexos, com múltiplas interpretações. Eles ressaltam que a quebra da criação de sentido pode gerar a quebra da coesão da equipe, principalmente com as inúmeras mudanças a que um projeto inovador e com alto nível de incerteza está sujeito. Nesse sentido, Thiry (2001) afirma que a falta de criação de sentido ancora as pessoas em paradigmas existentes. Assim, a sua existência pode ajudar a construir novos paradigmas com informações compartilhadas e cross-fertilization importantes para fazer a Gestão de Valor ${ }^{42}$ em projetos. Esse autor define o processo de criação de sentido como um sistema de interações entre diferentes atores que coletiva e individualmente criam sentido para a situação. O conceito principal é o do paradigma e sua construção ou modificação por meio da interpretação de discrepâncias. O

\footnotetext{
${ }^{42}$ Value Management - gestão usada para obter mais valor para os investimentos e aumentar a realização das expectativas dos stakeholders.
} 
processo é intersubjetivo, que pode ocorrer na esfera individual e na da organização. Se o processo for positivo, gera melhoria, porém, se negativo, gera resistência.

Além de a extração de sinais ser uma das propriedades da criação de sentido, o sinal precoce também pode ser um fator motivador da identificação da incerteza imprevisível em projetos. Assim, no próximo item a relação entre sinais precoces e projetos será detalhada.

\subsubsection{Sinais precoces em gestão de projetos}

A importância dos sinais fracos surgiu com ANSOF (1975), mostrando que o mundo real está inundado de informações, muitas vezes ambíguas, imprecisas e incompletas. Mesmo assim, passíveis de serem transformadas em vantagens significativas para as empresas. Muitas delas podem ser sinais fracos ou sinais precoces de uma interrupção no ciclo vigente, uma ruptura, benéfica ou maléfica para os negócios.

No âmbito dos projetos, esses sinais precoces assumem uma importância relevante, principalmente para projetos com incertezas imprevisíveis. Sánchez e Pérez (2004) avaliaram o uso dos avisos precoces ou sinais fracos em projetos de pesquisa e desenvolvimento na Espanha. Identificaram que seu tratamento é mais usado em grandes projetos e em empresas com maior volume de investimento nesses projetos, entretanto não avaliaram como eles eram tratados.

A taxonomia usada é variada: aviso precoce (NIKANDER, ELORANTA, 1997; 2001; PMI, 2008); primeiro sinal de alerta (SANCHEZ, PEREZ, 2004; KAPPELMAN et al., 2006); sinal de alerta (OGC, 2005); sinal futuro (HILTUNEN, 2008); sinal preliminar (NIKANDER, ELORANTA, 1997). Para este estudo foi adotada a taxonomia de sinal precoce.

Hiltunen (2008) estabeleceu três dimensões a eles: sinal, que se refere ao número e visibilidade dos sinais; interpretação, que depende do entendimento do receptor do sinal e o respectivo significado e questão, que é a questão emergente. Ela sugere que a avaliação objetiva do sinal precoce deve ser feita pela dimensão do sinal e da questão, por exemplo, no uso de indicadores, e a avaliação subjetiva deve ser feita pela dimensão de interpretação do sinal. 
Essa autora, também, classifica os sinais precoces em informação precoce e em primeiros sintomas. A informação precoce tem um número pequeno de sinais com pouca visibilidade, dificultando a interpretação, como no caso de inovações. Apesar de os primeiros sintomas apresentarem um número maior de sinais, a interpretação também pode ser dificultada pela falta de clareza em seu significado, como no caso da mudança de comportamento de uma pessoa. Na perspectiva de Nikander e Eloranta (2001), a similaridade dos sinais com os problemas, dependendo do momento em que são percebidos, faz com que possam ser interpretados como um aviso, um problema ou mesmo a causa dele.

Essas dificuldades de interpretação podem ser geradas por aquilo que Klein (2003) definiu como fontes de incerteza: falta de informação - quando não se possui, não se consegue localizá-la ou quando não se tem acesso a ela no momento oportuno; falta de confiança na informação pela desatualização, suspeita da origem, divergência entre várias fontes; informação conflituosa - quando se tem confiança na informação, mas há outras de outras fontes que não a confirmam; informação ruidosa - quando, pelo volume de informação recebida, ela se torna irrelevante, mas não há certeza sobre essa irrelevância; ou informação confusa - quando não se consegue interpretá-la ou há várias interpretações para a mesma informação.

No Quadro 7 estão listados os grupos de sinais precoces e exemplos de vários autores, dentro do ambiente de projetos. Os sinais podem-se manifestar de forma verbal, como contradições na fala; de forma não verbal, como o tom das mensagens e o espírito das pessoas; de forma escrita, como nos indicadores de relatórios de status quo e por eventos, como atraso na entrega por um fornecedor. 
Quadro 7 - Sinais precoces em projetos

\begin{tabular}{|c|c|c|c|c|}
\hline \begin{tabular}{lr|} 
Grupo de & Sinal \\
Precoce & em \\
projetos & \\
\end{tabular} & $\begin{array}{l}\text { Nikander, } \\
\text { Eloranta, } 1997\end{array}$ & $\begin{array}{l}\text { Nikander, Eloranta, } \\
2001\end{array}$ & $\begin{array}{l}\text { Sanchez, Perez, } \\
2004\end{array}$ & Kappelman et al., 2006 \\
\hline Gut feelings & Antecipações & $\begin{array}{l}\text { Sentimentos } \\
\text { intuitivos, sinal mais } \\
\text { difícil de detectar, } \\
\text { identificar } \\
\text { interpretar. }\end{array}$ & & \\
\hline Comunicação & $\begin{array}{l}\text { Fluxo da } \\
\text { comunicação, } \\
\text { dicas. }\end{array}$ & $\begin{array}{l}\text { Problemas, tom da } \\
\text { mensagem, conflito } \\
\text { de conhecimento, } \\
\text { insinuação. }\end{array}$ & \begin{tabular}{|l|l|}
\multicolumn{2}{|l|}{ Comunicação } \\
entre os \\
departamentos \\
durante $\quad$ o \\
projeto.
\end{tabular} & $\begin{array}{l}\text { Quebra na comunicação entre } \\
\text { stakeholders. }\end{array}$ \\
\hline $\begin{array}{l}\text { Expressão do } \\
\text { sponsor }\end{array}$ & & $\begin{array}{l}\text { Falta de suporte do } \\
\text { diretor executivo. }\end{array}$ & $\begin{array}{l}\text { Suporte da alta } \\
\text { direção } \\
\text { project } \\
\text { champion. }\end{array}$ & $\begin{array}{l}\text { Falta de suporte da alta gerência } \\
\text { e comprometimento com o } \\
\text { projeto. }\end{array}$ \\
\hline $\begin{array}{l}\text { Expressão do } \\
\text { cliente }\end{array}$ & $\begin{array}{|ll|}\text { Deficiências } & \text { nas } \\
\text { propostas, } & \\
\text { inadequação } & \text { no } \\
\text { planejamento, } & \\
\text { deficiência } & \text { na } \\
\text { tomada } & \text { de } \\
\text { decisão. } & \\
\end{array}$ & $\begin{array}{l}\text { Falta de decisão, } \\
\text { desaparecimento da } \\
\text { confiança, } \\
\text { congelamentos, } \\
\text { pesquisas adicionais, } \\
\text { aquisição. }\end{array}$ & $\begin{array}{l}\text { Interface com o } \\
\text { cliente }\end{array}$ & 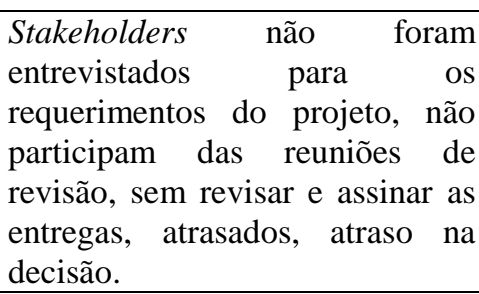 \\
\hline $\begin{array}{l}\text { Expressão do } \\
\text { usuário }\end{array}$ & & Recrutamento tardio & $\begin{array}{|lr|}\begin{array}{l}\text { Número } \\
\text { usuário } \\
\text { esperado }\end{array} & \text { final } \\
\end{array}$ & Falta de colaboração \\
\hline $\begin{array}{l}\text { Pessoal, time } \\
\text { do projeto }\end{array}$ & & $\begin{array}{lr}\text { Informação } & \text { não } \\
\text { verbal, } & \\
\text { comportamento das } \\
\text { pessoas, falta } & \text { de } \\
\text { contato com } & \text { o } \\
\text { cliente, } & \\
\text { planejamento } \\
\text { irrealista, mudança } \\
\text { de pessoas, falta de } \\
\text { recursos, habilidades } \\
\text { profissionais. }\end{array}$ & $\begin{array}{l}\text { Nível de } \\
\text { comprometime } \\
\text { nto das pessoas } \\
\text { envolvidas no } \\
\text { projeto, falta de } \\
\text { pessoas com } \\
\text { talento }\end{array}$ & $\begin{array}{l}\text { Falta de comprometimento do } \\
\text { time ao escopo e cronograma, } \\
\text { falta de habilidade ou } \\
\text { conhecimento do time do projeto, } \\
\text { especialista é superutilizado, } \\
\text { papéis e responsabilidade } \\
\text { indefinidos, falta de experiência } \\
\text { da equipe com a tecnologia. }\end{array}$ \\
\hline $\begin{array}{l}\text { Expressão do } \\
\text { fornecedor }\end{array}$ & $\begin{array}{l}\text { Tempo da } \\
\text { entrega } \\
\text { qualidade, } \\
\text { mobilização, } \\
\text { comportamento } \\
\text { das pessoas, } \\
\text { faturamento } \\
\text { antecipado, } \\
\text { desculpas. }\end{array}$ & $\begin{array}{l}\text { Faturamento } \\
\text { antecipado }\end{array}$ & & Falta de due diligence \\
\hline $\begin{array}{l}\text { Expressão } \\
\text { consultor }\end{array}$ & $\begin{array}{l}\text { Deficiências nos } \\
\text { contratos, início } \\
\text { problemático dos } \\
\text { trabalhos, } \\
\text { mudança de } \\
\text { pessoal, } \\
\text { explanação. } \\
\end{array}$ & & & \\
\hline $\begin{array}{lr}\text { Gerente } & \text { de } \\
\text { projetos } & \mathrm{e} \\
\text { gestão } & \end{array}$ & & $\begin{array}{l}\text { Qualidade do } \\
\text { gerente de projetos e } \\
\text { estilo de gestão. }\end{array}$ & & $\begin{array}{l}\text { Falta de liderança com a equipe e } \\
\text { comunicação com os clientes, } \\
\text { pouco treinamento, falta de } \\
\text { experiência. }\end{array}$ \\
\hline
\end{tabular}




\begin{tabular}{|c|c|c|c|c|}
\hline $\begin{array}{lr}\text { Grupo de } & \text { Sinal } \\
\text { Precoce } & \text { em } \\
\text { projetos } & \\
\end{array}$ & $\begin{array}{l}\text { Nikander, } \\
\text { Eloranta, } 1997\end{array}$ & $\begin{array}{l}\text { Nikander, Eloranta, } \\
2001\end{array}$ & $\begin{array}{l}\text { Sanchez, Perez, } \\
2004\end{array}$ & Kappelman et al., 2006 \\
\hline $\begin{array}{l}\text { Pressão sobre o } \\
\text { gerente } \quad \text { de } \\
\text { projetos }\end{array}$ & & & 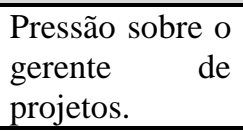 & \\
\hline $\begin{array}{l}\text { Planejamento } \\
\text { do projeto }\end{array}$ & & $\begin{array}{l}\text { Planos, material de } \\
\text { referência, contrato, } \\
\text { orçamentos. }\end{array}$ & $\begin{array}{l}\text { Ligação do } \\
\text { projeto com a } \\
\text { estratégia } \\
\text { organizacional }\end{array}$ & $\begin{array}{l}\text { Sem marcos de entregas, critérios } \\
\text { de sucesso indefinidos, sem } \\
\text { documentação de planejamento e } \\
\text { estimação, sem plano de } \\
\text { comunicação e recursos para } \\
\text { gerenciar as expectativas, sem } \\
\text { metodologia para GP, sem } \\
\text { project charter, } \\
\text { documentação e processo de } \\
\text { análise de risco ou problemas na } \\
\text { identificação de riscos, falta de } \\
\text { alinhamento estratégico. }\end{array}$ \\
\hline $\begin{array}{l}\text { Trabalho dentro } \\
\text { do projeto }\end{array}$ & & $\begin{array}{l}\text { Trabalhos iniciais, } \\
\text { mobilização, ações } \\
\text { repetidas, tipo de } \\
\text { organização. }\end{array}$ & & \\
\hline $\begin{array}{lr}\text { Controle } & \text { do } \\
\text { projeto } & \mathrm{e} \\
\text { relatórios } & \end{array}$ & $\begin{array}{ll}\text { Controle } & \text { do } \\
\text { tempo, } & \\
\text { supervisão } & \text { do } \\
\text { local } & \end{array}$ & $\begin{array}{lr}\text { Controle } & \text { do } \\
\text { progresso } & \text { e } \\
\text { monitoramento, } & \\
\text { correção } & \text { de } \\
\text { orçamento } & \end{array}$ & $\begin{array}{l}\text { Desvio de } \\
\text { custo e tempo, } \\
\text { atender } \\
\text { objetivos } \\
\text { tecnológicos }\end{array}$ & $\begin{array}{l}\text { Falta de controle do processo, } \\
\text { sem avaliação do status do } \\
\text { progresso, sem reconciliação dos } \\
\text { marcos do cronograma, atraso } \\
\text { precoce é ignorado, mudança } \\
\text { significativa logo após kickoff, } \\
\text { equipe superutilizada, sem } \\
\text { métrica de acompanhamento }\end{array}$ \\
\hline Documentos & $\begin{array}{l}\text { Falta de dados } \\
\text { iniciais, } \\
\text { qualidade e tom } \\
\text { dos relatórios }\end{array}$ & $\begin{array}{lr}\text { Qualidade, } & \text { nível, } \\
\text { tempo de entrega } \\
\text { dos relatórios; } \\
\text { mudanças nos planos } \\
\text { técnicos, revisões } \\
\text { incorretas, falta de } \\
\text { clarezarras } \\
\text { responsabilidades nas }\end{array}$ & $\begin{array}{l}\text { Qualidade dos } \\
\text { documentos }\end{array}$ & $\begin{array}{l}\text { Falta de documentação das } \\
\text { funções, desempenho, } \\
\text { requerimentos e escopo, sem } \\
\text { comprometimento escrito dos } \\
\text { stakeholders, falta de Business } \\
\text { Case }\end{array}$ \\
\hline $\begin{array}{lr}\text { Diferenças } & \mathrm{e} \\
\text { deficiências } & \text { na } \\
\text { cultura } & \text { de } \\
\text { projeto } & \end{array}$ & $\begin{array}{l}\text { Primeiros } \\
\text { contatos, } \\
\text { diferenças na } \\
\text { terminologia }\end{array}$ & $\begin{array}{l}\text { Primeira impressão, } \\
\text { terminologia r em } \\
\text { projetos, falta de } \\
\text { experiência, cultura } \\
\text { específica de uma } \\
\text { nação }\end{array}$ & & $\begin{array}{l}\text { Conflito cultural entre } \\
\text { organizações envolvidas }\end{array}$ \\
\hline Fontes externas & Fontes externas & Fontes externas & $\begin{array}{l}\text { Regulações } \\
\text { governamentais }\end{array}$ & \\
\hline $\begin{array}{ll}\text { Número } & \text { de } \\
\text { projetos } & \text { no } \\
\text { portfólio } & \\
\end{array}$ & & & $\begin{array}{ll}\text { Número } & \text { de } \\
\text { projetos } & \text { no } \\
\text { portfolio } & \end{array}$ & $\begin{array}{l}\text { Recursos passados para projetos } \\
\text { com mais alta prioridade }\end{array}$ \\
\hline
\end{tabular}

Kappelman et al. (2006) identificaram, em projetos de TI, que os sinais podem vir de três fontes: produto, processo e pessoas. As duas últimas fontes são as que mais ocorrem, corroborando com a visão de Nikander e Eloranta (2001). Eles afirmam que a maioria dos sinais está vinculada a fatores humanos, além de ocorrerem a qualquer momento do projeto. Esses autores também observaram que as características mais importantes de quem identifica 
os sinais precoces são a experiência e a perspicácia, mas que devem ser usados os métodos tradicionais de monitoramento e controle da GP. Nem sempre quem identifica o sinal é quem toma a decisão; este pode, inclusive, estar fora da equipe de projeto. Eles indicam que a sensibilidade para se identificarem os sinais precoces deve ser cultivada, para ser facilitado o convencimento dos decisores sobre sua importância.

Vários trabalhos sobre sinais precoces em GP tratam dos primeiros sintomas (KAPPELMAN et al., 2006; GERALDI et al., 2010; SÁNCHEZ, PÉREZ, 2004; NIKANDER, ELORANTA, 2001) tentando identificar ações corretivas para sua gestão, mais do que ações preventivas. Como um dos objetivos secundários deste estudo é levantar as práticas da criação de sentido para incertezas imprevisíveis, o item a seguir identificará as práticas usadas nos projetos e nas organizações para a criação de sentido, de maneira geral.

\subsubsection{Práticas para a criação de sentido}

$\mathrm{Na}$ mesma abordagem adotada na identificação de processos e práticas de GR, foram avaliadas as práticas para a criação de sentido nas organizações e nos projetos. Para as organizações, buscou-se literatura referente à $\mathrm{IC}^{43}$, que tem sido uma competência cada vez mais perseguida pelas empresas.

Dentro da IC, para o reconhecimento antecipado dos sinais precoces, é necessária a sua identificação e a compreensão do seu significado, pela criação de sentido. Esse processo concentra-se na análise e interpretação de informações e sinais obtidos de forma ativa durante o ciclo de monitoramento estratégico, podendo ter como resultado decisões e planos de ação (WEICK; 1995). Por isso o processo de Lesca (2003 apud JANISSEKMUNIZ et al., 2006), detalhado na Ilustração 13, foi utilizado como base para identificar as atividades, processos, $\mathrm{T} \& \mathrm{~F}$ que podem ser usadas.

\footnotetext{
${ }^{43}$ Inteligência Competitiva é um programa sistemático e ético para coletar, analisar qualquer combinação de dados, informações e conhecimento, relacionados com o ambiente de negócios no qual a empresa opera. Sua missão primária é gerar alertas estratégicos antecipados (SCIP, 2008).
} 


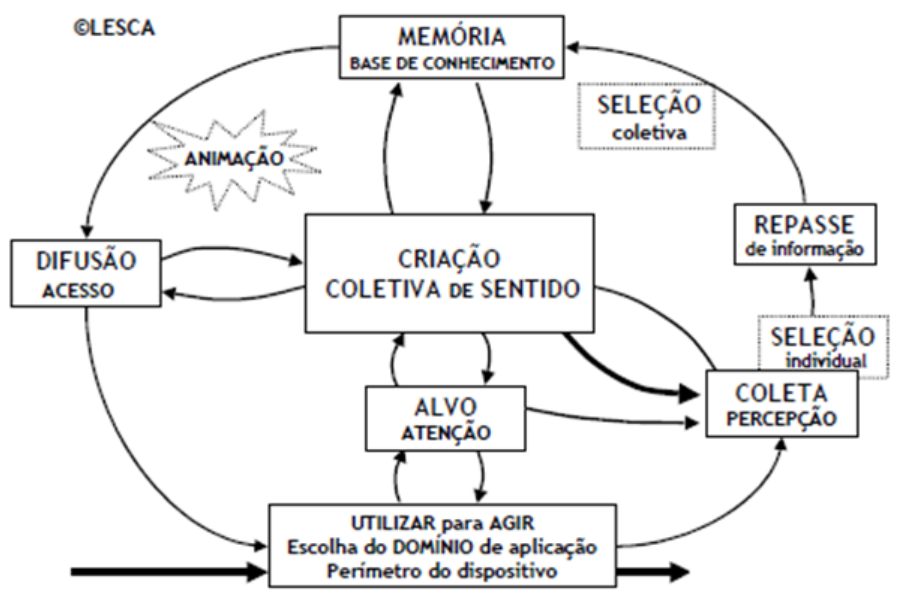

Ilustração 13 - Modelo conceitual de inteligência estratégica antecipada

Fonte: Lesca, 2003 apud Janissek-Muniz et al., 2006.

Para os projetos, foram identificados os processos utilizados na identificação da incerteza imprevisível, com o objetivo de superar uma lacuna do conhecimento em áreas de negócio, em problemas específicos (LOCH et al., 2008; LOCH et al., 2006) e outras que buscaram criar sentido aos sinais precoces (NIKANDER, 2002; NIKANDER, ELORANTA, 2001), mesmo que o foco tenha sido identificar problemas antecipadamente. Assim, foi elaborado o Quadro 8 para listar as atividades e processos de forma comparativa ${ }^{44}$.

Quadro 8 - Práticas para a criação de sentido

\begin{tabular}{|c|c|c|c|c|}
\hline Fonte & $\begin{array}{c}\text { Janissek-Muniz et al., } \\
2006\end{array}$ & $\begin{array}{l}\text { Loch et al., } 2008 \\
\text { Loch et al., } 2006\end{array}$ & Nikander, Eloranta, 2001 & Nikander, 2002 \\
\hline 1 & $\begin{array}{l}\text { Escolha de um } \\
\text { domínio de aplicação } \\
\text { para se agir sobre. }\end{array}$ & $\begin{array}{l}\text { Identificar as lacunas de } \\
\text { conhecimento. }\end{array}$ & $\begin{array}{l}\text { O processo inicia-se com um } \\
\text { sinal recebido e percebido. }\end{array}$ & $\begin{array}{l}1 \text { - Observação, } \\
\text { detecção do } \\
\text { sinal precoce. }\end{array}$ \\
\hline 2 & Definição de Alvo & $\begin{array}{l}\text { Uso de várias questões } \\
\text { exploratórias específicas } \\
\text { para cada parte da lacuna }\end{array}$ & $\begin{array}{l}\text { Escolher método para obter } \\
\text { mais informação }\end{array}$ & \\
\hline & & $\begin{array}{l}\text { Pesquisa aberta, sondar, } \\
\text { explorar }\end{array}$ & & \\
\hline 3 & Coleta & $\begin{array}{l}\text { Interação com outras } \\
\text { organizações e academia, } \\
\text { além de áreas internas por } \\
\text { meio de entrevistas com o } \\
\text { objetivo de identificar as } \\
\text { causas para insucessos, as } \\
\text { necessidades e os } \\
\text { problemas }\end{array}$ & $\begin{array}{l}\text { Obter mais informação, se } \\
\text { há tempo disponível e a } \\
\text { qualidade da informação não } \\
\text { é boa }\end{array}$ & \\
\hline
\end{tabular}

\footnotetext{
${ }^{44}$ Os trabalhos de Nikander não foram unificados no quadro, pois o artigo de 2001 era mais abrangente e detalhado e o de 2008 ficou específico para identificar sinais de problemas, porém de uma forma mais processual, o que pode enriquecer a comparação.
} 


\begin{tabular}{|c|c|c|c|c|}
\hline Fonte & $\begin{array}{l}\text { Janissek-Muniz et al., } \\
2006\end{array}$ & $\begin{array}{l}\text { Loch et al., } 2008 \\
\text { Loch et al., } 2006\end{array}$ & Nikander, Eloranta, 2001 & Nikander, 2002 \\
\hline & & $\begin{array}{l}\text { Não havia informação } \\
\text { histórica para as incertezas } \\
\text { imprevisíveis }\end{array}$ & $\begin{array}{l}\text { Usar um banco de dados } \\
\text { com informações históricas }\end{array}$ & \\
\hline \multirow[t]{3}{*}{4} & \multirow[t]{3}{*}{$\begin{array}{ll}\text { Seleção } & \text { de } \\
\text { Informações } & \\
\text { (individual } & \text { ou } \\
\text { coletiva) } & \end{array}$} & $\begin{array}{l}\text { São mencionadas pistas não } \\
\text { verbais úteis em reuniões } \\
\text { presenciais }\end{array}$ & $\begin{array}{l}\text { Aceitar o sinal e começa a } \\
\text { reagir }\end{array}$ & $\begin{array}{l}2 \\
\text { Interpretação, } \\
\text { aceitar ou } \\
\text { desprezar o sinal } \\
\text { observado }\end{array}$ \\
\hline & & \multirow{5}{*}{$\begin{array}{l}\text { Uso de um quadro para } \\
\text { registro, apagando e } \\
\text { recuperando-o diariamente }\end{array}$} & Avaliar sua usabilidade & \\
\hline & & & Rejeitar o sinal & \\
\hline 5 & $\begin{array}{l}\text { Repasse } \\
\text { informações }\end{array}$ & & & \\
\hline \multirow[t]{2}{*}{6} & \multirow{2}{*}{$\begin{array}{l}\text { Memória - Base de } \\
\text { conhecimento }\end{array}$} & & \begin{tabular}{|l|l|} 
Registrar o sinal \\
informação para uso futuro
\end{tabular} & \\
\hline & & & Usar ferramenta & \\
\hline \multirow{8}{*}{7} & \multirow{8}{*}{$\begin{array}{l}\text { Criação coletiva de } \\
\text { Sentido }\end{array}$} & $\begin{array}{l}\text { Comentam sobre } \\
\text { manifestações não verbais e } \\
\text { indicações }\end{array}$ & $\begin{array}{l}\text { Determinar o nível de } \\
\text { conhecimento adquirido a } \\
\text { partir do sinal }\end{array}$ & $\begin{array}{l}\text { 3-Avaliar nível } \\
\text { de } \\
\text { conhecimento } \\
\text { em relação ao } \\
\text { sinal e seu } \\
\text { significado }\end{array}$ \\
\hline & & Reflexão & $\begin{array}{l}\text { Determinar o significado da } \\
\text { informação para o projeto }\end{array}$ & $\begin{array}{l}4 \text { - Identificar o } \\
\text { risco emergente } \\
\text { e suas causas }\end{array}$ \\
\hline & & $\begin{array}{l}\text { Avaliação qualitativa das } \\
\text { lacunas de conhecimento e } \\
\text { vulnerabilidade }\end{array}$ & $\begin{array}{l}\text { Identificar o risco e suas } \\
\text { causas }\end{array}$ & \\
\hline & & \multirow{2}{*}{$\begin{array}{l}\text { Avaliação e revisão das } \\
\text { informações obtidas no } \\
\text { quadro com reuniões diárias } \\
\text { e semanais com a equipe }\end{array}$} & $\begin{array}{l}\text { Avaliar o tempo para } \\
\text { respostas }\end{array}$ & $\begin{array}{l}5-\text { Avaliar o } \\
\text { tempo } \\
\text { disponível para } \\
\text { respostas }\end{array}$ \\
\hline & & & $\begin{array}{l}\text { Usar respostas emergentes, } \\
\text { se há pouco tempo }\end{array}$ & $\begin{array}{l}6-\text { Identificar } \\
\text { respostas aos } \\
\text { riscos }\end{array}$ \\
\hline & & \begin{tabular}{|lcrr} 
Interagir & com & áreas \\
internas, & nas reuniões & \multicolumn{2}{c}{ reun } \\
diárias e & semanais ou \\
entrevistas & & & \\
\end{tabular} & & \\
\hline & & \begin{tabular}{|lll}
$\begin{array}{l}\text { Decisor fazia parte da } \\
\text { equipe }\end{array}$ & & \\
\end{tabular} & $\begin{array}{l}\text { Convencer o decisor sobre a } \\
\text { questão }\end{array}$ & \\
\hline & & $\begin{array}{l}\text { Revisão do nível de } \\
\text { conhecimento para passar } \\
\text { para os outros métodos de } \\
\text { gestão de subproblemas }\end{array}$ & $\begin{array}{l}\text { Usar métodos tradicionais de } \\
\text { GP, se há tempo disponível e } \\
\text { a informação é exata }\end{array}$ & \\
\hline 8 & Difusão & $\begin{array}{l}\text { Aprovou investimento com } \\
\text { outros dois capitalistas no } \\
\text { final }\end{array}$ & $\begin{array}{l}\text { Convencer a autoridade } \\
\text { externa sobre a questão para } \\
\text { decidir }\end{array}$ & \\
\hline 9 & Animação & & & \\
\hline
\end{tabular}

Apesar de que Weick (1995) afirmar que o processo de criação de sentido não tem início nem fim, neste caso há duas possibilidades de início, conforme processo 1 do Quadro 8. A primeira possibilidade é a busca para superar uma lacuna de conhecimento (JANISSEK- 
MUNIZ et al., 2006; LOCH et al., 2006; LOCH et al., 2008), que pode se iniciar num processo amplo de escolha de um domínio de aplicação ou por um problema específico do projeto. A outra possibilidade de início é quando a criação de sentido é acionada pela observação de um sinal.

Na primeira possibilidade de início, sabe-se que o mundo está em plena mudança e, por isso, busca-se identificar o que está ocorrendo ou o que ocorrerá de maneira proativa. Essa abordagem aplica-se aos projetos que, em seu início, possuem muitos requisitos que não foram totalmente compreendidos, portanto o seu correto diagnóstico e a busca por informações complementares para dar sentido a essas informações é importante para o sucesso do projeto. A segunda maneira pode-se dizer que é reativa.

O processo 2, definição de alvo, além de definir área, atores pertinentes hierarquizados, temas prioritários, especificação das informações e fontes de coleta, pode abranger também a escolha dos métodos para se obter a informação. Já o processo 3 busca sinais precoces sobre atores e temas; é a execução das técnicas e métodos estabelecidos identificados antes ou durante o processo. Na seleção de informações, processo 4, para a organização há uma distinção entre o processo individual e coletivo explicitamente, o que não ocorre com projetos. A literatura, representada no Quadro 8, não detalha as ações das pessoas para avaliar, entender e agir para dar sentido às mudanças ecológicas, porém Klein (2003) sugere algumas táticas para se lidar com a incerteza na tomada de decisão: postergar; procurar mais informação; aumentar a atenção; preencher as lacunas com premissas; construir uma interpretação, que está diretamente ligado ao conceito de criação de sentido; pressionar; agir antes de saber; desenhar cenários de decisão; simplificar o plano; preparar-se para o pior; usar decisões incrementais; aceitar a incerteza.

O processo 5, repasse, organiza a circulação de informação por fluxos internos ou por estoque, reunidos e armazenados de forma centralizada. A memória, processo 6 , constitui a base de conhecimento, com o registro dos significados encontrados. A criação coletiva de sentido, processo 7, transforma o conhecimento adquirido em informações para a tomada de decisão, pois nem sempre quem identifica e interpreta o sinal é quem toma decisão. Também há a necessidade de uma escalada na hierarquia para o tratamento adequado do sentido encontrado. Existe a alternativa de continuar a coleta de informações. O processo 8, difusão, 
nem sempre está presente nos projetos, poderia ser entendido como a transmissão da informação para as devidas áreas para a tomada de decisão.

Para que as informações sejam repassadas, o animador deve motivar as pessoas a acessarem as informações. Explicitamente, o processo 9, animação, não é tratado nos projetos, apesar de que Simon (2006) identificou que um gerente de projetos criativo age como um animador da equipe para gerar a criação de sentido. A questão da continuidade do processo é importante para a organização, pois torna-se um processo operacional. No caso dos projetos, a ausência de continuidade pode ser explicada pelas características deles: ter um término determinado e a busca ser focada num conhecimento específico e pontual.

Os processos estabelecidos formalmente, informalmente ou mesmo os improvisados podem ser influenciados por fatores que podem tanto facilitar o processo, quanto bloqueá-lo, por isso no próximo item esses fatores serão detalhados.

\subsubsection{Fatores facilitadores à criação de sentido de incerteza imprevisível}

Loch et al. (2006) comentam que a gestão de incertezas imprevisíveis requer cautela, pois exige experiência, flexibilidade e adaptação para os eventos inesperados, além de um grande investimento de recursos. O Quadro 9 resume as indicações de fatores facilitadores para a gestão de:

- $\quad$ incerteza imprevisível especificamente (LOCH et al., 2006);

- $\quad$ riscos emergentes, que podem surgir após o tratamento inicial dos riscos nos projetos (PMI, 2009; ALBERTS, DOROFEE, 2009);

- $\quad$ novos problemas (KLOSS-GROTE, MOSS, 2009);

- $\quad$ sinais não percebidos que se tornam problemas (SCHOEMAKER, DAY, 2009; LEVITT, SNYDER, 1997; HILTUNEN, 2008).

Os fatores facilitadores foram reunidos em quatro grupos: cultura da organização, metodologia em GP, metodologia em GR e ferramentas de GR e incertezas. Com relação à cultura de atenção ${ }^{45}$, Schoemaker e Day (2009) ressaltam a importância de se ter uma mente aberta e orientada para o futuro e Hiltunen (2008) destaca os problemas de excesso de

\footnotetext{
${ }^{45}$ mindfulness
} 
informação e filtros organizacionais. Loch et al. (2006) entendem que ela é presente quando há o reporte de problemas e valorização da diversidade, o que inclui experiência e capacidade de resolvê-los.

Quadro 9 - Fatores facilitadores na gestão de incertezas e riscos

\begin{tabular}{|c|c|c|c|c|c|c|c|c|}
\hline Grupo & Tipo & $\begin{array}{l}\text { Loch } \\
\text { et al., } \\
2006\end{array}$ & $\begin{array}{l}\text { PMI, } \\
2009\end{array}$ & $\begin{array}{l}\text { Alberts, } \\
\text { Dorofee, } \\
2009\end{array}$ & $\begin{array}{l}\text { Kloss- } \\
\text { Grote, } \\
\text { Moss, } \\
2009\end{array}$ & $\begin{array}{l}\text { Schoemaker } \\
\text {, Day, } 2009\end{array}$ & $\begin{array}{l}\text { Levitt, } \\
\text { Snyder } \\
, 1997\end{array}$ & $\begin{array}{l}\text { Hiltunen, } \\
2008\end{array}$ \\
\hline \multirow{3}{*}{$\begin{array}{l}\text { Cultura da } \\
\text { organização }\end{array}$} & Cultura de atenção & $\mathrm{x}$ & & & & $\mathrm{x}$ & & $\mathrm{x}$ \\
\hline & Múltiplas perspectivas & $\mathrm{x}$ & $\mathrm{x}$ & & $\mathrm{x}$ & & & \\
\hline & $\begin{array}{l}\text { Objetividade (diminuição } \\
\text { de vieses) }\end{array}$ & & $\mathrm{x}$ & & & & & $\mathrm{X}$ \\
\hline \multirow{3}{*}{$\begin{array}{l}\text { Metodologia } \\
\text { em GP }\end{array}$} & $\begin{array}{|lll|}\begin{array}{l}\text { Metodologia de gestão } \\
\text { diferenciada }\end{array} & \\
\end{array}$ & $\mathrm{x}$ & & & & & & \\
\hline & Gestão de stakeholder & $\mathrm{x}$ & & & & & & \\
\hline & $\begin{array}{l}\text { Cláusulas contratuais com } \\
\text { fornecedores incluindo unk } \\
\text { unks }\end{array}$ & $\mathrm{x}$ & & & & & $\mathrm{x}$ & \\
\hline \multirow{5}{*}{$\begin{array}{l}\text { Metodologia } \\
\text { em GR }\end{array}$} & Identificação antecipada & & $\mathrm{x}$ & & & & & \\
\hline & Identificação iterativa & $\mathrm{x}$ & $\mathrm{x}$ & & & & & \\
\hline & Identificação abrangente & $\mathrm{x}$ & $\mathrm{x}$ & & & & & \\
\hline & Identificação emergente & & $\mathrm{x}$ & & & & & \\
\hline & $\begin{array}{|lll|}\begin{array}{l}\text { Propriedade do risco e } \\
\text { nível de detalhe }\end{array} & \\
\end{array}$ & & $\mathrm{x}$ & & & & & \\
\hline \multirow{4}{*}{$\begin{array}{l}\text { Ferramentas } \\
\text { de GR e } \\
\text { incertezas }\end{array}$} & $\begin{array}{l}\text { Com base visão histórica / } \\
\text { passada }\end{array}$ & & $\mathrm{X}$ & $\mathrm{X}$ & $\mathrm{x}$ & $\mathrm{x}$ & & \\
\hline & $\begin{array}{l}\text { Para avaliação da situação } \\
\text { atual }\end{array}$ & $\mathrm{x}$ & $\mathrm{x}$ & & & & & \\
\hline & $\begin{array}{l}\text { Técnicas criativas para } \\
\text { identificar o futuro }\end{array}$ & & $\mathrm{x}$ & $\mathrm{X}$ & $\mathrm{x}$ & $\mathrm{x}$ & & \\
\hline & $\begin{array}{l}\text { Ferramentas de Gestão de } \\
\text { conhecimento }\end{array}$ & & & & $\mathrm{X}$ & & & \\
\hline
\end{tabular}

A cultura de atenção foi evidenciada por Weick e Sutcliffe (2007) por sua importância para gerenciar o inesperado nas operações de organizações de alta confiabilidade, como usinas nucleares, corpo de bombeiros, unidades de terapia intensiva nos hospitais. Eles levantaram cinco princípios - os três primeiros ligados à antecipação e os dois últimos, ao confinamento do problema:

a) preocupação com falhas - significa ter atenção com os sinais precoces das falhas, pois quanto antes eles forem notados, mais alternativas solucionadoras serão possíveis, mesmo com a dificuldade de entendê-los; assim como a necessidade de se reportarem os erros, mesmo aqueles difíceis de assumir;

b) relutância a simplificar - organização implica em simplificação, mas é preciso avaliar o todo antes de simplificar, para não se perder alguma informação importante; 
c) sensibilidade às operações - a visão operacional é mais importante que a tática e a estratégica, pois a primeira mostra a realidade da organização, percebendo os erros mais claramente;

d) compromisso com a resiliência - todo sistema possui falhas, porém o importante é que elas sejam pequenas e as soluções, mesmo improvisadas, façam com que o sistema fique em operação continuamente, por isso o profundo conhecimento da área em questão e o aprendizado com as falhas anteriores tornam-se relevantes;

e) deferência com a expertise - que implica diversidade de conhecimento, decisões tomadas nos vários níveis organizacionais e por quem tem mais conhecimento sobre aquele evento.

A múltipla perspectiva é importante para que todas as disciplinas envolvidas no projeto tenham o seu representante na equipe do projeto e sejam pessoas com mais experiência ou especialistas, para estimular a cross-fertilization entre os projetos passados e os atuais. Com relação ao problema da objetividade dos riscos, o PMI (2009) sugere que os vieses sejam expostos sempre que possível e que os riscos sejam identificados de maneira aberta e ampla.

A principal questão da metodologia em GP é a diferenciação da metodologia a ser aplicada, como foi discutido no item 2.2.3, página 52, pois exigirá infraestrutura diferenciada e adequada (LOCH et al., 2006). Outra questão importante é a gestão de stakeholders, principalmente fornecedores e aqueles que não estão diretamente ligados à equipe do projeto. Os contratos devem possuir cláusulas contratuais prevendo esse tipo de incerteza. Na GR, propriamente dita, o PMI (2009) sugere várias considerações, como a iteratividade, a identificação antecipada, abrangente e emergente, independente dos processos, além de um detalhamento suficiente dos riscos e eventos para que sejam utilizados nos próximos projetos.

Com relação às ferramentas, as várias técnicas possuem um foco no presente, na situação atual e no futuro, das quais a primeira e a última são as mais citadas. Loch et al. (2006) também ressaltam a importância da existência de uma proposta em comum na qual pode ser usado um mapa com as incertezas imprevisíveis. Essa proposta em comum é importante para não quebrar a criação de sentido da equipe durante as inúmeras mudanças que o projeto pode sofrer. As ferramentas de gestão de conhecimento são citadas por Kloss-Grote e Moss (2009), dado que eles avaliaram os eventos ocorridos nos projetos para verificar se a informação existia dentro da organização, o que permitiria seu reconhecimento antecipado. 


\subsection{Síntese e proposições de estudo}

Neste item propõe-se sintetizar os principais pontos explorados na fundamentação teórica, e, ao mesmo tempo, apresentar proposições de estudo. Eisenhardt (1989, p. 536) sugere não se ter teoria ou hipótese pré-definida para permitir maior flexibilidade à pesquisa, porém neste estudo foi seguida a recomendação de Yin (2005) para a definição de proposições de estudo, para definir a busca de informação e selecionar os tipos de evidência mais relevantes.

\subsubsection{Avaliação multidisciplinar de risco e incerteza}

Atualmente, risco é estudado de maneira multidisciplinar, podendo-se dividir epistemologicamente em dois grupos de teorias (LUPTON, 1999): perspectiva da ciência cognitiva, centrada no indivíduo; detalham-se a seguir a abordagem estatística probabilística e a abordagem comportamental e abordagem sociocultural, que parte da cultural simbólica, visão da sociedade e da cultura para o indivíduo, destacadas a seguir as abordagens da sociedade de risco e a da governamentalidade.

A abordagem estatística probabilística está ligada à teoria de decisão prescritiva, subjacente à área de GR em projetos (PENDER, 2001), com várias sobreposições. Essa teoria estrutura-se em modelos e métodos que levem à tomada de decisão ótima, baseando-se no conceito de que os indivíduos tentam ser racionais em suas decisões, apesar do ambiente de incerteza.

A escolha racional envolve dois tipos de suposições: a consequência futura das ações atuais e a preferência futura para essa consequência, porém a racionalidade ou inteligência dos indivíduos é limitada por fatores como preferências (MARCH, 1988). Há, também, desvios do padrão comportamental, sensíveis a uma série de condições, como a ambiguidade, que não é necessariamente uma falha na escolha humana a ser corrigida, mas uma forma de inteligência a ser refinada pela tecnologia de escolha, mais do que ignorada por ela (ZSAMBOK, 1997).

Essas questões foram mencionadas na abordagem comportamental, que ilustra o impacto das heurísticas e vieses nas decisões tomadas sem métodos e processos, baseadas na intuição. 
Apesar disso, Sadler-Smith e Leyborne (2006) verificaram que os gerentes de projeto usam mais a intuição e a improvisação, quando avaliaram as preferências entre o uso de processos racionais e a intuição. $\mathrm{O}$ sentido da intuição usado aqui encontra-se quando o decisor decide sem um raciocino formal e transparente, gerando as respostas com base na sua experiência de vida.

Um exemplo do uso de processos racionais foi dado por Lock et al. (2008). Nesse artigo é explorado o caso de um novo presidente da Escend, empresa que estava dando prejuízo, o qual precisava identificar se o negócio deveria ser fechado ou receber novos investimentos. Para isso, com o auxilio dos autores do artigo, o presidente da empresa aplicou o diagnóstico de incertezas no projeto, Ilustração 8, página 56, que entende o problema, divide-o em partes, avalia o nível de incerteza de cada parte e gerencia cada uma paralelamente, conforme o nível de incerteza. Dois dos problemas identificados eram incertezas imprevisíveis (unk unks) e, para geri-las, foi aplicado o método de aprendizado, iterativo e gradual, com flexibilidade e adaptação aos eventos imprevistos.

Porém não são todos os projetos que seguem um processo formal de diagnóstico e tratamento das incertezas. Em Russo e Sbragia (2010), foi explorado o caso da geração da tecnologia flexfuel, um caso de inovação na área automotiva brasileira. $\mathrm{O}$ foco do estudo foi a Magnetti Marelli, que gerou a tecnologia, e a Volkswagen do Brasil, a primeira a lançar um carro com essa tecnologia. A geração da tecnologia não seguiu nenhuma metodologia explicitamente e o caso foi avaliado nas quatro etapas - individual, grupal, intraorganizacional e interorganizacional, com base nas propriedades da criação de sentido. $\mathrm{O}$ resultado mostrou a importância da flexibilidade nas organizações para a existência de improviso para a geração da inovação, principalmente nas etapas e fases iniciais de desenvolvimento de produtos. Assim, surge a primeira proposição de estudo.

Proposição de estudo A - A improvisação é mais usada do que práticas estabelecidas para a criação de sentido das incertezas imprevisíveis.

Seguindo o resumo da teoria exposta, foi vista na abordagem sociocultural a importância da identidade do indivíduo com o grupo e no grau que a vida do indivíduo é regulada ou prescrita pelo seu papel social no grupo. Se a identificação com o grupo for baixa, ele não terá coesão ao grupo e poderá arriscar mais do que se tivesse alta identificação. Se, além disso, a sua vida 
pessoal tiver baixa regulação pelo grupo, ele poderá facilmente trocar de grupo ou mesmo gerar um novo grupo, como os empreendedores.

A criação de sentido inicia-se na esfera individual (sensemaker) com a manutenção ou o estabelecimento de uma identidade pessoal (WEICK, 1995). Com relação aos projetos, a identidade foi destacada por Loch et al. (2006) por ser primordial para gerar a coesão do grupo. Em projetos com alto nível de incerteza e, consequentemente, com muitas mudanças, estas podem causar a quebra da criação de sentido do projeto, refletindo na perda de coesão do grupo. Um gerente de projetos criativo tem o papel de sensemaker (SIMON, 2006), aquele que cria o sentido ao esforço da equipe, traduzindo a representação coletiva do projeto em significado compartilhado com todos os envolvidos, por meio de comunicações informais e reuniões formais.

Essas questões podem ser vinculadas ao questionamento da participação da equipe no processo de diagnóstico e tratamento das incertezas imprevisíveis. Assim, surge a seguinte proposição de estudo:

Proposição de estudo $B$ - O sentido das incertezas imprevisíveis é gerado mais pela criação coletiva de sentido do que pela criação de sentido individual.

Ampliando o espectro da abordagem sociocultural, foi visto que a sociedade de risco (BECK, 1992) amplia as incertezas e os riscos vividos atualmente por causa: dos novos riscos qualitativos produzidos pela sociedade moderna industrial de maneira não prevista e não intencional, como efeitos secundários, e da mudança nas desigualdades do nível das classes sociais para o nível do indivíduo, pois os riscos são globais e não afetam apenas a uma classe social, um país, uma região. As pessoas cada vez mais estão sendo responsabilizadas, principalmente no âmbito psicológico, pelas consequências dos riscos.

Dentro do âmbito dos projetos, isso ocorre tanto no contexto interno quanto no externo. No primeiro, pode-se verificar como o estilo de gestão do gerente, que pode querer expor-se mais aos riscos ou não; com a responsabilização percebida pelo sucesso do projeto, tenha tido ele condições de escolhas ou tenha sido empregada uma estratégia de sobrevivência; como a equipe identifica o que é risco. As atividades de edgework muitas vezes são tratadas como um projeto. Apesar de toda emoção e sensação envolvidas, as pessoas preparam-se e planejam-se 
muito bem para a atividade, avaliando e obtendo os recursos necessários, para que o limite não seja ultrapassado, como os projetos de navegação solitária de Amyr Klink.

No contexto externo, o projeto e o produto do projeto podem gerar consequências para os stakeholders; a sociedade é um deles, de maneira positiva ou negativa, ainda que essa visão dependa muito da situação de cada um. Por exemplo o projeto de lançamento de um novo produto exigiria horas extras de dedicação da equipe, o que afetaria a sua família e a organização, mas que poderia ser considerada uma situação normal, dependendo da cultura do grupo social. O produto do projeto gerado sem a preocupação com o meio-ambiente poderá afetar o seu lançamento e o mercado que pretende atingir, por não avaliar corretamente as escolhas atuais da sociedade. Com relação à governamentalidade, as políticas fiscais e ambientais podem sugerir que o gestor está tomando as devidas escolhas para gerar um produto responsável perante a sociedade. Porém, em pouco tempo, essa escolha pode-se mostrar insuficiente, pelo avanço da ciência e da tecnologia, assim como por mudanças originadas em acordos políticos, por leis reguladoras do mercado, ou pela própria conscientização dos cidadãos.

Essas abordagens podem contribuir para ampliar os objetivos para atender o trio da sustentabilidade: econômico, social e ambiental. Nas várias classificações para identificar sucesso do projeto (CLELAND, 1999; PINTO, SLEVIN, 1988; SBRAGIA et al.,1986; SHENHAR et al., 1997), os critérios de sucesso são, de maneira geral: eficiência do projeto, impacto no cliente, impacto organizacional, chegando-se até a preparação para o futuro da organização. Percebe-se que os vários níveis de sucesso se referem ao pilar econômico, mas o social e o ambiental precisam estar dentro dos requisitos de funcionalidade para serem contemplados.

\subsubsection{Gestão do risco e da incerteza na inovação}

Estrategicamente, as empresas precisam reconhecer as suas vantagens competitivas, para mantê-las ou gerar novas. Para isso, elas precisam inovar: em seus produtos, que podem ser um bem ou serviço; nos processos de produção ou distribuição; no marketing, com novas concepções dos produtos, no posicionamento no mercado, na sua promoção; ou na organização, com novas práticas de negócios, da organização do local de trabalho ou nas 
relações externas. Entretanto, para se configurar como inovação, ela deve ser no mínimo nova para a organização. O nível de novidade está atrelado ao de incerteza, que afeta diretamente as decisões estratégicas. Assim, surge a proposição de estudo:

Proposição de estudo $\mathrm{C}$ - Há diferença no tratamento das incertezas imprevisíveis nos projetos, conforme o tipo de inovação.

A implementação das estratégias está vinculada à geração de projetos que, dependendo do nível de incerteza e complexidade, podem ser considerados inovadores. Para essa identificação, foram detalhadas algumas tipologias, como as de Wheelwright e Clark (1992) que tratam somente de produtos e processos, diferenciando cinco tipos, dependendo do nível de mudança no produto e / ou no processo, conforme detalhado na Ilustração 6, página 46: pesquisa e desenvolvimento, ruptura, plataforma, derivados e os projetos de aliança e parceria.

Gallouj e Weinstein (1997) desenvolveram uma classificação que avalia a inovação não apenas pelo tipo de produto e tecnologia empregada, mas também pela competência gerada e exigida no processo de geração de um serviço. Eles avaliam as competências individuais, do grupo e as obtidas com os clientes para os quais o serviço está sendo desenvolvido. A tecnologia empregada são as ferramentas, modelos e rotinas organizacionais. A combinação da competência e tecnologia gera um novo produto ou serviço com determinadas características finais. A combinação desses três vetores - competências (C), tecnologia (T) e características do produto / serviço $(\mathrm{Y})$ - podem gerar seis modos de inovação em serviços: inovação radical, quando os vetores $\mathrm{C}, \mathrm{T}$ e $\mathrm{Y}$ são totalmente novos, ou pelos menos o $\mathrm{C}$ e o $\mathrm{T}$; aprimoramento, quando os vetores são modificados em sua qualidade ou nível de desempenho; incremental, quando o sistema de vetores é marginalmente modificado, pela adição ou substituição de componentes; ad hoc, quando a inovação é construída essencialmente por uma interação social com o cliente; inovação recombinante, quando novos serviços são desenvolvidos com base num estoque de conhecimento e tecnologia construídos pela trajetória de produtos anteriores; e, finalmente, inovação pela formalização, ocorre pela delimitação clara do que é o serviço, estabelecendo uma "ordem" e um formato definido que será compreendido pelas equipes internas e pelo cliente, normalmente um projeto anterior que será base dos demais tipos. 
Outra tipologia descrita foi a do modelo NTCP (SHENHAR, DVIR, 2007), que possui várias dimensões para classificar o projeto, sendo as quatro principais:

- $\quad$ inovação do produto - refere-se à incerteza externa, pois depende da aceitação do mercado e dos usuários. Ela se subdivide, de forma semelhante à de Wheelwright e Clark (1992), em derivado, plataforma e ruptura;

- tecnologia - incerteza interna, pois representa o nível de desconhecimento interno (organização e/ou equipe) da tecnologia a ser empregada no projeto, que se subdivide em quatro níveis - baixa, média, alta e muito alta;

- complexidade - nível de integração necessário entre as várias funcionalidades do projeto. Baccarini (1996) definiu a complexidade de um projeto como a interrelação das várias partes do projeto, operacionalizando-a em termos de diferenciação, número dos vários elementos que compõem o projeto, e da interdependência, nível de conectividade entre esses vários elementos. Pode-se subdividir essa dimensão em três níveis - baixa, média e alta;

- $\quad$ ritmo - representa a urgência do projeto para a organização e, consequentemente, quanto tempo disponível existe para o desenvolvimento do projetor. Essa dimensão é subdividida em regular, rápido / competitivo, tempo crítico e blitz.

Shenhar e Dvir (Ibid.) calculam o nível de incerteza do projeto pela combinação da inovação com a tecnologia, vide Quadro 3, página 48. Quanto mais alto o nível de inovação e de desconhecimento da tecnologia, maior é o nível de incerteza no projeto. Esses autores sugerem vários outros critérios que podem ser usados, como: a ligação com o objetivo do negócio, se operacional ou estratégico; o tipo de cliente, interno ou externo; a ligação com os objetivos estratégicos que podem ser melhoria, estratégico, solução de problemas, manutenção, utilitário, pesquisa e desenvolvimento. Surge mais uma proposição de estudo e seus desdobramentos:

Proposição de estudo D - Os projetos com mais incerteza na inovação do produto e menos inovação tecnológica tendem ser mais eficientes na identificação da incerteza imprevisível.

Proposição de estudo D1 - Os projetos com mais incerteza na inovação do produto e na inovação tecnológica e menos complexidade tendem a ser mais eficientes na identificação da incerteza imprevisível.

Proposição de estudo D2 - Os projetos com mais complexidade tendem a ser menos eficientes na identificação da incerteza imprevisível. 
Loch et al. (2008) sugerem avaliar o projeto por meio de um diagnóstico de incertezas (vide Ilustração 8, página 56) em quatro fases: identificação da estrutura do problema do projeto; divisão do problema em partes, entendendo cada uma dela; avaliação do nível de conhecimento de cada parte do problema definindo o perfil de incerteza, como variação, incerteza prevista e incerteza imprevisível; gestão de cada subproblema paralelamente com métodos distintos. Também é importante ressaltar que o diagnóstico é iterativo e gradual, pois, com o progresso do desenvolvimento do projeto, o desconhecido torna-se mais conhecido e a gestão também deve evoluir para que cada vez mais se torne um planejamento no qual apenas uma pequena variação seja esperada.

Para o perfil de incerteza variação, o processo de monitoramento e controle é suficiente para gerir os desvios de um planejamento-padrão. Para a incerteza prevista, a GR é apropriada para tratar o nível de desconhecimento com a geração de planos de contingência, se necessário. Entretanto a incerteza imprevisível pode ser gerida pelo método de aprendizado, que permite flexibilidade ao planejamento, como na tentativa e erro, ou o método de selecionismo, quando mais de uma opção é gerada concorrente ou sequencialmente com a seleção da melhor solução ex post. A opção entre o método de aprendizado e o de selecionismo deve ser feita conforme o nível de incerteza e complexidade, identificados no perfil de incerteza (vide Ilustração 2, página 14).

A gestão da incerteza imprevisível, exemplificada pelos autores (ibid.) usou o método de aprendizado. Foram feitas várias entrevistas, com vários stakeholders - internos e externos que geraram informações, que foram registradas, avaliadas, revistas, eliminadas, recuperadas. Isso ocorria diariamente até se chegar a uma conclusão sobre cada um dos subproblemas. $\mathrm{O}$ projeto continha alto nível de incerteza e alta complexidade, pois era preciso identificar o produto que o mercado esperava, portanto o método utilizado contradiz o sugerido pelos autores restando a dúvida se realmente no quadrante superior direito da Ilustração 2 deveria constar selecionismo ou aprendizado. Assim, surge mais uma proposição:

Proposição de estudo $\mathrm{E}$ - $\mathrm{O}$ método de aprendizado é mais usado para a gestão da incerteza imprevisível. 
Alguns dos padrões mais usados em GR para organizações são ISO 31000; gerenciamento de risco corporativo - estrutura integrada, desenvolvido pelo COSO (2007), Risk Management Standard (AIRMIC, ALARM, IRM, 2002), Orange Book (HM TREASURY, 2004). Para projetos os mais usados são PMI (2008; 2009), PRINCE2 (OGC, 2005) e SRM, desenvolvido para a SEI (HIGUERA, HAIMES, 1996).

Em todos os padrões a incerteza está ligada à probabilidade de um evento ocorrer e afetar os objetivos do projeto, o resultado do projeto todo ou a organização. O foco maior está no impacto negativo, ou seja, no risco como ameaça, apesar de todos reconhecerem os benefícios que podem ser obtidos com os eventos positivos, as oportunidades. Assim, observam-se duas dimensões do risco: probabilidade e impacto, que pode ser chamado de efeito também (PMI, 2009). A causa do risco também deve ser considerada em toda análise.

A GR em projetos é criticada (KLEIN, 2003; MURRAY-WEBSTER, PELLEGRINELLI, 2010; PENDER, 2001; PERMINOVA et al., 2008) por não esclarecer e endereçar as incertezas inerentes aos planos. As estimativas apresentam variabilidade normal, originadas pelo desconhecimento de determinados detalhes de disponibilidade de recursos ou mesmo de sua produtividade, que pode esconder avaliações enviesadas com possibilidades de melhorias. Outro problema é a tentativa de reduzir os riscos demasiadamente, para evitar problemas futuros, inviabilizando o resultado econômico do projeto.

Pode-se dizer que, em nenhum padrão, as incertezas imprevisíveis foram citadas e são tratadas. O PRINCE2 (OGC, 2005) cita o monitoramento dos sinais precoces, chamando de sinais e avisos antecipados, e a ISO 31000 (PURDY, 2009) ressalta a percepção e resposta às mudanças, que podem ocorrer de maneira lenta ou súbita. Os padrões possuem sugestões de fatores de risco, como listas iniciais para que sejam desenvolvidas e adequadas para a área de atuação e tipo de organização, tanto na implantação da GR, quanto em sua evolução. Os riscos podem ser externos, por surgirem externamente à organização; ou internos, relativos às operações internas da organização, no sentido de prover capacidade de produção e competência (HM TREASURY, 2004; COSO, 2004). Sinteticamente, os fatores de risco externo podem ser: políticos, regulatórios, econômicos, sociais, tecnológicos e do meio ambiente; o Guia PMBOK (PMI, 2008) considera nesse grupo, os fornecedores. Os fatores internos são: infraestrutura, pessoal, processo, tecnologia. Em projetos, os padrões incluem os 
fatores técnicos em termos de requerimentos, tecnologia, complexidade e interfaces, desempenho e confiança, qualidade. Esse tipo ainda pode ser desmembrado conforme as especificidades do produto ou do serviço.

A divisão entre fatores de risco internos e externos pode ser aprofundada pela ligação desse fator com a incerteza imprevisível no projeto. Assim, surge:

Proposição de estudo F - Os fatores externos de riscos geram mais incertezas imprevisíveis.

A GR em projetos é muito parecida com a estruturação da tomada de decisão (PENDER, 2001). Todo padrão em GR tem, praticamente, a mesma estrutura processual (Quadro 5): estabelecimento do contexto e planejamento; identificação de riscos, reconhecer os riscos, identificar a causa e a fonte, os impactos e registrá-los; análise, entendimento do risco, com a identificação das consequências e das probabilidades, e avaliação, pela comparação com critérios definidos anteriormente para a decisão sobre ações futuras; comunicação, importante para que o fluxo de informações não seja um obstáculo a essa gestão, mas que não aparece no PMI (2009) nem no PRINCE2 (OGC, 2005); formulação de respostas adequadas ao risco e monitoramento e controle dos riscos, para atualizar a situação do risco, tanto pelo decorrer do tempo, quanto pelo aumento de conhecimento da equipe sobre o projeto.

Existem 68 técnicas e ferramentas (Quadro 6) sugeridas para serem usadas na GR; a identificação possui o maior número (36), apesar de que uma grande parte das técnicas pode ser usada em mais de um processo. Há três tipos de ferramentas (PMI, 2009): as que se baseiam na revisão de informações passadas, como lista de verificação; as que avaliam o presente, comparando as características do projeto com modelos e estruturas-padrão, como a avaliação de premissas e restrições e as que usam a criatividade individual ou de um grupo, para identificar possíveis eventos que ocorrerão no futuro, como brainstorming.

Há alguns artigos que avaliaram se a GR era efetiva para o sucesso do projeto (RAZ et al., 2002; RUSSO et al., 2007), mas apenas Kloss-Grote e Moss (2008) geraram uma avaliação do nível de desempenho da GR. Mesmo a GR sendo criticada por não tratar a incerteza imprevisível, surge uma proposição de estudo. 


\section{Proposição de estudo G - As técnicas e as ferramentas que tentam vislumbrar o futuro são mais efetivas para se identificar a incerteza imprevisível.}

\subsubsection{Criação de sentido}

A criação de sentido é parte natural do processo da ação organizacional, pois os gerentes interpretam os eventos e suas crenças intuitivas que influenciam suas decisões (ANDERSON, 2006). Esse processo é caracterizado por ser um processo social, contínuo, retrospectivo, baseado na construção de uma realidade, plausível, que não tem começo nem fimm (WEICK, 1995). O autor afirma que primeiramente as pessoas agem e depois avaliam e refletem sobre suas ações para interpretar e entender o seu significado, construindo a realidade.

Weick et al. (2005) indicam que o processo de organizing (vide Ilustração 11, página 68) composto por mudança ecológica, enactment, seleção e retenção, pode representar as atividades de criação de sentido, quando reflete a iteratividade do processo. Este se inicia com a percepção de uma mudança ecológica no ambiente, alavancada pela discrepância ou equivocidade. Essa percepção ocorre dentro da relação entre a mudança e a atividade de enactment, recíproca e contínua no tempo, pois a impermanência é característica da criação de sentido. Os sinais são vistos e extraídos do ambiente para uma contextualização dentro de modelos mentais, crenças pessoais, regras, procedimentos e outros fatores, influenciado pelas questões sociais e pelo contexto.

O processo de enactment tem as atividades de notar e agrupar, rotulando a mudança, para entender e determinar o seu significado, na tentativa de enquadrar, articular ou gerar uma nova realidade, inclusive com inúmeras alternativas de sentido para o observado. As pessoas tentam articular uma ordem para o fluxo de informações, moldadas pelo exterior. Nesse processo, a improvisação é fundamental.

No processo de seleção, as inúmeras alternativas serão reduzidas na definição da estória mais plausível, naquele momento, tentando explicar o que está acontecendo, revelando os sinais e o significado das mudanças para a organização, usando o conhecimento das pessoas e as experiências passadas, individuais e organizacionais. Para esse processo é importante que as crenças sejam colocadas em dúvida ou mesmo descartadas, para que o novo possa aparecer. 
Weick (1995) preocupa-se com a falácia da importância, superestimação do conhecimento pelos especialistas, negando os fatos que eles não conseguem enquadrar em seu saber.

Corroborando com a preocupação de Weick (1995), Winch e Maytorena (2009) observaram na avaliação da eficiência de identificação de riscos pelo processo de criação de sentido que os gerentes de projetos mais experientes, não questionavam as informações recebidas e, consequentemente, não identificaram tantos riscos. Consequentemente, surge uma proposição de estudo:

\section{Proposição de estudo $H$ - As pessoas mais experientes buscam menos a incerteza imprevisível.}

O processo de retenção, Ilustração 11, página 68, ocorre na organização quando a plausibilidade da alternativa selecionada se efetiva. Esse processo armazena o conhecimento gerado para uso imediato ou futuro, tanto para tomada de decisão quanto para novos ciclos de criação de sentido. Logo, nesse ciclo contínuo, a estória plausível tende a se tornar cada vez mais substancial, tornando-se parte da experiência dos envolvidos como guia para futuras ações e decisões.

\subsubsection{Criação de sentido em projetos}

Os estudos dos temas de criação de sentido e projetos avaliaram como as pessoas dão sentido aos métodos estruturados de desenvolvimento de produto (CHRISTIANSEN, VARNES, 2009), verificando que a flexibilidade é uma característica marcante, mesmo que esses métodos sejam extensivos e elaborados. A figura do gerente de projetos mostra-se como um sensemaker (SIMON, 2006), na medida em que ele cria o sentido para o esforço da equipe, traduzindo a representação coletiva do projeto em significado compartilhado com todos os envolvidos. A criação de sentido é importante para se manter a coesão do grupo, principalmente em ambientes incertos e ambíguos (LOCH et al., 2006) e sua falta pode ancorar as pessoas nos paradigmas existentes (THIRY, 2001), diminuindo o valor dos projetos.

Mas, para iniciar a criação de sentido, é preciso reconhecer um sinal precoce no mundo real inundado de informações, muitas vezes ambíguas, imprecisas e incompletas. O estudo de 
sinais precoces em projetos mostrou que eles são monitorados, normalmente, em grandes projetos e em empresas com maior volume de investimento nesses projetos (SANCHEZ, PEREZ, 2004). A classificação de Hiltunen (2008) divide o sinal precoce em informação precoce, quando ocorre um número pequeno de sinais com pouca visibilidade, dificultando a interpretação e em primeiros sintomas, quando os sinais ocorrem em número maior, mas a interpretação também pode ser dificultada pela falta de clareza em seu significado.

Os sinais podem-se manifestar de forma verbal, como contradições na fala; de forma não verbal, como o tom das mensagens e o espírito das pessoas; de forma escrita, como nos indicadores de relatórios de status quo, e por eventos, como atraso na entrega por um fornecedor. Um resumo dos grupos de sinais precoces (vide Quadro 7, página 78) seria: gut feelings, comunicação; expressão do sponsor, do cliente, do usuário, do time do projeto, do fornecedor, do consultor; gerente de projetos e sua gestão; pressão sobre o gerente de projetos; planejamento, controle e relatórios, trabalho dentro do projeto, documentos; diferenças e deficiências na cultura de projeto; fontes externas; número de projetos no portfólio.

Vários trabalhos sobre sinais precoces em GP tratam dos primeiros sintomas (KAPPELMAN et al., 2006; GERALDI et al., 2010; SÁNCHEZ, PÉREZ, 2004; NIKANDER, ELORANTA, 2001) na tentativa de verificarem ações corretivas para sua gestão. Nikander e Eloranta (2001) observaram que as características mais importantes dos que identificam os sinais precoces são a experiência e a perspicácia. De fato, dentro da IC, para o reconhecimento antecipado dos sinais precoces é necessária a sua identificação, além da compreensão do seu significado, pela criação de sentido. Esse processo concentra-se na análise e interpretação de informações e sinais obtidos de forma ativa durante o ciclo de monitoramento estratégico, podendo ter como resultado decisões e planos de ação (WEICK, 1995). 


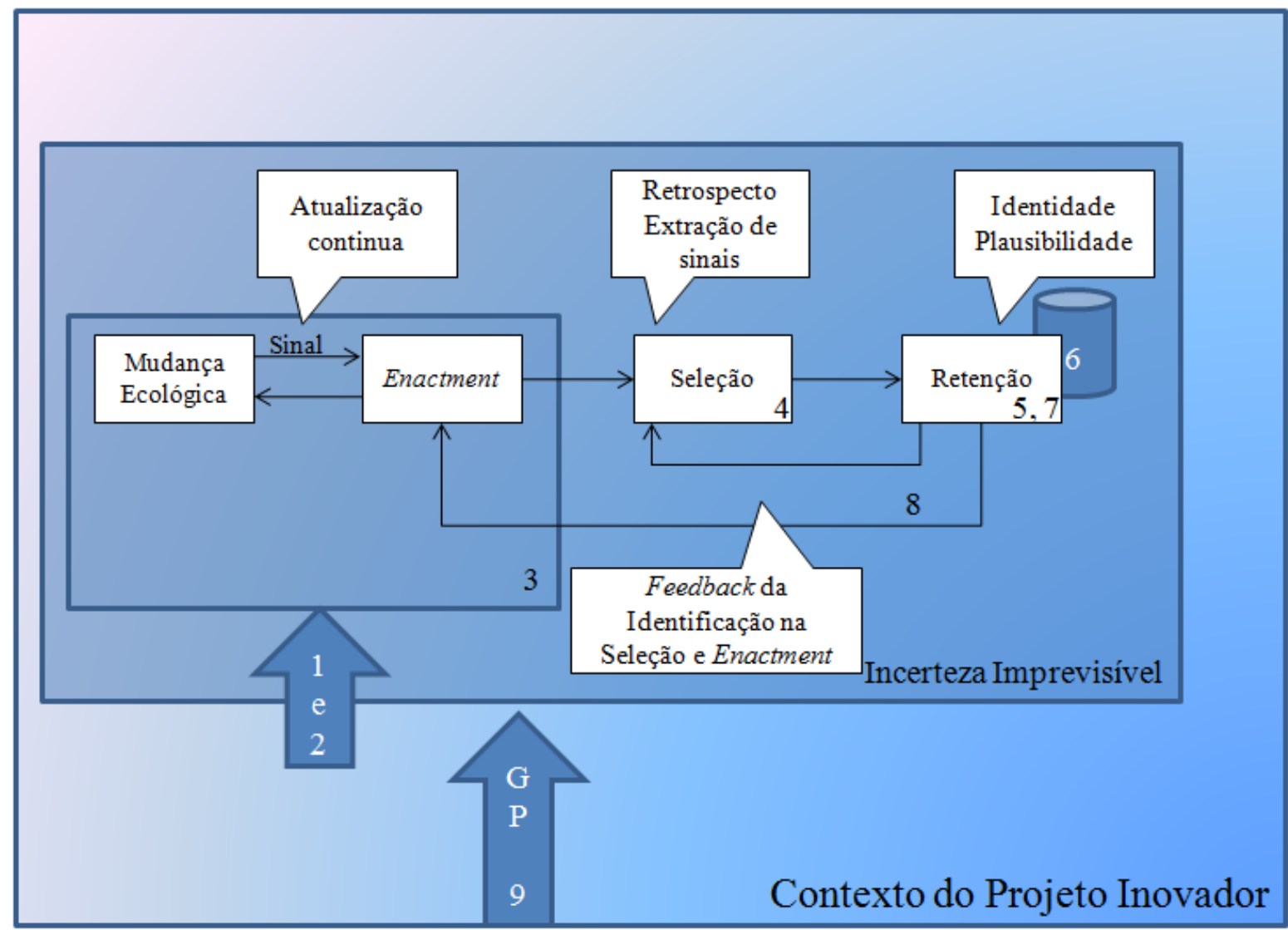

Ilustração 14 - Processos para criação de sentido da incerteza imprevisível

Fonte: Adaptado de Lesca, 2003 apud Janissek-Muniz et al., 2006; Loch et al., 2006; Loch et al., 2008; Nikander, 2008; Nikander, Eloranta, 2001;Weick et al., 2005.

$\mathrm{Na}$ Ilustração 14, destacam-se os três construtos, base deste estudo: projetos inovadores, incerteza imprevisível e o processo de criação de sentido. O construto projeto inovadores é o contexto no qual o fenômeno ocorre. O construto incerteza imprevisível é o fenômeno a ser explorado, descrito e explicado. O construto criação de sentido é a base para a interpretação qualitativa da ocorrência do fenômeno no tempo e no espaço, representado pela relaão entre organizing (vide Ilustração 11, página 68) e sensemaking.

Para sintetizar métodos e processos que geram criação de sentido (Quadro 8), unificou-se: os processos vindos da IC (LESCA, 2003 apud JANISSEK-MUNIZ et al., 2006); o diagnóstico de incertezas, cujo objetivo é superar uma lacuna do conhecimento em áreas de negócio e identifica o melhor método utilizado para gerir a incerteza imprevisível (LOCH et al., 2008; LOCH et al., 2006) e outras que buscaram criar sentido aos sinais precoces (NIKANDER, 2008; NIKANDER, ELORANTA, 2001), mesmo que o foco tenha sido identificar problemas antecipadamente. Os processos identificados estão enumerados na Ilustração 14. São eles: 
1) início pode ser pela busca de superação de uma lacuna de conhecimento, de maneira proativa, ou pela observação de um sinal, reativa;

2) definição do alvo implica definir área, atores pertinentes, informações, fontes e métodos de coleta;

3) coleta - execução das técnicas e métodos estabelecidos identificados antes ou durante o processo. Esse processo está representado pelo relacionamento entre a mudança ecológica e o enactment. O sinal será percebido e o indivíduo ou o grupo tentará enquadrá-lo num fluxo conhecido ou criará um novo, gerando alternativas;

4) seleção de informações - pode ser individual ou coletiva, com a interpretação, aceitação, avaliação e rejeição do sinal e das alternativas, representado pelo processo com o mesmo nome no Organizing;

5) repasse de informações - organiza a circulação de informação por fluxos internos ou estoque;

6) memória - base de conhecimento com o registro dos significados encontrados;

7) criação coletiva de sentido - transforma o conhecimento adquirido em informações para a tomada de decisão;

8) difusão - a transmissão da informação para as devidas áreas para, inclusive, a tomada de decisão;

9) animação - responsável por motivar as pessoas a acessarem as informações, participarem do processo, ou mesmo entenderem o significado dado às mudanças, que, em projetos, percebeu-se que ser a função do gestor do projeto.

As atividades identificadas foram: escolher método de obtenção de informações, pesquisar, sondar, explorar, interagir, entrevistar, usar banco de dados, aceitar o sinal precoce, rejeitar o sinal precoce, identificar, se reunir, reagir, avaliar, interpretar, registrar, usar ferramenta, determinar o nível de conhecimento, observar, refletir, diagnosticar, decidir, convencer, rever, difundir, animar.

Apesar de Weick (1995) afirmar que o processo de criação de sentido não tem início nem fim, nesse caso há duas possibilidades de início do reconhecimento da mudança ecológica no ambiente (vide Ilustração 14, página 99). A primeira possibilidade é a busca por superar uma lacuna de conhecimento (JANISSEK-MUNIZ et al., 2006; LOCH et al., 2006; LOCH et al., 2008) que pode iniciar-se num processo amplo de escolha de um domínio de aplicação ou por 
um problema específico do projeto, porém existem poucos exemplos do uso dessa técnica. A maioria dos estudos em projetos visa à identificação e tratamento de sinais precoces de mudança relativos a erros. Assim, surge uma proposição de estudo:

Proposição de estudo I - A criação de sentido das incertezas imprevisíveis inicia-se pelos sinais do ambiente mais do que pela busca da identificação da incerteza.

Loch et al. (2006) comentam que a gestão de incertezas imprevisíveis requer cautela, pois exige experiência, flexibilidade e adaptação para os eventos inesperados, além de um grande investimento de recursos. Os fatores facilitadores foram reunidos em quatro grupos (vide Quadro 9, página 85): cultura da organização, metodologia em GP, metodologia em GR e ferramentas de GR e incertezas.

Dentro da cultura da organização, foi destacada a cultura de atenção (SCHOEMAKER, DAY, 2009; HILTUNEN, 2008; LOCH et al., 2006), apesar de que ela não foi demonstrada pelos pesquisadores. Foi evidenciada por Weick e Sutcliffe (2007) por sua importância para gerenciar o inesperado nas operações de organizações de alta confiabilidade com os princípios de preocupação com falhas, relutância a simplificar, sensibilidade às operações, compromisso com a resiliência e deferência com a expertise. A múltipla perspectiva é importante para que todas as disciplinas envolvidas no projeto tenham o seu representante na equipe do projeto.

Com relação à metodologia em GP, a diferenciação da metodologia a ser aplicada foi aqui discutida e possui uma proposição de estudo. Outro fator importante é a gestão de stakeholders, principalmente no que diz respeito a fornecedores e seus contratos. Na GR, propriamente dita, o PMI (2009) sugere várias considerações como a iteratividade, a identificação antecipada, abrangente e emergente, esta independente dos processos, além de ressaltar a necessidade do detalhamento dos riscos e dos eventos para que sejam utilizados nos próximos projetos. Com relação às ferramentas, as várias técnicas possuem um foco no presente, na situação atual ou no futuro. Assim, surge mais uma proposição de estudo.

Proposição de estudo $\mathbf{J}$ - Os fatores facilitadores advindos da cultura da organização, principalmente a cultura de atenção, mostram-se mais relevantes que os da metodologia em GP, GR e as ferramentas. 
O próximo capítulo detalhará a metodologia a ser aplicada para atender ao objetivo primário e aos secundários, verificando-se as propostas de estudo descritas neste item. 


\section{METODOLOGIA}

Neste capítulo será descrito, no primeiro item, o método empregado neste estudo para atender aos seus objetivos. No segundo item, o design do estudo será exposto por meio do detalhamento da unidade de análise, o modelo conceitual, com as respectivas variáveis e escalas de mensuração, concluindo com a ligação dessas variáveis com as proposições de estudo. O terceiro item descreverá os procedimentos operacionais adotados por intermédio da explanação sobre a estratégia de coleta de dados, do perfil das entidades que participaram da pesquisa, dos instrumentos de coleta de dados e as técnicas qualitativas e quantitativas de análise dos dados aplicadas. No quinto item serão descritos os critérios de confiabilidade, validade e limitações metodológicas deste estudo. No final, será apresentada uma síntese deste capítulo.

\subsection{Método}

Esta pesquisa possui natureza descritiva, para atender o objetivo de formular e testar analiticamente uma teoria sobre o fenômeno estudado: criação de sentido da incerteza imprevisível em projetos inovadores. Como há pouca teoria sobre o fenômeno, o estudo passou por um processo exploratório para a identificação das práticas utilizadas para a criação de sentido. O nível de antecipação da identificação e o dos impactos do evento imprevisto foram então categorizados, para permitir identificar e descrever possíveis relações entre os vários fatores e as práticas e essas categorias. O objetivo é contribuir e estender as teorias existentes, baseado na criação de uma teoria descritiva (CARLILE, CHRISTENSEN, 2005) ou substantiva (DERVIN, 2008; EINSENHARD, 1989). 


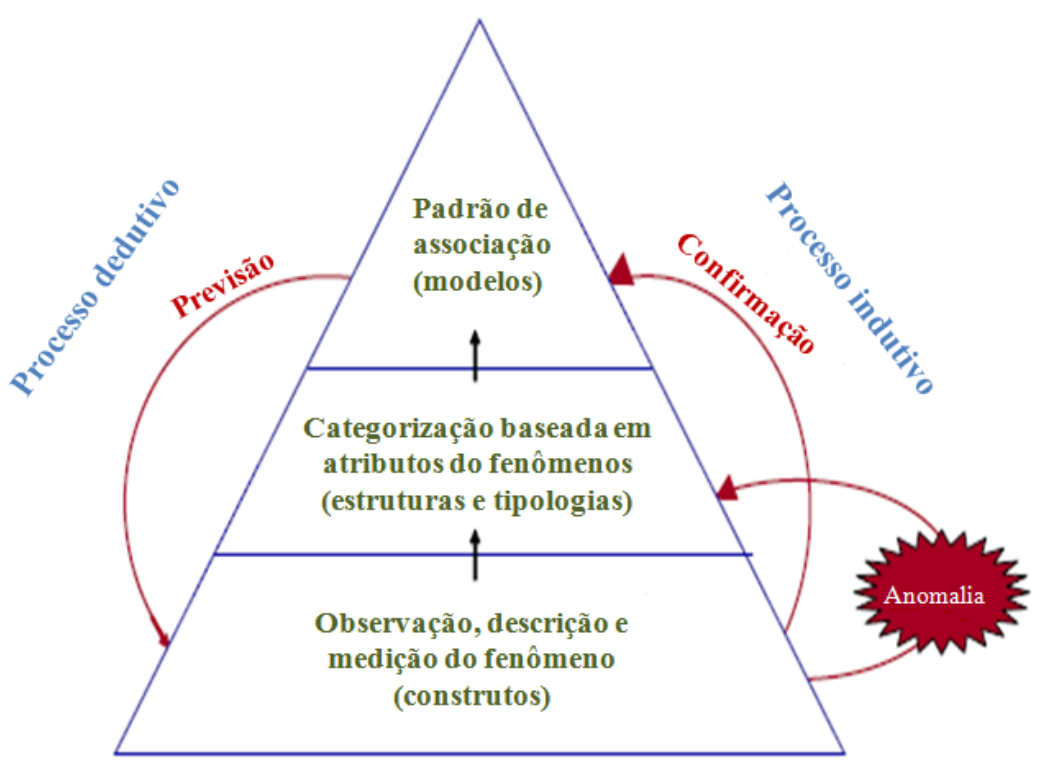

Ilustração 15 - Processo de construção de teoria Fonte: Carlile, Christensen, 2005.

Conforme a Ilustração 15, para gerar uma teoria indutivamente, os passos são: observar, descrever e medir o fenômeno, desenvolvendo construtos, que permitem conhecer profundamente o fenômeno e como ele ocorre; gerar categorias, com base nos atributos do fenômeno, definindo as estruturas e tipologias, simplificando o mundo real para que o construto possa ser medido com relação a resultados definidos e esperados; definir padrões de associação explicativos, que se tornam os modelos, com base em como as categorias foram associadas com os resultados encontrados; nesse estágio, normalmente as associações são tendências médias. Este estudo visa percorrer os dois primeiros passos, gerando a base para que o terceiro possa ser desenvolvido num estudo futuro.

Os pesquisadores usam outra base de informações; por exemplo, uma base similar de outro contexto para, dedutivamente, testar a teoria, conforme se vê no lado esquerdo da Ilustração 15, porém esse passo é ineficaz, pois não prova a teoria (CARLILE, CHRISTENSEN, 2005). O que a leva a ser provada é o encontro de anomalias, que permite aos pesquisadores buscar explicações em seus modelos ou, caso isso não ocorra, rever as estruturas e categorias para explicá-las. Assim, elas serão destacadas neste estudo, quando percebidas.

Para definir o método proposto, o construto criação de sentido (sensemaking) tornou-se o indutor. Na Teoria das Organizações (MORGAN, 1980), ele está incluso no paradigma interpretativo que vê a sociedade como um produto da experiência subjetiva e intersubjetiva 
dos indivíduos, sendo entendido pelo participante do ponto de vista de sua ação, mais do que como um observador. Portanto uma pesquisa nesse tema precisa considerar a opinião e percepção dos indivíduos em suas ações, o que torna a pesquisa qualitativa mais adequada. Creswell (2007, p. 26) chama de conhecimento socialmente construído, pois os pesquisadores criam uma teoria, em vez de começar com uma pronta.

Bomquist et al. (2010) destacam a importância de se fazer pesquisa, avaliando a prática, sugerindo o uso da praxiologia ${ }^{46}$, induzindo a conclusões operacionais. As dimensões consideradas são: práxis, as ações tomadas e situadas, que também podem ser o hábito; praticante, homem ou mulher que conduz a práxis, quem é ele e o seu contexto; as práticas, normas, rotinas, tradições e regras que guiam o comportamento do praticante, implícita ou explicitamente. Uma simples ação não tem significado sem a contextualização social na qual ela é representada. Por isso há outras camadas: histórica, social, cultural e institucional. Esta última foi a mais considerada neste estudo. Para adequar essa abordagem aos objetivos do estudo, é importante esclarecer que, apesar de eles mencionarem apenas a palavra prática, também buscam identificar a práxis, pois as ações de criação de sentido são essenciais. Além disso, foram avaliados outros envolvidos no projeto, além do gerente de projetos, conforme procedimento a ser descrito nos próximos itens.

Allard-Poesi (2005) fala do paradoxo de se tentar objetivar cientificamente a pesquisa subjetiva, pois as pessoas constroem a realidade por meio da interação e experiências do mundo, mas os pesquisadores querem separá-las e descobri-las; apesar de definirem a realidade social como fluida, precária e indeterminada e fundamentalmente tensa, tentam estabelecer regularidades, associações sistemáticas e sequenciais no processo de criação de sentido. A própria pesquisa é um processo de criação de sentido nela mesma.

\footnotetext{
${ }^{46}$ Praxiologia é a teoria epistemológica que estuda as ações humanas, o comportamento e suas leis.
} 


\subsection{Design do estudo}

\subsubsection{Unidade de análise}

A unidade de análise deste estudo consiste no projeto inovador, no sentido de conter alto nível de incerteza para a organização. A inovação pode se referir a um produto, um processo, uma mudança organizacional ou de marketing (OECD, 2005). Para identificar esses projetos, foi utilizada a seguinte tipificação:

- com relação ao produto da inovação, foi usada a tipificação de Gallouj e Weinstein (1997) que consideram as competências envolvidas, a tecnologia e as características do produto / serviço em si, inclusive se o produto foi criado especificamente para um cliente inovação radical, inovação incremental e inovação ad hoc;

- com relação ao nível da tecnologia empregada no projeto - deve ser alta, quando existe, mas é desconhecida na organização; ou muito alta, quando a tecnologia ainda não existe no início do projeto.

Shenhar e Dvir (2007) e Loch et al. (2006) definiram que os projetos altamente incertos possuem alta complexidade, característica da existência de muitos elementos interrelacionados e interdependentes que funcionam integrados para o atendimento de um objetivo. Porém, a avaliação desse critério faz parte das propostas de estudo e, portanto, foram necessários projetos com complexidade média e alta para melhor avaliação.

Em cada projeto foram avaliados pelo menos dois eventos imprevistos, unidades de análise incorporada, que materializam a incerteza imprevisível. Um dos eventos imprevistos deve ter sido identificado previamente durante o projeto e o outro não. Isso permitiu a comparação das práticas utilizadas para cada um desses eventos. 


\subsubsection{Modelo conceitual}

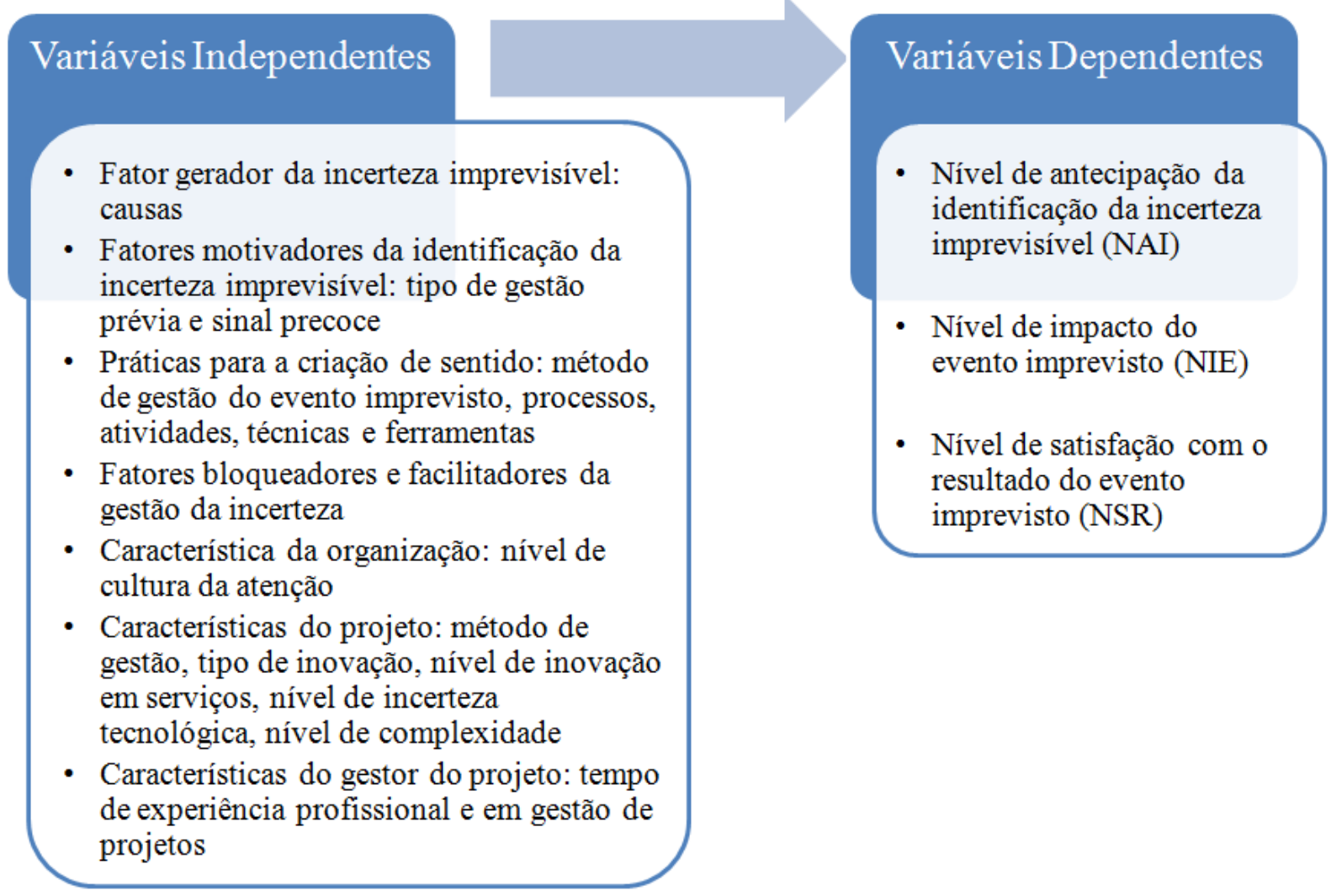

\section{Ilustração 16 - Modelo conceitual}

O modelo conceitual, representado na Ilustração 16, está baseado nos três grandes construtos: projeto inovador, incerteza imprevisível - representada pelo evento imprevisto, e criação de sentido. O construto projeto inovador é o contexto no qual o fenômeno ocorre. $\mathrm{O}$ construto incerteza imprevisível foi identificado nas variáveis independentes e nas variáveis dependentes. Finalmente, o construto criação de sentido é base para a interpretação qualitativa das variáveis dos outros construtos.

\subsubsection{Variáveis e escalas de mensuração}

Todas as variáveis estão detalhadas no Apêndice 1 - Descrição das variáveis, página 245,com informações sobre o respectivo enquadramento num construto, a escala de mensuração, as categorias possíveis e as fontes teóricas - base inicial para a geração das categorias. É preciso esclarecer que algumas delas foram usadas apenas para entender o contexto do projeto e do evento imprevisto, como as descrições do projeto, do produto, da inovação, da tecnologia empregada e justificativa da complexidade. 


\subsubsection{Variáveis dependentes}

O objetivo das variáveis dependentes é avaliar a eficiência da identificação da incerteza imprevisível. Essas variáveis, como podem ser vistas na Ilustração 16, foram compostas por: - NAI - nível de antecipação da identificação da incerteza imprevisível, sendo classificado como identificado previamente e identificado posteriormente à ocorrência do evento imprevisto;

- $\quad$ NIE - nível do impacto do evento imprevisto, que pode ter afetado negativamente os clientes, a organização e / ou o projeto e foi classificado em 'menos impacto', quando não houve impacto ou foi possível mitigá-lo, e 'mais impacto';

- $\quad$ NSR - nível de satisfação com o resultado do evento imprevisto, para o qual foi verificado o nível da satisfação do entrevistado com o resultado das práticas empregadas para a identificação e superação da incerteza imprevisível, classificado em satisfação negativa e positiva.

\subsubsection{Variáveis independentes}

As variáveis independentes, conforme pode ser visto na Ilustração 16, foram: o fator gerador da incerteza imprevisível, os fatores motivadores da identificação da incerteza imprevisível, as práticas para a criação de sentido, os fatores bloqueadores e facilitadores da gestão da incerteza e as características da organização, do projeto e do gestor do projeto.

O fator gerador da incerteza imprevisível, a causa da incerteza, foi baseado nos fatores de risco (COSO, 2004; HIGUERA, HAIMES, 1996; HM TREASURY, 2004; OGC, 2005; PMI, 2008). Esse fator foi avaliado em relação à ocorrência da causa externa, da causa organizacional e da causa com origem na GP para cada evento imprevisto. Em algumas análises, a causa organizacional e a causa com origem em GP foram consideradas causas internas.

Os fatores motivadores da identificação da incerteza imprevisível foram compostos por: - tipo de gestão prévia da incerteza imprevisível (LOCH et al., 2008), com três possibilidades - a gestão prévia por planejamento ou gestão de risco, a existência de uma busca por informação sobre a incerteza imprevisível e quando não houve gestão prévia; 
- $\quad$ sinal precoce - avaliado por meio de três características:

- tipo de sinal precoce, descritos no Quadro 7, página 78, classificados em 'com sinal precoce', quando houve a percepção de uma informação precoce ou um primeiro sintoma, e 'sem sinal precoce', quando o evento imprevisto ocorreu subitamente;

- quem percebeu o sinal precoce, categorizado em gerente de projetos, equipe e sponsor;

- momento da percepção do sinal precoce, que compreende a fase inicial do projeto e as demais fases - durante e final do projeto.

As práticas para a criação de sentido foram subdivididas em:

método de gestão do evento imprevisto, que pode ser planejamento, selecionismo e aprendizado, por improvisação ou experimentação (PICH et al., 2002; LOCH et al., 2006; LOCH et al., 2008);

- processos para a criação de sentido, definidos conforme as atividades identificadas no levantamento, baseadas no Quadro 8 - Práticas para a criação de sentido, página 81, sendo avaliados em relação à ocorrência de cada tipo de processo para cada evento imprevisto;

- atividades para a criação de sentido, identificadas no levantamento, também fundamentadas no Quadro 8, avaliadas em dois níveis:

- ocorrência de cada tipo de atividade e

- quantidade de atividades por tipo de participação, que pode ser individual, coletiva, externa e novo ciclo de criação de sentido;

- $\quad \mathrm{T} \& \mathrm{~F}$ - técnicas e ferramentas, descritas no Quadro 6, página 64, avaliadas em relação à ocorrência das técnicas de criatividade, de avaliação do presente, de revisão histórica e de apoio.

Também fazem parte das variáveis independentes os fatores bloqueadores e facilitadores da gestão da incerteza, baseados no Quadro 9 (ALBERTS, DOROFEE, 2009; HILTUNEN, 2008; KLOSS-GROTE, MOSS, 2009; LEVIT, SNYDER, 1997; LOCH et al., 2006; PMI, 2009; SCHOEMAKER, DAY, 2009), página 85. Foram avaliadas as ocorrências de cada fator em cada evento imprevisto, sendo classificados em: externos, organizacionais, oriundos da equipe, oriundos da GP e pessoais.

Há muitas características organizacionais, dos projetos e dos gestores dos projetos que poderiam afetar a gestão da incerteza, porém, para limitar o escopo deste estudo, optou-se por 
aquelas que poderiam advir diretamente do nível de incerteza do projeto e impactar no tratamento dos sinais precoces.

Com relação às características organizacionais foi avaliado apenas o nível de cultura de atenção da organização. Ela foi mensurada por intermédio do teste de Weick e Sutcliffe (2007). Esse teste possui nove afirmações (estímulos), caracterizando práticas referentes à cultura de atenção, em que os entrevistados informaram a sua reflexão sobre elas. Há três possibilidades de resposta: 1, quando a afirmação não se aplica; 2, quando a afirmação se aplica em algumas vezes; 3, quando reflete a maneira de atuar da organização. O nível é calculado com base na soma do valor das nove respostas. Se o valor calculado for maior que 17, significa que as práticas de cultura de atenção da organização são forte, o que representa um alto nível de cultura de atenção. Se o valor estiver entre 11 e 17, o nível é médio, dado que o uso das práticas é moderado. Abaixo de 11, o nível de cultura de atenção é baixo.

As variáveis relativas à característica do projeto foram:

método de gestão de projeto, que pode ser experimentação ou planejamento, que pode ser informal, macro e formal (PICH et al., 2002; LOCH et al., 2006; LOCH et al., 2008); - $\quad$ tipo de inovação do projeto, conforme padronização da OECD (2005), podendo ser produto, de marketing, processo e organizacional; para algumas análises as inovações no produto e as de marketing foram consideradas tipo de inovações externas, por afetarem diretamente os usuários e / ou os clientes da organização, enquanto as inovações de processo e organizacional foram consideradas internas, por serem mais visíveis dentro da organização;

- $\quad$ tipo de inovação em serviços, classificados em radical, incremental ou ad hoc, conforme detalhamento de Gallouj e Weinstein (1997). Com base nessa variável foi criada a variável NIS - nível de inovação em serviços, que considerou o tipo de inovação radical como 'mais inovador' e os demais como 'menos inovador';

- nível de incerteza tecnológica do projeto, possuindo quatro níveis - baixo, médio, alto, muito alto (SHENHAR, DVIR; 2007);

- $\quad$ nível de complexidade do projeto, com três níveis, baixa, média e alta (CRAWFORD et al., 2005). 
Com relação ao gestor do projeto, as variáveis avaliadas sobre suas características foram o tempo de experiência profissional e o tempo de experiência em GP. Consideraram-se apenas entrevistados gestores, portanto os gerentes de projetos e os sponsors.

\subsubsection{Proposições de estudo}

Yin (2005) cita como componentes de um projeto de pesquisa: as questões de estudo, as proposições, a unidade de análise, a lógica que une os dados às proposições e os critérios para interpretar as constatações. Mesmo não utilizando o método de estudo de caso, as proposições de estudo também foram aplicadas aqui. Essas proposições foram discutidas e numeradas na síntese da fundamentação teórica, mas, como as proposições A e F tratam da mesma variável, foram unificadas na proposição 4. As nove proposições de estudo estão descritas no Quadro 10, reorganizadas, com a indicação das variáveis utilizadas para aprofundar a questão levantada em cada uma delas e com os respectivos autores que fizeram alguma afirmação a respeito da proposição.

Quadro 10 - Ligação entre as proposições de estudo e as variáveis

\begin{tabular}{|c|c|c|c|c|}
\hline Proposições de estudo & \multicolumn{2}{|c|}{ Variáveis Independentes } & $\begin{array}{c}\text { Variáveis } \\
\text { dependentes }\end{array}$ & Autores citados \\
\hline $\begin{array}{l}\text { 1. Os fatores externos de } \\
\text { riscos geram mais incertezas } \\
\text { imprevisíveis. }\end{array}$ & \multicolumn{2}{|c|}{$\begin{array}{l}\text { Fator gerador da incerteza imprevisível } \\
\qquad \text { (causas) }\end{array}$} & $\begin{array}{l}\text { Eficiência da } \\
\text { identificação da } \\
\text { incerteza } \\
\text { imprevisível } \\
\text { (NAI e NIE) }\end{array}$ & $\begin{array}{c}\text { COSO, 2004; } \\
\text { HIGUERA, } \\
\text { HAIMES, 1996; } \\
\text { HM } \\
\text { TREASURY, } \\
\text { 2004; OGC, } \\
\text { 2005; PMI, 2008; } \\
\text { OGC, 2005 }\end{array}$ \\
\hline $\begin{array}{l}\text { 2. A criação de sentido das } \\
\text { incertezas imprevisíveis } \\
\text { inicia-se pelos sinais do } \\
\text { ambiente mais do que pela } \\
\text { busca da identificação da } \\
\text { incerteza. }\end{array}$ & \multicolumn{2}{|c|}{$\begin{array}{c}\text { Fatores motivadores da identificação da } \\
\text { incerteza imprevisível (tipo de gestão } \\
\text { prévia e sinal precoce) }\end{array}$} & $\begin{array}{c}\text { Eficiência da } \\
\text { identificação da } \\
\text { incerteza } \\
\text { imprevisível } \\
\text { (NAI e NIE) }\end{array}$ & $\begin{array}{l}\text { LOCK et al., } \\
\quad 2008\end{array}$ \\
\hline $\begin{array}{l}\text { 3. As pessoas mais } \\
\text { experientes buscam menos a } \\
\text { incerteza imprevisível. }\end{array}$ & $\begin{array}{l}\text { Tipo de gestão } \\
\text { prévia da incerteza } \\
\text { imprevisível }\end{array}$ & $\begin{array}{l}\text { Gestor do projeto } \\
\text { (experiência } \\
\text { profissional e em } \\
\text { GP) }\end{array}$ & & $\begin{array}{l}\text { WEICK, 1995; } \\
\text { WINCH, } \\
\text { MAYTORENA, } \\
2009\end{array}$ \\
\hline $\begin{array}{l}\text { 4. O método de aprendizado é } \\
\text { mais usado do que as práticas } \\
\text { estabelecidas para a criação } \\
\text { de sentido das incertezas } \\
\text { imprevisíveis. }\end{array}$ & $\begin{array}{l}\text { Práticas para a } \\
\text { criação de sentido } \\
\text { (método de gestão } \\
\text { do evento } \\
\text { imprevisto) }\end{array}$ & $\begin{array}{l}\text { Características do } \\
\text { projeto (método de } \\
\text { gestão do projeto) }\end{array}$ & $\begin{array}{c}\text { Eficiência da } \\
\text { identificação da } \\
\text { incerteza } \\
\text { imprevisível } \\
\text { (NAI e NIE) }\end{array}$ & $\begin{array}{c}\text { LOCK et al., } \\
\text { 2008; SADLER- } \\
\text { SMITH, } \\
\text { LEYBORNE, } \\
\text { 2006; RUSSO, } \\
\text { SBRAGIA, 2010 }\end{array}$ \\
\hline
\end{tabular}




\begin{tabular}{|c|c|c|c|c|}
\hline Proposições de estudo & \multicolumn{2}{|c|}{ Variáveis Independentes } & $\begin{array}{c}\text { Variáveis } \\
\text { dependentes }\end{array}$ & Autores citados \\
\hline $\begin{array}{l}\text { 5. O sentido das incertezas } \\
\text { imprevisíveis é gerado mais } \\
\text { pela criação coletiva de } \\
\text { sentido do que pela criação de } \\
\text { sentido individual. }\end{array}$ & \multicolumn{2}{|c|}{$\begin{array}{c}\text { Práticas (quantidade de atividades por } \\
\text { tipo de participação e processo de criação } \\
\text { coletiva de sentido) }\end{array}$} & $\begin{array}{l}\text { Eficiência da } \\
\text { identificação da } \\
\text { incerteza } \\
\text { imprevisível } \\
\text { (NAI e NIE) }\end{array}$ & $\begin{array}{l}\text { LOCK et al., } \\
\text { 1996; WEICK, } \\
\text { 1995; SIMON, } \\
2006\end{array}$ \\
\hline $\begin{array}{l}\text { 6. Há diferença no tratamento } \\
\text { das incertezas imprevisíveis } \\
\text { nos projetos, conforme o tipo } \\
\text { de inovação. }\end{array}$ & $\begin{array}{c}\text { Práticas para a } \\
\text { criação de sentido } \\
\text { (método de gestão } \\
\text { do evento } \\
\text { imprevisto, } \\
\text { processos, } \\
\text { atividades, técnicas e } \\
\text { ferramentas (T\&F)) } \\
\end{array}$ & $\begin{array}{l}\text { Características do } \\
\text { projeto (tipo de } \\
\text { inovação) }\end{array}$ & & \\
\hline $\begin{array}{l}\text { 7. Os projetos com mais } \\
\text { incerteza na inovação do } \\
\text { produto e menos inovação } \\
\text { tecnológica tendem a ser mais } \\
\text { eficientes na identificação da } \\
\text { incerteza imprevisível. }\end{array}$ & \multicolumn{2}{|c|}{$\begin{array}{l}\text { Características do projeto (tipo de } \\
\text { inovação, nível de inovação em serviços } \\
\text { (NIS), nível de incerteza tecnológica, } \\
\text { nível de complexidade) }\end{array}$} & $\begin{array}{l}\text { Eficiência da } \\
\text { identificação da } \\
\text { incerteza } \\
\text { imprevisível } \\
\text { (NAI e NIE) }\end{array}$ & $\begin{array}{l}\text { SHENHAR, } \\
\text { DVIR, } 2007\end{array}$ \\
\hline $\begin{array}{l}\text { 8. As técnicas e as } \\
\text { ferramentas que tentam } \\
\text { vislumbrar o futuro são mais } \\
\text { efetivas para se identificar a } \\
\text { incerteza imprevisível. }\end{array}$ & \multicolumn{2}{|c|}{$\begin{array}{l}\text { Práticas para a criação de sentido } \\
\text { (técnicas e ferramentas }(T \& F) \text { ) }\end{array}$} & $\begin{array}{c}\text { Eficiência da } \\
\text { identificação da } \\
\text { incerteza } \\
\text { imprevisível } \\
\text { (NAI e NIE) }\end{array}$ & $\begin{array}{c}\text { AIRMIC, } \\
\text { ALARM, IRM, } \\
\text { 2002; COSO, } \\
\text { 2004; ISO } \\
\text { 31010:2009; PMI, } \\
\text { 2009 } \\
\end{array}$ \\
\hline $\begin{array}{l}\text { 9. Os fatores facilitadores } \\
\text { advindos da cultura da } \\
\text { organização, principalmente a } \\
\text { cultura da atenção, mostram- } \\
\text { se mais relevantes que os da } \\
\text { metodologia em GP, GR e as } \\
\text { ferramentas. }\end{array}$ & $\begin{array}{c}\text { Fatores } \\
\text { bloqueadores e } \\
\text { facilitadores da } \\
\text { gestão da incerteza } \\
\text { (organizacionais e } \\
\text { GP) }\end{array}$ & $\begin{array}{l}\text { Característica da } \\
\text { Organização } \\
\text { (cultura da } \\
\text { atenção) }\end{array}$ & $\begin{array}{l}\text { Eficiência da } \\
\text { identificação da } \\
\text { incerteza } \\
\text { imprevisível } \\
\text { (NAI e NIE) }\end{array}$ & \begin{tabular}{|} 
HILTUNEN, \\
2008; LOCH et \\
al., 2006; PMI, \\
2009; \\
SCHOEMAKER, \\
DAY, 2009
\end{tabular} \\
\hline
\end{tabular}

\subsection{Procedimentos de campo}

Para responder aos objetivos deste estudo, a estratégia de pesquisa escolhida foi um levantamento de campo transversal, feito num dado momento no tempo (RICHARDSON, 1999, p. 148), com dados primários. Foram utilizadas questões abertas e qualitativas, com base na teoria SMM - Sensemaking Methodology. A amostra foi intencional e por conveniência (RICHARDSON, 1999, p. 160), pois os elementos relacionam-se com as características estabelecidas no plano formulado. A coleta de dados foi feita em dois passos: o primeiro consistiu num questionário eletrônico e o segundo, numa entrevista. Essa estratégia visou obter um maior número de projetos e também agilizar o processo de levantamento, permitindo que o respondente identificasse e avaliasse o projeto conforme a sua disponibilidade, além de possibilitar que o entrevistador avaliasse o enquadramento do projeto 
nos requisitos estipulados e aplicasse as questões mais relevantes na entrevista. As informações foram, então, analisadas qualitativa e quantitativamente.

\subsubsection{Estratégia de coleta de dados}

No primeiro passo da coleta de dados, utilizou-se o método de survey eletrônico (MALHOTRA, 2001, p. 185). O questionário foi disponibilizado numa página de um sítio na Internet, para que os respondentes o preenchessem. O seu preenchimento demorava em média 30 minutos. Esse método tem a desvantagem de ter o menor índice de respostas (MALHOTRA, 2001, p. 190), porém é rápido. Como os dados são armazenados em arquivos eletrônicos, com um pequeno tratamento podem ser utilizados nos softwares, diminuindo a possibilidade de erros introduzidos nas tabulações. Esse método permite, inclusive, a validação dos campos; nesse survey utilizou-se da obrigatoriedade de preenchimento na maioria dos campos. O convite para o preenchimento do questionário foi feito, por e-mail ou pessoalmente, para envolvidos com projetos inovadores e que se dispuseram a participar da pesquisa.

Com base nesse questionário, foram verificados os requisitos para a participação no segundo passo. Quando os requisitos não eram atendidos, o respondente era contatado para esclarecimentos ou mudança de projeto. Durante a coleta, avaliaram-se os casos obtidos para se obter uma população suficiente para avaliar todas as proposições de estudo:

- vários tipos de inovação;

- com alta inovação tecnológica e mais baixa inovação no produto;

- com alta inovação no produto e mais baixa na tecnologia;

- vários níveis de complexidade;

- várias causas de incerteza;

- fatores motivadores distintos;

- fatores bloqueadores e facilitadores distintos.

No segundo passo, foi feita uma entrevista presencial ou virtual. Entre o momento do preenchimento do questionário e a entrevista, houve uma demora de dias a semanas, pois essa dependia da disponibilidade do entrevistado e do entrevistador. Também, dependendo da localização e da disponibilidade do entrevistado, o entrevistador foi até o seu local de trabalho 
ou até um local público para fazer a entrevista. Na impossibilidade da reunião presencial, agendou-se uma entrevista virtual, por telefone ou por internet, por intermédio do software Skype. As entrevistas foram gravadas, por pelo menos dois dos seguintes meios digitais: $i$ phone, i-pad, celular comum, computador, add-ins do Skype. Isso foi feito para garantir a obtenção das informações e evitar a necessidade de refazer a entrevista.

O levantamento iniciou em abril de 2011, com o envio dos convites. As entrevistas iniciaram em maio e conclusas em dezembro do mesmo ano. Foram convidados 152 envolvidos com GP para participar da pesquisa. Desses, 33 mostraram-se dispostos, mas 17 projetos não atendiam aos requisitos exigidos, por isso foram desconsiderados. Houve um pré-teste antes do processo de qualificação deste estudo e três pré-testes após esse processo.

Tabela 1 - Ocorrências no levantamento

\begin{tabular}{|l|c|c|}
\hline Projetos utilizados na pesquisa & 16 & \\
\cline { 1 - 2 } Pré-teste pós-qualificação & 3 & \\
\cline { 1 - 2 } Pré-teste antes da qualificação & 1 & \multirow{2}{*}{152} \\
\cline { 1 - 2 } Projetos desconsiderados & 17 & \\
\cline { 1 - 2 } Solicitações de participação rejeitadas & 117 & \\
\hline
\end{tabular}

\subsubsection{Perfil dos entrevistados, organizações, projetos e eventos imprevistos}

Foram entrevistadas 16 pessoas, que correspondem a 16 projetos de 15 organizações diferentes. Foram solicitados na entrevista dois imprevistos para cada projeto, mas, como em alguns projetos o entrevistado reportou mais de um imprevisto, foram igualmente inclusos e contabilizados, resultando em 35 eventos imprevistos e não 30, como se planejou previamente. Os projetos e os eventos imprevistos estão descritos no Apêndice 6 - Descrição dos projetos e dos eventos imprevistos, página 268, entretanto as informações foram mascaradas para se preservar a confidencialidade dos dados.

\subsubsection{Entrevistados}

A grande maioria dos entrevistados pertence ao sexo masculino (81\%), portanto, para não ficar perceptível a diferenciação de gênero, todos os entrevistados foram referidos na forma masculina. O papel desempenhado pelos entrevistados nos projetos está refletido no Gráfico 
2. Os entrevistados, com o papel de consultor de PMO e membro da equipe, participaram praticamente durante todo o projeto e suas reflexões foram importantes para mostrar uma visão mais abrangente, assim como a relevante participação de sponsors. Todos os eventos imprevistos foram relatados por pessoas que participaram ativamente na sua gestão, assim como acompanharam o seu desfecho.

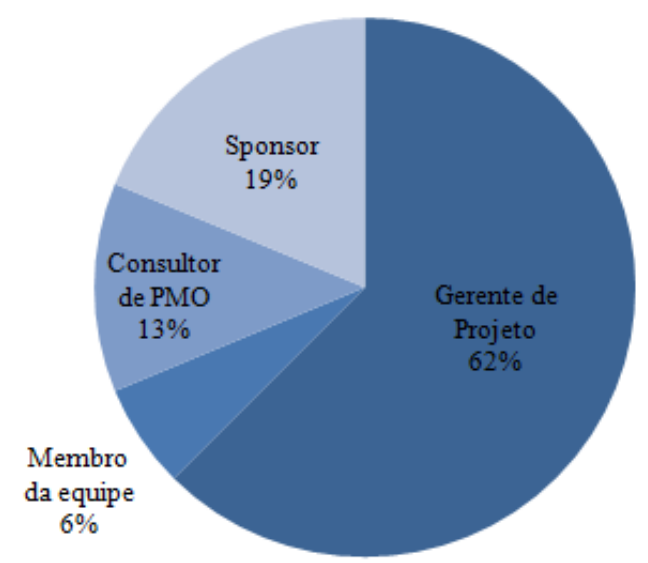

Gráfico 2 - Perfil dos entrevistados conforme o papel desempenhado no projeto

A experiência profissional e em GP dos entrevistados é relevante, conforme está demonstrado no Gráfico 3. Eles contavam com 11 a 39 anos de experiência profissional e com 7 a 39 anos de experiência em GP. A defasagem de alguns profissionais com bastante experiência profissional e menos tempo de experiência em GP deve-se à troca de área de atuação, como um administrador da área financeira, que passou a gerenciar projetos de uma organização sem fins lucrativos. 


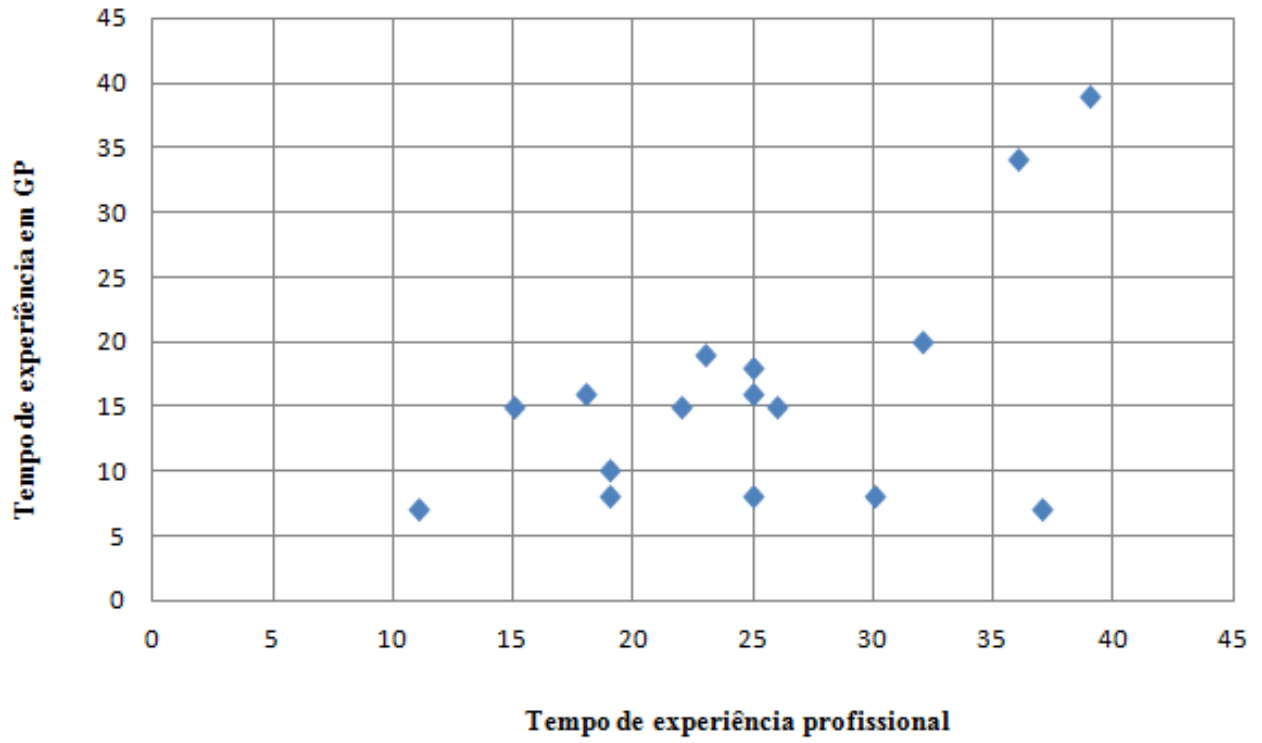

Gráfico 3 - Tempo de experiência profissional e em GP dos entrevistados

\subsubsection{Organização}

Dos 16 projetos, dois se referem à mesma organização, por isso o total são 15 . As organizações nas quais os projetos se desenvolveram foram todas da área de serviços, com exceção de um desenvolvido por uma indústria. Há predominância (75\%) de empresas nacionais e de grande porte (44\%). Para identificar-se o nível de inovação tecnológica no segmento foi usado o documento proposto pela OECD, adaptado pela Eurostat ${ }^{47}$ (HIGH_TECHNOLOGY, 2009). Conforme a OECD, doze empresas (75\%) atuam em serviços que utilizam intensivamente o conhecimento, como pode ser observado no Gráfico 4: serviços de mercado, serviços de alta tecnologia, serviços financeiros e outros serviços. Nesse gráfico, o grupo 'outros' aglutina uma organização do segmento com serviços menos intensivos em conhecimento; uma organização na qual a tecnologia utilizada no setor possui nível médio baixo de inovação tecnológica e outra que possui baixo nível de inovação. Assim, pode-se dizer que a maioria das organizações utiliza intensivamente o conhecimento.

\footnotetext{
${ }^{47}$ Statistical Office of the European Communities - Escritório estatístico da Comunidade Comum Europeia.
} 


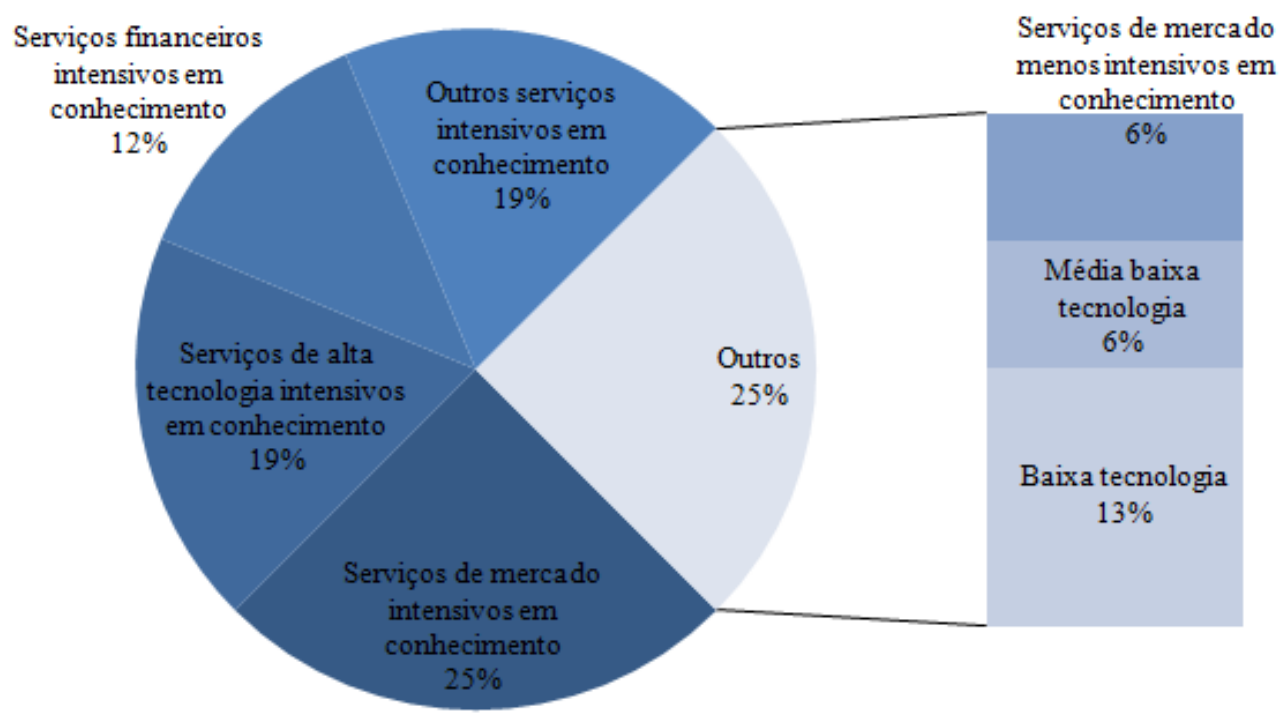

Gráfico 4 - Frequência do nível de inovação tecnológica do segmento das organizações

Há várias entidades organizacionais que trabalharam no projeto, além da organização executora, como parceiros, fornecedores e clientes. Conforme a interação do projeto, citado pelo entrevistado, pode-se identificar alguns focos de sua atuação, detalhados na Ilustração 17. Apenas dois projetos foram desenvolvidos interorganização (projeto 1 e 15), porém houve o envolvimento de outros departamentos.

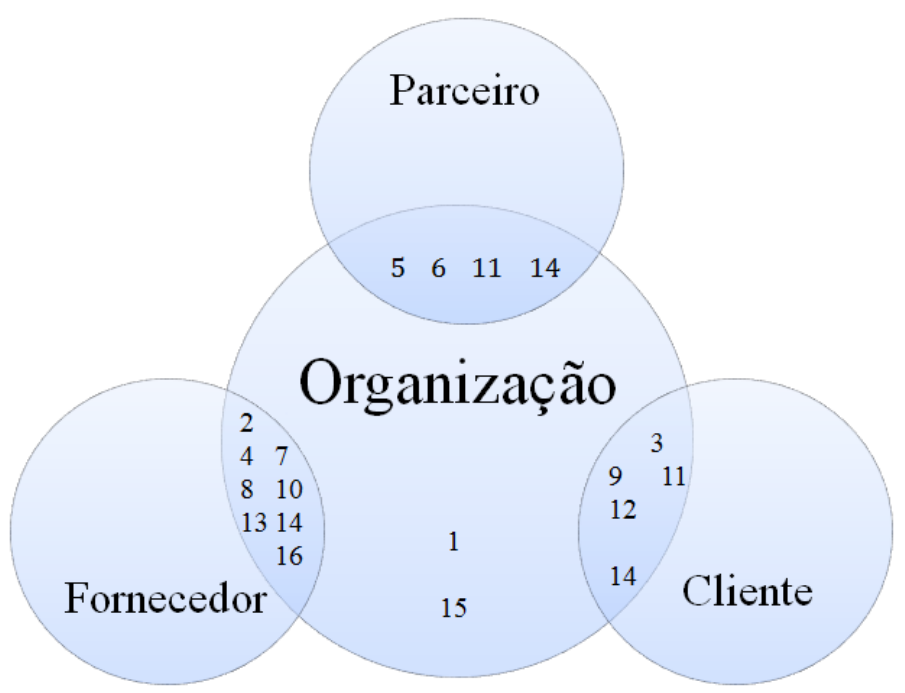

Ilustração 17 - Interação das organizações envolvidas nos projetos 


\subsubsection{Projetos}

Os projetos, que são a unidade de análise desta pesquisa, possuíam predominantemente inovação no produto ou serviço $(50 \%)$ e inovação organizacional $(31 \%)$, conforme pode ser observado no Gráfico 5. Os projetos iniciaram em 1996 (1), 2000 (1), 2006 (1), 2007 (4), 2008 (2), 2009 (5), 2010 (1) e 2011 (1). Três projetos de 2009 e um projeto de 2010 ainda não haviam terminado na data da entrevista. Apesar de alguns projetos serem antigos, os fatos foram relevantes e marcantes, com vasto detalhamento, o que permitiu a sua inclusão neste estudo.

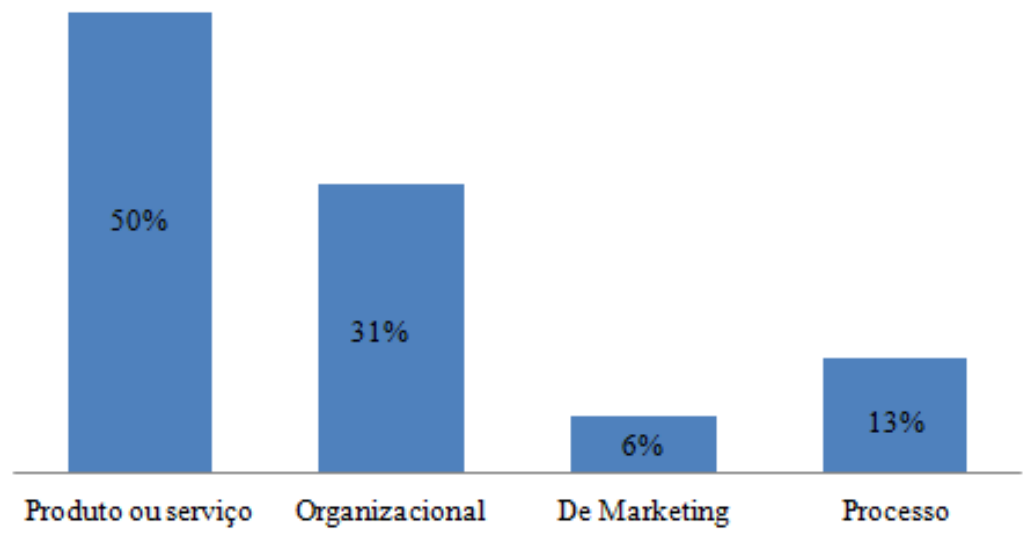

Gráfico 5 - Frequência dos tipos de inovação dos projetos

Em termos de ritmo do projeto, eles estão distribuídos praticamente igualitariamente por três tipos: rápido/competitivo, regular e tempo crítico. Mas pode-se considerar que a maioria deles, onze dos 16 projetos, sofreu uma pressão maior para terminar antes ou dentro do prazo.

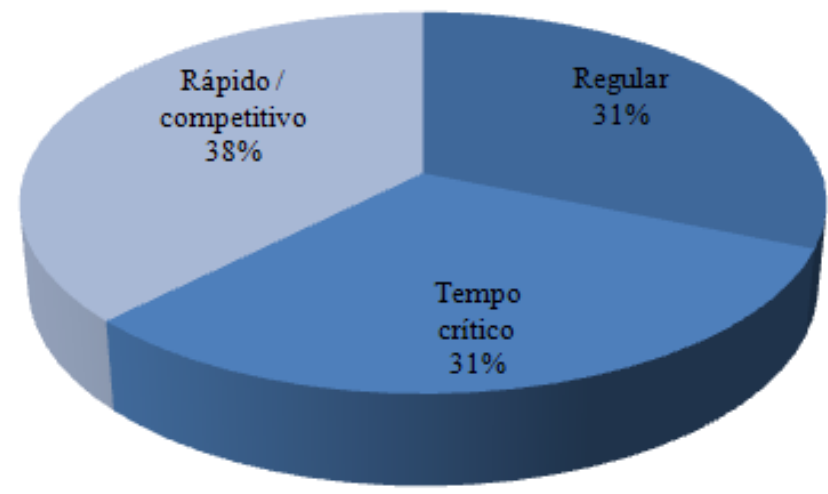

Gráfico 6 - Frequência do tipo de ritmo dos projetos 


\subsubsection{Eventos imprevistos}

No questionário aplicado nesta pesquisa, o primeiro evento informado pelo entrevistado deveria ser um imprevisto que conseguiu ser identificado antes de sua ocorrência e o segundo deveria ter sido identificado depois. Durante a entrevista, percebeu-se que, muitas vezes, o que o entrevistado considerou como previsto antecipadamente, na realidade foi identificado apenas em sua ocorrência e vice-versa. O problema foi discutido com o entrevistado e atingiuse um consenso. Apesar disso, em três projetos (número 6, 12 e 13) não foi possível encontrar-se um evento imprevisto identificado antes de sua ocorrência, sendo inclusos os dois eventos imprevistos identificados posteriormente. Para alguns, foi possível identificar um terceiro evento, que também se mostrou relevante e, portanto, foi considerado. Assim, foram identificados 35 eventos imprevistos, dos quais 21 (60\%) foram percebidos antes da ocorrência do evento e 14 (40\%) depois da ocorrência.

Foi indagado aos entrevistados qual seria o nível de impacto provável do evento imprevisto, caso ele não tivesse sido identificado previamente. Como, em alguns casos, o evento imprevisto impactou o projeto, o impacto foi considerado real. Conforme pode ser observado no Gráfico 7, a grande maioria dos eventos $(83 \%)$ teria ou teve um impacto alto ou muito alto impacto, realçando a importância dos eventos escolhidos.

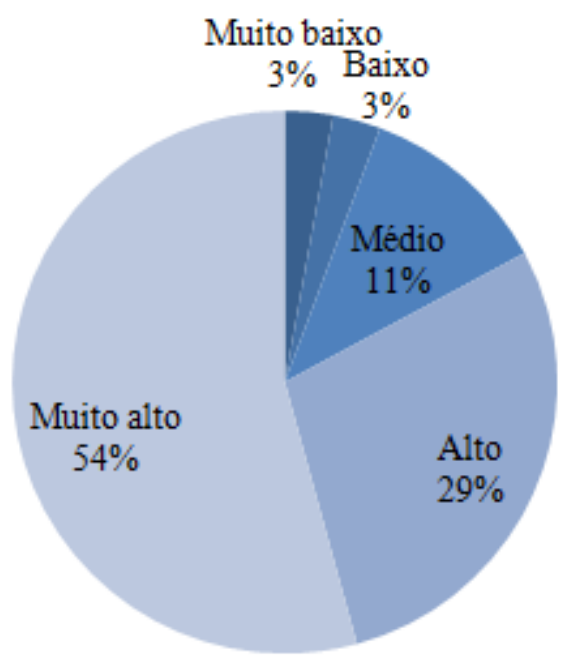

Gráfico 7 - Frequência do nível de impacto provável ou real dos eventos imprevistos

Para cada evento imprevisto, foi identificada a duração da gestão da incerteza, que reflete o tempo disponível que a equipe do projeto teve para obter conhecimento e diminuir a incerteza. A duração foi avaliada em relação ao tempo gasto desde o momento da percepção do sinal 
precoce até o momento em que o entrevistado entendeu que a incerteza tinha sido superada. Observação: a duração nem sempre é possível ser estipulada pelo gestor, pois ele deve atender as exigências do projeto e de seu contexto. O Gráfico 8 demonstra a duração da gestão da incerteza para os eventos imprevistos.

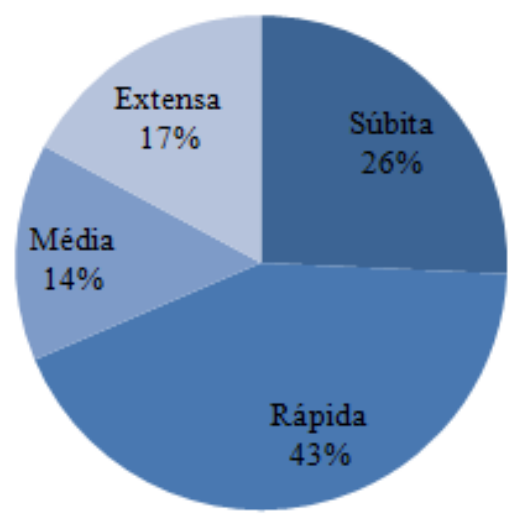

\section{Gráfico 8 - Frequência da duração da gestão da incerteza nos eventos imprevistos}

Os eventos imprevistos que ocuparam mais de $60 \%$ do tempo do projeto foram classificados como duração extensa, representando $17 \%$ dos casos; os que despenderam de 20 a $60 \%$ do tempo do projeto foram classificados como duração média, representando $14 \%$ dos eventos; os que levaram menos de $20 \%$ do tempo foram chamados de duração rápida, que representam $43 \%$ e, finalmente, os que ocorreram de maneira súbita representam $26 \%$ dos eventos imprevistos. Concluindo, a maioria (69\%) ocorreu de forma súbita ou rápida.

\subsubsection{Instrumentos de coleta de dados}

Foram utilizados dois instrumentos de coleta, conforme a estratégia: um questionário que consta no Apêndice 2 - Questionário pré-entrevista, página 247, e uma entrevista que consta no Apêndice 3 - Roteiro de Entrevista, página 254.

\subsubsection{Questionário}

A maioria das questões foi de múltipla escolha, com exemplos, para facilitar o preenchimento.

O questionário foi composto de seis partes: 
- informações gerais - informações sobre a pesquisa, requisitos para preenchimento da pesquisa e aviso sobre a confidencialidade das informações fornecidas;

- informações sobre o entrevistado - características pessoais como nome, e-mail, telefone e tempo de experiência profissional e em GP;

- informações sobre o projeto - duração, papel do entrevistado no projeto, equipe;

- informações sobre o tipo de projeto - detalhes sobre as características do projeto;

- informações sobre o evento imprevisto - informações sobre como escolher um evento imprevisto, detalhes sobre o evento imprevisto, justificativa sobre a escolha de cada evento, nível de impacto do evento imprevisto e comentários sobre os impactos reais ou prováveis;

- informações sobre a organização executora do projeto - área, segmento de atuação e práticas de gestão de projeto utilizadas e questionamento sobre a cultura de atenção;

- fechamento - agradecimentos.

\subsubsection{Entrevistas}

As entrevistas foram focadas (SELLTIZ et al., 1987b; YIN, 2005) nos fatos e na experiência subjetiva e intersubjetiva dos entrevistados para a identificação das incertezas imprevisíveis, para avaliação das práticas, assim como pela definição da situação, permitindo liberdade de expressão destes, mas com o direcionamento do entrevistador. Ela pode ser considerada semiestruturada por ter um roteiro a ser seguido (BARDIN, 2002) e durou de uma a duas horas cada uma.

Foi usada a metodologia SMM - Sensemaking Methodology, que vem sendo desenvolvida por Dervin $(1983 ; 1992 ; 1999 ; 2008)$ e seus colegas desde 1972, com o intuito de estudar informantes, quaisquer que sejam eles. Ela tem sido aplicada em estudos qualitativos e quantitativos, principalmente em gestão da informação e comunicação, como busca e uso de informação, desenho de campanha e avaliação de impacto, recepção da audiência, avaliação de opinião pública. Além das questões adaptadas da SMM, comentadas no Apêndice 4 Aplicação do método SMM nas entrevistas, foram acrescentadas outras questões específicas para complementar as informações.

O roteiro foi dividido em quatro partes: abertura, evento imprevisto identificado previamente, evento imprevisto identificado posteriormente a sua ocorrência e fechamento. A primeira 
delas era a abertura, com comentários sobre o objetivo da pesquisa, estímulos para o entrevistado responder às questões, autorização para gravação, comentários sobre o projeto e os eventos imprevistos identificados no questionário. Nesse momento, aproveitava-se para esclarecer dúvidas sobre as informações fornecidas no questionário e a escolha dos eventos imprevistos.

A segunda parte da entrevista, aplicada a cada evento imprevisto identificado previamente, possuía a seguinte composição:

- evento imprevisto - três questões para identificar o contexto, como se percebeu a incerteza imprevisível e a experiência passada do entrevistado sobre o projeto e o evento imprevisto;

- práticas para a criação de sentido - havia quatro questões para se identificar o método empregado, os processos, as atividades e as técnicas e ferramentas; identificar quem participou do processo, o momento da percepção da incerteza imprevisível, além do que representou o impacto do evento imprevisto para o entrevistado;

- resultados e fatores bloqueadores / facilitadores - três questões para identificar a satisfação com o resultado da identificação da incerteza imprevisível, os fatores que ajudaram a alcançar o resultado e os fatores que dificultaram a identificação ou a gestão da incerteza imprevisível.

$\mathrm{Na}$ terceira parte, para cada evento imprevisto não identificado previamente havia cinco questões para identificar o contexto, o que foi feito sobre o evento, o que representou o impacto do evento para o entrevistado e os fatores bloqueadores à sua identificação. A décima sexta questão identificava fatores que poderiam ter auxiliado a identificação da incerteza imprevisível. No fechamento, ficava-se à disposição para outras informações que o entrevistado quisesse fornecer e para comentários gerais, finalizando-se com os agradecimentos.

\subsubsection{Estratégia e técnicas de análise dos dados qualitativos}

Como estratégia de análise, foram seguidos os seis passos indicados por Creswell (2007, p. 195): organização, leitura, codificação, descrição de categorias, previsão da representação das informações e extração da interpretação final. Deve-se esclarecer que esses passos não foram 
sequenciais, dado que as análises de cada projeto e dos respectivos eventos imprevistos eram feitas logo após a entrevista. Houve também um processo de maturação das categorias dentro de cada variável, o que levou a um refinamento contínuo, pela reanálise dos casos já codificados. Todos os processos foram comentados num diário de acompanhamento, relatando as dificuldades, as decisões e os procedimentos adotados.

No primeiro passo, organização, foram estabelecidos os processos e os respectivos softwares a serem usados. Todas as entrevistas seriam gravadas por mais de uma mídia. A mídia mais completa e / ou com melhor nitidez seria utilizada. O formato escolhido foi o MP3; para casos que o áudio estivesse em formato diferente ou utilizasse vários arquivos, o software Audacity seria utilizado para a conversão. A transcrição foi terceirizada, o que gerou a busca por um especialista adequado e com custo reduzido. Na conferência da transcrição foi estabelecido o uso do software Express Scribe para agilizar o processo e permitir algumas marcações de tempo. A transcrição integral das entrevistas, assim como as informações obtidas no questionário seriam armazenadas no software NVivo9, pois esse software também seria utilizado para codificar e analisar os dados. As questões fechadas do questionário, que utilizou o software e provedor surveymonkey, poderiam ser incluídas no NVivo9 por meio de uma planilha Excel, porém como havia necessidade de incorporação das informações a cada entrevista, optou-se por incluí-las manualmente, por meio da geração de um arquivo PDF com todas as questões e respectivas respostas. O software Statistical Package for Social Sciences 15 for Windows (SPSS 15) foi escolhido para os tratamentos e cálculos das provas estatísticas.

O passo de leitura, feita para se obter um sentido geral do projeto, iniciou-se com a conferência da transcrição, cada entrevista gerou de 30 a 60 páginas. Nos casos em que houve dúvida sobre a compreensão de algum ponto, o entrevistado foi contatado por e-mail para saná-la. Alguns entrevistados forneceram documentos sobre o projeto, como artefatos referentes à GP, material de propaganda sobre o projeto e material sobre o tema do projeto. Também foram acessados, por iniciativa do pesquisador, sítios institucionais e artigos sobre as empresas e os projetos, para triangular as informações mais gerais sobre eles. Houve uma intensa comparação entre o informado no questionário, o obtido nas entrevistas e os dados secundários. 
No passo de codificação dos dados, privilegiaram-se as técnicas da teoria fundamentada (STRAUSS, CORBIN, 2008), como o uso de questionamento e, principalmente, análises de frases e comparações entre os eventos imprevistos. A codificação foi executada pelo registro no software NVivo9, com base em 48 variáveis identificadas no Apêndice 1 - Descrição das variáveis, página 245. Cada variável foi relacionada a pelo menos um item da entrevista ou do questionário, tendo cada variável categorias definidas a partir da fundamentação teórica. Assim, tanto para a entrevista quanto para o questionário, codificou-se as frases citadas pelos entrevistados, tentando-se utilizar as categorias identificadas. Para auxiliar a codificação, foi gerado um checklist, para facilitar a codificação inicial, assim como para perceber a perda da codificação devido a algum erro, no momento de conferência. Essa conferência foi feita por meio de relatórios formatados especificamente para isso no NVivo9. Além disso, gerou-se relatórios para comparar as categorias dos vários projetos e eventos imprevistos, para identificar semelhanças e diferenças entre as codificações.

Durante a codificação, foram feitas as seguintes melhorias na estrutura das variáveis e na estratégia de codificação:

- inovação no serviço substituiu a variável inovação do produto, pois a codificação de tipo de projetos com base em Shenhar e Dvir (2007) não englobavam todos os projetos, especificamente os de serviços, utilizando-se então a categorização de Gallouj e Weinstein (1997);

- método de gestão do projeto previsto inicialmente para ser enquadrado apenas como experimentação, planejamento e selecionismo, mostrou-se insuficiente, dado que foi percebido vários níveis de planejamento dos projetos (informal, macro e formal);

- causa da incerteza que tinha muitas categorias, porém devido ao pequeno número de eventos, foi resumida em apenas três tipos - externa, organizacional e gestão de projetos;

- tipo de gestão prévia, inicialmente, os eventos imprevistos deveriam se enquadrar em gestão prévia por busca de informação ou em não gerido previamente, porém surgiram eventos imprevistos que haviam sido objeto de certo planejamento, mas como foram impactantes, contrastando e trazendo semelhanças com eventos imprevistos de outros projetos, optou-se por incluir também esse tipo de gestão do evento imprevisto - gestão prévia por planejamento ou gestão de riscos;

- quem percebeu o sinal precoce e quando esse sinal foi percebido, variáveis incluídas posteriormente quando se percebeu que poderiam agregar valor à tipificação do sinal precoce, dado que as informações sobre elas estavam disponíveis; 
- método de gestão do evento imprevisto foi incluída a categoria procrastinação para permitir enquadrar todos os eventos imprevistos;

- processo de criação de sentido, apesar de algumas tentativas intermediárias, os tipos de processos foram gerados após a codificação de todas as atividades de todos os eventos imprevistos. Os tipos previstos inicialmente foram modificados para se adequarem melhor ao que foi obtido nas entrevistas;

- tipo de participação na atividade, foi codificado da mesma forma que o processo de criação de sentido, quando surgiu a necessidade de inclusão de novos tipos como externo e novo ciclo de criação de sentido;

- fatores bloqueadores, facilitadores e idealizados para os quais foram incluídas novas categorias - pessoais e da equipe. Os fatores pessoais, vieses e heurística, exigiram o aumento da abrangência dos vieses que constavam nas fundamentação teórica, para codificar os vieses encontrados;

- tipos de impacto, como havia informação detalhada sobre cada impacto, optou-se por codificá-los de maneira a dar mais confiabilidade a variável nível de impacto, o que gerou mais três variáveis.

Além da codificação propriamente dita, foram geradas notas de codificação que registraram ideias, interpretações e descrições de cada evento imprevisto, que pertencem ao passo de descrição das categorias. Dentro desse passo, ao final da codificação de todas as entrevistas, avaliou-se detalhadamente o enquadramento de cada citação em cada categoria, ajustando-se quando necessário para obter uma uniformidade de codificação. O detalhamento de cada categoria de cada variável será explorado no item 4.1 - Análise qualitativa e descritiva, no qual se destacará as frases dos entrevistados, de forma a justificar as codificações realizadas. Quando se notava algum fator relevante ou anomalia, uma nota teórica era registrada.

Com 75\% das entrevistas codificadas, iniciou-se a descrição da análise qualitativa na tese e avaliação das proposições de estudo, quando se optou pela apresentação dos dados de maneira comparativa por categoria e não por evento imprevisto ou por projeto. Esse passo se refere a previsão da representação da narrativa. Essa opção deve-se ao caráter sigiloso dos dados, devido ao conhecimento público de alguns projetos, que se tornaria precário, se os casos fossem expostos individualmente. A demonstração das informações foi feita por tabela e descrição, que foram montadas a partir de consultas do NVivo9, elaboradas ao longo de toda a análise. 
Para avaliar a significância das informações, optou-se por aplicar tratamento estatístico nas categorias encontradas, o que gerou sustentação para a interpretação final. Nesse momento, as notas teóricas foram revistas e avaliadas. A interpretação foi elaborada durante as análises, para responder as nove proposições de estudo, mas escrita e estruturada após o fechamento das análises. Nessa interpretação também se buscou identificar as contribuições teóricas e práticas, assim como as recomendações.

\subsubsection{Técnicas de tratamento estatístico dos dados}

Após o fechamento da análise qualitativa, os dados foram analisados primeiramente pelo autor e depois com o apoio de um profissional estatístico, para garantir a qualidade do trabalho. Neste estudo foram empregadas análises descritivas uni e bivariadas, análise relacional e análise exploratória multivariada. $\mathrm{Na}$ análise descritiva, para as variáveis do tipo nominal e ordinal, utilizaram-se estatísticas, como tabelas de frequência, gráficos de colunas, barras e de pizza. Para as variáveis com mensuração intervalar, os dados foram descritos por média, mediana, moda, desvio-padrão, coeficiente de variação, mínimo e máximo.

Os instrumentos de pesquisa podem incorrer em erros de medição, assim como desvios nas variáveis devido à amostragem, impedindo que o resultado represente $100 \%$ de acerto. Assim, estabelece-se o nível de significância (ou margem de erro) de 10\% na análise relacional, expressando que a conclusão (rejeição da hipótese) das provas estatísticas devem representar 90\% de possibilidade de estarem corretas. Esse valor é aceitável, pelo tamanho reduzido da amostra e por este ser um estudo de Ciências Sociais (SIEGEL, CASTELLAN JR, 2006, p. $30)$.

As análises entre as variáveis devem avaliar se há associação na relação entre a variável independente e a dependente. Os grupos avaliados para as variáveis dependentes foram: o NAI - prévia ou posterior à ocorrência do evento imprevisto; o NIE - menos ou mais impacto; tipo de inovação do projeto - externo ou interno à organização; o NIS - mais ou menos inovador. 
Para variáveis com mensuração nominal e ordinal, foi efetuada a prova do Qui-Quadrado $\left(\chi^{2}\right)$ ou a prova de Fisher, para testar a hipótese teórica de dois grupos diferirem em determinadas características, ou seja, sobre a frequência relativa (ou \% de coluna) de cada um dos dois grupos. Quando o percentual de células com valores esperados menores do que cinco eram maiores do que 25\%, foi necessário aplicar a prova de Fischer que não tem essa exigência, porém a tabela precisa ser quadrada: no caso, $2 \times 2$. Por isso as categorias de algumas variáveis foram ajustadas para poder atender a esse requisito, como será descrito na análise relacional.

Para variáveis com mensuração intervalar, foi efetuada a prova de Mann-Whitney, para testar a hipótese de que os valores da variável quantitativa discreta são os mesmos (estocasticamente) para os dois grupos considerados. A estatística da prova Mann-Whitney baseou-se na média de postos por grupo. Os postos foram atribuídos a todas as respostas; o posto mais alto (35) ao valor mais alto e o menor posto (1), ao mínimo dos valores. Em caso de empate de valores, foi atribuída a média dos postos. Na sequência, para cada grupo, calculou-se a média e a soma de postos.

Com relação à hipótese teórica de que o tempo de experiência, profissional e/ou em GP, do gestor do projeto, ser um fator de influência quanto ao tipo de gestão prévia da incerteza aplicado no evento imprevisto, procedeu-se à prova não-paramétrica de Kruskal-Wallis. Essa prova permite decidir se os três grupos de tipo de gestão foram semelhantes quanto ao tempo de experiência, profissional e/ou em GP. Assim como a prova Mann-Whitney, ela também é baseada na média de postos por grupo. Entretanto, quando o resultado da prova é significante, precisa-se identificar qual grupo é diferente dos outros. Para isso foi aplicada a comparação múltipla entre tratamentos, que pode ser entendida como uma complementação da KruskalWallis (SIEGEL, CASTELLAN JR, 1988, p. 242-243).

A análise multivariada, desenvolvida por meio da análise de correspondência múltipla, objetivou resumir os resultados referentes às análises relacionais entre as variáveis independentes e dependentes. Uma das características fundamentais dessa técnica é permitir representar os resultados geometricamente, como pontos de um espaço com um número reduzido de dimensões (PESTANA, GAGEIRO, 2000), como o bidimensional, usado nesta pesquisa. Esse resultado chama-se mapa perceptual, pois facilita a interpretação da informação. A posição relativa das diferentes categorias nesse espaço traduz a natureza da 
relação entre elas. Assim, categorias com distribuições semelhantes aparecem representadas por pontos próximos, indicando que essas categorias estão associadas.

\subsection{Pré-teste}

\subsubsection{Pré-teste executado antes do processo de qualificação}

O questionário e o roteiro de entrevistas passaram por um pré-teste antes da fase de qualificação deste estudo. Esse pré-teste foi realizado com um profissional com 20 anos de experiência, 10 anos em GP. Doutor em administração com especialização em GP e, portanto, além da experiência profissional, também possui profundo conhecimento acadêmico da área. $\mathrm{O}$ entrevistado era membro da equipe de um projeto de consultoria, com o objetivo de gerar uma "[...] análise estratégica de um setor industrial para identificação de oportunidades de crescimento a partir da utilização de tecnologias e produtos atuais e do desenvolvimento de novas tecnologias e produtos." A área de atuação do cliente era desconhecida pela equipe de projeto e, por isso, foi considerado um projeto inovador. $\mathrm{O}$ fato de o projeto ser um serviço foi importante no pré-teste para demonstrar alguns pontos de melhoria específicos, principalmente na classificação de projetos.

O questionário do pré-teste era composto por 16 questões divididas em cinco partes. Ele foi enviado por e-mail num texto em Word, com o tipo de informação esperada e a indicação de obrigatoriedade em alguns campos. Pelas respostas recebidas e pela discussão posterior com o entrevistado, percebeu-se a necessidade de simplificação de determinados enunciados e problemas de entendimento em outros: nomenclatura sobre a complexidade do projeto, alterada para ficar mais genérica; significado de tecnologia para um serviço de consultoria, que mostrou a necessidade de melhor exemplificação; informações sobre a empresa executora, confundida com a empresa cliente, evidenciando a necessidade de melhorar o enunciado; a dificuldade de separar as questões sobre a cultura de atenção do projeto e da organização, tendo-se optado por questionar apenas a cultura da organização.

Entre o preenchimento do questionário e a entrevista passaram-se duas semanas. A entrevista foi presencial, durando cerca de uma hora, conforme o previsto. Percebeu-se a necessidade de lembrar o entrevistado no início da entrevista sobre o projeto, foco do questionário. As 
questões elaboradas com base na metodologia SMM mostraram-se muito genéricas e, por isso, foram criadas perguntas vinculadas, para ajustar as informações fornecidas pelo entrevistado ao foco esperado, principalmente aos objetivos que se referem às práticas. Também foi percebida a necessidade de listar exemplos para cada questão para esclarecer o enunciado e / ou ajudar o entrevistado a lembrar do ocorrido. Das 16 questões utilizadas, quatro foram exclusas por causa da inclusão de perguntas vinculadas e de algumas sobreposições. Apesar de o entrevistado indicar três grandes eventos imprevistos, tratados como lacunas no começo da entrevista, ele só detalhou um deles, porém ele realmente representava o desconhecimento mais relevante. Mesmo assim, foram criados pontos de verificação no roteiro para avaliar cada um dos eventos imprevistos identificados nas próximas entrevistas.

Outro ponto importante foi a observação do tempo gasto para transcrição: seis vezes o tempo de entrevista, indicando a necessidade de ajuda profissional. Deve-se mencionar que a análise inicial desenvolvida por meio do software NVivo9 demonstrou a potencialidade de seu auxílio, porém indicou a necessidade de uma formatação prévia, para facilitar o enquadramento dos casos nas variáveis, categorias e classificações.

\subsubsection{Pré-teste executado após o processo de qualificação}

O primeiro pré-teste foi feito com um projeto simples e com baixo nível de inovação. $\mathrm{O}$ entrevistado era um gerente de projetos experiente e com profundos conhecimentos desse tipo de gestão, principalmente na área de TI - Tecnologia da Informação. Ele tem conhecimentos acadêmicos, pois era doutorando. O questionário foi respondido ainda num documento em Word e a entrevista foi virtual e gravada por add-ins do software Skype. Por causa de problemas na gravação, a transcrição não ficou boa. Por isso, foram criados procedimentos para se gravar a entrevista de várias formas, para garantir a gravação e a qualidade. Ao final, o entrevistado disse que as questões estavam muito abertas. Também se percebeu que as questões ainda usavam um jargão muito próprio da técnica SMM e, por isso, foram alteradas para ficarem mais claras, mais focadas e com uma linguagem mais próxima da linguagem do gestor de projetos. 
O segundo entrevistado era um profundo conhecedor da área de GP, professor há muito tempo nessa área, com mestrado. O projeto também era de porte pequeno, mas altamente inovador, tendo recebido reconhecimento internacional por isso. O pré-teste do questionário utilizou o sítio na internet. A entrevista foi codificada no software NVivo9 e houve uma avaliação para se saber se as questões conseguiam trazer as informações previstas, o que indicou a necessidade de algumas mudanças. Percebeu-se que a expressão 'incerteza imprevisível' estava dificultando o entendimento, pois o respondente estava mencionando riscos identificados na gestão de riscos do projeto como incertezas imprevisíveis. A expressão foi alterada para 'evento imprevisto', evitando o viés de entendimento da incerteza como probabilidade. Percebeu-se, também, que as questões sobre metodologia de gestão de projetos poderiam ficar no próprio questionário, para agilizar o processo da entrevista, permitir uma comparação da avaliação subjetiva sobre o método utilizado e corrigir o viés da ligação de GR com a gestão da incerteza imprevisível. Outra mudança necessária foi incluir no questionário a indicação do evento imprevisto, para que, na entrevista, houvesse apenas a validação das informações dadas. Algumas questões também foram simplificadas, como as questões para identificar o contexto.

A terceira entrevista foi feita com um gerente de projetos com muita experiência na área e com mestrado acadêmico. Ele relatou o projeto da criação de uma empresa com a introdução de um produto inovador para o mercado nacional. Nessa entrevista percebeu-se que algumas questões poderiam ser formuladas no questionário, como o nível de impacto do evento imprevisto, permitindo uma validação na entrevista, agilizando-a ao mesmo tempo. Essa entrevista também foi codificada no NVivo9 e percebeu-se que as questões estavam possibilitando obter as informações necessárias ao estudo, com um pequeno ajuste de algumas questões na entrevista.

\subsection{Confiabilidade, validade e limitações metodológicas}

As escolhas e opções adotadas pelo pesquisador limitam a forma, o conteúdo e o poder de contribuição de qualquer pesquisa. Algumas dessas limitações foram destacadas nos itens anteriores, como as limitações do problema e dos objetivos, comentadas no último item da introdução. Neste item, serão ressaltadas as limitações mais relevantes, com foco na confiabilidade e validade. Portanto as limitações descritas neste item envolvem: o método 
escolhido, a criação das variáveis, os casos selecionados, os instrumentos utilizados para a coleta de dados, a interpretação do entrevistado, as técnicas empregadas para análise e interpretação dos dados, tanto na fase qualitativa quanto na quantitativa, e finalmente, a perspectiva do pesquisador.

A escolha do método de levantamento qualitativo trouxe dificuldades para se obter uma quantidade elevada e proporcional de entrevistas conforme o previsto, principalmente por causa dos seguintes fatores: número restrito de projetos altamente inovadores nas organizações, pequena quantidade de pessoas dispostas a participar de uma pesquisa, tempo disponível reduzido dos profissionais para participar e excessivo tempo gasto para analisar e codificar cada entrevista.

Além disso, identificar e gerir as incertezas é um processo desestruturado, pois não tem procedimentos explícitos e predeterminados na organização. Basear-se na memória dos entrevistados para relatar o que ocorreu pode trazer problemas de falha de memória e distorção dos fatos. O ideal seria observar o projeto pessoalmente desde o seu início, acompanhar a antecipação e a ocorrência dos eventos imprevistos, porém isso consumiria muitos recursos e inviabilizaria a obtenção da quantidade de projetos e a variabilidade necessária. Ressalta-se, ainda, que a opção pelo entrevistado único limitou as respostas às percepções do entrevistado; obter mais de um entrevistado para o mesmo projeto, porém, dificultaria ainda mais obter o número previsto de projetos. Esses foram, em sua maioria, recente e / ou muito relevante para os entrevistados, assim assumiu-se a premissa de que foi capturado o que ocorreu de mais importante, mas certamente nem tudo.

Um limitante importante desta pesquisa foi a transformação do construto criação de sentido em variáveis mensuráveis, mesmo que de forma qualitativa. Não foi encontrada na literatura uma descrição que pudesse ser utilizada, além do processo de organizing (WEICK et al., 2005) e das sete propriedades da criação de sentido (WEICK, 2001). Assim, optou-se por utilizar a criação de sentido como meio de interpretação das ações, tanto pela utilização da técnica SMM nas entrevistas, quanto na verificação das propriedades da criação de sentido em cada evento imprevisto. 
Os casos selecionados, embora estivessem atendendo aos requisitos estabelecidos, não podem ser considerados representativos de uma população de projetos inovadores, tanto pelo tamanho da amostra, quanto pela diferenciação do significado e do porte da inovação de cada organização. Como foram apenas 16 projetos, a maioria de serviços, outra amostra poderia apresentar alguns resultados distintos dos aqui obtidos. Não está no escopo deste estudo generalizar o resultado para todos os projetos, dado que pelo tipo de amostragem isso não seria adequado (SELLTIZ et al., 1987a, p. 99). A generalização foi analítica (EISENHARDT, 1989; YIN, 2005), tendo a restrição aos tipos de projeto pesquisados. Logo, as conclusões se referem apenas à amostra em questão.

Com relação aos instrumentos de coleta, a principal estratégia para garantir a confiabilidade das informações consistiu em se averiguar a mesma informação entre os dois instrumentos utilizados e entre as questões formuladas. Além de o questionário ter sido discutido durante a entrevista, há na entrevista várias questões que levaram o entrevistado a ter de voltar a apresentar as práticas para a criação de sentido novamente, por exemplo. Isso também possibilitou maior validade de conteúdo (MARTINS, 2006), na medida em que se obtiveram as informações por várias questões formuladas, para atender o recorte teórico-empírico adotado. Durante as entrevistas, houve poucas mudanças nas informações e, quando isso ocorreu, foi devido a problemas de entendimento das questões formuladas.

Quanto à interpretação do entrevistado, a imposição do problema pelo roteiro de entrevistas pode ter dificultado o entrevistador de explorar determinado tópico adequadamente, apesar do emprego de vários pré-testes para validar o roteiro. Ele pode ter dificultado, também, o entrevistado de entender a estruturação do problema, pois não está numa linguagem com que ele está acostumado. Para minimizar esse problema, o entrevistador utilizou a linguagem do entrevistado, traduzindo as questões para o seu entendimento, conforme a metodologia SMM sugere, mas essa tentativa, também é limitada ao conhecimento do entrevistador. Além disso, o processo de criação de sentido é caracterizado por ser um processo social, contínuo, retrospectivo, baseado na construção de uma realidade, de um resultado plausível, mas que não apresenta começo nem fim (WEICK, 1995). Por isso, assim como ocorreu com outros autores (GERALDI et al., 2010), os entrevistados sentiram dificuldades para identificar as incertezas imprevisíveis (unknown unknowns), pelo próprio viés da retrospectiva 
(BAZERMAN, MOORE, 2009), apesar da utilização da metodologia SMM para diminuir esse viés.

$\mathrm{Na}$ análise e interpretação dos dados, como a estratégia de coleta de dados envolveu apenas a entrevista com um participante de cada projeto, não foi possível usar várias estratégias para validar as informações (CRESWELL, 2007), tais como interrogatório de pares, descrição rica e densa e auditor externo. Utilizou-se a triangulação de várias fontes apenas quando foi possível obter informações fornecidas pelo próprio entrevistado ou quando elas eram públicas, o que ocorreu em metade dos projetos. Segundo Richardson (1999), a confiabilidade interna, que é a "[...] possibilidade de outros pesquisadores fazerem as mesmas relações entre os conceitos e os dados [...]”, é uma área crítica na análise qualitativa, pela complexidade dessas relações. Para minimizar isso, a análise qualitativa demonstrará e exemplificará a composição de cada categoria de cada variável.

Outro fator que dificultou a análise específica de quem identificou o sinal precoce e o evento imprevisto foi o uso do termo "a gente" ou "nós". Esse uso foi causado muitas vezes, pela modéstia do entrevistado. Como haviam vários momentos que se perguntava sobre o evento precoce houve uma tentativa de identificar quais pessoas realmente estavam envolvidas nesse momento. Entretanto, de uma maneira geral, sempre que esses termos foram utilizados registrou-se como uma atividade coletiva ou da equipe.

A respeito das análises relacionais, algumas variáveis com três ou mais categorias tiveram de ser transformadas em duas categorias para que alguma prova estatística pudesse ser aplicada, por causa do pequeno tamanho da amostra. Esse procedimento pode ter feito com que informações importantes fossem perdidas. Além disso, no início deste estudo, as características da organização, do projeto e do gestor do projeto foram consideradas como possíveis variáveis moderadoras da relação entre as variáveis independentes e dependentes, mas, pelo pequeno número de casos obtidos na pesquisa, essa avaliação não foi possível. Elas foram avaliadas como variáveis independentes, entretanto, pois também poderiam influenciar tanto o nível de antecipação da identificação da incerteza imprevisível quanto o nível de impacto do evento imprevisto. 
Segundo Creswell (2007), “[...] a pesquisa qualitativa é fundamentalmente interpretativa [...]”; isso significa que as informações foram interpretadas à luz do conhecimento e experiência do pesquisador, portanto não é possível evitar a sua visão pessoal. O pesquisador tem o maior interesse, além da GP, pela tomada de decisão, por isso os fatores bloqueadores pessoais, baseados nos vieses e heurísticas tornaram-se bastante aprofundados, o que pode ser tanto um limitante, quanto uma contribuição.

\subsection{Síntese dos procedimentos metodológicos}

Neste capítulo, foram descritos os procedimentos metodológicos utilizados neste estudo: métodos do estudo, natureza e tipo da pesquisa, unidade de análise, modelo conceitual, procedimentos de campo e instrumentos de coleta, estratégias e técnicas de análise. As informações estão resumidas no Quadro 11. No próximo capítulo, serão apresentadas as análises qualitativas e quantitativas dos resultados do levantamento de campo, conforme a aplicação desses procedimentos.

\section{Quadro 11 - Síntese dos procedimentos metodológicos}

\begin{tabular}{|c|c|c|}
\hline & Estudo Qualitativo & Estudo Quantitativo \\
\hline Natureza da pesquisa & Exploratória & Descritiva \\
\hline Tipo de pesquisa & \multicolumn{2}{|l|}{ Levantamento de campo transversal } \\
\hline População & \multicolumn{2}{|c|}{152 projetos inovadores, com 33 responderam, 17 desconsiderados } \\
\hline Amostra & \multicolumn{2}{|c|}{$\begin{array}{l}\text { Não probabilística, intencional, selecionada por conveniência entre projetos } \\
\text { inovadores }\end{array}$} \\
\hline Tamanho da amostra & \multicolumn{2}{|l|}{16 projetos e 35 eventos imprevistos } \\
\hline Unidade de análise & \multicolumn{2}{|c|}{ Projetos inovadores, incorporação de eventos imprevistos } \\
\hline Coleta de dados & \multicolumn{2}{|c|}{ Questionário, entrevista e material auxiliar - metodologia SMM } \\
\hline Tratamento dos dados & $\begin{array}{l}\text { - Transcrição das entrevistas } \\
\text { - Leitura } \\
\text { - Organização - Nvivo } 9 \\
\text { - Codificação, análise de frases e } \\
\text { comparações entre unidades de análise } \\
\text { - Descrição de categorias - notas de } \\
\text { codificação } \\
\text { - Previsão da representação - notas } \\
\text { teóricas }\end{array}$ & $\begin{array}{l}\text { - Estabelecido margem de significância } \\
\text { de } 10 \% \\
\text { - Estatística descritiva de cada variável } \\
\text { - Provas estatísticas: } \\
\text {-- Qui-Quadrado }\left(\chi^{2}\right) \\
\text {-- Fisher } \\
\text {-- Mann-Whitney } \\
\text {-- Kruskal-Wallis } \\
\text {-- Comparação Múltipla } \\
\text { - Análise de correspondência múltipla }\end{array}$ \\
\hline
\end{tabular}




\section{ANÁLISE DOS RESULTADOS}

Neste capítulo apresentar-se-á, primeiramente, a análise qualitativa e descritiva das variáveis independentes e dependentes, a partir dos dados obtidos no levantamento. Na segunda parte, será analisada a associação entre as variáveis dependentes e independentes para atender as proposições de estudo feitas anteriormente. Ao final será apresentada uma síntese das análises, para suportar as conclusões e recomendações deste estudo.

\subsection{Análise qualitativa e descritiva}

Com base na codificação efetuada nas entrevistas, será descrita a análise qualitativa de cada categoria das variáveis dependentes e independentes, demonstradas na Ilustração 16 - Modelo conceitual, página 107. De maneira geral, todos os projetos e os eventos imprevistos serão comentados, mas para se preservar a confidencialidade dos dados. Ao final da análise qualitativa de cada variável, constará a respectiva análise descritiva.

\subsubsection{Variáveis dependentes}

Para categorizar a eficiência da identificação da incerteza imprevisível, variáveis dependentes, foram utilizadas três variáveis descritas nos próximos itens: NAI - nível de antecipação da identificação da incerteza imprevisível; NIE - nível do impacto do evento imprevisto e NSR nível de satisfação do entrevistado com o resultado do evento imprevisto.

\subsubsection{Nível de antecipação da identificação da incerteza imprevisível - NAI}

Dos 16 entrevistados, três (projetos 6, 12 e 13) não conseguiram relatar um evento imprevisto com o nível de antecipação prévio, entretanto foi possível identificar dois eventos desse nível num dos projetos (projeto 9), totalizando 14 eventos identificados previamente. Com relação aos eventos identificados após a sua ocorrência, dois entrevistados (projeto 4 e 14) conseguiram relatar um terceiro evento com esse nível de antecipação. Assim, quanto ao nível de antecipação da identificação da incerteza imprevisível, $40 \%$ dos eventos foram identificados previamente e $60 \%$, posteriormente. 


\subsubsection{Nível de impacto do evento imprevisto - NIE}

Conforme relato dos entrevistados, em apenas cinco casos (14\%) não houve impacto negativo; em 13 casos (37\%) houve impacto, mas ainda foi possível mitigá-lo, porém em 17 casos (49\%), o impacto foi total. Assim, pode-se dizer que praticamente metade dos eventos imprevistos $(51 \%)$ teve menos impacto - sem ou com o impacto mitigado - e o restante teve mais.

Conforme pode ser visto no Quadro 12, foi possível classificar os impactos informados em três tipos: negativo, positivo e provável, caso a incerteza não pudesse ser percebida a tempo. Somando todos os tipos, foram contabilizadas 102 ocorrências.

Quadro 12 - Tipo de impacto dos eventos imprevistos

\begin{tabular}{|c|c|c|c|c|c|c|c|c|c|c|c|c|c|c|c|c|c|c|c|c|c|c|c|c|c|c|c|c|c|c|c|c|c|c|c|}
\hline & & Evento imprevisto & 1 & 2 & 3 & 4 & 5 & 6 & 7 & 8 & 9 & 10 & $11 \mid 1$ & 12. & 13 . & & 15 & & 17 & 181 & & $20 \mid 21$ & 122 & 23 & $24 \mid 2$ & $25 \mid 2$ & $26 \mid 27$ & $7|28|$ & 29 & 30 & $31 \mid 3$ & & & 35 & Total \\
\hline \multirow{10}{*}{ 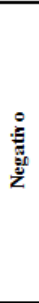 } & Cliente & Cliente & & & & $\mathrm{x}$ & & & & & & & & & & & & & & & & & & & & & & & & & & & & & 1 \\
\hline & \multirow{3}{*}{ Organização } & Financeiro & & & & & & & & & & $\mathrm{x}$ & $\mathrm{x}$ & & $\mathrm{x}$ & & & & & $\mathrm{x}$ & & & & & $\mathrm{x}$ & & & $\mathrm{x}$ & & & & & & & 6 \\
\hline & & Imagem da empresa & & & & $\mathrm{x}$ & & & & & & & & & & & & & & & & & & & & & & & & $\mathrm{x}$ & & & & & 2 \\
\hline & & Negócio & & & & & & & & & & $\mathrm{x}$ & & & $\mathrm{x}$ & & & & & & & & & & & & & & & $\mathrm{x}$ & & & & & 3 \\
\hline & \multirow{6}{*}{ Projeto } & Controle & & & & & & & & $\mathrm{x}$ & & & & & & & & & & & & & & & & & & & & & & & & $\mathrm{x}$ & 2 \\
\hline & & Custo & & $\mathrm{x}$ & & $\mathrm{x}$ & & & & & $\mathrm{x}$ & & & & & & & & \begin{tabular}{l|l}
$x$ \\
\end{tabular} & & & & & $\mathrm{x}$ & & & & & $\mathrm{x}$ & $\mathrm{x}$ & & & & & 7 \\
\hline & & Equipe & & & $\mathrm{x}$ & & $\mathrm{x}$ & & & & & & $\mathrm{x}$ & & $\mathrm{x}$ & & $\mathrm{x}$ & & & & & $\mathrm{x}$ & $\mathrm{x}$ & & & \begin{tabular}{l|l}
$\mathrm{x}$ & 2 \\
\end{tabular} & $\mathrm{x}$ & & 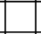 & 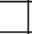 & \begin{tabular}{l|l}
$x$ \\
\end{tabular} & $\mathrm{x}$ & $\mathrm{x}$ & $\mathrm{x}$ & 13 \\
\hline & & Escopo & & & & & & $\mathrm{x}$ & $\mathrm{x}$ & & & & & & & & & & & & & & & $\mathrm{x}$ & $\mathrm{x}$ & & & & & 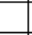 & 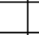 & & & 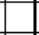 & 4 \\
\hline & & Prazo & & $\mathrm{x}$ & & & & & $\mathrm{x}$ & & & & & $\mathrm{x}$ & & & & & & & $\mathrm{x}$ & & & $\mathrm{x}$ & $\mathrm{x}$ & & $\mathrm{x}$ & & $\mathrm{x}$ & $\mathrm{x}$ & & & & $\mathrm{x}$ & 10 \\
\hline & & Qualidade & & & & & & & & & & & & & & & & & & & & & & & & & & & & & & & $\mathrm{x}$ & & 1 \\
\hline \multirow{8}{*}{ 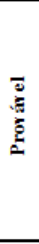 } & Cliente & Aceitação do cliente & & & & & $\mathrm{x}$ & & & & & $\mathrm{x}$ & & & & & & & & & & & & $\mathrm{x}$ & & & & & & & & & & & 3 \\
\hline & \multirow{2}{*}{ Organização } & Financeiro & & & & & & & & & & & & & & & & & & $\mathrm{x}$ & & & & & & & & & & & & & & & 1 \\
\hline & & Problema legal & & & & & & & & & & & & & & & & $\mathrm{X}$ & & & & & & & & & & & & & & & & & 1 \\
\hline & \multirow{5}{*}{ Projeto } & Custo & & & & & & & & & & & & & & & & $\mathrm{X}$ & & & & & & & & & & & & & & & & & 1 \\
\hline & & Divergência na equipe & & & & & $\mathrm{x}$ & & & & & & & & & & & & & & & & & & & & & & & & & & & & 1 \\
\hline & & Entrega do projeto & $\mathrm{x}$ & & $\mathrm{x}$ & & & & & & $\mathrm{x}$ & & & & & & & & & & & $\mathrm{x}$ & & & & $\mathrm{x}$ & & & & & & & & & 5 \\
\hline & & Escopo & & & & & $\mathrm{x}$ & & & & & & & & & & & & & & & $\mathrm{x}$ & & & & & & & & & & & & & 2 \\
\hline & & Prazo & & & & & & & & & & & & & & $\mathrm{x}$ & & & & 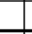 & & & & & & & \begin{tabular}{l|l}
$x$ & $x$ \\
\end{tabular} & & $\mathrm{x}$ & & $\mathrm{x}$ & $\mathrm{x}$ & $\mathrm{x}$ & & 7 \\
\hline \multirow{14}{*}{$\begin{array}{l}\stackrel{0}{\tilde{z}} \\
\stackrel{\hat{b}}{\hat{b}}\end{array}$} & \multirow{7}{*}{ Organização } & Imagem do departamento & & & & & & & & & & & & & & $\mathrm{x}$ & & & & & & & & & & & & & & & & & & & 1 \\
\hline & & Informações & & & & & & & & & & & & & & & & $\mathrm{x}$ & & $\mathrm{x}$ & & & & & & & & & 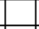 & & & & & & 2 \\
\hline & & Mostrar pontos de melhoria - & & & & & & & & $\mathrm{x}$ & $\mathrm{x}$ & & & & & & $\mathrm{x}$ & & $\mathrm{x}$ & $\mathrm{x}$ & & & & & & & $\mathrm{x}$ & & & & & & & & 6 \\
\hline & & Negócio & & & & $\mathrm{x}$ & & & & & & & & & & & & & & & & & & & & & & & & & & & & & 1 \\
\hline & & Nova competência & & & & & & & & & & $\mathrm{x}$ & & & & $\mathrm{x}$ & & & & & & & & & & & \begin{tabular}{l|l}
$x$ & $x$ \\
\end{tabular} & & & & & & & & 4 \\
\hline & & Nova parceria & & & & & & & & & & & & & & & & & & & & & & & & & $\mathrm{x}$ & & & & & & & & 1 \\
\hline & & $\begin{array}{l}\text { Retorno maior que } \\
\text { investimento }\end{array}$ & & & & & & & & & & & & & & & & & & & & $\mathrm{x}$ & & & & & & & & & & & & & 1 \\
\hline & \multirow{5}{*}{ Projeto } & $\begin{array}{l}\text { Imagem do projeto ou } \\
\text { programa }\end{array}$ & & & & & $\mathrm{x}$ & $\mathrm{x}$ & & & & & & & & & & & & & & $\mathrm{x}$ & & & & & & & & & & & & & 3 \\
\hline & & \begin{tabular}{|l|} 
Mostrar pontos de melhoria - \\
\end{tabular} & & & & & & & & & & & & & & & & & & & & & & & & & & & $\mathrm{x}$ & & & & $\mathrm{x}$ & & 2 \\
\hline & & Qualidade & & & & & & & & & & & & & & & & & & & & & & & & & & & & & & & $\mathrm{x}$ & & 1 \\
\hline & & Retração de mudanças & & & & & & & & & & & & & & & & & & & & & & & & & & & $\mathrm{x}$ & & & & & & 1 \\
\hline & & Solucionar o problema & $\mathrm{x}$ & & & & & & & & & & & & & & & & & & & $\mathrm{x}$ & & & & & $\mathrm{x}$ & & & & $\mathrm{x}$ & & & & 4 \\
\hline & \multirow{2}{*}{ Pessoal } & Imagem pessoal & & & & & & & & & & & & & & $\mathrm{x}$ & & & & & & & & & & & $\mathrm{x}$ & & & & & & & & 2 \\
\hline & & Mostrar pontos de melhoria - & & & & & & & & & & & & & $\mathrm{x}$ & & & & & 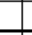 & & 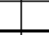 & & 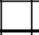 & 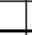 & & \begin{tabular}{l|l}
$\mathrm{x}$ & $\mathrm{x}$ \\
\end{tabular} & & 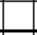 & & - & 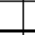 & - & $\square$ & 3 \\
\hline \multicolumn{3}{|c|}{ Total por imprevisto } & 2 & 2 & 2 & 4 & 5 & 2 & 2 & 2 & 3 & 4 & 2 & 1 & \begin{tabular}{l|l}
4 \\
\end{tabular} & \begin{tabular}{|l|}
4 \\
\end{tabular} & 2 & \begin{tabular}{|l|l|}
3 & \\
\end{tabular} & 2 & \begin{tabular}{l|l}
4 & \\
\end{tabular} & \begin{tabular}{l|l}
1 & 3 \\
\end{tabular} & \begin{tabular}{|l|l}
3 & 3 \\
\end{tabular} & 1 & \begin{tabular}{|l|l|}
4 \\
\end{tabular} & \begin{tabular}{|l|l|}
3 \\
\end{tabular} & \begin{tabular}{|l|l|}
2 \\
\end{tabular} & \begin{tabular}{l|l}
5 & 7 \\
\end{tabular} & \begin{tabular}{|l|l|}
7 & 1 \\
\end{tabular} & 5 & 4 & \begin{tabular}{|l|l|}
3 & \\
\end{tabular} & \begin{tabular}{|l|}
2 \\
\end{tabular} & \begin{tabular}{l|l}
3 & 2 \\
\end{tabular} & \begin{tabular}{|l|}
3 \\
\end{tabular} & 102 \\
\hline
\end{tabular}

No Gráfico 9, resumem-se as ocorrências dos tipos de impacto positivo e negativo dos eventos imprevistos. O impacto negativo sobre o projeto (77\%) foi o que mais ocorreu; a organização também foi impactada negativamente em 23\% dos casos; os impactos positivos também aconteceram, porém em menor proporção, entre $34 \%$ e $11 \%$, e o impacto negativo sobre o cliente foi quase inexistente $(3 \%)$. 


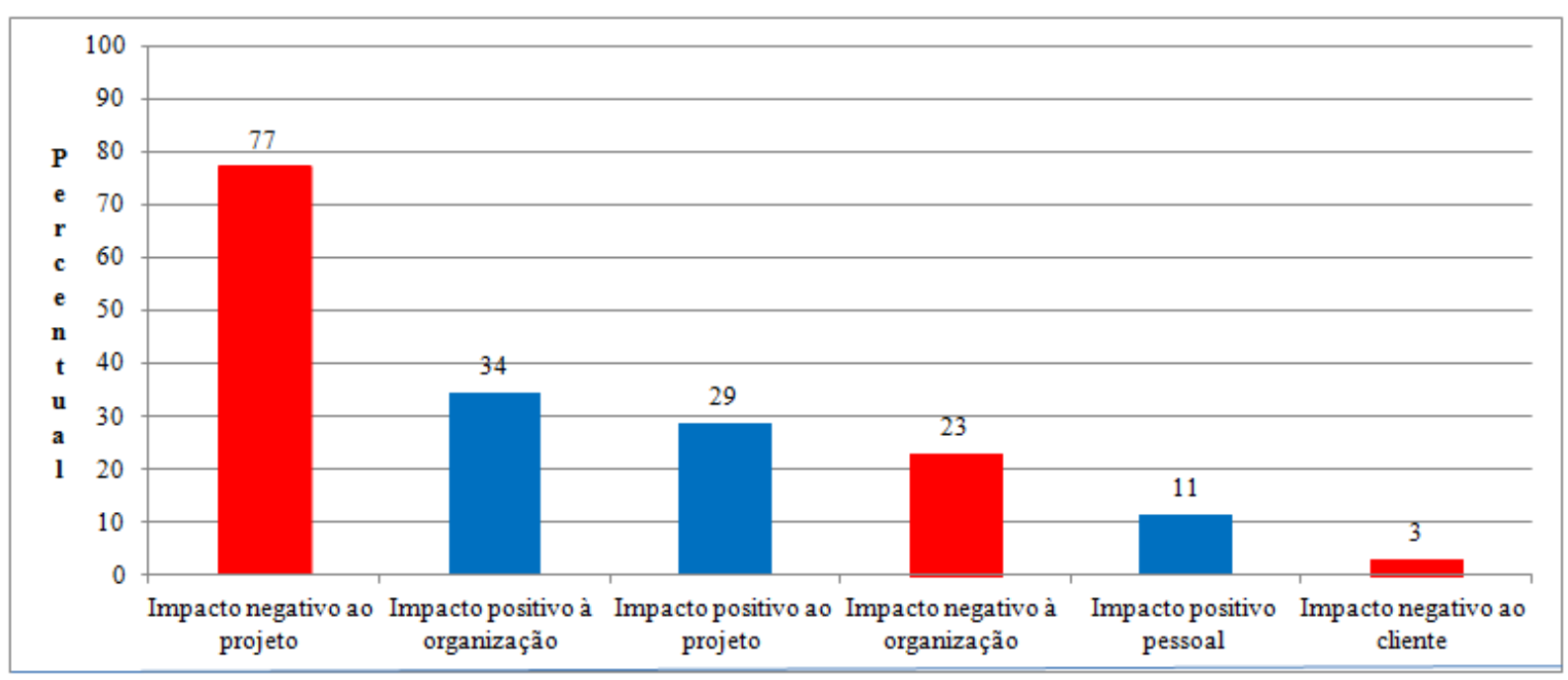

Gráfico 9 - Frequência dos impactos negativos e positivos nos eventos imprevistos

\subsection{Tipo de impacto negativo}

Houve impactos negativos em 30 eventos imprevistos (86\%), quanto ao cliente, à organização e ao projeto, como pode ser visto no Quadro 12. Quanto ao cliente, houve apenas um caso (3\%) no qual os clientes não conseguiam ser atendidos na implantação do sistema, devido à alta demanda.

Em oito casos (23\%), ocorreram impactos negativos do tipo organizacional, que podem ser classificados em:

- $\quad$ impacto financeiro ocorrido em seis casos, devido à demora em se receberem receitas do projeto; por não se receber mais pelo investimento feito no projeto, por causa do término antecipado; pelo investimento necessário para superar a incerteza num novo projeto; pela diminuição da expectativa do retorno financeiro do projeto;

- imagem da empresa impactada em dois casos, quando os clientes e os usuários do projeto perceberam a ocorrência do imprevisto;

- negócio que afetou três casos, em consequência tanto do impacto financeiro, já que a organização com menos recursos não podia fazer os investimentos previstos para alavancar novos negócios, quanto da imagem da empresa, quando novos clientes aguardavam a implantação, sempre postergada, para adquirir o novo serviço.

Porém a maior quantidade de impactos negativos refere-se ao projeto, com 27 dos eventos imprevistos $(77 \%)$, que podem ser categorizados em: 
- $\quad$ aumento do nível de controle - exigência em dois casos para que a equipe assegurasse a qualidade do projeto;

- aumento do custo - impactado em sete casos, como na necessidade de ampliar a infraestrutura; pela inclusão de novas atividades ou subprojetos; por acionamento de especialistas não previstos inicialmente; pela necessidade de geração de novos pilotos para testes; manutenção de sistemas antigos e respectiva equipe de manutenção, por postergarem a implantação do novo sistema;

- $\quad$ equipe - afetada em treze casos, tanto com a insatisfação da equipe, por não ter uma resposta a ser fornecida ao cliente, pela briga entre os sócios da empresa e por conflitos entre os integrantes da equipe, quanto com o aumento de esforço requerido para superar a incerteza, como a dura negociação para restringir ao mínimo os requisitos a serem implantados, a busca por novos interlocutores no parceiro, as noites para resolver o problema a tempo, as discussões com as várias áreas da organização do cliente, as negociações com fornecedores para atender o custo e o prazo estipulados na proposta com o cliente;

- escopo - impactado em quatro casos, como quando precisou ser alterado, pois o direcionamento do trabalho não atenderia as expectativas; quando precisou ser definido para o fornecedor, pois ele não o conhecia profundamente e quando a estratégia de lançamento da empresa teve de ser modificada;

- $\quad$ prazo - impactado em dez casos, sempre com a prorrogação do cronograma;

- $\quad$ qualidade - mencionada no caso da falta de voluntários.

\subsection{Tipo de impacto provável}

Os impactos prováveis, como podem ser observados no Quadro 12, foram identificados em 18 eventos $(51 \%)$, relacionados com os clientes, com a organização e com o projeto. O cliente foi citado em três casos (9\%), pois poderia rejeitar o produto do projeto, quando não atendessem suas expectativas ou não estivessem motivados por mecanismos de marketing adequados.

Os impactos que poderiam afetar a organização foram mencionados em dois casos (6\%). Um deles foi o impacto financeiro, pois, se não executasse a atividade de forma adequada, o retorno do investimento não seria eficiente. $\mathrm{O}$ outro foi o impacto referente a problema legal, 
pois, apesar de o projeto atender totalmente a legislação, um mal-entendido do cliente poderia acarretar, indevidamente, denúncias ao órgão regulador.

A maioria dos impactos prováveis, 15 casos (43\%), assim como nos impactos reais, foi relacionada ao projeto. Esses podem ser classificados em:

- custo - mencionado apenas no caso de que trâmites legais e a necessidade de contratação de especialistas poderiam afetar o orçamento;

- divergência na equipe - sobre a atitude perante o cliente sobre uma decisão a ser tomada pela equipe do projeto;

- entrega do projeto - poderia ser afetada em cinco casos, inclusive paralisando o projeto ou abortando o lançamento, até que o problema fosse resolvido;

- $\quad$ aumento do escopo - relatado em dois casos, com a possível necessidade de incluir requisitos e funcionalidades não previstas;

- $\quad$ prazo - o projeto poderia ser impactado em sete casos, sempre com a prorrogação do cronograma, inclusive a data final de implantação.

\subsection{Tipo de impacto positivo}

Como pode ser observado no Quadro 12, os impactos positivos foram percebidos em 21 dos 35 casos (60\%). Eles estão relacionados com a organização, o projeto ou a pessoa entrevistada. Diferentes dos tipos de impacto real e provável, os impactos positivos percebidos sobre a organização foram aqueles em maior número, doze (34\%). Foram classificados em:

- imagem do departamento ficou melhor, num caso, pois a empresa demonstrou maturidade para lidar com a questão;

- $\quad$ a superação da incerteza gerou informações, em dois casos, que não existiam antes e agora geram valor para a organização;

- pontos de melhoria organizacional foram identificados em seis casos, como a introdução de processos que reduziram custos, roteiros de implantação melhorados, melhor controle na geração de sistemas, melhor gestão dos recursos antes terceirizados, visão da importância da GR em projetos pela diretoria;

- negócio que se mostrou muito rentável, apesar dos problemas enfrentados; 
- obtenção de nova competência organizacional, mencionada em quatro casos, como a capacidade de distribuição do produto, feita pelo parceiro; a gestão de portfólio, não aplicada anteriormente; o aprendizado de várias técnicas para uma determinada atividade, por causa da incorporação de novos parceiros; a utilização inovadora de uma tecnologia no projeto, que posteriormente foi muito utilizada pela organização;

- nova parceria gerada para superar a incerteza num projeto, que acabou gerando novos projetos por causa do networking estabelecido;

- $\quad$ retorno maior do que o investimento em publicidade, gerando propaganda positiva para o projeto.

Os impactos positivos relativos ao projeto foram mencionados em dez eventos imprevistos (29\%). Podem ser classificados em:

- $\quad$ imagem do projeto ou programa - impactada em três casos: um comportamento político neutro perante o cliente terminou resolvendo o problema; pela geração de um resultado que atende a expectativas diferentes dos dois sponsors e quando obteve o apoio da sociedade para o projeto;

- $\quad$ pontos de melhoria no projeto - ocorreram em dois casos: em um deles, as equipes estão mais integradas e, no outro, a solução, que não pôde ser adotada no projeto, foi adotada em outros;

- $\quad$ qualidade na formulação do projeto, pois a solução encontrada permitiu partir de uma base inicial com informações mais robustas e completas;

- $\quad$ retração de mudanças solicitadas pelo cliente - permitiu mais estabilidade ao projeto; - $\quad$ solução do problema - segundo quatro entrevistados, conseguiram prever e solucionar o problema, com o menor impacto possível e atendendo as necessidades.

Em quatro casos (11\%), foram identificados impactos positivos em questões pessoais. A imagem pessoal foi relatada em dois casos: para um entrevistado, ele saiu fortalecido da situação e, para outro, houve o reconhecimento da importância das atividades que ele desempenhava. Em três casos, o reconhecimento de pontos de melhoria pessoal também foram relatados, como no caso em que o sponsor achava que já dominava totalmente o assunto e percebeu que isso não era verdade; no caso do gerente de projetos que percebeu que a liderança precisa ser muito mais participativa quando se trabalha com voluntários; quando se percebeu a importância de conceitos como gestão de programas. 


\subsection{Relação entre o NIE e os tipos de impacto}

A Tabela 2 foi criada para se avaliar a robustez da informação do nível de impacto do evento imprevisto, comparando-a com os tipos de impactos relatados. Para os que não tiveram impacto, realmente não há impacto negativo relatado. Além disso, percebe-se que, dos treze eventos imprevistos com impacto mitigado, nove (70\%) identificaram impactos positivos, assim como em sete dos 17 eventos (41\%) com impacto negativo também identificaram eventos positivos.

Tabela 2 - Quantidade de eventos imprevistos por NIE e os tipos de impacto

\begin{tabular}{|c|c|c|c|}
\hline \multirow{4}{*}{ NII } & $\begin{array}{c}\text { Ocorrência de } \\
\text { impacto }\end{array}$ & $\begin{array}{c}\text { Tipos de } \\
\text { impacto }\end{array}$ & $\begin{array}{c}\text { Quant. } \\
\text { eventos } \\
\text { imprevistos }\end{array}$ \\
\hline \multirow{4}{*}{$\begin{array}{c}\text { Menos } \\
\text { impacto }\end{array}$} & \multirow{3}{*}{ Sem impacto } & Negativo & $\mathbf{0}$ \\
\cline { 3 - 4 } & & Provável & $\mathbf{5}$ \\
\cline { 3 - 4 } & \multirow{2}{*}{$\begin{array}{c}\text { Com impacto } \\
\text { mitigado }\end{array}$} & Positivo & $\mathbf{5}$ \\
\cline { 3 - 4 } & & Negativo & $\mathbf{1 3}$ \\
\cline { 3 - 4 } Mais & \multirow{3}{*}{$\begin{array}{c}\text { Com impacto } \\
\text { impacto }\end{array}$} & Positivel & $\mathbf{1 3}$ \\
\cline { 3 - 4 } & & Negativo & $\mathbf{9}$ \\
\cline { 3 - 4 } & & Provável & $\mathbf{1 7}$ \\
\cline { 3 - 4 } & & Positivo & $\mathbf{7}$ \\
\hline
\end{tabular}

\subsubsection{Nível de satisfação com o resultado do evento imprevisto (NSR)}

Pode-se classificar o nível de satisfação em positivo e negativo, como se observa no Quadro 13. Em onze eventos imprevistos não foi possível obter essa informação. Constatou-se, também, que a satisfação foi vista pelo entrevistado geralmente de maneira mais global, por isso os eventos imprevistos também foram agrupados nesse quadro por projeto. Se o entrevistado indicou que a satisfação se referia ao projeto e não apenas àquele evento imprevisto, as células do projeto foram destacadas, como no caso dos imprevistos 1 e 2, nos quais a satisfação organizacional e a profissional se referem ao projeto. Para complementar a análise, o nível do impacto do evento imprevisto foi incluso. 
Quadro 13 - NSR por evento imprevisto e por projeto

\begin{tabular}{|c|c|c|c|c|c|c|c|c|c|c|c|c|c|c|c|c|c|c|c|c|c|c|c|c|c|c|c|c|c|c|c|c|c|c|c|c|c|}
\hline \multirow{2}{*}{\multicolumn{2}{|c|}{$\begin{array}{rr}\text { Projeto } \\
\text { Erento imprevisto } \\
\end{array}$}} & \multicolumn{2}{|c|}{1} & \multicolumn{2}{|c|}{2} & \multicolumn{2}{|c|}{3} & \multicolumn{3}{|c|}{4} & \multirow{2}{*}{\multicolumn{2}{|c|}{\begin{tabular}{|c|c|} 
\\
\end{tabular}}} & \multicolumn{2}{|c|}{6} & \multirow{2}{*}{\multicolumn{2}{|c|}{\begin{tabular}{|c|c|}
7 \\
14
\end{tabular}}} & \multicolumn{2}{|c|}{8} & \multicolumn{3}{|c|}{9} & \multicolumn{2}{|c|}{10} & \multicolumn{2}{|c|}{11} & \multicolumn{2}{|c|}{12} & \multicolumn{2}{|c|}{13} & \multicolumn{3}{|c|}{14} & \multicolumn{2}{|c|}{15} & \multicolumn{2}{|c|}{16} & \\
\hline & & 1 & 2 & 3 & 4 & 5 & 6 & 7 & 8 & 9 & & 11 & 12 & 13 & & 15 & 16 & 17 . & 18 & 19 & 20 & 21 & 222 & 23 & 24 & 252 & 26 & 27 & 28 & 29 & 30 & 31 & 32 & 33 & 34 & & \\
\hline \multirow{2}{*}{ Negativa } & Não satisfação organizacional & & & & & & & & & & $\mathrm{x}$ & & & & $\mathrm{x}$ & & & & & & 4 & & 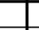 & & & 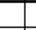 & & & & & & & 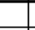 & 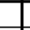 & 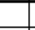 & & 2 \\
\hline & Não satisfação pessoal & & & & & $\mathrm{x}$ & & & & & & & $\mathrm{x}$ & $\mathrm{x}$ & & $\mathrm{x}$ & & & & & & $\mathrm{x}$ & & & & & & $\mathrm{x}$ & & $\mathrm{x}$ & & & & & & $\mathrm{x}$ & 8 \\
\hline \multirow{4}{*}{ Positiva } & Organizacional & $\mathrm{x}$ & & $\mathrm{x}$ & & & & & & & $\mathrm{X}$ & & & & $\mathrm{x}$ & & & & & & & & & & & & & & & & & & & & & & 4 \\
\hline & Projeto & & & & & & & & & & & & & & & & $\mathrm{x}$ & & $\mathrm{x}$ & & $\mathrm{x}$ & $\mathrm{x}$ & & $\mathrm{x}$ & & $\mathrm{x}$ & & & & $\mathrm{x}$ & & & & & $\mathrm{x}$ & & 8 \\
\hline & Profissional & $\mathrm{x}$ & & $\mathrm{x}$ & $\mathrm{x}$ & $\mathrm{x}$ & $\mathrm{x}$ & $\mathrm{x}$ & $\mathbf{x}$ & $\mathrm{x}$ & & & & & & & & & & & & & & & & & & $\mathrm{x}$ & & & & & & & & & 9 \\
\hline & Pessoal & $\mathrm{x}$ & & $\mathrm{x}$ & & & $\mathrm{x}$ & & $\mathbf{x}$ & & & & $\mathrm{x}$ & & & & & & & & 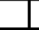 & & & & & 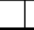 & & 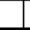 & & 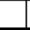 & 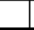 & & $\mathrm{x}$ & & 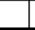 & $\mathrm{x}$ & 7 \\
\hline \multicolumn{2}{|r|}{ Total por imprevisto } & 3 & 0 & 3 & 1 & 2 & 2 & 1 & 2 & 1 & 2 & \begin{tabular}{|l|}
0 \\
\end{tabular} & 2 & 1 & 2 & 1 & 1 & 0 & 1 & 0 & 1 & 2 & 0 & 1 & 0 & 1 & 0 & 2 & 0 & 2 & 0 & 0 & 1 & 0 & 1 & 2 & 38 \\
\hline & $\mathrm{NIF}$ & - & + & - & + & - & + & + & + & - & - & + & + & + & - & + & - & + & \begin{tabular}{|l}
- \\
\end{tabular} & + & - & - & + & - & + & - & - & - & + & - & + & - & - & + & - & + & \\
\hline
\end{tabular}

A satisfação negativa ocorreu em dez eventos imprevistos (29\%) e advém de:

- não satisfação organizacional - mencionada em dois casos, quando o resultado financeiro do projeto não foi satisfatório e quando houve a identificação da falta de padronização da GP no departamento;

- não satisfação pessoal - relacionada com oito casos: no primeiro, a falta de um discurso único da equipe para a procrastinação de uma decisão gerava muita pressão e desgaste; no segundo e terceiro casos, o sponsor saiu da sociedade, perdendo o investimento feito; no quarto, a utilização de mais análise e da GR não atendeu as expectativas de se evitarem problemas do tipo do evento; no quinto, o entrevistado demonstrou a frustração de não ter evitado o imprevisto; no sexto, o entrevistado ficou "[...] mais ou menos [...]" satisfeito, provavelmente porque o projeto não atendeu aos respectivos objetivos; no sétimo, a integração com o cliente poderia ter sido feita ainda no momento da proposta, o que evitaria alguns problemas; no último, o entrevistado ficou muito frustrado com o nível de trabalho do fornecedor.

Os entrevistados relataram satisfação positiva em 22 eventos imprevistos (63\%) e em todos os projetos, podendo ela ser classificada em:

- satisfação organizacional - mencionada em quatro casos, quando o resultado financeiro do projeto foi satisfatório; houve aprendizado organizacional, inclusive para funcionários que vieram do exterior; o projeto gerou um ativo para a empresa, para o qual foi aplicado o conhecimento e a liderança da área; pelo resultado apresentado, com o envolvimento de várias áreas, e pela adoção da gestão de portfólio;

- satisfação com projeto - esteve presente em oito casos, como quando gerou conhecimento e práticas para lidar com o problema; a antecipação do problema gerou eficiência no processo operacional, antes mesmo da implantação do novo sistema; a avaliação dos stakeholders gerou estabilização para o programa; a antecipação permitiu a solução do 
problema a tempo; os resultados do projeto estavam satisfatórios, dado que o projeto não havia terminado; o resultado do projeto foi muito satisfatório e a superação dos problemas com a ajuda do cliente também ajudou; o entrevistado ficou satisfeito com a retração de demandas de alteração, pois gerou estabilidade ao projeto; a solução encontrada acabou alavancando o início do projeto;

- $\quad$ satisfação profissional - comentada em nove casos, com o projeto como um diferencial na carreira; o gerente de projetos que conseguiu trabalhos de consultoria decorrentes do projeto objeto da pesquisa; o projeto atenderia com folga a previsão inicial, que se tornou insuficiente devido à demanda irreal; o resultado atendeu as expectativas e o cliente ficou satisfeito; a integração com o cliente foi muito boa; o entrevistado percebeu que o seu trabalho agregou valor à empresa e, no último caso, o entrevistado ficou satisfeito em perceber que os processos estabelecidos funcionaram, apesar dos imprevistos;

- $\quad$ satisfação pessoal - ocorreu em sete casos, como relatado pelo entrevistado que teve prazer em gerar o projeto; outro comentou que foi uma loucura divertida; o terceiro, que foi muito interessante; o quarto, que houve um aprendizado pessoal em lidar com pessoas e áreas diferentes; o quinto, que o projeto provou que o produto idealizado por ele era factível; o sexto comentou que foi a realização do desejo de gerar um projeto com planejamento bem feito; o sexto também teve um aprendizado intenso no período e no último, o entrevistado pôde pôr em prática a sua dissertação de mestrado.

É interessante notar que foram relatados mais casos de satisfação positiva do que negativa, apesar de a maior parte dos eventos (18 de 25) terem mais impacto. Se relacionarmos o NIE com o nível de satisfação, demonstrados no Quadro 13, pode-se perceber que, dos 18 imprevistos com menos impacto, a maioria, 16, há pelo menos uma satisfação positiva, entretanto em seis há uma satisfação negativa. Dos 17 eventos com mais impacto, em quatro houve uma relação com a satisfação negativa e em seis, com a positiva; três foram relacionados com a satisfação profissional e quatro com a satisfação pessoal do entrevistado. Por conseguinte, pode-se dizer que, mesmo havendo mais impacto, alguns entrevistados obtiveram alguma satisfação com o processo. 


\subsubsection{Variáveis independentes}

Esse grupo de variáveis é composto pelo fator gerador da incerteza imprevisível, por fatores motivadores de sua identificação, pelas práticas para a criação de sentido, pelos fatores bloqueadores e facilitadores da gestão da incerteza e das características da organização, do projeto e do entrevistado.

\subsubsection{Fator gerador da incerteza imprevisível: causas}

Como pode ser observado no Quadro 14, identificaram-se nas entrevistas efetuadas três tipos de causas de incerteza imprevisível, que geraram os eventos imprevistos: externas à organização, internas à organização e originadas na GP. Numa pequena parcela dos eventos imprevistos (20\%), houve mais de uma causa para sua existência, totalizando 41 causas para os 35 eventos imprevistos.

Quadro 14 - Tipos de causa da incerteza imprevisível por evento imprevisto

\begin{tabular}{|c|c|c|c|c|c|c|c|c|c|c|c|c|c|c|c|c|c|c|c|c|c|c|c|c|c|c|c|c|c|c|c|c|c|c|c|c|c|}
\hline & Evento imprevisto & 1 & 2 & 3 & 4 & 5 & 6 & 7 & 8 & 9 & 10 & 11 & 12 & 13 & 14 & 15 & 16 & 17 & 18 & 19 & 20 & 21 & 22 & 23 & 24 & 25 & 26 & 27 & 28 & 29 & 30 & 31 & 32 & 33 & 34 & 35 & Total \\
\hline \multirow{4}{*}{ Externo } & Cliente & & & & $\mathrm{x}$ & $\mathrm{x}$ & $\mathrm{x}$ & & & & & & & & & & & & & & $\mathrm{x}$ & & & $\mathrm{x}$ & & $\mathrm{x}$ & $\mathrm{x}$ & & & & & & & & & & 7 \\
\hline & Meio ambiente & & & & & & & & & & & & & & & & & & $\mathrm{x}$ & & & & & & & & & $\mathrm{x}$ & $\mathrm{x}$ & & & & & & & & 3 \\
\hline & Mercado & & & & & & & & & & $\mathrm{x}$ & & & $\mathrm{x}$ & & & $\mathrm{x}$ & & & & & & & & & & & & & & & & & & & & 3 \\
\hline & $\begin{array}{l}\text { Parceiro ou } \\
\text { Fornecedor }\end{array}$ & & & & & & & $\mathrm{x}$ & $\mathrm{x}$ & & $\mathrm{x}$ & $\mathrm{x}$ & $\mathrm{x}$ & & & & & $\mathrm{x}$ & & & & & $\mathrm{x}$ & & $\mathrm{x}$ & & & & & & $\mathrm{x}$ & $\mathrm{x}$ & & & & $\mathrm{x}$ & 11 \\
\hline \multirow{2}{*}{$\begin{array}{l}\text { Organi- } \\
\text { zação }\end{array}$} & Falta de estrutura & $\mathrm{x}$ & & $\mathrm{x}$ & & & & $\mathrm{x}$ & & & & & & & & & & & & & & & & & & & & & & & & & & & & & 3 \\
\hline & $\begin{array}{c}\text { Falta de integração } \\
\text { das áreas }\end{array}$ & & & & & & & & & $\mathrm{x}$ & & & & & $\mathrm{x}$ & & & & & & & & & & & & & & & $\mathrm{x}$ & & & & & $\mathrm{x}$ & & 4 \\
\hline \multirow{4}{*}{$\begin{array}{l}\text { Gestão de } \\
\text { Projetos }\end{array}$} & $\begin{array}{c}\text { Falha na } \\
\text { comunicação }\end{array}$ & & & & & $\mathrm{x}$ & & & & & & & & & & & & & & & & $\mathrm{x}$ & & & & & & & & & & & & & & & 2 \\
\hline & $\begin{array}{c}\text { Falha no } \\
\text { planejamento }\end{array}$ & & & & & & & & & & & & & & & $\mathrm{x}$ & & & & & & & & & & & & & & & & & $\mathrm{x}$ & & & & 2 \\
\hline & $\begin{array}{l}\text { Problemas na } \\
\text { Equipe }\end{array}$ & & & & & & & & & & & & & $\mathrm{x}$ & & & & & & $\mathrm{x}$ & & & & & & & $\mathrm{x}$ & & & & & & & $\mathrm{x}$ & & & 4 \\
\hline & Solução emergencial & & $\mathrm{x}$ & & $\mathrm{x}$ & & & & & & & & & & & & & & & & & & & & & & & & & & & & & & & & 2 \\
\hline \multicolumn{2}{|c|}{ Total por impreristo } & 1 & 1 & 1 & 2 & 2 & 1 & 2 & 1 & 1 & 2 & 1 & 1 & 2 & 1 & 1 & 1 & 1 & 1 & 1 & 1 & 1 & 1 & 1 & 1 & 1 & 2 & 1 & 1 & 1 & 1 & 1 & 1 & 1 & 1 & 1 & 41 \\
\hline
\end{tabular}

A causa externa à organização ocorreu na maioria dos casos, 23 (66\%). Ela pode ser classificada em:

- $\quad$ cliente - relatado em sete casos, é o tipo que explicita uma mudança social, como no caso em que o entrevistado citou que "Ninguém esperava que fosse ter aquela demanda." Apesar de o produto ser uma grande novidade aguardada pelo mercado nacional; ou quando o projeto necessitaria uma mudança cultural dos clientes, como no caso em que foi preciso conhecer a opinião dos vários stakeholders sobre os impactos do projeto e obter o seu apoio; 
- meio-ambiente - observado em três casos, como citado pelos entrevistados que a "geologia não era conhecida", "a localização era muito ruim", ou "devido a mudanças climáticas que tinham acontecido";

mercado - observado em três casos; em dois deles as necessidades econômicas geraram a incerteza, como no uso da coopetição ${ }^{48}$ que "era para blindar a ação da concorrência" e no da crise de 2008 que fez um dos maiores futuros compradores suspender a possível compra do produto; no terceiro caso, foram restrições regulatórias do produto que limitavam a amplitude do projeto;

- $\quad$ parceiro ou fornecedor - com onze casos; o maior número nessa categoria, que pode ser entendido como a inexistência de parceiro, exemplificado pelo desenvolvimento de um novo produto que "[...] tem inúmeros fabricantes de bomba no mundo [...]", mas nenhum que fabricasse o equipamento com aquelas características; informações incorretas repassadas pelo fornecedor, como na informação de que ele poderia desenvolver um novo produto ou que utilizaria determinado tempo para o desenvolvimento, porém, quando a informação foi aprofundada, mostrou-se inconsistente; liderança, como na saída do presidente da organização parceira, que gerou falta de liderança e incentivo para a parceria e falta de transparência, pois foram feitas mudanças estruturais na organização parceira, sem prévio aviso, causando impacto ao projeto.

Outra categoria identificada foi a causa organizacional, originada nas características da estrutura e de procedimentos da organização, com sete casos (20\%). Os tipos dessa categoria podem ser:

- falta de estrutura, com três casos, como a falta de disponibilidade de outras áreas, conforme relatado por um entrevistado, pois “[...] não tinha ninguém de TI [Tecnologia da Informação] para que pudesse avaliar com a gente." O usuário não tinha ainda sido contratado para definir os requisitos e, no último caso, o produto era tão novo para a organização que não havia área com a competência necessária para desenvolvê-lo;

- falta de integração das áreas, com quatro casos, como no uso de códigos distintos para o mesmo material; falta de gestão de portfólio de projetos, como relatado que "Nós não percebemos, mas nós mesmos tínhamos colocado vários projetos críticos para implantar no mesmo final de semana." No terceiro caso, duas equipes que trabalhavam para o mesmo

\footnotetext{
${ }^{48}$ Conceito que combina a cooperação para geração de um negócio entre competidores (NALEBUFF, BRANDENBURGER, 1996)
} 
projeto desconhecendo a interdependência entre elas e, no quarto caso, não havia conhecimento do departamento em que as informações necessárias para o projeto estariam disponíveis dentro da organização.

A terceira categoria, causas com origem na gestão de projetos, foi mencionada em dez eventos imprevistos (29\%) e refere-se a falhas de gestão das áreas de conhecimento ligadas a projetos. Foram observados três tipos:

- falha na comunicação - foi relatada em apenas dois casos, apesar de normalmente ser citada como uma das maiores causas de problemas em projetos; no primeiro, o entrevistado informa que aquela necessidade do cliente "[...] não era conhecida de partida, mas teve vários momentos em que isso ficou meio que nas entrelinhas[...]" e, no segundo, os clientes deveriam "[...] ter achado que estava faltando alguma coisa, mas eles não falaram nada.", porém o gerente do projeto também não os questionou sobre o assunto;

- falha no planejamento - no primeiro dos dois casos, o entrevistado relata que "é um risco que a gente devia mapear sempre em qualquer tipo de projeto", portanto deveria ter sido incluso na GR; no segundo, relatou-se que "[...] não foram exploradas devidamente as exceções do negócio deles [...]”, portanto não se avaliaram corretamente os requisitos do escopo;

- problemas na equipe - com quatro casos, como o que ocorreu no projeto que utilizavam voluntários, no qual eles "simplesmente não apareceram, não fizeram, não cumpriram com o prometido." Em outro projeto que também usava voluntários, alguns deles não puderam continuar no projeto, por causa da demora da aprovação pelo cliente; no terceiro, a discordância sobre a solução de um impacto econômico no projeto gerou a incompatibilidade de membros da equipe; no quarto, não havia especialista no mercado com as habilidades exigidas pelo projeto;

- $\quad$ solução emergencial - ocorre quando uma solução para resolver um problema gera um impacto em outra área do projeto, como no caso em que a solução para diminuir um problema com os clientes gerou uma demanda temporária e irreal ao projeto, que não pôde dar a vazão adequada.

Identificando-se as principais causas dos eventos imprevistos, percebe-se que as externas foram origem de 19 casos (54\%) e as causas internas, divididas em organizacional, com nove casos (26\%) e com origem na gestão de projetos, com sete casos (20\%). 


\subsubsection{Fatores motivadores da identificação da incerteza imprevisível}

O início da criação de sentido das incertezas pode ocorrer pela busca de informação ou pela percepção de sinais precoces. Por isso os fatores motivadores da identificação da incerteza imprevisível foram tratados em dois itens: um relativo ao tipo de gestão prévia e outro aos sinais precoces. Esse, por sua vez, foi avaliado quanto ao tipo de sinal precoce, momento da sua percepção e quem o percebeu.

\subsection{Tipo de gestão prévia da incerteza imprevisível}

Nas entrevistas verificou-se se a incerteza imprevisível havia sido gerida previamente e como. Em sete eventos imprevistos (20\%), a incerteza estava sendo gerida pelo planejamento ou GR. Esses casos poderiam ser descartados desta pesquisa, mas permaneceram para efeito de comparação com as outras categorias e, também, porque foram encontradas situações peculiares. Uma delas é o caso do projeto da geração de um novo produto que exigia um equipamento com certa capacidade técnica não usual. Na análise prévia foram identificadas inúmeras empresas, no Brasil e no exterior, que informavam em seu sítio na internet que poderiam produzir um equipamento específico, caso ele não existisse. Assim, em sua GR foi gerada uma ação contingencial para a importação desse equipamento na impossibilidade de ele ser contratado no mercado nacional. Entretanto, na busca no exterior, percebeu-se que o equipamento não existia, nem seria possível ser fabricado pelas empresas. Por conseguinte, foi necessário que ele fosse projetado e sua fabricação, liderada pela equipe.

Para efeito desta pesquisa, é importante identificar os eventos para os quais houve busca de informação para superar a incerteza imprevisível, a forma mais proativa de tratar a incerteza, conforme recomendado por Loch et al. (2008). Foram identificados cinco eventos imprevistos (14\%) desse tipo. No primeiro caso, a busca do conhecimento e do melhor parceiro para distribuir o produto do projeto foi um objetivo pensado desde o início do desenvolvimento do produto, inclusive para torná-lo mais atrativo ao mercado. No segundo caso, houve uma busca para conhecer o porte e a influência de um grupo de especialistas que não aprovava o produto do projeto, pois, conforme o entrevistado, “[...] a gente sabia que tinha, mas a gente não tinha ideia do tamanho disso." O terceiro caso ocorreu em consequência do acompanhamento de 
fatores impactantes ao projeto, por meio de fontes externas à organização, o que permitiu identificar uma variável que não era considerada em nenhum projeto similar no Brasil. O quarto caso é de um projeto com muitos stakeholders externos como cidadãos munícipes, prefeitura, ONGs: "quando ele foi lançado existiam várias dúvidas, principalmente de como ele deveria atuar, então havia uma necessidade grande de criar uma agenda positiva[...]" $\mathrm{O}$ último caso é de um projeto que precisava de informações e sistemas cuja origem não estava definida.

Desse modo, foi gerada a variável tipo de gestão prévia da incerteza imprevisível com as categorias de não gerido previamente, que representam $66 \%$ dos casos; busca de informação, com $14 \%$ dos casos e os gerido previamente por planejamento ou GR, com $20 \%$ dos casos.

O Gráfico 10 demonstra a distribuição das causas externas e das internas - organizacionais e com origem na gestão de projetos - por tipo de gestão prévia da incerteza imprevisível. Observa-se nesse gráfico que os eventos imprevistos com causa interna provavelmente têm mais possibilidades de ter uma gestão por planejamento ou de risco, enquanto a causa externa tem mais chance de não ser gerida previamente.

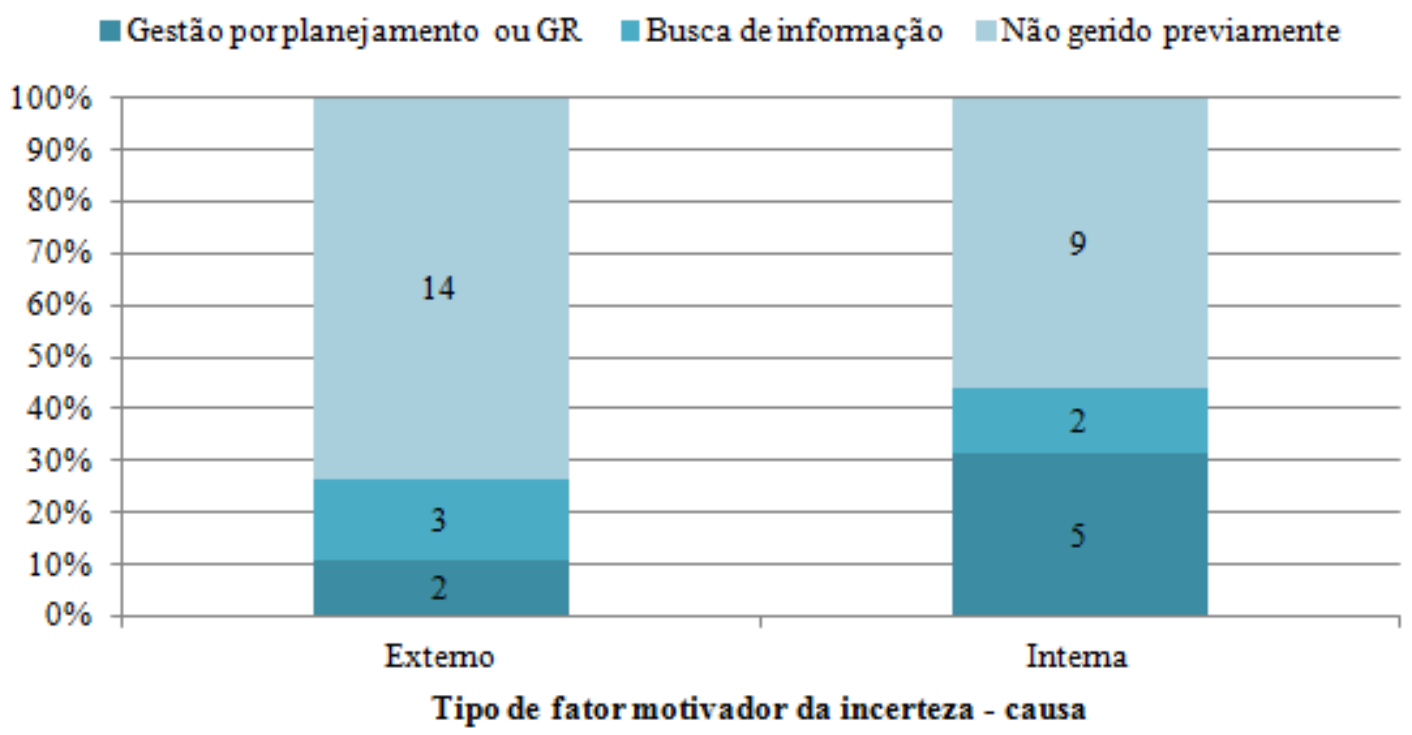

Gráfico 10 - Distribuição do tipo de causa da incerteza imprevisível por tipo de gestão prévia da incerteza imprevisível 


\subsection{Sinal precoce}

Hiltunen (2008) classifica os sinais precoces em dois tipos: informação precoce e primeiros sintomas. A informação precoce tem um número pequeno de sinais e pouca visibilidade, portanto são mais difíceis de serem percebidos, como os identificados em dez entrevistas (21\%): na comunicação entre departamentos da organização, nas informações passadas pela equipe do projeto, pela expressão do cliente, pela expressão do parceiro, por fontes externas e por gut feelings. Os primeiros sintomas apresentam sinais precoces mais fáceis de serem identificados, como os doze casos (30\%) encontrados e classificados em: controle do projeto e relatórios, expressão do cliente, expressão do usuário e trabalho dentro do projeto. Uma terceira categoria foi criada para representar um evento imprevisto não percebido antecipadamente, os súbitos. Deve-se considerar que outros sinais podem ter sido emitidos, mas não foram observados ou considerados relevantes pelos entrevistados.

O Quadro 15 apresenta as três características do sinal precoce: os tipos de sinais precoces identificados nas entrevistas, o momento na qual essa percepção ocorreu e quem o percebeu, iniciando-se, assim, a criação de sentido para a incerteza. Pode haver mais de um sinal precoce para um mesmo evento, por isso foram totalizados 42 sinais para os 35 eventos imprevistos. As células desse quadro que estão com ' $X$ ' e destacadas significam que um sinal precoce foi comentado durante a entrevista, mas não foi considerado antes de o evento ocorrer, portanto esses casos foram desconsiderados na contabilização, mas considerados relevantes para o entendimento do que pode ocorrer.

Quadro 15 - Percepção do sinal precoce, quando ocorreu e quem percebeu

\begin{tabular}{|c|c|c|c|c|c|c|c|c|c|c|c|c|c|c|c|c|c|c|c|c|c|c|c|c|c|c|c|c|}
\hline \multicolumn{3}{|c|}{$\begin{array}{r}\text { Evento impreristo } \\
\end{array}$} & 2 & 3 & 4 & 5 & \begin{tabular}{l|l}
6 & 7 \\
\end{tabular} & $8 \mid$ & \begin{tabular}{|l|l|}
9 & 10 \\
\end{tabular} & $0 \mid 11$ & \begin{tabular}{|l|l|l|}
12 & 13 \\
\end{tabular} & \begin{tabular}{l|l|}
3 & 14 \\
\end{tabular} & $15 \mid 16$ & \begin{tabular}{l|l|}
16 & 17 \\
\end{tabular} & 18 & \begin{tabular}{|l|l|}
19 & 20 \\
\end{tabular} & $20 \mid 21$ & \begin{tabular}{|l|l|l|}
22 & 2 \\
\end{tabular} & $23 \mid 2$ & $24|25|$ & \begin{tabular}{|l|l|}
26 & 27 \\
\end{tabular} & $27|28|$ & $29 \mid 30$ & $0|31|$ & \begin{tabular}{|l|l|l}
32 & 3 \\
\end{tabular} & \begin{tabular}{l|l}
33 & 34 \\
\end{tabular} & 445 & \\
\hline \multicolumn{2}{|c|}{$\begin{array}{r}\text { Momento do projeto no qual se percebeu o } \\
\text { sinal precoce }\end{array}$} & & 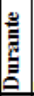 & 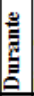 & & 竎 & 氙 & 总 & 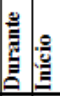 & ] & & 农 & & 恼 & . & & 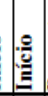 & & & 至 & & 气 & 总 & 竎 & & & 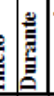 & $\begin{array}{c}\text { Total } \\
\text { por } \\
\text { sinal } \\
\end{array}$ \\
\hline \multirow{6}{*}{$\begin{array}{c}\text { Informação } \\
\text { Precoce }\end{array}$} & Comunicação & & & & & & & & & & & & & & & & & & & & & & & & $\mathrm{GP}$ & $\mathrm{GH}$ & $\mathrm{P}$ & 2 \\
\hline & Equipe do projeto & GP & & & & & & & & & & & & & & & & & & & & & & & & & & 1 \\
\hline & Expressão do cliente & & & & & $\mathrm{EQ}$ & & & & & & & EQ & & & & & & & & & & & & & & & 2 \\
\hline & Expressão do parceiro & & & & & & & & & $\mathrm{X}$ & & & & & & & & & & & & & & & & & & 1 \\
\hline & Fontes externas & & & & & & & & & & & & GP & & EQ & & & & & & & & & & & & & 2 \\
\hline & Gut feelings & & & & & & & & GP & & & & & & & GP & & & & & & & SP & $\mathrm{P}$ & & & & 3 \\
\hline \multirow{4}{*}{$\begin{array}{c}\text { Primeiros } \\
\text { sintomas }\end{array}$} & Controle do projeto e relatórios & & & & & & & MI & & & & & & & & & & & & & $\mathrm{MI}$ & 正 $\mathrm{x}$ & & & & & & 3 \\
\hline & Expressão do cliente & & & & & EQ & & & & & & & EQ & & & & M目 & & & & & & & & & & & 3 \\
\hline & Expressão do usuário & & & & & & & & & & & & & & & & & & EO & & & & & & & & & 1 \\
\hline & Trabalho dentro do projeto & & & GP & & EQ & & & MI & & & SP & & & & & & & & & & & MF & SP & & & & 6 \\
\hline \multirow[t]{2}{*}{ Súbito } & & & $\mathrm{EQ}$ & & EQ & & $\mathrm{MISP}$ & $\mathrm{P}$ & & EQE & $\mathrm{EQ} \mathrm{EQ}$ & & $\mathrm{EQ}$ & GP & & $\mathrm{GP}$ & & $\mathrm{EQ}$ & & QGP & $\mathrm{GP}$ & $\mathrm{EQ}$ & $\mathrm{EQ}$ & & & $\mathrm{EQ}$ & $\mathrm{EQ}$ & 18 \\
\hline & Total por imprevisto & 1 & 1 & 1 & 1 & \begin{tabular}{|l|l}
3 & 1 \\
\end{tabular} & \begin{tabular}{l|l}
1 & 1 \\
\end{tabular} & \begin{tabular}{l|l|}
1 & 1 \\
\end{tabular} & \begin{tabular}{|l|l|}
1 & 1 \\
\end{tabular} & 2 & \begin{tabular}{|l|l|}
1 & 1 \\
\end{tabular} & 1 & \begin{tabular}{l|l}
1 & 3 \\
\end{tabular} & 1 & 1 & \begin{tabular}{|l|l|}
1 & 1 \\
\end{tabular} & 1 & \begin{tabular}{l|l}
1 & 1 \\
\end{tabular} & \begin{tabular}{l|l}
1 & 1 \\
\end{tabular} & 1 & \begin{tabular}{|l|l}
1 & 1 \\
\end{tabular} & 2 & \begin{tabular}{|l|l|}
1 & 2 \\
\end{tabular} & 1 & \begin{tabular}{|l|l}
1 & 1 \\
\end{tabular} & \begin{tabular}{l|l}
1 & 1 \\
\end{tabular} & 1 & 42 \\
\hline
\end{tabular}

Quem percebeu o sinal precoce (Quadro 15) pode ser: a equipe, quando o entrevistado não mencionou especificamente uma pessoa, mas citou a percepção do sinal ou do problema pela 
equipe, representando $45 \%$ dos casos; o gerente de projetos, que compreende $26 \%$ dos casos; o membro da equipe, com $14 \%$ dos casos; ou o sponsor, em $10 \%$ dos casos. Excluindo os casos para os quais a percepção do problema ocorreu subitamente, os números modificam-se e o gerente de projetos passa a responder por $29 \%$ dos casos, a equipe também por $29 \%$, o membro da equipe por $21 \%$ e o sponsor permanece com $10 \%$. Observa-se que a percepção da equipe somada à do membro da equipe totalizam $50 \%$ dos casos, demonstrando a importância da abertura para a discussão de problemas na equipe para que a informação alcance os tomadores de decisão.

Cada tipo de projeto possui um ciclo de vida e respectivas fases, definidos de acordo com o produto do projeto. Para identificar o momento no qual o sinal precoce foi percebido, gerouse uma nomenclatura básica que pudesse abranger qualquer projeto. Assim, foram definidos três momentos, conforme pode ser observado no Quadro 15: início, quando o projeto está em sua fase inicial de planejamento e primeira fase de desenvolvimento da solução; durante, quando o produto ou serviço está em pleno desenvolvimento ou execução e final, quando o produto já está desenvolvido e prestes a entrar em fase de operação ou lançamento. Dos 35 imprevistos, onze ocorreram no início do projeto (31\%), 17 durante o projeto e sete ao seu final.

A informação precoce do tipo comunicação, como pode ser visto no Quadro 15, representa a obtenção de um sinal durante a comunicação entre departamentos durante o projeto (SANCHEZ, PEREZ, 2004). Ele ocorreu em dois dos 42 casos (5\%), como no de um gerente de projetos, novo na organização, que trabalhava numa sala com vários outros gerentes de projeto, quando descobriu que os trâmites para determinadas atividades demoravam muito mais do que o tempo previsto por ele: "Os amigos aqui em volta começaram me disponibilizar as informações [...]” Em outro caso, o gerente de projetos buscava algum sistema com informações básicas para seu projeto, quando outro gerente sugeriu que ele fosse procurar num determinado departamento. Ele encontrou não um sistema informatizado como procurava, mas informações mais completas do que ele havia imaginado, porém manuscritas.

O único caso (2\%) com a informação precoce vindo da equipe do projeto ocorreu no início de um projeto. O gerente de projetos percebeu durante um brainstorm: “[...] senti a necessidade de eles entenderem melhor [...] para poderem escrever [...] eles precisavam 
entender." No caso, eles eram a nova equipe que entendia muito sobre como desenvolver um determinado produto, mas desconheciam totalmente o mercado que este produto atenderia.

O sinal precoce é percebido pela expressão do cliente, na interface com a equipe do projeto (SANCHEZ, PEREZ, 2004). Foram encontradas cinco menções a esse tipo de sinal, dos quais dois (5\%) foram classificados como informação precoce e três (7\%), como primeiros sintomas. No primeiro caso, o entrevistado comentou que "Dava para perceber que existia um ou outro diretor que estava mais interessado [...]" em liderar aquele projeto dentro da organização-cliente, classificado como informação precoce. Logo depois, os clientes "[...] se manifestaram abertamente em um workshop [...]" sobre o assunto, o que foi considerado como um primeiro sintoma. No segundo caso, logo nas primeiras visitas aos clientes, percebeu-se o parecer deles sobre o projeto. Passado um tempo, tornou-se um primeiro sintoma, pois ocorreram “[...] alguns incidentes, um ou outro [membro da equipe] que aconteceu de ficar na situação meio constrangedora [...]" No terceiro evento imprevisto, o membro da equipe percebeu a falta de uma funcionalidade, mas ainda havia tempo para negociar com o fornecedor para incluí-la. Os dois primeiros casos demonstram como os sinais vão ficando mais fortes, passando de informação precoce a primeiros sintomas.

A única ocorrência da expressão do parceiro foi manifestada pelo líder na organização parceira, que viabilizaria a distribuição do produto do projeto. O parceiro responsável saiu da organização, surpreendendo a equipe que não deu sentido a sinais anteriores, pois "Ele mesmo já tinha falado que ele estava muito cansado, que ele estava esgotado [...]” Segundo o próprio entrevistado, isso ocorreu porque "a gente talvez não quisesse acreditar naquele cenário."

Ocorreram dois casos $(5 \%)$ de informação precoce obtida de fontes externas. No primeiro caso, o gerente de projetos tinha percebido a rejeição de seu produto por algumas organizações, pois "Existem congressos, existem eventos que a gente participa [...] onde, no contato, a gente percebia que tinha algumas [pessoas que] se manifestavam [...]" negativamente quanto ao produto. No segundo caso, o acompanhamento de informações com base em institutos especialistas indicou que, além dos fatores ambientais controlados no projeto, outro fator inédito também deveria ser incorporado. 
Três eventos imprevistos (7\%) foram antecedidos por gut feelings (NIKANDER, ELORANTA, 1997; 2001), que também pode ser chamado de intuição. No primeiro caso, o entrevistado disse que "É como se a gente tivesse [desde o início] fazendo algum produto para atrair esses grandes players." Nessa mesma entrevista, o entrevistado cita a necessidade de se pensar sobre a intuição, pois, apesar de eles terem a informação de que aquele parceiro não tinha dado certo em outras parcerias internacionais, investiram na parceria. No outro caso, o entrevistado comentou que "[...] foram nove anos lidando com órgãos públicos, principalmente prefeituras, eu já tinha experiência de que [...] eu fui envolvido em reuniões com a comunidade." Isso o fez perceber a importância de buscar informações aprofundadas sobre os stakeholders. No terceiro caso, o sponsor, assim que foi designado para o projeto, pediu para a equipe enviar o cronograma ao cliente, mas isso demorou alguns meses para acontecer. Logo que o cliente viu o cronograma, percebeu atividades com prazo inferior ao que ele considerava adequado, devido a sua experiência na implantação do sistema vigente. Essa avaliação foi confirmada posteriormente.

Em três casos (7\%), os primeiros sintomas foram obtidos por meio do controle do projeto e relatórios. Num deles, o membro da equipe percebeu, ao avaliar detalhadamente as informações de controle do fornecedor, que esses controles poderiam estar sendo fraudados. Em outro caso, também o membro da equipe percebeu pelo controle do cronograma que, no ritmo em que o projeto estava, o prazo final não seria atendido, o que permitiu identificar o problema e agir. No último caso, apesar da sinalização do atraso nas atividades, o responsável postergava as datas do cronograma sem explicar as causas, ignorando o sinal de que algum problema estava ocorrendo.

O primeiro sintoma percebido pela expressão do usuário ocorreu em apenas um caso (2\%) quando a equipe percebeu, durante a fase-piloto, que o nível de envolvimento dos consumidores com o produto não estava acontecendo como havia sido previsto.

O tipo de sinal precoce mais comentado pelos entrevistados, seis casos (14\%), foi o primeiro sintoma que ocorreu durante o trabalho dentro do projeto. Os casos são:

a) o gerente não pôde obter a definição de requisitos durante ao desenvolvimento do projeto, pois a área usuária ainda não havia sido estruturada; 
b) durante o projeto, ficou evidente a necessidade de uma definição sobre o líder do processo na empresa-cliente, enquanto a consultoria desenhava os processos e as atividades;

c) enquanto discutiam os cenários de teste do sistema, um membro da equipe percebeu que havia diferentes procedimentos entre os departamentos para uma mesma atividade fundamental para o projeto;

d) o sponsor estava tentando definir com uma área de suporte o período que ela estaria à disposição do projeto, quando percebeu que vários sistemas estavam previstos para serem implantados na mesma data, o que seria impossível;

e) durante uma conversa com o cliente, um membro da equipe que desenvolvia o novo sistema percebeu a falta de sincronia com a equipe que dava manutenção ao sistema antigo, pois esta trabalhava em pedidos de alteração que ele desconhecia;

f) o último evento foi percebido pelo sponsor quando ele soube da mudança de um software no novo sistema, pois havia impedimentos técnicos e relativos à equipe ao seu uso, que poderiam impactar o prazo de implantação.

O tipo de sinal precoce súbito reflete a percepção da ocorrência de um problema, na maioria das vezes não havendo mais tempo para ações para minimizar o seu impacto. Como pode observado no Quadro 15, foram identificados 18 eventos (51\%) dessa categoria. Em dois casos, foi relatada a percepção de um sinal precoce, mas não dado sentido a ele. Assim, os sinais ignorados transformaram-se em problemas percebidos subitamente. Os 18 eventos imprevistos que ocorreram subitamente foram:

a) em decorrência de uma solução emergencial para o projeto, a equipe se viu à frente de um problema técnico, depois solucionado;

b) também em decorrência de uma solução emergencial, a equipe viu a demanda dos clientes aumentar para um nível bem superior ao suportado pelo projeto e naquele momento não se pôde fazer nada;

c) o entrevistado comentou que "Foi uma total surpresa[...]" que os dois sponsors clientes tivessem opiniões tão diferentes sobre o direcionamento do projeto, o que só foi descoberto perto do seu final, quando o segundo sponsor pôde ser entrevistado;

d) na apresentação do sistema, ao final do prazo do projeto, os sponsors perceberam que o sistema adquirido não atendia as necessidades da organização; 
e) o líder na empresa parceira se desligou de forma muito rápida, sem um substituto, o que impactou a parceria, apesar de ele já ter dado sinais de sua insatisfação. Segundo o entrevistado, “A gente não imaginava que ele fosse sair tão rápido.”;

f) havia a previsão da importação de um equipamento com certa capacidade técnica; na impossibilidade de ser contratado no mercado nacional e na busca no exterior, percebeu-se que o equipamento não existia, nem seria possível ser gerado pelos fornecedores existentes;

g) na crise financeira mundial de 2008, os sócios se desentenderam sobre as ações a serem tomadas e, após outro pequeno problema, resolveram dissolver a sociedade; segundo o entrevistado essa era "[...] a parte que não estava sendo monitorada e, quando foi percebido, era muito tarde.";

h) num processo de dress rehearsal ${ }^{49}$, duas semanas antes da implantação, foram encontrados "[...] riscos ou eventos, issues mesmo, que poderiam inviabilizar a implementação.";

i) apesar de a empresa adotar a terceirização para não ter problemas trabalhistas, foi acionada judicialmente;

j) após quatro meses de procura, o gerente de projetos chegou “[...] à conclusão que não havia no mercado os profissionais para exercer aquela atividade [...]";

k) a mudança no tipo de contratação de funcionários, que trabalhavam como terceiros e aplicada sem prévio aviso ao contratante, acabou afetando o projeto, pois muitos membros da equipe não quiseram adotar a mudança e saíram da equipe;

1) as parcerias eram fundamentais para o projeto, mas elas não se viabilizaram por causa das prioridades e das estratégias internas dos supostos parceiros;

m) uma das entregas do projeto foi desenvolvida, segundo o entendimento da equipe, mas, perto do final do projeto, uma lei mudou a forma da entrega, o que implicaria refazê-lo;

n) o cliente demorou tanto para aprovar o projeto, que membros-chaves da equipe não puderam participar da forma planejada;

o) segundo um membro da equipe, que cuidava da GR, "A gente recebeu a notícia que [o projeto] tinha sido abandonado.” Isso ocorreu devido à perda de um equipamento, quando em nenhum momento, havia sido cogitado;

\footnotetext{
49 dress rehearsal é um ensaio para a migração de sistema; normalmente simula-se a implantação do novo sistema em um ambiente controlado com características muito próximas do ambiente definitivo.
} 
p) a complexidade dos testes não foi bem avaliada na fase de proposta, o que levou o parceiro a gastar seis meses e 18 recursos em vez de cinco semanas e três recursos;

q) o projeto contava com muitos voluntários e depois das tarefas distribuídas, alguns deles não as executaram;

r) a capacidade de entendimento do problema, pelo fornecedor, foi sendo percebida como problemática, à medida que o projeto se desenrolava, o que acabou inviabilizando o contrato de fornecimento.

Identificando-se o primeiro sinal precoce percebido para cada evento imprevisto, percebe-se o seguinte:

- a maioria dos sinais precoces ocorreu subitamente (51\%); os outros dois tipos ocorreram quase na mesma proporção - informação precoce $(23 \%)$ e primeiros sintomas $(26 \%)$;

- a maioria dos sinais precoces foi percebida pela equipe (57\%); em segundo lugar, pelo gerente de projetos $(31 \%)$ e, por último, pelo sponsor $(11,4 \%)$;

- $\quad$ metade dos sinais precoces (49\%) foi percebida durante o projeto, onze casos (31\%) no início e o restante $(20 \%)$ ao final.

\subsection{Relação entre as características do sinal precoce}

As próximas avaliações a serem descritas foram feitas com base no primeiro sinal precoce percebido. Devido à pequena quantidade de eventos imprevistos, as provas estatísticas não puderam ser aplicadas, portanto as análises serão apenas qualitativas.

Para avaliar a relação entre o tipo de sinal precoce e o momento de sua percepção, foi gerada a Tabela 3. Nota-se que a maioria dos casos de informação precoce ocorreu no início do projeto e a maioria dos primeiros sintomas ocorreu durante o projeto, assim como os eventos súbitos, que ocorreram mais durante e ao final do projeto.

Tabela 3 - Quantidade de eventos imprevistos por tipo de sinal precoce e momento de sua percepção

\begin{tabular}{|c|c|c|c|}
\hline \multirow{2}{*}{ Tipo de sinal precoce } & \multicolumn{3}{|c|}{ Momento da percepção do sinal precoce } \\
\cline { 2 - 4 } & Início & Durante & Final \\
\hline Informação precoce & 6 & 2 & 0 \\
\hline Primeiros sintomas & 2 & 7 & 0 \\
\hline Súbito & 3 & 8 & 7 \\
\hline
\end{tabular}

A Tabela 4 demonstra que tipo de sinal precoce foi percebido por quem no evento imprevisto. Para essa análise, as ocorrências relativas ao membro da equipe foram somadas às da equipe. 
Observa-se que os gerentes de projeto foram os responsáveis pela maioria das percepções das informações precoces. Quanto aos primeiros sintomas, a equipe foi o tipo mais numeroso. A maioria dos eventos subitamente percebidos também o foi pela equipe do projeto (67\%).

Tabela 4 - Quantidade de eventos imprevistos por tipo de sinal precoce e quem o percebeu

\begin{tabular}{|c|c|c|c|}
\hline \multirow{2}{*}{ Tipo de sinal precoce } & \multicolumn{3}{|c|}{ Quem percebeu o sinal precoce } \\
\cline { 2 - 4 } & Equipe & $\begin{array}{c}\text { Gerente de } \\
\text { projetos }\end{array}$ & Sponsor \\
\hline Informação precoce & 2 & 6 & 0 \\
\hline Primeiros sintomas & 6 & 1 & 2 \\
\hline Súbito & 12 & 4 & 2 \\
\hline
\end{tabular}

Foi gerada a Tabela 5 para se avaliar a relação entre quem percebeu o sinal precoce e quando ele foi percebido. Observa-se que o gerente de projetos foi o que mais percebeu no início do projeto e o que menos percebeu durante o projeto. A equipe percebeu mais durante o projeto, assim como o sponsor, com poucas ocorrências.

Tabela 5 - Quantidade de eventos imprevistos por momento da percepção e quem o percebeu

\begin{tabular}{|c|c|c|c|}
\hline \multirow{2}{*}{$\begin{array}{c}\text { Momento da percepção } \\
\text { do sinal precoce }\end{array}$} & \multicolumn{3}{|c|}{ Quem percebeu o sinal precoce } \\
\cline { 2 - 4 } & Equipe & $\begin{array}{c}\text { Gerente de } \\
\text { projetos }\end{array}$ & Sponsor \\
\hline Início & 4 & 7 & 0 \\
\hline Durante & 11 & 2 & 4 \\
\hline Final & 5 & 2 & 0 \\
\hline
\end{tabular}

\subsubsection{Práticas para a criação de sentido}

Nas entrevistas, foram avaliadas as ações tomadas pela equipe para dar sentido às incertezas imprevisíveis desde a percepção do sinal precoce até o momento em que o entrevistado considerou que a incerteza tinha diminuído ou terminado. Essas ações referem-se a atividades, agrupadas em processos que, por sua vez, fazem parte de métodos empregados na gestão do evento imprevisto. Além disso, as T\&F utilizadas em cada evento imprevisto também foram avaliadas. Nos próximos itens, essas práticas serão analisadas.

\subsection{Atividades para a criação de sentido}

As atividades para a criação de sentido foram classificadas em 27 categorias. $\mathrm{O}$ detalhamento dessas atividades consta no Apêndice 5 - Atividades e processos obtidos nas entrevistas, página Apêndice 5 - Atividades e processos obtidos nas entrevistas264, além da respectiva 
cronologia e quem participou de cada atividade. Para simplificar a visualização das informações desse apêndice, foi criado o Quadro 16, que demonstra para cada evento imprevisto as atividades utilizadas e o tipo de participação dos envolvidos na atividade. $\mathrm{O}$ tipo de participação pode ser: individual, coletivo, externo ou um novo ciclo de criação de sentido. As atividades ocorreram 177 vezes nos 35 eventos imprevistos, com uma média de 5,05 atividades por evento. A maior quantidade de atividades foi nove e em três eventos só houve uma. Em alguns eventos imprevistos, a mesma atividade ocorreu mais de uma vez, em momentos distintos.

\section{Quadro 16 - Atividades para a criação de sentido por tipo de participação e por evento imprevisto}

\begin{tabular}{|c|c|c|c|c|c|c|c|c|c|c|c|c|c|c|c|c|c|c|c|c|c|c|c|c|c|c|c|c|c|c|c|c|c|c|c|c|c|}
\hline \multicolumn{2}{|c|}{ Atividade } & Total & 1 & 2 & 3 & 4 & 5 & 6 & 7 & 8 & 9 & 10 & 11 & 12 & 13 & \begin{tabular}{|l|l}
14 & 1 \\
\end{tabular} & 15 & 16 & 17 & 18 & 19 & 20 & 21 & 22 & 23 & 24 & 25 & 26 & $27 \mid 2$ & 28 & 29 & $30 \mid 3$ & 31 & 32 & 33 3 & 34 & 35 \\
\hline \multicolumn{2}{|l|}{ Abortar } & 5 & & & & & & & & & & $\mathrm{E}$ & C & & I & & & & & & & & & & & & & & & $\mathrm{C}$ & & & & & & & $\mathrm{C}$ \\
\hline \multirow{2}{*}{\multicolumn{2}{|c|}{$\begin{array}{l}\text { Avaliar } \\
\text { Buscar especialista }\end{array}$}} & 6 & C & & & & & & C & & & & & C & & & $\mathrm{C}$ & & & & & C & & & & & & & & & & C & & & & & \\
\hline & & 4 & & C & C & & & & $\mathrm{I}$ & & & & & & & & & & & & & & & & & & & & & & & C & & & & & \\
\hline \multicolumn{2}{|c|}{ Buscar fornecedor } & 5 & & & & & & & & & & & & $\mathrm{C}$ & & & & & & & $\mathrm{C}$ & & & & $\mathrm{C}$ & & & & & & & & $\mathrm{C}$ & & & $\mathrm{C}$ & \\
\hline \multirow{2}{*}{\multicolumn{2}{|c|}{ Buscar parceiros }} & & & & & & & & & & & C & & C & & & & & & & & & & & & $\mathrm{C}$ & & C & & & & & & & & & \\
\hline & & 3 & & & & & & & & & & $\mathrm{C}$ & & & & & & & & & & & & & & & & & & & & & & & & & \\
\hline \multicolumn{2}{|c|}{ Buscar patentes } & 1 & & & & & & & & & & & & C & & & & & & & & & & & & & & & & & & & & & & & \\
\hline \multirow{2}{*}{\multicolumn{2}{|c|}{$\begin{array}{l}\text { Checar a informação } \\
\text { Classificar }\end{array}$}} & 8 & & & & & & $\mathrm{C}$ & & & & & & & & & & & & & I & & $\mathrm{C}$ & & $\mathrm{C}$ & & I & & & & & & & I & & I & C \\
\hline Classificar & & 2 & & & & & & & I & & & & & & & & & & & & & & & & & & & & & & $\mathrm{C}$ & & & 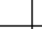 & & & \\
\hline \multicolumn{2}{|l|}{ Compartilhar } & 7 & $\mathrm{C}$ & & & & & $\mathrm{C}$ & C & & & & & & & & & C & & $\mathrm{C}$ & & & & & & & & & & & $\mathrm{C}$ & & & $\mathrm{C}$ & & & \\
\hline \multicolumn{2}{|c|}{ Cumprir o planejado } & 5 & C & & & & & & & & & C & C & & & & $\mathrm{C}$ & & & & & & & & & & & & & & & & & $\mathrm{C}$ & & & \\
\hline \multicolumn{2}{|c|}{ Diagnosticar problema } & 9 & & & & & & & $\mathrm{I}$ & & $\mathrm{E}$ & & & & & C & & & $\mathrm{C}$ & & & $\mathrm{C}$ & & & & & I & & I & & & E & & I & & & \\
\hline \multicolumn{2}{|c|}{ Discutir com a equipe } & 11 & & & C & & C & $\mathrm{C}$ & & C & $\mathrm{C}$ & & & & & & C & & & & & & & C & & & & & & & C & & C & & & C & $\mathrm{C}$ \\
\hline \multirow{2}{*}{\multicolumn{2}{|c|}{$\begin{array}{l}\text { Elaborar pesquisa } \\
\text { Envolver outros departamentos }\end{array}$}} & 1 & & & & & & & & & & & & & & & & & & & & C & & & & & & & & & & & & & & & \\
\hline & & 9 & & & C & & & $\mathrm{C}$ & C & & $\mathrm{C}$ & & & & & C & & C & & & & & & & & & $\mathrm{C}$ & & & & & & & $\mathrm{C}$ & & C & \\
\hline \multicolumn{2}{|l|}{ Fechar acordo } & 8 & & & & & & & $\mathrm{I}$ & & & C & & & & & & & & & & & $\mathrm{C}$ & & & $\mathrm{C}$ & C & C & & & C & C & & & & & \\
\hline Gerar novo cic & & 6 & & & & & & & & & $\mathrm{~N}$ & & $\mathrm{~N}$ & & & & & & & $\mathrm{~N}$ & & & & & $\mathrm{~N}$ & & & & & & & & $\mathrm{~N}$ & & & & $\mathrm{~N}$ \\
\hline Identificar alte & nativas & 10 & C & C & & & & & & & & & & $\mathrm{C}$ & & $\mathrm{C}$ & & I & & & & & & & & $\mathrm{C}$ & $\mathrm{C}$ & & $\mathrm{C}$ & & & & $\mathrm{C}$ & & & $\mathrm{C}$ & \\
\hline Mudar ideias & & 4 & & & & & & & & & & $\mathrm{C}$ & & & & & & C & & & $\mathrm{C}$ & & & & & & & & & & & & & & & & $\mathrm{C}$ \\
\hline Negociar & & 3 & & & & & & & & & & & & & & C & & & & & & & $\mathrm{C}$ & & & & $\mathrm{C}$ & & & & & & & & & & \\
\hline Obter evidênc & & 8 & & & & & & & C & $\mathrm{I}$ & $\mathrm{E}$ & & & & & $\mathrm{C}$ & & C & & & & C & & & & & $\mathrm{C}$ & & & & $\mathrm{C}$ & & & & & & \\
\hline Pesquisar & & 5 & & & & & & & & & & $\mathrm{C}$ & & C & & & & & & I & & $\mathrm{C}$ & & & C & & & & & & & & & & & & \\
\hline Planejar & & 6 & C & & & & & & & & & C & & & & & & & & & & & & & $\mathrm{C}$ & & & $\mathrm{C}$ & & & & $\mathrm{C}$ & & C & & & \\
\hline Procrastinação & & 6 & & & & C & C & & & & & $\mathrm{E}$ & $\mathrm{E}$ & & $\mathrm{I}$ & & & & & & & & & & & & & & & & & & & & $\mathrm{C}$ & & \\
\hline Registrar & & 6 & C & I & I & & & & & & & & & & & I & & C & & & & & & & & & & & & & $\mathrm{C}$ & & & & & & \\
\hline Revisar & & 6 & I & I & & & & $\mathrm{C}$ & & & & & & & & & & & & & & & C & & & & & & & & $E$ & C & & & & & \\
\hline Solucionar & & 26 & C & $\mathrm{C}$ & C & & $\mathrm{E}$ & $\mathrm{C}$ & C & C & $\mathrm{C}$ & & & \begin{tabular}{l|l} 
\\
\end{tabular} & & \begin{tabular}{|l|l}
$\mathrm{C}$ & \\
\end{tabular} & I & \begin{tabular}{l|l} 
C \\
\end{tabular} & C & C & C & C & C & C & $\mathrm{C}$ & C & I & & $\mathrm{C}$ & & & & C & I & & C & \\
\hline & & 20 & & & & & & & & & & & & & & & & & & & & $\mathrm{C}$ & & & & & & & & & & & & & & & \\
\hline Tentativa de & & 5 & & & C & & & $\mathrm{C}$ & & $\mathrm{I}$ & & & C & & & & & & & & & & & & & & & & & & & 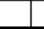 & & & & & $\mathrm{C}$ \\
\hline & Individual (I) & 25 & 1 & 2 & 1 & 0 & 0 & 0 & 4 & 2 & 0 & 0 & 0 & 0 & \begin{tabular}{|l|l|}
2 \\
\end{tabular} & \begin{tabular}{|l|l|}
1 & \\
\end{tabular} & 1 & \begin{tabular}{|l|l|}
1 \\
\end{tabular} & 0 & \begin{tabular}{|l|l|}
1 \\
\end{tabular} & 1 & 0 & \begin{tabular}{|l|}
0 \\
\end{tabular} & \begin{tabular}{l|l}
0 \\
\end{tabular} & 0 & 0 & 3 & 0 & \begin{tabular}{l|l}
1 & \\
\end{tabular} & 0 & 0 & 0 & 0 & 3 & 0 & 1 & 0 \\
\hline Tipo de & Coletivo (C) & 138 & 7 & 3 & 5 & 1 & 2 & 7 & 5 & 2 & 3 & 7 & 3 & \begin{tabular}{|l|}
7 \\
\end{tabular} & \begin{tabular}{|l|l|}
0 \\
\end{tabular} & \begin{tabular}{|l|l|}
6 & \\
\end{tabular} & \begin{tabular}{l|l}
3 \\
\end{tabular} & \begin{tabular}{|l|l|}
6 \\
\end{tabular} & \begin{tabular}{|l|}
2 \\
\end{tabular} & \begin{tabular}{|l|l|}
2 \\
\end{tabular} & 3 & 7 & \begin{tabular}{|l|}
5 \\
\end{tabular} & 2 & 5 & 4 & 5 & 3 & 2 & 1 & 6 & 5 & 4 & 4 & 1 & \begin{tabular}{l|l}
5 \\
\end{tabular} & 5 \\
\hline participação & Externo (E) & 8 & 0 & 0 & 0 & 0 & 1 & 0 & 0 & 0 & 2 & 2 & 1 & 0 & \begin{tabular}{|l|l|}
0 \\
\end{tabular} & \begin{tabular}{l|l}
0 \\
\end{tabular} & 0 & \begin{tabular}{|l|l|}
0 \\
\end{tabular} & \begin{tabular}{|l|}
0 \\
\end{tabular} & \begin{tabular}{|l|l|}
0 \\
\end{tabular} & 0 & 0 & \begin{tabular}{|l|}
0 \\
\end{tabular} & 0 & 0 & 0 & 0 & 0 & 0 & 0 & 1 & 1 & 0 & 0 & 0 & \begin{tabular}{l|l}
0 \\
\end{tabular} & 0 \\
\hline & Novo ciclo (N) & 6 & 0 & 0 & 0 & 0 & 0 & 0 & 0 & 0 & 1 & 0 & 1 & \begin{tabular}{l|l}
0 \\
\end{tabular} & \begin{tabular}{|l|}
0 \\
\end{tabular} & \begin{tabular}{|l|l|}
0 & \\
\end{tabular} & 0 & \begin{tabular}{|l|}
0 \\
\end{tabular} & \begin{tabular}{|l|}
0 \\
\end{tabular} & \begin{tabular}{|l|l|}
1 \\
\end{tabular} & \begin{tabular}{|l|}
0 \\
\end{tabular} & 0 & \begin{tabular}{|l|l|}
0 \\
\end{tabular} & \begin{tabular}{|l|l|}
0 \\
\end{tabular} & 1 & 0 & 0 & 0 & \begin{tabular}{l|l}
0 & \\
\end{tabular} & 0 & 0 & 0 & 1 & 0 & 0 & 0 & 1 \\
\hline Total por ex & nto imprevisto & 177 & 8 & 5 & 6 & 1 & 3 & 7 & 9 & 4 & 6 & \begin{tabular}{|l|}
9 \\
\end{tabular} & 5 & 7 & \begin{tabular}{|l|l|}
2 & \\
\end{tabular} & \begin{tabular}{|l|l}
7 & \\
\end{tabular} & 4 & \begin{tabular}{|l|l}
7 & \\
\end{tabular} & 2 & 4 & 4 & 7 & 5 & \begin{tabular}{|l|l|}
2 & \\
\end{tabular} & 6 & 4 & 8 & 3 & \begin{tabular}{l|l}
3 & 1 \\
\end{tabular} & 1 & 7 & 6 & 5 & 7 & 1 & 6 & 6 \\
\hline
\end{tabular}

Os envolvidos nas atividades podem ser internos à organização, como: a equipe, que atuou em $61 \%$ das 177 atividades; o gerente de projetos, que atuou de forma isolada ou com outras áreas em 22\% das atividades; um membro específico da equipe, responsável ou participante de forma isolada, em 5\%; pessoas de outros departamentos da organização participaram em $13 \%$ das atividades; o sponsor foi responsável ou participou de $10 \%$ das atividades, e os usuários internos participaram diretamente em $2 \%$ das atividades.

Em 23 dos 35 eventos imprevistos (66\%), estiveram presentes pessoas ou organizações externas, como: a academia, acionada em 3\% das atividades; o cliente, que participou 
ativamente em 9\%; o fornecedor em 7\%; o mercado, em que o produto do projeto foi negociado, em 2\% das atividades; os parceiros envolvidos, em $7 \%$ das atividades e, finalmente, usuários externos e toda a sociedade, cada um foi envolvido em $1 \%$ das atividades.

Dos 27 tipos de atividades, que constam no Quadro 16, foram criadas apenas 20 variáveis, totalizando 167 ocorrências, devido aos seguintes motivos:

- $\quad$ por causa do pequeno número de ocorrências, algumas atividades foram descartadas elaborar pesquisa, classificar, mudar ideias e negociar;

- pelo baixo número de ocorrência individual e por representar uma busca externa de informações, algumas atividades foram unificadas em um só tipo - buscar especialista, fornecedores, parceiros e patentes.

$\mathrm{Na}$ análise descritiva das 20 atividades, demonstrada no Gráfico 11, percebe-se que as atividades com mais ocorrências foram: solucionar, presente em $71 \%$ dos casos; buscar informação externamente, presente em $34 \%$ dos casos; discutir com a equipe, presente em $31 \%$ e identificar alternativas, $29 \%$.

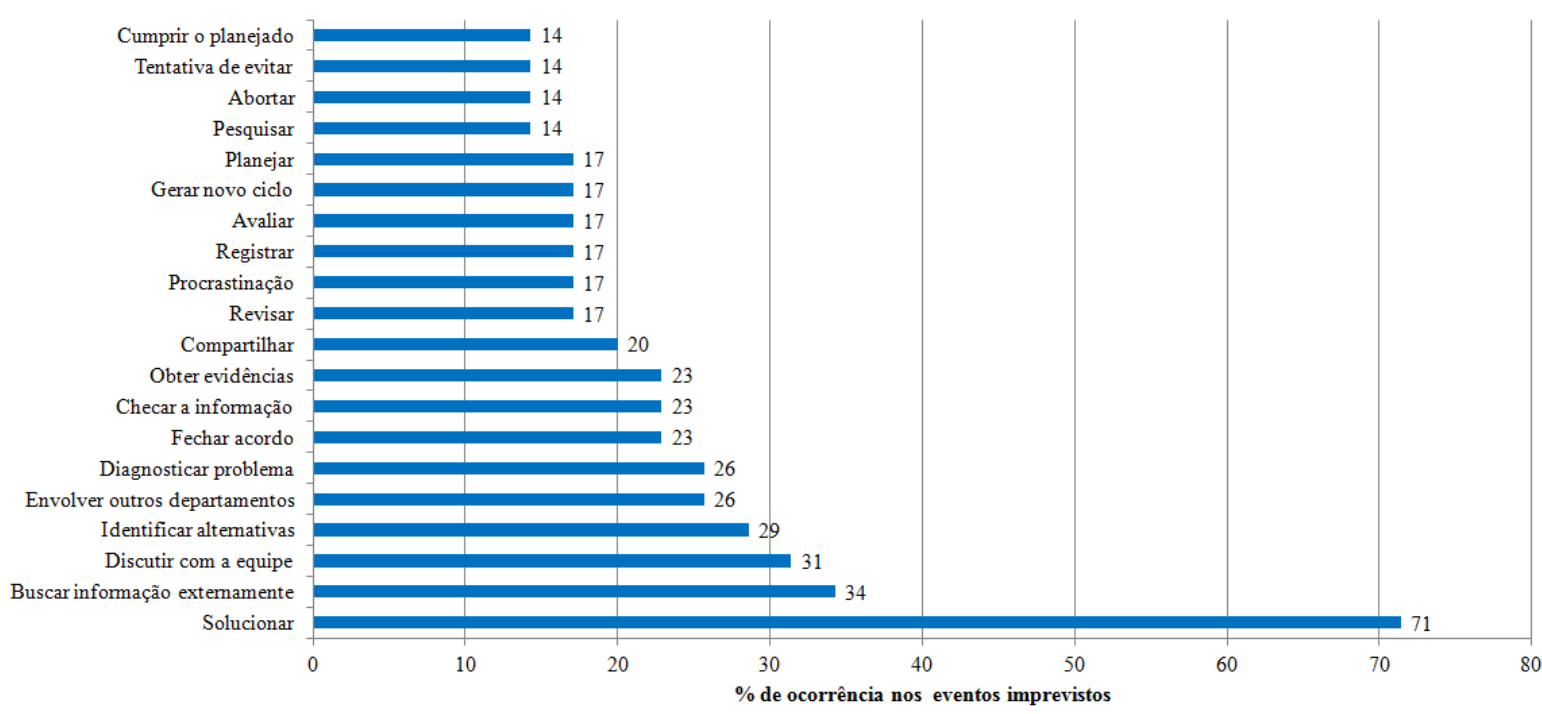

Gráfico 11 - Frequência de ocorrência dos tipos de atividade nos eventos imprevistos

O tipo de participação na atividade foi considerado individual (I), quando apenas um dos envolvidos, como o gerente do projeto, um membro da equipe ou o sponsor participou. Esse tipo de atividade representou $14 \%$ do total, conforme pode ser observado no Quadro 16 . O 
tipo de participação coletiva (C), quando houve a participação de várias pessoas e, assim, o conhecimento foi gerado socialmente, ocorreu na maioria dos casos (78\%). Logo, pode-se deduzir que a comunicação é um processo importante para que o conhecimento seja gerado. Foram bem poucas $(5 \%)$ as participações externas (E), atividades geradas por outros departamentos, clientes ou fornecedores, mas em alguns casos foram importantes, como quando o próprio cliente tomou uma decisão sobre um problema que a equipe do projeto havia postergado por questões políticas. Pode ocorrer, também, o início de um novo ciclo de criação de sentido $(\mathrm{N})$, que ocorreu em $3 \%$ dos casos, como a necessidade de um novo projeto para se aprofundar ou resolver a incerteza percebida.

Em praticamente todos os eventos imprevistos pesquisados, o tipo de atividade coletivo ocorreu em maior número que o tipo individual, o externo e o novo ciclo, conforme pode ser constatado nas totalizações do Quadro 16. Essa constatação realça a importância da socialização na resolução dos problemas. Em apenas um caso, evento imprevisto 13, as atividades individuais ocorreram em número maior do que as coletivas. Neste caso, mesmo percebendo que algo não estava bem, o sponsor procrastinou uma ação para modificar a situação. Essa piorou e ele e outros sócios preferiram sair do projeto, mesmo perdendo o investimento financeiro efetuado.

O Gráfico 12 mostra a distribuição da quantidade de atividades por tipo de participação no evento imprevisto. É notável como o tipo de atividade coletivo foi mais presente e com uma quantidade alta de ocorrências, dado que mais de 50\% dos casos apresentavam acima de três atividades coletivas. O tipo de participação externo e o de novo ciclo de criação de sentido foram menos presentes. 


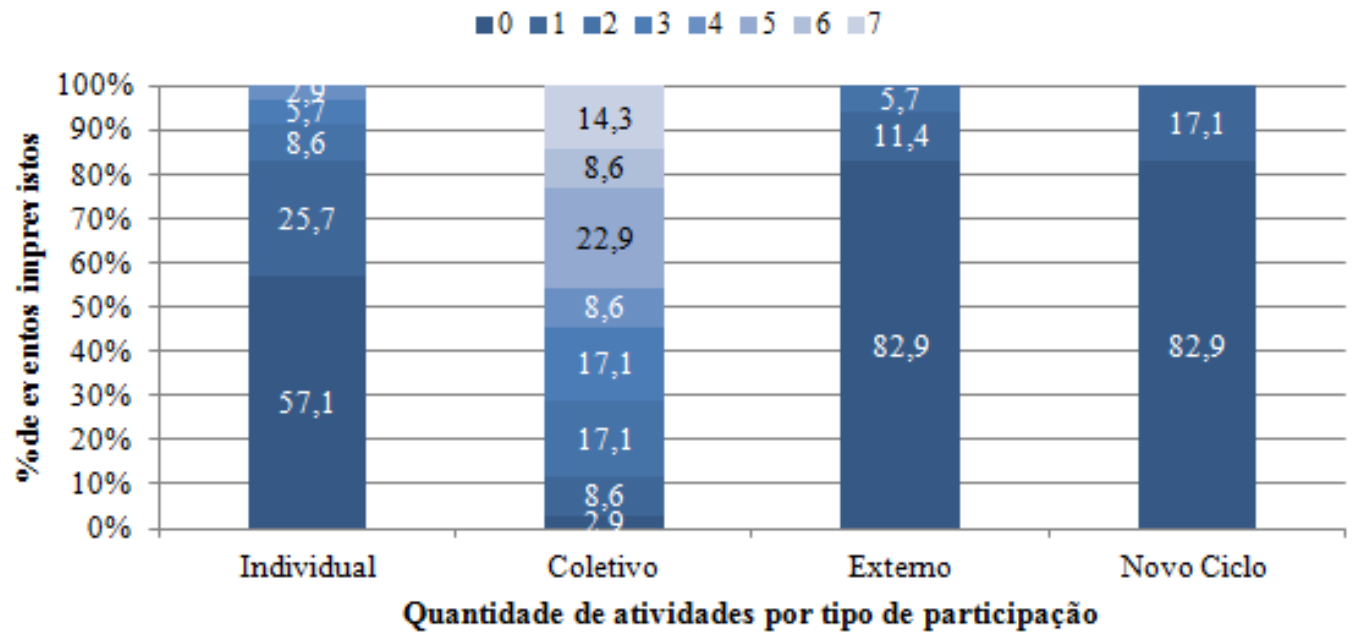

Gráfico 12 - Frequência de ocorrência da quantidade de atividades por tipo de participação no evento imprevisto

\subsection{Processos para a criação de sentido}

Avaliando-se a cronologia das atividades de cada evento imprevisto, detalhado no Apêndice 5, página 264, foi possível identificar sete processos, representados na Ilustração 18 , que sugerem uma sequência de ações: coleta de informações, diagnóstico, criação coletiva de sentido, decisão, memória, execução e novo ciclo de criação de sentido. A ligação entre o ambiente e a coleta de informação é a percepção dos sinais precoces emitidos pelo ambiente ou a busca de informação para superar a lacuna de conhecimento.

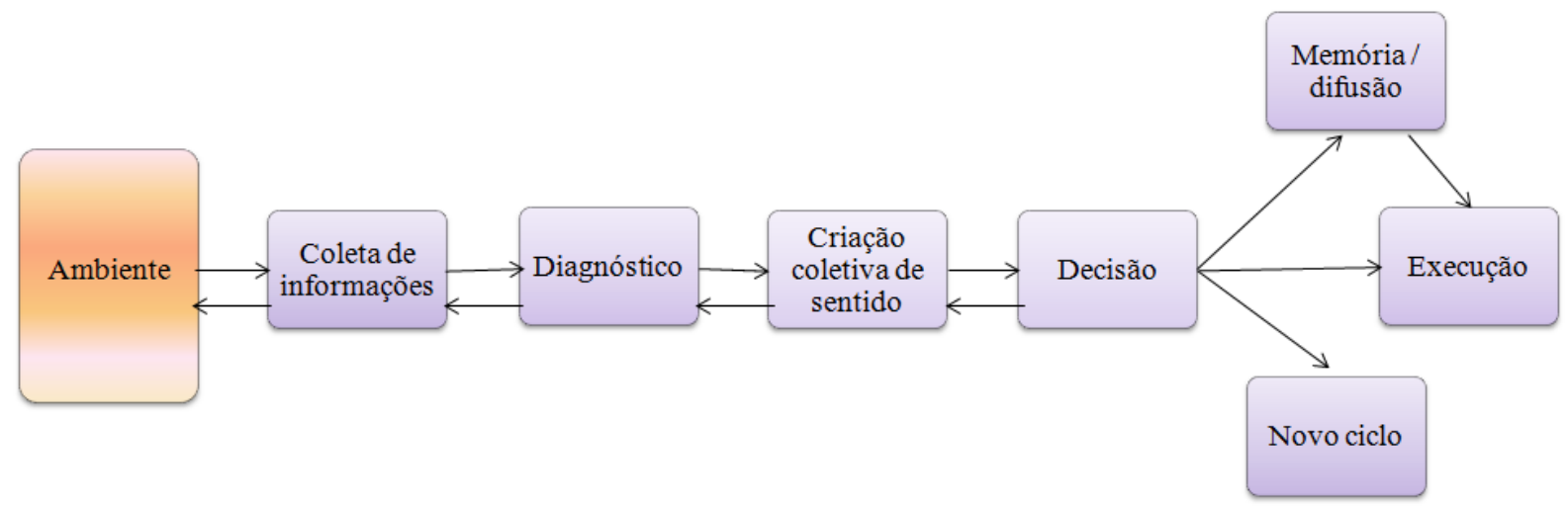

Ilustração 18 - Modelo de processos da gestão da incerteza

Para facilitar a visualização e análise, foi gerado o Quadro 17; a sequência de atividades consta no Apêndice 5. Os números nas células do Quadro mostram a sequência da atividade 
no evento imprevisto. Pode-se observar que nem sempre os processos foram executados na sequência apresentada na Ilustração 18, assim como não estão presentes em todos os eventos imprevistos.

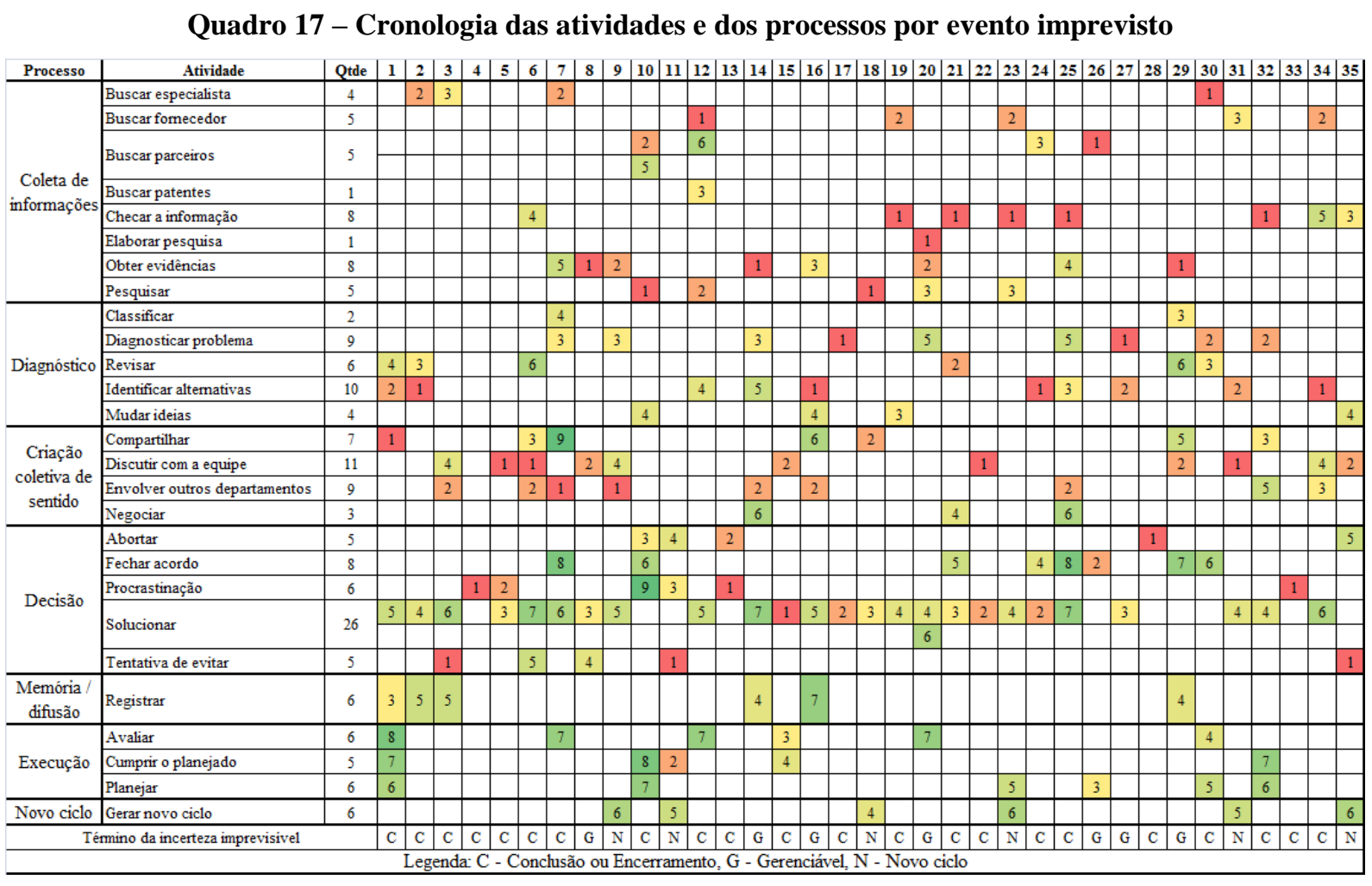

O processo de coleta de informações envolve as atividades de buscar especialista, fornecedor, parceiro ou patente, checar a informação recebida, obter evidências, elaborar pesquisa e pesquisar. Esse processo esteve presente em $69 \%$ dos eventos imprevistos e, em $40 \%$, a gestão da incerteza iniciou-se por ele. O processo de diagnóstico compreende as atividades de diagnosticar um problema, identificar alternativas, assim como classificar, revisar ou mudar de ideia. Esse processo consta em $63 \%$ dos eventos imprevistos e foi o primeiro em $17 \%$ deles. O processo de criação coletiva de sentido visa compartilhar a informação, discutir com a equipe, envolver outros departamentos na gestão da incerteza e negociar com fornecedores e parceiros. Não significa que nos outros processos não exista a criação de sentido; nesse processo, as pessoas estão discutindo as questões envolvidas, preparando-se para a tomada de decisão. Ele consta em $54 \%$ dos eventos e foi o primeiro a ser executado em $20 \%$ deles. 
Em todos os eventos imprevistos, existiram atividades relacionadas a uma tomada de decisão, como solucionar a incerteza, fechar um acordo com o departamento, parceiro ou fornecedor, tentar evitar ou mesmo procrastinar a decisão. Ele foi o primeiro processo em seis casos $(23 \%)$.

O processo de memória / difusão tem apenas uma atividade - registrar - e ocorreu apenas em $17 \%$ dos eventos imprevistos, mas nem sempre ocorreu após o processo de decisão. O processo de execução representa as ações ocorridas após a tomada de decisão como avaliação, planejamento e execução do planejamento, atividades presentes em $31 \%$ dos eventos. Esse processo demonstra que a incerteza foi considerada como superada apenas após uma avaliação, se a ação tomada realmente apresentou os efeitos desejados. O processo de novo ciclo de criação de sentido tem também apenas uma atividade presente em $17 \%$ dos eventos. Isso significa que foi necessária a criação de um novo ciclo no projeto, por exemplo uma nova fase ou mesmo um novo projeto para que a incerteza fosse considerada superada. Esse novo ciclo de criação de sentido não fez parte desta pesquisa.

O término da incerteza imprevisível avaliada está demonstrado na última linha do Quadro 17. Esse término pode ser categorizado de três formas:

- conclusão ou encerramento - categoria da maioria dos eventos (63\%), ocorreu quando, após as atividades executadas para a superação da incerteza imprevisível, foi eliminada e, portanto, conclusa ou seu impacto gerou o encerramento do projeto;

- gerenciável - seria a passagem para o known unknowns, quando se tem informação suficiente sobre o assunto para ser possível gerenciar o nível de incerteza, o que ocorreu em $20 \%$ dos eventos;

- $\quad$ novo ciclo de criação de sentido - situação de $17 \%$ dos eventos, que também pode ser considerado known unknowns, representado pela atividade de gerar novo ciclo.

O Gráfico 13 resume a análise descritiva dos processos para a criação de sentido. Nele está demonstrado que o processo de decisão ocorreu em todos os eventos imprevistos. O processo de coleta de informações foi o mais recorrente (69\%), o processo de diagnóstico (63\%) também possuia um alto percentual de ocorrência e os demais ocorreram bem menos. 


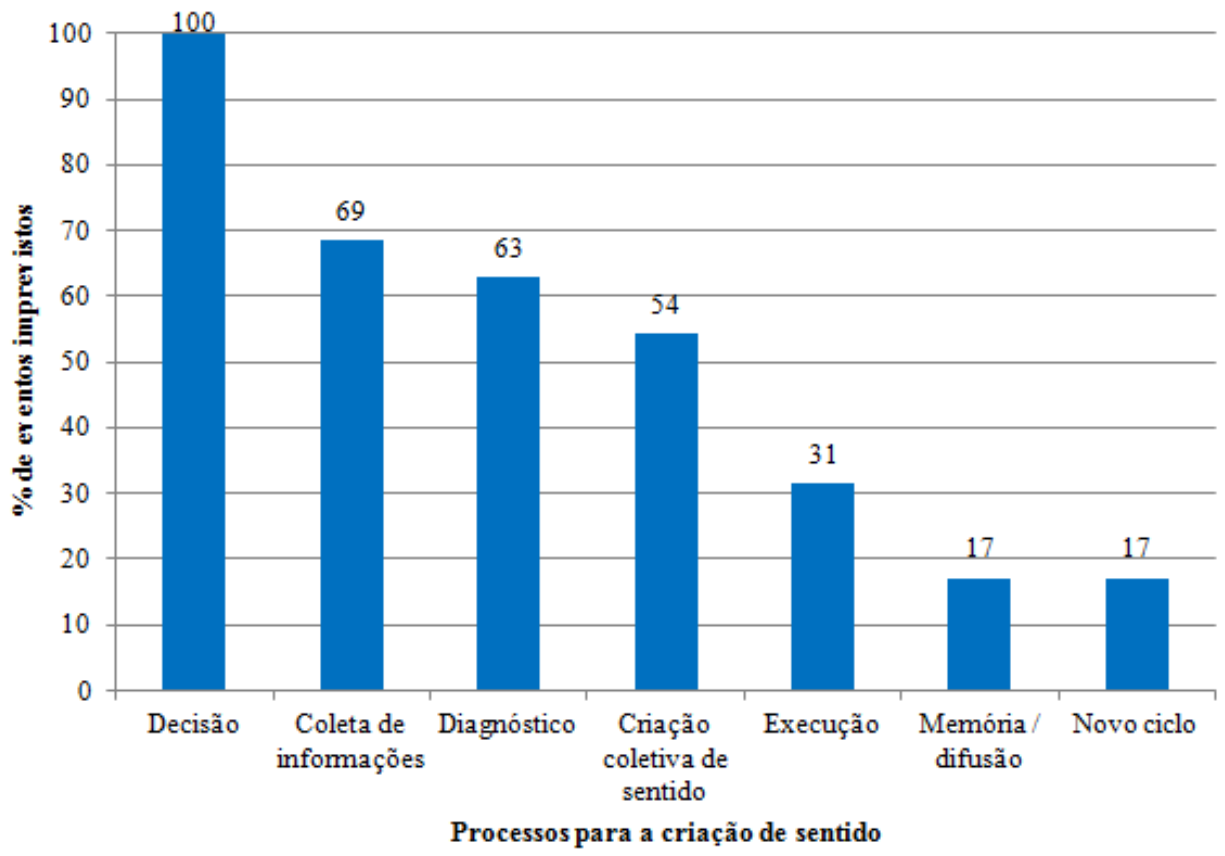

Gráfico 13 - Frequência de ocorrência dos processos para a criação de sentido nos eventos imprevistos

\subsection{Método de gestão do evento imprevisto}

Conforme pode ser observado no Gráfico 14, a maioria (66\%) dos eventos imprevistos usou o método de aprendizado, que engloba a experimentação e a improvisação. Foi possível aplicar o planejamento em apenas $20 \%$ dos casos. A categoria de procrastinação foi inclusa para representar os cinco casos (14\%) nos quais se postergou a solução, ou quando a ocorrência do imprevisto gerou o abandono do projeto.

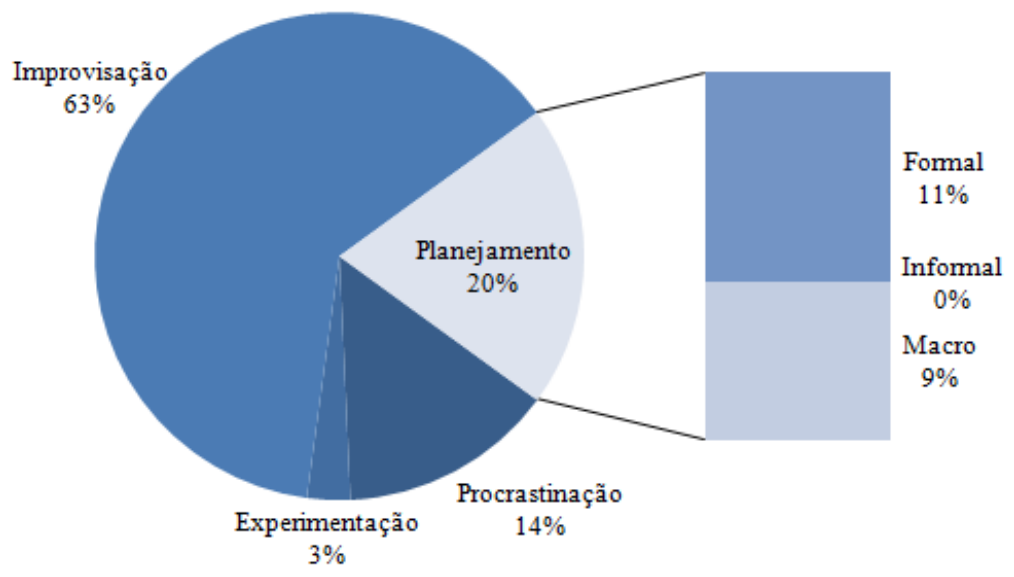

Gráfico 14 - Frequência do método de gestão dos eventos imprevistos 


\subsection{T\&F utilizadas}

Foram identificadas 17 técnicas e ferramentas utilizadas nos eventos imprevistos (vide Quadro 18). Pode ser que a técnica ou a ferramenta tenha sido usada em todo o projeto, mas foi considerada apenas no evento imprevisto no qual foi citada. Em grande parte dos eventos (46\%), não se mencionou nenhuma técnica ou ferramenta e, em poucos, foi usada mais de uma (23\%), totalizando 30 ocorrências. As técnicas mais citadas foram: o treinamento, utilizado em $17 \%$ dos eventos imprevistos; o plano de riscos, em $11 \%$ e o piloto, em $9 \%$.

\section{Quadro 18 - T\&F utilizadas por evento imprevisto}

\begin{tabular}{|c|c|c|c|c|c|c|c|c|c|c|c|c|c|c|c|c|c|c|c|c|c|c|c|c|c|c|c|c|c|c|c|c|c|c|c|c|}
\hline Tipo & Evento imprevisto & 1 & 2 & 3 & 4 & 5 & 6 & 7 & 8 & 9 & 10 & 11 & 12 & 13 & 14 & 15. & 16 . & 17 . & 18 & 192 & 202 & 212 & 222 & $23 \mid 2$ & $24 \mid 2$ & $25 \mid 2$ & $26 \mid 2$ & 272 & 829 & 3 & 031 & 32 & 33 & 34 & 35 & Total \\
\hline \multirow{3}{*}{$\begin{array}{l}\text { Técnicas de } \\
\text { criatividade }\end{array}$} & Brainstorming & $\mathrm{x}$ & & & & & & & & & & & & & & & & & & & & & & & & & & & & & & & & & & 1 \\
\hline & Estudo de viabilidade & $\mathrm{x}$ & & & & & & & & & & & & & & & & & & & & & & & & & & & & & & & & & & 1 \\
\hline & Pesquisa de mercado & & & & & & & & & & & & & & & & & & & & & & & $\mathrm{x}$ & & & & & & & & & & & & 1 \\
\hline \multirow{8}{*}{$\begin{array}{l}\text { Avaliação } \\
\text { do presente }\end{array}$} & Análise de stakeholder & & & & & & & & & & & & & & & & & & & & $\mathrm{x}$ & & & & & & & & & & & & & & & 1 \\
\hline & Construtibilidade & & & & & & & & & & & & & & & & & & & & & & & & & & & $\mathrm{x}$ & & & & & & & & 1 \\
\hline & Entrevista & & & & & & $\mathrm{x}$ & & & & & & & & & & & & & & & & & & & & & & & & & & & & & 1 \\
\hline & Piloto & & & & & & & & & & & & $\mathrm{x}$ & & & & & & & & & & & \begin{tabular}{l|l}
$x$ & 2 \\
\end{tabular} & $\mathrm{X}$ & & & & & & & & & & & 3 \\
\hline & Protótipo & & & & & & & & & & & & & & & & & & & & & $\mathrm{x}$ & & & & & & & & & & & & & & 1 \\
\hline & \begin{tabular}{|l|} 
Questionário \\
\end{tabular} & & & & & & & & & & & & & & & & $\mathrm{x}$ & & & & & & & & & & & & & & & & & & & 1 \\
\hline & $\begin{array}{l}\text { Reunião de planejamento e } \\
\text { análise }\end{array}$ & & & & & & & & & & & & & & & & & & & & & & & & & & & & & $\mathrm{x}$ & & $\mathrm{x}$ & & & & 2 \\
\hline & Simulação & & & & & & & & & & & & & & & $\mathrm{x}$ & & & & & & & & & & & & $\mathrm{x}$ & & & & & & & & 2 \\
\hline $\begin{array}{l}\text { Revisão } \\
\text { histórica }\end{array}$ & Reunião de status & & & $\mathrm{x}$ & & & & & & & & & & & & & & & & & & & & & $\mathrm{x}$ & & & & & & & & & & & 2 \\
\hline \multirow{5}{*}{$\begin{array}{l}\text { Técnicas e } \\
\text { ferramentas } \\
\text { de apoio }\end{array}$} & Contrato & & & & & & & & & & & & & & & & & $\mathrm{x}$ & & & & & & & & & & & & & & & & & & 1 \\
\hline & Matriz de responsabilidade & & & & & & & & & & & & & & & & & & & & $\mathrm{x}$ & & & & & & & & & & & & & & & 1 \\
\hline & Plano de comunicação & & & & & & & & & & & & & & & & & & & & $\mathrm{x}$ & & & & & & & & & & & & & & & 1 \\
\hline & \begin{tabular}{|l} 
Plano de Risco \\
\end{tabular} & $\mathrm{x}$ & & & & & & & & & & & $\mathrm{x}$ & & & $\mathrm{x}$ & & & & & & & & & & & & I & $\mathrm{x}$ & & & & & & & 4 \\
\hline & Treinamento & $\mathrm{x}$ & & & & & & $\mathrm{x}$ & $\mathrm{x}$ & & $\mathrm{x}$ & & & & & & $\mathrm{x}$ & & & $\mathrm{x}$ & & & & & & & & & & & & & 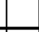 & & 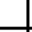 & 6 \\
\hline \multicolumn{2}{|r|}{ Total por imprevisto } & 4 & 0 & 1 & 0 & 0 & \begin{tabular}{|l|l|l|}
1 & \\
\end{tabular} & 1 & \begin{tabular}{|l|l|l|l|l|}
1 &
\end{tabular} & \begin{tabular}{|l|l|}
0 \\
\end{tabular} & 1 & 0 & 2 & 0 & 0 & 2 & 2 & 1 & 0 & 1 & 3 & 1 & 0 & 2 & 20 & 0 & \begin{tabular}{l|l}
0 & 2 \\
0
\end{tabular} & 2 & 10 & \begin{tabular}{l|l}
0 & 1 \\
0
\end{tabular} & $\begin{array}{lll}1 & 0 \\
1\end{array}$ & 1 & 0 & 0 & 0 & 30 \\
\hline
\end{tabular}

Essas T\&Fs foram classificadas nas seguintes categorias: técnicas de criatividade, dois eventos; avaliação do presente, onze eventos; revisão histórica, dois eventos e técnicas e ferramentas de apoio, presente em doze eventos. A análise descritiva é demonstrada no Gráfico 15, que mostra terem sido elas pouco utilizadas. 


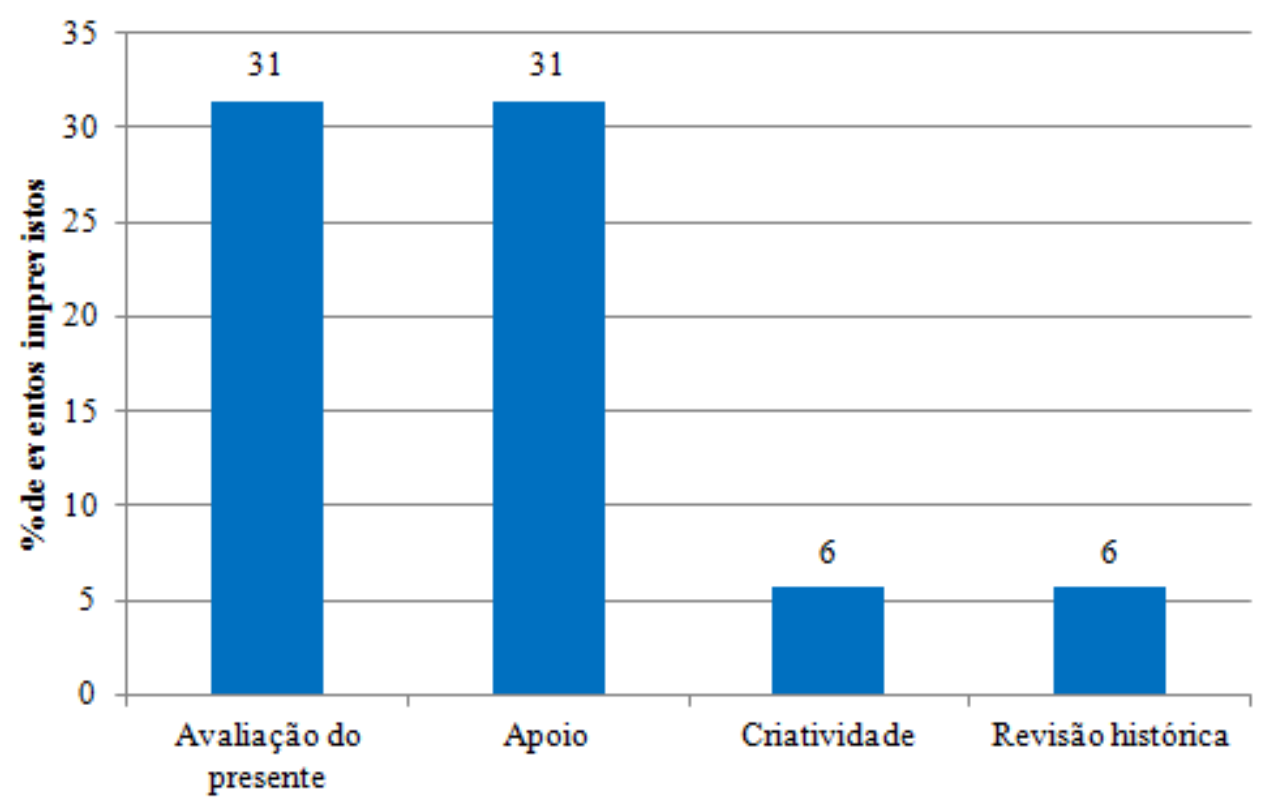

Tipos de técnicas e ferramentas

Gráfico 15 - Frequência de ocorrência de utilização de T\&F nos eventos imprevistos

\subsubsection{Fatores bloqueadores e facilitadores da gestão da incerteza}

Para cada evento imprevisto, foram avaliados os fatores bloqueadores e facilitadores da gestão da incerteza e para cada projeto questionou-se o entrevistado quais os fatores facilitadores poderiam auxiliar a identificar a incerteza imprevisível em qualquer tipo de projeto. Esses fatores serão detalhados a seguir.

\subsection{Fatores bloqueadores da gestão da incerteza}

Os fatores bloqueadores da gestão da incerteza são condições que dificultaram a gestão da incerteza, incluindo a sua identificação. Conforme Quadro 19, foram mencionados 17 fatores nas entrevistas que podem ser classificados em cinco tipos: externos à organização, internos à organização, gerados pela equipe, ligados à gestão de projetos e pessoais. Esses fatores totalizaram 48 ocorrências. Em cinco eventos imprevistos (14\%), não foi possível identificar nenhum fator bloqueador, mas em alguns deles (40\%) houve o reconhecimento de mais de um fator bloqueador, gerando uma média de 1,37 por evento imprevisto. 
Quadro 19 - Fatores bloqueadores da gestão da incerteza por evento imprevisto

\begin{tabular}{|c|c|c|c|c|c|c|c|c|c|c|c|c|c|c|c|c|c|c|c|c|c|c|c|c|c|c|c|c|c|c|c|c|}
\hline & Erento impreristo & 1 & 2 & 3 & 4 & 5 & 6 & 78 & $8 \leq$ & $9 \mid 1$ & 011 & $|12| 1$ & $13 \mid 1$ & 14 & 1516 & 17 & 18 & $19 \mid 2$ & 2021 & 22 & 23 & 24 & $25 \mid 2$ & $6 \mid 27$ & 28 & 29 & $30 \mid 3$ & & & 34 & & rotal \\
\hline \multirow{5}{*}{ Externo } & Meio ambiente & & & & & & & & & & & & & & & & & & & & & & & $\mathrm{x}$ & & & & & & & & 1 \\
\hline & Problemas com o cliente & & & & & & $\mathrm{x}$ & & & & & & & & & & & & & & & & & & & & & & & & & 1 \\
\hline & Problemas com o fornecedor & & & & & & & & $\mathrm{x}$ & $\mathrm{x}$ & & & & & & & & & & & & & & & $\mathrm{x}$ & & & & & & & 2 \\
\hline & Problemas com parceiro & & & & & & & & & & $\mathrm{x}$ & & & & & & & & & & & & & & & $\mathrm{x}$ & & & & & & 2 \\
\hline & Situação do mercado & & & & & & & & & & & $\mathrm{x}$ & & & & & $\mathrm{x}$ & $\mathrm{x}$ & & & & & & & & & & & & & & 3 \\
\hline \multirow{3}{*}{$\begin{array}{l}\text { Organi } \\
\text { zação }\end{array}$} & $\begin{array}{c}\text { Defesa dos interesses da } \\
\text { área } \\
\end{array}$ & & & & & & & & & & & & $x$ & $\mathrm{x}$ & & & & & & & & & & & & & & & & & & 1 \\
\hline & Falta de estrutura & & & & $\mathrm{x}$ & & & & & & & & & & & & & & & & & & & & & & & & & & & 1 \\
\hline & Falta de padronização & & & & & & & & & & & & $\mathrm{x}$ & $\mathrm{x}$ & & & & & & & & & & & & & & & & & & 1 \\
\hline Equipe & $\begin{array}{l}\text { Falta de experiência ou } \\
\text { conhecimento }\end{array}$ & & & & & & & & & & & & & & $\mathrm{x}$ & $\mathrm{x}$ & & $\mathrm{x}$ & $\mathrm{x}$ & & & $\mathrm{x}$ & & & & $\mathrm{x}$ & & $\mathrm{x}$ & & & & 7 \\
\hline \multirow{4}{*}{$\begin{array}{l}\text { Gestão de } \\
\text { Projeto }\end{array}$} & Falha na comunicação & & & & & $\mathrm{x}$ & & & & & & & $\mathrm{x} \mid \mathrm{x}$ & $\mathrm{x}$ & & & & & & & & & & & & & $\mathrm{x}$ & & $\mathrm{x}$ & & & 5 \\
\hline & Falta de definição & $\mathrm{x}$ & $\mathrm{x}$ & & & $\mathrm{x}$ & & & & & & & & & & & & & & & & & $\mathrm{x}$ & & & & & & & & & 4 \\
\hline & Falta de gestão de RH & & & & & & & & & & & & $\mathrm{x}$ & & & & & & & & & & & & & & & & & & & 1 \\
\hline & Problema no planejamento & & & & & & $\mathrm{x}$ & & & & & & & & & & & & $\mathrm{x}$ & & & & & $\mathrm{x}$ & & & $\mathrm{x}$ & $\mathrm{x}$ & & & & 5 \\
\hline \multirow{4}{*}{ Pessoal } & Ancoragem & & & & & & $\mathrm{x}$ & & & & & & & & & & & & & & & & & & & & & & & & & 1 \\
\hline & Consciência limitada & & & & & & & $\mathrm{x}$ & & & & & & & & & & & & & $\mathrm{x}$ & & & & & & & & & & $\mathrm{x}$ & 4 \\
\hline & $\begin{array}{c}\text { Escalada do } \\
\text { comprometimento }\end{array}$ & & & & & & & & & & $\mathrm{x}$ & & & & & & & & & & & & & & $\mathrm{x}$ & & & & & & & 2 \\
\hline & Excesso de confiança & & & & & & & & & $\mathrm{x}$ & & $\mathrm{x}$ & & $\mathrm{x}$ & $\mathrm{x}$ & $\mathrm{x} \mid$ & & $\mathrm{x}$ & & & & $\mathrm{x}$ & & $\mathrm{x}$ & & & & & & & & 7 \\
\hline & Total por imprevisto & 1 & 1 & 0 & 1 & 2 & \begin{tabular}{l|l}
3 & \\
\end{tabular} & \begin{tabular}{l|l}
1 & 0 \\
\end{tabular} & \begin{tabular}{l|l}
0 & 1 \\
\end{tabular} & \begin{tabular}{l|l}
1 & 1 \\
\end{tabular} & $\begin{array}{l}12 \\
\end{array}$ & 2 & \begin{tabular}{l|l}
2 & 3 \\
\end{tabular} & \begin{tabular}{l|l}
3 & 1 \\
\end{tabular} & \begin{tabular}{l|l}
1 & 1 \\
\end{tabular} & 2 & 1 & \begin{tabular}{|c|cc}
3 & 1 & $r$
\end{tabular} & \begin{tabular}{l|l}
0 & 2 \\
\end{tabular} & 0 & 1 & 2 & 1 & 3 & 2 & 2 & 2 & \begin{tabular}{l|l}
1 & 1 \\
\end{tabular} & & 1 & 1 & 48 \\
\hline
\end{tabular}

Os fatores com origem externa à organização ocorreram em nove dos eventos imprevistos (26\%) e os tipos podem ser:

- meio ambiente - identificado em um caso, impactou devido à demora em se obter a licença ambiental, diminuindo o tempo de avaliação do ambiente;

- $\quad$ problemas com o cliente - mencionado em apenas um caso; devido à ausência de um dos dois sponsors, por motivos particulares, no início do diagnóstico não foi possível identificar a diferença de expectativa entre eles;

- problemas com o fornecedor - no primeiro caso, o problema poderia ter sido identificado antes, caso tivesse havido um diagnóstico prévio e, no segundo, apesar de o fornecedor ser experiente, não avaliou que o ambiente poderia causar a perda do equipamento principal;

- $\quad$ problemas com o parceiro - houve problemas como a falta de decisão e a priorização do projeto dentro da organização parceira, ou a falta de habilidade em gerir projetos complexos;

- $\quad$ situação do mercado - no primeiro caso, houve dificuldade em haver fornecedores com conhecimento profundo do equipamento; no segundo, o assunto era muito novo e não havia pesquisas na área acadêmica no Brasil; no ultimo, as especialidades dos profissionais 
necessários para montagem da equipe ou era muito recente no Brasil, ou havia alta demanda, o que dificultava a contratação dos membros da equipe.

Os fatores relativos a problemas internos à organização ocorreram em dois eventos imprevistos $(6 \%)$ em três tipos diferentes. O primeiro caso refere-se à falta de estrutura da área para atender o excesso de demanda, embora a estrutura adquirida pudesse atender com folga as previsões. No segundo caso, a defesa dos interesses da área, sem visualizar o que seria importante para a organização, dificultou obter uma solução de consenso. Neste último caso, também ocorreu a falta de padronização na GP nos vários departamentos, que dificultou a avaliação da incerteza.

A equipe é a responsável por desenvolver o projeto com base em seu conhecimento e experiência. Assim, foi identificado apenas um tipo de fator bloqueador, em sete eventos imprevistos (20\%): a falta de experiência ou conhecimento. Esse tipo caracteriza-se pelo desconhecimento das necessidades do usuário, de questões jurídicas e de terceirização, de desenvolvimento de sistemas, da situação e das estratégias das prováveis empresas parceiras e das práticas organizacionais vigentes.

A gestão de projetos foi um fator bloqueador em doze eventos imprevistos (34\%). Esse fator bloqueador pode ser classificado em:

- falha na comunicação - identificada em cinco eventos, como pouco tempo para discussão e compartilhamento com a equipe; falta de comunicação e de transparência entre os sponsors; falta de comunicação oportuna com outras áreas; falta de comunicação de requisitos para o parceiro; falta de comunicação e entrega de documentos no momento oportuno para o cliente; falta de contato com o parceiro para compartilhar sua experiência e conhecimento;

- falta de definição - identificada em quatro eventos. Nos dois primeiros, pertencentes ao mesmo projeto, a definição faltante era do produto em geral; no terceiro, o contrato estava muito aberto, o que permitia solicitações pelo cliente de atividades não previstas, e, no último, a definição de uma entrega do projeto, não formalizada, poderia permitir que uma alteração do cliente pudesse afetar o projeto;

- $\quad$ falta de gestão de RH - Recursos Humanos - mencionada como faltava uma pessoa da área de RH, para perceber que a equipe não estava se entendendo e para fazer a integração dos membros; 
- problema no planejamento - identificado em cinco eventos, como na falta de percepção de que um dos dois sponsors não participaria do diagnóstico no início; falha na profundidade dos levantamentos efetuados; cronograma que não refletia a realidade; a avaliação na geração da proposta ao cliente não identificou o tempo real de implantação de um software auxiliar, nem as habilidades necessárias à equipe para essa implantação; na revisão da proposta não foi percebido que o tempo de testes era muito pequeno para a complexidade do projeto.

Convém discutir três pontos abordados pelos entrevistados como fator bloqueador oriundo da gestão de projetos. $\mathrm{O}$ primeiro refere-se à falta de definição do produto. $\mathrm{O}$ projeto possuía um nível de inovação para o qual não se podia esperar definição do produto logo no início do projeto, porém o método de gestão do evento imprevisto utilizado foi o planejamento. Como esse método exige essa definição, provavelmente o método de gestão dessa incerteza não foi adequado ou o gerente não soube avaliar os principais pontos de incerteza do projeto. $\mathrm{O}$ segundo ponto refere-se à falta de gestão de RH para perceber a falta de entrosamento da equipe; como isso também é responsabilidade do gestor de projeto, como um sensemaker (LOCH et al., 2006; SIMON, 2006), na realidade o gestor não estava desempenhando adequadamente as suas funções. $\mathrm{O}$ terceiro item refere-se aos problemas no planejamento; os dois eventos imprevistos pertencem ao mesmo projeto, indicando problemas de percepção de incerteza na geração da proposta, mesmo ela sendo submetida a especialistas globais no assunto.

Em 14 eventos imprevistos (40\%), foram citados fatores bloqueadores pessoais, como heurísticas e vieses. A ancoragem, viés na tomada de decisão, foi percebida em apenas um caso, pois a organização estava mais acostumada a um determinado direcionamento do trabalho e, “[...] por conta própria, caminhou muito mais neste sentido [...]”, tendo que mudar o rumo posteriormente, dado que um dos sponsors queria outro tipo de direcionamento.

A consciência limitada, viés na tomada de decisão, representa a limitação das pessoas em notar, procurar, usar e compartilhar informações que seriam relevantes, úteis, facilmente disponíveis. Ela transpareceu em quatro eventos imprevistos (8\%). No primeiro deles, o alto escalão fez uma parceria com uma empresa de software para automatizar processos de uma área da organização, confiando na palavra dos fornecedores de que eles tinham todas as 
funcionalidades e sem o apoio da respectiva área de TI da organização. Esse caso pode ser enquadrado na ilusão por foco (SCHKADEL, KAHNEMAN, 1998), pois provavelmente os sponsors focaram a solução do negócio, sem ver outras implicações como capacidade do fornecedor, integração com sistemas existentes, situação das áreas na organização, causando problemas para a implantação dos novos processos. No segundo caso de consciência limitada, o entrevistado indicou, como um dos problemas que não permitiu perceber o nível de incerteza sobre o assunto, que eles tomaram "[...] como base alguns achismos nossos e não uma pesquisa mais profunda, mais correta.” Isso demonstra a falta de percepção do grupo sobre o nível insuficiente de conhecimento sobre a classe econômica dos usuários do produto, diferente daquela a que normalmente se destinava. Como comentou o entrevistado: "A gente achou que conhecia o comportamento dele." No terceiro caso, o foco inicial da busca de informação estava errado, pois "A gente quer algo pronto no sistema e não tinha, não tinha, não dava, não dava." Quando o gerente do projeto percebeu que, numa área da organização, havia as informações, entretanto, em registros manuais, o que exigiu a geração de um sistema não previsto. $\mathrm{O}$ quarto caso ocorreu no mesmo projeto e demonstra que o fornecedor não percebeu a amplitude do produto do projeto: “[...] a visão dele era um pouco simplista a respeito, porque não é um banco de dados, é um sistema, é banco de dados, é relatório, é pesquisa, é gráfico, é um sistema e é interativo." Essa falta de visão gerou dificuldades e aliou-se a outros problemas que inviabilizaram a continuidade do contrato de serviço com aquele fornecedor.

A escalada do comprometimento representa o comprometimento com um curso de ação previamente selecionado até um ponto além daquele que um modelo racional de tomada de decisão prescreveria. Este tipo de comprometimento foi percebido em dois casos. No primeiro, o entrevistado relata um pensamento: “Ah, já que eu cheguei até aqui eu vou investir mais tempo." O próprio entrevistado ressalta que essa visão só foi perceptível agora, pois, no final do projeto, resolveram trocar de parceiro. O segundo caso demonstra uma das causas da escalada do comprometimento: a gestão da impressão de outros sobre você (BAZERMAN, MOORE, 2009, p. 111). O gerente era de outra área e foi chamado para gerar uma solução provisória que anteciparia a entrega do produto do projeto, até que a solução definitiva fosse implantada. No desenrolar do projeto, ele foi modificando o cronograma, sem explicações. Se ele afirmasse que o plano continha imprecisões, deveria assumir um erro cometido na primeira tomada de decisão. Portanto, cada vez mais, ele precisava mostrar que 
implantaria o projeto dentro do prazo. O projeto atrasou tanto, que depois só serviria como mitigação do risco da solução definitiva não ficar pronta no prazo. De repente, o projeto teve de parar quando o principal equipamento foi inutilizado, situação não prevista pela equipe.

Outro viés na tomada de decisão é o excesso de confiança, gerado pelo excessivo otimismo nas possibilidades de sucesso ou na comparação com o desempenho de outras pessoas. Foi um dos tipos que mais ocorreu: sete casos (14\%). O primeiro caso pode ser enquadrado como overestimation (MOORE, HEALY, 2007), pois o entrevistado superestimou as possibilidades de sucesso da parceria. O entrevistado havia feito uma grande pesquisa sobre os possíveis parceiros, avaliando, inclusive, a respectiva atuação no exterior. $\mathrm{O}$ parceiro escolhido, uma multinacional, seria a segunda opção, pois nos países nos quais ele se havia instalado existiam muitas dificuldades para sua adaptação ao contexto local e às parcerias. Ele relatou que "Talvez a gente tenha tido o viés de interpretar erradamente a chance de sucesso de uma empreitada [...]" da empresa, pois ela foi muito lenta na introdução do produto em sua carteira, o que inviabilizou a blindagem da concorrência.

Os próximos casos são exemplos de overprecision (MOORE, HEALY, 2007), excessiva confiança na precisão de estimativas subjetivas. No primeiro caso, como a equipe havia pensando no evento, incluíram-no na GR, mas a probabilidade de que ocorresse era muito baixa. O segundo evento foi incluso na GR, inclusive com a contingência de que, se não existisse a tecnologia no mercado nacional, obteriam no exterior, mas também lá não existia. Como reportado pelo entrevistado: “[...] a gente não tinha ido a fundo o suficiente para saber que não existia." No terceiro caso, as pessoas "[...] estavam muito mais preocupadas com outras situações do ambiente e esta [...] eles acharam que era uma coisa muito tranquila [...]", porém ocorreu um incidente que quase inviabilizou a implantação estratégica do sistema. No quarto caso, conforme o entrevistado, "A gente tinha certeza que não ia acontecer e aconteceu!". Houve a ação trabalhista do terceiro, mas o entrevistado mesmo justifica-se dizendo que não tinha experiência sobre o assunto e havia falta de conhecimento jurídico também. No quinto caso, houve “[...] excesso de otimismo para encontrar esse profissional no mercado [...]”, porque era uma atividade muito específica e eles não contavam com esse tipo de profissional na organização para avaliar a oferta. No sexto caso, a equipe "[...] subestimou o impacto do relevo e a condição climática [...]” do local físico de implantação do projeto. 
O Gráfico 16 resume a distribuição dos fatores bloqueadores da gestão da incerteza. Os fatores pessoais (40\%) e os relativos à gestão de projetos (34\%) foram os de maior ocorrência, diferentemente do fator gerador da incerteza imprevisível, em que a causa externa foi a mais comum. Como fator bloqueador, o tipo externo ocupa a terceira posição.

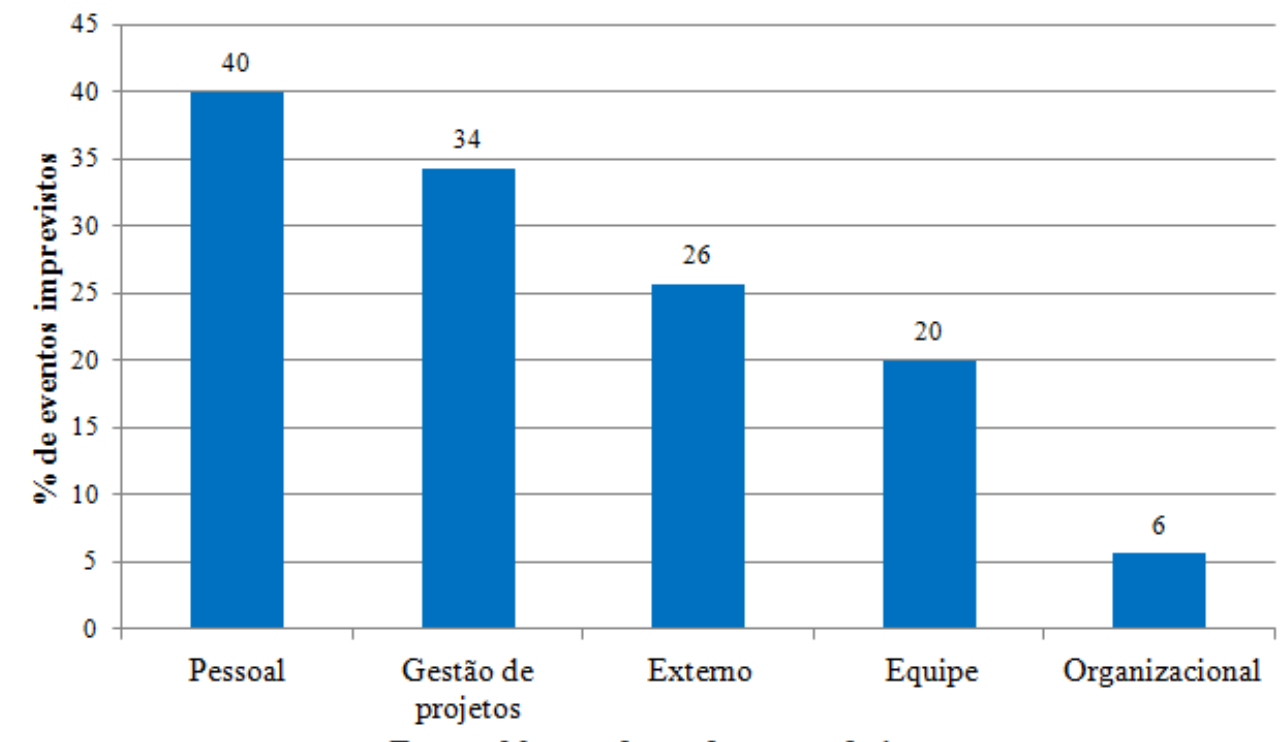

Fatores bloqueadores da gestão da incerteza

Gráfico 16 - Frequência de ocorrência dos fatores bloqueadores nos eventos imprevistos

\subsection{Fatores facilitadores da gestão da incerteza}

Os fatores facilitadores existentes foram classificados, da mesma forma que os bloqueadores, em: externo à organização, interno à organização, relativo à equipe, relativo à GP e pessoal, conforme pode ser visto no Quadro 20. Foram identificadas 39 ocorrências para os 35 imprevistos; em doze eventos imprevistos (34\%), não foi possível identificar fatores facilitadores, apesar de nove outros (26\%) apresentarem mais de um fator. 
Quadro 20 - Fatores facilitadores da gestão da incerteza por evento imprevisto

\begin{tabular}{|c|c|c|c|c|c|c|c|c|c|c|c|c|c|c|c|c|c|c|c|c|c|c|c|c|c|c|c|c|c|c|c|c|c|c|c|}
\hline & Evento imprevisto & 1 & 2 & 3 & 4 & 5 & 6 & 7 & 8 & 9 & 10 & 11 & 12 & 131 & 14 . & 15 & 16 . & 17 & 181 & 192 & 2021 & 22 & 23 & 24 & 25 & 262 & 272 & 2829 & 930 & 31 & 32 & 33 & 34 & 35 & Total \\
\hline \multirow{2}{*}{ Externo } & Facilitação do cliente & & & & & $\mathrm{x}$ & & & & & & & & & & & & & & & & & & & $\mathrm{x}$ & & & & & & & & & & 2 \\
\hline & Facilitação do fornecedor & & & & & & & & & & & & & & & & & & & & $\mathrm{x}$ & & & & & & & & & & & & & & 1 \\
\hline \multirow{3}{*}{$\begin{array}{l}\text { Organi } \\
\text { zação }\end{array}$} & Apoio de pares & & & & & & & & & & & & & & $\mathrm{x}$ & & & & & & & & & & & & & & & & & & $\mathrm{x}$ & & 2 \\
\hline & Apoio do sponsor & & & $\mathrm{x}$ & $\mathrm{x}$ & & & & $\mathrm{x}$ & & & & & & $\mathrm{x}$ & & & & & & $\mathrm{x}$ & & & & & & & & & & & & & & 5 \\
\hline & Assunção de risco & & & & & $\mathrm{x}$ & & & & & & & & & & & & & & & & & & & & & & & & & & & & & 1 \\
\hline \multirow{6}{*}{ Equipe } & Abertura para problemas & & & $\mathrm{x}$ & & & & $\mathrm{x}$ & $\mathrm{x}$ & & & & & & & & & & & & & & & & & & & & & & & & & & 3 \\
\hline & Multidisciplinaridade & & & & & & & & & & & & & & & & & & $\mathrm{x}$ & & & & & & & & & & & & & & & & 1 \\
\hline & $\begin{array}{c}\text { Pessoas com poder de } \\
\text { decisão }\end{array}$ & & & & & & & & & & & & & & & & & & & & & & & & & & $\mathrm{x}$ & & & & & & & & 1 \\
\hline & Proximidade com o cliente & & & & & & & & & & & & & & & & & & & & & & & & & & & $\mathrm{x}$ & $\mathrm{x}$ & & & & & & 1 \\
\hline & Trabalho em Equipe & $\mathrm{x}$ & & & & & $\mathrm{x}$ & & & & & & & & & & & & & & & & & & & $\mathrm{x}$ & & & & & $\mathrm{x}$ & & & $\mathrm{x}$ & 5 \\
\hline & Visão externa do problema & & & & & & & & & & & & $\mathrm{x}$ & & & & & & & & & & & & & & & & & & & & & & 1 \\
\hline \multirow{3}{*}{$\begin{array}{c}\text { Gestão de } \\
\text { Projetos }\end{array}$} & Busca de informação & & & & & & & & & & & & & & & & $\mathrm{x}$ & & & & $\mathrm{x}$ & & $\mathrm{x}$ & & & & & & & & & & & & 3 \\
\hline & Flexibilidade & & & & & & & & & & & & & & & & & & & & & & $\mathrm{x}$ & & & & & & & & & & & & 1 \\
\hline & Objetivo claro & & & $\mathrm{x}$ & & & & & & & & & & & & & & & $\mathrm{x}$ & & & & & & & & & & & & & & & & 2 \\
\hline \multirow{3}{*}{ Pessoal } & Comprometimento & & & $\mathrm{x}$ & & & & & & & & & & & & & & & & & & & & & & & & & & & $\mathrm{x}$ & & & & 2 \\
\hline & Criatividade & & $\mathrm{x}$ & & & & & & & & & & & & & & & & & & & & & & & & $\mathrm{x}$ & & & & & & & & 2 \\
\hline & Experiência & & & $\mathrm{x}$ & & & & & & & $\mathrm{x}$ & & $\mathrm{x}$ & & $\mathrm{x}$ & & & & $\mathrm{x}$ & & & & & & & & $\mathrm{x}$ & & & & & & & & 6 \\
\hline \multicolumn{2}{|c|}{ Total por evento imprevisto } & 1 & 1 & 5 & 1 & 2 & 1 & 1 & 2 & 0 & 1 & 0 & 2 & 0 & 3 & 0 & 1 & 0 & 3 & \begin{tabular}{l|l}
0 & 1
\end{tabular} & \begin{tabular}{l|l}
1 & 2
\end{tabular} & 0 & 2 & 0 & 1 & 1 & \begin{tabular}{l|l}
3 & 0
\end{tabular} & \begin{tabular}{l|l}
0 & 1
\end{tabular} & \begin{tabular}{l|l}
1 & 0
\end{tabular} & 0 & 2 & 0 & 1 & 1 & 39 \\
\hline
\end{tabular}

Os fatores facilitadores externos ocorreram em três eventos imprevistos (9\%). Dois foram facilitados pelo cliente; no primeiro, o cliente tomou a decisão, resolvendo um impasse; no outro, o cliente permitiu que o projeto fosse encerrado sem uma das entregas, pois ela havia sido modificada por uma legislação, após o início do projeto e não poderia ser atendida dentro do escopo e orçamento previstos. O fornecedor permitiu uma alteração sem custo, provavelmente pelo fato de a organização ser um cliente novo, segundo o próprio entrevistado.

A organização facilitou a gestão em sete eventos imprevistos (20\%), podendo ser classificada em:

- apoio de pares - no primeiro caso, os gerentes das áreas funcionais também estavam envolvidos na solução do problema, mas, no segundo caso, foi um compartilhamento de informação entre a equipe de gerentes de projetos para identificarem uma solução;

- $\quad$ apoio do sponsor - mencionado em quatro casos; esse apoio permitiu, em um caso, a agilização das iniciativas e no outro motivou a equipe, pois "Todas as equipes foram muito 
elogiadas o tempo todo." No terceiro, foi mencionado o forte apoio do patrocinador e, no último, o apoio da alta diretoria foi total;

- $\quad$ assunção de risco - relatado em um caso no qual a consultoria decidiu procrastinar a escolha de um líder para a implantação do processo no cliente, mas havia o risco político dessa indicação, além do aumento do escopo do projeto para selecionar esse líder.

Algumas características da equipe facilitaram a gestão do imprevisto em doze eventos imprevistos (34\%). São elas:

- abertura para problemas - ocorreu em três casos. No primeiro, o gerente pediu para a equipe informar os problemas enfrentados: "Se tiver que falar que quer show stopper ${ }^{50}$ você fala, que a gente vai negociar [...]"; o segundo e terceiro eventos imprevistos são do mesmo projeto, no qual o sponsor queria saber o que realmente estava acontecendo;

- multidisciplinaridade da equipe - facilitou o projeto em um caso, pois o tema era inovador e abrangia várias especialidades, representadas na equipe;

- pessoas com poder de decisão na equipe - ajudaram a implantar as alternativas criativas geradas por elas, para solucionar o problema em um caso;

- proximidade com o cliente - permitiu, em um caso, que a equipe identificasse antecipadamente o imprevisto numa conversa com ele;

- $\quad$ trabalho em equipe - mencionado em cinco eventos, como a integração e suporte da equipe para a solução dos problemas, a integração com o cliente para desenvolver uma solução mais adequada, o esforço das pessoas, mesmo sendo voluntárias, para obter um bom resultado e o respeito entre os integrantes da equipe;

- $\quad$ visão externa do problema - relatada por um entrevistado, que era o sponsor, esse tipo de visão distinguiu alternativas que não são percebidas por quem está diretamente envolvido no problema.

A gestão de projetos, compreendendo métodos e procedimentos dentro das várias áreas de conhecimento, facilitou cinco eventos imprevistos (14\%). Os tipos encontrados foram:

- busca de informação - relatada em três casos; no primeiro deles, o entrevistado salientou o fato de eles irem "[...] a campo e identificar quais são as dificuldades e tomar medidas positivas [...]"; no segundo caso, o entrevistado apontou a experiência de gerar e implantar a comunicação sobre o projeto para os stakeholders; no último, o entrevistado

\footnotetext{
${ }^{50}$ Show stopper significa a impossibilidade de cumprir a data prevista de implantação do projeto.
} 
indicou a identificação da falta do conhecimento e, consequentemente, a busca de informação para superá-la;

- $\quad$ flexibilidade - relatada em um caso, no qual houve a decisão de replanejar o projeto para testar as mudanças efetuadas, criando um novo piloto;

- objetivo claro - mencionado em dois casos; no primeiro, apesar dos objetivos específicos de cada área, havia um bem claro para a equipe que era a implantação do projeto dentro do prazo; no segundo caso, o planejamento ajudou a "[...] conseguir deixar bem claro qual que era o objetivo."

Os fatores pessoais que impactaram em oito eventos imprevistos (23\%) foram:

- $\quad$ o comprometimento - indicado em dois casos; no primeiro, citou-se que "Todo mundo tinha iniciativa de contribuir para definir, reduzir as dúvidas e fazer [...]", consequência do comprometimento com os clientes que já haviam comprado o produto; no segundo, essa foi uma característica dos voluntários;

- a criatividade - muito importante em dois projetos; no primeiro, para gerar a solução e, no segundo, para gerar as alternativas. Conforme o entrevistado, "Você precisa ter pessoas que têm uma visão de mais fora da caixa";

a experiência das pessoas na equipe contribuiu em seis casos; no primeiro, a multinacional trouxe alguns especialistas que haviam implantado aquele tipo de projeto no exterior; no segundo caso, o líder do projeto trouxe mais de 20 anos de experiências na área; no terceiro caso, o sponsor indicou que a volta às origens e a conceitos antigos os ajudou na busca da solução; no quarto caso, o conhecimento do sponsor ajudou a formular a solução com base na gestão de portfólio; no quinto, o conhecimento dos termos científicos foi importante e, no último, o conhecimento das alternativas tecnológicas foi fundamental.

Resumindo, o Gráfico 17 mostra o percentual de ocorrência de cada tipo de fator facilitador nos eventos imprevistos. Nele pode-se observar que os fatores relativos à equipe foram os mais citados. 


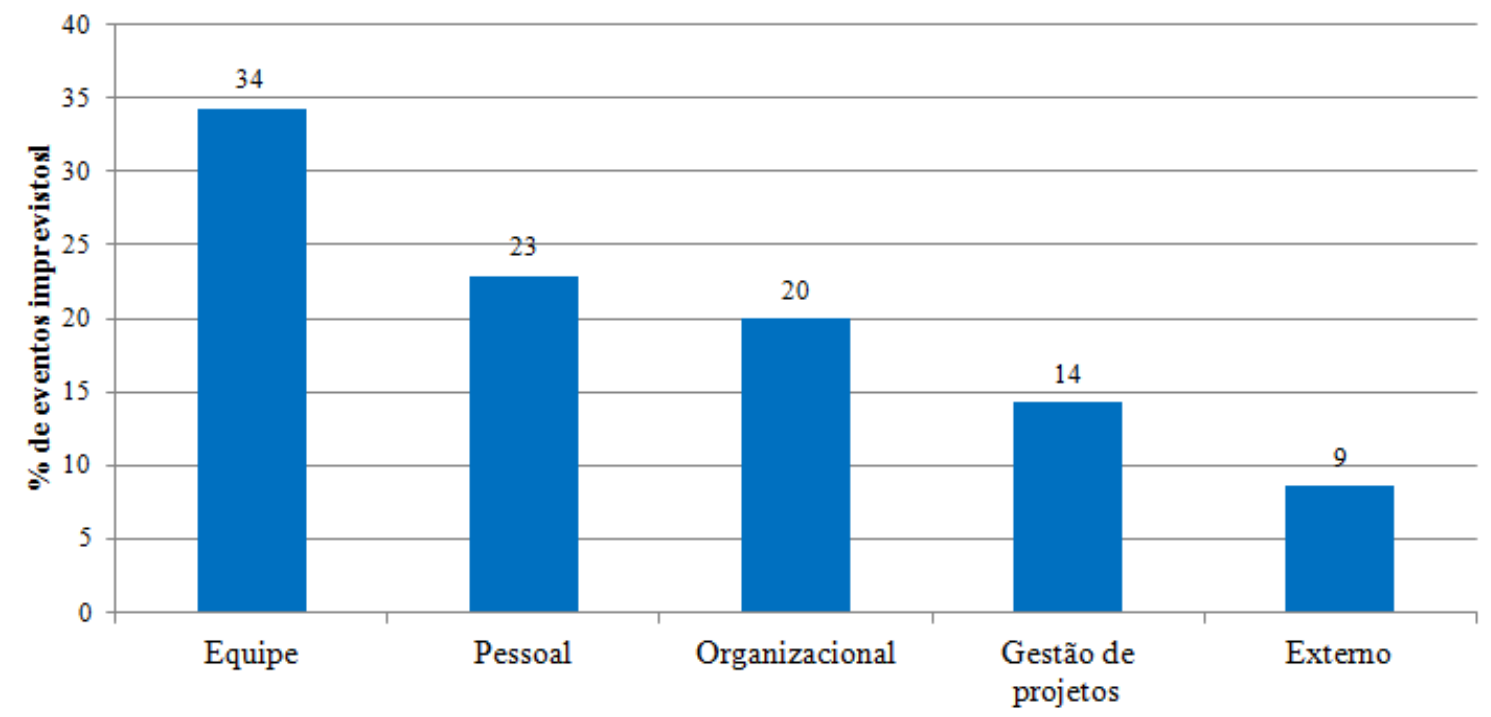

Fatores facilitadores da gestão da incerteza

Gráfico 17 - Frequência de ocorrência dos fatores facilitadores nos eventos imprevistos

\subsection{Fatores facilitadores idealizados da gestão da incerteza}

Além dos fatores que efetivamente influenciaram a identificação da incerteza imprevisível, foram avaliados aqueles que poderiam auxiliar a identificar eventos imprevistos em qualquer tipo de projeto, independentemente da utilização do projeto, objeto dessa pesquisa. Essa análise será feita, portanto, por projeto e não por evento imprevisto, como nas análises anteriores. Eles foram chamados de fatores idealizados, pois não há garantia de sua eficiência nem de seu uso. O Quadro 21 apresenta os 17 fatores idealizados mencionados nas entrevistas, que correspondem a 28 ocorrências. Esses fatores idealizados foram categorizados nos seguintes tipos: externo, organizacional, referente à gestão de projetos, referente a $T \& F$ e a pessoal. 
Quadro 21 - Fatores facilitadores idealizados da gestão da incerteza por projeto

\begin{tabular}{|c|c|c|c|c|c|c|c|c|c|c|c|c|c|c|c|c|c|c|c|c|c|c|}
\hline & Projeto & 1 & 2 & 3 & 4 & 5 & 6 & 7 & 8 & 9 & 10 & 11 & 12 & 13 & 14 & 15 & 16 & \begin{tabular}{|c|} 
Total \\
Fator \\
Idealizado
\end{tabular} & $\begin{array}{c}\text { Total } \\
\text { Fator } \\
\text { Facilitador }\end{array}$ & $\begin{array}{c}\text { Total } \\
\text { Fator } \\
\text { Bloqueado }\end{array}$ & $\begin{array}{c}\text { Total } \\
\text { Causa }\end{array}$ & $\begin{array}{l}\text { Total } \\
\text { T\&F }\end{array}$ \\
\hline \multirow{3}{*}{ Externo } & $\begin{array}{c}\text { Consultoria ou parceria } \\
\text { externa }\end{array}$ & & & & & I & $\mathrm{F}$ & & I & & & & I & I & & & & 4 & 1 & 0 & 0 & 0 \\
\hline & Informação disponivel & & & & & & & & & B & & I & & & & & & 1 & 0 & 1 & 0 & 0 \\
\hline & $\begin{array}{c}\text { Transparência do } \\
\text { fornecedor }\end{array}$ & & & & & B & & & & & & & & B & & & I & 1 & 0 & 2 & 0 & 0 \\
\hline \multirow{2}{*}{ Organização } & Apoio do sponsor & & $\mathrm{F}$ & & F & & & $\mathrm{F}$ & & & & $\mathrm{F}$ & & I & & & & 1 & 4 & 0 & 0 & 0 \\
\hline & $\begin{array}{c}\text { Envolvimento de outras } \\
\text { áreas }\end{array}$ & & & & $\mathrm{I}, \mathrm{C}$ & & & $\mathrm{C}$ & & & & & & & C & & I, C & 2 & 0 & 0 & 4 & 0 \\
\hline \multirow{4}{*}{$\begin{array}{l}\text { Gestão de } \\
\text { Projetos }\end{array}$} & Busca de informação & & & I & & & & & I & F & I & $\mathrm{F}$ & & & & I & & 4 & 2 & 0 & 0 & 0 \\
\hline & Integração com o cliente & & & & & & & & & & & & & & I, F & & & 1 & 1 & 0 & 0 & 0 \\
\hline & Integração das pessoas & $\mathrm{F}$ & & F & & & I & & & & & & $\mathrm{F}$ & & I & $\mathrm{F}$ & $\mathrm{F}$ & 2 & 5 & 0 & 0 & 0 \\
\hline & Planejamento & & & I, B & I & & & & & I & B & & & B & I, B & & & 4 & 0 & 4 & 0 & 0 \\
\hline \multirow{7}{*}{$\begin{array}{l}\text { Técnicas e } \\
\text { Ferramentas }\end{array}$} & Brainstorming & I, T & & & & & & & & & & & & & & & & 1 & 0 & 0 & 0 & 1 \\
\hline & Cenário & & & I & & & & & & & & & & & & & & 1 & 0 & 0 & 0 & 0 \\
\hline & Dicionário de riscos & & & & & & & I & & & & & & & & & & 1 & 0 & 0 & 0 & 0 \\
\hline & Matriz de estratégia & & & I & & & & & & & & & & & & & & 1 & 0 & 0 & 0 & 0 \\
\hline & Simulação & I & & & & & & $\mathrm{T}$ & & & & & & $\mathrm{T}$ & & & & 1 & 0 & 0 & 0 & 2 \\
\hline & SWOT & I & & & & & & & & & & & & & & & & 1 & 0 & 0 & 0 & 0 \\
\hline & Treinamento & $\mathrm{T}$ & & & I, T & $\mathrm{T}$ & & & $\mathrm{T}$ & $\mathrm{T}$ & & & & & & & & 1 & 0 & 0 & 0 & 5 \\
\hline Pessoal & Criatividade & $\mathrm{I}, \mathrm{F}$ & & & & & & & & & & & & & & & & 1 & 1 & 0 & 0 & 0 \\
\hline \multicolumn{2}{|c|}{ Total de fatores idealizados por projeto } & 4 & 0 & 4 & 3 & 1 & 1 & 1 & 2 & 1 & 1 & 1 & 1 & 2 & 3 & 1 & 2 & 28 & 14 & 7 & 4 & 8 \\
\hline
\end{tabular}

Para avaliar a abrangência do fator facilitador idealizado, ele será comparado com outros fatores e indicadores da pesquisa. Assim, no Quadro 21, as ocorrências identificadas como fator idealizado estão marcadas com a letra I; apenas em um projeto não foi possível identificar um fator facilitador idealizado. As células em verde e com a letra $\mathrm{F}$ representam que aquele fator foi indicado como facilitador. As células em vermelho referem-se ao fator gerador da incerteza imprevisível - causas - e estão marcadas com a letra $C$; aquelas em cinza, marcadas com a letra B, referem-se a fatores bloqueadores da gestão da incerteza. As técnicas e ferramentas estão em azul e com a letra T.

Os fatores externos que poderiam contribuir para a identificação da incerteza foram mencionados em seis projetos $(17 \%)$. A consultoria ou parceria externa caracteriza-se pela contratação ou formatação formal de uma parceria para se obter uma visão ou informação externa à organização, mencionada em quatro projetos. No primeiro, o entrevistado informou que uma consultoria externa poderia ajudá-lo a melhorar algumas avaliações, e isso foi comentado para compensar os fatores bloqueadores pessoais. No segundo projeto, um 
especialista poderia ter alertado a equipe para os alguns fatores, compensando a falta de conhecimento desses pela equipe. No terceiro projeto, o apoio de uma universidade seria muito proveitoso, tanto no que se refere ao fornecimento de mão de obra quanto ao de conhecimento. No último caso, o entrevistado sentiu a necessidade de um especialista para trazer mais conhecimento para a equipe, também para compensar um fator bloqueador da equipe, relativo à falta de conhecimento. Esse tipo de facilitador idealizado pôde ser relacionado com o fator facilitador da gestão da incerteza, mencionado em um caso, enquadrado no tipo 'visão externa do problema' pela equipe, conforme pode ser visto na célula verde destacada no Quadro 21.

Com relação à informação disponível, um entrevistado mencionou que ele gostaria de ter acesso a algum estudo sobre o resultado de projetos semelhantes, nacional ou internacional, ou mais informações sobre esse tipo de projeto. O projeto 9 também indicou a falta de estudos acadêmicos como um fator bloqueador externo da gestão da incerteza. A transparência do fornecedor foi crítica para um entrevistado. Ele comentou que “[...] eles [os representantes do fornecedor] dizem que é possível, porque as pessoas também sonham." Depois se percebe, entretanto, a inviabilidade da solução ou o prazo maior do que o estabelecido inicialmente. Esse fator está relacionado com o fator bloqueador externo, problema com fornecedores, mencionado por outros dois projetos.

Pode-se concluir que os fatores idealizados externos referem-se a ter mais informação e com qualidade, pois a consultoria ou parceria externa deveriam auxiliar a equipe a ter mais informação disponível. A transparência do fornecedor também poderia contribuir na medida em que geraria uma avaliação mais adequada, prevendo em algum nível as dificuldades que seriam enfrentadas.

O fator idealizado da categoria organizacional foi mencionado em três projetos (19\%). Segundo um entrevistado, o apoio do sponsor permitiria que o consultor do PMO pudesse cobrar mais efetivamente as informações sobre os riscos do gerente do projeto. Esse fator foi também identificado como facilitador organizacional em quatro outros projetos. Em dois projetos, os entrevistados comentaram que o envolvimento de outras áreas, desde o início do projeto, poderiam ter - pelo menos - minimizado os problemas enfrentados. Esse fator foi o único a ser relacionado com as causas da incerteza imprevisível, especificamente com a 
causa organizacional. Isso ocorreu pela falta de integração das áreas em eventos imprevistos de quatro projetos.

A gestão de projetos foi o fator idealizado mais mencionado nos projetos, com nove ocorrências (26\%). A busca de informação está relacionada com ações que a equipe poderia ter desenvolvido durante o projeto e foi mencionada por quatro entrevistados. O primeiro considera que se poderiam buscar informações sobre o evento imprevisto antecipadamente, inclusive pela internet. No segundo projeto, o entrevistado indicou que ele poderia ter-se informado com outras empresas sobre o processo de terceirização. O terceiro disse que "[...] procuraria por anormalidades, coisas que não estão dentro do comum." O último, do mesmo modo que o segundo entrevistado, conversaria com as empresas com projetos semelhantes há mais tempo. A busca de informação também foi identificada como um fator facilitador em outros dois projetos.

A integração com o cliente foi indicada como relevante por um dos entrevistados, pois o profundo conhecimento do cliente contribuiria com informações que poderiam, inclusive, ter antecipado um dos eventos imprevistos. Nesse mesmo projeto, o cliente também foi citado como um facilitador, pela proximidade da equipe com ele. Isso pode significar que essa proximidade não foi aproveitada de forma efetiva por parte da equipe.

A integração das pessoas foi percebida em dois projetos: em um deles, a falta de integração das pessoas gerou um dos eventos imprevistos e, no segundo, o próprio sponsor sentiu que poderia ter contribuído mais para o projeto. $\mathrm{O}$ trabalho em equipe foi citado como um fator facilitador em outros cinco projetos, como se pode observar nas células azuis do Quadro 21.

O planejamento foi indicado como um fator idealizado em quatro projetos. No primeiro caso, o entrevistado considerou que a equipe poderia ter planejado mais, tanto como responder ao cliente, criando uma contingência, quanto no planejamento das atividades. $\mathrm{O}$ entrevistado também citou, como fator bloqueador da identificação, a falha no planejamento. No segundo caso, o entrevistado aplicaria um planejamento com “[...] uma elaboração progressiva, desenvolver por incrementos." No terceiro caso, o entrevistado acha fundamental o tempo para planejar, pensar bem antes de executar, considerando que a falta desse tempo é um problema cultural dos brasileiros. No quarto caso, o sponsor sentiu a falta de um modelo 
de governança do projeto, com a definição de responsabilidade pelas atividades, tendo indicado, inclusive, como um fator bloqueador num dos imprevistos do projeto. Outros dois projetos também indicaram falhas no planejamento como fator bloqueador da gestão da incerteza.

Em quatro projetos, $11 \%$, as técnicas e ferramentas foram apontadas como fatores que idealmente poderiam contribuir para diminuir as incertezas do projeto; cada uma delas foi mencionada apenas em um projeto. Apenas três das sete ferramentas citadas - brainstorming, simulação e treinamento - foram utilizadas nos eventos imprevistos. Pode-se considerar que as técnicas e ferramentas pertencem à GP, dado que é a gestão que define qual delas deverá ser usada. Assim, se avaliarmos esses dois grupos de fatores conjuntamente, eles foram indicados em onze projetos $(31 \%)$.

O último fator é o que envolve as características pessoais dos membros da equipe, mencionado em apenas um dos projetos. A criatividade foi mencionada como fundamental para esse processo. Esse mesmo entrevistado também relatou a criatividade como um fator facilitador.

Concluindo, pode-se perceber, no Quadro 21, que todos os fatores idealizados mencionados, com exceção de algumas técnicas e ferramentas, também foram citados como uma causa da incerteza imprevisível, um fator bloqueador ou facilitador da gestão da incerteza, ou uma T\&F utilizada no evento imprevisto.

\subsubsection{Características da organização: nível de cultura de atenção}

Podem existir várias características da organização que influenciam a gestão da incerteza, mas será avaliado apenas o seu nível de cultura de atenção. A Tabela 6 mostra a frequência do nível de cultura de atenção nas organizações pesquisadas. Apesar de serem 16 projetos, dois deles se referem à mesma organização, por isso o total foi 15 organizações. O nível com valor zero refere-se a uma organização que não pôde responder ao questionamento, por causa do pequeno porte e especificidades organizacionais. Quase a totalidade das organizações apresenta forte nível de cultura, caracterizada pelo valor do nível ser maior do que 17 - doze em 15 casos, a média é próxima de 20 (ou outras estatísticas centrais no valor de 22 ou 23), 
podendo ser considerada uma amostra relativamente homogênea quanto a essa variável, com coeficiente de variação próximo de $30 \%$.

Tabela 6 - Estatísticas do nível de cultura de atenção da organização

\begin{tabular}{|c|c|}
\hline $\begin{array}{c}\text { Nível de cultura de } \\
\text { atenção da organização }\end{array}$ & Frequência \\
\hline 0 & 1 \\
\hline 14 & 1 \\
\hline 15 & 1 \\
\hline 18 & 2 \\
\hline 21 & 2 \\
\hline 22 & 1 \\
\hline 23 & 3 \\
\hline 24 & 1 \\
\hline 25 & 2 \\
\hline 27 & 1 \\
\hline Total & 15 \\
\hline
\end{tabular}

\begin{tabular}{|c|c|}
\hline Estatísticas & $\begin{array}{c}\text { Nível de cultura de } \\
\text { atenção da organização }\end{array}$ \\
\hline Média & 19,9 \\
\hline Mediana & 22 \\
\hline Moda & 23 \\
\hline Desvio-padrão & 6,6 \\
\hline Coeficiente de Variação & $33 \%$ \\
\hline Mínimo & 0 \\
\hline Maximo & 27 \\
\hline
\end{tabular}

\subsubsection{Características do projeto}

Serão avaliadas, nos próximos itens, cinco características dos projetos, uma referente ao método de gestão e as outras quatro em relação à tipologia dos projetos: tipo de inovação, tipo de inovação em serviços, nível de incerteza tecnológica e nível de complexidade.

\subsection{Método de gestão do projeto}

Sobre os métodos de gestão do projeto, praticamente a totalidade dos projetos, 15 dos 16 , utilizou métodos de planejamento, como demonstrado no Gráfico 18, pelo uso de práticaspadrão, por exemplo o Guia PMBOK (PMI, 2008) e o PRINCE2 (OGC, 2005). O método de planejamento incorpora três tipos de aplicação: 
- formal - utilizado em $50 \%$ dos projetos, que compreende o uso da maioria dos processos sugeridos pelas melhores práticas, como comenta um entrevistado “[...] a gente tinha um cronograma, trabalhamos em cima de um projeto master, de um plano master e tinha 'n' riscos e as suas mitigações, seguindo todos os padrões de projeto [...]";

- $\quad$ macro - 38\% dos projetos nos quais não há formalização de todas as práticas, como comentado por um entrevistado "A gente só fazia aquele acompanhamento, quase diário do projeto todo. Era mapeado dia a dia, porque não houve intenção de fazer um projeto completo.";

- $\quad$ informal - ocorreu em apenas um projeto, quando a formalização da GP foi terceirizada a uma empresa parceira, mas, depois de enfrentar alguns problemas, a organização criou um planejamento macro.

Não houve casos de aplicação do método de selecionismo e improvisação nos projetos estudados e apenas um projeto foi considerado gerido por experimentação. Esse é um planejamento de curto prazo, com a previsão de revisão periódica da situação, incluindo a possibilidade de modificar o planejamento ou mesmo refazer alguma parte do produto. $\mathrm{O}$ projeto refere-se ao desenvolvimento de um novo serviço de uma consultoria, desenvolvido por partes, sendo avaliado ao final de cada uma delas; segundo o entrevistado: "Não tem muita formalização, se você olhar dentro daquele safári de estratégia, eu acho que a gente está enquadrado mais naquele tipo de empresa que é do aprendizado. Sabe aquela coisa que você vai aprendendo, vai-se realimentando, então todo dia a estratégia pode mudar."

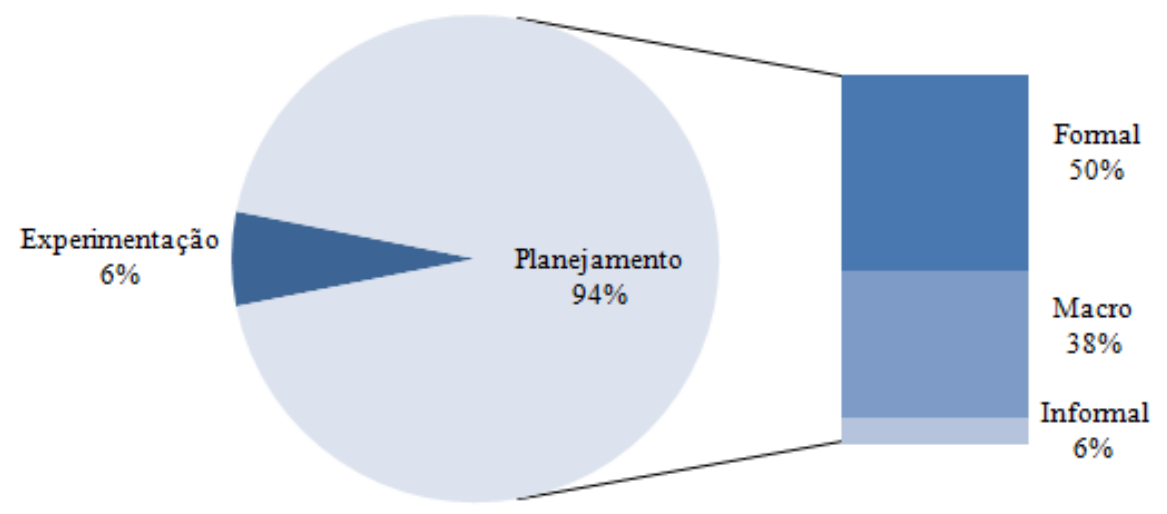

Gráfico 18 - Frequência do método de gestão do projeto 


\subsection{Tipologia do projeto}

O Quadro 22 apresenta as características dos projetos pesquisados que serão comentados neste item, por tipo de inovação, tipo de inovação em serviços, nível de incerteza tecnológica e nível de complexidade. Para complementar a análise dessas características, as seguintes colunas foram inclusas no quadro: quantidade de pessoas envolvidas, novas competências para a organização, novo produto / serviço para a organização, novo mercado para a organização e novo produto / serviço para o mercado nacional.

Quadro 22 - Características dos projetos pesquisados

\begin{tabular}{|c|c|c|c|c|c|c|c|c|c|}
\hline Projeto & $\begin{array}{l}\text { Tipo de } \\
\text { inovação }\end{array}$ & $\begin{array}{c}\text { Tipo de } \\
\text { inovação em } \\
\text { serviços }\end{array}$ & $\begin{array}{c}\text { Nível de } \\
\text { incerteza } \\
\text { Tecnológica }\end{array}$ & $\begin{array}{c}\text { Nível de } \\
\text { complexidade }\end{array}$ & $\begin{array}{l}\text { Quantidade } \\
\text { de pessoas } \\
\text { envolvidas }\end{array}$ & $\begin{array}{c}\text { Novas } \\
\text { competências } \\
\text { para a } \\
\text { organização }\end{array}$ & \begin{tabular}{|c|} 
Novo \\
produto/serviço \\
para a \\
organização
\end{tabular} & $\begin{array}{c}\text { Novo mercado } \\
\text { para a } \\
\text { organização }\end{array}$ & $\begin{array}{c}\text { Novo } \\
\text { produto/serviço } \\
\text { para o mercado } \\
\text { nacional }\end{array}$ \\
\hline 1 & Produto & Radical & Alta & Alta & 6 & Sim & Sim & Sim & Sim \\
\hline 2 & Produto & Radical & Alta & Alta & 20 & Sim & Sim & Sim & Sim \\
\hline 3 & Organizacional & Ad hoc & Alta & Média & 10 & Sim & Não & Não aplicável & Não \\
\hline 4 & Organizacional & Ad hoc & Alta & Alta & 250 & Sim & Sim & Não aplicável & Não \\
\hline 5 & Produto & Radical & Alta & Média & 5 & Sim & Sim & $\mathrm{Sim}$ & Sim \\
\hline 6 & Produto & Radical & Muito alta & Alta & 45 & Sim & Sim & Sim & Não \\
\hline 7 & Processo & Incremental & Alta & Alta & 35 & Sim & Não & Não aplicável & Não \\
\hline 8 & De Marketing & Incremental & Alta & Média & 10 & Sim & Sim & Não & Não \\
\hline 9 & Organizacional & Radical & Muito alta & Alta & 50 & Sim & Sim & Não & Sim \\
\hline 10 & Organizacional & Ad hoc & Média & Média & 5 & Sim & Não & Não aplicável & Não \\
\hline 11 & Produto & Incremental & Alta & Alta & 20 & Sim & Sim & Não & Não \\
\hline 12 & Produto & Radical & Alta & Média & 20 & Sim & Sim & Sim & Sim \\
\hline 13 & Processo & Incremental & Média & Média & 60 & Sim & Não & Não aplicável & Não \\
\hline 14 & Produto & Ad hoc & Média & Alta & 20 & Sim & Sim & Sim & Sim \\
\hline 15 & Organizacional & Incremental & Alta & Média & 5 & Sim & $\mathrm{Sim}$ & Não aplicável & Não \\
\hline 16 & Produto & Radical & Muito alta & Alta & 5 & Sim & Sim & Não & Sim \\
\hline
\end{tabular}

Os projetos podem ser enquadrados nos seguintes tipos de inovação (OECD, 2005), demonstrados no Gráfico 5, página 118:

- $\quad$ produto - oito casos (50\%); sete deles $(88 \%)$ referem-se a projetos de serviços, como o modelo de segmentação de clientes, o da rede telefônica corporativa, a criação de nova empresa para prestação de serviços para uma determinada classe econômica, a capacitação para identificação e registro da flora numa área de proteção ambiental; e o único projeto de produto utilizou material plástico reciclável como matéria-prima;

- $\quad$ processo - dois casos (13\%), que se referem aos projetos de produção, como o de implantação de novo sistema de BackOffice de uma instituição financeira; ou de distribuição, como a implantação de nova distribuição de produtos para clientes;

- $\quad$ marketing - que se refere à implantação de relacionamento com formadores de opinião sobre produtos farmacêuticos;

- organizacional - cinco casos $(31 \%)$ que se referem, por exemplo, ao projeto da implantação de um modelo de gestão. 
O Gráfico 19 mostra a distribuição do tipo de inovação em serviços, classificação de Gallouj e Weinstein (1997), gerada observando-se as seguintes vertentes, demonstradas no Quadro 22: - competências - colunas novas competências para a organização e novo produto / serviço para a organização;

- tecnologias - coluna nível de incerteza tecnológica, pois se alta ou muito alta foi uma nova tecnologia para a organização;

- características do produto / serviço - coluna novo produto ou serviço para o mercado nacional.

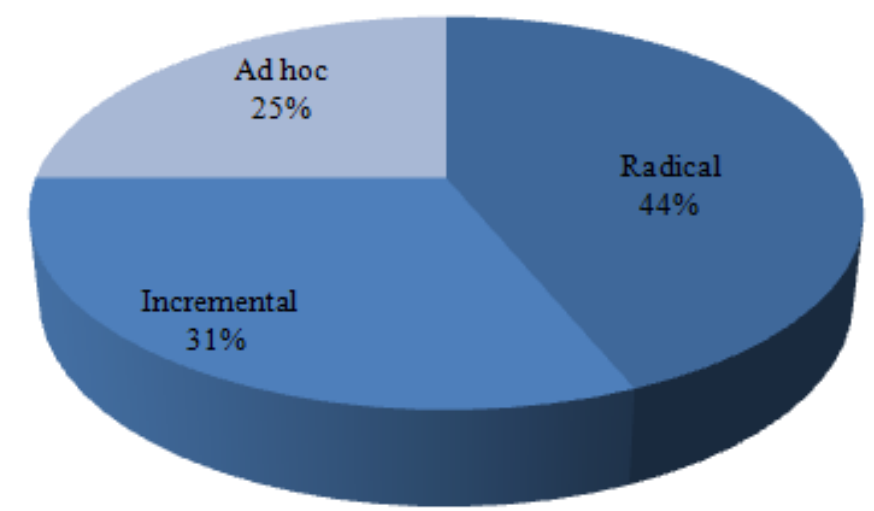

Gráfico 19 - Frequência do tipo de inovação em serviços dos projetos

Um projeto com o tipo de inovação em serviços do tipo ad hoc é caracterizado pela construção do serviço por meio de uma interação social com o cliente, com a modificação ou adição de componentes dos vetores de competência e tecnologia. Houve quatro projetos nesse enquadramento. $\mathrm{O}$ projeto três era uma consultoria para gerar um novo processo organizacional num cliente, e a área de atuação desse cliente não era conhecida da consultoria. No projeto 4 , a organização fez uma parceria com um fornecedor para a implantação de um sistema novo, com algumas funcionalidades já utilizadas por outras organizações, entretanto ainda necessitava de adaptações para integração e funcionamento dentro de requisitos internos. O projeto 10 tinha um gerente de projetos terceirizado e foi desenvolvido por um fornecedor, para automatizar um processo organizacional, com a incorporação de novas tecnologias para agilizar a integração com os clientes. O projeto 14 se constituía de um novo serviço para a organização e compreendia o outsourcing completo de uma área de BackOffice de um grande cliente. Além desse serviço, a organização deveria manter os sistemas antigos até serem substituídos pelos novos, ainda em desenvolvimento por 
outro parceiro, garantindo a integração com os sistemas legados do cliente e com a previsão de adoção por outros.

O nível de inovação incremental modifica ou adiciona componentes dos vetores de competência e tecnologia, tendo sido o enquadramento de cinco projetos (31\%). No projeto 7 , a implantação de uma nova plataforma global para o processamento de um produto da organização exigiu novas competências das áreas para lidar com o novo sistema, com as novas tecnologias e novos procedimentos. $\mathrm{O}$ projeto 8 foi uma iniciativa inovadora de marketing para o mercado, mas a tecnologia era conhecida pelo mercado, tanto que ela terceirizou parte do processo. O projeto 11 constituía-se na geração de nova empresa para desenvolver e operacionalizar um novo produto, com similares no mercado, mas não para aquele público e parceiros. No projeto 13, a competência existia na organização, mas em outra área de negócio, por isso foi designada uma pessoa dessa área para gerenciar o projeto. Porém o meio ambiente onde seria aplicada a tecnologia era distinto, portanto havia desconhecimento de como aquela tecnologia se comportaria. O projeto 15 era totalmente novo para a organização e exigiu novas competências, contudo os modelos e os softwares já eram utilizados em outras organizações.

O maior número de projetos (44\%) foi enquadrado no tipo de inovação em serviços radical. Nesse caso, os vetores de competência, tecnologia e características do produto / serviço são novos, ou seja, não se baseiam na modificação do sistema de vetores de um produto anterior. Os projetos 1, 2, 5 e 12 se enquadraram nessa categoria, como se pode perceber no Quadro 22, dado que as organizações precisaram de novas competências e de nova tecnologia, além de o produto e o mercado serem novos para a organização, assim como o produto também era novo para o mercado. Os projetos 9 e 16 também foram considerados radicais, apesar de o mercado ser conhecido da organização. O projeto 9 era um serviço completamente novo, que a organização disponibilizaria para a comunidade. O projeto 6 substituiria um produto existente no mercado, porém a aplicação daquela matéria-prima no produto era inédita no mercado, comparando-se com o exemplo citado por Gallouj e Weinstein (1997) da troca da carroça puxada a cavalo pelo automóvel. 
O nível de incerteza tecnológica, segundo Shenhar e Dvir (2007), representa as incertezas internas, pois depende do nível de conhecimento da equipe ou organização sobre a tecnologia. Esses projetos desta pesquisa possuem os seguintes níveis de incerteza tecnológica:

- média, quando a tecnologia é conhecida, mas foram incorporadas novas funções, compreendendo três projetos $(19 \%)$;

- alta, quando a tecnologia está disponível no início do projeto, mas era totalmente nova para a organização, com dez projetos (63\%), principalmente os de tecnologia da informação e novos processos organizacionais;

- muito alta, caracterizada pela inexistência da tecnologia no início do projeto, como a usada nos novos produtos e serviços, que ocorreu em três projetos (19\%).

Ainda utilizando-se a classificação de Crawford et al. (2007), o nível de complexidade dos projetos pesquisados foi classificado em:

- média, quando há várias funções ou mesmo grupo de funções e há interface com vários sistemas, compreendendo sete projetos (44\%);

- alta, quando centraliza vários sistemas, produtos ou serviços que funcionam altamente integrados para o atendimento de um objetivo, com $56 \%$ dos projetos.

Para contribuir com a avaliação do nível de complexidade, foi verificado também o número de envolvidos no projeto. O número mediano - valor mais representativo e mais frequente foi de 20 pessoas, com média de 35 pessoas. A média foi mais elevada do que a mediana, por causa de um projeto com número extremado de envolvidos (250 pessoas), o que também acarreta alta dispersão relativa dessa informação (169\%). Pode-se perceber, no Quadro 22, que a quantidade de pessoas envolvidas tende a ser maior nos projetos com mais alta complexidade. Calculando-se a média para cada nível de complexidade, obteve-se a média de 50 pessoas para projetos de alta complexidade e 16 para o outro nível, o que é compatível com o esperado para cada nível de complexidade. 
Tabela 7 - Estatísticas da quantidade de envolvidos por projeto

\begin{tabular}{|c|c|}
\hline Quantidade de envolvidos no projeto & Frequência \\
\hline 5 & 4 \\
\hline 6 & 1 \\
\hline 10 & 2 \\
\hline 20 & 4 \\
\hline 35 & 1 \\
\hline 45 & 1 \\
\hline 50 & 1 \\
\hline 60 & 1 \\
\hline 250 & 1 \\
\hline Total & 16 \\
\hline
\end{tabular}

\begin{tabular}{|l|c|}
\hline \multicolumn{1}{|c|}{ Estatísticas } & Quantidade de envolvidos no projeto \\
\hline Média & 35,4 \\
\hline Mediana & 20 \\
\hline Desvio-padrão & 59,9 \\
\hline Coeficiente de Variação & $169 \%$ \\
\hline Mínimo & 5 \\
\hline Máximo & 250 \\
\hline
\end{tabular}

\subsubsection{Características do gestor do projeto: tempo de experiência}

Foram avaliados o tempo de experiência profissional e o tempo de experiência em GP, em anos, para o gestor do projeto, que pode ser o gerente de projetos ou o sponsor. Essa diferenciação foi feita porque os demais respondentes poderiam não ter responsabilidade direta sobre a decisão de como gerir a incerteza. O mais comum, nesta pesquisa, foi o gestor ter entre 21 a 30 anos de experiência profissional, sete em 13 casos. A idade média / mediana ou mais frequente (três casos) de experiência profissional foi de 25 anos, com máximo de 39 anos e mínimo de 11 anos, conforme pode ser observado na Tabela 8. 
Tabela 8 - Estatísticas do tempo de experiência profissional do gestor do projeto

\begin{tabular}{|c|c|}
\hline Tempo de experiência profissional do gestor do projeto (em anos) & Frequência \\
\hline $11-20$ & 2 \\
\hline $21-30$ & 7 \\
\hline $31-40$ & 4 \\
\hline Total & 13 \\
\hline
\end{tabular}

\begin{tabular}{|c|c|}
\hline Estatísticas & Tempo de experiência profissional do gestor do projeto (em anos) \\
\hline Média & 26,9 \\
\hline Mediana & 25 \\
\hline Moda & 25 \\
\hline Desvio-padrão & 7,8 \\
\hline Coeficiente de Variação & $29 \%$ \\
\hline Mínimo & 11 \\
\hline Máximo & 39 \\
\hline
\end{tabular}

Com relação à experiência em GP do gestor do projeto, a média cai para 16,6 anos ou mediana igual a 15, como pode ser observado na Tabela 9. A metade da amostra tem de 11 a 20 anos de experiência em GP, apresentando mínimo de 7 e máximo de 39 anos. Há maior dispersão relativa do que a variável referente ao tempo de experiência profissional.

Tabela 9 - Estatísticas do tempo de experiência em GP do gestor do projeto

\begin{tabular}{|c|c|}
\hline Tempo de experiência em GP do gestor do projeto (em anos) & Frequência \\
\hline até 10 & 5 \\
\hline $11-20$ & 6 \\
\hline $21-40$ & 2 \\
\hline Total & 13 \\
\hline
\end{tabular}

\begin{tabular}{|c|c|}
\hline Estatísticas & Tempo de experiência em GP do entrevistado (em anos) \\
\hline Média & 16,6 \\
\hline Mediana & 15 \\
\hline Moda & 15 \\
\hline Desvio-padrão & 10 \\
\hline Coeficiente de Variação & $60 \%$ \\
\hline Mínimo & 7 \\
\hline Máximo & 39 \\
\hline
\end{tabular}

\subsection{Análise relacional}

Para esta análise, as provas estatísticas foram realizadas no nível de significância de $10 \%$. É adequado lembrar que a não rejeição da hipótese de nulidade, num determinado nível de significância, não significa afirmar que essa hipótese seja verdadeira, apenas que não foram encontradas evidências para negá-la. A hipótese de nulidade neste estudo sempre se refere à 
semelhança entre os grupos considerados. Uma das possíveis razões para não se rejeitar a hipótese de nulidade pode ser o reduzido tamanho da amostra.

\subsubsection{Relação entre as variáveis dependentes}

Por meio da prova do Qui-quadrado $\left(\chi^{2}\right)$, concluiu-se pela associação entre o nível de impacto do evento imprevisto (NIE) e o nível de antecipação da identificação da incerteza imprevisível (NAI), com nível de significância de $10 \%(\mathrm{p}=0,00 \%)$. Conforme as informações da Tabela 10, nota-se que, enquanto todos os eventos imprevistos com mais impacto foram identificados depois de sua ocorrência, apenas $22 \%$ daqueles com menos impacto também foram identificados depois. Isso indica que, se a incerteza imprevisível é percebida antecipadamente, há mais probabilidade de se ter menos impacto. Mesmo havendo essa forte associação entre as variáveis dependentes, optou-se por considerar a eficiência por ambas, pois o nível de impacto do evento imprevisto complementa a informação sobre o nível de antecipação da identificação da incerteza imprevisível.

Tabela 10 - Distribuição do NAI por NIE

\begin{tabular}{|c|c|c|c|c|}
\hline \multirow{2}{*}{ NAI } & \multicolumn{2}{c|}{ NIE } \\
\cline { 2 - 5 } & Menos impacto & Mais impacto & Total \\
\hline \multirow{2}{*}{ Prévia } & Frequência & 14 & 0 & 14 \\
\cline { 2 - 5 } & \% & $77,80 \%$ & $0,00 \%$ & $40,00 \%$ \\
\hline \multirow{2}{*}{ Posterior } & Frequência & 4 & 17 & 21 \\
\cline { 2 - 5 } & \% & $22,20 \%$ & $100,00 \%$ & $60,00 \%$ \\
\hline \multirow{2}{*}{ Total } & Frequência & 18 & 17 & 35 \\
\cline { 2 - 5 } & \% & $100,00 \%$ & $100,00 \%$ & $100,00 \%$ \\
\hline
\end{tabular}

O nível de satisfação com o resultado do evento imprevisto (NSR) não será avaliado estatisticamente, pois dos 35 eventos imprevistos apenas $24(69 \%)$ relataram algum tipo de satisfação, dificultando a possibilidade de aplicar as provas estatísticas. Além disso, nos relatos sobre a satisfação, ela foi mencionada mais com foco no projeto, como comentado no item 4.1.1.3, página 141, do que propriamente ao evento imprevisto. 


\subsubsection{Relação entre as variáveis independentes e as dependentes}

A grande maioria das variáveis independentes foi nominal ou ordinal, sendo intervalares apenas as seguintes: quantidade de atividades por tipo de participação no evento imprevisto, o nível de cultura da atenção e o tempo de experiência profissional e em GP do gestor do projeto. Primeiro será comentada a análise das variáveis do tipo nominal e ordinal e, na sequência, as do tipo intervalar.

Para testar a hipótese de a variável NAI e de a variável NIE ser independente na associação com as variáveis com mensuração do tipo nominal ou ordinal, foi efetuada a prova do QuiQuadrado $\left(\chi^{2}\right)$ ou a prova de Fisher. Os resultados e o tipo de prova aplicado a essas variáveis constam na Tabela 11. As provas não puderam ser aplicadas nas seguintes variáveis:

- processo de decisão, pois ela está presente em todos os eventos imprevistos, não sendo, portanto, uma variável aleatória, mas uma variável constante;

- $\quad$ tipo de gestão prévia da incerteza imprevisível que não atende às condições para a prova do Qui-Quadrado nem para a prova de Fisher, pois possui três categorias. 
Tabela 11 - Resultado estatístico da relação entre as variáveis independentes nominais / ordinais e as dependentes

\begin{tabular}{|c|c|c|c|c|c|c|}
\hline \multirow{3}{*}{\multicolumn{2}{|c|}{ Variáveis Independentes }} & \multirow{3}{*}{ Variáveis } & \multicolumn{4}{|c|}{ Variáveis dependentes } \\
\hline & & & \multicolumn{2}{|r|}{ NAI } & \multicolumn{2}{|r|}{ NIE } \\
\hline & & & p & $\begin{array}{c}\text { Prova } \\
\text { Estatística }\end{array}$ & $\mathbf{p}$ & $\begin{array}{c}\text { Prova } \\
\text { estatística }\end{array}$ \\
\hline \multirow{3}{*}{\multicolumn{2}{|c|}{$\begin{array}{c}\text { Fator gerador da incerteza } \\
\text { imprevisível }\end{array}$}} & Ocorrência de causa externa & 0,031 & Fisher & 0,193 & $\chi^{2}$ \\
\hline & & Ocorrência de causa organizacional & 0,01 & Fisher & 0,088 & Fisher \\
\hline & & Ocorrência de causa com origem na gestão de projetos & 0,704 & Fisher & 0,471 & Fisher \\
\hline \multirow{3}{*}{\multicolumn{2}{|c|}{$\begin{array}{c}\text { Fator motivador da } \\
\text { identificação da incerteza } \\
\text { imprevisível } \\
\end{array}$}} & Tipo de sinal precoce* & 0,000 & $\chi^{2}$ & 0,000 & $\chi^{2}$ \\
\hline & & Quem percebeu o sinal precoce* & 0,128 & Fisher & 0,013 & $\chi^{2}$ \\
\hline & & Momento da percepção do sinal precoce * & 0,073 & Fisher & 0,015 & $\chi^{2}$ \\
\hline \multirow{31}{*}{$\begin{array}{c}\text { Práticas para } \\
\text { a criação de } \\
\text { sentido }\end{array}$} & $\begin{array}{l}\text { Método de } \\
\text { gestão }\end{array}$ & Método de gestão do imprevisto* & 0,666 & Fisher & 0,427 & Fisher \\
\hline & \multirow{6}{*}{ Processos } & Ocorrência do processo de coleta de informações & 0,137 & Fisher & 0,053 & $\chi^{2}$ \\
\hline & & Ocorrência do processo de diagnostico & 0,392 & $\chi^{2}$ & 0,238 & $\chi^{2}$ \\
\hline & & Ocorrência do processo de criação de sentido coletivo & 0,019 & $\chi^{2}$ & 0,028 & $\chi^{2}$ \\
\hline & & Ocorrência do processo de memória / difusão & 0,028 & Fisher & 0,177 & Fisher \\
\hline & & Ocorrência do processo de execução & 0,721 & Fisher & 0,803 & $\chi^{2}$ \\
\hline & & Ocorrência do processo de novo ciclo & 0,664 & Fisher & 0,658 & $\chi^{2}$ \\
\hline & \multirow{20}{*}{ Atividades } & Ocorrência da atividade de buscar informação externamen & 0,721 & Fisher & 0,903 & $\chi^{2}$ \\
\hline & & Ocorrência da atividade de checar a informação & 0,685 & Fisher & 0,691 & Fisher \\
\hline & & Ocorrência da atividade de obter evidências & 0,221 & Fisher & 0,228 & Fisher \\
\hline & & Ocorrência da atividade de pesquisar & 0,134 & Fisher & 0,338 & Fisher \\
\hline & & Ocorrência da atividade de diagnosticar problema & 1,000 & Fisher & 0,443 & Fisher \\
\hline & & Ocorrência da atividade de revisar & 0,664 & Fisher & 1 & Fisher \\
\hline & & Ocorrência da atividade de identificar alternativas & 1,000 & Fisher & 0,264 & Fisher \\
\hline & & Ocorrência da atividade de compartithar & 0,090 & Fisher & 0,402 & Fisher \\
\hline & & Ocorrência da atividade de discutir com a equipe & 0,721 & Fisher & 0,803 & $\chi^{2}$ \\
\hline & & Ocorrência da atividade de envolver outros departamentos & 0,112 & Fisher & 0,121 & Fisher \\
\hline & & Ocorrência da atividade de abortar & 0,627 & Fisher & 0,177 & Fisher \\
\hline & & Ocorrência da atividade de fechar acordo & 1,000 & Fisher & 0,691 & Fisher \\
\hline & & Ocorrência da atividade de procrastinação & 1,000 & Fisher & 0,402 & Fisher \\
\hline & & Ocorrência da atividade de solucionar & 0,252 & Fisher & 0,146 & Fisher \\
\hline & & Ocorrência da atividade de tentativa de evitar & 0,627 & Fisher & 0,177 & Fisher \\
\hline & & Ocorrência da atividade de registrar & 0,028 & Fisher & 0,177 & Fisher \\
\hline & & Ocorrência da atividade de avaliar & 1,000 & Fisher & 0,402 & Fisher \\
\hline & & Ocorrência da atividade de cumprir o planejado & 0,369 & Fisher & 1 & Fisher \\
\hline & & Ocorrência da atividade de planejar & 0,191 & Fisher & 0,177 & Fisher \\
\hline & & Ocorrência da atividade de gerar novo ciclo & 0,664 & Fisher & 0,658 & Fisher \\
\hline & \multirow{4}{*}{$\begin{array}{l}\text { Técnicas e } \\
\text { Ferramentas }\end{array}$} & Ocorrência de $T \& F$ de criatividade & 0,153 & Fisher & 0,486 & Fisher \\
\hline & & Ocorrência de T\&F de avaliação do presente & 0,721 & Fisher & 0,803 & $\chi^{2}$ \\
\hline & & Ocorrência de $\mathrm{T} \& \mathrm{~F}$ de revisão histórica & 1,000 & Fisher & 1 & Fisher \\
\hline & & Ocorrência de T\&F de apoio & 1,000 & Fisher & 0,227 & $\chi^{2}$ \\
\hline \multirow{10}{*}{$\begin{array}{c}\text { Fatores } \\
\text { bloqueadores } \\
e \\
\text { facilitadores } \\
\text { da gestão da } \\
\text { incerteza }\end{array}$} & \multirow{5}{*}{$\begin{array}{c}\text { Fatores } \\
\text { bloqueadores }\end{array}$} & Ocorrência de bloqueador externo & 0,712 & Fisher & 0,711 & Fisher \\
\hline & & Ocorrência de bloqueador organizacional & 1,000 & Fisher & 1 & Fisher \\
\hline & & Ocorrência de bloqueador oriundo da equipe & 0,401 & Fisher & 1 & Fisher \\
\hline & & Ocorrência de bloqueador oriundo da gestão de projetos & 0,721 & Fisher & 0,555 & $\chi^{2}$ \\
\hline & & Ocorrência de bloqueador pessoal & 0,067 & $\chi^{2}$ & 0,027 & $\chi^{2}$ \\
\hline & \multirow{5}{*}{$\begin{array}{c}\text { Fatores } \\
\text { facilitadores }\end{array}$} & Ocorrência de facilitador externo & 0,551 & Fisher & 0,229 & Fisher \\
\hline & & Ocorrência de facilitador organizacional & 0,09 & Fisher & 0,402 & Fisher \\
\hline & & Ocorrência de facilitador oriundo da equipe & 1,000 & Fisher & 0,555 & $\chi^{2}$ \\
\hline & & Ocorrência de facilitador oriundo da gestão de projetos & 0,006 & Fisher & 0,045 & Fisher \\
\hline & & Ocorrência de facilitador pessoal & 0,221 & Fisher & 0,228 & Fisher \\
\hline \multirow{5}{*}{\multicolumn{2}{|c|}{ Características do projeto }} & Metodo de gestão do projeto & 0,89 & $\chi^{2}$ & 0,862 & $\chi^{2}$ \\
\hline & & Tipo de inovação do projeto & 0,324 & $\chi^{2}$ & 0,89 & $\chi^{2}$ \\
\hline & & NIS - Nivel de inovação em serviços & 1 & $\chi^{2}$ & 0,845 & $\chi^{2}$ \\
\hline & & Nivel de incerteza tecnológica do projeto & 0,676 & Fisher & 1 & Fisher \\
\hline & & Nivel de complexidade do projeto & 0,673 & $\chi^{2}$ & 0,581 & $\chi^{2}$ \\
\hline
\end{tabular}


Nos próximos subitens será apresentada a associação das variáveis dependentes apenas em relação às variáveis significativas, conforme células destacadas na Tabela 11. As variáveis que apresentam um '*' após seu nome tiveram suas categorias agrupadas para permitir as provas estatísticas. Essas modificações também serão detalhas nos próximos itens.

Para fazer a avaliação de a associação das variáveis NAI e NIE ser independente na associação com as variáveis intervalares, foi efetuada a prova de Mann-Whitney. Conforme informações da Tabela 12, percebe-se que apenas as atividades coletivas foram associadas com o NAI e o NIE, pois o nível descritivo da prova (p) foi menor do que o de significância exigido. Essa variável também será detalhada nos próximos subitens. Para as demais variáveis não foi possível chegar-se a uma conclusão se há diferença entre os dois grupos das variáveis NAI e NIE.

Tabela 12 - Resultado estatístico da relação entre as variáveis independentes intervalares e dependentes

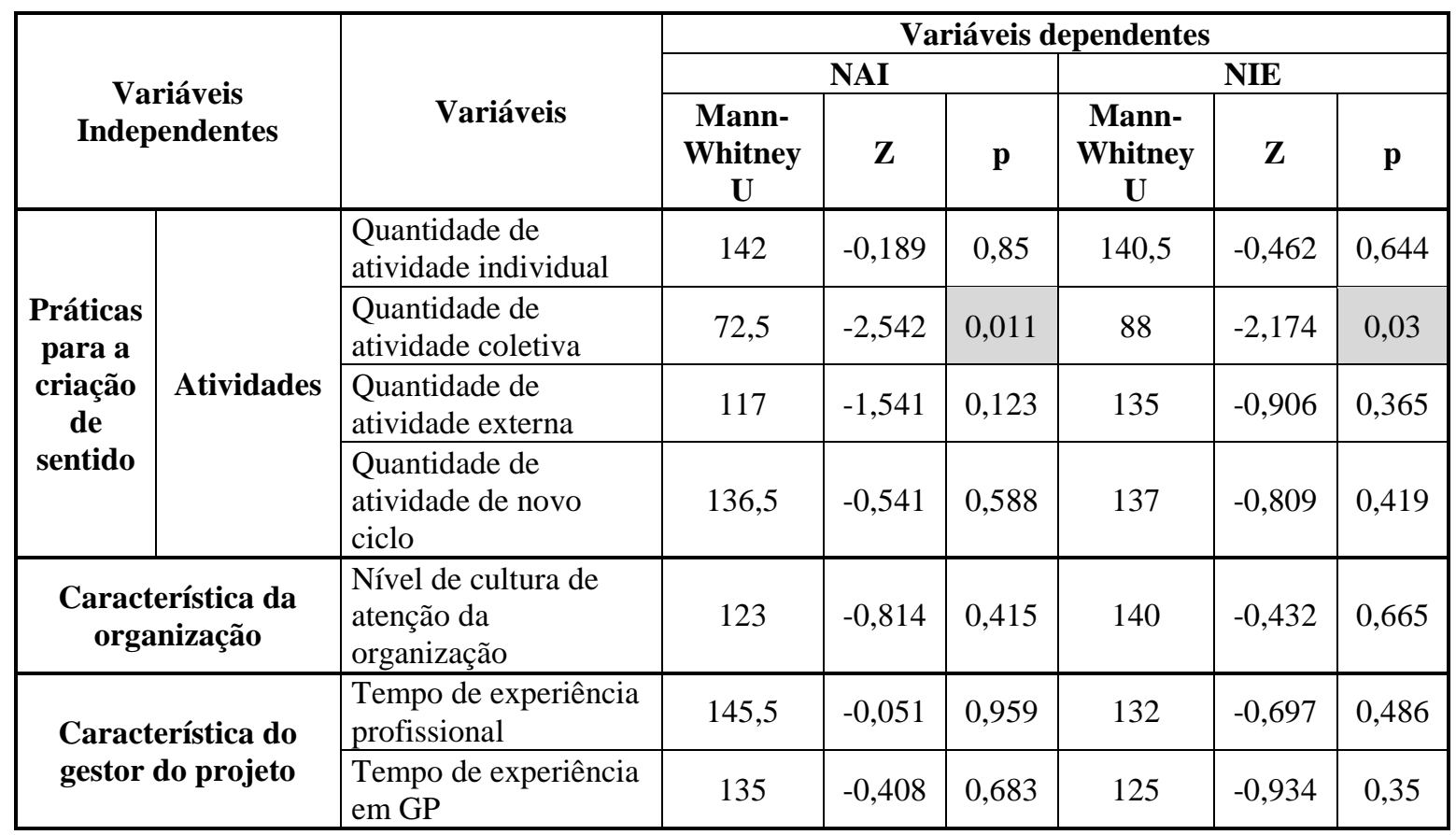

\subsubsection{Relação entre o fator gerador da incerteza imprevisível e o NAI e o NIE}

Com relação ao fator gerador da incerteza imprevisível, a causa organizacional pôde ser associada tanto com o NAI quanto com o NIE, mas a causa externa pôde ser associada apenas com o NAI. A Tabela 13 apresenta a distribuição da ocorrência de causa externa por NAI. Percebe-se que a identificação posterior à ocorrência do evento imprevisto foi causada mais 
por fatores externos $(81 \%)$ do que a identificação prévia, proporcionalmente. Isso confirma o que vários padrões de gestão de risco (HM TREASURY, 2004; COSO, 2004) indicam: que esse tipo de causa pode apenas ser mitigado e não evitado. Nesta amostra houve seis casos de identificação prévia à ocorrência do evento imprevisto e com causa externa; quatro deles utilizaram a busca de informação, como gestão prévia, e dois casos não foram geridos previamente. Em um destes, o cliente acabou resolvendo a questão que havia sido procrastinada e, no outro, foi possível identificar a incerteza imprevisível ainda na fase de piloto do projeto.

Tabela 13 - Distribuição da ocorrência de causa externa por NAI

\begin{tabular}{|c|c|c|c|c|}
\hline \multirow{2}{*}{\multicolumn{2}{|c|}{ Ocorrência de causa externa }} & \multicolumn{2}{|c|}{ NAI } & \multirow{2}{*}{ Total } \\
\hline & & \multirow{2}{*}{$\begin{array}{c}\text { Prévia } \\
8\end{array}$} & \multirow{2}{*}{$\begin{array}{c}\text { Posterior } \\
4\end{array}$} & \\
\hline Sem causa & Frequência & & & 12 \\
\hline externa & $\%$ & $57,10 \%$ & $19,00 \%$ & $34,30 \%$ \\
\hline \multirow{2}{*}{$\begin{array}{c}\text { Com causa } \\
\text { externa }\end{array}$} & Frequência & 6 & 17 & 23 \\
\hline & $\%$ & $42,90 \%$ & $81,00 \%$ & $65,70 \%$ \\
\hline \multirow{2}{*}{ Total } & Frequência & 14 & 21 & 35 \\
\hline & $\%$ & $100,00 \%$ & $100,00 \%$ & $100,00 \%$ \\
\hline
\end{tabular}

Com relação à causa organizacional, a Tabela 14 apresenta a distribuição das ocorrências dessa causa pelo NAI e pelo NIE. Percebe-se que houve maior concentração de eventos imprevistos com identificação posterior à sua ocorrência $(95,2 \%)$ sem causa organizacional, ante os $57,1 \%$ dos eventos identificados previamente. A quase totalidade dos eventos com mais impacto $(94,1 \%)$ também não tiveram causa organizacional e houve uma grande proporção com menos impacto $(66,7 \%)$. Relativamente, a causa organizacional tem maior ocorrência em imprevistos identificados previamente e com menos impacto. Comparando-se os dois tipos de causa, pode-se dizer que as causas externas têm maior probabilidade de serem identificadas posteriormente, enquanto com relação à causa interna, há maior probabilidade de que seja identificada previamente.

Tabela 14 - Distribuição da ocorrência de causa organizacional por NAI e NIE

\begin{tabular}{|c|c|c|c|c|c|c|}
\hline \multirow{2}{*}{$\begin{array}{c}\text { Ocorrência de causa } \\
\text { organizacional }\end{array}$} & \multicolumn{2}{|c|}{ NAI } & \multicolumn{2}{c|}{ NIE } & \multirow{2}{*}{ Total } \\
\cline { 2 - 7 } & Prévia & Posterior & Menos impacto & Mais impacto & \\
\hline \multirow{2}{*}{$\begin{array}{c}\text { Sem causa } \\
\text { organizacional }\end{array}$} & Frequência & 8 & 20 & 12 & 16 & 28 \\
\cline { 2 - 7 } & $\%$ & $57,10 \%$ & $95,20 \%$ & $66,70 \%$ & $94,10 \%$ & $80,00 \%$ \\
\hline $\begin{array}{c}\text { Com causa } \\
\text { organizacional }\end{array}$ & Frequência & 6 & 1 & 6 & 1 & 7 \\
\hline \multirow{2}{*}{ Total } & Frequência & $42,90 \%$ & $4,80 \%$ & $33,30 \%$ & $5,90 \%$ & $20,00 \%$ \\
\cline { 2 - 7 } & $\%$ & $100,00 \%$ & $100,00 \%$ & $100,00 \%$ & $100,00 \%$ & $100,00 \%$ \\
\hline
\end{tabular}




\subsubsection{Relação entre os fatores motivadores da identificação da incerteza imprevisível e as variáveis dependentes}

Como pode ser observado na Tabela 11, página 190, há três variáveis que compõem o fator motivador da identificação da incerteza imprevisível, relativo ao sinal precoce: tipo de sinal precoce, momento da percepção do sinal precoce e quem o percebeu.

Para ser possível a prova estatística, as quantidades das ocorrências do tipo de sinal precoce informações precoces e primeiros sintomas - foram somadas, criando-se uma categoria chamada 'com sinal precoce'. Os casos de sinal precoce súbito foram categorizados como 'sem sinal precoce'. Conforme demonstrado na Tabela 15, para a totalidade dos eventos identificados previamente à ocorrência do evento imprevisto, houve percepção dos sinais precoces; porém, quando a identificação foi posterior, ela tendeu a ter proporcionalmente mais eventos imprevistos sem sinal precoce. Por sua vez, a grande maioria dos com menos impacto $(88,9 \%)$ foram eventos para os quais se percebeu pelo menos um sinal precoce, enquanto a quase totalidade dos eventos imprevistos com mais impacto $(94,1 \%)$ o sinal precoce não foi percebido. A percepção do sinal precoce foi, relativamente, mais presente nos eventos imprevistos com o nível de antecipação da identificação prévia e naqueles com menos impacto; o inverso ocorre quando não se percebe o sinal precoce.

Tabela 15 - Distribuição do tipo de sinal precoce por NAI e NIE

\begin{tabular}{|c|c|c|c|c|c|c|}
\hline \multirow{2}{*}{ Tipo de sinal precoce } & \multicolumn{2}{|c|}{ NAI } & \multicolumn{2}{c|}{ NIE } & \multirow{2}{*}{ Total } \\
\cline { 2 - 7 } & Prévia & Posterior & Menos impacto & Mais impacto & \\
\hline \multirow{2}{*}{$\begin{array}{c}\text { Com sinal } \\
\text { precoce }\end{array}$} & Frequência & 14 & 3 & 16 & 1 & 17 \\
\cline { 2 - 7 } & $\%$ & $100,00 \%$ & $14,30 \%$ & $88,90 \%$ & $5,90 \%$ & $48,60 \%$ \\
\hline \multirow{2}{*}{$\begin{array}{c}\text { Sem sinal } \\
\text { precoce }\end{array}$} & Frequência & 0 & 18 & 2 & 16 & 18 \\
\cline { 2 - 7 } & $\%$ & $0,00 \%$ & $85,70 \%$ & $11,10 \%$ & $94,10 \%$ & $51,40 \%$ \\
\hline \multirow{2}{*}{ Total } & Frequência & 14 & 21 & 18 & 17 & 35 \\
\cline { 2 - 7 } & $\%$ & $100,00 \%$ & $100,00 \%$ & $100,00 \%$ & $100,00 \%$ & $100,00 \%$ \\
\hline
\end{tabular}

Há duas informações da Tabela 15 que merecem ser analisadas mais detalhadamente, pois poderiam ser consideradas anomalias. A primeira refere-se aos três casos de identificação posterior à ocorrência de evento imprevisto e com sinal precoce. Os eventos imprevistos foram geridos previamente por planejamento ou gestão de riscos; em dois deles, a gestão não foi aprofundada suficientemente, surgindo fatores inesperados. No terceiro caso, apesar do uso da terceirização como mitigação do risco e de todos os cuidados da equipe, não foi possível evitar-se uma ação trabalhista, inesperada pelo gerente de projetos. A segunda 
informação que merece ser aprofundada revela dois casos nos quais houve menos impacto, mesmo com o sinal precoce não tendo sido percebido antecipadamente. Em um deles, quando o gerente de projetos percebeu a ocorrência do imprevisto, negociou com o cliente, pois ele não teria recursos humanos nem financeiros para atender a mudança legal ocorrida durante o projeto. Após algumas consultas jurídicas, a proposta foi aceita pelo cliente. No segundo caso, os principais elementos da equipe de especialistas, montada e aprovada pelo cliente, não puderam iniciar o projeto, por causa da demora de aprovação por parte do cliente, mas foi possível se adotarem soluções paliativas, evitando maior impacto ao projeto.

A respeito da variável quem percebeu o sinal precoce, também para permitir a prova estatística, os eventos imprevistos identificados pelo sponsor foram exclusos, por causa do baixo número de ocorrências (4). Essa variável só foi associada com o NIE, conforme a distribuição demonstrada na Tabela 16. Os eventos com menos impacto tenderam a ser, proporcionalmente, mais percebidos pelo gerente de projetos $(56,2 \%)$, enquanto a grande maioria dos com mais impactos $(86,7 \%)$ foram percebidos pela equipe. Pode-se observar na Tabela 5, página 156, que o gerente de projetos tendeu a perceber o sinal precoce no início do projeto. A Tabela 4, página 156, mostra que ele tendeu a perceber mais o tipo de sinal informação precoce. Essas constatações podem explicar por que os eventos imprevistos percebidos por ele tenderam a ter menos impacto.

Tabela 16 - Distribuição de quem percebeu o sinal precoce por NIE

\begin{tabular}{|c|c|c|c|c|}
\hline \multirow{2}{*}{ Quem percebeu o sinal precoce } & \multicolumn{2}{|c|}{ NIE } & \multirow{2}{*}{ Total } \\
\cline { 3 - 5 } & Menos impacto & Mais impacto & \\
\hline \multirow{2}{*}{ Equipe } & Frequência & 7 & 13 & 20 \\
\cline { 2 - 5 } & $\%$ & $43,80 \%$ & $86,70 \%$ & $64,50 \%$ \\
\hline \multirow{2}{*}{ Gerente de projetos } & Frequência & 9 & 2 & 11 \\
\cline { 2 - 5 } & $\%$ & $56,20 \%$ & $13,30 \%$ & $35,50 \%$ \\
\hline \multirow{2}{*}{ Total } & Frequência & 16 & 15 & 31 \\
\cline { 2 - 5 } & $\%$ & $100,00 \%$ & $100,00 \%$ & $100,00 \%$ \\
\hline
\end{tabular}

Quanto ao momento da percepção do sinal precoce, as ocorrências de percepção durante o projeto e ao seu final foram somadas, para permitir a aplicação da prova estatística. A Tabela 17 demonstra a associação dessa variável com o NAI e o NIE. Pode-se perceber que na grande maioria dos casos identificados posteriormente à ocorrência do evento imprevisto (81\%), houve a percepção do sinal precoce durante ou ao final do projeto, enquanto a identificação prévia divide-se em proporções iguais entre o início e durante / final do projeto. 
Com relação ao NIE, quase a totalidade de eventos $(88,2 \%)$ com mais impacto, perceberam o sinal precoce durante ou ao final do projeto, no entanto, quando houve menos impacto, existiu uma proporção igualitária entre os percebidos no início e os que foram durante ou ao final do projeto. A percepção logo no início do projeto, relativamente, está mais presente em eventos com menos impacto, enquanto a percepção durante ou ao final do projeto provavelmente foi motivo de maior impacto. Pode-se deduzir que, quanto mais tarde se percebe a incerteza imprevisível, maior a possibilidade de ocorrer impacto no projeto e de que ele não seja identificado previamente.

Tabela 17 - Distribuição do momento da percepção do sinal precoce por NAI e NIE

\begin{tabular}{|c|c|c|c|c|c|c|}
\hline \multirow{2}{*}{$\begin{array}{c}\text { Momento da percepção do } \\
\text { sinal precoce }\end{array}$} & \multicolumn{2}{|c|}{ NAI } & \multicolumn{2}{c|}{ NIE } & \multirow{2}{*}{ Total } \\
\cline { 2 - 7 } & Prévia & Posterior & Menos impacto & Mais impacto & 11 \\
\hline \multirow{2}{*}{ Início } & Frequência & 7 & 4 & 9 & 2 & $11,80 \%$ \\
\cline { 2 - 7 } & $\%$ & $50,00 \%$ & $19,00 \%$ & $50,00 \%$ & $31,40 \%$ \\
\hline \multirow{2}{*}{ Durante / Final } & Frequência & 7 & 17 & 9 & 15 & 24 \\
\cline { 2 - 7 } & $\%$ & $50,00 \%$ & $81,00 \%$ & $50,00 \%$ & $88,20 \%$ & $68,60 \%$ \\
\hline \multirow{2}{*}{ Total } & Frequência & 14 & 21 & 18 & 17 & 35 \\
\cline { 2 - 7 } & $\%$ & $100,00 \%$ & $100,00 \%$ & $100,00 \%$ & $100,00 \%$ & $100,00 \%$ \\
\hline
\end{tabular}

\subsubsection{Relação entre as práticas para a criação de sentido e as variáveis dependentes}

Com relação às práticas para a criação de sentido, apenas as seguintes variáveis foram associadas com as variáveis dependentes: três processos (coleta de informações, criação coletiva de sentido e memória / difusão); duas atividades (compartilhar e registrar) e a quantidade de atividades coletivas do evento imprevisto. Para cada uma dessas variáveis serão feitas, a seguir, análises mais aprofundadas para se entenderem as associações identificadas.

Na Tabela 18 consta a distribuição da ocorrência do processo de coleta de informações pelo NIE, na qual se pode perceber que, quando houve menos impacto, a grande maioria dos eventos imprevistos $(83,3 \%)$ tendeu a ter utilizado esse processo. No caso dos eventos imprevistos com mais impacto, o processo de coleta de informações também foi utilizado pela maioria $(52,9 \%)$. Por causa da alta concentração dos com menos impacto que utilizaram esse processo, pode-se afirmar que suas atividades, como a busca por informações externamente, checar a informação, obter evidências e pesquisar, podem contribuir para haver menos impacto no projeto. 
Tabela 18 - Distribuição do processo de coleta de informações por NIE

\begin{tabular}{|c|c|c|c|c|}
\hline \multirow{2}{*}{$\begin{array}{c}\text { Ocorrência do processo de } \\
\text { coleta de informações }\end{array}$} & \multicolumn{2}{|c|}{ NIE } & \multirow{2}{*}{ Total } \\
\cline { 2 - 5 } Sem processo & Frequência & 3 & 8 & 11 \\
\cline { 2 - 5 } & $\%$ & $16,70 \%$ & $47,10 \%$ & $31,40 \%$ \\
\hline \multirow{2}{*}{ Com processo } & Frequência & 15 & 9 & 24 \\
\cline { 2 - 5 } & $\%$ & $83,30 \%$ & $52,90 \%$ & $68,60 \%$ \\
\hline \multirow{2}{*}{ Total } & Frequência & 18 & 17 & 35 \\
\cline { 2 - 5 } & $\%$ & $100,00 \%$ & $100,00 \%$ & $100,00 \%$ \\
\hline
\end{tabular}

A distribuição das ocorrências do processo de criação coletiva de sentido pelas categorias do NAI e do NIE está demonstrada na Tabela 19. Observa-se que a maioria dos casos de identificação prévia $(78,6 \%)$ à ocorrência do evento imprevisto utilizou esse processo; a maioria dos que identificaram posteriormente $(61,9 \%)$, porém, não o utilizaram. Da mesma forma, a maioria com menos impacto $(72,2 \%)$ utilizou o processo de criação coletiva de sentido e, quando houve mais impacto $(64,7 \%)$, proporcionalmente, ele foi menos utilizado. Como esse processo foi composto pelas atividades de compartilhar a informação, discutir com a equipe, envolver outros departamentos na gestão da incerteza e negociar com fornecedores e parceiros, pode-se dizer que o uso de uma dessas atividades pode contribuir para a incerteza ser tratada mais eficientemente. Aliás, a atividade de compartilhar foi uma das poucas associadas com, pelo menos, uma das variáveis dependentes.

Tabela 19 - Distribuição do processo de criação coletiva de sentido por NAI e NIE

\begin{tabular}{|c|c|c|c|c|c|c|}
\hline \multirow{2}{*}{$\begin{array}{c}\text { Ocorrência do processo de } \\
\text { criação coletiva de sentido }\end{array}$} & \multicolumn{2}{|c|}{ NAI } & \multicolumn{2}{c|}{ NIE } & \multirow{2}{*}{ Total } \\
\cline { 2 - 7 } & Prévia & Posterior & $\begin{array}{c}\text { Menos } \\
\text { impacto }\end{array}$ & $\begin{array}{c}\text { Mais } \\
\text { impacto }\end{array}$ & 16 \\
\hline \multirow{2}{*}{ Sem processo } & Frequência & 3 & 13 & 5 & 11 & 16 \\
\cline { 2 - 7 } & $\%$ & $21,40 \%$ & $61,90 \%$ & $27,80 \%$ & $64,70 \%$ & $45,70 \%$ \\
\hline \multirow{2}{*}{ Com processo } & Frequência & 11 & 8 & 13 & 6 & 19 \\
\cline { 2 - 7 } & $\%$ & $78,60 \%$ & $38,10 \%$ & $72,20 \%$ & $35,30 \%$ & $54,30 \%$ \\
\hline \multirow{2}{*}{ Total } & Frequência & 14 & 21 & 18 & 17 & 35 \\
\cline { 2 - 7 } & $\%$ & $100,00 \%$ & $100,00 \%$ & $100,00 \%$ & $100,00 \%$ & $100,00 \%$ \\
\hline
\end{tabular}

O processo de memória / difusão só pode ser associado com o NAI, como consta na Tabela 20. Nos eventos imprevistos cuja incerteza imprevisível foi identificada previamente, a maioria $(64,3 \%)$ não utilizou esse processo, assim como na identificação posterior a sua ocorrência $(95,2 \%)$. Nota-se que esse processo é, relativamente, mais utilizado quando há uma identificação prévia. Como a atividade de registrar é a única atividade desse processo, ela ocorre, provavelmente, para registrar a situação peculiar identificada e as ações tomadas para 
futuro compartilhamento com a equipe, outros departamentos da organização, ou até mesmo cliente e fornecedores.

Tabela 20 - Distribuição do processo de memória / difusão por NAI

\begin{tabular}{|c|c|c|c|c|}
\hline \multirow{2}{*}{$\begin{array}{c}\text { Ocorrência do processo de } \\
\text { memória / difusão }\end{array}$} & \multicolumn{2}{|c|}{ NAI } & \multirow{2}{*}{ Total } \\
\cline { 2 - 5 } Sem processo & Frequência & 9 & Posterior & \\
\cline { 2 - 5 } & $\%$ & $64,30 \%$ & $95,20 \%$ & $82,90 \%$ \\
\hline \multirow{2}{*}{ Com processo } & Frequência & 5 & 1 & 6 \\
\cline { 2 - 5 } & $\%$ & $35,70 \%$ & $4,80 \%$ & $17,10 \%$ \\
\hline \multirow{2}{*}{ Total } & Frequência & 14 & 21 & 35 \\
\cline { 2 - 5 } & $\%$ & $100,00 \%$ & $100,00 \%$ & $100,00 \%$ \\
\hline
\end{tabular}

A distribuição da ocorrência da atividade de compartilhar pelo NAI consta na Tabela 21. Essa atividade não esteve presente na maioria dos casos nos quais a incerteza imprevisível foi identificada previamente $(64,3 \%)$ e na quase totalidade dos identificados posteriormente (90,5\%). Pode-se perceber que, apesar do pequeno número, quando a atividade esteve presente no evento imprevisto, ela tendeu, proporcionalmente, a ser associada com eventos identificados previamente. Essa associação pode indicar que o compartilhamento da percepção ou das informações com o cliente, com especialistas, com o sponsor, com a equipe ou mesmo com o fornecedor estava relacionado com a superação da lacuna do conhecimento sobre a incerteza imprevisível.

Tabela 21 - Distribuição da atividade de compartilhar por NAI

\begin{tabular}{|c|c|c|c|c|}
\hline \multirow{2}{*}{$\begin{array}{c}\text { Ocorrência da atividade de } \\
\text { compartilhar }\end{array}$} & \multicolumn{2}{|c|}{ NAI } & \multirow{2}{*}{ Total } \\
\cline { 2 - 5 } Sem atividade & Frequência & 9 & 19 & 28 \\
\cline { 2 - 5 } & $\%$ & $64,30 \%$ & $90,50 \%$ & $80,00 \%$ \\
\hline \multirow{2}{*}{ Com atividade } & Frequência & 5 & 2 & 7 \\
\cline { 2 - 5 } & $\%$ & $35,70 \%$ & $9,50 \%$ & $20,00 \%$ \\
\hline \multirow{2}{*}{ Total } & Frequência & 14 & 21 & 35 \\
\cline { 2 - 5 } & $\%$ & $100,00 \%$ & $100,00 \%$ & $100,00 \%$ \\
\hline
\end{tabular}

Concluindo este item, a Tabela 22 mostra a distribuição da quantidade de atividades coletivas do evento imprevisto por NAI e por NIE. Pode-se observar que, quanto maior a quantidade de atividades coletivas do evento imprevisto, a tendência é de a identificação ter sido prévia à ocorrência do evento imprevisto e, proporcionalmente, menos impacto. Essas associações corroboram com a importância da socialização do conhecimento para se superar a lacuna do conhecimento. 
Tabela 22 - Quantidade de atividades coletivas do evento imprevisto por NAI e NIE

\begin{tabular}{|c|c|c|c|c|c|}
\hline $\begin{array}{c}\text { Quantidade de } \\
\text { atividades coletivas } \\
\text { do evento imprevisto }\end{array}$ & \multicolumn{2}{|c|}{ Frequência do NAI } & \multicolumn{2}{c|}{ Frequência do NIE } & \multirow{2}{*}{ Total } \\
\cline { 2 - 5 } & Prévia & Posterior & Menos impacto & Mais impacto & \\
\hline 0 & 0 & 1 & 0 & 1 & 1 \\
\hline 1 & 0 & 3 & 0 & 3 & 3 \\
\hline 2 & 2 & 4 & 3 & 3 & 6 \\
\hline 3 & 1 & 5 & 2 & 4 & 6 \\
\hline 4 & 1 & 2 & 2 & 1 & 3 \\
\hline 5 & 4 & 4 & 5 & 3 & 8 \\
\hline 6 & 3 & 0 & 3 & 0 & 3 \\
\hline 7 & 3 & 2 & 3 & 2 & 5 \\
\hline Total & 14 & 21 & 18 & 17 & 35 \\
\hline
\end{tabular}

\subsubsection{Relação entre os fatores bloqueadores e facilitadores e as variáveis dependentes}

Com relação aos fatores bloqueadores, apenas o do tipo pessoal, o mais numeroso, pode ser associado ao NAI e ao NIE, demonstrado na Tabela 23. Nota-se que, nos casos nos quais houve identificação da incerteza imprevisível prévia, a grande maioria $(78,6 \%)$ não teve esse tipo de bloqueador; nos casos de identificação posterior à ocorrência do imprevisto, na maioria $(52,4 \%)$ o bloqueador pessoal esteve presente. Com relação ao nível de impacto do evento imprevisto, percebe-se que há maior concentração $(77,8 \%)$ nos casos de menos impacto nos quais esse tipo de bloqueador não ocorreu, porém, na maioria $(58,8 \%)$ em que ocorreu mais impacto houve a presença desse bloqueador. Assim, poderia afirmar-se que na presença de um bloqueador pessoal a identificação da incerteza imprevisível tende a ser posterior à sua ocorrência e a ter mais impacto.

Tabela 23 - Distribuição do bloqueador pessoal por NAI e NIE

\begin{tabular}{|c|c|c|c|c|c|c|}
\hline \multirow{2}{*}{$\begin{array}{c}\text { Ocorrência de bloqueador } \\
\text { pessoal }\end{array}$} & \multicolumn{2}{|c|}{ NAI } & \multicolumn{2}{c|}{ NIE } & \multirow{2}{*}{ Total } \\
\cline { 2 - 7 } & Prévia & Posterior & Menos impacto & Mais impacto & \\
\hline \multirow{2}{*}{$\begin{array}{c}\text { Sem } \\
\text { bloqueador }\end{array}$} & Frequência & 11 & 10 & 14 & 7 & 21 \\
\cline { 2 - 7 } $\begin{array}{c}\text { Com } \\
\text { bloqueador }\end{array}$ & Frequência & 3 & $47,60 \%$ & $77,80 \%$ & $41,20 \%$ & $60,00 \%$ \\
\cline { 2 - 7 } & $\%$ & $21,40 \%$ & $52,40 \%$ & $22,20 \%$ & 10 & 14 \\
\hline \multirow{2}{*}{ Total } & Frequência & 14 & 21 & 18 & $17,80 \%$ & $40,00 \%$ \\
\cline { 2 - 7 } & $\%$ & $100,00 \%$ & $100,00 \%$ & $100,00 \%$ & $100,00 \%$ & $100,00 \%$ \\
\hline
\end{tabular}

A Tabela 24 demonstra a distribuição da ocorrência do fator facilitador organizacional por NAI. Percebe-se que, quando houve identificação prévia da incerteza imprevisível, na maioria dos casos $(64,3 \%)$ esse facilitador está ausente, como ocorreu quando a identificação foi 
posterior, ele está ausente na quase totalidade dos casos (90,5\%). Relativamente, esse fator está mais relacionado com o nível de antecipação prévia. A análise qualitativa mostra que, em seis dos sete casos, esses fatores estão vinculados à obtenção de apoio do sponsor e dos pares para entender a incerteza imprevisível para gerar a uma solução plausível. No sétimo caso, a assunção de risco da organização trouxe a possibilidade de procrastinar a decisão. Assim, deduz-se que, quando há identificação prévia de uma incerteza, o apoio dos pares, do sponsor e da própria organização para superar a incerteza foi considerado relevante pelos entrevistados.

Tabela 24 - Distribuição do facilitador organizacional por NAI

\begin{tabular}{|c|c|c|c|c|}
\hline \multirow{2}{*}{$\begin{array}{c}\text { Ocorrência de facilitador } \\
\text { organizacional }\end{array}$} & \multicolumn{2}{|c|}{ NAI } & \multirow{2}{*}{ Total } \\
\cline { 2 - 4 } Sem facilitador & Frequência & 9 & 19 & 28 \\
\cline { 2 - 5 } & $\%$ & $64,30 \%$ & $90,50 \%$ & $80,00 \%$ \\
\hline \multirow{2}{*}{ Com facilitador } & Frequência & 5 & 2 & 7 \\
\cline { 2 - 5 } & $\%$ & $35,70 \%$ & $9,50 \%$ & $20,00 \%$ \\
\hline \multirow{2}{*}{ Total } & Frequência & 14 & 21 & 35 \\
\cline { 2 - 5 } & $\%$ & $100,00 \%$ & $100,00 \%$ & $100,00 \%$ \\
\hline
\end{tabular}

A distribuição da ocorrência do facilitador oriundo da GP pelo NAI e pelo NIE consta na Tabela 25. Observa-se que, na maioria $(64,3 \%)$ dos casos com o nível de antecipação da identificação da incerteza imprevisível prévia, esse facilitador não esteve presente, como para a totalidade dos com identificação posterior. Quando o evento imprevisto teve menos impacto, a maioria $(72,2 \%)$ não teve esse facilitador, como para a totalidade dos com mais impacto. Relativamente, esse facilitador só ocorreu em eventos com identificação prévia da incerteza imprevisível e com menos impacto. As características desse facilitador foram a busca de informação, a flexibilidade e objetivos claros. Mais uma vez, a busca antecipada de informação mostra-se relevante e, nesse caso, reconhecida pelos próprios entrevistados.

Tabela 25 - Distribuição do facilitador oriundo da GP por NAI e NIE

\begin{tabular}{|c|c|c|c|c|c|c|}
\hline \multirow{2}{*}{$\begin{array}{c}\text { Ocorrência de } \\
\text { facilitador oriundo da } \\
\text { GP }\end{array}$} & \multicolumn{2}{|c|}{ NAI } & \multicolumn{2}{c|}{ NIE } & \multirow{2}{*}{ Total } \\
\cline { 2 - 7 } & Prévia & Posterior & $\begin{array}{c}\text { Menos } \\
\text { impacto }\end{array}$ & $\begin{array}{c}\text { Mais } \\
\text { impacto }\end{array}$ & \\
\hline \multirow{2}{*}{$\begin{array}{c}\text { Sem } \\
\text { facilitador }\end{array}$} & Frequência & 9 & 21 & 13 & 17 & 30 \\
\cline { 2 - 7 } $\begin{array}{c}\text { Com } \\
\text { facilitador }\end{array}$ & Frequência & $64,30 \%$ & $100,00 \%$ & $72,20 \%$ & $100,00 \%$ & $85,70 \%$ \\
\cline { 2 - 7 } & $\%$ & $35,70 \%$ & $0,00 \%$ & $27,80 \%$ & $0,00 \%$ & $14,30 \%$ \\
\hline \multirow{2}{*}{ Total } & Frequência & 14 & 21 & 18 & 17 & 35 \\
\cline { 2 - 7 } & $\%$ & $100,00 \%$ & $100,00 \%$ & $100,00 \%$ & $100,00 \%$ & $100,00 \%$ \\
\hline
\end{tabular}




\subsubsection{Síntese das análises entre variáveis independentes e dependentes}

Com a finalidade de sintetizar e visualizar a associação entre as variáveis independentes e dependentes utilizadas nesta pesquisa, procedeu-se à análise de correspondência múltipla que resulta numa representação gráfica bidimensional. Por meio da análise desse gráfico, é possível se identificarem padrões de associações existentes entre as variáveis investigadas visualmente, pois, quanto mais próximas estiverem as categorias no gráfico, maior o nível de associação existente entre elas.

De acordo com os resultados referentes à análise da prova do Qui-Quadrado $\left(\chi^{2}\right)$, prova de Fisher e prova de Mann-Whithey, as variáveis consideradas para a análise de correspondência múltipla foram:

- $\quad$ variáveis dependentes - nível de antecipação da identificação da incerteza imprevisível e nível de impacto do evento imprevisto;

- variáveis independentes:

- $\quad$ fator gerador da incerteza imprevisível - causa externa e causa organizacional;

- fator motivador da identificação da incerteza imprevisível - tipo de sinal precoce, momento da percepção do sinal precoce e quem percebeu o sinal precoce;

- $\quad$ práticas para a criação de sentido:

○ processos - coleta de informações, criação coletiva de sentido, memória / difusão;

○ atividades - compartilhar e quantidade de atividades coletivas do evento imprevisto;

- $\quad$ fatores bloqueadores e facilitadores - bloqueador pessoal, facilitador oriundo da GP e facilitador organizacional.

Ao se reduzir um número de variáveis da pesquisa em dimensões - eixos dos gráficos - é importante conhecer quanto da variabilidade total dos dados é explicada pelos eixos, o que é expressa pela taxa de inércia. Conforme pode ser verificado na Tabela 26, a primeira dimensão é a de maior inércia (33,2\%), ou seja, a que mais explica a variabilidade dos dados. A segunda dimensão, por sua vez, explica $13,7 \%$ da variabilidade dos dados e a terceira dimensão, 11,5\%, totalizando 58,4\% de explicação para as três dimensões. Para interpretar as associações, apenas a primeira dimensão seria suficiente, dado que ela explica $33,2 \%$ da 
variabilidade dos dados, mais de duas vezes o que explica a segunda dimensão. Entretanto o mapa perceptual utilizará as duas primeiras dimensões, para melhor visualização.

Tabela 26 - Taxa de inércia por dimensão do mapa perceptual

\begin{tabular}{|c|c|c|}
\hline Dimensão & Inércia & \% Variância acumulada \\
\hline 1 & 0,332 & $33,2 \%$ \\
\hline 2 & 0,137 & $46,9 \%$ \\
\hline 3 & 0,115 & $58,4 \%$ \\
\hline 4 & 0,084 & $66,8 \%$ \\
\hline 5 & 0,078 & $74,7 \%$ \\
\hline Total & 0,747 & \\
\hline
\end{tabular}

O Gráfico 20 mostra as variáveis que mais contribuem para a explicação ou interpretação de cada eixo. As variáveis com maior discriminação na primeira dimensão - eixo horizontal foram: nível de antecipação da identificação da incerteza imprevisível, tipo de sinal precoce e nível de impacto do evento imprevisto. Com relação às variáveis que mais discriminaram a segunda dimensão - eixo vertical - tem-se momento da percepção do sinal precoce e quem percebeu o sinal precoce. Assim, a primeira dimensão será chamada de eficiência da identificação da incerteza imprevisível e a segunda, de fatores e práticas influenciadores da identificação da incerteza imprevisível.

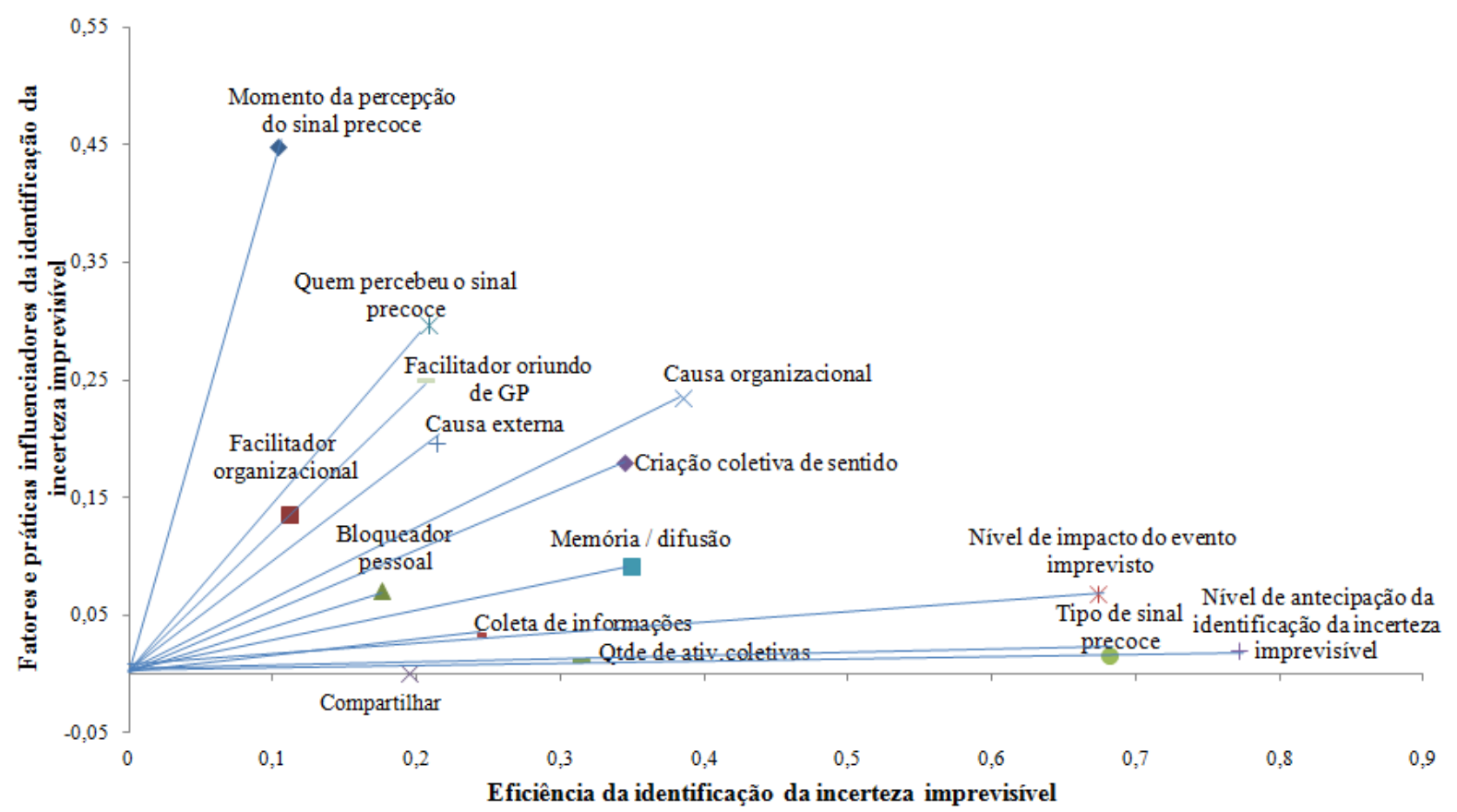

Gráfico 20 - Medidas de discriminação das variáveis nas dimensões do mapa perceptual 
No Gráfico 21, gerado pela análise de correspondência múltipla, é possível visualizar dois grupos. Do lado esquerdo do eixo, situam-se eventos imprevistos identificados previamente e com menos impacto, destacando-se as seguintes características: o fator gerador da incerteza imprevisível foi uma causa organizacional; houve percepção do sinal precoce, provavelmente no início do projeto, e ele foi percebido pelo gerente do projeto ou pelo sponsor; houve um facilitador organizacional ou oriundo da GP; os processos de compartilhar, criação coletiva de sentido ou memória / difusão foram utilizados; também foi utilizada a atividade de compartilhar; houve maior quantidade de atividades coletivas no evento imprevisto; em suma, tudo o que contribuiu para a identificação prévia da incerteza imprevisível e para a ausência do impacto ou em sua redução.

O outro grupo encontra-se à direita do eixo vertical, representando os eventos imprevistos identificados posteriormente à sua ocorrência e com mais impacto, com as seguintes características: o fator gerador da incerteza imprevisível foi uma causa externa; não houve a percepção de um sinal precoce, o evento imprevisto foi percebido durante ou ao final do projeto, provavelmente, pela equipe; ocorreu um fator bloqueador pessoal; houve menos atividades coletivas; não foram utilizados os processos e as atividades associados à eficiência da identificação da incerteza imprevisível. 


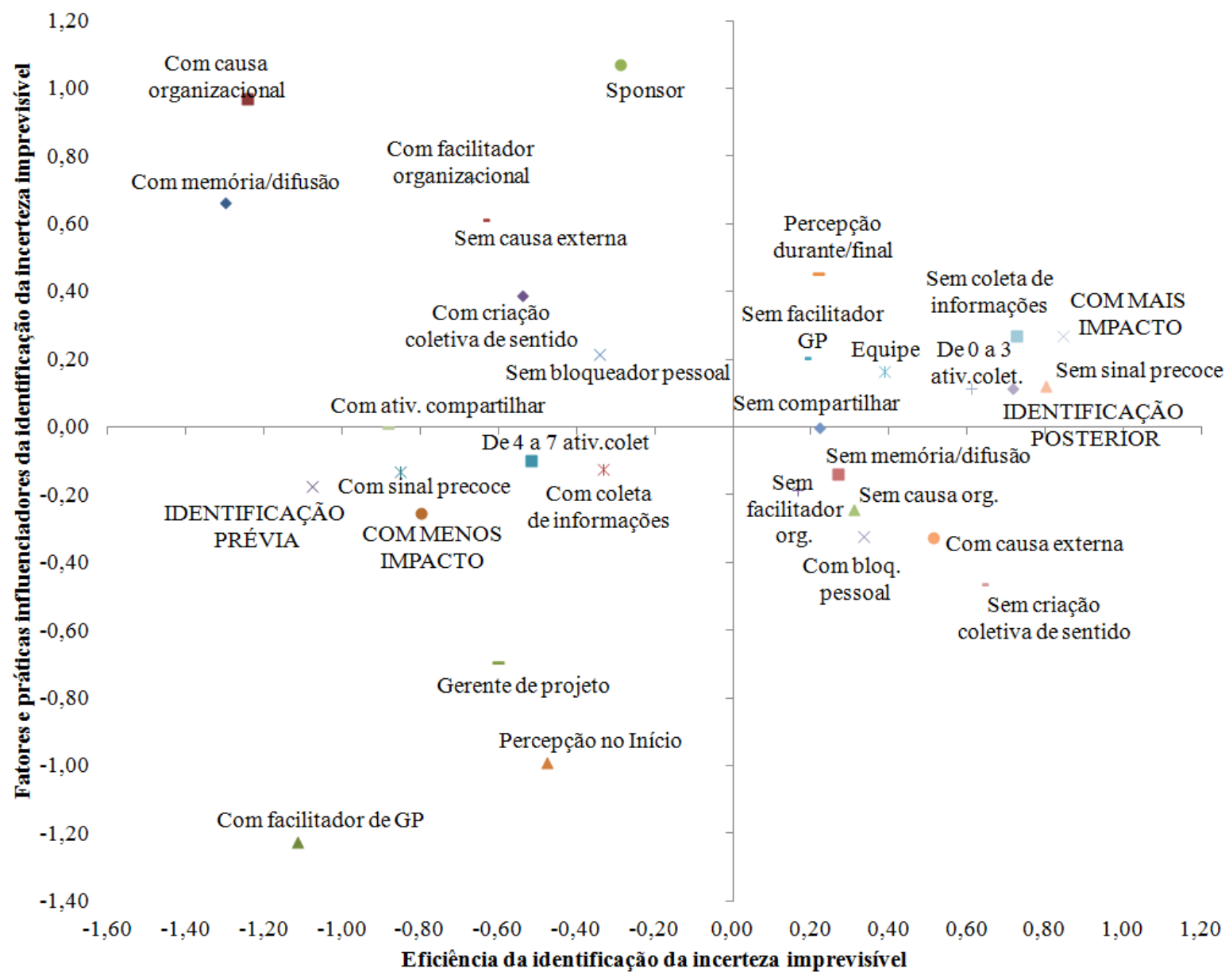

Gráfico 21 - Mapa perceptual da associação entre variáveis dependentes e independentes

\subsubsection{Relação entre as variáveis independentes}

Devido ao pequeno número de registros na amostra, não foi possível verificar a influência das variáveis moderadoras, por isso serão feitas neste item algumas avaliações entre as variáveis independentes para se atenderem as propostas de estudo não compreendidas pelas análises anteriores.

\subsubsection{Relação do tempo de experiência do gestor do projeto com o tipo de gestão prévia da incerteza imprevisível}

Para se decidir se os três grupos de tipo de gestão prévia da incerteza imprevisível foram semelhantes em relação ao tempo de experiência profissional e em GP do gestor do projeto, avaliado em quantidade de anos, procedeu-se à prova não-paramétrica de Kruskal-Wallis, conforme Tabela 27. Essa avaliação foi feita apenas para os projetos nos quais foi entrevistado o gerente de projetos ou o sponsor, pois os demais respondentes poderiam não 
ter responsabilidade direta sobre a decisão de como gerir a incerteza, totalizando 13 projetos e 28 eventos imprevistos. Mais especificamente, espera-se que a busca de informação ocorra mais entre os menos experientes.

Tabela 27 - Resultado estatístico da relação do tipo de gestão prévia por tempo de experiência do gestor do projeto

\begin{tabular}{|c|c|c|}
\hline Prova e resultado & $\begin{array}{c}\text { Tempo de } \\
\text { experiência } \\
\text { profissional do } \\
\text { gestor do } \\
\text { projeto }\end{array}$ & $\begin{array}{c}\text { Tempo de } \\
\text { experiência em } \\
\text { GP do gestor do } \\
\text { projeto }\end{array}$ \\
\hline Qui-quadrado & 6,161 & 3,245 \\
\hline $\mathrm{P}$ & 0,046 & 0,197 \\
\hline
\end{tabular}

A prova aplicada indica que os três grupos do tipo de gestão prévia da incerteza imprevisível diferiram entre si, apenas quanto ao tempo de experiência profissional $(p=0,046<0,10)$. Ao rejeitar a hipótese de nulidade foi necessário identificar-se qual dos grupos do tipo de gestão prévia da incerteza imprevisível era diferente. Para tanto, realizou-se a prova de comparações múltiplas. O resultado dessa prova, conforme Tabela 28, à taxa de $10 \%$, foi conclusivo que apenas a busca de informação difere dos outros tipos de gestão prévia. Descritivamente, notase que a busca de informação foi realizada por quem tem menos tempo de experiência, em média 19,8 anos ante 28,9 anos de experiência dos que não fazem gestão prévia da incerteza.

Tabela 28 - Média do tempo de experiência do gestor do projeto por tipo de gestão prévia da incerteza imprevisível

\begin{tabular}{|c|c|c|c|c|}
\hline $\begin{array}{c}\text { Tipo de gestão prévia da } \\
\text { incerteza imprevisível }\end{array}$ & $\begin{array}{c}\text { Gestão por } \\
\text { planejamento } \\
\text { ou risco }\end{array}$ & $\begin{array}{c}\text { Busca de } \\
\text { informação }\end{array}$ & $\begin{array}{c}\text { Não gerido } \\
\text { previamente }\end{array}$ & Total \\
\hline $\begin{array}{c}\text { Média do tempo de } \\
\text { experiência profissional do } \\
\text { gestor do projeto (em anos) }\end{array}$ & 26,0 & 19,8 & 28,9 & 26,7 \\
\hline
\end{tabular}

\subsubsection{Relação das variáveis independentes com o tipo de inovação do projeto}

Para permitir a avaliação da associação do tipo de inovação em relação às variáveis independentes, o tipo de inovação foi agrupado em inovações externas (produtos e de marketing) e internas (organizacionais e de processo). No primeiro tipo, os clientes ou usuários são diretamente afetados e no segundo a visibilidade tende a se restringir aos setores 
internos da organização. Na Tabela 29 constam os resultados e o tipo de prova aplicado a essas variáveis.

Tabela 29 - Resultado estatístico da relação entre as variáveis independentes e tipo de inovação do projeto

\begin{tabular}{|c|c|c|c|c|}
\hline \multirow{2}{*}{\multicolumn{2}{|c|}{ Variáveis Independentes }} & \multirow{2}{*}{ Variáveis } & \multicolumn{2}{|c|}{ Tipo de inovação do projeto } \\
\hline & & & $\mathbf{p}$ & Prova Estatística \\
\hline \multirow{3}{*}{\multicolumn{2}{|c|}{$\begin{array}{l}\text { Fator gerador da incerteza } \\
\text { imprevisível }\end{array}$}} & Ocorrência de causa externa & 0,279 & $\chi^{2}$ \\
\hline & & Ocorrência de causa organizacional & 1,000 & Fisher \\
\hline & & Ocorrência de causa oriunda da gestão de projetos & 0,454 & Fisher \\
\hline \multirow{4}{*}{\multicolumn{2}{|c|}{$\begin{array}{c}\text { Fator motivador da identificação } \\
\text { da incerteza imprevisível }\end{array}$}} & Tipo de gestão prévia da incerteza & 0,728 & $\chi^{2}$ \\
\hline & & Tipo de sinal precoce $*$ & 0,404 & $\chi^{2}$ \\
\hline & & Quem percebeu o sinal precoce * & 0,258 & Fisher \\
\hline & & Momento da percepção do sinal precoce * & 0,983 & $\chi^{2}$ \\
\hline \multirow{31}{*}{$\begin{array}{c}\text { Práticas para } \\
\text { a criação de } \\
\text { sentido }\end{array}$} & Método de gestão & Método de gestão do imprevisto * & 0,600 & $\chi^{2}$ \\
\hline & \multirow{6}{*}{ Processos } & Ocorrência do processo de coleta de informações & 0,478 & $\chi^{2}$ \\
\hline & & Ocorrência do processo de diagnostico & 0,458 & $\chi^{2}$ \\
\hline & & Ocorrência do processo de criação de sentido coletivo & 0,115 & $\chi^{2}$ \\
\hline & & Ocorrência do processo de memória / difusão & 0,187 & Fisher \\
\hline & & Ocorrência do processo de execução & 0,452 & $\chi^{2}$ \\
\hline & & Ocorrência do processo de novo ciclo & 0,666 & Fisher \\
\hline & \multirow{20}{*}{ Atividades } & Ocorrência da atividade de buscar informação externamente & 0,013 & $\chi^{2}$ \\
\hline & & Ocorrência da atividade de checar a informação & 1,000 & Fisher \\
\hline & & Ocorrência da atividade de obter evidências & 0,424 & Fisher \\
\hline & & Ocorrência da atividade de pesquisar & 1,000 & Fisher \\
\hline & & Ocorrência da atividade de diagnosticar problema & 0,245 & Fisher \\
\hline & & Ocorrência da atividade de revisar & 0,666 & Fisher \\
\hline & & Ocorrência da atividade de identificar alternativas & 0,071 & Fisher \\
\hline & & Ocorrência da atividade de compartilhar & 0,677 & Fisher \\
\hline & & Ocorrência da atividade de discutir com a equipe & 0,478 & $\chi^{2}$ \\
\hline & & Ocorrência da atividade de envolver outros departamentos & 0,700 & Fisher \\
\hline & & Ocorrência da atividade de abortar & 0,347 & Fisher \\
\hline & & Ocorrência da atividade de fechar acordo & 0,244 & Fisher \\
\hline & & Ocorrência da atividade de procrastinação & 0,666 & Fisher \\
\hline & & Ocorrência da atividade de solucionar & 0,071 & Fisher \\
\hline & & Ocorrência da atividade de tentativa de evitar & 1,000 & Fisher \\
\hline & & Ocorrência da atividade de registrar & 0,187 & Fisher \\
\hline & & Ocorrência da atividade de avaliar & 1,000 & Fisher \\
\hline & & Ocorrência da atividade de cumprir o planejado & 1,000 & Fisher \\
\hline & & Ocorrência da atividade de planejar & 0,187 & Fisher \\
\hline & & Ocorrência da atividade de gerar novo ciclo & 0,666 & Fisher \\
\hline & \multirow{4}{*}{$\begin{array}{c}\text { Técnicas e } \\
\text { Ferramentas }\end{array}$} & Ocorrência de $T \& F$ de criatividade & 0,489 & Fisher \\
\hline & & Ocorrência de T\&F de avaliação do presente & 0,478 & $\chi^{2}$ \\
\hline & & Ocorrência de $T \& F$ de revisão histórica & 0,489 & Fisher \\
\hline & & Ocorrência de T\&F de apoio & 0,478 & $\chi^{2}$ \\
\hline \multirow{10}{*}{$\begin{array}{c}\text { Fatores } \\
\text { bloqueadores } \\
\mathrm{e} \\
\text { facilitadores }\end{array}$} & \multirow{5}{*}{$\begin{array}{c}\text { Fatores } \\
\text { bloqueadores }\end{array}$} & Ocorrência de bloqueador externo & 0,245 & Fisher \\
\hline & & Ocorrencia de bloqueador organizacional & 1,000 & Fisher \\
\hline & & Ocorrência de bloqueador oriundo da equipe & 1,000 & Fisher \\
\hline & & Ocorrência de bloqueador oriundo da gestão de projetos & 0,713 & $\chi^{2}$ \\
\hline & & Ocorrência de bloqueador pessoal & 0,782 & $x^{2}$ \\
\hline & \multirow{5}{*}{$\begin{array}{c}\text { Fatores } \\
\text { facilitadores }\end{array}$} & Ocorrência de facilitador externo & 0,582 & Fisher \\
\hline & & Ocorrência de facilitador organizacional & 0,677 & Fisher \\
\hline & & Ocorrência de facilitador oriundo da equipe & 0,713 & $\chi^{2}$ \\
\hline & & Ocorrência de facilitador oriundo da gestão de projetos & 1,000 & Fisher \\
\hline & & Ocorrência de facilitador pessoal & 1,000 & Fisher \\
\hline
\end{tabular}


Foi efetuada a prova do Qui-Quadrado $\left(\chi^{2}\right)$ ou prova de Fisher, para testar a hipótese de a variável tipo de inovação do projeto ser independente das variáveis dos tipos nominal e ordinal. O processo de decisão, como foi sempre utilizado nos eventos imprevistos desta amostra, tornou-se uma variável constante, para a qual não há possibilidade de análise referencial. Conforme as células destacadas nessa tabela, pode-se perceber que apenas três atividades foram associadas: buscar informação externamente, identificar alternativas e solucionar. A seguir será analisada a associação do tipo de inovação do projeto apenas em relação a essas três atividades.

Quanto à atividade de buscar informação externamente, observando-se a Tabela 30, percebese que, para os eventos imprevistos de projetos com inovação do tipo externa, essa atividade tendeu a estar presente no evento imprevisto $(52,6 \%)$. Porém, quando o tipo de inovação era interno, a grande maioria dos eventos $(87,5 \%)$ não executou essa atividade. Relativamente, essa atividade esteve mais presente em eventos imprevistos de projetos com tipo de inovação externa. Logo, pode-se deduzir que, nesses casos, desconhecendo-se o produto ou serviço a ser desenvolvido, há uma estratégia de se buscarem informações com especialistas, fornecedores, parceiros ou mesmo uma patente, o que não tende a acontecer em inovações internas.

Tabela 30 - Distribuição da atividade de buscar informação externamente por tipo de inovação do projeto

\begin{tabular}{|c|c|c|c|c|}
\hline \multirow{2}{*}{$\begin{array}{c}\text { Ocorrência da atividade de } \\
\text { buscar informação } \\
\text { externamente }\end{array}$} & \begin{tabular}{c} 
Tipo de inovação do projeto \\
Externa \\
\cline { 2 - 4 }
\end{tabular} & $\begin{array}{c}\text { Interna } \\
\text { (Produto / Marketing) }\end{array}$ & Total \\
(Processo / Organizacional) & \\
\hline \multirow{2}{*}{ Sem atividade } & Frequência & 9 & 14 & 23 \\
\cline { 2 - 5 } & $\%$ & $47,40 \%$ & $87,50 \%$ & $65,70 \%$ \\
\hline \multirow{2}{*}{ Total } & Frequência & 10 & 2 & 12 \\
\cline { 2 - 5 } & $\%$ & $52,60 \%$ & $12,50 \%$ & $34,30 \%$ \\
\cline { 2 - 5 } & Frequência & 19 & 16 & $100,00 \%$ \\
\hline
\end{tabular}

Na Tabela 31 demonstra-se a associação entre a atividade de se identificarem alternativas e o tipo de inovação do projeto; observa-se que, nos casos com inovação do tipo externa, a maioria dos eventos imprevistos $(57,9 \%)$ não utilizou essa atividade. Da mesma forma que nos eventos imprevistos dos projetos com tipo de inovação interna, a grande maioria $(87,5 \%)$ também não utilizou essa atividade. Porém, relativamente, quando essa atividade foi utilizada, o tipo de inovação foi externo. Pode-se deduzir que o gestor do projeto tende a buscar mais de 
uma alternativa quando percebe uma incerteza imprevisível em projetos que inovam externamente, não entendendo que essa atividade seja necessária para projetos com inovação organizacional ou nos processos de distribuição.

Tabela 31 - Distribuição da atividade de identificar alternativas por tipo de inovação do projeto

\begin{tabular}{|c|c|c|c|c|}
\hline \multirow{2}{*}{$\begin{array}{c}\text { Ocorrência da atividade de } \\
\text { identificar alternativas }\end{array}$} & \begin{tabular}{c} 
Tipo de inovação do projeto \\
Externa \\
\cline { 2 - 4 }
\end{tabular} & $\begin{array}{c}\text { Interna } \\
\text { (Produto / Marketing) }\end{array}$ & \multirow{2}{*}{ Total } \\
\hline \multirow{2}{*}{ Sem atividade } & Frequência & 11 & 14 & 25 \\
\cline { 2 - 5 } & $\%$ & $57,90 \%$ & $87,50 \%$ & $71,40 \%$ \\
\hline \multirow{2}{*}{ Com atividade } & Frequência & 8 & 2 & 10 \\
\cline { 2 - 5 } & $\%$ & $42,10 \%$ & $12,50 \%$ & 35 \\
\hline \multirow{2}{*}{ Total } & Frequência & 19 & 16 & $100,00 \%$ \\
\cline { 2 - 5 } & $\%$ & $100,00 \%$ & $100,00 \%$ & $30 \%$ \\
\hline
\end{tabular}

Como pode ser observado na Tabela 32, para eventos imprevistos de projetos com tipo de inovação externa, a maioria $(57,9 \%)$ utilizou a atividade de solucionar. Quando o tipo de inovação era interna, a atividade de solucionar também esteve presente na maioria dos casos $(87,5 \%)$. Relativamente, a atividade está mais relacionada com o tipo de inovação interno. Isso pode indicar que nesse tipo de projeto os eventos imprevistos foram enfrentados mais como problemas a serem solucionados.

Tabela 32 - Distribuição da atividade de solucionar por tipo de inovação do projeto

\begin{tabular}{|c|c|c|c|c|}
\hline \multirow{2}{*}{\multicolumn{2}{|c|}{$\begin{array}{l}\text { Ocorrência da atividade } \\
\text { de solucionar }\end{array}$}} & \multicolumn{2}{|c|}{ Tipo de inovação do projeto } & \multirow{3}{*}{$\begin{array}{c}\text { Total } \\
10\end{array}$} \\
\hline & & \multirow{2}{*}{$\begin{array}{c}\begin{array}{c}\text { Externa } \\
\text { (Produto / Marketing) }\end{array} \\
8 \\
\end{array}$} & \multirow{2}{*}{$\begin{array}{c}\text { Interna } \\
\text { (Processo / Organizacional) } \\
2 \\
\end{array}$} & \\
\hline \multirow{2}{*}{ Sem atividade } & Frequência & & & \\
\hline & $\%$ & $42,10 \%$ & $12,50 \%$ & $28,60 \%$ \\
\hline \multirow{2}{*}{ Com atividade } & Frequência & 11 & 14 & 25 \\
\hline & $\%$ & $57,90 \%$ & $87,50 \%$ & $71,40 \%$ \\
\hline \multirow{2}{*}{ Total } & Frequência & 19 & 16 & 35 \\
\hline & $\%$ & $100,00 \%$ & $100,00 \%$ & $100,00 \%$ \\
\hline
\end{tabular}

\subsubsection{Relação das variáveis independentes com o NIS}

O tipo de inovação em serviços classifica-se em: radical, ad hoc e incremental. Essa variável originou o NIS - nível de inovação em serviços, que possui dois grupos: o primeiro contém os 15 eventos imprevistos dos projetos com tipo de inovação 'radical' e o segundo grupo, com os projetos dos demais tipos, que totalizaram 20 eventos. O primeiro grupo denominou-se 'mais inovador' e o segundo 'menos inovador'. Para testar a hipótese de a variável NIS ser 
independente das variáveis do tipo nominal e ordinal, foi efetuada a prova do Qui-Quadrado

$\left(\chi^{2}\right)$ ou prova de Fisher; os resultados e o tipo de prova aplicado a cada variável constam na

Tabela 33.

Tabela 33 - Resultado estatístico da relação entre as variáveis independentes e NIS

\begin{tabular}{|c|c|c|c|c|}
\hline \multirow{2}{*}{\multicolumn{2}{|c|}{ Variáveis Independentes }} & \multirow{2}{*}{ Variáveis } & \multicolumn{2}{|r|}{ NIS } \\
\hline & & & $\mathbf{p}$ & Prova Estatística \\
\hline \multirow{3}{*}{\multicolumn{2}{|c|}{$\begin{array}{l}\text { Fator gerador da incerteza } \\
\text { imprevisível }\end{array}$}} & Ocorrência de causa externa & 0,918 & $\chi^{2}$ \\
\hline & & Ocorrência de causa organizacional & 1,000 & Fisher \\
\hline & & Ocorrência de causa oriunda da gestão de projetos & 0,712 & Fisher \\
\hline \multirow{4}{*}{\multicolumn{2}{|c|}{$\begin{array}{c}\text { Fator motivador da identificação } \\
\text { da incerteza imprevisível }\end{array}$}} & Tipo de gestão prévia da incerteza & 0,918 & $\chi^{2}$ \\
\hline & & Tipo de sinal precoce $*$ & 0,380 & $\chi^{2}$ \\
\hline & & Quem percebeu o sinal precoce * & 0,044 & $\chi^{2}$ \\
\hline & & Momento da percepção do sinal precoce * & 0,027 & Fisher \\
\hline \multirow{31}{*}{$\begin{array}{c}\text { Práticas para } \\
\text { a criação de } \\
\text { sentido }\end{array}$} & Método de gestão & Método de gestão do imprevisto * & 0,666 & Fisher \\
\hline & \multirow{6}{*}{ Processos } & Ocorrência do processo de coleta de informações & 0,721 & Fisher \\
\hline & & Ocorrência do processo de diagnostico & 0,762 & $\chi^{2}$ \\
\hline & & Ocorrência do processo de criação de sentido coletivo & 0,142 & $\chi^{2}$ \\
\hline & & Ocorrência do processo de memória / difusão & 1,000 & Fisher \\
\hline & & Ocorrência do processo de execução & 0,467 & Fisher \\
\hline & & Ocorrência do processo de novo ciclo & 1,000 & Fisher \\
\hline & \multirow{20}{*}{ Atividades } & Ocorrência da atividade de buscar informação externamente & 0,181 & $\chi^{2}$ \\
\hline & & Ocorrência da atividade de checar a informação & 0,700 & Fisher \\
\hline & & Ocorrência da atividade de obter evidências & 0,419 & Fisher \\
\hline & & Ocorrência da atividade de pesquisar & 0,141 & Fisher \\
\hline & & Ocorrência da atividade de diagnosticar problema & 0,244 & Fisher \\
\hline & & Ocorrência da atividade de revisar & 0,680 & Fisher \\
\hline & & Ocorrência da atividade de identificar alternativas & 0,712 & Fisher \\
\hline & & Ocorrência da atividade de compartilhar & 0,672 & Fisher \\
\hline & & Ocorrência da atividade de discutir com a equipe & 0,281 & Fisher \\
\hline & & Ocorrência da atividade de envolver outros departamentos & 0,700 & Fisher \\
\hline & & Ocorrência da atividade de abortar & 0,141 & Fisher \\
\hline & & Ocorrência da atividade de fechar acordo & 1,000 & Fisher \\
\hline & & Ocorrência da atividade de procrastinação & 0,367 & Fisher \\
\hline & & Ocorrência da atividade de solucionar & 0,266 & Fisher \\
\hline & & Ocorrência da atividade de tentativa de evitar & 0,631 & Fisher \\
\hline & & Ocorrência da atividade de registrar & 1,000 & Fisher \\
\hline & & Ocorrência da atividade de avaliar & 1,000 & Fisher \\
\hline & & Ocorrência da atividade de cumprir o planejado & 0,631 & Fisher \\
\hline & & Ocorrência da atividade de planejar & 1,000 & Fisher \\
\hline & & Ocorrência da atividade de gerar novo ciclo & 1,000 & Fisher \\
\hline & \multirow{4}{*}{$\begin{array}{c}\text { Técnicas e } \\
\text { Ferramentas }\end{array}$} & Ocorrência de $T \& F$ de criatividade & 1,000 & Fisher \\
\hline & & Ocorrência de $T \& F$ de avaliação do presente & 0,069 & Fisher \\
\hline & & Ocorrência de $T \& F$ de revisão histórica & 1,000 & Fisher \\
\hline & & Ocorrência de $T \& F$ de apoio & 1,000 & Fisher \\
\hline \multirow{10}{*}{$\begin{array}{c}\text { Fatores } \\
\text { bloqueadores } \\
\mathrm{e} \\
\text { facilitadores }\end{array}$} & \multirow{5}{*}{$\begin{array}{c}\text { Fatores } \\
\text { bloqueadores }\end{array}$} & Ocorrência de bloqueador externo & 1,000 & Fisher \\
\hline & & Ocorrencia de bloqueador organizacional & 1,000 & Fisher \\
\hline & & Ocorrência de bloqueador oriundo da equipe & 0,199 & Fisher \\
\hline & & Ocorrência de bloqueador oriundo da gestão de projetos & 0,411 & $\chi^{2}$ \\
\hline & & Ocorrência de bloqueador pessoal & 1,000 & $\chi^{2}$ \\
\hline & \multirow{5}{*}{$\begin{array}{c}\text { Fatores } \\
\text { facilitadores }\end{array}$} & Ocorrência de facilitador extemo & 1,000 & Fisher \\
\hline & & Ocorrência de facilitador organizacional & 1,000 & Fisher \\
\hline & & Ocorrência de facilitador oriundo da equipe & 0,537 & $\chi^{2}$ \\
\hline & & Ocorrência de facilitador oriundo da gestão de projetos & 0,631 & Fisher \\
\hline & & Ocorrência de facilitador pessoal & 0,246 & Fisher \\
\hline
\end{tabular}


Conforme as células destacadas nessa tabela, pode-se perceber que apenas três variáveis foram associadas com a variável NIS, dentro do nível de significância estabelecido: quem percebeu o sinal precoce, momento no qual o sinal precoce foi percebido e ocorrência de $\mathrm{T} \& \mathrm{~F}$ de avaliação do presente. A seguir, será analisada as associações apenas em relação a essas três variáveis.

Dentro do fator motivador da identificação da incerteza imprevisível, duas variáveis foram associadas com o NIS. A primeira delas foi 'quem percebeu o sinal precoce', detalhada na Tabela 34. O total de casos não é 35, porque foram desconsiderados quatro casos referentes aos eventos imprevistos com sinal precoce percebido pelo sponsor, para permitir a aplicação das provas estatísticas. A concentração dos eventos imprevistos de projetos com NIS mais inovador percebida pelo gerente de projetos $(53,3 \%)$ não é substancial, enquanto nos casos menos inovadores, a grande maioria $(81,2 \%)$ teve o sinal precoce percebido pela equipe. Relativamente, pode-se dizer que o gerente de projetos percebe mais os sinais precoces em projetos mais inovadores, os do tipo 'radical', e a equipe percebe mais os dos menos inovadores. Isso pode indicar uma atenção mais concentrada do gerente de projetos quando o nível de inovação é maior.

Tabela 34 - Distribuição de quem percebeu o sinal precoce por NIS

\begin{tabular}{|c|c|c|c|c|}
\hline \multicolumn{2}{|c|}{$\begin{array}{c}\text { Quem percebeu o sinal } \\
\text { precoce }\end{array}$} & \multicolumn{2}{|c|}{ NIS } & \multirow{2}{*}{ Total } \\
\cline { 2 - 5 } & Mais inovador & Menos inovador & \\
\hline \multirow{2}{*}{ Equipe } & Frequência & 7 & 13 & 20 \\
\cline { 2 - 5 } & $\%$ & $46,70 \%$ & $81,20 \%$ & $64,50 \%$ \\
\hline \multirow{2}{*}{$\begin{array}{c}\text { Gerente de } \\
\text { projetos }\end{array}$} & Frequência & 8 & 3 & 11 \\
\cline { 2 - 5 } & $\%$ & $53,30 \%$ & $18,80 \%$ & $35,50 \%$ \\
\hline Total & Frequência & 15 & 16 & 31 \\
\cline { 2 - 5 } & $\%$ & $100,00 \%$ & $100,00 \%$ & $100,00 \%$ \\
\hline
\end{tabular}

A segunda variável referente aos fatores motivadores de identificação é o momento da percepção do sinal precoce. Observa-se, na Tabela 35, que para os casos mais inovadores uma relativa maioria foi identificada no início do projeto $(53,3 \%)$. Nos casos dos projetos menos inovadores, a grande maioria (85\%) foi percebida durante ou ao final do projeto. Os oito eventos imprevistos de projetos mais inovadores identificados pelo gerente de projetos, descritos na Tabela 34, não são os mesmos identificados no início do projeto. Entretanto a análise feita na Tabela 5, página 156, indica que o gerente de projetos tendeu a perceber o sinal precoce no início do projeto. 
Tabela 35 - Distribuição do momento de percepção do sinal precoce por NIS

\begin{tabular}{|c|c|c|c|c|}
\hline \multirow{2}{*}{$\begin{array}{c}\text { Momento da percepção do sinal } \\
\text { precoce }\end{array}$} & \multicolumn{2}{|c|}{ NIS } & \multirow{2}{*}{ Total } \\
\cline { 2 - 4 } Início & Frequência & Mais inovador & Menos inovador & \\
\cline { 2 - 5 } & $\%$ & $53,30 \%$ & 3 & 11 \\
\hline \multirow{2}{*}{ Durante/Final } & Frequência & 7 & $15,00 \%$ & $31,40 \%$ \\
\cline { 2 - 5 } & $\%$ & $46,70 \%$ & $85,00 \%$ & 24 \\
\hline \multirow{2}{*}{ Total } & Frequência & 15 & 20 & $35,60 \%$ \\
\cline { 2 - 5 } & $\%$ & $100,00 \%$ & $100,00 \%$ & $100,00 \%$ \\
\hline
\end{tabular}

As práticas para a criação de sentido foram associadas com o NIS apenas por meio da variável de ocorrência de utilização da T\&F de avaliação do presente, a mais utilizada nesta pesquisa. Conforme as informações da Tabela 36, percebe-se que a grande maioria $(86,7 \%)$ dos eventos imprevistos vinculados a projetos mais inovadores não utilizou essa ferramenta, assim como em projetos menos inovadores as ferramentas foram, proporcionalmente, menos utilizadas (55\%). Entretanto, relativamente, esse tipo de T\&F foi mais utilizada em projetos menos inovadores. Fazem parte dessa categoria os seguintes tipos de T\&F: análise de stakeholder, construtibilidade, entrevistas, pilotos, protótipos, questionários, reuniões de planejamento e análise e simulação. Pode-se, assim, deduzir que, pelo nível de inovação existente no projeto, essas T\&F não foram consideradas adequadas pelos gestores de projetos para se superar a lacuna de conhecimento em projetos mais inovadores.

Tabela 36 - Distribuição de ocorrência de T\&F de avaliação do presente por NIS

\begin{tabular}{|c|c|c|c|c|}
\hline \multirow{2}{*}{$\begin{array}{c}\text { Ocorrência de T\&F de avaliação } \\
\text { do presente }\end{array}$} & \multicolumn{2}{|c|}{ NIS } & \multirow{2}{*}{ Total } \\
\cline { 2 - 4 } Não presente & Frequência & 13 & 11 & 24 \\
\cline { 2 - 5 } & $\%$ & $86,70 \%$ & $55,00 \%$ & $68,60 \%$ \\
\hline \multirow{2}{*}{ Presente } & Frequência & 2 & 9 & 11 \\
\cline { 2 - 5 } & $\%$ & $13,30 \%$ & $45,00 \%$ & $31,40 \%$ \\
\hline \multirow{2}{*}{ Total } & Frequência & 15 & 20 & 35 \\
\cline { 2 - 5 } & $\%$ & $100,00 \%$ & $100,00 \%$ & $100,00 \%$ \\
\hline
\end{tabular}

\subsection{Síntese das análises}

Com base nas 15 organizações, nos 16 projetos e nos 35 eventos imprevistos obtidos nas entrevistas, foi desenvolvida a análise conforme o modelo conceitual, descrito na página 107. Nele se caracterizam as variáveis independentes com base em seis tipos: fator gerador da incerteza imprevisível; os fatores motivadores da identificação da incerteza; as práticas para a criação de sentido; os fatores bloqueadores e facilitadores à gestão da incerteza; as características da organização do projeto e do gestor do projeto. 
No modelo conceitual, as variáveis independentes, caracterizando a eficiência da identificação da incerteza imprevisível, foi composta por três variáveis: NAI - nível de antecipação da identificação da incerteza imprevisível; 40\% dos eventos foram identificados previamente à sua ocorrência e $60 \%$ foram identificados posteriormente; NIE - nível de impacto do evento imprevisto; $51 \%$ dos eventos imprevistos tiveram menos impacto; os impactos podem ter afetado o cliente, a organização ou o projeto; NSR - nível de satisfação com o resultado do evento imprevisto que, por ter sido informado em apenas 24 eventos imprevistos e alguns relatados de uma forma mais abrangente, não foi utilizado nas avaliações estatísticas. Percebeu-se, nos eventos imprevistos desta pesquisa, que, quando a incerteza imprevisível é percebida antecipadamente, há mais probabilidade de se ter menos impacto.

O fator gerador da incerteza imprevisível foi avaliado em relação à ocorrência de três causas: externa, que ocorreu na maioria dos casos (66\%), com origem no cliente, no meio ambiente, no mercado, no parceiro ou no fornecedor; organizacional, com poucos casos (20\%), relacionados à falta de estrutura ou à falta de integração das áreas e oriundas da GP, que afetou $29 \%$ dos casos, quando houve falha na comunicação, falha no planejamento, problemas na equipe ou uma solução emergencial. As causas externas foram associadas com a identificação posterior à ocorrência do evento imprevisto, enquanto a causa organizacional teve maior ocorrência em imprevistos identificados previamente e com menos impacto.

Os fatores motivadores da identificação da incerteza imprevisível foram compostos por:

- $\quad$ tipo de gestão prévia da incerteza imprevisível - gestão prévia por planejamento ou gestão de risco, responsável por $20 \%$ dos 35 eventos imprevistos; busca por informação sobre a incerteza, com apenas $14 \%$ dos casos, e não gerido previamente; com $66 \%$ dos casos;

- $\quad$ sinal precoce foi avaliado por intermédio de três itens:

- tipo de sinal precoce - informação precoce, que ocorreu em $21 \%$ dos eventos imprevistos oriundos de comunicação, da equipe do projeto, expressão do cliente, expressão do parceiro, fontes externas e gut feelings; primeiro sintoma, com $30 \%$ casos, oriundos do controle do projeto e relatórios, expressão do cliente e do usuário e trabalho dentro do projeto, e súbito, quando o sinal precoce não é percebido, ocorreu em $51 \%$ dos casos. Houve dois casos nos quais os entrevistados se lembraram de ter percebido o sinal precoce, mas não deram sentido a ele naquele momento. A percepção do sinal precoce foi, 
relativamente, mais presente nos eventos imprevistos identificados antes de sua ocorrência e com menos impacto, ocorrendo o inverso quando o sinal não é percebido;

- quem percebeu o sinal precoce - categorizado em gerente de projetos, com $32 \%$ dos casos; equipe, incluindo os percebidos por apenas um membro da equipe, totalizando $57 \%$, e sponsor, com $11 \%$ dos casos. Os eventos com menos impacto tenderam a ser, proporcionalmente, mais percebidos pelo gerente de projetos (56\%), enquanto a grande maioria dos com mais impactos $(87 \%)$ foram percebidos pela equipe;

- momento da percepção do sinal precoce - compreende a fase inicial do projeto, com $31 \%$ dos casos, e as demais fases - durante (49\%) e final do projeto (20\%). A percepção durante ou ao final do projeto foi motivo de maior impacto e identificação posterior à sua ocorrência.

As práticas para a criação de sentido foram subdivididas em:

- método de gestão do evento imprevisto. A maioria (66\%) dos eventos imprevistos usou o método de aprendizado, que engloba a experimentação e a improvisação, e os demais $20 \%$ utilizaram o planejamento, de maneira formal, que incluí a maioria das melhores práticas, ou macro, quando apenas algumas práticas são aplicadas;

- processos para a criação de sentido - coleta de informações, o processo mais presente (69\%) e quando presente, o evento imprevisto tendeu a ter menos impacto; diagnóstico, presente em $63 \%$ dos casos; criação coletiva de sentido, que ocorreu em $54 \%$ dos casos, quando era utilizada, o evento imprevisto tendeu a ser identificado previamente e a ter menos impacto; decisão, presente em todos os eventos imprevistos; execução, que ocorreu em $31 \%$ dos casos; memória / difusão, que ocorreu em apenas 17\% dos casos, relativamente mais utilizada em casos identificados previamente; e, finalmente, novo ciclo de criação de sentido, pouco utilizado (17\%);

atividades para a criação de sentido foram avaliadas em dois níveis:

- ocorrência de cada tipo de atividade. Foram analisadas 20 atividades, das quais foram mais presente as atividades de solucionar (71\%), de buscar informação externamente (34\%), de discutir com a equipe (31\%) e de identificar alternativas (29\%). Entretanto, estão associadas à eficiência da identificação apenas duas atividades - compartilhar, quando presente no evento imprevisto, este tendeu, proporcionalmente, a ser associado com eventos identificados previamente, e registrar, a única atividade do processo de memória e difusão, já descrito; 
- quantidade de atividades por tipo de participação, que pode ser individual, quando apenas um dos envolvidos participou na atividade, totalizando $14 \%$ dos eventos imprevistos; coletiva, quando houve participação de várias pessoas na atividade, o que ocorreu na maioria dos casos (78\%); externa, quando a atividade foi executada por outro departamento, pelo cliente ou pelo fornecedor, compreendendo apenas 5\% dos casos, e novo ciclo, que representa o início de um novo ciclo de criação de sentido, que ocorreu em $3 \%$ dos casos. Foi possível concluir apenas com relação à quantidade de atividades coletivas do evento imprevisto, pois quanto maior ela foi, maior a tendência de que a identificação tenha sido prévia à sua ocorrência e se tenha, proporcionalmente, menos impacto;

- técnicas e ferramentas foram pouco utilizadas - técnicas de criatividade, $6 \%$ dos casos, que compreendem brainstorming, estudo de viabilidade e pesquisa de mercado; avaliação do presente, 31\%, que engloba análise de stakeholders, construtibilidade, entrevista, piloto, protótipo, questionário, reunião de planejamento e análise, simulação; revisão histórica, como a revisão de status que ocorreu em $6 \%$ dos casos e técnicas e ferramentas de apoio, como contrato, matriz de responsabilidade, plano de comunicação, plano de risco e treinamento, presente em $31 \%$ dos eventos.

Foram avaliadas as ocorrências de cada fator bloqueador e facilitador da gestão da incerteza em cada evento imprevisto. Os fatores bloqueadores foram classificados nos seguintes tipos: externo, tendo ocorrido em $26 \%$ dos casos, oriundos do meio ambiente, problemas com o cliente, com o fornecedor, com o parceiro, ou devido a uma situação do mercado; organizacional, que ocorreu em $6 \%$ dos casos, devido à defesa dos interesses da área, à falta de estrutura e à falta de padronização em GP; oriundos da equipe, responsável por $20 \%$ dos casos, basicamente por causa da falta de experiência ou conhecimento; oriundos da GP, que ocorreu em 34\% dos casos, devido à falha na comunicação, à falta de definição, à falta de gestão de RH ou a problemas no planejamento e pessoal, a categoria mais numerosa (40\%), no qual constam a ancoragem, a consciência limitada, a escalada do comprometimento e o excesso de confiança. Quando esse fator esteve presente, o evento imprevisto tendeu a ser identificado depois de sua ocorrência e a possuir mais impacto.

Os fatores facilitadores também foram classificados em cinco tipos: externo, que ocorreu em $9 \%$ dos casos por causa da facilitação do cliente ou do fornecedor; organização, com $20 \%$ 
dos casos, ocorreu devido ao apoio dos pares, do sponsor ou da assunção de riscos, e quando presente, o evento imprevisto tendeu a ser identificado previamente à sua ocorrência; oriundo da equipe, sendo o tipo mais numeroso (34\%) devido à abertura para problemas, multidisciplinaridade, poder de decisão, proximidade com o cliente, trabalho em equipe e visão externa do problema; oriundo da GP, com 14\% dos casos devido à utilização da busca de informação, flexibilidade nas atividades e objetivos claros, que, presentes, os eventos foram identificados previamente e tiveram menos impacto; e, finalmente, pessoal, com $23 \%$ dos casos, devido ao comprometimento, criatividade e experiência dos membros da equipe.

Com relação às características organizacionais, foi avaliado apenas o nível de cultura de atenção da organização; das 15 organizações, 14 tinham alto nível de cultura de atenção, o que impediu verificar a associação com a eficiência da identificação da incerteza imprevisível.

As variáveis relativas à característica do projeto foram:

- $\quad$ método de gestão do projeto, classificados em experimentação (6\%), informal (6\%), macro (38\%) e formal, o mais utilizado $(50 \%)$;

- $\quad$ tipo de inovação do projeto foi em sua maioria geração de novos produtos (50\%), $6 \%$ continham inovação em marketing, $13 \%$ tinham inovação no processo de produção e $31 \%$ tinham inovação organizacional. Percebeu-se que os projetos com inovações externas (produto e de marketing) foram mais associados à ocorrência de atividade de busca de informação externa e à atividade de identificar alternativas e os projetos com inovações internas (processo e organizacional) foram associados com a ocorrência de atividade de solucionar;

- $\quad$ NIS - Nível de inovação em serviço - os projetos classificados como mais inovadores, os radicais, foram a minoria (44\%), os demais, incrementais e ad hoc, representaram 56\%. Notou-se que nos projetos mais inovadores houve uma tendência do gerente de projetos ter percebido os sinais precoces e nos projetos menos inovadores, a tendência é que a equipe tenha percebido o sinal precoce, durante ou ao final do projeto, tendo utilizado uma T\&F de avaliação do presente;

- nível de incerteza tecnológica do projeto foi alto na maioria dos projetos (63\%), poucos com nível médio (19\%) ou muito alto (19\%);

- nível de complexidade do projeto também foi alto na maioria (56\%) e no restante foi médio. 
Quanto ao gestor do projeto, as variáveis sobre suas características foram: o tempo de experiência profissional e o tempo de experiência em GP. Sobre o tempo de experiência profissional, a maioria tinha de 21 a 30 anos, e em GP, a maioria tinha entre 11 a 20 anos. Observou-se que a gestão prévia da incerteza do tipo busca de informação foi mais utilizada por gestores (gerentes de projetos e os sponsors) menos experientes, o que não ocorre para o tipo de gestão por planejamento ou risco ou o tipo não gerido previamente. 
216 


\section{SÍNTESE, CONCLUSÕES E RECOMENDAÇÕES}

\section{$5.1 \quad$ Síntese do estudo}

Este estudo foi planejado e conduzido com o objetivo principal de entender e descrever qual é o fator gerador da incerteza imprevisível, quais são os fatores motivadores de sua identificação e quais são as práticas que contribuem para a criação de sentido das incertezas imprevisíveis em projetos inovadores. Esse objetivo principal foi desmembrado nos seguintes objetivos secundários:

a) descrever o fator gerador da incerteza imprevisível - causas - e os fatores motivadores de sua identificação - tipo de gestão prévia da incerteza imprevisível e sinal precoce;

b) levantar as práticas de criação de sentido para a identificação e a gestão da incerteza imprevisível - métodos de gestão do evento imprevisto, processos, atividades, técnicas e ferramentas;

c) entender os fatores que bloqueiam e os que facilitam a gestão da incerteza imprevisível;

d) avaliar a eficiência da identificação da incerteza imprevisível;

e) analisar as relações da eficiência da identificação da incerteza imprevisível com o fator gerador, os fatores motivadores, as práticas para a criação de sentido, os fatores bloqueadores, os facilitadores e as características organizacionais, do projeto e dos gestores.

A natureza da pesquisa foi descritiva, mediante o uso de um processo exploratório inicial para atender os quatro primeiros objetivos listados acima. O propósito deste estudo foi contribuir e estender a teoria de Loch et al. (2006; 2008). A unidade de análise foi o projeto inovador, seus eventos imprevistos foram a unidade de análise incorporada, em um total de 16 projetos e 35 eventos. Esses projetos se caracterizaram por ser em grande parte projetos de serviços, ter tipo de inovação em serviços radical, com alta incerteza tecnológica. Porém, houve também projetos ad hoc e incrementais para efeito de comparação.

No modelo conceitual foram consideradas como variáveis independentes: o fator gerador da incerteza imprevisível - suas causas; os fatores motivadores da identificação da incerteza tipo de gestão prévia da incerteza imprevisível e sinal precoce; as práticas para a criação de sentido - método de gestão do evento imprevisto, processos, atividades, técnicas e 
ferramentas; os fatores bloqueadores e facilitadores à gestão da incerteza; as características da organização - nível de cultura de atenção; as características do projeto - método de gestão, tipo de inovação, NIS - nível de inovação em serviço, nível de incerteza tecnológica e nível de complexidade; assim como o tempo de experiência profissional e em GP do gestor de projetos. A variável dependente (eficiência da identificação da incerteza imprevisível) foi composta pelo NAI - nível de antecipação da identificação da incerteza imprevisível, pelo NIE - nível de impacto do evento imprevisto e o NSR - nível de satisfação com o resultado obtido.

O procedimento metodológico para atender ao método qualitativo, por meio de um levantamento de campo, compreendeu duas etapas: na primeira, utilizou-se um questionário para obter informações iniciais sobre o projeto e, na segunda, entrevistas aprofundadas foram aplicadas e dirigidas por um roteiro com perguntas abertas. As etapas de análise, auxiliadas pela ferramenta NVivo 9, foram: transcrição das entrevistas; organização das informações; codificação, por meio da análise de frases e comparações entre unidades de análise; descrição de categorias, auxiliada por notas com comentários sobre as codificações, e previsão da representação, auxiliada por notas teóricas. $\mathrm{Na}$ análise quantitativa, foi estabelecida a margem de significância de $10 \%$ para os testes das hipóteses e foram usadas provas estatísticas não paramétricas.

\subsection{Conclusões}

As conclusões serão apresentadas na forma de análise das proposições elaboradas para este estudo, com a inserção de algumas considerações obtidas na codificação e na análise qualitativa, especialmente quando houve discrepâncias. Deve-se ressaltar que as conclusões emitidas neste estudo se referem aos projetos analisados, não devendo, portanto, serem generalizadas..

Proposição de estudo 1 - Os fatores externos geram mais incertezas imprevisíveis.

Foram identificados três tipos de causas para as incertezas imprevisíveis: externas, organizacionais e com origem na GP. As causas externas - cliente, meio ambiente, mercado, parceiro / fornecedor - foram as mais numerosas, pois ocorreram em $57 \%$ dos casos e foram 
as principais em 54\%. Segundo os padrões de GR (HM TREASURY, 2004; COSO, 2004), a causa externa pode apenas ser mitigada e não evitada. Essa linha de pensamento foi confirmada, pois as causas externas tenderam a ser identificadas posteriormente, além de que os fatores externos também foram considerados bloqueadores da gestão da incerteza em $26 \%$ dos eventos imprevistos. Quando a causa externa pôde ser identificada previamente foi utilizada, na maioria dos casos (67\%), a gestão prévia da incerteza imprevisível por busca de informação, indicando a relevância do diagnóstico de incertezas, sugerido por Loch et al. (2006; 2008).

As causas organizacionais - falta de estrutura, falta de integração das áreas - foram a principal causa em $26 \%$ dos casos. Os demais casos foram relativos à GP - falha na comunicação, falha no planejamento, problemas na equipe e solução emergencial. Quando houve uma causa organizacional, o evento imprevisto tendeu a ser identificado previamente, assim como seu respectivo nível de impacto foi menor. Isso indica uma diferença entre os tipos de causas, pois, enquanto a causa externa tendeu a ser mais difícil de ser prevista, a causa organizacional tendeu a ser mais fácil e a gerar menos impacto. Outra dedução que se pode fazer é a de que os sinais precoces dentro do ambiente organizacional tendem a ser percebidos mais facilmente do que os sinais do ambiente externo. Por conseguinte, o exposto por esta proposição de estudo pode ser confirmado, apesar de o fator externo ser mais numeroso e tender a ser identificado posteriormente, não se pode dizer que os eventos imprevistos com essas causas gerem mais impacto.

Proposição de estudo 2 - A criação de sentido das incertezas imprevisíveis inicia-se pelos sinais do ambiente mais do que pela busca da identificação da incerteza.

Apenas cinco eventos imprevistos (14\%) iniciaram por uma busca de informação - tipo de gestão prévia da incerteza imprevisível - e mesmo esses foram precedidos por sinais precoces. Assim, pode-se confirmar que a criação de sentido das incertezas imprevisíveis inicia-se mais pelos sinais do ambiente do que pela busca de identificação das incertezas. $\mathrm{O}$ sinal precoce está ligado a uma propriedade da criação de sentido chamada de extração de sinais. Estes são percebidos e extraídos do ambiente conforme o modelo mental, as crenças pessoais, regras, procedimentos e outros fatores. 
De fato, pode-se observar que os cinco casos nos quais não houve impacto foram identificados previamente; nove dos treze casos (69\%) dos eventos, com impacto mitigado, foram identificados previamente e todos os eventos imprevistos com impacto total não foram percebidos antecipadamente. Foram citados pelos entrevistados, como uma idealização, a associação ou a contratação de uma consultoria ou mesmo o simples acesso a mais informações, auxiliariam a equipe a identificar previamente os eventos imprevistos.

Também deve ser ressaltado que o processo de coleta de informações esteve presente na maioria dos eventos imprevistos $(69 \%)$ e, quando presente, houve menos impacto. Essa observação está alinhada com a estratégia sugerida por Zack (1999) para diminuir a incerteza quando há informação insuficiente para se predizer o futuro. Novamente, a recomendação de Loch et al. (2008), de diagnosticar as incertezas para geri-las de modo diferenciado, se mostra bastante relevante.

Muitas vezes, pelo fato de o projeto já ter passado por várias fases de aprofundamento e de aprovação, como no caso do método de stage-gates, ou mesmo já ter elaborado a GR, a equipe pode se sentir mais confiante, sem avaliar que ainda há incertezas imprevisíveis que podem ocorrer. Os sete eventos imprevistos (20\%) enquadrados no tipo de gestão prévia da incerteza imprevisível por planejamento e GR podem ser os representantes dessa situação.

Com relação ao tipo de sinal precoce percebido, os sinais identificados no Quadro 7, página 80 (KAPPELMAN et al., 2006; NIKANDER, ELORANTA, 1997; 2001; SANCHEZ, PEREZ, 2004), se mostraram bastante efetivos para identificar os tipos de sinal precoce. A categoria de informação precoce esteve menos presente que o tipo primeiro sintoma e o tipo súbito. Isto pode ser explicado pelos poucos sinais que são emitidos e de sua pouca visibilidade, o que dificulta a sua interpretação (HILTUNEN, 2008). Porém, o sinal precoce tende a ser percebido quando houve uma identificação prévia da incerteza e quando houve menos impacto.

Quando a identificação da incerteza foi posterior à ocorrência do evento imprevisto e houve mais impacto, a percepção tendeu a ser súbita. Em dois casos, o entrevistado relatou sinais precoces aos quais não deu relevância, o que fez que o evento ocorresse de forma súbita. As exceções a se ter mais impacto na percepção súbita demonstram a inclusão da sorte, como no 
caso em que houve negociação com o cliente, pois não havia recursos humanos e financeiros para atender uma mudança legal que impactava as entregas do projeto. Nesse caso, a plausibilidade da criação de sentido, uma de suas propriedades, pode ser percebida, pois apesar de não ser o melhor resultado para aquele projeto, era o resultado plausível para aquele momento.

Há influência também do momento da percepção do sinal precoce, pois quando houve identificação posterior e houve mais impacto, o sinal precoce tendeu a ser percebido durante ou ao final do projeto. Isto pode indicar uma tendência a se ter menos eficiência ao longo do tempo. Poder-se-ia associar essa eficiência à propriedade de continuidade da criação de sentido, pois no início do projeto há probabilidade de existir um tempo maior para refinar o entendimento pelas ações tomadas. Assim, quanto antes o sinal precoce é percebido, mais tempo se tem para entender e superar a lacuna de conhecimento, e, portanto, maior a probabilidade de se obter um bom resultado no evento imprevisto.

Proposição de estudo 3 - As pessoas mais experientes buscam menos a incerteza imprevisível.

O sentido desta proposição de estudo foi confirmado, pois se percebeu que entre os gerentes de projeto e os sponsors que participaram desta pesquisa, os que tinham menos tempo de experiência profissional utilizaram, como tipo de gestão prévia da incerteza imprevisível, a busca de informação. Para os outros tipos de gestão prévia, a média do tempo de experiência não se distingue da média geral. Isto pode ser explicado pela falácia da importância (WEICK, 1995), que representa a superestimação do conhecimento pelos especialistas, negando os fatos que eles não conseguem enquadrar em seu saber.

Outro fator que também influencia a eficiência é quem percebeu o sinal precoce. Apesar de a equipe ter percebido mais os sinais precoces, provavelmente por ter percebido um maior número dos primeiros sintomas e dos súbitos e mais durante o desenvolvimento do projeto, os eventos imprevistos que elas identificaram tenderam a ter mais impactos negativos. Por outro lado, os eventos imprevistos com menos impacto tendem a ter os sinais precoces percebidos pelo gerente de projetos, provavelmente porque ele foi responsável pela percepção da maioria das informações precoces e das percepções no início do projeto. Essa constatação esta 
alinhada, de certa maneira com que Kappelman et al. (2006) observaram: as características mais importantes dos que percebem os sinais precoces foram a experiência e a perspicácia; eles assumiram a premissa de que o gerente de projetos normalmente tem mais experiência do que a equipe.

Poder-se-ia afirmar que a influência de quem percebeu o sinal precoce está diretamente ligada à propriedade da construção da identidade, da criação de sentido, na medida em que o envolvido se preocupa com sua identidade no contexto social e se empenha mais em aprender sobre o projeto. Por exemplo, em um dos projetos, o entrevistado informou que ele havia conquistado esse projeto de maneira a poder implantar todo o planejamento que ele sentia necessidade de usar, para obter bons resultados, além basear esse planejamento em sua experiência com organizações externas de vários níveis, que seriam parceiras nesse projeto. Assim, ele acabou percebendo que havia uma variável, que nenhum produto similar contemplava, e caso não fosse tratada diminuiria consideravelmente o resultado do projeto na fase de operação, após a implantação.

Proposição de estudo 4 - O método de aprendizado é mais usado do que as práticas estabelecidas para a criação de sentido das incertezas imprevisíveis.

Nessa pesquisa, observou-se que 23 casos (66\%) dos eventos imprevistos utilizaram o método de aprendizado, que compreende a improvisação e a experimentação, confirmando assim o sentido desta proposição de estudo. Quanto aos métodos de gestão de projetos, apenas um projeto usou a experimentação e os outros usaram algum nível de planejamento, com formalização completa em $50 \%$ dos projetos. Assim, o método de gestão do imprevisto é distinto do método do projeto, em 24 casos (69\%), excluindo-se os cinco eventos imprevistos nos quais houve procrastinação, não se empregando nenhum método.

Isto está alinhado com os resultados obtidos de Sadler-Smith e Leyborne (2006) que verificaram que os gerentes de projeto usam mais a intuição e a improvisação, quando avaliaram as preferências entre o uso de processos racionais e a intuição. Estes procedimentos também foram sugeridos por Russo e Sbragia (2010) para a geração da inovação, principalmente nas etapas iniciais de desenvolvimento de produtos. Também está de acordo com que Loch et al. (2008) indicam: usar uma metodologia diferenciada, conforme o nível de 
incerteza; usar os métodos de aprendizado e selecionismo apenas nas partes do projeto que são mais incertas. Porém, nenhum entrevistado relatou um diagnóstico de incertezas para se isolar as partes com mais incerteza e aplicação de uma gestão específica, conforme o nível de incerteza, como foi sugerido por esses autores.

Supõe-se que o método de aprendizado está mais alinhado com a propriedade de enactment da criação de sentido, pois há mais abertura, nesses casos, para uma ação ou reação ao ambiente, para que se possa dar sentido ao que está ocorrendo, agindo de diferentes maneiras, observando-se os resultados intermediários.

Aprofundando a escolha do método a ser empregado no projeto, convém discutir o relatado por um entrevistado sobre a falta de definição do produto do projeto, como fator bloqueador. Com o nível de novidade que o projeto possuía em seu início, não se podia esperar que o produto estivesse definido, mas como foi usado o método de planejamento, isso se tornou realmente um bloqueador. Assim, pode-se afirmar que o gerente não avaliou os principais pontos de incerteza do projeto, aplicando um método de gestão inadequado.

Proposição de estudo 5 - O sentido das incertezas imprevisíveis é gerado mais pela criação coletiva de sentido do que pela criação de sentido individual.

O tipo de participação coletiva nas atividades do evento imprevisto ocorreu na maioria dos 35 casos $(78 \%)$ e foi associado ao nível de impacto do evento imprevisto. Portanto, pode-se dizer que, quando há menos impacto, há uma tendência a se ter mais atividades coletivas, assim a criação de sentido tende a ser mais eficiente. Além disso, as ações coletivas foram objeto de destaque como fator facilitador à gestão das incertezas, por causa da multidisciplinaridade e do trabalho da equipe. Também foi citado como fator idealizado dentro da gestão de projetos, pois os entrevistados consideram que se usassem mais integração com o cliente e com as pessoas, de uma maneira geral, os imprevistos poderiam ter sido identificados antes. Assim, pode-se confirmar o sentido desta proposição de estudo.

A respeito das práticas de criação de sentido que puderam ser associadas à eficiência da identificação da incerteza imprevisível, pode-se dizer o seguinte: 
- $\quad$ o processo de coleta de informações esteve presente na maioria dos eventos imprevistos $(69 \%)$ e, em muitos deles, a gestão da incerteza se iniciou por ele (40\%); quando houve menos impacto, esse processo tendeu a estar presente;

o processo de criação coletiva de sentido revelou uma tendência de o evento imprevisto ser identificado antes e a produzir menos impacto. De fato, a criação coletiva de sentido visa o compartilhamento das informações, o envolvimento de outros departamentos, reforçando a propriedade social da criação de sentido. Como o sentido é criado e não apenas descoberto, a interação social é fator preponderante no processo. Essas atividades estão alinhadas a estratégia para diminuir a ambiguidade (falta de um modelo conceitual para interpretar a informação) de Zack (1999);

o processo de memória e difusão ocorreu em poucos eventos, mas quando a incerteza imprevisível foi identificada previamente, houve uma tendência de ele estar presente. Esse processo possui apenas a atividade de registrar, usada tanto para transcrever o processo e os resultados intermediários, quanto às decisões tomadas, dado que ela não ocorreu apenas após a decisão. Este processo pode ser remetido à propriedade de retrospecção, pois Weick (1995) afirma que as ideias são reconhecidas após a sua execução. Assim o registro das ideias e da situação pode permitir essa reflexão e também o compartilhamento das informações para decisões futuras;

- das 20 atividades, apenas duas foram associadas com o nível de antecipação da identificação da incerteza imprevisível, ambas com a tendência a estarem presentes em eventos identificados antes de sua ocorrência. As duas atividades são registrar, já comentada no processo de memória e difusão, e compartilhar. Esta última também pode ser ligada a socialização da informação, dado que ela compartilha a percepção ou as informações com o cliente, os especialistas, o sponsor, a equipe ou mesmo com o fornecedor.

Outro ponto que merece destaque é a procrastinação. Ela é uma alternativa a ser considerada no processo de criação de sentido, mas convém comentar que em pelo menos dois eventos imprevistos, em que aparece, ela não foi bem aplicada. Em um deles, apesar do imprevisto não ter impactado, ela gerou frustração e desconforto, por causa da falta de um discurso único da equipe para aquela situação. Isso pode indicar que o gerente do projeto não atuou como sensemaker, como definido por Simon (2006), pois mesmo a decisão tendo sido apropriada, dado que economizou recursos e evitou desgaste político entre a organização e o cliente, não houve criação de sentido pela equipe. Em outro evento imprevisto, mesmo percebendo que 
algo não estava bem, o sponsor procrastinou uma ação para modificar a situação, esta piorou e ele preferiu sair do projeto, para não se prejudicar profissionalmente, assim como outros sócios.

Proposição de estudo 6 - Há diferença no tratamento das incertezas imprevisíveis nos projetos, conforme o tipo de inovação.

As inovações no produto e as de marketing foram consideradas tipo de inovações externas, por afetarem diretamente os usuários e / ou os clientes da organização, enquanto as inovações de processo e organizacional foram consideradas internas, por serem mais visíveis dentro da organização. Foi possível identificar a associação de eventos imprevistos de projetos com tipo de inovação externa, com a ocorrência das atividades de buscar informação externamente e identificar alternativas. Já os eventos imprevistos de projetos com inovação interna foram associados com a atividade de solucionar. Como era esperado por esta proposição de estudo, houve uma diferenciação entre as práticas que criam sentido, conforme o tipo de inovação do projeto. Entretanto, pode-se dizer também que essa diferenciação é pequena, dado que ela atinge apenas três das 20 atividades e não engloba o método de gestão do evento imprevisto, os processos e as técnicas e ferramentas. Quanto aos outros fatores estudados como variáveis independentes, essa diferenciação também não foi encontrada.

Proposição de estudo 7 - Os projetos com mais incerteza na inovação do produto e menos inovação tecnológica tendem a ser mais eficientes na identificação da incerteza imprevisível.

As avaliações estatísticas não permitiram identificar nenhuma associação entre as características do projeto - nível de incerteza tecnológica, complexidade do projeto, nível de inovação em serviços e tipo de inovação do projeto - e a eficiência da identificação da incerteza imprevisível. Isso impediu a avaliação desta proposição.

A proposição de estudo 8 - As técnicas e as ferramentas que tentam vislumbrar o futuro são mais efetivas para se identificar a incerteza imprevisível.

Em parte dos eventos imprevistos (46\%) não foi citada nenhuma técnica ou ferramenta e em poucos eventos foi usada mais de uma (23\%). A identificação prévia da incerteza 
imprevisível, assim como o nível de impacto do evento imprevisto, não puderam ser associados com as técnicas e ferramentas que tentam vislumbrar o futuro. Deve-se ressaltar que os outros tipos de técnicas e ferramentas - avaliação do presente, revisão histórica e de apoio - também não puderam ser associados com as variáveis da eficiência da identificação da incerteza imprevisível. Notou-se apenas que os projetos menos inovadores, com tipo de inovação em serviços 'ad hoc' e 'incremental', utilizaram mais as técnicas e ferramentas de avaliação do presente. Logo, pode-se dizer que esta proposição não se confirmou, porém uma das causas pode ser o pequeno número de eventos imprevistos da amostra.

Proposição de estudo 9 - Os fatores facilitadores advindos da cultura da organização, principalmente a cultura de atenção, mostram-se mais relevantes que os da metodologia em GP, GR e as ferramentas.

O nível de cultura de atenção da organização se mostrou forte na grande maioria das organizações, por isso não pode ser relacionada à eficiência da identificação da incerteza imprevisível. Deve-se ressaltar que ela não foi mencionada em nenhum momento pelos entrevistados, mesmo tendo tido um questionário específico sobre o assunto. $\mathrm{O}$ apoio de pares, do sponsor e da assunção de risco por parte da organização, considerados fator facilitador organizacional da gestão da incerteza, foi identificado em apenas sete dos 35 eventos imprevistos $(20 \%)$. A cultura da organização também foi considerada como um fator idealizado, em 19\% dos casos, pois foi comentado pelos entrevistados que se houvesse mais apoio do sponsor e envolvimento de outras áreas, as incertezas imprevisíveis poderiam ser identificadas previamente. Por sua vez, ela foi considerada um bloqueador em menor número (6\%) do que outros fatores bloqueadores. Assim, a cultura da organização foi percebida por poucos entrevistados como relevante.

Os fatores facilitadores oriundos da GP respondem por apenas $14 \%$ dos casos. Aspectos da gestão de projetos, como a busca de informação sobre a incerteza imprevisível, a flexibilidade nas atividades e o estabelecimento de objetivos claros foram citados pelos entrevistados. Além disso, a GP foi mencionada como fator facilitador idealizado, ou seja, se as práticas tivessem sido aplicadas, o evento imprevisto seria identificado previamente em nove casos (26\%). Foram citados aspectos como a busca de informação, integração com o cliente, integração da equipe e planejamento. Entretanto, a GP foi mencionada como bloqueadora em 
doze eventos imprevistos (34\%), em situações de falha na comunicação, falta de definição clara do escopo ou do produto do projeto, falta de gestão de $\mathrm{RH}$ ou problema de planejamento. Pode-se concluir, para esta amostra, que uma GP com base em um forte planejamento não contribui muito, mas a falta dela pode prejudicar em alguns casos.

Também não foi identificada, como fator facilitador, a gestão de riscos, sendo mencionado apenas como técnicas e ferramentas. Estas últimas foram mencionadas como fatores idealizados ( $31 \%$ dos casos), isto é, que se técnicas e ferramentas, como brainstorming, análise de cenário, dicionário de riscos, matriz de estratégia, simulação e SWOT, fossem usadas, poderiam contribuir com a identificação da incerteza imprevisível. Essa situação também mostra que a GR, assim como indicado na literatura (LOCH et al., 2008, KLEIN, 2003; MURRAY-WEBSTER, PELLEGRINELLI, 2010; PENDER, 2001; PERMINOVA et $a l ., 2008)$ não esclarece e endereça adequadamente as incertezas imprevisíveis.

Nas entrevistas surgiram fatores não previstos ou comentados especificamente na literatura: o com origem externa à organização, o relacionado à equipe e o relacionado à características pessoais. Os fatores externos foram os menos citados como facilitadores (9\%), idealmente poderiam ter contribuído em $17 \%$ dos casos e foram citados mais como bloqueadores (26\%). Assim, pode-se considerar que sua relevância foi considerada relevante por poucos entrevistados.

Deve-se ressaltar que o fator relativo à equipe (34\%) foi o mais citados como fator facilitador, mencionado como a abertura a problemas, a multidisciplinaridade e poder de decisão da equipe e, principalmente, o trabalho em equipe. Por outro lado, a falta de conhecimento da equipe foi considerada bloqueadora por $20 \%$ dos casos.

Apesar do fator pessoal ser considerado facilitador em $23 \%$ dos casos, ele foi o fator bloqueador que mais ocorreu (40\%). As características pessoais consideradas positivas para a identificação das incertezas imprevisíveis são o comprometimento, a criatividade e a experiência. Como bloqueador foram percebidos os vieses, como ancoragem, consciência limitada, escalada do comprometimento e vários tipos de excesso de confiança. Ressaltando a importância do fator pessoal, pode-se dizer que, quando esse fator bloqueador ocorre, há uma tendência da identificação da incerteza ser posterior e haver mais impacto referente ao evento 
imprevisto. Portanto, pode-se concluir que, para esta amostra, os fatores pessoais, os da equipe e os da gestão de projetos foram mais relevantes que os fatores organizacionais ou mesmo externos.

\subsection{Recomendações e contribuições}

O objetivo deste estudo é contribuir para a extensão de teorias já existentes sobre o diagnóstico de incertezas imprevisíveis em projetos (LOCH et al., 2006; LOCH et al., 2008). Este estudo chamou esse processo de gestão de incertezas. Assim, conforme o resultado apresentado no item anterior, far-se-á recomendações e contribuições sobre seis itens:

- aplicação do diagnóstico de incertezas em projetos;

- busca de informação;

- aplicação de metodologias diferenciadas;

- atenção aos sinais precoces;

- importância da criação coletiva de sentido;

- fatores facilitadores e bloqueadores da gestão da incerteza.

Com relação ao primeiro, sugere-se que o diagnóstico de incertezas, detalhado por Loch et al. (2006; 2008), seja incorporado às práticas de gestão de riscos em projetos, como uma fase prévia para se identificar suas áreas mais incertas, tendo como consequência uma atuação mais preventiva e efetiva. Essas áreas devem ser tratadas pela gestão da incerteza até a obtenção de conhecimentos suficiente para que possa ser tratada pela gestão de riscos, propriamente dita. Esse diagnóstico permitiria também a busca de informação focada na superação das lacunas de conhecimento da equipe, os unk unks, e a aplicação de metodologias diferenciadas e adequadas ao nível de incerteza de cada parte do projeto.

O segundo item refere-se à importância da busca de informação para as partes mais complexas e incertas, que foi citada, mas não explorada aprofundadamente por Loch et al. (2006; 2008). Essa importância pôde ser percebida nos três projetos que aplicaram a busca de informação em partes que continham incerteza imprevisível, ajudando a evitar as causas externas que, assim, puderam ser identificadas previamente. Além disso, o processo de coleta de informações mostrou-se relevante para diminuir os impactos dos eventos imprevistos. A busca de informação se constitui em procedimentos simples, por isso, além da recomendação 
teórica, sugere-se que os gerentes de projetos a adotem na prática, dado que isso não exigiria muito esforço ou treinamento específico.

O terceiro item refere-se à aplicação de metodologias diferenciadas conforme o nível de incerteza, também sugerido por LOCH et al. (2006; 2008). Percebeu-se que o método de aprendizado, como a improvisação e a experimentação, sofre de certo preconceito por parte dos entrevistados, tanto que foi preciso alterar o roteiro de perguntas para evitar esse problema. Entretanto, verificou-se pelas atividades envolvidas na criação de sentido dos eventos imprevistos que esse método foi o mais aplicado na gestão da incerteza. Os vários cursos de GP, tanto os da área acadêmica quanto os de consultorias, focam muito em metodologias que tendem ao instrucionismo, como o Guia PMBOK (PMI, 2008) e PRINCE2 (OGC, 2005). Também, não se faz aqui a apologia do método; mas, sim, a consciência de qual é a melhor maneira para se enfrentar cada situação, pois a identificação do melhor método para cada nível de incerteza e o treinamento nessa metodologia pode contribuir para que os projetos sejam mais bem sucedidos. Assim, assumir que não se pode aplicar o método de aprendizado a qualquer projeto, ainda precisa ser entendido. Recomenda-se, assim, que o método de aprendizado e de selecionismo sejam incorporados nos cursos de GP e na gestão dos projetos.

O terceiro item foi incorporado à gestão de incerteza para permitir uma atenção adequada aos sinais precoces de mudança no ambiente do projeto. Há vários estudos que avaliaram a gestão dos sinais precoces em projetos, mas alguns os relacionavam com o sucesso dos projetos (KAPPELMAN et al., 2006; SANCHEZ, PEREZ, 2004), com problemas (NIKANDER, ELORANTA, 1997; NIKANDER, 2002) e ainda com riscos (NIKANDER, ELORANTA, 2001). Porém em nenhum deles as práticas para a criação de sentido dos sinais precoces são avaliadas. Alguns gerentes de projetos acham que percebê-los é uma questão de sorte: "A sorte de algum momento você enfrentar ou ser alertado numa situação que está passando na sua frente que você não tinha pensado antes [...]", pois as pessoas estão sempre fazendo muitas coisas e não têm tempo de perceber: "[...] a cabeça está sempre carregada de coisas assim é difícil você capturar do nada, assim pensando: 'ah, eu acho que este projeto pode dar problema aqui'." Esta é uma atitude reativa. Como foi observada nos projetos deste estudo, a incerteza imprevisível pode ocorrer em projetos com qualquer nível de inovação, em qualquer fase, mesmo tendo utilizado métodos de gestão como o stage-gates ou tendo aplicado a gestão 
de riscos. Os sinais precoces compõem uma área de conhecimento bastante utilizada na inteligência competitiva e pode ser de grande valia para integrar a área teórica da gestão dos projetos. Alguns padrões, como o Prince2 (OGC, 2005) já os cita, chamando-os de sinais de alerta.

Os gerentes de projeto por mais experientes que sejam não devem confiar apenas em sua experiência passada, pois as inovações trazem incertezas ainda não vivenciadas, muitas vezes nem de forma similar na própria organização. Por isso, a atenção ao que está ocorrendo dentro e fora do projeto se torna primordial, para se perceber, por meio dos sinais precoces, as mudanças no ambiente. Sugere-se também que a observação dos sinais precoces seja incluída nos padrões de metodologia, no monitoramento e controle para que essa prática seja de conhecimento dos gerentes de projetos. Não se está dizendo aqui que a incerteza imprevisível pode ser controlada; pois, como comentou um dos entrevistados, "Nem sempre a antecipação é suficiente." O que se recomenda é a consciência do nível de incerteza e das partes do projeto mais incertas para tentar identificar os sinais de que uma mudança está para ocorrer, sem simplesmente aguardar e torcer para tomar as melhores ações em sua ocorrência.

O quinto fator relevante a ser integrado na área teórica de gestão de incertezas, contribuição específica desse estudo, é a criação coletiva de sentido. A importância do social, das ações coletivas nas práticas para a criação de sentido revela-se na confirmação de que o sentido das incertezas imprevisíveis é gerado mais pela criação coletiva de sentido do que pela criação de sentido individual. Essa constatação faz com que a atuação do gestor de projetos, como um sensemaker, se destaque. Ele tem um importante papel a desempenhar para que a equipe e os envolvidos deem sentido para a situação, atuando na construção de sua identidade dentro do projeto, compartilhando e socializando o conhecimento de cada elemento da equipe entre todos. A falta de criação de sentido ficou clara nos casos de procrastinação e falta de transparência, que, apesar de alguns terem sido bem sucedidos no final do projeto, fez com que a equipe ficasse bastante incomodada por não ter conseguido dar um sentido completo ao que estava ocorrendo.

Quanto aos fatores bloqueadores e facilitadores da gestão da incerteza, este estudo revelou fatores não destacados na literatura acessada. A literatura indicava fatores relevantes para a identificação e gestão das incertezas imprevisíveis quanto à: organização, como a cultura da 
atenção, múltiplas perspectivas e objetividade; à metodologia em GP, como uso de metodologia diferenciada, gestão de stakeholder e cláusulas contratuais especificas para o tratamento de unk unks; metodologia em GR, com a identificação antecipada, iterativa, abrangente e emergente; além de ferramentas de GR e incertezas, como as que tem como base uma visão histórica ou passada, a avaliação da situação atual, técnicas criativas para identificar o futuro e as baseadas na gestão de conhecimento. Os novos fatores que surgiram foram: os externos, como a facilitação do cliente e do fornecedor; os ligados à falta de conhecimento da equipe do projeto; os ligados às características pessoais, como os vieses e as heurísticas, o comprometimento, a criatividade e a experiência. Os novos fatores junto com problemas na GP se mostraram mais relevantes, tanto para facilitar a identificação da incerteza imprevisível, quanto por bloquear essa identificação, que os fatores organizacionais.

Deve-se ressaltar a importância da discussão da ocorrência dos eventos imprevistos nos projetos, por exemplo, na atividade final de registrar e apresentar lições aprendidas do projeto. Isso poderia ser feito não só para identificar maneiras de evitá-los, pela inclusão em uma lista de verificação, mas também de que maneira eles poderiam ter sido percebidos antecipadamente e como se poderia ter dado significado a eles. Pois como se observou nos eventos pesquisados neste estudo, muitos fatores bloqueadores pessoais foram impeditivos, gerando eventos com alto impacto no projeto. $\mathrm{O}$ enfrentamento da incerteza mostrou pontos de melhoria em dois projetos. Em um deles, as equipes ficaram mais integradas e, no outro, a solução que não pode ser adotada naquele momento começou a ser adotada em outros projetos. Muitos destacaram os processos de aprendizado organizacional, com a incorporação de novas técnicas, o aprendizado em novas áreas de GP, como portfólio, e inclusive o aprendizado pessoal.

Para March (1999, p. 227), ainda que só a história possa identificar as boas estratégias, a organização deve tentar incentivar os gênios (aqueles que têm as loucas ideias certas) e os heréticos (aqueles que questionam a situação e os processos vigentes). Isso pode ocorrer por meio de recompensas por falhas interessantes, como projetos malsucedidos, em que usaram a imaginação; a ilusão de eficácia, isto é, o indivíduo deve pensar que ser um visionário compensa e de um comportamento dirigido pela obrigação, ao invés da consequência, já que um visionário com o senso de obrigação de gerar novas ideias não será afetado pela possibilidade de ser considerado tolo ou ineficiente. 


\section{$5.4 \quad$ Sugestões para novos estudos}

O estudo conjunto dos temas de incerteza imprevisível, de sinal precoce, de criação de sentido e de gestão de projetos, por ser ainda pouco explorado, além de permitir novos estudos, permite ainda o aprofundamento nas questões levantadas neste estudo, inclusive adotando-se outras abordagens metodológicas.

A respeito da abordagem metodológica, um dos fatores que mais restringiram a aplicação das provas estatísticas foi o pequeno número de projetos e de eventos imprevistos. Sugere-se que, com base nas variáveis e categorias identificadas, se faça um levantamento qualitativo mais amplo para se obter um número maior de casos ou um levantamento quantitativo. Isso permitiria a avaliação de algumas variáveis moderadoras na relação e a aplicação de técnicas multivariadas que levam em consideração, de forma simultânea, um conjunto de variáveis. Neste último caso, o objetivo seria a construção de um modelo estatístico, relacionando variáveis dependentes com as independentes. Ou seja, obter como resultado uma equação que forneça informações da influência de cada variável independente na formação da variável dependente, no caso a eficiência da identificação da incerteza imprevisível.

Outra sugestão refere-se à seleção dos projetos participantes da pesquisa, de maneira a focar principalmente em projetos de serviços e a englobar projetos com vários níveis de inovação, inclusive os com nível baixo, para se ampliar a comparação. A ampliação da amostra também poderia incluir projetos nos quais tivesse sido usado o método de selecionismo, pelo menos em algum momento do projeto. Esse método gera sequencial ou concomitantemente várias soluções para o mesmo subproblema, selecionando a mais adequada num determinado momento. A inclusão desse método poderia validar as indicações de LOCH et al. (2006; 2008), quanto ao método mais adequado conforme o nível de incerteza e complexidade de cada parte incerta do projeto.

Os projetos dessa amostra usaram metodologias baseadas no Guia PMBOK (PMI,2008). Há várias metodologias de desenvolvimento de produtos, que podem ter processos, técnicas e ferramentas mais efetivas para identificar e gerir as incertezas imprevisíveis nos projetos inovadores, como o design thinking (BROWN, 2010), discovery-driven planning 
(McGRATH, MacMILLAN, 1999) ou mesmo a metodologia ágil (FERNANDEZ, FERNANDEZ, 2009). Portanto, sugere-se um estudo de casos, no qual se comparassem essas metodologias para avaliar sua atuação perante as incertezas imprevisíveis.

Não foi possível avaliar a influência do nível de cultura de atenção da organização, pois a grande maioria das organizações tinha um nível forte de uso da atenção, conforme o teste aplicado nos projetos. Como não havia questões que verificassem não só a existência dos procedimentos, mas também a sua utilização, essa avaliação poderia ser objeto de novos estudos.

Comentou-se, durante a conclusão deste estudo, a importância da incorporação do diagnóstico de incertezas, sugerido por Loch et al. (2008), na gestão de riscos do projeto. Uma questão que poderia ser explorada, por intermédio de um focus group, é como esse diagnóstico poderia ser incorporado na gestão de riscos e qual a dificuldade para essa incorporação pelas organizações.

Outra recomendação feita foi a inclusão do uso do método de aprendizado, de forma consciente, na gestão dos projetos e das incertezas. Porém, o uso da improvisação para gerir os eventos imprevistos, mesmo em projetos com planejamento formal, suscita a dúvida da sua efetividade e como a equipe poderia ser treinada para obter melhores resultados com essa aplicação. Esse método é, normalmente, associado com o uso nas fases iniciais do projeto, como na geração de ideias, mas poderia ser estudado como a sua aplicação melhoraria as outras fases do projeto.

Uma questão que surgiu na análise das entrevistas, podendo ser foco de futuras pesquisas, é o nível de utilização e incorporação das competências dos clientes ou parceiros. Essa questão pôde ser percebida nos casos nos quais o cliente percebeu ou tinha conhecimento sobre a incerteza, mas que, de alguma forma, a informação não foi utilizada pela equipe do projeto. Isto não se refere só à gestão de stakeholders, mas também a socialização dos conhecimentos do cliente e transparência dos controles do projeto.

Outra questão que surgiu é o papel do gerente do projeto, como um sensemaker, para fazer que a equipe perceba os sinais e dê sentido ao que está ocorrendo no projeto. Não foi possível 
afirmar se essa atuação é significativa, em relação ao sucesso do projeto. A influência do gerente de projetos na relação entre as práticas para a criação de sentido e a identificação da incerteza poderia ser avaliada, por meio de questões específicas, não aplicadas neste estudo.

\subsection{Limitações}

As limitações metodológicas já foram detalhadas no respectivo capítulo, mas é salutar ressaltar que houve limitações referentes ao método escolhido, à criação das variáveis, aos casos selecionados, aos instrumentos utilizados para a coleta de dados, a interpretação dada pelo entrevistado às questões formuladas, às técnicas empregadas para análise e interpretação dos dados, tanto na fase qualitativa quanto na quantitativa. Destacam-se aqui as três mais importantes limitações:

a) os casos selecionados, pois mesmo que tenham atendido os requisitos estabelecidos, não podem ser considerados representativos de uma população de projetos inovadores, tanto pelo tamanho da amostra, quanto pelo significado e porte da inovação de cada organização;

b) a opção pelo entrevistado único em um levantamento de campo restringiu as respostas às percepções do entrevistado, impedindo outras estratégias de validação das informações, como interrogatório de pares;

c) a transformação que algumas variáveis sofreram na análise relacional para que as provas estatísticas pudessem ser aplicadas, em razão do pequeno tamanho da amostra, pode ter impedido a identificação de outras relações relevantes.

Não está no escopo deste estudo generalizar o resultado para todos os projetos, dado que pelo tipo de amostragem isso não seria adequado (SELLTIZ et al., 1987a, p. 99). A generalização foi analítica (EISENHARDT, 1989; YIN, 2005), tendo a restrição aos tipos de projeto pesquisados. Assim para se desenvolver uma teoria normativa com ampla generalização, outros estudos estatísticos aprofundados deverão ser feitos futuramente. 


\section{REFERÊNCIAS}

Association of Insurance and Risk Managers- AIRMIC; National Forum for Risk AIRMIC Management in the Public Sector - ALARM; Institute of Risk Management - IRM. A Risk Management Standard. London: 2002. Disponível em: http://www.theirm.org/publications/PUstandard.html. Acesso em: 13.10.2010.

ALBERTS, Christopher J.; DOROFEE Audrey J. A Framework for Categorizing Key Drivers of Risk. Technical Report CMU/SEI-2009-TR-007, April 2009.

ALLARD-POESI, F. The Paradox of Sensemaking in Organizational Analysis. Organization, v.12, n.2, p. 169-196, 2005.

ANDERSON, M. H. How Can We Know What We Think Until We See What We Said?: A citation and citation context analysis of Karl Weick's The Social Psychology of Organizing. Organization Studies, v. 27, n.11, p. 1675-1692, 2006.

ANSOFF, Igor. Managing Strategic Surprise by Response to Weak Signals. California Management Review, p.21-33, Winter 1975.

ARIELY, D. Predictably Irrational: the hidden forces that shape our decisions. New York: HarperCollins, 2008.

BACCARINI, D. The concept of project complexity - a review. International Journal of Project Management, v. 14, n. 4, p. 71-77, 1996.

BARDIN, Laurence. Análise de conteúdo. Trad. Luís Antero Reto e Augusto Pinheiro. Lisboa: Edições 70, 2002.

BAZERMAN, M H.; MOORE, D. Judgment in managerial decision making. 7th ed. Local: John Wiley \& Sons, 2009.

BECK, U. Risk society.Towards a New Modernity. Londres: Sage Publications, 1992.

BERNSTEIN, Peter L. Desafio aos deuses: a fascinante história do risco. Trad. Ivo Korylowski. Rio de Janeiro: Campus, 1997.

BOMQUIST, T., HALlGREN, M., NILSSON, A., SODERHOLM, A. Project-as-Practice: In Search of Project Management Research that Matters. Project Management Journal, v. 41, n.1, p. 5-16, 2010.

BROWN, Tim. Design thinking: uma metodologia poderosa para decretar o fim das velhas ideias. Trad. Cristina Yamagami. Rio de Janeiro: Elsevier, 2010.

CARLILE, P.R.; CHRISTENSEN, C. The Cycle of Theory Building in Management Research. HBS Working Paper, n. 05-057, February 2005. Disponível em: http://hbswk.hbs.edu/item/5422.html. Acesso em: 01.07.2006. 
CASTIEL, L. D. Vivendo entre exposições e agravos: a teoria da relatividade do risco. História, Ciência e Saúde - Manguinhos III, n. 2, p. 237-264, 1996.

CHAPMAN, Chris; WARD Stephen. Estimation and evaluation of uncertainty: a minimalist first pass approach. International Journal of Project Management, v.18, n.6, p. 369-383, 2000.

CHOO, Chun Wei. Environmental scanning as information seeking and organizational learning. Special issue of Information Research, v.7, n.1, 2001.

The knowing organization: How organizations use information to construct meaning, create knowledge and make decisions. International journal of information management, v. 16, n. 5, p. 329-340, October 1996.

CHRISTIANSEN, John K.; VARNES, Claus J. Formal Rules in Product Development: Sensemaking of Structured Approaches. Product Development \& Management Association, v. 26, n. 5, p. 502-519, September 2009.

CHUGH, Dolly; BAZERMAN, Max H. Bounded Awareness: What You Fail to See Can Hurt You. HBS Working Paper \#05-037. Revised: 25.8.2005. Disponível em: http://www.people.hbs.edu/mbazerman/Papers/05-037.pdf. Acesso em: 09.02.2012.

CLELAND, D. I. Project leadership in Project management: strategic design and implementation. $3^{\text {rd }}$. ed. Local: McGraw-Hill, 1999.

CLEMEN, Robert T.; REILLY, Terence. Making Hard Decisions. An introduction to Decision Analysis. 2nd. Ed. Belmont CA: Duxbury Press, 1996.

COOPER, Robert G.; EDGETT Scott J.; KLEINSCHMIDT Elko J. Optimizing the StageGate ${ }^{\circledR}$ Process - part one. Research Technology Management, v. 45, n. 5, 2002. Disponível em http://www.stage-gate.com/downloads/working_papers/wp_14.pdf. Acesso em: 16.04.2012.

COOPER, Robert G.; EDGETT Scott J.; KLEINSCHMIDT Elko J. Optimizing the StageGate ${ }^{\circledR}$ Process - part two. Research Technology Management, v. 45, n. 5, 2002 Disponível em: http://www.stage-gate.com/downloads/working_papers/wp_15.pdf. Acesso em: 16.04.2012.

COOPER, Robert G.; EDGETT, Scott J. Best Practices in the Idea-to-Launch: Process and Its Governance Reference. Paper \#45. Research Technology Management, March-April, p. 43-54, 2012.

Committee of Sponsoring Organizations of the Treadway Commission.- COSO Gerenciamento de risco corporativo - estrutura integrada, 2007. Disponível em: http://www.coso.org/documents/COSO_ERM_ExecutiveSummary_Portuguese.pdf. Acesso em: 26.01.2011.

COURTNEY, Hugh; KIRKLAND, Jane; VIGUERIE, Patrick. Strategy under uncertainty In: Harvard Business Review on Managing Uncertainty. Boston: Harvard Business School Press, p. 1-31, 1999. 
CRAWFORD, L. H.; HOBBS, J. Brian; TURNER, J Rodney. Project Categorization Systems: Aligning Capability with Strategy for Better Results. Newtown Square, PA: PMI, 2005.

CRESWELL, John W. Projeto de Pesquisa: métodos qualitativo, quantitativo e misto. Trad. Luciana de Oliveira da Rocha. 2. ed. Porto Alegre: Artmed, 2007.

DACORSO, Antonio Luis Rocha. Tomada de Decisão e Risco: A Administração da Inovação em Pequenas Indústrias Químicas. Tese de Mestrado em Administração Departamento de Administração da Faculdade de Economia, Administração e Contabilidade, Universidade de São Paulo - FEA-USP, São Paulo-SP, 2000.

DERVIN, Brenda. An Overview of Sense-Making Research: Concepts, Methods, and Results to Date. In: International Communication Association, Dallas, 1983.

From the mind's eye of the user: The Sense-Making qualitative-quantitative methodology. In: GLAZIER, J. D.; POWELL, R. R. (Eds.), Qualitative research in information management. Englewood, CO: Libraries Unlimited, p. 61-84, 1992.

On studying information seeking methodologically: The implications of connecting metatheory to method. Information Processing and Management, v. 35, p. 727-750, 1999.

Interviewing as Dialectical Practice: Sense-Making Methodology as Exemplar. In: International Association of Media and Communication, Stockholm, Sweden, July 20 25,2008 .

DIMAGgiO, P. (ed.) The twenty-first-century firm: changing economic organization in international perspective. EUA: Princeton University Press, 2001.

DREYFUS, H.L. Intuitive, deliberative, and calculative models of expert performance. In: ZSAMBOK, Caroline E.; KLEIN,Gary. Naturalistic decision making. New Jersey: LEA, 1997.

EISENHARDT, Kathleen M. Building theories from case studies. Academy of Management Review, v. 14, n. 4, p. 5-13, 1989.

EISENHARDT, Kathleen M.; GRAEBNER, M.E. Theory building from cases: opportunities and challenges. Academy of Management Journal, v.50, n.1, p. 25-32, 2007.

FOLHA.COM. BP ignorou riscos de vazamento de petróleo; três Estados declaram emergência nos EUA. Disponível em: <http://www1.folha.uol.com.br/folha/ambiente/ult10007u728727.shtml>. Acesso em: 19.08.2010.

FERNANDEZ, Daniel J; FERNANDEZ, John D. Agile project management - agilism versus traditional approaches. The Journal of Computer Information Systems, v. 49, n. 2, p.1017 Winter 2008/2009.

GALLOUJ, Faiz; WEINSTEIN, Olivier. Innovation in services. Research Policy. v. 26, n. 4/5, p. 537-556, 1997. 
GERALDI Joana G.; LEE-KELLEY, Liz; KUTSCH, Elmar The Titanic sunk, so what? Project manager response to unexpected events. International Journal of Project Management, v. 28, n.6, p. 547-558, 2010.

HAMEL, Gary. Three forces that will transform management. What Matters. McKinsey \& Company, 2009. Disponível em: http://whatmatters.mckinseydigital.com/organization/threeforces-that-will-transform-management. Acesso em: 14.02.2011.

HAMMOND, John S.; KEENEY, Ralph L.; RAIFFA, Howard. Decisões Inteligentes: Como avaliar alternativas e tomar a melhor decisão, (1999) $5^{\mathrm{a}}$ edição. Trad. Marcelo Filardi Ferreira. Rio de Janeiro: Elsevier, 2004.

HIGH-TECHNOLOGY and knowledge based services aggregations based on NACE Rev. 2. Luxembourg: Statistical Office of the European Communities - Eurostat, 2009. Disponível em: < http://epp.eurostat.ec.europa.eu/cache/ITY_SDDS/Annexes/htec_esms_an3.pdf>. Acesso em: 15.01.2011.

HIGUERA, R.; HAIMES, Y. Software Risk Management. Pittsburgh: Carnegie Mellon, Software Engineering Institute, 1996.

HILTUNEN, Elina. The future sign and its three dimensions. Futures, v. 40, n. 3, p. 247-260, 2008.

HM TREASURY. Orange Book: Management of Risk - Principles and Concepts. London: HMSO publications, 2004.

INSTITUTO ANTÔNIO HOUAISS - IAH [HOUAISS]. Dicionário Eletrônico Houaiss da Língua Portuguesa. Editora Objetiva Ltda, 2001.

INSTITUTO BRASILEIRO DE ESTATÍSTICA - IBGE, Coordenação da Indústria. Rio de Janeiro: IBGE PINTEC - Pesquisa de inovação tecnológica: 2008/2010. Disponível em http://www.pintec.ibge.gov.br/index.php?option=com_content\&view=article\&id=45\&Itemid =12. Acesso em: 10.12.2010.

International Organization for Standardization - ISO. ISO/DIS 31000: Risk management Principles and guidelines on implementation. Switzerland, 2008.

JAAFARI Ali. Management of risks, uncertainties and opportunities on projects: time for a fundamental shift. International Journal of Project Management, v. 19, n. 2, p. 89-101, 2001.

JANISSEK-MUNIZ, R., LESCA, H.; FREITAS, H. Inteligência Estratégica Antecipativa e Coletiva para Tomada de Decisão. In: 3rd CONTECSI - International Conference on Information Systems and Technology Management and 11th WCA - World Continuous Auditing Conference. Anais. 31/05 a 02/06/2006 - USP São Paulo/SP. 14p.

KAHNEMAN, D.; SLOVIC, P.; TVERSKY, A. Judgement under uncertainty: Heuristics and Biases. New York: Cambridge, 1982.

KAHNEMAN, D.; TVERSKY, A. Prospect theory: an analysis of decision under risk. Econometrica, v. 47, n. 2, p. 263-291, 1979. 
KAPPELMAN, Leon A.; MCKEEMAN, Robert; ZHANG, Lixuan. Early warning signs of it project failure: the dominant dozen. Information Systems Management; v. 23, n. 4; p. 31; Fall, 2006.

KLEIN, Gary. The power of intuition: how to use your gut feelings to make better decisions at work. USA: Doubleday, 2003.

KLEIN, Gary; MOON, B.; HOFFMAN, R. R. Making Sense of Sensemaking 1: Alternative Perspectives. IEEE Intelligent Systems, v. 21, n. 4, p. 70-73, 2006 a.

Making sense of Sensemaking 2: A macrocoginitive model. IEEE Intelligent System, v. 21, n. 5, p. 88-92, 2006b.

KLOSS-GROTE, B.; MOSS, M. A. How to measure the effectiveness of risk management in engineering desing projects? Presentation of RMPASS: a new method for assessing risk management performance and the impact of knowledge management - including a few results. Research in Engineering Design, v. 19, n. 2, 2008.

KWAK, Young Hoon; ANBARI Frank T. Analyzing project management research: Perspectives from top management journals International Journal of Project Management, v. 27, n. 5, p. 435, July, 2009.

LEEDOM, D.K. Final Report: Sensemaking Symposium. Technical Report prepared under contract for Office of Assistant Secretary of Defense for Command, Control, Communications \& Intelligence. Vienna, VA: Evidence Based Research. Inc. Disponível em: http://www.dodccrp.org/files/sensemaking_final_report.pdf, 2001. Acesso em: 19.06.2008.

LEVITT, Steven D.; SNYDER, Christopher M. Is no News Bad News? Information Transmission and the Role of "Early Warning" in the Principal-Agent Model. The RAND Journal of Economics, v. 28, n. 4, p. 641-661 Winter, 1997.

LOCH, Christoph H.; SOLT, Michael E.; BAILEY, Elaine M. Diagnosing Unforeseeable Uncertainty in a New Venture. Journal of Product Innovation Management, v. 25, n. 1, p. 28-46, January 2008.

LOCH, Christoph H.; MEYER, A. D.; PICH, M. T. Managing the Unknown: a new approach to managing high uncertainty and risk in projects. New Jersey: John Wiley \& Sons. 2006.

LUPTON, Deborah Risk. London: Routledge, 1999.

LYNG, Stephen. Edgework, Risk, and Uncertainty. In: Zinn, J.O. (Ed.). Social Theories of Risk and Uncertainty: An Introduction. Malden, MA: Wiley-Blackwell, p. 106-137, 2008.

LYONS, Terry; SKITMORE, Martin. Project risk management in the Queensland engineering construction industry: a survey. International Journal of Project Management, v. 22, n. 1, p. 51-61, 2004.

LAKATOS, Eva M.; MARCONI, Marina de A. Metodologia Científica. $6^{\text {a }}$ ed. São Paulo: Atlas, 2011. 
MALHOTRA, N. Pesquisa de Marketing: uma orientação aplicada. Trad. Nivaldo Montigelli Jr e Alfredo Alves de Farias. $3^{\text {a }}$ ed. Porto Alegre: Bookman, 2001.

MARCH, J.G. Bounded Rationality, Ambiguity, and the Engineering of Choice. In BELL, D. E,; RAIFFA, H.; TVERSKY, A. (Eds.). Decision Making - descriptive, normative, and prescriptive interactions. Cambridge: Cambridge University Press, 1988.

MARCH, J.G. The pursuit of Organizational Intelligence. Great Britain: Osfordshire, 1999. MARTINS, Gilberto de A. Estudo de caso: uma estratégia de pesquisa. São Paulo: Atlas, 2006.

McGRATH, Rita Gunther; MACMILLAN, Ian C. Discovery-Driven Planning - Turning Conventional Planning on its Head. In: Harvard Business Review on Managing Uncertainty. EUA: HBR, 1999.

MINTZBERG, Henry; Raisinghani, Duru; Théorêt, Andrés. The structure of "unstructured" decision processes. Administrative Science Quarterly, v. 21, n. 2, p. 246-275, June 1976.

MOORE, Don; HEALY, Paul. The Trouble with Overconfidence. Draft of May 22, 2007. Disponível em: http://research.chicagobooth.edu/cdr/workshop/MooreHealy.pdf. Acesso em: 06.02.2012.

MORGAN, Gareth. Paradigms, Metaphors, and Puzzle Solving in Organization Theory. Administrative Science Quarterly, v. 25, n. 4, p. 605-622, December 1980.

MURRAY-WEBSTER, Ruth; PELLEGRINELLI, Sergio. Risk management reconceived: reconciling economic rationality with behavioural tendencies Journal of Project, Program \& Portfolio Management, v. 1, n. 1, p. 1-16, 2010.

NALEBUFF, Barry J.; BRANDENBURGER, Adam M. Co-opetição: 1.um conceito revolucionário que combina competição com cooperação, 2. a estratégia da teoria do jogo que está mudando o jogo dos negócios. Trad. Alberto Lopes. Rio de Janeiro: Rocco, 1996.

NIDUMOLU, Ram; PRAHALAD, C.K.; RANGASWAMI, M.R. Why sustainability is now the key driver of innovation. Harvard Business Review, September, 2009.

NIKANDER, Ilmari O. Early warnings: a phenomenon in project management. Espoo, Tese de doutorado em ciência da tecnologia - Helsinki Universit of Technology, 2002.

NIKANDER, Ilmari O.; ELORANTA, Eero Preliminary signals and early warnings in industrial investment projects. International Journal of Project Management, v. 15, n. 6, p. 371-376, 1997.

NIKANDER, Ilmari O.; ELORANTA, Eero Project management by early warnings. International Journal of Project Management, v. 19, n. 7, p. 385-399, 2001.

Office of Government Commerce - OGC. Managing successful projects with Prince2. 4th. ed. London: The Stationery Office, 2005.

Organization for Economic Co-Operation and Development - OECD. Oslo manual: guidelines for collecting and interpreting innovation data. 3rd ed. Paris: OECD, 2005. 
PENDER, Steven. Managing incomplete knowledge: Why risk management is not sufficient International Journal of Project Management, v.19, n. 2, p. 79-87, February 2001.

PERMINOVA, Olga; MAGNUS, Gustafsson; WIKSTRO, Kim. Defining uncertainty in projects - a new perspective. International Journal of Project Management, v. 26, n. 1, p. 73-79, January 2008.

PESTANA, Maria Helena; GAGEIRO, João Nunes. Análise de dados para ciências sociais - a complementaridade do SPSS. 2a . ed. Lisboa: Sílabo, 2000.

PICH Michael T.; LOCH Christoph H.; MEYER Arnoud De. On uncertainty, ambiguity, and complexity in project management. Management Science, v. 48, n. 8; p. 1008-1023, August 2002.

PINTO, J. K.; SLEVIN, D. P. Project Success: Definitions and Measurement Techniques. Project Management Journal, v. 19, n. 1, p. 67-72, 1988.

Project Management Institute - Chapters Brasileiros - PMI Brasil. Estudo de Benchmarking em Gerenciamento de Projetos Brasil 2010. Disponível em: http://www.pmsurvey.org. Acesso em: 15.01.2011.

Project Management Institute - PMI. Guia PMBOK - Um Guia do Conjunto de Conhecimentos em Gerenciamento de Projetos, $4^{\text {th }}$ ed., Newton Square: PMI, 2008.

Practice Standard for Project Risk Management. Newton Square: PMI, 2009.

PORTER, M. The competitive advantage of Nation. Harvard Business Review, MarchApril, 1990.

PURDY, G. ISO31000:2009 - Setting a new standard for risk management. Risk analysis, v. 30, n. 6, p. 881-886, 2009.

RAZ T., MICHAEL, E. Use and benefits of tools for project risk management. International Journal of Project Management, v.19, n. 1, p. 9-17, 2001.

RAZ, T.; SHENHAR, A. J.; DVIR, D. Risk Management, project success, and technological uncertainty. R\&D Management, v. 32, n. 2, p. 101-109, 2002.

RICHARDSON, Roberto Jarry. Pesquisa Social: Métodos e Técnicas. $3^{\mathrm{a}}$. ed. São Paulo: Atlas, 1999.

ROTH, E.M. Analysing decision making in process control: multidisciplinary approaches to understand and aiding human performance in complex tasks. In: ZSAMBOK, Caroline E.; KLEIN,Gary. Naturalistic decision making. New Jersey: LEA, 1997.

RUSSO, J. Edward; SCHOEMAKER, Paul J. H. Decisões vencedoras: como tomar a melhor decisão, como acertar na primeira tentativa. Trad. Hugo Melo. Rio de Janeiro: Campus, 2002.

RUSSO, Rosária F.S.M.; FERREIRA, Geraldo; KRUGLIANSKAS, Isak; SBRAGIA, Roberto. Uma análise da associação entre a prática de Gestão de Riscos com o sucesso do projeto: estudo no contexto brasileiro. In: ALTEC 2007 - XI Seminario Latinoiberoamericano de Gestión Tecnológica, Buenos Aires, 2007. 
RUSSO, Rosária F.S.M.; SBRAGIA, Roberto. Sensemaking na Inovação: O Caso da Tecnologia Flexfluel na Indústria Automotiva Brasileira. In: XXVI Simpósio de Gestão da Inovação Tecnológica, 2010, Vitória. XXVI Simpósio de Gestão da Inovação Tecnológica. Rio de Janeiro: Anpad, v. 1, p. 1-16, 2010.

SADLER-SMITH, S.; LEYBORNE, E. The role of intuition and improvisation in project management. International Journal of Project Management, v. 24, n. 6, p. 483-492, 2006.

SANCHEZ, Angel Martinez; PEREZ, Manuela Perez. Early warning signals for $R \& D$ projects: An empirical study. Project Management Journal, v. 35, n.1, p. 11-23, 2004.

SAVAGE, Leonard J. The foundations of statistics. $2^{\text {nd }}$ ed. London: Dover, 1972.

SBRAGIA, Roberto; MAXIMIANO, Antonio C. Amaru; KRUGLIANSKAS, Isak. O gerente de projetos: seu papel e habilidades. Revista de Administração, v. 21, n. 3, p. 24-31, julho/setembro/1986.

SCHKADE, David; KAHNEMAN, Daniel. Does living in California make people happy? A Focusing Illusion in Judgments of Life Satisfaction. Psychological Science. v. 9, n. 5, September 1998.

SCHOEMAKER Paul J. H.; DAY, George S. Why We Miss the Signs. Mit Sloan Management Review, Winter 2009

Society of Competitive Intelligence Professionals - SCIP. Disponível em: <www.scip.org>. Acessado em: 03.07.2008.

SELlTIZ, C.; WRIGHTSMAN, L.; COOK, S.; KIDDER, L. Métodos de pesquisa nas relações sociais v. 1 - Delineamentos de pesquisa. Org. da $4^{\text {a }}$ ed. americana Louise H. Kidder. Trad. Maria Martha Hubner d’Oliveira e Miriam Marinotti Del Rey. $2^{\mathrm{a}}$ ed.. São Paulo: EPU, 1987a.

SElltiZ, C.; WRIGHTSMAN, L.; COOK, S.; KIDDER, L. Métodos de pesquisa nas relações sociais v. 2 - Medidas na Pesquisa Social. Org. da $4^{\mathrm{a}}$ ed. americana Louise H. Kidder. Coord. 2a . ed. brasileira J.R. Malufe; B. A. Gatti. São Paulo: EPU, $1987 b$.

SHENHAR, A.; DVIR, D. Reinventing Project management: the diamond approach to sucessful growth and innovation. Boston: Harvard Business School Press, 2007.

SHENHAR, A.J; LEVY, O.; DVIR, D. Mapping the Dimensions of Project Success. Project Management Journal, v. 28, n. 2, p.5-13, June 1997.

SIEGEL, S.; CASTELLAN JR, N. J. Estatística não-paramétrica para as ciências do comportamento. Trad. Sara Ianda Corea Carmona. $2^{a}$ edição. Porto Alegre: Artmed, 2006.

SIMON, L. Managing creative projects: an empirical synthesis of activities. International Journal of Project Management, v. 24, n. 2, p. 116-126, February 2006.

STRAUSS, Anselm; CORBIN, Juliet. Pesquisa qualitativa: técnicas e procedimentos para o desenvolvimento de teoria fundamentada. Trad. Luciane de O. da Rocha. $2^{a}$ edição. Porto Alegre: ARTMED, 2008. 
TAYLOR-GOOBY, P,; ZINN, J. The Current Significance of Risk In: TAYLOR-GOOBY, P,; ZINN, J.O (Eds.) Risk in Social Science. Oxford: University of Kent, p. 1-19, 2008.

THIRY, Michel. Sensemaking in value management practice. International Journal of Project Management, v. 19, n. 2, p. 71-77, 2001.

TILLY, C. Welcome to the Seventeenth Century In: DIMAGGIO, P. (ed.) The twenty-firstcentury firm: changing economic organization in international perspective. EUA: Princeton University Press, 2001.

VASCONCELOS, F. C.; CYRINO, A. B. Vantagem competitiva: os modelos teóricos atuais e a convergência entre a estratégia e a teoria organizacional. RAE - Revista de Administração de Empresas, v. 40, n. 4, p. 20-37, 2000.

WEICK, K. E. Faith, Evidence, and Action: Better Guesses in an Unknowable World. Organization Studies, v. 27, n. 11, p. 1723-1736, 2006.

WEICK, Karl E. Sensemaking in Organizations. London: Sage, 1995.

Making Sense of the organization. Singapore: Blackwell Publishing. 2001.

A estética da imperfeição em orquestras e organizações. RAE - Revista de Administração de Empresas, 3, p. 6-18. jul./set. de 2002.

Faith, Evidence, and Action: Better Guesses in an Unknowable World. Organization Studies, v. 27, n. 11, p. 1723-1736, 2006.

WEICK, Karl E.; SUTCLIFFE, Kathleen M. Managing the unexpected: resilient performance in an age of uncertainty. 2nd Ed. EUA: John \& Sons, 2007.

WEICK, Karl E.; SUTCLIFFE, Kathleen M.; OBSTFELD, David. Organizing and the process of sensemaking. Organization science, v.16, n.4, p. 409-421, Jul./Aug. 2005.

WHEELWRIGHT, Steven C.; CLARK, Kim B. Creating project plans to focus product development. Harvard Business Review, March-April 1992.

WIDEMAN, R. Max (ed.) Project and Program Risk Management: A Guide to Managing Project Risks and Opportunities. PMI, 1992. Disponível em: http://pmi.books24x7.com/viewer.asp?bookid=5607. Acesso em: 04.11.2010.

WILLIAMS, T. M. The need for new paradigms for complex project. International Journal of Project Management, v. 17, n. 5, p. 269-273, October 1999.

WINCH, Graham. M.,; MAYTORENA, Eunice. Making Good Sense: Assessing the Quality of Risky Decision-making. Organization Studies, v. 30, n. 2 -3, p. 181-203, February-March 2009.

WYNNE, Brian. Uncertainty and environmental learning: Reconceiving science and policy in the preventive paradigm. Global Environmental Change, V. 2, n. 2, p. 111-127, June 1992.

YIN, R. K. Estudo de Caso: Planejamento e Métodos. Trad. Daniel Grassi. $3^{\text {a }}$. ed. Rio de Janeiro: Bookman, 2005. 
YU, Abraham S.O. (coord.) Tomada de decisão nas organizações: uma visão multidisciplinar. São Paulo: Saraiva, 2011.

ZACK, MH. Managing Organizational Ignorance. Knowledge Directions, Volume 1, Summer, $\quad$ p. $\quad 36-49, \quad 1999 . \quad$ Disponível em: http://web.cba.neu.edu/ mzack/articles/orgig/orgig.htm. Acesso em: 23.06.2008.

ZSAMBOK, Caroline E. Naturalistic decision making: where are we now? In: ZSAMBOK, Caroline E.; KLEIN,Gary. Naturalistic decision making. New Jersey: LEA, 1997. 


\section{APÊNDICE 1 -DESCRIÇ̃̃O DAS VARIÁVEIS}

\begin{tabular}{|c|c|c|c|c|c|c|c|c|c|c|c|c|c|c|}
\hline \multirow{2}{*}{\multicolumn{2}{|c|}{ Construtos $\vec{v}$}} & \multirow{2}{*}{ Variáveis } & \multirow{2}{*}{ Escara } & \multirow{2}{*}{ Categoria final } & \multirow{2}{*}{ Fonte } & \multicolumn{6}{|c|}{ Proposições } & \multirow{2}{*}{\begin{tabular}{r|} 
Item na \\
questionár
\end{tabular}} & \multirow{2}{*}{\begin{tabular}{|r|} 
Item $\mathbf{n}_{i}$ \\
entrevista
\end{tabular}} & \multirow{2}{*}{ Tipo de variáveı } \\
\hline & & & & & & \begin{tabular}{l|l}
1 & 2 \\
\end{tabular} & \begin{tabular}{|l|l|}
2 & 3 \\
\end{tabular} & $4:$ & \begin{tabular}{|l|l|}
5 & 6 \\
\end{tabular} & \begin{tabular}{l|l|}
6 & 7 \\
\end{tabular} & \begin{tabular}{|l|l|}
8 & 9 \\
\end{tabular} & & & \\
\hline & & Nome & Nominal & & & & & & & & & 19 & Abertura & \\
\hline & & Área de atuação & Nominal & Indústria e Serviços & & & & & & & & 20 & & \\
\hline & & $\begin{array}{l}\text { Segmento da área de } \\
\text { atuação }\end{array}$ & Nominal & Conforme informado & & & & & & & & 21 & Abertura & \\
\hline & Organização & $\begin{array}{l}\text { Nivel de inovação do } \\
\text { segmento }\end{array}$ & Nominal & $\begin{array}{l}\text { alta, média-alta, média-baixa e } \\
\text { baixa intensidade tecnológica } \\
\text { ou intensivo em conhecimento } \\
\text { ou menos intensivo em } \\
\text { conhecimento }\end{array}$ & \begin{tabular}{|c} 
HIGH- \\
TECHNOLOGY, \\
2009
\end{tabular} & & & & & $\mathrm{x}$ & & $\mathrm{x}$ & & \\
\hline & & Cultura da Atenção & $\begin{array}{l}\text { Interval } \\
\text { ar }\end{array}$ & $\begin{array}{l}>17 \text { Forte, } \\
11 \text { a } 17 \text { Moderada, } \\
<11 \text { Baixa, vide item 3.3.2. }\end{array}$ & $\begin{array}{c}\text { WEICK, } \\
\text { SUTCLIFFE, } 2007\end{array}$ & & & & & & & 23 & & independente \\
\hline \multirow{5}{*}{\multicolumn{2}{|c|}{ Entrevistado }} & Nome, e-mail, telefone & Nominal & & & & & & & & & $1,2 \mathrm{e} 3$ & & \\
\hline & & Gênero & Nominal & Feminino, masculino & & & & & & & & & & \\
\hline & & $\begin{array}{l}\text { Papel do entrevistado no } \\
\text { projeto }\end{array}$ & Nominal & $\begin{array}{l}\text { Sponsor, gerente de projeto, } \\
\text { membro da equipe, consultor } \\
\text { PMO }\end{array}$ & PMI, 2008 & & & & & & & 7 & Abertura & \\
\hline & & \begin{tabular}{|l|}
$\begin{array}{l}\text { Tempo de experiência } \\
\text { profissional }\end{array}$ \\
\end{tabular} & \begin{tabular}{|l|} 
Interval \\
ar
\end{tabular} & em anos & & & $\mathrm{x}$ & & & & & 4.1 & & independente \\
\hline & & $\begin{array}{l}\text { Tempo de experiência em } \\
\text { gerenciamento } \\
\text { projetos }\end{array}$ & $\begin{array}{l}\text { Interval } \\
\text { ar }\end{array}$ & em anos & & & $\mathrm{x}$ & & & & & 4.2 & & independente \\
\hline \multirow{7}{*}{\begin{tabular}{l|l}
$P$ & \\
$r$ & \\
0 & \\
$j$ & \\
$e$ & \\
$t$ &
\end{tabular}} & \multirow{5}{*}{ Descrição } & Descrição do projeto & Nominal & Conforme informado & & & & & & & & 6 & Abertura & \\
\hline & & Descrição do produto & Nominal & Conforme informado & & & & & & & & 10.1 & Abertura & \\
\hline & & Descrição da inovação & Nominal & Conforme informado & & & & & & & & 11.1 & Abertura & \\
\hline & & Descrição da tecnologia & Nominal & Conforme informado & & & & & & & & 12.1 & Abertura & \\
\hline & & $\begin{array}{l}\text { Justificativa da } \\
\text { complexidade }\end{array}$ & Nominal & Conforme informado & & & & & & & & 13.1 & Abertura & \\
\hline & \multirow{2}{*}{ Situação } & Duração Prevista & $\begin{array}{l}\text { Interval } \\
\text { ar }\end{array}$ & $\begin{array}{l}\text { em anos, calculado com base } \\
\text { nas datas de inicio e término } \\
\text { previsto }\end{array}$ & & & & & & & & $5.1,5.2$ & Abertura & \\
\hline & & Duração Real & Interval & $\begin{array}{l}\text { em anos, calculado com base } \\
\text { nas datas de inicio e término } \\
\text { real }\end{array}$ & & & & & & & & 5.1 .5 .3 & Abertura & \\
\hline $\begin{array}{l}\mathrm{t} \\
0\end{array}$ & \multirow{6}{*}{ Classificação } & Tipo de inovação & Nominal & $\begin{array}{l}\text { Produto, Processo, } \\
\text { Organizacional, de Marketing }\end{array}$ & $\mathrm{OCDE}, 2005$ & & & & $\mathrm{x}$ & $\mathrm{x}|\mathrm{x}|$ & & 10 & Abertura & independente \\
\hline \multirow{7}{*}{$\begin{array}{l}\mathrm{i} \\
\mathrm{n} \\
\mathrm{o} \\
\mathrm{v} \\
\mathrm{a} \\
\mathrm{d} \\
\mathrm{o} \\
\mathrm{r}\end{array}$} & & Inovação no serviço & Nominal & Radical, ad hoc, incremental & \begin{tabular}{|c|} 
GALLOUJ, \\
WEINSTEIN, 1997 \\
\end{tabular} & & & & $\mathrm{x}$ & $\mathrm{x} \mid \mathrm{x}$ & & 11 & Abertura & independente \\
\hline & & Incerteza Tecnológica & Ordinal & Baixa, Média, Alta, Muito alta & \multirow{3}{*}{$\begin{array}{l}\text { SHENHAR,DVIR, } \\
2007\end{array}$} & & & & & $\mathrm{x}$ & & 12 & Abertura & independente \\
\hline & & \begin{tabular}{|l} 
Complexidade \\
\end{tabular} & Ordinal & Baixa, Média, Alta & & & & & & $\mathrm{x}$ & & 13 & Abertura & \begin{tabular}{|l|} 
independente \\
\end{tabular} \\
\hline & & Ritmo & Nominal & $\begin{array}{l}\text { Regular, Rápido, Tempo critico, } \\
\text { Blitz }\end{array}$ & & & & & & & & 14 & & \\
\hline & & $\begin{array}{l}\text { Metodo de gestão de } \\
\text { projetos }\end{array}$ & Nominal & $\begin{array}{l}\text { Experimentação, Informal, } \\
\text { Macro, Formal }\end{array}$ & $\begin{array}{l}\text { PICH et al, 2002; } \\
\text { LOCH et al, 2006; } \\
\text { LOCH et al, 2008 } \\
\end{array}$ & & & $\mathrm{x}$ & & & & 22 & Abertura & independente \\
\hline & \multirow[t]{2}{*}{ Equipe } & Quantidade de pessoas & \begin{tabular}{|l|} 
Interval \\
ar
\end{tabular} & \begin{tabular}{|l|} 
Quanto maior o número de \\
pessoas envolvidas, maior o \\
nivel de complexidade
\end{tabular} & & & & & & & & 8 & Q6 & \\
\hline & & $\begin{array}{l}\text { Áreas e empresas } \\
\text { envolvidas }\end{array}$ & Nominal & & & & & & & & & 9 & Q6 & \\
\hline
\end{tabular}




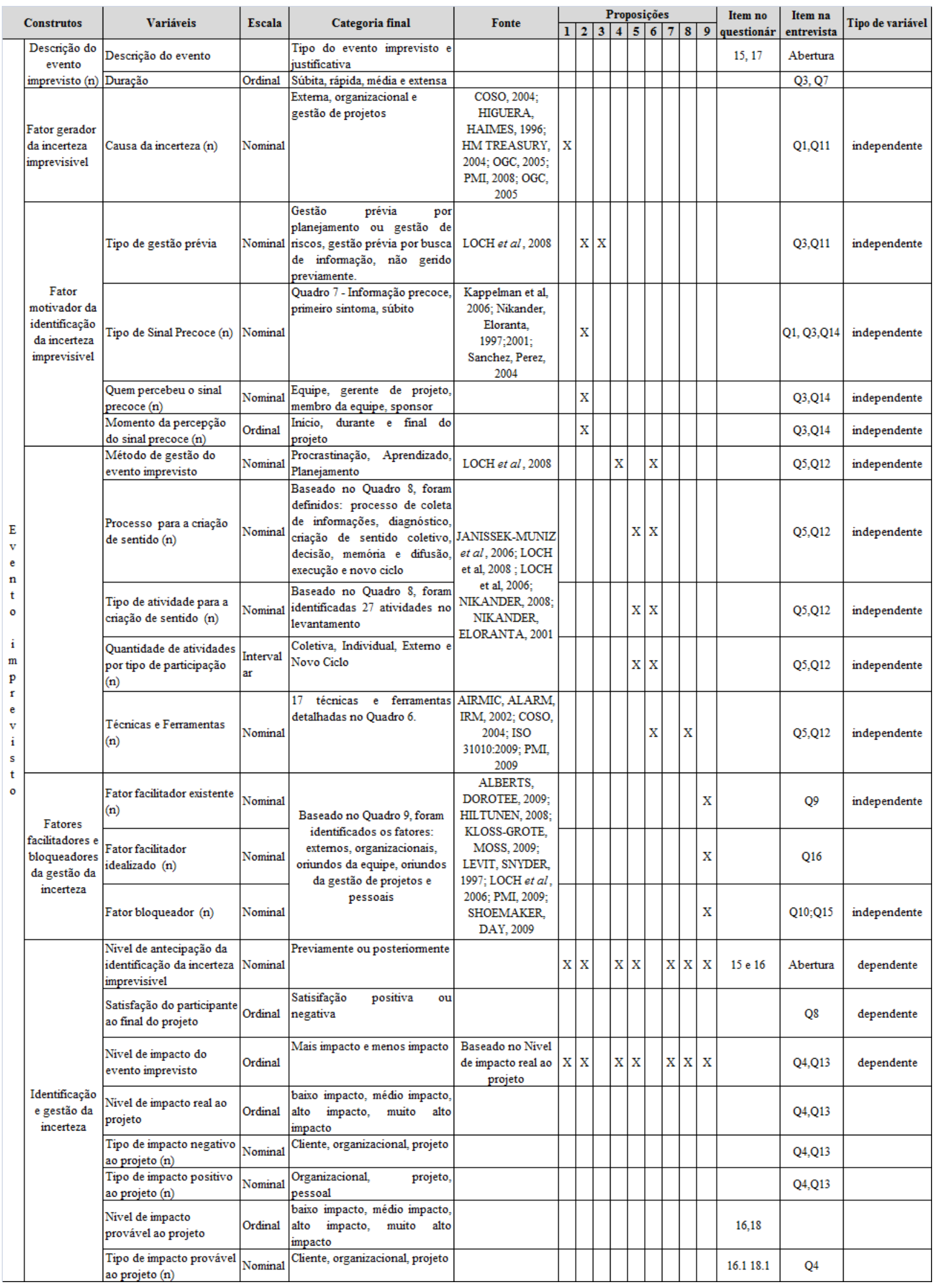


APÊNDICE 2-QUESTIONÁRIO PRÉ-ENTREVISTA

\section{Parte 1 - Informações gerais}

A pesquisa dá-se sobre a identificação de eventos desconhecidos ou imprevisíveis (unk unks). Um projeto com essas características cria algo novo ou uma nova geração de um produto (ou serviço, processo, negócio, forma de distribuição, forma de trabalho).

A pesquisa terá duas fases:

Fase 1 - preenchimento desse questionário, em cerca de 30 minutos, para se obterem informações sobre o contexto do projeto e identificar se ele se enquadra nos requisitos acima. O questionário é composto de cinco páginas com informações sobre: o entrevistado, o projeto, o tipo de projeto, os eventos desconhecidos e sobre a organização que executou o projeto.

Fase 2 - entrevista presencial ou virtual, com cerca de uma hora de duração, para aprofundar e entender como os eventos desconhecidos foram identificados ou como poderiam ter sido identificados previamente.

Todas as informações são confidenciais e não serão divulgadas no todo nem em parte, para não se reconhecer o entrevistado nem a organização que participou da pesquisa.

Os campos marcados com * são obrigatórios.

\section{Parte 2 - Sobre o entrevistado}

1. * Nome:

2. E-mail:

3. Telefone: (

4. * Tempo de experiência (em anos):

profissional:

gerenciamento de projetos: 


\section{Parte 3 - Sobre o projeto}

Escolha um projeto que tenha iniciado a partir de janeiro de 2007 e que seja altamente inovador. Esse projeto deve ser no mínimo novo para a organização, mas também pode ser novo para o mercado ou novo para o mundo.

5. * Duração do projeto:

Início:

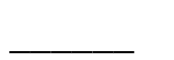

/

Fim previsto:
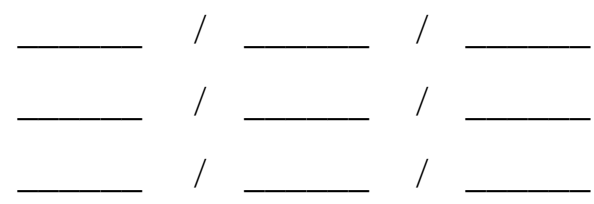

Fim real:

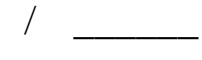

Fim real:

6. Breve descrição do projeto:

7. * Papel do entrevistado:
( ) sponsor
( ) gerente de projetos
( ) membro da equipe
( ) gerente de risco
( ) consultor do PMO
( ) outro:

8. * Quantidade máxima de pessoas envolvidas na equipe do projeto (incluindo o gerente de projetos):

9. Breve descrição das áreas e/ou empresas envolvidas: 


\section{Parte 4 - Sobre o tipo de projeto}

O projeto escolhido na página anterior deve ser do tipo 'Plataforma' (nova geração de uma linha de produtos para o mercado ou para um novo mercado) ou 'Ruptura' (criação de um produto novo com uma inovação radical para o mercado).

Caso o projeto escolhido não atenda a esse requisito, pedimos que escolha um novo projeto e volte para a página anterior para ajustar as informações.

10. * Tipo de inovação:

( ) Produto (bem ou serviço)

( ) Processo (processo de produção ou distribuição dos produtos)

( ) de Marketing (mudanças na concepção do produto ou em sua embalagem, no posicionamento do produto, em sua promoção ou na fixação de preços)

( ) Organizacional (novas práticas de negócio, na organização do local de trabalho ou nas relações externas)

Breve descrição do produto/processo/mudança/prática:

11. * Nível de inovação:

( ) Derivado (modificação, melhoria ou extensão de um produto existente)

( ) Plataforma (nova geração de uma linha de produtos para o mercado ou para um novo mercado)

( ) Ruptura (criação de um produto novo com uma inovação radical para o mercado)

Breve descrição da inovação:

12. *Nível de inovação na tecnologia empregada (conhecimento, método, processo, técnica, ferramenta, instrumento): 
( ) Baixa (conhecimento é do domínio da organização)

( ) Média (tecnologia conhecida, mas serão incorporadas novas funções)

( ) Alta (tecnologia está disponível no início do projeto, mas é totalmente nova para a organização)

( ) Muito alta (quando a tecnologia não existe no início do projeto)

Breve descrição da tecnologia empregada:

13. *Complexidade do projeto:

( ) Baixa (uma função específica, como um subsistema ou um componente ou um diagnóstico)

( ) Média (várias funções ou mesmo grupo de funções, interface com vários sistemas)

( ) Alta (centraliza vários sistemas, produtos ou serviços que funcionam altamente integrados para o atendimento de um objetivo)

\section{4. *Ritmo/Passo}

( ) Regular (tempo não é um fator crítico para o sucesso do projeto)

( ) Rápido/competitivo (tempo crítico para atender uma janela de oportunidade)

( ) Tempo crítico (data final é uma restrição forte e determinada)

( ) Blitz (projeto para solucionar uma crise ou um evento inesperado)

\section{Parte 5 - Sobre eventos imprevistos}

Imprevistos existem por causa do total desconhecimento de a possibilidade de um evento ocorrer. Portanto, esse tipo de incerteza não é gerenciado até o momento em que se percebe previamente que ela pode existir ou quando subitamente ela ocorre.

O desconhecimento pode ter como origem a inovação introduzida no projeto e pode-se relacionar com: o mercado, o cliente, o usuário, as características do produto, a tecnologia a ser empregada, a capacidade de distribuição, a capacidade de produção, o parceiro etc. 
Para responder às duas questões a seguir, lembre-se de eventos imprevistos relevantes do projeto selecionado, preferencialmente ligados à inovação, que você ou sua equipe conseguiu ou não identificar antes que eles ocorressem.

15. * Cite um evento imprevisto que foi possível identificar antes de sua ocorrência. Justifique sua escolha e conte o que aconteceu.

16. *Qual seria o impacto para o sucesso do projeto, caso não tivesse sido tratado?

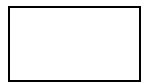

Comente o impacto que poderia ter:

17. *Cite um evento imprevisto que NÃO foi possível identificar antes de sua ocorrência. Justifique sua escolha.

18. *Qual foi o impacto para o projeto?

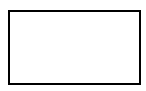

Comente o impacto que teve: 
Avalie as afirmações abaixo em relação à organização executora do projeto. Essa organização é a responsável por entregar o projeto aos clientes e aos usuários e à qual, normalmente, o gerente de projetos está vinculado.

19. Nome:

20. * Área de atuação: ( ) Indústria ( ) Serviço

21. * Segmento da área de atuação:

Exemplos: Tecnologia da Informação, Telecomunicação, Consultoria, Petróleo, Química, Farmacêutica, Educação, Indústria Têxtil, Metalúrgica, Varejista, ONG

22. * As práticas utilizadas (formais ou informais) na gestão desse projeto compreendiam:

\begin{tabular}{|l|l|l|l|l|}
\hline & Práticas formais & Práticas informais & Não aplicadas & Não sei \\
\hline Escopo & & & & \\
\hline Custo & & & & \\
\hline Prazo & & & & \\
\hline Recursos Humanos & & & & \\
\hline Comunicação & & & & \\
\hline Qualidade & & & & \\
\hline Riscos & & & & \\
\hline Aquisições & & & & \\
\hline Integração & & & & \\
\hline Meio Ambiente & & & & \\
\hline
\end{tabular}

23. Como as afirmações abaixo se aplicam à organização executora do projeto?

\begin{tabular}{|l|l|l|l|}
\hline \multicolumn{1}{|c|}{ Afirmações } & $\begin{array}{c}1-\text { não se } \\
\text { aplica }\end{array}$ & $\begin{array}{c}2-\text { se aplica } \\
\text { até certo } \\
\text { ponto }\end{array}$ & $\begin{array}{c}3-\text { se } \\
\text { aplica } \\
\text { muito }\end{array}$ \\
\hline $\begin{array}{l}\text { Nós temos um bom mapa dos talentos e habilidades de cada } \\
\text { pessoa. }\end{array}$ & & & \\
\hline Nós falamos sobre os erros e maneiras de aprender com eles. & & & \\
\hline $\begin{array}{l}\text { Nós discutimos nossas habilidades especiais com cada um, } \\
\text { assim sabemos quem tem uma habilidade ou conhecimento } \\
\text { relevante. }\end{array}$ & & & \\
\hline $\begin{array}{l}\text { Nós discutimos alternativas de como fazer as nossas atividades } \\
\text { normais. }\end{array}$ & & & \\
\hline $\begin{array}{l}\text { Quando discutimos problemas emergentes com colegas de } \\
\text { trabalho, normalmente discutimos o que está por trás. }\end{array}$ & & & \\
\hline $\begin{array}{l}\text { Quando tentamos resolver um problema, aproveitamos a } \\
\text { vantagem das habilidades especiais de nossos colegas. }\end{array}$ & & & \\
\hline
\end{tabular}




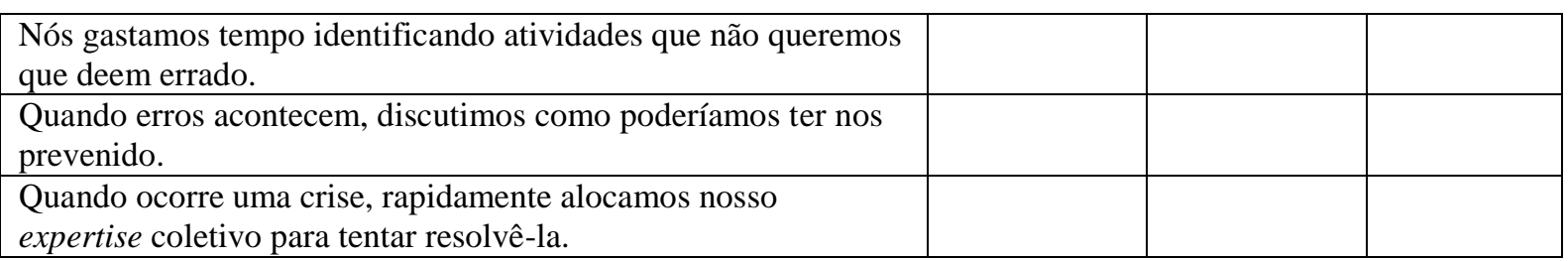

\section{Parte 7 - Fechamento}

Agradeço muito a sua participação e, em breve, retornarei para marcamos uma entrevista, na forma e na data que for mais conveniente para você.

Rosária Russo, MSc, MBA, PMP

Doutoranda FEA/USP 
APENDICE 3 - ROTEIRO DE ENTREVISTA

Data: I

Hora Início: Hora Término:

Nome:

Abertura

Entrevistador solicita autorização expressa para gravação, mesmo que tome nota dos itens principais: Você autoriza a gravação da entrevista? Todos os detalhes são importantes e a gravação permitirá uma análise mais rica e mais profunda.

Entrevistador comenta novamente o objetivo da pesquisa: $\mathrm{O}$ objetivo é avaliar o processo de identificação do desconhecido ou unk unks. Para isso serão avaliados dois eventos imprevistos: primeiro o que foi possível identificar antes de sua ocorrência e, depois, o que não foi possível identificar antes. Todas as questões referem-se a esses eventos.

Se o projeto foi escolhido num momento anterior (questionário pré-entrevista): lembrar qual foi o projeto escolhido, ler o questionário anterior e repassar as informações, verificando se há alguma dúvida. Senão, aplicar o questionário pré-entrevista.

Entrevistador busca estimular o entrevistado a detalhar as atividades dentro de sua perspectiva: É importante que você mostre o seu ponto de vista sobre o assunto, com base nas motivações, nas opiniões e na sua experiência. $O$ anonimato do entrevistado, da empresa, do projeto e das respostas é garantido. Você deve-se sentir livre para interromper, pedir esclarecimentos e criticar o tipo de pergunta.

\section{Evento imprevisto identificado previamente}

Entrada crítica 1: Pense no evento [cite o imprevisto que foi citado no questionário] que conseguiu ser identificado antes de sua ocorrência.

\section{Parte 1 - Evento imprevisto}

Q1 - O que aconteceu em relação a esse evento imprevisto?

Mais detalhes do contexto. 
Q2 - Como isso se conecta com a sua experiência?

Retrospectiva.

Q3 - Como se percebeu que faltava conhecimento sobre esse evento?

Identificar o sinal ou se houve diagnóstico.

Quando isso aconteceu? Em que momento do projeto?

\section{Parte 2 - Práticas (pontes)}

\section{Q4 - O que foi feito em relação a esse evento imprevisto?}

\section{CRONOLOGIA DOS FATOS.}

METODOLOGIA: Verificar se usou Planejamento (Guia PMBOK), Aprendizado ou Selecionismo.

PROCESSO: Quadro 8 - observação de sinal ou busca de superação da lacuna de conhecimento, definição de alvo, coleta, seleção de informações, repasse, memória, criação coletiva, difusão, animação, ver se foi usada a gestão de riscos.

ATIVIDADES: Exemplos escolher método de obtenção de informações, pesquisar, sondar, explorar, interagir, entrevistar, usar banco de dados, aceitar o sinal precoce, rejeitar o sinal precoce, identificar, se reunir, reagir, avaliar, interpretar, registrar, usar ferramenta, determinar o nível de conhecimento, observar, refletir, diagnosticar, decidir, convencer, rever, difundir, animar.

TÉCNICAS E FERRAMENTAS: Caso ele não se lembre de nenhuma, dê exemplos, quadro 6: lista de verificação, avaliação de premissas e restrições, brainstorming, análise de monte Carlo, análise multicritérios, FMEA, entrevistas, análise de cenário, análise de árvore de falhas, análise de impacto no negócios, SWOT, auditoria de risco, DELPHI, Diagrama de causa e efeito, HAZOP, matriz de probabilidade e impacto, questionário etc.

\section{Q5 - Quem participou desse processo?}

QUEM - Identificar participação da equipe.

COMO - trabalhavam: isolados ou em grupos?

Havia discussão sobre o que tinha sido identificado?

Houve alguém com papel de destaque no processo?

Qual era o nível de experiência das pessoas?

\section{Q6 - Em que momento se concluiu que a incerteza tinha diminuído?}

O objetivo consiste em ver se a superação da lacuna foi total, ou se se chegou a um resultado plausível e se teria continuidade.

- Houve continuidade no processo?

- O que o levou a essa avaliação? 
Q7 - O que o impacto desse evento no projeto representou para você?

Identificar o nível de identidade do entrevistado com o problema.

\section{Parte 3 - Resultados e facilitadores/bloqueadores}

Entendendo que resultado é o conhecimento adquirido sobre o evento imprevisto para o projeto.

Q8 - Você ficou satisfeito com esse resultado? Por quê?

- Em qual você se enquadra: insatisfeito, pouco satisfeito, satisfeito, muito satisfeito e totalmente satisfeito?

Q9 - O que você considera que ajudou a chegar a esse resultado?

Identificar fatores que possam ter facilitado a identificação: cultura da organização (cultura de atenção, múltiplas perspectivas, objetividade), metodologia em gestão de projetos (metodologia diferenciada, gestão de stakeholder, cláusulas contratuais), metodologia em GR (identificação iterativa, abrangente, emergente, antecipada) e ferramentas de GR e incertezas (baseadas no passado, presente ou futuro e em gestão do conhecimento).

- Mais algum outro?

Q10 - O que você considera que atrapalhou ou dificultou para chegar a esse resultado?

Identificar fatores que possam ter bloqueado a identificação, como os acima.

\section{Parte 4 - Evento imprevisto não identificado}

Entrada crítica 2: Pense no evento [cite o evento imprevisto que foi citado no questionário] que $N \tilde{A} O$ conseguiu ser identificado antes de sua ocorrência.

Q11 - O que aconteceu em relação a esse evento?

Identificar o contexto do evento.

Quando isso aconteceu? Em que momento do projeto?

Identificar o momento do projeto, inclusive com datas,

Q12 - O que foi feito em relação a esse evento?

Identificar o contexto do evento. 
Q13 - O que o impacto desse evento representou para você?

Identificar o nível de identidade do entrevistado com o problema.

Q14 - Por que o evento não foi identificado previamente? Houve sinais prévios de sua ocorrência, sintomas?

Identificar o sinal

Q15 - O que você considera que impediu a identificação desse evento antes?

Identificar fatores que possam ter bloqueado a identificação: cultura da organização (cultura de atenção, múltiplas perspectivas, objetividade), metodologia em gestão de projetos (metodologia diferenciada, gestão de stakeholder, cláusulas contratuais), metodologia em GR (identificação iterativa, abrangente, emergente, antecipada) e ferramentas de GR e incertezas (baseadas no passado, presente ou futuro e em gestão do conhecimento).

- Mais algum outro?

Q16 - Se você pudesse usar uma varinha mágica, o que teria feito para ajudar a identificar eventos desconhecidos ou imprevistos?

Metodologia, processo, atividade, técnica e ferramenta, pessoas,

Mais algum outro?

\section{Fechamento da Entrevista}

Abrir espaço para o entrevistado acrescentar alguma informação ou destacar algum ponto que considerou interessante. Agradecer e perguntar se há possibilidade desse projeto, com aval da organização, participar do estudo de caso. 


\section{APÊNDICE 4 - APLICAÇÃO DO MÉTODO SMM NAS ENTREVISTAS}

Inicialmente, Dervin (1983) definia o sensemaking 51 como um “[...] comportamento, tanto interno (cognitivo) quanto externo (procedimento) os quais permitem que o indivíduo construa e desenhe seu movimento dentro de um tempo e espaço." ${ }^{52}$ Ele é um comportamento na comunicação. Posteriormente, ela (Id., 1999) distinguiu a metodologia do fenômeno sugerindo que a metodologia seja usada nos mais variados contextos, para o estudo do sensemaking e sense-unmaking das pessoas.

Apesar de Dervin (1999) afirmar explicitamente que não há relação entre o fenômeno que ela estuda e o sensemaking de Weick (1995), as propriedades deste último podem ser relacionadas diretamente com suas principais premissas teóricas (DERVIN, 1983):

a) “[...] a realidade não é completa nem constante, e sim cheia de descontinuidades fundamentais e difusas ou lacunas. [...] porque todas as coisas não estão conectadas e porque mudam constantemente."53 (Ibid., p. 2) A questão da impermanência é listada por Weick (2006) como uma das características da criação de sentido;

b) a informação "[...] é um produto da observação humana [...]" 54, aplicando-se a observações diretas ou pelas feitas por outros. Porém, elas nunca são diretas, pois a observação é mediada, no sentido de ser restringida, pela mente das pessoas que selecionam o que observar, como observar e como interpretar o produto da observação. Weick (1995) também menciona que os sinais extraídos do ambiente são contextualizados dentro de um modelo mental, crença pessoal, regras, procedimentos e outros fatores sociais. Assim o sinal e o seu entendimento estão ligados à identidade da pessoa, como ela se move para dar sentido às mensagens;

\footnotetext{
${ }^{51}$ Dervin ressalta o uso do hífen nas palavras, tentando diferenciar o conceito usado por ela das outras teorias, mas, para padronizar, iremos utilizar sem o hífen.

52 "[...] behavior, both internal (i.e. cognitive) and external (i.e. procedural) which allows the individual to construct and design his/her movement through time-space."

53 " [...] reality is neither complete nor constant but rather filled with fundamental and pervasive discontinuities or gaps. [...] because all things in reality are not connected and because things are constantly changing."

54 “[...] a product of human observing."
} 
c) "[...] toda informação é subjetiva." ${ }^{55} \mathrm{O}$ termo mais adequado é restrição e não viés, pois este supõe um padrão externo a ser comparado, pelo qual o observado possa ser julgado. Também não é limitação, pois esta assume que o observador estaria preso, sem possibilidade de responder à mudança de condições e quebrar o velho padrão ou estrutura. As restrições são:

a. limitações na fisiologia humana, restrições de nossa história coletiva, diferente de outras espécies;

b. limitação do presente tempo-espaço, pois o que se observa num dado momento é restringido por aquilo que se é naquele momento - conceituação ligada à criação da identidade, uma das propriedades da criação de sentido;

c. limitação da presença do tempo e espaço, pois as nossas observações são influenciadas pelo nosso passado. Isso é a retrospecção (WEICK, 1995), pois o presente é reconhecido e baseado nas experiências passadas;

d. limitação do futuro tempo-espaço, como se está em diferentes lugares, as observações de hoje se baseiam, ao menos em parte, no lugar em que as pessoas se veem no futuro;

d) a busca de informação e o seu uso são atividades construtivas, e não transmissão, assim o sensemaking assume que a construção envolve o compartilhamento de informação, numa série de construções e desconstruções, nas interações dentro de um contexto. Na mesma linha que Weick (1995) caracteriza a criação de sentido como social, pois o sentido é criado na interação com as pessoas ou no que o individuo imagina que as outras pessoas entendem, num processo contínuo. A interação com o ambiente é o enactment;

e) sensemaking foca em como o indivíduo usa as observações de outros, assim como suas próprias para construir seus desenhos da realidade e usa esses desenhos para guiar o comportamento. O comportamento do sensemaking é frequentemente dado pelas exigências das condições humanas de preencher as lacunas (bridge gaps). Esse conceito está diretamente ligado ao enactment (WEICK, 1995) que é a criação da realidade por aquilo que as pessoas falam e fazem.

Com base nas constatações acima, optou-se por empregar esse método. Na abordagem SMM, Dervin (2008) usa o modelo baseado em três dimensões, conforme pode ser visto na Ilustração 19: situação é o contexto no tempo-espaço no qual o sentido é construído; lacuna é

\footnotetext{
55 "[...] all information is subjective."
} 
a necessidade de abrir caminho (necessidade de informação) ou as questões que as pessoas têm para construir o sentido e se mover pelo tempo-espaço; resultado, o sentido criado, assim como a situação para o próximo passo; ponte são as ideias, atitudes, crenças, valores, sentimentos, intuições, memórias, estórias, narrativas que fizeram com que o sentido fosse construído. Na SMM também são fundamentais os conceitos de movimento, horizonte (passado, presente e futuro), poder, restrição, experiência, mudança, flexibilidade, caos, fantasia, hábito, inflexibilidade, rigidez e constância.

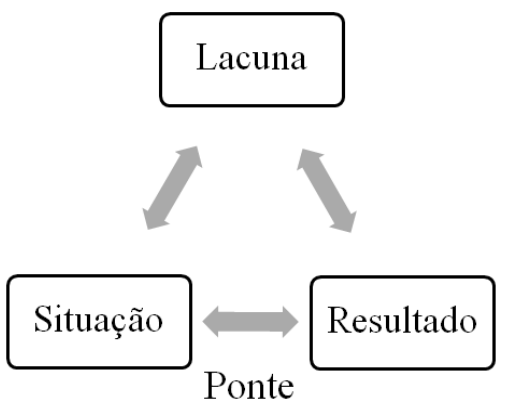

Ilustração 19 - Triângulo metafórico do SMM

Fonte: Dervin, 2008

Essa metodologia apresenta os seguintes métodos de entrevista (DERVIN, 2008):

- SMM micromomento na linha do tempo ${ }^{56}$ - o entrevistador solicita ao entrevistado descrever a criação, ou a não criação de sentido a cada passo de um processo numa dada situação. Essa abordagem avalia profundamente cada passo do processo; o triângulo metafórico, Ilustração 19, é analisado a cada passo e em vários níveis;

- SMM linha do tempo - o entrevistador solicita que o entrevistado descreva como ocorreu a criação de sentido, ou não numa dada situação dentro de uma linha do tempo. Essa situação enquadra-se num modelo definido, como situações de enfrentamento de risco, de aprendizado na vida sobre determinado assunto, falhas em questionamentos;

- SMM microelemento - quando a avaliação é feita para uma situação única, que o entrevistado elege, por ser o passo mais importante, ou escolhe um, por atender parâmetros pré-estabelecidos;

- SMM cadeia de resultados - avalia profundamente os bloqueadores e facilitadores, ambos ou apenas um, em cada situação, podendo questionar as consequências, como ajuda e como pode atrapalhar;

\footnotetext{
${ }^{56}$ SMM micro-moment time-line interview.
} 
- $\quad$ SMM message q/ing - feito pela leitura de um texto, o entrevistado marca no texto quando tem alguma questão ou comentário a fazer, que são depois analisados;

- SMM focus group - a diferença do focus group tradicional está em que não há interrupção na fala das pessoas com um questionamento fortemente dirigido por questões prédefinidas. A restrição de tempo é compensada pela resposta por escrito de cada participante sobre o questionamento dos casos apresentados.

Foi usado o tipo de entrevista SMM micromomento na linha do tempo, pelos seguintes motivos: o tratamento na linha do tempo reflete melhor o objetivo de se obterem as atividades envolvidas na criação de sentido das incertezas imprevisíveis desde a sua percepção até a sua superação; o passo a passo da avaliação do micromomento pode-se refletir no método e nos processos para a identificação da incerteza imprevisível; como as lacunas, incertezas imprevisíveis, podem ser mais de uma por projeto, o passo a passo de cada uma pode se sobrepor, o que ficou mais claro nesse tipo de entrevista; as atividades são as pontes que os entrevistados usaram para sair da situação de desconhecimento para a identificação da lacuna, portanto se focaram questões nesse sentido.

Essa técnica exige que o entrevistador identifique uma entrada crítica para que o entrevistado possa localizar-se no tempo e espaço, dentro da situação objetiva a ser analisada. As questões devem ser adaptadas com o vocabulário e a narrativa, conforme a entrevista transcorre, para que o entrevistador articule-se com o entrevistado.

No decorrer do desenvolvimento do projeto, podem existir vários momentos nos quais a incerteza imprevisível foi tratada, assim o entrevistador deve observar que podem ocorrer vários triângulos metafóricos (Ilustração 19). Especificamente, o estudo tratará de - no mínimo - dois eventos.

No quadro abaixo constam as questões do método SMM (DERVIN, 2008, p. 19) com as respectivas questões aplicadas nas entrevistas do levantamento. 
Quadro 23 - Indicação da utilização das questões SMM no roteiro de entrevista

\begin{tabular}{|c|c|c|c|c|c|}
\hline $\begin{array}{l}\text { Para explorar } \\
\text { e aprofundar }\end{array}$ & \multicolumn{2}{|r|}{ Questões SMM } & \multirow{2}{*}{$\begin{array}{c}\text { Questões estudo } \\
\text { O que aconteceu em relação a } \\
\text { esse evento imprevisto? }\end{array}$} & \multirow{2}{*}{$\frac{\text { Propriedades }}{\text { Enactment }}$} & \multirow{2}{*}{$\begin{array}{c}\mathbf{L V} \\
1 \\
11\end{array}$} \\
\hline \multirow{5}{*}{ Situação } & 1 & What happend? & & & \\
\hline & 2 & What stood in the way? & & & \\
\hline & 3 & What were you trying to deal with? & & & \\
\hline & 4 & $\begin{array}{c}\text { How did that connect with past } \\
\text { events? }\end{array}$ & $\begin{array}{c}\text { Como isso se conecta com a sua } \\
\text { experiência? }\end{array}$ & Retrospecção & 2 \\
\hline & 5 & $\begin{array}{c}\text { How did it connect to forces of } \\
\text { power in family, community, } \\
\text { society? }\end{array}$ & & & \\
\hline \multirow{3}{*}{ Lacunas } & 6 & What were your big question? & $\begin{array}{c}\text { Como se percebeu que faltava } \\
\text { conhecimento sobre esse } \\
\text { evento? }\end{array}$ & Sinal extraído & 3 \\
\hline & 7 & $\begin{array}{c}\text { What were you were trying to } \\
\text { unconfuse, figure out, learn about? }\end{array}$ & & & \\
\hline & 8 & What did you struggle with? & $\begin{array}{l}\text { O que foi feito em relação a } \\
\text { esse evento imprevisto? }\end{array}$ & $\begin{array}{l}\text { Enactment, } \\
\text { Contínuo, } \\
\text { Social }\end{array}$ & $\begin{array}{c}4 \\
12\end{array}$ \\
\hline \multirow{3}{*}{ Pontes } & 9 & $\begin{array}{l}\text { What conclusions /ideas did you } \\
\text { come to? }\end{array}$ & & & \\
\hline & 10 & $\begin{array}{c}\text { What emotions / feelings did you } \\
\text { come to? }\end{array}$ & $\begin{array}{l}\text { Você ficou satisfeito com esse } \\
\text { resultado? Por quê? }\end{array}$ & Feedback & 8 \\
\hline & 11 & $\begin{array}{c}\text { What led you to that } \\
\text { conclusion/idea/emotion/feeling? }\end{array}$ & $\begin{array}{l}\text { O que te levou a essa conclusão } \\
\text { / ideia? }\end{array}$ & $\begin{array}{l}\text { Sinal extraído } \\
\text { Social } \\
\end{array}$ & \\
\hline \multirow{4}{*}{$\begin{array}{l}\text { Resultados } \\
\text { obtidos e / ou } \\
\text { procurados }\end{array}$} & 12 & $\begin{array}{l}\text { How did that [name that] help? } \\
\text { Facilitate? [And, how did that } \\
\text { help? And, how did that help?] }\end{array}$ & $\begin{array}{c}\text { O que você considera que } \\
\text { ajudou a chegar a esse } \\
\text { resultado? }\end{array}$ & & 9 \\
\hline & \multirow{2}{*}{13} & \multirow{2}{*}{$\begin{array}{l}\text { How did that [name that] hinder? } \\
\text { [And, how did that hind? And, how } \\
\text { did that hind?] }\end{array}$} & $\begin{array}{l}\text { O que você considera que } \\
\text { atrapalhou ou dificultou ou } \\
\text { impediu para chegar a esse } \\
\text { resultado? }\end{array}$ & & $\begin{array}{l}10 \\
15\end{array}$ \\
\hline & & & $\begin{array}{c}\text { Por que o evento não foi } \\
\text { identificado previamente? } \\
\text { Houve sinais prévios de sua } \\
\text { ocorrência, sintomas? }\end{array}$ & Sinal extraído & 14 \\
\hline & 14 & $\begin{array}{c}\text { if you could wave a magic wand, } \\
\text { what would have helped? }\end{array}$ & $\begin{array}{c}\text { Se você pudesse usar uma } \\
\text { varinha mágica, o que teria feito } \\
\text { para ajudar a identificar eventos } \\
\text { desconhecidos ou imprevistos? }\end{array}$ & Feedback & 16 \\
\hline \multirow{3}{*}{$\begin{array}{l}\text { lacunas e as } \\
\text { lutas }\end{array}$} & 15 & What was missing? & & & \\
\hline & 16 & How did that stand in the way? & $\begin{array}{c}\text { O que o impacto desse evento } \\
\text { no projeto representou para } \\
\text { você? }\end{array}$ & Identidade & $\begin{array}{c}7 \\
13\end{array}$ \\
\hline & 17 & $\begin{array}{c}\text { And, how did that prevent you } \\
\text { getting more help? }\end{array}$ & & & \\
\hline \multirow{3}{*}{$\begin{array}{l}\text { o que o levou } \\
\text { a uma } \\
\text { avaliação }\end{array}$} & 18 & What led you to that assessment? & $\begin{array}{c}\text { Em que momento se concluiu } \\
\text { que a incerteza tinha } \\
\text { diminuído? }\end{array}$ & $\begin{array}{l}\text { Sinal extraído } \\
\text { Plausibilidade }\end{array}$ & 6 \\
\hline & 19 & $\begin{array}{c}\text { How did that evaluation connect } \\
\text { with your situation? }\end{array}$ & & & \\
\hline & 20 & $\begin{array}{c}\text { What was limited or incomplete } \\
\text { about that? }\end{array}$ & & & \\
\hline \multirow{2}{*}{$\begin{array}{c}\text { Como as } \\
\text { coisas ajudam }\end{array}$} & 21 & And, how did that help? & & & \\
\hline & 22 & $\begin{array}{c}\text { What did that allow you to } \\
\text { do/achieve/think? }\end{array}$ & & & \\
\hline
\end{tabular}


O significado de cada coluna é:

- para explorar e para aprofundar são as categorias da metodologia SMM;

- questões SMM são as questões originais da metodologia SMM.

- questões estudo contêm as questões traduzidas e adaptadas para este estudo.

- propriedades lista a respectiva propriedade da criação de sentido que a questão visa atender, conforme o entendimento do autor do estudo.

- LV relaciona a questão a ser aplicada nas entrevistas do levantamento, conforme Apêndice 3 - Roteiro de Entrevista.

A questão 5 foi inclusa para avaliar a participação da equipe, do fornecedor e do cliente no processo de criação de sentido. Essa questão é específica da proposta de estudo que poderia não ser atendida pelas questões do método SMM, caso não ficasse explícita. 


\section{APÊNDICE 5 -ATIVIDADES E PROCESSOS OBTIDOS NAS ENTREVISTAS}

Os 27 tipos de atividade estão detalhados a seguir:

- abortar ocorre quando o projeto para, pois o imprevisto o inviabilizou ou a equipe se desfez e teve de ser retomado com outra equipe ou outro fornecedor;

- avaliar está relacionado com estimar o impacto, como o uso de piloto com a respectiva análise do resultado, avaliação do resultado de decisões sobre a incerteza, emissão de parecer pela equipe;

- buscar especialista envolve a busca por uma pessoa experiente ou com conhecimento em determinado assunto, como explicado numa entrevista quando foram procuradas " [...] pessoas que tivessem, efetivamente, vivência [...]";

- buscar fornecedor representa o acesso a outras organizações - empresas, institutos de pesquisas, entidade de classe - que fornecerão produtos, serviços ou informações;

- buscar parceiro, quando a equipe ou o gerente de projetos conversam com outras organizações, para que possam trabalhar ou continuar a trabalhar juntas no projeto;

- buscar patentes ocorreu em apenas um caso de desenvolvimento de novo produto;

- checar a informação é o confronto de informações verbais ou escritas, que pode ser também a busca de informação, como quando houve testes para a equipe confirmar o direcionamento do sponsor, por meio de consultas ou entrevistas; checagem em requisitos definidos com os clientes; pesquisa em outros projetos; comparações entre as informações recebidas e os produtos do projeto;

- $\quad$ classificar quando se determina um grupo para a informação;

- compartilhar quando houve o compartilhamento da percepção ou das informações com o cliente, com especialistas, com o sponsor, com a equipe ou mesmo com o fornecedor, podendo ser inclusive por meio de treinamentos;

- cumprir o planejado, atividades previstas são executadas conforme o planejado;

- diagnosticar problema representa uma análise e constatação de causas de um problema a ser tratado, como a falta de definições das necessidades num novo sistema, identificação de procedimentos diferentes entre departamentos para uma mesma atividade, falta de gestão de um portfólio de projetos estratégicos, constatação de erros no planejamento;

- discutir com a equipe ocorre para confirmar o entendimento, esclarecer dúvidas, propor e/ou gerar uma solução para uma questão;

- elaborar pesquisa foi feita com a ajuda de fornecedores e de departamento especializado para obter a opinião do mercado sobre o projeto; 
- envolver outros departamentos significa solicitar a participação de outros departamentos da organização ou do cliente, para tirar dúvidas sobre a incerteza ou ajudar a criar a solução, como no caso em que o entrevistado comenta que "Eu fui falar com todo mundo, descobri o tremendo caos que ia ser.”;

- fechar acordo está relacionado ao fechamento de contratos de fornecimento de serviços, distribuição ou parcerias, além de ajustes no contratado, devido a mudanças;

- gerar novo ciclo significa iniciar um novo processo de criação de sentido, como a geração de um novo projeto para aprofundar a incerteza percebida; a necessidade de criação de uma nova fase no projeto, como a geração de um piloto;

- identificar alternativas é levantar as possíveis soluções, buscar novas ideias e novas alternativas, identificar fragilidades e conexões das alternativas; a alternativa gerada pode ser discutida e complementada, inclusive por outros departamentos da organização, por parceiros e por clientes;

- mudar ideias refere-se a situações nas quais as alternativas escolhidas não se mostram como as melhores ou as possíveis, então é formulada uma nova alternativa ou revistas as alternativas existentes;

- negociar refere-se a discutir com o cliente, com o fornecedor ou outros departamentos da organização, uma mudança em termos que já estavam comprometidos;

- obter evidências é buscar fatos, informações que diminuam as dúvidas existentes, como reuniões para discussões, auditorias, testes, solicitar relatórios, listagem, verificar procedimentos;

- pesquisar engloba pesquisas de opinião, pesquisas com líderes sobre o assunto, estudar o mercado no qual o produto do projeto atuará, identificar pesquisas na academia;

- planejar pode-se referir tanto ao cronograma do projeto, quanto a outros planos, que podem envolver outros departamentos, clientes e parceiros;

- procrastinar é o adiar uma decisão, postergar ações comprometidas ou a suspender a decisão, quando não é possível fazer nada para atuar-se naquela situação;

- registrar é reter o conhecimento pela formalização, como no registro em documentos, relatórios, ensaios, planos, planilhas, listas, artigos em revistas;

- revisar refere-se a casos em que as alternativas elaboradas e as informações obtidas precisam ser validadas pelo gerente do projeto, pela equipe, pelo cliente ou pelo usuário; 
- $\quad$ solucionar engloba as decisões tomadas para solucionar um problema ou gerar uma resposta plausível para a incerteza; ela depende muito do produto do projeto e pode inclusive definir o início de um novo projeto;

- tentativa de evitar ocorre quando alguma ação paliativa é tomada na tentativa de mitigar o problema ou reverter uma situação, como quando a expectativa de sponsor era muito diferente e a organização tentou manter a expectativa do primeiro deles.

O símbolo '<>' significa que houve interação entre os stakeholders, isto é, a atividade é coletiva. Quando a atividade envolvia parte ou toda a equipe do projeto (EQ) também foi considerada como interação. As células em destaque mostram quando ocorreu alguma interação. As atividades para cada evento imprevisto foram ordenadas cronologicamente e avaliadas em relação ao envolvimento e à interação dos stakeholders.

\begin{tabular}{|c|c|c|c|c|c|c|c|c|c|c|c|c|c|}
\hline Atividade & Processo & 1 & 2 & 3 & 4 & 5 & 6 & 7 & 8 & 9 & 10 & 11 & 12 \\
\hline Abortar & Decisão & & & & & & & & & & 3-PA & 4-EQ & \\
\hline Avaliar & Execução & 8-EQ & & & & & & $7-\mathrm{EQ} \diamond \mathrm{Usi}$ & & & & & 7-EQ \\
\hline Buscar especialista & Coleta de informacôes & & 2-EQ>AC & 3-EQ>AC & & & & $2-\mathrm{SP}>\mathrm{MR}$ & & & & & \\
\hline Buscar formecedor & Coleta de informações & & & & & & & & & & & & $1-\mathrm{EQ} \odot \mathrm{FN}$ \\
\hline \multirow{2}{*}{ Buscar parceiros } & \multirow{2}{*}{ Coleta de informações } & & & & & & & & & & $2-E Q \diamond P A$ & & $6-\mathrm{EQ} \odot \mathrm{MR}$ \\
\hline & & & & & & & & & & & $5-\mathrm{EQ} \odot \mathrm{PA}$ & & \\
\hline Buscar patentes & Coleta de informações & & & & & & & & & & & & $3-E Q \odot M R$ \\
\hline Checar a informação & Coleta de informações & & & & & & $4-E Q \diamond S P$ & & & & & & \\
\hline Classificar & \begin{tabular}{|l} 
Diagnostico \\
\end{tabular} & & & & & & T-LQ & 4-GP & & & & & \\
\hline Compartilhat & Criação de sentido coletivo & 1-GP $\diamond \mathrm{EQ}$ & & & & & $3-\mathrm{EQ} \odot \mathrm{OD}$ & $9-\mathrm{ME} \diamond \mathrm{FN}$ & & & & & \\
\hline Cumprix o planejado & Execução & 7-EQ & & & & & & & & & $8-E Q \odot \mathrm{ME}$ & 2-EQ & \\
\hline Diagnosticar problem & Diagnostico & & & & & & & 3-GP & & 3-OD & & & \\
\hline Discutir com a equipe & Criação de sentido coletivo & & & 4-EQ & & $1-E Q$ & $1-\mathrm{EQ}$ & & 2-EQ & 4-EQ & & & \\
\hline Elaborar pesquisa & Coleta de informações & & & & & & & & & & & & \\
\hline Envolver outros depa & Criação de sentido coletivo & & & 2-GP $\odot O D$ & & & $2-\mathrm{EQ} \diamond \mathrm{OD}$ & $1-\mathrm{SP} \odot \mathrm{OD}$ & & $1-\mathrm{ME} \diamond \mathrm{OD}$ & & & \\
\hline Fechar acordo & Decisão & & & & & & & 8-GP & & & 6-EQ $\diamond P A$ & & \\
\hline Gerar novo ciclo & Novo ciclo & & & & & & & & & $\begin{array}{l}\text { 6-(projeto) } \\
\text { Novo ciclo }\end{array}$ & & $\begin{array}{l}5 \text { - (parceiro) } \\
\text { Novo ciclo }\end{array}$ & \\
\hline Identificar altemativas & Diagnostico & 2-EQ & 1-EQ & & & & & & & & & & 4-EQ \\
\hline Mudar ideias & Diagnostico & & & & & & & & & & 4-EQ & & \\
\hline Negociar & Criação de sentido coletivo & & & & & & & & & & & & \\
\hline Obter evidências & Coleta de informações & & & & & & & 5-EQ & $1-\mathrm{ME}>\mathrm{FN}$ & $2-O D$ & & & \\
\hline Pesquisar & Coleta de informaçōes & & & & & & & & & & \begin{tabular}{|l|}
$1-\mathrm{EQ}>\mathrm{ME}$ \\
\end{tabular} & & 2-EQ $>A C$ \\
\hline Planejar & Execução & 6-EQ & & & & & & & & & 7-EQ $\odot \mathrm{PA}$ & & \\
\hline Procrastinação & Decisão & & & & 1-EQ & 2-EQ & & & & & 9-PA & 3-PA & \\
\hline Registrar & Memória / Difusão & 3-EQ & 5-GP & 5-GP & & & & & & & & & \\
\hline Revisar & Diagnostico & 4-GP & 3-GP & & & & 6-EQ & & & & & & \\
\hline Solucionar & Decisão & 5-EQ & 4-EQ & 6-EQ & & 3-CL & 7-EQ & 6-EQ & 3-EQ & 5-EQ & & & 5-EQ \\
\hline & & & & & & & 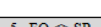 & & & & & & \\
\hline Tentativa de evitar & Decisão & & & $1-\mathrm{EQ}$ & & & $5-\mathrm{EQ} \diamond \mathrm{SP}$ & & 4-ME & & & $1-\mathrm{EQ}$ & \\
\hline
\end{tabular}

Legenda: AC - Academia, CL - Cliente, EQ - Equipe, FN - Fornecedor, GP - Gerente de projetos, ME Membro da equipe, MR - Mercado, OD - Outros departamentos, PA - Parceiro, SOC - Sociedade, SP Sponsor, USe - Usuário externo e USi - Usuário interno 


\begin{tabular}{|c|c|c|c|c|c|c|c|c|c|c|c|c|c|}
\hline Atividade & Processo & 13 & 14 & 15 & 16 & 17 & 18 & 19 & 20 & 21 & 22 & 23 & 24 \\
\hline Abortar & Decisão & 2-SPeME & & & & & & & & & & & \\
\hline Avaliar & Execução & & & 3-EQ & & & & & 7-EQ & & & & \\
\hline Buscar especialista & Coleta de informaçōes & & & & & & & & & & & & \\
\hline Buscar fomecedor & Coleta de informaçōes & & & & & & & $2-\mathrm{SP} \odot \mathrm{FN}$ & & & & 2-EQ $\diamond F N$ & \\
\hline Buscar parceiros & Coleta de informaç̃es & & & & & & & & & & & & 3-EQ $\odot \mathrm{PA}$ \\
\hline Buscar patentes & Coleta de informações & & & & & & & & & & & & \\
\hline Checar a informação & Coleta de informações & & & & & & & $1-\mathrm{SP}>\mathrm{MR}$ & & 1-GP $\diamond \mathrm{Usi}$ & & $1-\mathrm{EQ} \diamond \mathrm{OD}$ & \\
\hline Classificar & Diagnostico & & & & & & & & & & & & \\
\hline Compartilhar & Criaçăo de sentido coletivo & & & & $6-\mathrm{EQ} \odot \mathrm{FN}$ & & 2-GP $\diamond A C$ & & & & & & \\
\hline Cumprir o planejado & \begin{tabular}{|l|} 
Execução \\
\end{tabular} & & & 4-EQ & & & & & & & & & \\
\hline Diagnosticar probleme & Diagnostico & & 3-EQ & & & 1-EQ & & & 5-EQ & & & & \\
\hline Discutir com a equipe & Criação de sentido coletivo & & & 2-EQ & & & & & & & 1-EQ & & \\
\hline Elaborar pesquisa & Coleta de informações & & & & & & & & $\begin{array}{c}1-\mathrm{OD}+\mathrm{GP} \odot \\
\mathrm{FN}\end{array}$ & & & & \\
\hline Envolver outros depar & Criaçăo de sentido coletivo & & $2-\mathrm{SP} \diamond \mathrm{OD}$ & & $2-\mathrm{EQ} \diamond \mathrm{OD}$ & & & & & & & & \\
\hline Fechar acordo & Decisão & & & & & & & & & $5-\mathrm{GP} \odot \mathrm{FN}$ & & & $4-\mathrm{EQ} \diamond \mathrm{PA}$ \\
\hline Gerar no & Novo ciclo & & & & & & $\begin{array}{l}4 \text { - (projeto) } \\
\text { Novo ciclo }\end{array}$ & & & & & 6-Novo ciclo & \\
\hline Identificar alternativas & Diagnostico & & $5-\mathrm{SP} \odot \mathrm{OD}$ & & 1-GP & & & & & & & & 1-EQ \\
\hline Mudar ideias & 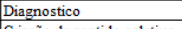 & & & & 4-GP $\diamond \mathrm{EQ}$ & & & 3-EQ & & & & & \\
\hline Negociar & Criação de sentido coletivo & & $6-\mathrm{SP} \odot \mathrm{OD}$ & & & & & & & 4-GP $\diamond \mathrm{FN}$ & & & \\
\hline Obter evidências & Coleta de informaçôes & & $1-\mathrm{EQ} \diamond \mathrm{SP}$ & & $3-E Q \diamond$ Use & & & & 2-EQ & & & & \\
\hline Pesquisar & Coleta de informações & & & & & & 1-GP $>A C$ & & $3-\mathrm{EQ} \odot \mathrm{SOC}$ & & & $3-\mathrm{EQ} \diamond$ Use & \\
\hline Planejar & \begin{tabular}{|l} 
Execução \\
\end{tabular} & & & & & & & & & & & 5-EQ & \\
\hline Procrastinação & Decisão & 1-SP & & & & & & & & & & & \\
\hline Registrar & Memória / Difusão & & 4-SP & & 7-EQ & & & & & & & & \\
\hline Revisar & Diagnostico & & & & & & & & & 2-GP $\diamond \mathrm{Usi}$ & & & \\
\hline Solucionar & Decisão & & 7 $-\mathrm{SP} \diamond \mathrm{OD}$ & 1-ME & 5-EQ & 2-EQ & 3-EQ & 4-EQ & 4.EQ & 3-GP $\diamond \mathrm{Usi}$ & 2-EQ & 4-EQ & 2-EQ \\
\hline Tentativa de evitar & Decisão & & & & & & & & 6-EQ & & & & \\
\hline
\end{tabular}

\begin{tabular}{|c|c|c|c|c|c|c|c|c|c|c|c|c|}
\hline Atividade & Processo & 25 & 26 & 27 & 28 & 29 & 30 & 31 & 32 & 33 & 34 & 35 \\
\hline Abortar & Decisão & & & & $1-\mathrm{GP} \triangle \mathrm{FN}$ & & & & & & & $5-\mathrm{EQ}$ \\
\hline Avaliar & Execução & & & & & & 4-EQ & & & & & \\
\hline Buscar especialista & Coleta de informações & & & & & & $1-E Q>O D$ & & & & & \\
\hline Buscar formecedor & Coleta de informações & & & & & & & $3-\mathrm{EQ} \diamond \mathrm{FN}$ & & & $2-\mathrm{GP} \diamond \mathrm{OD}$ & \\
\hline Buscar parceiros & Coleta de informações & & 1-GP $\diamond \mathrm{PA}$ & & & & & & & & & \\
\hline Buscar patentes & Coleta de informacões & & & & & & & & & & & \\
\hline$\frac{\text { Buscar patentes }}{\text { Checar a informacão }}$ & $\begin{array}{l}\text { Ooleta ae intormaçoes } \\
\text { Coleta de informaçôes }\end{array}$ & 1.GP & & & & & & & 1-GP & & 5-GP & 3-EQ \\
\hline Classificar & Diagnostico & & & & & $3-\mathrm{EQ}$ & & & & & & \\
\hline Compartilhar & Criacão de sentido coletivo & & & & & $5-\mathrm{EQ} \diamond \mathrm{CL}$ & & & 3-GP $\triangle \mathrm{SP}$ & & & \\
\hline Cumprir o planejado & \begin{tabular}{|l|} 
Execuçãao \\
\end{tabular} & & & & & & & & 7-EQ $\odot \mathrm{OD}$ & & & \\
\hline Diagnosticar problema & Diagnostico & 5-GP & & $1-\mathrm{ME}$ & & & $2-O D$ & & 2-GP & & & \\
\hline Discutir com a equipe & Criação de sentido coletivo & & & & & 2-EQ & & 1-EQ & & & 4-EQ & $2-\mathrm{EQ} \diamond \mathrm{FN}$ \\
\hline Elaborar pesquisa & Coleta de informacões & & & & & & & & & & & \\
\hline Envolver outros depart & Criação de sentido coletivo & $2-\mathrm{GP} \diamond \mathrm{CL}$ & & & & & & & $5-\mathrm{SP} \odot \mathrm{OD}$ & & 3-GP $\odot \mathrm{OD}$ & \\
\hline Fechar acordo & Decisão & $8-\mathrm{GP} \odot \mathrm{CL}$ & 2-GP $\diamond \mathrm{PA}$ & & & $7-\mathrm{EQ} \diamond \mathrm{CL}$ & 6-EQ $\diamond \mathrm{PA}$ & & & & & \\
\hline Gerar novo ciclo & Novo ciclo & & & & & & & \begin{tabular}{|l|}
$5-(-)$ Novo \\
ciclo
\end{tabular} & & & & 6-Novo ciclo \\
\hline Identificar altermativas & Diagnostico & 3-GP $\diamond \mathrm{CL}$ & & 2-EQ & & & & $2-E Q$ & & & $1-\mathrm{GP} \diamond \mathrm{OD}$ & \\
\hline Mudar ideias & Diagnostico & & & & & & & & & & & $4-\mathrm{EQ} \diamond \mathrm{FN}$ \\
\hline Negociar & Criação de sentido coletivo & $6-\mathrm{GP} \diamond \mathrm{CL}$ & & & & & & & & & & \\
\hline Obter evidèncias & 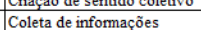 & $\frac{0-\mathrm{GP} \diamond \mathrm{CL}}{4-\mathrm{GP} \diamond \mathrm{CL}}$ & & & & 1-EQ & & & & & & \\
\hline Pesquisar & Coleta de informaçōes & & & & & & & & & & & \\
\hline Planejar & Execução & & 3-EQ & & & & $5-\mathrm{EQ} \diamond \mathrm{Cl}$ & & $6-\mathrm{GP} \diamond \mathrm{OD}$ & & & \\
\hline Procrastinação & Decisão & & & & & & & & & $1-\mathrm{GP} \odot \mathrm{EQ}$ & & \\
\hline Registrar & \begin{tabular}{|l|} 
Memória / Difusão \\
\end{tabular} & & & & & 4-EQ & & & & & & \\
\hline Revisar & Diagnostico & & & & & $6-\mathrm{CL}$ & $3-E Q$ & & & & & \\
\hline Solucionar & Decisão & 7-GP & & 3-EQ & & & & 4-EQ & 4-SP & & $6-E Q \odot O D$ & \\
\hline & & & & & & & & & & & & \\
\hline Tentativa de evitar & Decisão & & & & & & & & & & & $1-E Q$ \\
\hline
\end{tabular}




\section{Projeto 1: Desenvolvimento de um serviço novo para a organização, aproveitando as competências internas para levar esse conhecimento para outras organizações e usuários.}

Imprevisto 1: Necessidade de compartilhamento de conhecimento entre os elementos da equipe.

Alguns especialistas com o conhecimento no desenvolvimento daquele tipo de produto foram contratados especificamente para o projeto. Durante um brainstorming no início do projeto, o gerente de projetos percebeu que os conhecimentos técnicos da organização não eram de conhecimento desses especialistas, assim como o conhecimentos desses especialistas precisavam ser repassados para os demais membros da equipe para que o produto pudesse ser definido. Surgiu assim a necessidade de um treinamento para os especialistas e o conhecimento deles foi sendo compartilhado no desenvolvimento do projeto, com a geração e registro de ideias, revisões e decisões em equipe.

Imprevisto 2: Necessidade de novas competências por causa de uma mudança no projeto. Após a especificação inicial do produto, surgiu uma nova ideia de como desenvolvê-lo, o que o tornaria mais adequado para os clientes. A mudança exigia competências inexistentes na equipe, que ficou temerosa em não conseguir atender de forma satisfatória. Por meio de consultas a especialistas, criatividade e comprometimento da equipe para a criação de uma solução em conjunto, conseguiu-se gerar uma alternativa que atendeu as expectativas e evoluiu ao longo do projeto, apesar dos impactos nos custos e prazos.

\section{Projeto 2: Implantação de um serviço na área de tecnologia da informação, totalmente inovador no mercado nacional.}

Imprevisto 3: Indefinição dos requisitos funcionais para o sistema do Call Center

Como a implantação do projeto foi muito extensa, a equipe operacional que deveria definir o sistema de funcionamento do Call Center começou a demorar para ser contratada. Assim, decidiu-se primeiro implantar a estrutura tecnológica e de sistemas, de forma a agilizar o processo. Para se antecipar a definição dos requisitos, decidiu-se pelo uso de pessoas de outros departamentos e de consultores, dado que já tinham implantado aquele tipo de projeto em outros países. Com a contratação da equipe efetiva, no fechamento dos procedimentos, houve muita discussão e conflitos, com a respectiva negociação para atender os responsáveis contratados para a área. O que facilitou esse processo foi a abertura a problemas da organização, da liderança, dos objetivos claros do projeto e comprometimento da equipe.

\section{Imprevisto 4: Sobrecarga não prevista no Call Center}

Para minimizar um problema de demanda de clientes nas lojas, foi definido um processo que acabou gerando uma demanda não prevista para o Call Center, além de ser fictícia, pois a maioria dos acessos era apenas para verificar o andamento da respectiva compra. Essa demanda era bem superior ao máximo previsto, o que promoveu uma imagem negativa da empresa perante o mercado e os clientes. A solução afetou os custos, pois, para corrigir o problema, foi necessário aumentar os postos no Call Center. Mas isso representava também o sucesso do projeto, pois a demanda refletia uma grande geração de negócios para a organização. 


\section{Projeto 3: Desenvolvimento de um serviço de consultoria para implantação de novo tipo de gestão no cliente.}

Imprevisto 5: Definir uma liderança formal do processo de gestão no cliente

A consultoria tenha experiência com o tipo de gestão, mas o segmento de atuação do cliente era totalmente novo. Ao longo do diagnóstico, a equipe percebeu que era necessário identificar uma pessoa para ser o líder da implantação da iniciativa no cliente, assim como responsável por dar continuidade ao processo implantado. Apesar de o assunto ser discutido internamente, o gerente de projeto postergou a decisão, pois implicava em levantamentos não previstos no escopo inicial, e em questões políticas, que surgiriam a partir da sugestão de um nome. Essa estratégia foi boa, pois o próprio cliente tomou a decisão, sem problemas para eles. Porém a equipe ficou insatisfeita por não saber o que dizer para o cliente durante o processo, temendo gerar informações conflitantes.

Imprevisto 6: Divergência de opinião entre sponsors a respeito do produto do projeto Um dos sponsors foi um dos últimos a ser entrevistado na fase de diagnóstico, por problemas dele e de planejamento da consultoria. Seu direcionamento para os processos a serem implantados foi contra a indicação do outro sponsor. Como a consultoria estava mais ajustada com o direcionamento anterior, ela checou com as áreas do cliente envolvidas, tentou evitar a mudança com o segundo gestor, mas ele foi firme e a mudança, inevitável. Mas o resultado foi satisfatório para todos os envolvidos, dado que conseguiu contemplar o direcionamento solicitado.

\section{Projeto 4: Desenvolvimento conjunto com fornecedor de uma plataforma de sistemas, que seria futuramente utilizada por outras organizações do mesmo segmento.}

Imprevisto 7: Falta de entendimento do problema por parte do fornecedor

Perto da data de entrega, durante os testes preliminares, percebeu-se que a solução não atenderia as necessidades do cliente, o que causou o reinício do projeto, postergando a data de entrega. Várias áreas foram então envolvidas, sendo definido um gestor para o projeto e a contratação de um consultor de PMO para acompanhar o projeto. Além da geração de um diagnóstico do problema, a identificação das funcionalidades e a definição de requisitos do projeto, com ampla discussão das áreas, também foi criada uma metodologia de desenvolvimento a ser implantada pelo fornecedor, para garantir a qualidade do projeto. Essa metodologia, inclusive, foi alvo de treinamento.

Imprevisto 8: Descumprimento de acordo por parte do fornecedor O fornecedor tinha assumido a responsabilidade de executar uma série de atividades, principalmente testes, no software que estava sendo desenvolvido. Na avaliação das informações dos relatórios, um membro da equipe do cliente percebeu que ele não estava executando as ações, confirmado por uma auditoria-surpresa em sua fábrica de software. $\mathrm{O}$ problema foi levado a instâncias superiores, o que provocou cobranças para execução do acordado, por parte do cliente, e uma segunda rodada de treinamento para a equipe.

Imprevisto 9: Funcionalidades do sistema tendo procedimentos diferenciados entre áreas No levantamento de requisitos e funcionalidades do novo sistema, o membro da equipe percebeu que poderia ter uma disfunção organizacional, já que várias áreas executavam a mesma função, mas de maneira e com códigos distintos. Isso inviabilizaria a padronização exigida pelo novo sistema. O membro da equipe pediu para a área responsável pelo sistema 
para avaliar a amplitude e o impacto disso para as várias áreas. O problema foi levado a instancias superiores e gerado um projeto auxiliar para adequar a função na organização.

\section{Projeto 5: Desenvolvimento de um serviço para clientes, inexistente no mercado nacional, com processos e cálculos baseados em informações públicas.}

Imprevisto 10: Falta de comprometimento do parceiro

A organização fez uma pesquisa no mercado nacional e estrangeiro, para conhecer as condições dos competidores e, como ela é pequena, percebeu que era preciso se aliar a algum deles para poder distribuir o seu produto. Ela passou por processos de negociação em dois deles, decidindo-se pela parceria com uma multinacional, que já se sabia ter dificuldades para se instalar em países estrangeiros. Após o fechamento do acordo, a equipe do parceiro foi treinada para que conhecessem o produto e planejaram ações para lançá-lo no mercado. Mas o parceiro tinha inúmeros produtos e não deu a prioridade esperada ao projeto, o que fez com que o lançamento ocorresse poucos meses antes de outro competidor. Os impactos negativos foram financeiros e de novos negócios, mas que, sem a parceira, também não teriam sido viabilizados. A equipe ao final considerou que adquiriu a competência da distribuição.

Imprevisto 11: Ausência de liderança no parceiro

Apesar de o líder do projeto no parceiro ter dado indicações de sua insatisfação com a organização, após o início do projeto, o gerente de projetos não acreditou que ele pudesse sair e também não avaliou que sua saída fosse tão importante, já que tinham um contrato em andamento. Após a saída, a equipe decidiu continuar o contrato, pois muito tempo havia sido investido na parceria, tentando identificar um novo líder para a distribuição de seus produtos. Mas a organização parceira tinha problemas para decidir, procrastinando as decisões. Isso trouxe impactos negativos como o esforço despendido e a falta de receitas previstas.

Projeto 6: Desenvolvimento de um produto por uma empresa desenvolvedora de tecnologias, utilizando plástico reciclável de forma inexistente no mercado mundial.

Imprevisto 12: Necessidade de criar nova tecnologia

Para o desenvolvimento do novo produto, era necessário um equipamento diferenciado, que na gestão de riscos tinha sido contingenciado, pois, se não houvesse no mercado nacional, a equipe procuraria no internacional. Mesmo a busca internacional foi infrutífera, pois não foi possível desenvolver esse equipamento pelas empresas existentes. A equipe teve de buscar informações nas academias, em patentes, usando seu networking científico. Identificaram e elencaram alternativas e contataram fábricas para gerar as partes do equipamento, fazendo o papel de integradores. A equipe foi persistente e, apesar dos gastos financeiros, conseguiram gerar a solução para o produto.

Imprevisto 13: Desentendimento entre os investidores

Quando o projeto estava terminando, houve um momento de crise no mercado que gerou uma discordância sobre o direcionamento do projeto entre os líderes da equipe, que também eram os investidores. Uma segunda discordância fez com que parte da equipe que detinha o knowhow do produto resolvesse sair da sociedade, por problemas pessoais. Esse desfecho foi atribuído a uma falta de inteligência emocional da equipe, que se dedicou inteiramente a gerir os aspectos técnicos do projeto, mas não observou questões como comunicação e pessoas.

Projeto 7: Implantação e integração de uma nova plataforma mundial de BackOffice, com várias inovações tecnológicas, sendo o Brasil o projeto-piloto. 
Imprevisto 14: Conflito de agenda na implantação dos projetos da organização

O sponsor percebeu, numa reunião de trabalho, que uma determinada área não poderia atender os testes do projeto, pois já havia se comprometido com outros projetos. Na conversa com outros departamentos percebeu que havia inúmeros projetos a serem implantados na mesma época, o que era inviável. Então, obteve informações de todas as fases dos projetos da área, identificaram os problemas, montando numa planilha Excel o portfólio da área. Identificou alternativas para solucionar o problema com os outros departamentos e as negociou com os outros diretores. Eles decidiram qual seria a prioridade de cada projeto, principalmente para este, que era estratégico. $\mathrm{O}$ controle gerado para essa tomada de decisão continuou a ser usado, criando uma nova competência na organização. A solução foi encontrada por causa do apoio dos pares e do sponsor.

Imprevisto 15: Incompatibilidade de informações na simulação da implantação

Logo no início do processo de ensaio geral para implantar o sistema na produção, um erro, por causa da incompatibilidade de informações, o inviabilizou. A gestão de riscos falhou em prever o erro e na previsão das consequências. O planejamento previa apenas mais um fim de semana para uma simulação, mas se ocorresse algum erro não haveria tempo de corrigir e implantar o sistema, o que causaria grande prejuízo para a organização. O problema foi corrigido e foram aplicados testes em outro ambiente, sem todas as garantias do ensaio geral. Entretanto, esses testes indicaram a possibilidade de a implantação ser viável e atender a data prevista. Fizeram uma reunião com toda a equipe, inclusive pessoas que estavam fora do país, como o fornecedor do sistema, para discutir a viabilidade da implantação e após a avaliação e pareceres decidiram não postergá-la. Isso mostrou pontos de melhoria na GP da organização.

\section{Projeto 8: Desenvolvimento de relacionamento inovador com formadores de opinião sobre os produtos da organização, em ambiente altamente regulamentado.}

Imprevisto 16: Nível de rejeição do produto por formadores de opinião

Era sabido no mercado que há ONGs que atuam contra o produto da empresa. Muitos formadores de opinião também são dessa linha, mas no começo do projeto não havia noção de quantos seriam, nem o que eles poderiam fazer contra o produto, quando fossem procurados. Ações de rejeição poderiam resultar em problemas legais e consequentemente falta de aceitação do usuário final, assim como custos. A equipe foi alertada para estar preparada para isso, mas mesmo assim nas primeiras visitas houve acompanhamento de alguma pessoa da organização para entender o que poderia acontecer e dar suporte. Houve alguns incidentes sem gravidade. Assim, apesar de no início acharem que quando fosse encontrada uma opinião divergente deveria haver uma tentativa de convencimento, mudaram de ideia e decidiram que quando a rejeição fosse detectada, o formador de opinião não deveria ser mais contatado. Além disso, elaboraram um questionário, para obter mais informações sobre ele, que se tornou depois um banco de dados com vários tipos de informações importantes para a organização. Foi um processo contínuo, aprendido ao longo do projeto. A falta de conhecimento do mercado e dos líderes de opinião não foram suficientes para impedir o entendimento, assim como a abertura para problemas, os ajudou a superá-los. Houve sempre participação de várias áreas da organização.

Imprevisto 17: Acionamento judicial trabalhista por um terceiro

Apesar dos esforços de planejamento inicial para que as condições de trabalho e remuneração dos terceiros, contratados para trabalhar na equipe do projeto, fossem respeitadas, checagem dos custos e do contrato feito com o fornecedor, a empresa acabou sendo corresponsável 
numa ação trabalhista na justiça, após a dispensa de um terceiro. Essa situação não era prevista, pois achava-se que o risco havia sido eliminado. Houve custos para o acompanhamento do processo além da preocupação e tempo envolvidos. Mas esse evento mostrou que os controles poderiam ser mais ágeis se a equipe fosse interna, assim como o efetivo atendimento à legislação trabalhista, o que foi decidido de forma coletiva. Contribuiu para isso o desconhecimento da jurisdição trabalhista, sendo que posteriormente foi contratada uma assessoria para sanar essa lacuna.

\section{Projeto 9: Desenvolvimento de um serviço inovador, no âmbito brasileiro, com impacto no meio ambiente.}

Imprevisto 18: Nova condição ambiental que impactava o produto do projeto

O programa previa apenas a avaliação de uma determinada condição ambiental, mas em 2008 e 2009 a equipe percebeu que a combinação dessa condição com outra prejudicou bastante o município. A primeira ação foi pesquisar na comunidade informações sobre comportamento dessa nova variável: não foram encontradas informações práticas nem científicas. Em discussão com toda a equipe (de vários departamentos da organização), decidiu-se por gerar um projeto específico para fazer os estudos para aprofundar a questão, gerando um novo ciclo de criação de sentido. Houve compartilhamento de informações com pesquisadores internacionais sobre o assunto.

Imprevisto 19: Falta de mão de obra especialista

No início do projeto foi preciso contratar especialistas para definir as principais funções do projeto, mas, após quatro meses de procura, de entrevistas, consultas, solicitações ao sindicado, perceberam que o profissional não existia. Revisaram o plano e optaram por profissionais com um nível mais baixo de qualificação e, seis a dez meses depois, deram-lhes um treinamento para poder suprir as habilidades e competências que não existiam. Isso impactou, principalmente, o prazo do projeto.

Imprevisto 20: Opinião dos stakeholders sobre o serviço

O gerente do projeto, logo após o seu início, percebeu que seria necessário um processo de mapeamento e interação com os stakeholders (população do município, organizações representativas, órgãos públicos, ONGs), pois eles tinham uma percepção desconhecida do problema e poderiam se colocar contra o serviço a ser desenvolvido. A primeira ação foi de pesquisa qualitativa de opinião para os líderes das organizações envolvidas sobre o assunto e quantitativa para a população em geral. Foi gerado um plano de comunicação para o primeiro ano (selecionando a melhor solução), com emissões de comunicados semanais para conhecimento da população do objetivo e andamento do projeto.

\section{Projeto 10: Implantação de um sistema com funcionalidades inovadoras para a integração de serviços com clientes e funcionários.}

Imprevisto 21: Funcionalidades do sistema não previstas

A organização que não tinha experiência em desenvolver softwares contratou um especialista que, por sua vez, não tinha conhecimento profundo do negócio da organização. Logo após o fechamento da negociação com o fornecedor do desenvolvimento do software, o sponsor apontou uma funcionalidade que não havia sido requisitada anteriormente. Para se certificar de que o escopo estava bem definido, o gestor do projeto checou com os usuários mais algumas operações, discutiu com a equipe outras possibilidades, redefiniram-se alguns 
procedimentos, criou-se uma solução. Com ela abriu nova negociação com o fornecedor que fechou o acordo para atender a nova solução, sem impactar o acordo anterior.

Imprevisto 22: Troca de equipe do fornecedor

O fornecedor do software resolveu mudar o tipo de contrato de trabalho de seus funcionários, o que não foi aceito por vários membros da equipe. Assim, o fornecedor mudou a equipe sem prévio aviso para o cliente. Nessa troca, algumas revisões nos procedimentos foram solicitadas pelos novos participantes, talvez por perda de documentação já definida, o que gerou mais esforço do cliente em redefinir o que já havia sido feito.

\section{Projeto 11: Criação de uma organização para lançamento de um produto inovador para o tipo de cliente e parceiros, em âmbito nacional.}

Imprevisto 23: Desconhecimento da opinião dos usuários do novo serviço

No primeiro piloto gerado para o público, a equipe percebeu que o público não estava reagindo como era previsto. Assim, identificou-se que havia muito desconhecimento do assunto e foram buscar informações em outros projetos, num instituto de pesquisa sobre essa classe, fizeram pesquisa de campo para avaliar o seu comportamento e decidiram replanejar a estratégia, por outros motivos também, o que gerou um novo piloto. Tudo isso impactou o prazo, os custos e o escopo do projeto.

Imprevisto 24: Dificuldade em fechar parcerias

O projeto precisava de parceiros de grande porte para participar do projeto que, para isso, deveriam desenvolver algumas integrações e ajustes em seus sistemas. As parcerias foram inviabilizadas, por causa do backlog de mudanças já existentes e com mais prioridade do que as exigidas pelo projeto. Assim, foi preciso identificar novas alternativas de parcerias. A primeira contava com parceiros de menor porte, mas que também extrapolavam o prazo previsto. Uma empresa de integração de meios de pagamentos foi a solução mais rápida. Conseguiram, então, fechar um acordo.

\section{Projeto 12: Capacitação de pessoas e criação de serviços a serem disponibilizados à população, com integração de várias ONGs e órgão público.}

Imprevisto 25: Nova regulamentação sobre uma das entregas do projeto

$\mathrm{Na}$ aprovação do projeto, o cliente exigiu que um dos artefatos do projeto fosse entregue a uma instituição vinculada ao cliente, mas não especificou como isso deveria ser feito. Perto do final do projeto, o gerente do projeto foi verificar qual as condições a serem atendidas para aquela entrega. Numa segunda tentativa, meses depois, ele obteve as informações. Os procedimentos tinham sido estabelecidos recentemente e requeriam procedimentos científicos que não haviam sido adotados durante o projeto. Isso significava refazer todo o trabalho por meio de apoio de especialistas. Ele acionou a comissão de acompanhamento do projeto que sugeriu uma reunião com a instituição vinculada. Eles conversaram e tentaram avaliar algumas alternativas, mas todas implicavam refazer o trabalho. Nessa conversa, ficou claro que a regra havia sido estabelecida depois do acordo com o fornecedor. $\mathrm{O}$ gerente de projetos avaliou novamente as opções e iniciou uma negociação com o cliente sugerindo que o resultado do trabalho ficasse no fornecedor à disposição do cliente e da instituição. O cliente aceitou a argumentação e o projeto foi finalizado.

Imprevisto 26: Membros da equipe, aprovados pelo cliente, não puderam participar do projeto 
O projeto foi aprovado após muitos meses do envio da proposta. Nesse momento, uma das responsáveis por parte do projeto estava grávida e não poderia mais participar da forma como havia sido previsto. Outro participante importante também teve de ser substituído. O gerente ficou aflito, pois muito do conhecimento do projeto estava com a responsável grávida. Uma parte das atividades dela foram replanejadas para outros participantes que atuaram de maneira muito superior às expectativas. Para a outra parte das atividades, houve uma busca por novos parceiros que, além de cumprirem essas atividades, ainda colaboraram em muito com o projeto, pois puderam ter duas metodologias para o desenvolvimento do produto que gerou maior competência para a organização.

\section{Projeto 13: Implantação de um produto, com uso de uma tecnologia inovadora, que era parte de um programa de serviços à população.}

Imprevisto 27: Dificuldades com o relevo e o clima

Sabia-se que o clima e o relevo da região poderiam impactar o projeto, mas houve otimismo no planejamento. Só após a obtenção da licença ambiental é que puderam fazer algumas avaliações, mas assim mesmo com pouco tempo. Iniciada a execução do projeto, o consultor de PMO percebeu que a produtividade das atividades tinha caído e, assim, gerou uma simulação do cronograma. Com base nessas informações, a equipe pôde decidir se mantinha o cronograma, tentava recuperar o prazo ou mudava o projeto. Essa alternativa foi escolhida. As equipes modificaram o projeto para alocar uma das bases de um equipamento em um lugar onde o relevo era mais favorável. Para diminuir o impacto das condições climáticas também foi usado um equipamento pela primeira vez, na organização. Essa alternativa já havia sido avaliada no planejamento inicial, mas, por questões de custos, não tinha sido adotada, condição agora mudada pela premência do tempo.

Imprevisto 28: Perda do principal equipamento para a implantação do projeto

$\mathrm{O}$ consultor de PMO percebeu que as atividades atrasavam e que o cronograma era sempre postergado, mas, quando perguntava ao gerente de projetos as razões, não obtinha respostas convincentes. Havia uma empresa contratada, especialista no assunto, assim como o gerente de projetos, alocado de outra área da organização com experiência nesse tipo de projeto. A causa dos problemas era a geologia do lugar, que nunca havia sido trabalhada, gerando uma avaliação problemática dos tempos das atividades. A inconsistência do monitoramento e controle dificultou sobremaneira a geração de mitigações, culminando com o cancelamento do projeto pela quebra irreparável do equipamento, condição que não havia sido avaliada na gestão de riscos.

Projeto 14: Outsourcing total de uma empresa de serviços, com a geração de nova plataforma de sistemas e BackOffice, com vistas a ser replicado para empresas do mesmo ramo.

Imprevisto 29: Falta de sincronicidade entre sistema legado e novo

Este projeto, além de envolver três empresas, duas delas, as maiores em seus respectivos setores, envolvia o outsourcing total de uma área do cliente com a substituição do sistema informatizado, por um novo. As mudanças no ambiente de negócio são contínuas e eram solicitadas pelo cliente para a equipe que cuidava dos sistemas legados, mas não eram repassadas para a equipe que cuidava do novo sistema. O gerente do projeto executivo já alertara o cliente que ele deveria diminuir essas modificações. De repente, uma pessoa da equipe do sistema novo, conversando com o cliente, percebeu o descompasso entre os sistemas. Houve uma reunião entre as equipes na qual o gerente do projeto executivo solicitou 
a lista das alterações para a equipe do legado, ela foi gerada, discutida entre as equipes, as modificações foram selecionadas, classificadas e listadas. Foi compartilhada com o cliente a situação que validou a classificação e decidiu em que versão do sistema elas seriam geradas. Isso impactou o prazo e o custo do projeto.

Imprevisto 30: Testes exigiram mais recursos do que o previsto

A empresa demorou para enviar o cronograma de atividades detalhado e conferido por especialistas para o cliente. Quando ele recebeu, percebeu que os prazos para determinadas atividades estavam bem inferiores ao que seria o normal. A empresa de serviços convocou novamente os serviços de um especialista para avaliar a informação e este, com informações do cliente, confirmou e prorrogou enormemente os prazos. No princípio, a empresa não quis aceitar a mudança, mas, quando começou executar as atividades e incorporar os devidos procedimentos percebeu que o especialista e o cliente estavam corretos.

Imprevisto 31: Dificuldades para implantação de ferramenta

Quando o gerente de projetos executivo começou a trabalhar no projeto identificou que uma das ferramentas que seria adotada no sistema legado, que estavam sendo implantadas para viabilizar o outsourcing, era diferente da usada no sistema legado. Ele percebeu que haveria problemas: prazo previsto muito curto para a adequação do sistema e dificuldade com o idioma, já que a nova ferramenta estava disponível apenas nos EUA e a equipe não falava inglês fluentemente. Sugeriram outra ferramenta, que ele já havia utilizado, quando apontou outros possíveis problemas. Cotaram novas ferramentas: com uma nova empresa e com a que já fornecia a ferramenta para o sistema legado. Por causa, principalmente, de custos, decidiram continuar com a que estava sendo usada.

\section{Projeto 15: Estímulo à excelência de gestão na área pública, sem similar no nível de atuação.}

Imprevisto 32: Prazo estipulado para compras era insuficiente

O gerente de projetos não havia trabalhado em empresas públicas e, portanto, não conhecia todos os procedimentos, nem o tempo que eles demandavam. O projeto já estava em andamento quando ele foi designado. Com o passar dos meses e com a integração com sua área, percebeu que as atividades relativas a um evento final, importante para o projeto, não haviam sido detalhadas e ele já estava com o prazo estourado, se fosse adotar os procedimentos-padrão de compras. Levou o problema para o seu superior, que envolveu outros departamentos para ajudá-lo. Eles montaram um plano de ação em conjunto, e apesar do esforço extra despendido, foi seguido e monitorado, atingindo as metas previstas.

Imprevisto 33: Desistência de voluntários durante o projeto

O projeto envolvia muitos voluntários de várias áreas para que mais de uma pessoa avaliasse um determinado trabalho. Após a distribuição das análises a cada um deles, alguns não fizeram a sua parte e outros não avisaram que não poderiam dar continuidade. Esse fato poderia trazer menor qualidade para o processo, o que teve de ser garantido pelo maior envolvimento e esforço do gerente de projetos. Esse fato demonstrou melhorias que o projeto deveria contemplar, apesar de difíceis de serem aplicadas.

\section{Projeto 16: Geração de indicadores com informações de todo o município para direcionar ações públicas, sem similar nacional e com tecnologias inovadoras.}

Imprevisto 34: Informações necessárias para o projeto estavam em meio manual 
O gerente de projetos foi designado para um projeto já em andamento, mas ainda na fase inicial. $\mathrm{O}$ gerente procurava bases de dados em sistemas automatizados dos quais pudesse extrair as informações que comporiam os indicadores definidos. Vários departamentos da organização foram procurados, em alguns o acesso foi negado, sem que fosse possível obter as informações necessárias. Por sugestão de um membro da equipe do PMO, o gerente procurou determinada área que sugeriu a utilização de suas informações que, entretanto, estavam em papel. Quando o gerente avaliou as informações, percebeu que $80 \%$ de sua necessidade seriam supridas por elas. Foi avaliada a possibilidade de se gerar um sistema para tratá-las, o que foi feito na sequência. Apesar da necessidade de geração de um novo sistema, economizou-se muito tempo do projeto com o encontro dessas informações.

Imprevisto 35: Dificuldades no desenvolvimento do sistema

Como o projeto é de uma área bem peculiar, a equipe teve muita dificuldade em gerar o sistema informatizado, de forma que atendesse os requisitos, pois os analistas e programadores do fornecedor queriam modificar as condições necessárias para facilitar o seu trabalho. Essas dificuldades não foram geradas somente pelos fornecedores, mas também pela equipe de TI interna. Fora isso, o sistema gerava informações erradas, o que fez com que a equipe precisasse checar todas as informações que saíam antes de entregar para os usuários. Fizeram um esforço extra para detalhar mais as informações e com isso ter menos erros do sistema, mas, como isso não foi suficiente para sanar os problemas, a empresa fornecedora teve de ser trocada. 